UNIVERSIDAD POLITÉCNICA DE MADRID

ESCUELA TÉCNICA SUPERIOR DE ARQUITECTURA

DEPARTAMENTO DE PROYECTOS ARQUITECTÓNICOS

\title{
EL DISPOSITIVO \\ FRONTERA \\ LA CONSTRUCCIÓN \\ ESPACIAL DESDE LA \\ NORMA Y EL CUERPO \\ MIGRANTE
}

TESIS DOCTORAL, 2019

ANTONIO GIRÁLDEZ LÓPEZ 

D.12

Tribunal nombrado por el Mgfco. Y Excmo. Sr. Rector de la Universidad Politécnica de Madrid, el día

Presidente D.

Vocal D.

Vocal D.

Vocal D.

Secretario D.

Realizado el acto de defensa y lectura de Tesis el día en la Escuela Técnica Superior de Arquitectura de Madrid

Calificación:

EL PRESIDENTE

LOS VOCALES

EL SECRETARIO 

A todas las personas que han llevado, llevan y llevarán la frontera a cuestas. 

AGRADECIMIENTOS 

Esta tesis ha surgido, crecido y desplegado a través de infinitas conversaciones, del apoyo y confianza de una gran red de personas a las que siempre estaré agradecido por formar parte de ella. Una red de afectos que cose y da cuerpo a una investigación que me acompaña de manera recurrente desde 2012 y que ha ido tomando diferentes formas hasta, finalmente, la de una investigación doctoral.

A Concha, por darme alas desde el primer viaje que hicimos al Estrecho de Gibraltar a finales de 2014, por ponerme frente a la valla del Benzú, por cruzar el Tarajal y el Estrecho junto a ella, por habitar los paisajes de frontera y animarme a sorprenderme con cada nuevo hallazgo y cada nuevo mapa. Por enseñarme desde donde ha de construir cada uno el paisaje y el valor de las cartografías. A Atxu, por habernos encontrado a lo largo de esta tesis en trincheras compartidas y haberlas llenado con un increíble rigor metodológico y, a la vez, explorar nuevos caminos. A ellas dos, mis directoras, por haberme acompañado, cuidado y aconsejado durante todo este tiempo. También a Lucía, por ser cómplice en esta aventura como co-directora de una tesis fin de master que ha sentado las bases de todo lo que, cinco años más tarde, es esta investigación.

Quiero agradecer también a Andreas por abrirme las puertas del Law\&Theory Lab en Londres en el invierno de 2018, por las discusiones, primero en su despacho y continuadas después por correo electrónico acerca de la ley, el cuerpo y el espacio. Sin esta visión imposible de situar en una única disciplina la tesis no se sustentaría con la misma solidez sobre los conceptos que lo hace.

A Ignacio, Branda, Cristina, Débora, Sergio, Laurent, David y el resto de personas de los encuentros en Bilbao por haber propiciado debates tan necesarios entre diferentes disciplinas. Especialmente a Ignacio y Branda, por su generosidad a la hora de contar conmigo en Bilbao año tras año, haciéndome ver la necesidad de abordar la frontera y espacio securitario contemporáneo también desde la arquitectura. A Ibon, Ula y Blanca por invitarme a participar en Geografias y formas de poder, y reconocer en la cartografía una herramienta útil para abordar la realidad. Al conjunto de personas con las que he coincidido en diferentes foros, por permitirme mostrar, confrontar, retomar y cuestionar todo lo que he ido produciendo.

A Graft, comisarios del Pabellón Alemán de la Bienal de Venecia, por darme la beca Unbuilding Walls, y ofrecerme la oportunidad de viajar con detenimiento y recorrer una vez más todos los lugares analizados en la tesis. Sin duda alguna, el trabajo de campo realizado gracias a ellos ayudó a constatar los hallazgos obtenidos.

A las personas que forman el Departamento de Proyectos, por sus aportes. A mis compañeras del Máster de Proyectos, por haber viajado también a la frontera. A Gaizka, Felipe, Borja y demás compañeros del doctorado, porque este camino compartido se lleva mejor. A Juan y Fernando, por sus indicaciones, conversaciones e intereses compartidos. A Sergio y Luis, por haberme obligado a posicionarme a la contra de una ortodoxia y un modo de entender la investigación que limita en vez de proponer nuevos caminos. A la Secretaría del Departamento por su ayuda y, especialmente, a Blanca por su infinita paciencia.

A Magdalini, Ana, Luis, Jesús y Juan por haber hecho una lectura tan atenta del manuscrito completo. Y también a Ignacio, Andreas, Lucía, Miguel, María, Débora y Uriel por haberse prestado a formar parte del tribunal.

Esta tesis se construye también de afectos que van más allá de lo académico. A Pablo, por haber experimentado juntos a lo largo de estos años la potencia de muchas ideas e intuiciones que también impregnan las páginas de esta investigación. A Belén, por su hospitalidad y amistad. A Carlos y Duarte, por estar siempre ahí. A Laura, por haberme desbordado con su calidez en la recta final.

Por último, tengo que agradecer a mis padres el amor que me han transmitido por el saber, por la investigación pero también por la necesidad de posicionarse políticamente. A mis padres, pero especialmente a mi madre, por sus ánimos constantes, paciencia y amor a lo largo de estos años. A ella, por desde el primer momento animarme y hacer todo lo posible para que esta tesis llegase a buen puerto. 

ABSTRACT
RESUMEN 
The Border, despite the deceptive simplicity of geopolitical maps, hides in its thickness an enormous complexity linked to its construction. The contemporary Border -versus the precise immaterial line traced over the map-articulates through multiple constructions, human and non-human agents that expand their logic over any point over the territory. The Border configures an infrastructure that adapts precisely to precise needs, that is always changing, and that adopts multiple configurations. Therefore it can only be enounced as an apparatus: The Border Apparatus. The Border, therefore, as an assemblage that needs to be mapped from the architectural discipline to unveil the spatial consequences of a specific mode of territorial and spatial production. A mode, based on exceptionality, that not acts building clear boundaries but variable intensities fields. In these fields, the mere presence of certain bodies triggers and deploy -instantaneous and temporary- architectural assemblages that respond with high precision to each situation to neutralize it. We have named this body, which positions itself physically in denied political space, migrant body. This research has been based on the architectures and scenarios that this body occupies to revert the spatial violence they suffer.

Naming the Border as an apparatus of territorial production, events that appear as not connected can be seen as a whole to comprehend which logics, procedures and characteristics conform them. To do so, it is a necessary position the research in the intersection between Law, body, and space. And, from there, interrogate the potential of each of these three variables in borderspace production. A law that is not only understood as written Law, but wholly embodied in the architectural matter, a body that is not human but assembled with other realities and a space that emerges as a dynamic intertwining between Law and Body, but that also modifies both.

Thus, this doctoral research appears as an operative cartography that unveils contemporary border spatial production modes -focused on the Spanish Border-, through a path that connects three different scales and expands the scapes associated with it. The research shows how the Border has overlayed over the whole territory -by increasing order of deterritorialization-, from the stable architecture of the fence, the enclosure's architectures, to post-metropolitan Border. A territorial apparatus that operates as a software including in their spatial production agents of different nature. Agents that are temporary captured transformed or altered to generate a specific spatiality. But it is also an apparatus that can be altered by the transgression of a body that claims -through minor architectural tactics- their right to produce their own spatiality. 
La frontera, pese a la simplicidad falaz de los mapas geopolíticos, esconde en su espesor una inmensa complejidad ligada a su construcción. Frente a la línea inmaterial trazada con precisión sobre el mapa, la frontera contemporánea se articula a través de múltiples construcciones, edificios, agentes humanos y no-humanos capaces de expandir sus lógicas a cualquier punto del territorio. Esto configura una infraestructura territorial que se adapta con precisión a las necesidades de cada momento, cambiante y que adopta múltiples configuraciones, y por tanto solo puede ser enunciada como un dispositivo: el dispositivo frontera. Este complejo ensamblaje necesita ser cartografiado desde la disciplina arquitectónica para desvelar las consecuencias espaciales de un modo de entender los territorios y espacios que ya no opera en base a la construcción de recintos claros sino a través de la creación de campos de intensidades variables. Campos donde la presencia de determinados cuerpos detona y despliega ensamblajes arquitectónicos efímeros e instantáneos que responden con gran precisión para neutralizar y contenerlos. A este cuerpo, que se sitúa físicamente en un espacio que políticamente le es negado, lo hemos llamado el cuerpo migrante. En base a las arquitecturas y escenarios que transita, subvierte y transforma para revertir la violencia espacial que sufre en sus carnes hemos construido esta tesis doctoral: una cartografía operativa que desvela los modos de producción espacial de la frontera contemporánea.

Al enunciar la frontera como un dispositivo de producción territorial, sucesos y escenarios que parecían independientes entre sí pueden conectarse para comprender qué lógicas, procedimientos y características los conforman. Para ello, es necesario situarse en la intersección entre norma, cuerpo y espacio, y desde ahí entender la potencia que cada una de estas tres variables ejerce en la construcción del espacio fronterizo. Una norma que no es sólo entendible como ley escrita, sino que está plenamente embebida en la materia arquitectónica; un cuerpo que ha dejado de ser humano para ensamblarse con otras realidades y un espacio que surge como interrelación dinámica de las anteriores dos y, a su vez las modifica.

Así pues, esta tesis doctoral se presenta como una cartografía operativa que desvela los modos de producción espacial de la frontera contemporánea, centrado en el caso español, a través de un recorrido por tres escalas que expande los paisajes asociados a ella. Por orden creciente de desterritorialización, desde la arquitectura más sólida asociada a la frontera -la valla-y las arquitecturas del internamiento, hasta la postmetropolis, la investigación muestra cómo la frontera se ha superpuesto a la totalidad del territorio. Un dispositivo territorial que opera como un software, incluyendo en su construcción espacial agentes de diferente naturaleza, a los que captura, transforma y altera de manera temporal para generar una espacialidad determinada; pero también un dispositivo capaz de ser alterado por la transgresión de un cuerpo que reclama -desde tácticas menores- su derecho a construir la suya. 

ÍNDICE 
1.1. “SECURE THE BORDER! BUILD A WALL!”

1.1.1. "Va a ser un muro real". Evolución del muro entre Mexico y Estados Unidos 21 (2014-2018).

1.1.2. "If we don't have borders, we don't have a country".Función simbólica del 24 muro.

1.2. “Building the wall?" El muro como materia arquitectónica.

1.2.1. "WE WON'T BUILD YOUR WALL." Oposición al muro.

1.2.2. "We take no position. We remain politically neutral". El muro como problema de diseño.

1.3. “China built a wall that's 13,000 miles long 2,000 years ago. My ambition is for ours to be much higher." La construcción del muro y su funcionamiento operativo.

1.3.1. "Va a ser un muro grande, gordo y bonito". Ocho muros en el desierto.

1.3.2. "WE WILL NOT LET THEM THROUGH". Construcción del cuerpo migrante.

1.4. Otros muros.

1.4.1. Europa como muro (1990-2018).

1.4.2. España como laboratorio de prácticas de construcción de frontera.

1.4.3. El muro estadounidense como reflejo.

\section{INTRODUCCIÓN.}

2.1. Objetivos e hipótesis de la investigación. Desvelar las implicaciones arquitectónicas de la frontera contemporánea.

2.2. Estrategia de investigación. Entre lo material y lo virtual.

2.3. Estructura y contenidos.

2.4. Metodología. Devenir cartógrafos y forenses.

2.5. Una aproximación al estado de la cuestión. Estudios, paisajes y estéticas fronterizas.

*Interludio A: Una aproximación territorial a

la lógica de los dispositivos

\section{LA VALLA. ARQUITECTÓNICAS DE DELIMITACIÓN E IMPERMEABILIZACIÓN.}

3.1. Un cuerpo sobre la línea.

3.1.1. Arquitecturas punitivas. Carne, cuerpos y arquitectura.

3.1.2. Evolución histórica de la materialización arquitectónica de la frontera.

3.2. Ensamblajes territoriales de las líneas fronterizas.

3.2.1. Arquitecturas dispersas.

3.2.2. Ensamblajes territoriales de Ceuta y Melilla.

3.2.3. La inoperancia de la arquitectura de la norma. Mecanismos arquitectónicos efímeros en el paso fronterizo del Benzú.

3.3. Fronteras elásticas, arquitecturas operativas y sistemas de impermeabilización de masas.

3.3.1. Introducción.

3.3.2. Fronteras elásticas.

3.3.3. Despliegues operativos y sistemas de impermeabilización de masas.

3.4. Subversión de funciones arquitectónicas a través de la operatividad. El papel de la puerta. 


\section{ARQUITECTÓNICAS DEL INTERNAMIENTO Y LA DEPORTACIÓN.}

4.1. Transformación tipológica. Evolución histórica: desde la prisión franquista al CIE contemporáneo.

4.1.1. Origen histórico de los CIEs y su encaje normativo. Evolución y transformación.

4.1.2. El CIE como extensión del calabozo policial. CIEs de primera generación (1985-1989).

4.1.3. El CIE como arquitectura apropiada. ClEs autónomos (1990-2005) .

4.1.4. El CIE de segunda generación. Renovación higienista e institucionalización del internamiento (2005-2011).

4.2. Hacia un CIE desterritorializado. Estado actual de los Centros de Internamiento en funcionamiento y alternativas espaciales.

4.2.1. Infraestructura territorial actual.

4.2.2. Hacia los estándares penitenciarios. El CIE de Algeciras y su visibilización mediática.

4.2.3. Alternativas espaciales.

4.3. CIES interconectados. Del funcionamiento autónomo a dispositivos operativos.

4.3.1. Especialización territorial y funcionamiento en red.

*Interludio C: De territorios a cuerpos.

5. LA POST-METRÓPOLIS. ARQUITECTÓNICAS DEL CONTROL EN ESPACIOS URBANOS.

5.1. Llevar la frontera a cuestas.

5.2. Fronteras extensivas. Normativas, operaciones policiales y espacio público.

5.2.1. El paisaje legal de la Unión Europea

5.2.2. Operación Mos Maiorum. Protocolos y espacio público

5.3. Dispositivos espaciales de control en entornos urbanos. Lavapiés como

5.3.1. Características y consecuencias urbanas del Plan Integral de Mejora de la

Seguridad y Convivencia de Lavapiés

5.3.2. Sistemas de vigilancia pasiva y activa

5.3.3 Arquitecturas cómplices. El papel de la arquitectura urbana en el control espacial

5.3.4 Enclaves urbanos y espacio público ritualizado

5.4. Los manteros como paradigma de la frontera encarnada.

5.4.1. Ocupaciones temporales y criminalización de la venta ambulante. El caso

6. CONCLUSIONES. LA FRONTERA COMO OBJETO MÚLTIPLE E INABARCABLE. 



\section{WOULD NOT WE BUILD YOUR WALL?}

1.1. “SECURE THE BORDER! BUILD A WALL!"

1.1.1. "Va a ser un muro real". Evolución del muro entre Mexico y Estados Unidos (2014-2018).

1.1.2. "If we don't have borders, we don't have a country".Función simbólica del muro.

1.2. "Building the wall?" El muro como materia arquitectónica.

1.2.1. "WE WON'T BUILD YOUR WALL." Oposición al muro.

1.2.2. "We take no position. We remain politically neutral". El muro como problema de diseño.

1.3. "China built a wall that's 13,000 miles long 2,000 years ago. My ambition is for ours to be much higher." La construcción del muro y su funcionamiento operativo.

1.3.1. "Va a ser un muro grande, gordo y bonito". Ocho muros en el desierto.

1.3.2. "WE WILL NOT LET THEM THROUGH". Construcción del cuerpo migrante.

\subsection{Otros muros.}

1.4.1. Europa como muro (1990-2018).

1.4.2. España como laboratorio de prácticas de construcción de frontera.

1.4.3. El muro estadounidense como reflejo. 
SECURE THE BORDER! BUILD A WALL! 


\subsection{SECURE THE BORDER! \\ BUILD A WALL!'}

\subsection{1 "VA A SER UN MURO REAL". LA EVOLUCIÓN DEL MURO (2014-2018)}

Va a ser un muro real, va a ser un muro alto, va a ser un muro bonito, va a ser un muro que funcione ${ }^{2}$.

Donald Trump

Con tan sólo veintisiete caracteres, el 5 de agosto de 2014 a las 13:34, Donald Trump esbozaba por primera vez una de las máximas que definirían su discurso político. Prácticamente un año antes del inicio de su campaña oficial para la presidencia de Estado Unidos pronunciaba una idea tan vaga como rotunda: "PROTEGER LA FRONTERA! CONSTRUIR UN MURO!"3. Su tuit encerraba un statement político e ideológico que enarbolaba la lucha contra la inmigración centroamericana como uno de los ejes claros de su gobierno, pero también suponía un auténtico statement arquitectónico, al implicar la transformación de más de $3200 \mathrm{~km}$ lineales de frontera en una construcción sólida y rotunda. Los bocetos y acciones de Christo y Jeanne Claude, las acciones de Richard Long dibujando una línea sobre el terreno, las intervenciones de Smithson o los collages de Superstudio cobraban una dimensión distópica y mucho más tangible al plantearse simplemente la posibilidad de que una infraestructura territorial tan clara, simple y a la vez violenta en su materialización -un muro- recorriese sin detenerse ante nada la línea geopolítica que separaba Estados Unidos de Méxicó. Pero, además, sus palabras a lo largo de toda la campaña tuvieron ecos y movimientos en la comunidad arquitectónica estadounidense lo que demuestra cómo una construcción tan simple y aparentemente ajena a la disciplina interpelaba de manera directa a arquitectos y urbanistas que sentían que la materialización de un muro constituía también parte de la materia arquitectónica.

1 Donald Trump, SECURE THE BORDER, BUILD A WALL!, 5 de agosto de 2014, 13:34. https://twitter.com/realDonaldTrump/status/496756082489171968

2 Face the Nation. Programa del 23 de agosto de 2015. CBS,23 de agosto de 2015.

3 Existen varias referencias anteriores a la necesidad de proteger y reforzar la frontera -“Un país que no puede proteger sus fronteras es un país destinado al fracaso. Otra promesa rota por nuestros líderes en Washington”, "Si nuestra frontera no es segura, podemos esperar otro ataque. Un país con fronteras abiertas está abierto a los terroristas”-. Sin embargo, esta es la primera referencia pública donde reclama la necesidad de construcción de un muro. Añadir referencias.

$4 \mathrm{El}$ discurso poético de los artistas y arquitectos mencionados había sido sustituido por el discurso político de Donald Trump y el partido al que representaba. Hasta el propio New York Times se preguntaba encabezaba un artículo tras la construcción de los prototipos del muro en el desierto californiano si “¿Es Donald Trump, constructor jefe de muros, un artista conceptual?”. Es importante señalar que al igual que en todos estos artistas, la potencia de calado del discurso y su influencia a lo largo del tiempo en una audiencia más amplia no requiere la materialización física de la obra para que ésta alcance su máximo impacto a todos los niveles, mediático y político en el caso de Trump. Añadir referencia
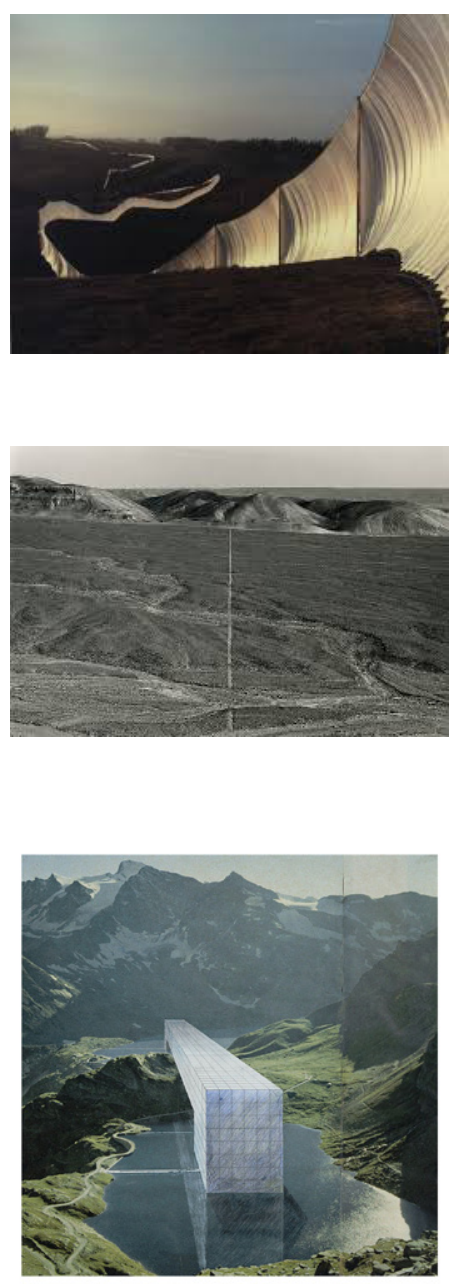

Running Fence, Christo y Jeanne Claude (California, 1976).

Walking line, Richard Long (Wiltshire, 1967).

The Continuous Monument, Superstudio (1969). 

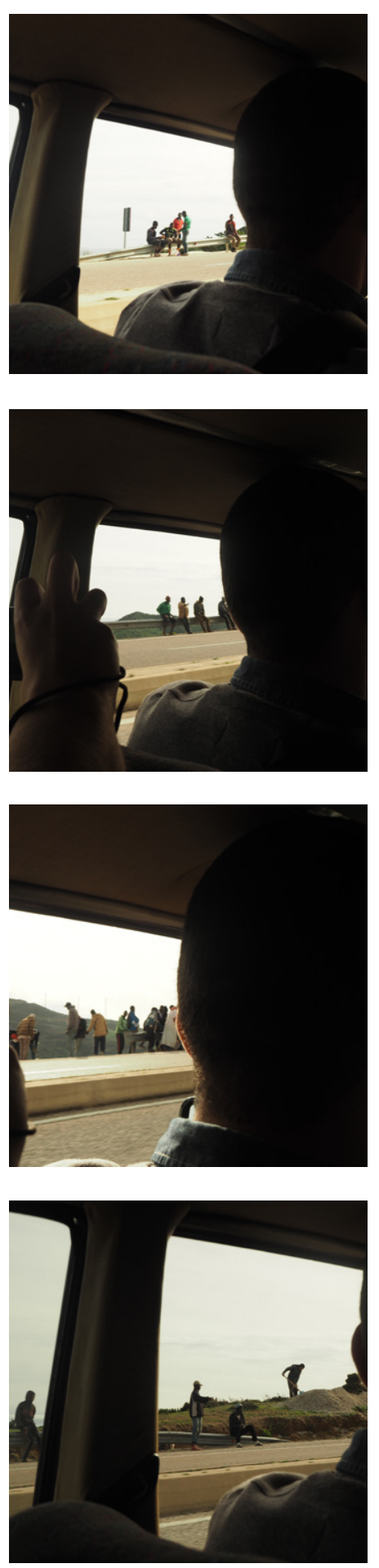

Migrantes en los montes marroquís limítrofes con Ceuta (Elaboración propia; Marruecos, 2014).
Tan solo dos meses después de la publicación del tuit, arrancaba esta investigación en el marco del Máster de Proyectos Arquitectónicos Avanzados, como parte de un laboratorio de investigación que durante dos cuatrimestres y bajo el título Borderscapes, pretendía analizar la realidad múltiple y compleja de un entorno geográfico tan singular como el del Estrecho de Gibraltar a través de la superposición de investigaciones individuales sobre un mismo territorio. Como parte del trabajo de campo, nos desplazamos hasta la Ciudad Autónoma de Ceuta, donde tuvimos oportunidad de estar a escasos metros de una valla que ha sido objeto de infinidad de cruces - así como de polémica por la violencia que es capaz de desplegar contra los cuerpos que la cruzan-. La aparente fragilidad física de su materialización nos hizo ver que no solo a través del muro se estaba construyendo la frontera, sino que eran necesarias otras tecnologías -técnicas y humanas- que lograsen asegurar la función espacial de la valla: impedir cruces no regulados; algo que hasta el propio Trump llegó a considerar: "no necesitas un muro completo porque tenemos gente maravillosa, la Border Patrol, que pueden hacer el trabajo. Pero sí necesitas muros en ciertas secciones, sin ninguna duda"s. Por ello, aparte de visitar las vallas fronterizas de Benzú y Tarajal -donde meses antes habían muerto catorce personas ahogadas entre los disparos de pelotas de goma por parte de fuerzas policiales-, visitamos otras arquitecturas y escenarios vinculados a la construcción de la frontera a un lado y otro del Estrecho. Así, nos aproximamos al CIE de Isla Palomas, en Tarifa, una antigua infraestructura militar hoy reconvertida en centro de internamiento de extranjeros, lugar de retención y acogida de migrantes recién llegados en patera. Una construcción muy similar a la que Matthew Albance, número dos del Departamento de Inmigración y uno de los responsable políticos del dispositivo de detención de migrantes en Estados Unidos calificaba de "campamento de verano [...] con oportunidades recreacionales y educativas" ${ }^{6}$, a pesar de que las imágenes tuviesen gran impacto mediático por sus deficientes condiciones espaciales. Por último, también recorrimos la carretera que atraviesa los montes marroquíes próximos al perímetro de Ceuta, donde nos encontramos con multitud de migrantes, la otra cara del muro de Trump. Y es que, como señala Thomas Nail en sus libros conectados Theory of the border ${ }^{7} \mathrm{y}$ The figure of the migrant ${ }^{8}$, el análisis de la frontera no puede separarse de las figuras que la cruzan y que a través de sus prácticas de resistencia la definen. Un hecho que también comprendió Trump al construir su muro sobre la figura de los migrantes centroamericanos, convirtiéndolos en un Enemigo al que se le debía impedir el paso a toda costa; así, en un discurso plagado de inconsistencias, el migrante que pretendía entrar por la frontera se convertía en traficante de drogas, asesino, o incluso terrorista del ISIS -"LOS TERRORISTAS PUEDEN ATRAVESAR LA FRONTERA MEXICANA A VOLUNTAD"9-. Y, sobre esta amenaza, consiguió levantar el muro.

Prácticamente al mismo tiempo que Donald Trump se postulaba como aspirante a candidato presidencial por el Partido Republicano -aparentemente sin muchas probabilidades de conseguirlo-, esta investigación se comenzaba a gestar en forma de tesis fin de máster, donde se defendía, utilizando el barrio de Lavapiés como el caso de estudio principal, que la frontera no era solo constituida por un muro sino por un dispositivo que conectaba diferentes arquitecturas, agentes y

5 Entrevista con Donald Trump en el Erin Burnett Outfront, programa del 25 de junio de 2015. CNN, 25 de junio de 2015 .

6 Tal Kopan, « ICE official stands by comparing detention centers to 'summer camp,' won't say if he'd send his kids to one.», CNN, I8 de septiembre de 2018.

7 Thomas Nail, Theory of the Border (Nueva York: Oxford University Press, 2016).

8 Thomas Nail, The figure of the migrant (Stanford: Stanford University Press, 2015).

9 Donald Trump, @Americanist: @ofccadjust@AnnCoulter GW Bush was open borders like @JebBush. TERRORISTS CAN COME ACROSS MEXICAN BORDER AT WILL!”, I8 de octubre de 2015, 21:59. https://twitter.com/realdonaldtrump/status/655853353793159168 
espacios. La frontera no era una línea construida, sino algo que iba mucho más allá de ella. Desde la presentación de "El dispositivo frontera: la construcción espacial desde el cuerpo migrante y el aparato de estado" ${ }^{\circ}$, en octubre de 2015, hasta la redacción de esta tesis doctoral, el discurso de Trump ha ido evolucionando y modulándose, como veremos a continuación. Los acontecimientos se han sucedido, sobrepasando en muchos casos la planificación de la agenda política. Sin embargo, lo que en 2015 veíamos aún como intuiciones palpables respecto a la realidad de la frontera -dispersión geográfica, carácter dinámico, relevancia arquitectónica, pérdida de relevancia del muro como sistema de control espacial...-, tres años después se han confirmado a un y otro lado del Atlántico. Por ello, a pesar de la distancia geográfica que el muro de Trump presenta respecto al campo de estudio de nuestra investigación, este paralelismo cronológico y la relevancia mediática que ha tenido a nivel global, nos obliga a detenernos en estos acontecimientos antes de profundizar en la construcción de la Frontera sur en España. Además, la claridad y vehemencia de su discurso durante los últimos años, así como las diferentes reacciones que ha tenido nos permite entender las relaciones -no exentas de conflicto- entre el discurso político y su materialización arquitectónica; de la misma forma el papel que como diseñadores desempeñamos en la construcción de estas arquitecturas, puesto que nuestra postura nunca es neutral.

El muro de Trump se iba definiendo con palabras a medida que su carrera hacia la presidencia de Estados Unidos avanzaba; un proyecto territorial que modificaba su programa y materialización en función de ruedas de prensa, tuits y entrevistas. Tanto su forma como su función se transformaban a través de su deriva política, su implantación en el territorio disminuía a medida que era contestado por expertos u opositores -"Son dos mil millas [de muro], pero necesitamos mil; existen barreras naturales. Necesitamos mil millas" ${ }^{\text {II-, }}$ al contrario que su altura, que si un principio la fijaba en "treinta y cinco a cuarenta pies [diez a doce metros] de alto. Eso es alto. Eso es un verdadero muro" ${ }^{12}$, aumentaban en función de la tensión generada con el gobierno mexicano -"acaba de crecer otros tres metros"-. En la evolución de su discurso también se puede observar como el territorio pasa de ser un simple medio -un plano base y abstracto sobre el que se superpone una realidad material- a un agente activo, que puede llegar a ser utilizado como una tecnología más de frontera - "Tenemos montañas que son mucho mejores que un muro. Tenemos ríos violentos a los que nadie se acerca... No se necesita un muro donde hay una barrera natural que es mucho mejor que cualquier muro que podría construirse ¿ok?” ${ }^{13}$; una realidad que en el contexto europeo ha sido

10 Antonio Giráldez López, « El dispositivo frontera: la construcción espacial desde el cuerpo migrante y el aparato de estado» (Tesis fin de máster en Proyectos Arquitectónicos Avanzados, Universidad Politécnica de Madrid, 2015).

11 "Speech: Donald Trump in Manassas, VA", vídeo de Youtube, 1:19:15. Factbasevideos. 2 de diciembre de 2015. https://www.youtube.com/watch?v=sVvUZEcXoUU

12 Es necesario contextualizar la altura de este muro con otros homólogos reconocidos internacionalmente. El muro construido por Israel, de hormigón prefabricado, alcanza los 7 metros de alto y el grosor de todo el dispositivo arquitectónico que lo acompaña supera en puntos concretos los cien metros de espesor. Por su parte, la valla de Ceuta y Melilla, tras su ampliación en el año 2005, posee una altura de seis metros de alto y un espesor que puede superar los cincuenta metros de longitud contando el perímetro de seguridad establecido por el gobierno de Marruecos. Resulta curioso, viendo que la componente horizontal de estas construcciones, prima por encima de la componente vertical, que Donald Trump apele exclusivamente a la segunda. Es probable que, mientras la horizontal -en toda su complejidad de capas sucesivas y elementos de diferente naturaleza- tenga una mayor efectividad operativa, la vertical tenga una componente simbólica mucho mayor -tanto en el plano discursivo que maneja Donald Trump como en un plano fenomenológico para quien se enfrenta a ella-.

13 Wall Street Journal, « Transcript of Donald Trump Interview With The Wall Street Journal», The New York Times, I4 de enero de 2018. https://www.wsj.com/articles/transcript-ofdonald-trump-interview-with-the-wall-street-journal-151571548I 
empleada activamente al usar el Mediterráneo como una de las tecnologías más efectivas -y más mortíferas- de construcción de frontera. Todo ello podrían parecer simples eslóganes electorales, de no ser porque todas estas declaraciones estaban constituyendo, por un lado, un análisis de los principales factores intervinientes en la construcción de la frontera -materialización, implantación territorial, uso de recursos naturales como fronteras operativas, ejecución, inclusión de agentes dinámicos, disputa y fricción entre soberanías...- y por otro, un proyecto arquitectónico que tardaría poco en tomar forma.

\subsection{2 “IF WE DON'T HAVE BORDERS, WE DON'T HAVE A COUNTRY!” LA FUNCIÓN SIMBÓLICA DEL MURO.}

Donald Trump es consciente de que, por encima de las características técnicas y su materialización, de la altura o longitud total, e incluso la inviabilidad presupuestaria de fortificar los tres mil doscientos kilómetros de frontera estadounidense, se superpone una realidad discursiva que prima sobre todo lo demás. La funcion primaria del muro no es la detención efectiva de migrantes ilegales, tráfico irregular o entrada de terroristas a través de la impermeabilización de la línea soberana, sino la construcción de un discurso. La arquitectura, una vez más, encarna un símbolo y un discurso político de manera simple, efectiva y directa. $\mathrm{Al}$ igual que en el cuento de Kafka "La construcción de la muralla China" arquitectura opera como un vector de construcción nacional por encima de su funcionamiento efectivo. En este relato, el narrador nos advierte del fracaso de su función impermeabilizadora nada más empezar: "La Muralla, como universalmente se proclamó y como nadie ignora, había sido concebida como una defensa contra las naciones del Norte. Pero, ¿qué defensa puede ofrecer una muralla discontinua? Ninguna, y la Muralla misma está en incesante peligro." ${ }^{\prime 6}$, para prácticamente a continuación ofrecernos la clave de la verdadera función que encierra la construcción de la muralla:

Cada compatriota era un hermano para el que levantaban una muralla protectora y que les agradecería toda su vida, con todo lo que tenía y lo que era. ¡Unidad! ¡Unidad! Hombro contra hombro, una cadena de hermanos, una sangre no ya encerrada en la mezquina circulación del cuerpo, sino circulando con dulzura y sin embargo regresando sin fin a través de la China infinita. ${ }^{17}$

A lo largo del texto se explica con precisión un sistema de construcción nacional que logra crear un sistema de ordenación que cohesiona los diferentes pueblos de China ante la amenaza inexistente de un único enemigo, tan abstracto como temido por cualquier siervo del emperador: los Pueblos del Norte. La vocación de construcción nacional a través de un solo enemigo común, y su defensa a través de una única construcción arquitectónica es algo que Donald Trump afirma explícitamente -"Una nación SIN FRONTERAS, no es del todo una nación. Debemos tener un muro. El cumplimiento de la ley importa", "Nosotros, como país, o tenemos fronteras o no las tenemos. SI NO TENEMOS FRONTERAS, NO TE-

14 Donald Trump, We, as a country, either have borders or we don't. IF WE DON'T HAVE BORDERS, WE DON'T HAVE A COUNTRY!, I2 de noviembre de 2015, o7:50.

15 Franz Kafka, «La construcción de la muralla china», en Cuentos Completos (Madrid: Valdemar, 2010).

16 Kafka, «La construcción de la muralla china».

17 Kafka, «La construcción de la muralla china». 
NEMOS UN PAÍS”18_. Así, la frontera, como infraestructura territorial, se convierte en un "dispositivo de construcción nacional estrechamente ligado al Estado y su cuerpo militar", como señala Keller Easterling respecto a la importancia de los relatos en el espacio infraestructural, para puntualizar a continuación la desconexión latente entre discurso y funcionamiento operativo; es decir, entre su función pública y sus funciones reales.

El énfasis desmesurado que Donald Trump ha hecho en la necesidad de construir el muro constata una realidad que, de manera global se ha producido durante las últimas décadas, con un especial incremento desde la caída del muro de Berlín en 1989: la aparente necesidad de fortalecimiento ante fuerzas que ya no son nacionales -Estados-, sino extranacionales o infranacionales. A través de materializaciones y discursos diversos, el muro como encarnación de la frontera, y por tanto como extensión última de la soberanía estatal, ha cobrado especial relevancia con ejemplos tan claros como la valla de Ceuta y Melilla, el muro de Israel o la fortificación del paso de Calais - pero también con los grandes campamentos de refugiados próximos a los pasos fronterizos de varios países africanos y Oriente Medio, o los centros de detención que se replican por todo el mundo, otras tipologías arquitectónicas vinculadas indisolublemente a la frontera-. Sin embargo, todos ellos, repiten un mismo esquema que Wendy Brown ha señalado en su obra Estados amurallados, soberanía en declive ${ }^{19}$, la espectacularización y grandilocuencia de su materialización arquitectónica contrasta con el fracaso del poder soberano, nacional y estatal que pretenden representar:

A pesar de sus dimensiones impresionantes y contundentes, los nuevos muros funcionan a menudo como escenificaciones teatrales, proyectando un poder y una eficacia que en realidad no ejercen ni pueden ejercer y que ellos mismos contradicen performativamente. [...] Esta teatral y espectacular performance del poder soberano en las fronteras nacionales soñadas o reales pone de relieve el residuo teológico que subsiste en la soberanía del Estado nación. Aunque los muros no ejerzan realmente la disuasión que ha sido su impulso y su legitimación, y aunque institucionalicen perversamente el estatus discutido y degradado de los límites que ellos delimitan, escenifican tanto la jurisdicción soberana como un aura de poder soberano y temor reverencial. Los muros soportan así la ironía de ser entidades mudas, materiales y prosaicas, y a la vez potencialmente generadoras de un temor reverencial teológico para nada relacionado con su funcionamiento y fracaso cotidiano ${ }^{20}$.

La arquitectura se convierte en una mera representación física de unos valores o funciones que poco o nada tienen que ver con aquellas que rigen su construcción. Hay una desviación crítica entre las intenciones declaradas y las no declaradas de toda producción arquitectónica, desviación fácilmente detectable en una construcción de este tipo, muy próxima a las infraestructuras militares al estar aparentemente desposeída de toda retórica. Y es que, como afirma Easterling al señalarnos donde debe ponerse el foco "algunos de los resultados políticos de mayor relevancia del espacio infraestructural no se declaran en los relatos que los retratan. La información reside en las tecnologías así como en las intenciones declaradas o discursos" ${ }^{21}$. Este paralaje explícito entre la operatividad y la capacidad simbólica de la arquitectura no es ajeno al candidato Trump, que juega con él consciente de la construcción discursiva que está realizando más allá de la materialización que, tres años después del inicio de su campaña, comienza a ser levantada en la frontera.

18 Trump, 2 de noviembre de 2015, 07:50.

19 Wendy Brown, Estados amurallados, soberanía en declive (Madrid: Herder Editorial, 2015).

20 Brown, Estados amurallados, soberanía en declive (2015), 36.

21 Keller Easterling, Extrastatecraft, (Londres: Verso, 2014). 


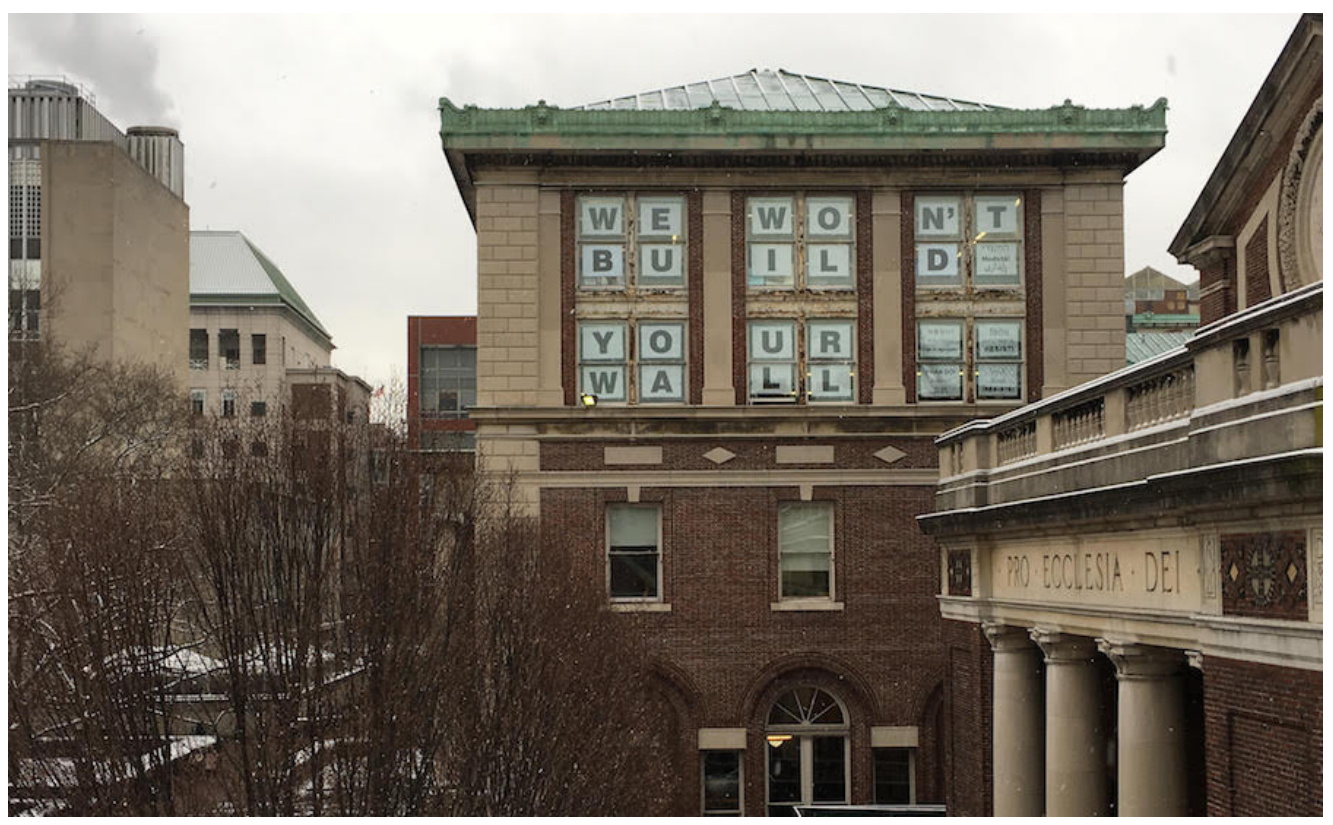

Instalación de pancarta con el lema We Won't Build Your Wall en la Escuela de Arquitectura de Columbia (Biayna Bogoi-

sian; Nueva York, 2017) 


\subsection{BUILDING THE WALL? \\ EL MURO COMO MATERIA ARQUITECTÓNICA.}

\subsubsection{WE WON'T BUILD YOUR WALL. LA OPOSICION AL MURO.}

Durante demasiado tiempo, los arquitectos han sido cómplices del enjaulamiento de humanos diseñando y construyendo estas estructuras. Los arquitectos han diseñado las instalaciones donde los niños llaman a sus padres por las noches. También han diseñado la extensiva red de instalaciones donde sus padres tiemblan en frías celdas de detención. La historia nos ha enseñado que lo que es estrictamente legal no es siempre justo. Ha llegado el momento de terminar con esto. Hacemos una llamada para que se unan a nuestro compromiso: Nosotros no diseñaremos jaulas para gente ${ }^{22}$.

ASDPR y The Architecture Lobby.

Hay ocasiones para levantarse, nombrar un oponente, o asumir una estancia binaria de resistencia contra un poder autoritario, pero suplementando a estas formas de disenso hay posiciones activistas que son a la vez difíciles de localizar y menos interesadas en tener razón. Así como varios de los regimenes mundiales más poderosos encuentran oportuno operar con proxies y dobles en el espacio infraestructural, las formas más comunes de activismo se podrían beneficiar de usar aliados no declarados o ayudantes no ortodoxos, aunque sólo sea para allanar el camino y ofrecer una posibilidad mayor de éxito ${ }^{23}$. Keller Easterling.

En los días próximos a las elecciones del 20 de enero de 2017 -donde Donald Trump finalmente consiguió acceder al despacho presidencial-, apareció el siguiente mensaje en varias universidades estadounidenses: "No construiremos tu muro". Impresos al mayor tamaño posible, los estudiantes de arquitectura de Columbia ocuparon, con cada letra, todas las ventanas de una de sus fachadas ${ }^{24}$. En la universidad de Yale, todo el ventanal del tercer piso estaba empapelado con la misma frase sobre fondo negro. Una acción que se repitió por varias universi-

22 «Statement on Inmigration Enforcement», ASDPR, acceso el 12 de mayo de 2019. https:// www.adpsr.org/blog/2018/8/8/statement-on-immigration-enforcement-in-the-united-states?rq=cages

23 Easterling, Extrastatecraft: The power of infrastructure space, (Londres: Verso, 2014), 213.

24 Son innegables los ecos en esta acción del grupo The Architect's Resistance, surgido en esta misma universidad al calor de las protestas estudiantiles en 1968 a los que posteriormente se unieron estudiantes, personal y profesionales de otras universidades -entre otras Yale-. Este grupo de acción o lobby, tal como ellos mismos se han definido, tomó posición política a través de la redacción de panfletos, organización de piquetes y exposiciones frente a diferentes temas por los que ni la Academia ni la disciplina del momento se sentían directamente interpelados. Dos de los objetivos claros de su movilización política y arquitectónica fueron las instalaciones nucleares y la materialización del apartheid a través de la arquitectura y el planeamiento urbano. No sólo los ecos del \#wewontbuildyourwall se sienten en la comunidad educativa, sino en el espacio mismo. El hall de la biblioteca Avery, a escasa distancia del ventanal donde fueron desplegados los mensajes, también fue escenario de protestas donde el compromiso político de la arquitectura adquiría un nuevo significado. En 1968, la Black Architectural Resistance, en el marco de protestas estudiantiles en contra de la segregación racial, apuntaba directamente a la disciplina arquitectónica al reclamar una nueva relación de la arquitectura y el urbanismo con las comunidades afroamericanas, así como la propia ocupación de la universidad de Columbia dentro de Harlem. Hechos que son recogidos por Sharon E. Sutton en su libro Cuando las torres de marfil eran negras. 


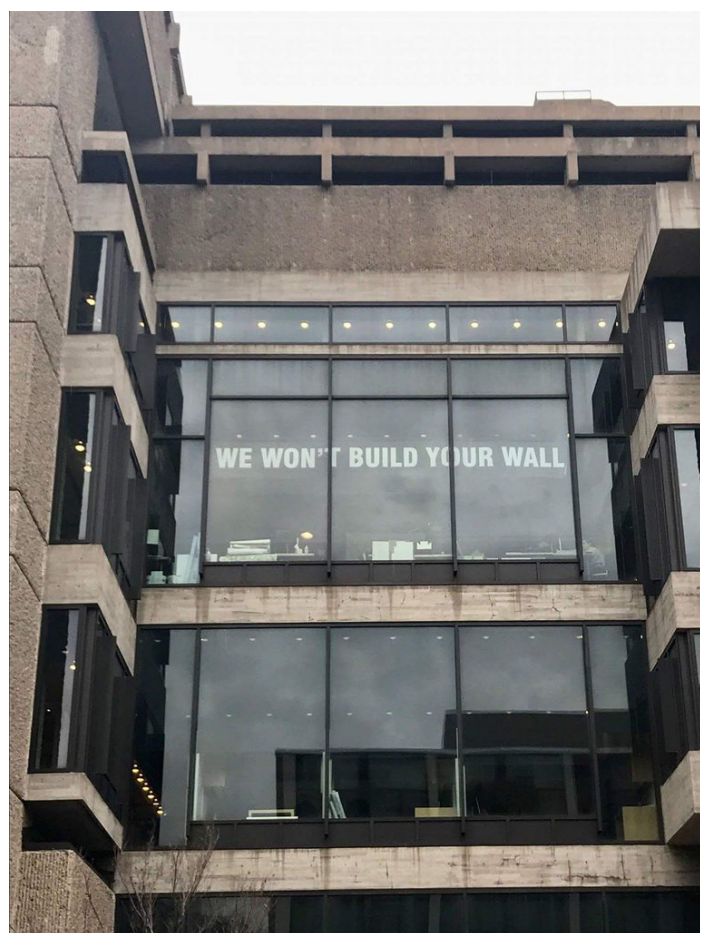

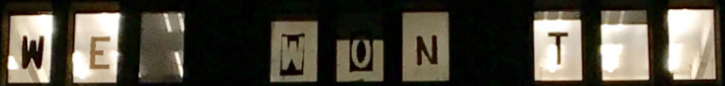

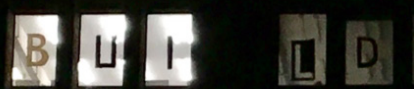

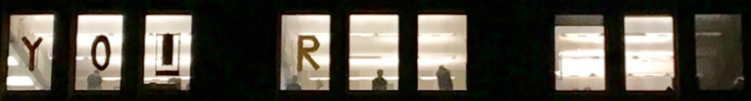

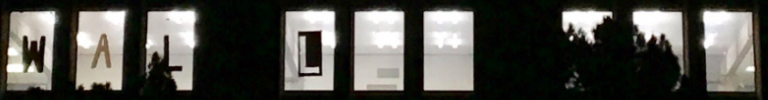
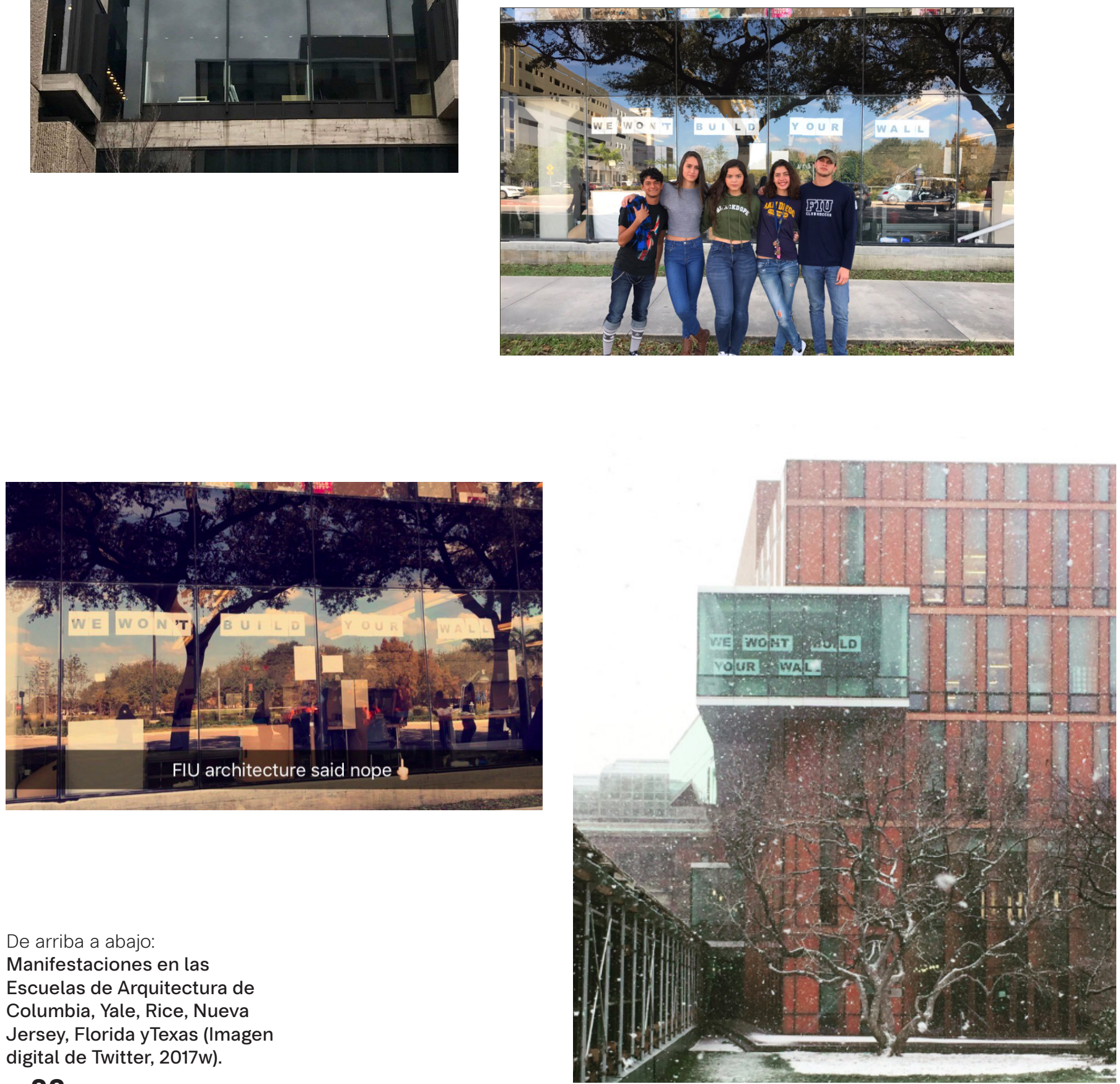

De arriba a abajo:

Manifestaciones en las

Escuelas de Arquitectura de

Columbia, Yale, Rice, Nueva

Jersey, Florida yTexas (Imagen

digital de Twitter, 2017w). 
dades estadounidenses; Barnard, Rice, Nueva Jersey, Florida, Texas, apoyada por una movilización mediática bajo el hashtag homónimo \#wewontbuildyourwall y protestas estudiantiles en los diferentes campus. El posicionamiento de la Academia parecía claro, no sólo no estaba dispuesta a ser la mano ejecutora del muro entre Estados Unidos y México, sino que además rechazaba frontalmente esta decisión política. Pero, por encima de eso, la Academia estadounidense reconocía el muro como una agencia disciplinar de la que eran parte, tanto durante el proceso de diseño como en la ejecución. El muro, por tanto, era materia arquitectónica incluso antes de haber sido levantado.

Esta ola de indignación no se limitó al plano educativo sino que adquirió ecos en el ámbito profesional dos meses más tarde, al mismo tiempo que el Departamento de Seguridad Nacional, Aduanas y Protección de Fronteras [DSNAPF en adelante] publicaba las bases del siguiente concurso el 24 de febrero de 2017:

Se solicita en formato electrónico el 6 de Marzo de 2017 el diseño y construcción del prototipado de varias estructuras de muros en las proximidades de la frontera entre México y Estados Unidos. El proceso será ejecutado en dos fases, la primera requiere a los participantes un diseño de su prototipo el ro de Marzo de 2017, que será evaluado y seleccionado el 20 de Marzo de $2017^{25}$.

Tras esta resolución, la organización sindical The Architecture Lobby ${ }^{26}$, con presencia en importantes ciudades estadounidenses, convocó un día de acción para el mismo día de entrega del concurso ${ }^{27}$. Bajo el hashtag \#notourwall, el documento de la convocatoria recogía un paro coordinado de "cuarenta y cinco minutos de acción colectiva de arquitectos e ingenieros para que abandonen sus puestos de trabajo y salgan a la calle a demostrar el poder de ampliar nuestra agencia individual" ${ }^{28}$. Una pausa de menos de una hora y una manifestación en la vía pública como un gesto menor y colectivo de resistencia frente a una decisión política, pero también laboral y disciplinar a la que se oponían frontalmente; y además como espacio-tiempo de encuentro y organización de futuras acciones orientadas contra las oficinas que finalmente concurriesen al concurso. Junto a esta llamada a la acción, planteaban otra serie de medidas específicamente orientadas a aquellos trabajadores y trabajadoras cuyas empresas estuviesen desarrollando el prototipo tales como la movilización colectiva de toda la plantilla o, en caso de no ser autorizados por la empresa, plantear reuniones para manifestar su desacuerdo frente a la elaboración de dicho proyecto. Sin embargo, más allá de una convocatoria concreta, el texto de Architecture Lobby recogía un posicionamiento disciplinar donde se asumían de manera clara la relación inherente entre arquitectura y política:

25 «Design-Build Structure», Federal Business Oportunities, acceso el 12 de mayo de 2019. https://www.fbo.gov/index?s=opportunity\&mode=form\&id=b8erb2a6876519caoaedd748ere49icf\&tab=core

26 Organización estadounidense de "trabajadores precarios" ligado a la industria arquitectónica organizada que aboga por el valor que puede aportar la disciplina para el bien común. A través de una organización en red formada por estudiantes y profesionales, han acometido diferentes proyectos fundamentalmente enfocados a la lucha contra la precarización laboral, así como al desarrollo de iniciativas que aumenten la relevancia social de la práctica arquitectónica.

27 Anteriormente el American Institute of Architects había denunciado en un comunicado oficial el riesgo que suponía denegar la entrada de ciudadanos de países de religión musulmana. Un comunicado planteado en términos de beneficios y costes para las empresas y oficinas que representaban - La restricción selectiva de áreas geográficas específicas puede provocar impactos comerciales profundamente negativos-.

28 La capacidad de acción conjunta de un cuerpo colectivo, que va más allá de la suma de individualidades para devenir un nuevo sujeto o agente, es una constante que -a través del cuerpo migrante- se recoge en cada uno de los capítulos de esta tesis. 
Mientras que hay innumerables razones para estar en contra de las políticas migratorias del presente gobierno y de este proyecto en concreto, esta convocatoria está motivada por la creencia de que los campos de la arquitectura y la ingeniería están fundamentalmente ligados a un objetivo de mejorar nuestras sociedades a través de la producción de estructuras que generen sociedades más justas, igualitarias y bellas. El muro en la frontera suroeste se encuentra en una posición opuesta a este fin.

$\mathrm{Al}$ participar en esta convocatoria, los arquitectos e ingenieros dejarán claro no sólo a esta y futuras administraciones, sino también a ellos mismos y al resto, que su agencia no será explotada al servicio de la xenofobia, la discriminación y el racismo ${ }^{29}$.

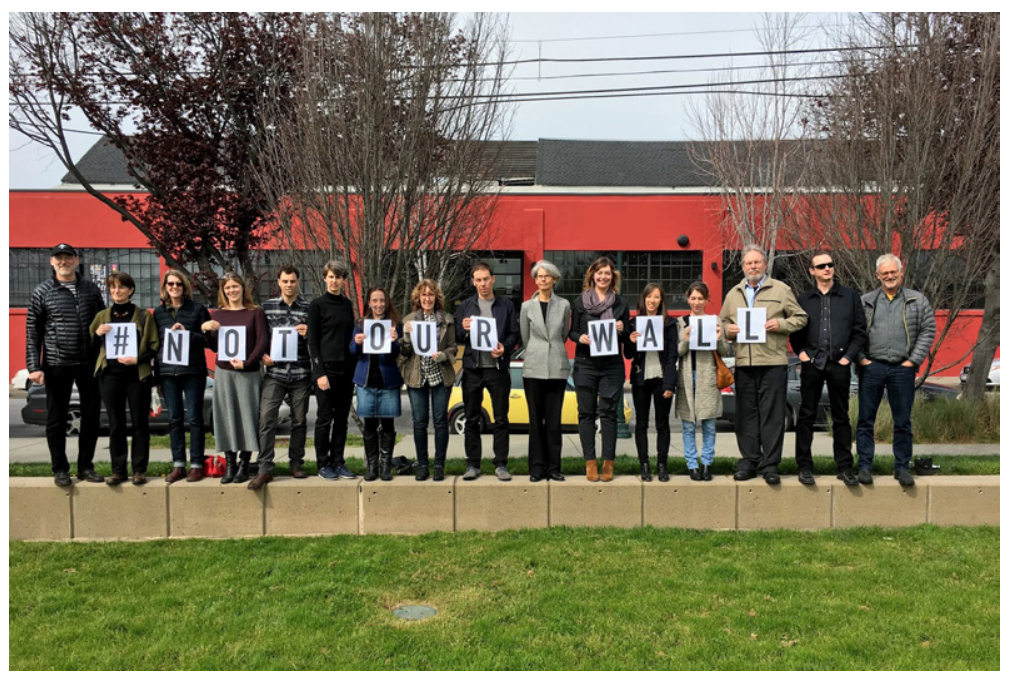

Manifestación \#notourwall (Emerville, California, Siegel and Strain Architects, 2017).
Con todo, podría argumentarse desde diferentes posiciones que su ejercicio de resistencia erraba el tiro al apuntar exclusivamente al muro como muestra de disenso, ya que tanto en el dispositivo frontera como en las políticas migratorias de Estados Unidos la sombra de la arquitectura es mucho más alargada. La primera de estas sombras se proyecta sobre lo que acabamos de señalar y que será el hilo argumental de toda la tesis: las arquitecturas de la frontera van mucho más allá de la línea perimetral y se impregnan en la totalidad del territorio asumiendo diferentes roles. Focalizar todo el rechazo a las políticas migratorias de Trump en una arquitectura singular implica asumir los términos y posiciones de Trump como propios, aunque sólo sea para rechazarlos después. La necesidad de objetualización que la arquitectura ha necesitado históricamente impide ir más allá del diseño de formas estáticas -frente a formas activas, disposiciones o ensamblajes de arquitecturas dispersas-, cuando la principal construcción espacial y territorial que define la frontera no puede plantearse exclusivamente en estos términos. Un ejemplo claro de esta ingenuidad por parte de las diferentes convocatorias puede verse en la invitación que se hace desde una de ellas al arquitecto Ronald Dael, autor de Borderwall as architecture: A manifesto for the US-Mexico boundary ${ }^{30}$ a dar una charla como parte de la programación cultural de dicha llamada a la acción; el libro hace un análisis territorial lúcido de la realidad de la frontera contemporánea, mientras que propone como alternativa una serie de propuestas irónicas donde la valla se transforma, por ejemplo, en un balancín infantil entre ambas soberanías -o el aprovechamiento de la infraestructura como generador de energía renovable o incluso puestos de trabajo-.

29 «\#notourwall», Architecture Lobby. Acceso el 12 de mayo de 2019. http://architecture-lobby.org/project/notourwall/

30 Ronald Dael, Borderwall as architecture: A manifesto for the US-Mexico boundary, (San Francisco: University of California Press, 2017). 
Conscientes seguramente de esta dimensión expandida de la noción de frontera, The Architecture Lobby y la organización Architects/Designers/Planners for Social Responsability ${ }^{3}$ (ADSPR) emitieron un comunicado conjunto un año más tarde, el 6 de abril de 20r8, en el que se desplazaba el foco de las fronteras a las políticas migratorias y reformas del gobierno republicano. En él se extendía el campo arquitectónica a otras infraestructuras territoriales que habían ido cobrando protagonismo mediático a la par que el muro -ya en vías de desarrollo- perdía fuelle: "cualquier infraestructura que refuerce las leyes de inmigración, lo que incluye pero no se limita a muros, puestos fronterizos, oficinas de Inmigración y Seguridad Aduanera, centros de detención, centros de gestión o albergues juveniles"32. Esta misma organización, que secundó el paro de marzo, propuso además un boicot operativo del proceso concursal, al reclamar a las más de setecientas personas que la integran que participasen en él, enviando propuestas alternativas que materializasen el muro, "haciendo un mejor uso de los recursos financieros y el talento profesional solicitado para realizar este proyecto" ${ }^{33}$. Y, sobre todo, planteando la construcción de esta infraestructura arquitectónica en términos de rentabilidad social y ecológica para las comunidades y territorios vinculados a ella.

Podemos agrupar las posiciones explícitas de rechazo al muro en dos grandes bloques. La primera de ellas, la negativa rotunda a participar en el proceso de diseño y la movilización social -virtual o física-. La segunda, proponer realidades alternativas, asumiendo punto por punto las demandas establecidas en las bases del concurso: la construcción de un muro; una posición que como ya se ha mencionado antes, peca no sólo de cierta ingenuidad respecto a la elaboración de las propuestas, sino también respecto a las intenciones del DSPNAPF. ¿Acaso son estas las únicas respuestas posibles de disenso dadas desde la disciplina arquitectónica? Pregunta que nos lleva directamente al segundo punto de debate: ¿Es posible alcanzar una posición ética como diseñadores respecto a la construcción del muro?. Y y debemos hacerla extensible a toda producción arquitectónica.

Aaron Betsky, un mes después de la recepción de las propuestas para el muro fronterizo, ilustraba de manera clara -y cínica también- las diferentes posturas de este debate, preguntándose dónde debía trazarse el límite entre lo que era permisible y lo que no:

El caso parece bastante simple. Al igual que los médicos escogen no infligir daño, los arquitectos no deben participar en esta particular táctica política cuyos motivos encontramos repulsivos, como mínimo, la mayoría de nosotros. $[\ldots]$

Pero ¿dónde trazamos el límite? Durante años, muy buenos arquitectos han diseñado puestos fronterizos para la misma institución que va a evaluar el muro y como parte de la misma actitud sobre vigilar a quien permitimos la entrada en este país. [...]

La diferencia entre arquitectos y médicos, sin embargo, es que cada decisión individual no es a vida o muerte. Un arquitecto o arquitecta puede simplemente preferir no hacerlo, y salvar su alma. El problema por tanto es que esa
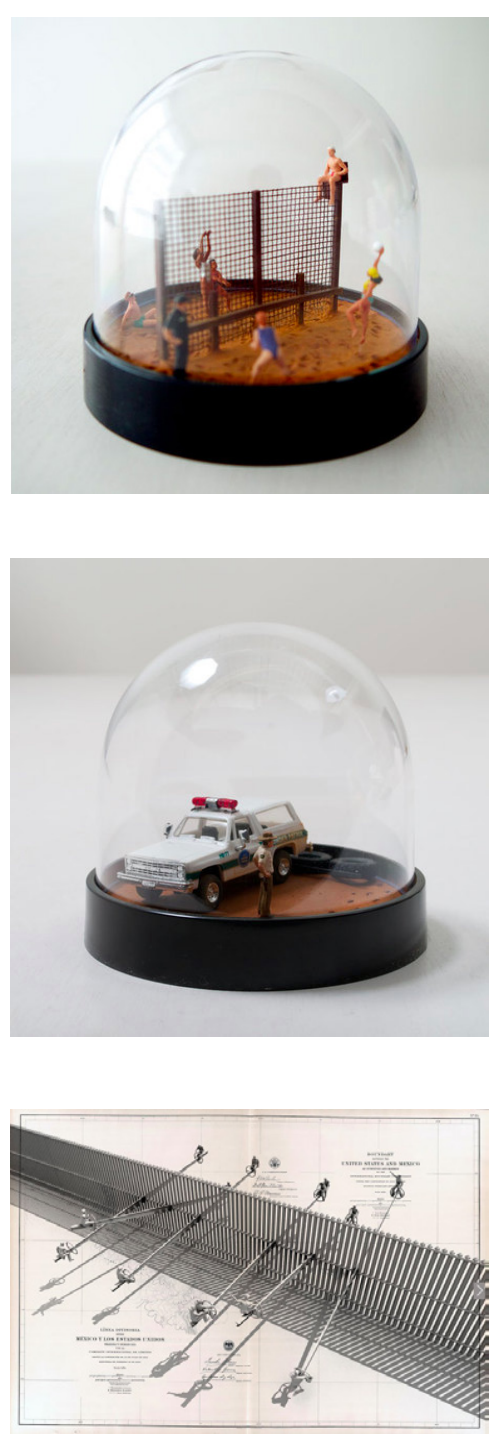

Proyectos para la frontera entre Mexico y Estados Unidos. Borderwall as architecture: $A$ manifesto for the US-Mexico boundary (Ronald Dael, 2017).

31 Organización sin ánimo de lucro que agrupa profesionales del campo de la arquitectura, el urbanismo y el diseño. Surgida en el año 1981 al calor de las movilizaciones a favor del desarme nuclear, ha desarrollado desde entonces multitud de iniciativas en campañas, foros y debates. Parten del reconocimiento de la implicación disciplinar en el desarrollo de arquitecturas contrarias a los Derechos Humanos para, desde ahí, generar una oposición crítica y activa al respecto.

32 «Statement on Inmigration Enforcement», ASDPR, acceso el 12 de mayo de 2019.

33 «Statement on Inmigration Enforcement», ASDPR, acceso el 12 de mayo de 2019. 
decisión puede conducir a un muro que pueda ser peor, una prisión más inhumana o un edificio en China que desperdicia más recursos y refuerza el poder estatal de lo que debería ser. [...]

La arquitectura es, siempre ha sido, y siempre lo será, la afirmación construida del status quo social, político y económico.

Los arquitectos tendrán que tomar decisiones difíciles respecto a dicha situación si quieren hacer lo correcto. Puede que incluso, para salvar sus almas mortales, tengan que trabajar en el muro ${ }^{34}$.

A lo largo del texto, Aaron Betsky plantea un dilema disciplinar de difícil solución o consenso. Por un lado, negarse a hacer el muro implica que otra propuesta será finalmente construida, y que ésta no tendrá por qué responder a los criterios éticos defendidos desde el rechazo. Por otro lado, aceptar a participar -bien de forma irónica, bien intentando revertir el posible impacto del muro- legitima las bases del encargo. Este dilema ha sido recogido por Eyal Weizman en su libro The least of possible evils ${ }^{35}$, en el que recurre a la noción de "mal menor", planteada por Hannah Harendt, para evidenciar los conflictos y fricciones de un dilema polarizado, aparentemente, en dos únicas soluciones posibles. Es decir, estamos ante lo que Léopold Lambert ha denominado "la imposibilidad de la inocencia" ${ }^{6}$, una situación ante lo que cualquier respuesta implicará un desarrollo de los acontecimientos más o menos opuesto a nuestros intereses éticos. Sin embargo, puntualiza:

La respuesta ética a esta pregunta [construir o no una prisión] está ligada invariablemente a la consideración ética del resultado.[...] En cualquier caso, cuando nos enfrentamos a una situación donde todas las opciones parecen apuntar al mismo resultado éticamente inaceptable uno puede recordar las palabras de Arendt donde 'el desorden es preferible al orden' y 'un rechazo a cooperar (es) casi siempre mejor que la colaboración ${ }^{37}$.

Existe una tercera argumentación que permite sustraernos del debate ético hasta ahora planteado y que adquirir una mayor dimensión operativa como diseñadores: ir más allá del muro. Para ello es necesario desplazar los términos del debate arquitectónico, no sólo en términos del cómo, sino también del qué, y para ello también resulta necesario desplazar al objeto arquitectónico -el muro- como única solución espacial posible. Esta tercera posición pasa, en primer lugar, por reconocer la frontera como una infraestructura territorial ensamblada por diferentes arquitecturas y condiciones que van mucho más allá de lo arquitectónico -cuestión señalada en el primer punto-. Es decir, como señala Keller Easterling en el último capítulo de Extrastatecraft ${ }^{38}$, frente a la posición de activismo clásico aquí visibilizado aparecen otras posibilidades de actuación complementarias que superan la confrontación o rechazo directo - "Técnicas auxiliares de distracción que son menos heroicas, con una oposición menos automáticas, más efectivas y

34 Aaron Betsky, «"Architects may, heaven save their mortal souls, have to work on Trump's wall”», Dezeen, 27 de abril de 2018, acceso el 15 de mayo de 2019. https://www.dezeen.

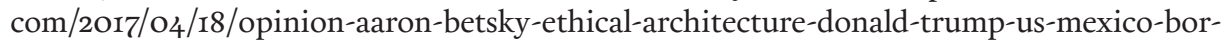
der-wall/

35 Eyal Weizman, The least of all possible evils: a short history of humanitarian violence. (Londres: Verso, 20II).

36 Léopold Lambert, Weaponized Architecture: The impossibility of Innocence (Barcelona: DPR, 2012).

37 Léopold Lambert, «\# weaponized architecture /// Temple Grandin's humane slaughterhouses and the architectural politics of the lesser evil», The Funambulist. 
astutas"39-. Frente a la dualidad sí o no, Easterling presenta un repertorio de tácticas y activistas -el saber hacer, el hacker, el emprendedor, el rumor o hoax, la complicidad exagerada...- que van mucho más allá. Todas ellan, asumen esta realidad múltiple y conflictiva, operan con formas activas; esto es, configuraciones espaciales que permiten y promocionan ciertas prácticas mientras que dificultan otras. Lo importante de esta oposición activa es que se aleja del planteamiento inicial -a favor o en contra del muro- para visibilizar otros escenarios posibles de conflicto, resistencia y transformación a través del compromiso activo como diseñadores. Eso sí, nos advierte de la necesidad de cambiar las lógicas de producción y la agencia del diseño para alcanzar una oposición efectiva: "para diseñadores acostumbrados a la realización de objetos formales o activistas acostumbrados a hacer declaraciones, este repertorio estético y político alternativo tal vez no resulte familiar" 40 .

\subsubsection{WE TAKE NO POSITION. WE REMAIN POLITICALLY NEUTRAL. EL MURO COMO PROBLEMA DE DISEÑO.}

Las cifras de seguimiento de las diferentes convocatorias dan cuenta de una realidad concreta acerca del sentimiento que la decisión de Donald Trump despertaba directamente en las diferentes ramas de la disciplina arquitectónica. Tanto las movilizaciones universitarias como el paro laboral fueron anecdóticas a nivel nacional. El rechazo disciplinar por parte de un sector concreto y con gran impacto mediático no debe confundirnos y llevarnos a tomar tal rechazo como única opción posible, cuando probablemente la posición mayoritaria sea de indiferencia o apoyo. Algo que, por otra parte, más allá del impacto concreto de la convocatoria, no invalida la evidencia de un sentimiento de interpelación directa ante la construcción del muro y la agencia arquitectónica implícita en todo el proceso de diseño y ejecución.

Así que, volvamos a la campaña presidencial pues antes incluso de las movilizaciones estudiantiles en los campus estadounidenses, una parte de la disciplina arquitectónica se había posicionado de manera diferente. Bajo el lema Building the border wall, la desconocida fundación Third Mind Foundation ${ }^{41}$ publicaba el cuatro de marzo la convocatoria de un concurso en el portal Archdaily ${ }^{42}$, el medio digital de arquitectura más visitado a nivel global ${ }^{43}$, que pronto adquiría relevancia -y polémica- internacional por las bases explícitas que proponía:

39 Easterling, Extrastatecraft, (Londres: Verso, 2014), 213.

40 Easterling, Extrastatecraft, (Londres: Verso, 2014), 238.

41 Desconocida hasta el punto que, a día de hoy, el dominio web de la Fundación se halla inactivo y, como ha declarado la organización del concurso en uno de sus comunicados " The Third Mind Foundation es un grupo de arquitectos, diseñadores y artistas que desea permanecer en el anonimato" y no se le conoce actividad posterior o anterior a la organización de este concurso.

42 Archdaily, «Call for Entries: Building the Border Wall?», Archdaily, 4 de marzo de 2016.

43 Es importante señalar que, por otro lado, el portal Bustler, perteneciente a Archinect, se negó a publicar las bases arguyendo la siguiente razón: "Estamos en conflicto con la naturaleza del concurso y tememos que promueva la xenofobia. El concurso va en contra de nuestros estándares éticos con los que nos alineamos”. Añadir referencia 
No importa en que posición del espectro político nos encontremos, la idea de una barrera fronteriza entre Mexico y Estados Unidos no puede ser descartada. [...] El estado de la actual barrera -una confusión de vallas, planchas de metal corrugado, piezas prefabricadas de hormigón, cámaras de vigilancia, drones y otras estructuras y dispositivos (sin mencionar los más de veintiunmil agentes fronterizos)- es triste, ineficiente y poco elegante, de tal manera que no respeta ninguno de los lados del debate. [...] ¿Puede ser mejor que esto? ¿Puede la disciplina arquitectónica crear una solución mejor? Creemos que sí. Este es el objetivo del concurso: aplicar la capacidad de resolución de la disciplina así como sus capacidades estéticas para crear una estructura que cumpla su cometido - una barrera que ralentice, e incluso detenga, el flujo de inmigración ilegal- y hacerlo de tal manera que sea creativa, atractiva e innovadora $^{44}$.

Sólo dos semanas más tarde el arquitecto Fabrizio Gallanti llamase al boicot ${ }^{45}$ no sólo del concurso sino de la propia plataforma Archdaily, lo que llevó a cambios sustanciales en las bases del concurso. El más llamativo, la inclusión de un interrogante al final del título: Building the border wall?, con una aclaración explícita respecto a tal modificación ${ }^{46}$. Y, el segundo de ellos, la transformación del texto inicial, que ahora incluía una frase que condensa la posición ideológica de la organización: "Seamos claros: No tomamos posición en este asunto. Permanecemos políticamente neutrales. Por el contrario, estamos interesados en abordar el problema desde múltiples perspectivas. [...] ¿Puede una barrera tener valor arquitectónico?" 4 . Primero en forma de declaración implícita y, en este comunicado posterior ya de manera explícita, incluso resaltado en negrita, dejaban claro que la propuesta arquitectónica no estaba vinculado de manera alguna a una posición ideológica, ni en contra ni a favor. Pero, ¿es esto cierto? ¿Acaso no estaban tomando verdadera posición política -o ideológica- en este asunto?

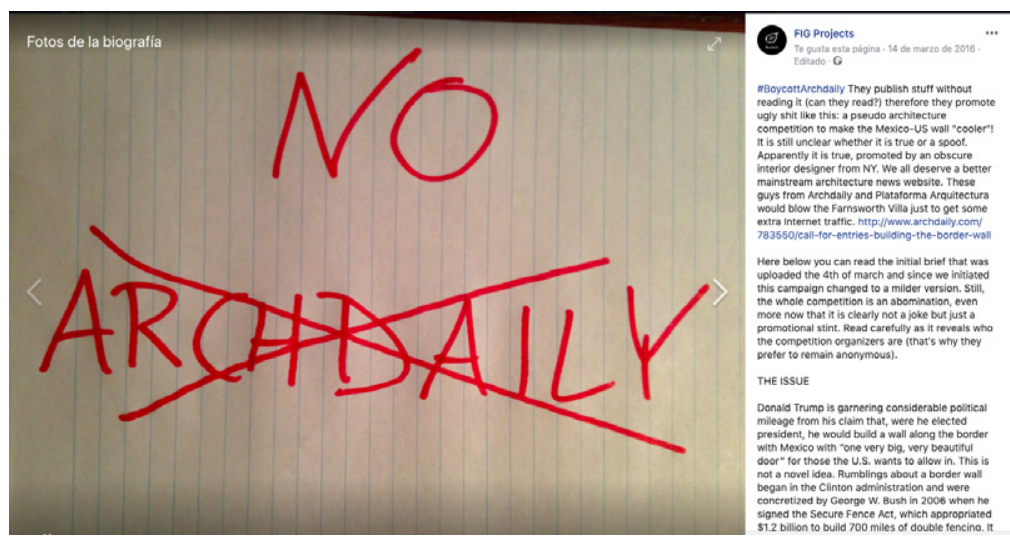

Boicot a Archdaily, FIG Projects (Imagen de Facebook, 2016).
Antes incluso que la propuesta de construcción del muro al ganar Trump las elecciones cobrase peso real, una parte de la arquitectura - desde una posición de equidistancia- buscaba su materialización. Los argumentos para construir un

44 Building the Border Wall, versión del sitio web del 15 de marzo de 2016, acceso el 15 de mayo de 2019.

http://web.archive.org/web/20160315183030/http://buildingtheborderwall.com/

45 A través de su cuenta de Facebook publicaron un comunicado donde se responsabilizaba no sólo al concurso sino cómo Archdaily carecía de cualquier filtro ético a la hora de publicar contenido de interés arquitectónico.

Fig Projects, «\#BoycottArchdaily», Facebook. 14 de marzo de 2016. https://www.facebook. com/figprojects/photos/a.701219669935886/1082652245125958/?type=3\&theater

46 Building the Border wall?, acceso el 15 de mayo de 2019. http://buildingtheborderwall.com/ 47 Building the Border wall?, acceso el 15 de mayo de 2019. http://buildingtheborderwall.com/ [Resaltado en el original] 
muro "agradable estéticamente" ${ }^{8} \mathrm{e}$ "innovador" 49 era, según la organización, la única implicación arquitectónica en todo el proceso, pero en realidad estaba generando un catálogo de propuestas posibles que legitimaba el tuit original de Donald Trump: construir un muro. No había alternativa, simplemente cuestiones estéticas y programáticas a discutir sobre una premisa dada de antemano.

Lo curioso es que los resultados premiados en este concurso no distaban mucho de las de otros dos grupos que partían de premisas totalmente diferentes. En primer lugar, utilizaban un lenguaje de comunicación muy similar: uso de vegetación en renders, apelación a la sostenibilidad del proyecto, impacto visual y medioambiental... También, presentaban otros elementos comunes con las propuestas presentadas por la ADPSR: vinculación con la comunidad local, uso de la tecnología, reducción del impacto ecológico, generación de zonas transfronterizas... Desde tres posiciones ideológicas aparentemente tan distantes la respuesta a una misma premisa -la materialización de un muro- era sorprendentemente similar. Esto puede deberse fundamentalmente a que ninguno de los tres puntos de partida: I) los contratistas que asumían las bases sin cuestionarlas- la parte creativa se resumía a una optimización pragmática de los recursos y una maximización del resultado-, 2) la oposición crítica que asumía las bases desde una posición irónica consciente -la premisa era evidenciar la capacidad creativa de la disciplina al plantear soluciones espaciales alternativas al muro con valores éticos- y 3) la posición supuestamente neutral de Building the Border Wall? -centrada en evidenciar la capacidad creativa de la disciplina sin entrar a valorar la dimensión ética de la premisa-. En definitiva, ninguna era capaz de sustraerse de la premisa pronunciada por Donald Trump y posteriormente confirmada por el ejecutivo estadounidense. Tal vez, precisamente esta imposibilidad de sustraerse del marco discursivo generado o de los mecanismos tradicionales a través de los cuales la disciplina arquitectónica ha elaborado propuestas solicitadas o no solicitadas, encontremos explicación a esta similitud formal entre todas las propuestas de construcción del muro ${ }^{50}$.

48 Building the Border wall?, acceso el 15 de mayo de 2019. http://buildingtheborderwall.com/ 49 Building the Border wall?, acceso el 15 de mayo de 2019. http://buildingtheborderwall.com/ 50 Resulta por ello importante traer de nuevo al discurso las ideas que Keller Easterling recoge en Extrastatecraft y otros textos (Disposition, Medium Design, Victor Hugo TED's Talk Añadir referencias) respecto a la importancia del diseño de formas activas frente a objetos formales. El espacio infraestructural, y la frontera no es ajena a esta categoría sino uno de sus ejemplos más claros y simples, está completamente colmatado de diferentes formas activas que lo configuran y modifican con cada acción. 


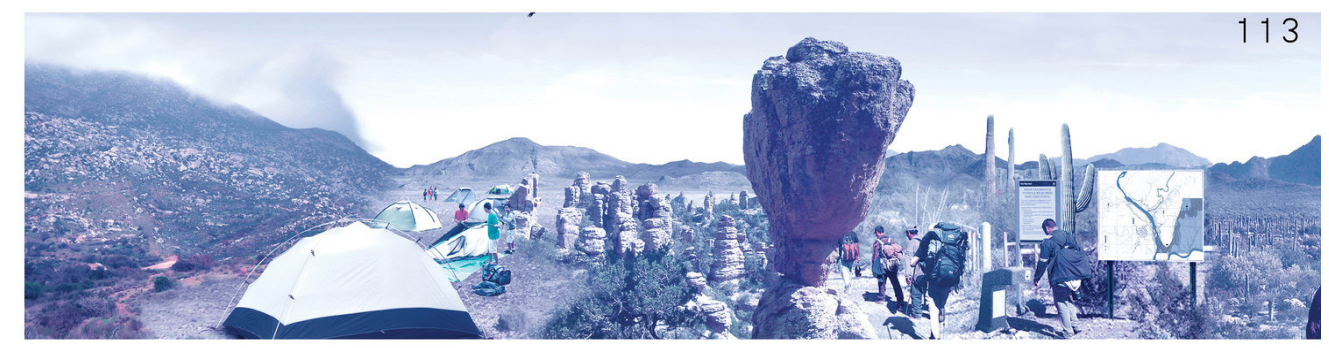

Propuestas premiadas en el concurso Building the Border Wall? (Third Mind Foundation, 2018).
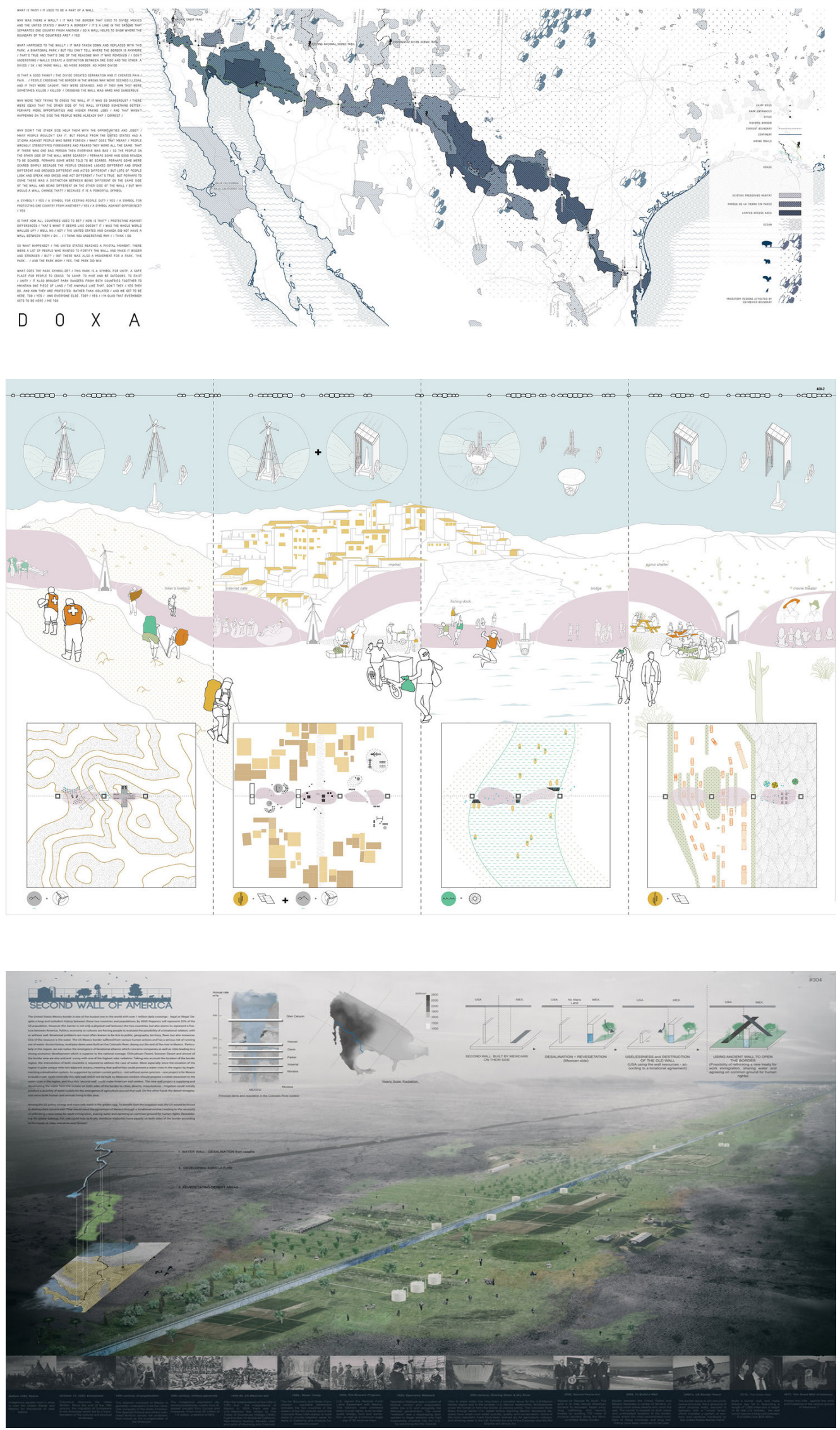
Propuestas presentadas en

el concurso organizado por la DSNAPF. (DSNAPF, 2018).
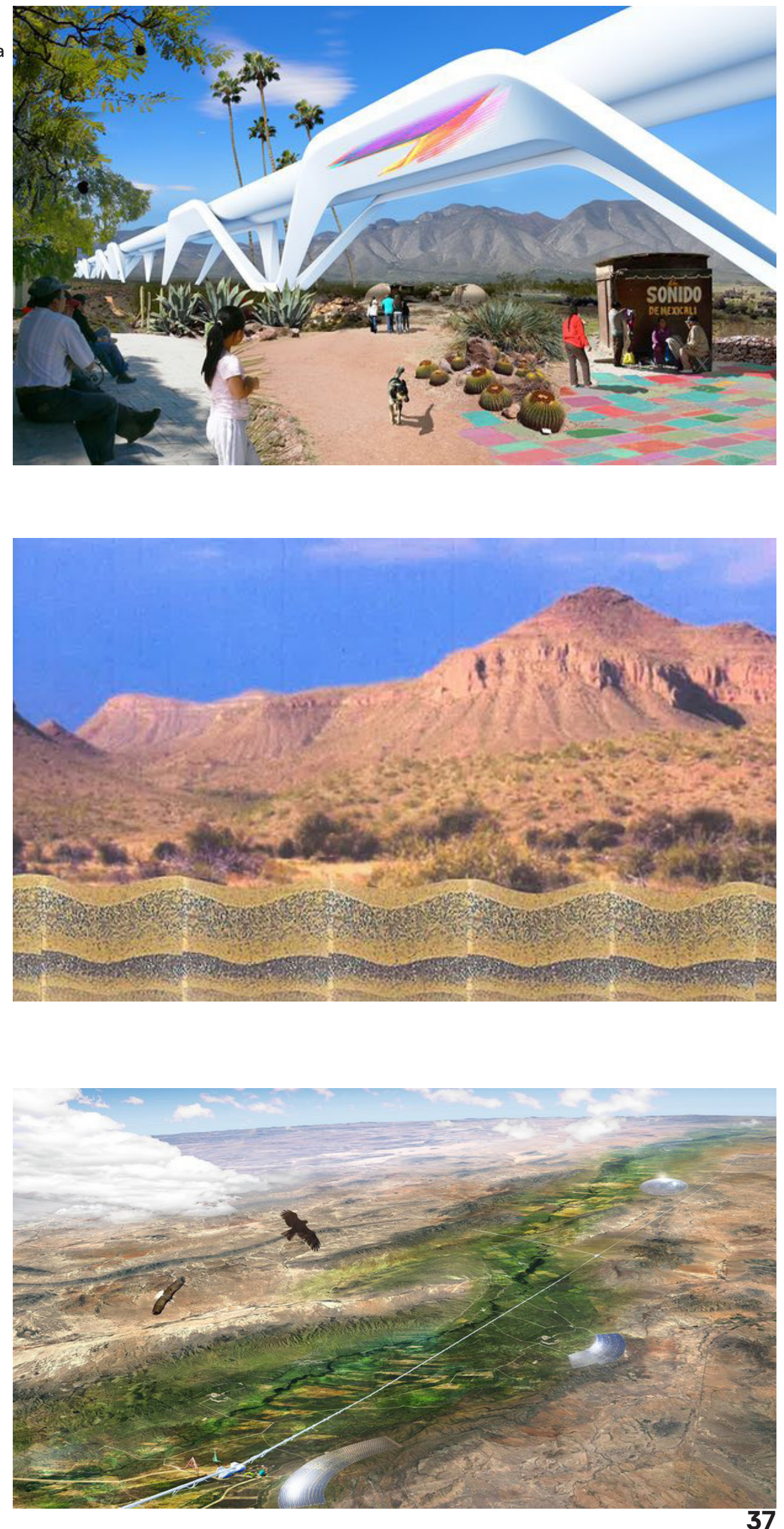


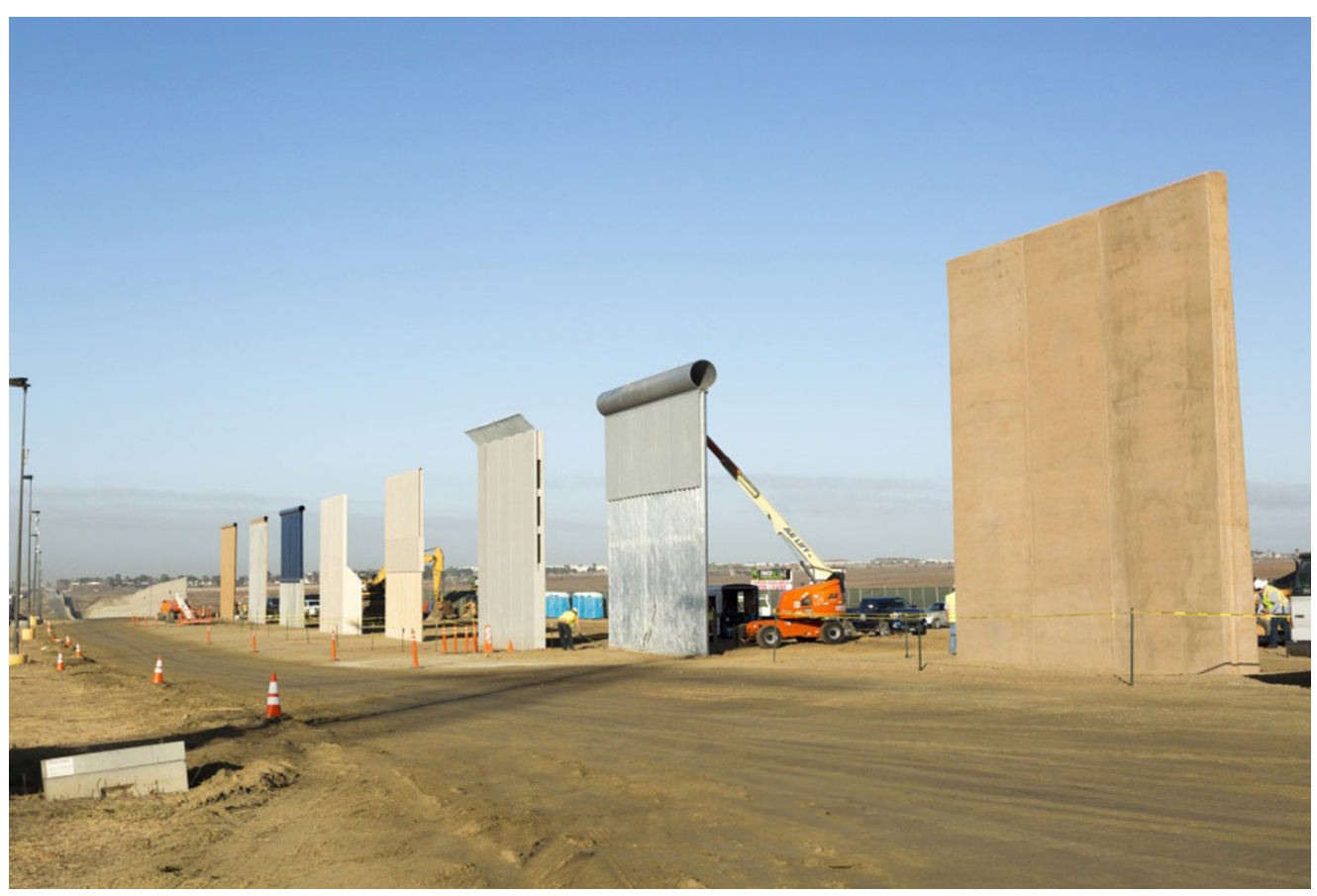




\section{3.“CHINA BUILT A WALL THAT'S 13,000 MILES LONG 2,000 YEARS AGO. MY AMBITION IS FOR OURS TO BE MUCH HIGHER." LA CONSTRUCCIÓN DEL MURO Y SU FUNCIONA- MIENTO OPERATIVO.}

\subsection{1 "VA A SER UN MURO GRANDE, GORDO Y BONITO" OCHO MUROS EN EL DESIERTO.}

Va a ser un muro grande, gordo y bonito. Donald Trump.

Trasladémonos ahora en el espacio hasta el desierto de California, hasta la línea fronteriza entre San Diego y Mexico; y en el tiempo hasta el otoño de 2017. Tras el concurso de licitación, seis empresas - dos de ellas con sendos modelos alternativos- resultaron candidatas para acceder a la siguiente ronda, la construcción de un prototipo de cerca de nueve metros de altura que permitiese testear la solide $^{51} \mathrm{y}$ características de cada una de las propuestas. Ocho piezas, separadas entre sí apenas quince metros, se levantaron formando una línea recta paralela a la valla fronteriza actual. Los materiales empleados, los sistemas constructivos, e incluso las consideraciones estéticas y ecológicas recogidas en las memorias del concurso, mostraban las grandes diferencias que cada una de las constructoras había tenido en consideración. Cada construcción atendía e intentaba mejorar los puntos recogidos en las bases y las demandas realizadas por los agentes fronterizos. Así, aparecen modelos colmatados por tubos de acero que impedían el anclaje de ganchos o cuerdas en la parte superior, secciones variables para asegurar su robustez y estrías verticales que dificultaban el trepado. También existían diferencias constructivas notables, desde el empleo de hormigón armado o prefabricado - la opción que, tras las pruebas, resultó más convincente a la organización-, hasta estructuras metálicas. Sin embargo, más allá de los aspectos meramente funcionales, otra de las exigencias que se intentó resolver fue la demanda de que fuese un muro "estéticamente agradable", demanda que de nuevo muestra la escasa divergencia entre la praxis militar pura y gubernamental de las bases del concurso conceptual Build the Wall. Así se puede entender el juego de colores azul y blanco - presentes en la bandera de Estados Unidos- en el prototipo de ELTA North America, la gama cromática en tonos terrosos de la mayoría de propuestas conseguida al colorear el hormigón mediante aditivos -similar a la propia arena del desierto californiano- o el uso de patrones ornamentales -imitando mampostería en bajorrelieve o a través del modulado del estriado- sobre la superficie de varios de ellos. Hasta se podría afirmar que la materialidad opaca del muro se cuestionó en dos de las propuestas al emplear un sistema de perfiles de acero discontinuos hasta la mitad o tercio superior que conectaban visualmente ambas partes del muro -algo que además mejoraba la capacidad de visión de los agentes sin tener que recurrir a medios tecnológicos-. En resumen, incluso con un punto de partida radicalmente diferente y con unos objetivos aparentemente opuestos se pueden encontrar trazas en cada uno de los prototipos que van

51 Entre las pruebas realizadas se incluyó el despliegue durante tres semanas de unidades tácticas del ejército estadounidense y del servicio de Vigilancias Fronteriza. Así, los agentes emplearon "martillos, sierras, antorchas y otras herramientas y sistemas de escalada" con el fin de traspasar la altura total o atravesarlo por la base. 
más allá de la mera funcionalidad. La tríada enunciada por Trump, grande, gordo y bonito, lograba alinearse en ciertos aspectos con las consideraciones generales de las bases de los concursos alternativos, pero también las propuestas concretas construidas y aquellas críticas que se quedaron en planos y bocetos guardaban cierta relación ${ }^{52}$.

Sin entrar a analizar en detalle cada uno de los prototipos, es reseñable el prototipo levantado por la empresa Texas Sterling Co porque su diseño encarna una serie de cuestiones que deben ser mencionadas. El muro de la constructora tejana está compuesto por piezas de hormigón prefabricado de dos metros de alto coronadas por una estructura tridimensional de acero que sirve como soporte del alambre de espino. Una construcción aparentemente simple, hasta que nos fijamos en la asimetría de los elementos. Las piezas de hormigón están ornamentadas con un acabado superficial, al que ya hemos hecho referencia, imitando mampostería de piedra por el lado que mira a Estados Unidos. La alambrada tampoco se coloca a $90^{\circ}$ respecto a la horizontal sino inclinada hacia el lado mexicano del muro, pensada así para impedir el trepado exclusivamente desde esta posición. Estas decisiones de diseño no sólo evidencian una respuesta precisa a las demandas del gobierno estadounidense sino una asimetría en las relaciones establecidas entre las dos soberanías, ya que la frontera está planteada como una infraestructura territorial común a ambas, que las delimita y la separa. Sin embargo, la realidad operativa que muestra este diseño es claramente diferente.

\title{
1.3.2 “WE WILL NOT LET THEM THROUGH”. LA CONSTRUCCIÓN DEL CUERPO MIGRANTE.
}

\author{
WE WILL NOT LET THEM THROUGH. Big Danger ${ }^{53}$. \\ Donald Trump.
}

Estas ocho piezas autónomas levantadas en mitad del desierto, a escasos metros de la obsoleta y oxidada valla actual, separadas entre sí, evocan el proyecto de la Muralla China del cuento de Kafka. Por más que Trump haya insistido en la impermeabilización total de la frontera, la realidad geográfica y presupuestaria pesa más que el discurso político, hasta el punto de que éste se ha ido matizando conforme el proyecto cobraba consistencia. El muro, lejos de ser una línea continua que cruza de costa a costa, será construido como fragmentos y materialidades independientes en función de la orografía, de la proximidad y relación con los diferentes núcleos de población, e incluso en función del presupuesto disponible. Así, podemos imaginar que el futuro de esa frontera impenetrable será más similar a los prototipos construidos, piezas dispersas a lo largo de los más de $3000 \mathrm{~km}$ de líneas, con variaciones y diferencias notables entre las partes, por más que la exhibición gubernamental muestre ocho piezas rotundas.

52 Un aspecto que será mencionado y analizado desde diferentes ópticas a lo largo de la investigación es cómo la arquitectura, como hecho construido, guarda una cierta independencia y autonomía respecto al diseño y función para la que ha sido creada. Por tanto, puntos de partida supuestamente contrarios pueden converger en una materialización similar. Una independencia que no es ajena también a su carácter estético; es decir, sin poder conocer objetivamente si ha habido una intencionalidad de amabilidad estética -ocultación del carácter violento del muro- en las diferentes propuestas, se pueden reconocer gestos y acciones como las mencionadas que sí responden a esta cuestión.

53 Trump, Arizona, together with our Military and Border Patrol, is bracing for a massive surge at a NON-WALLED area. WE WILL NOT LET THEM THROUGH. Big danger. Nancy and Chuck must approve Boarder Security and the Wall!, 6 de diciembre de 2018, 22:15. 

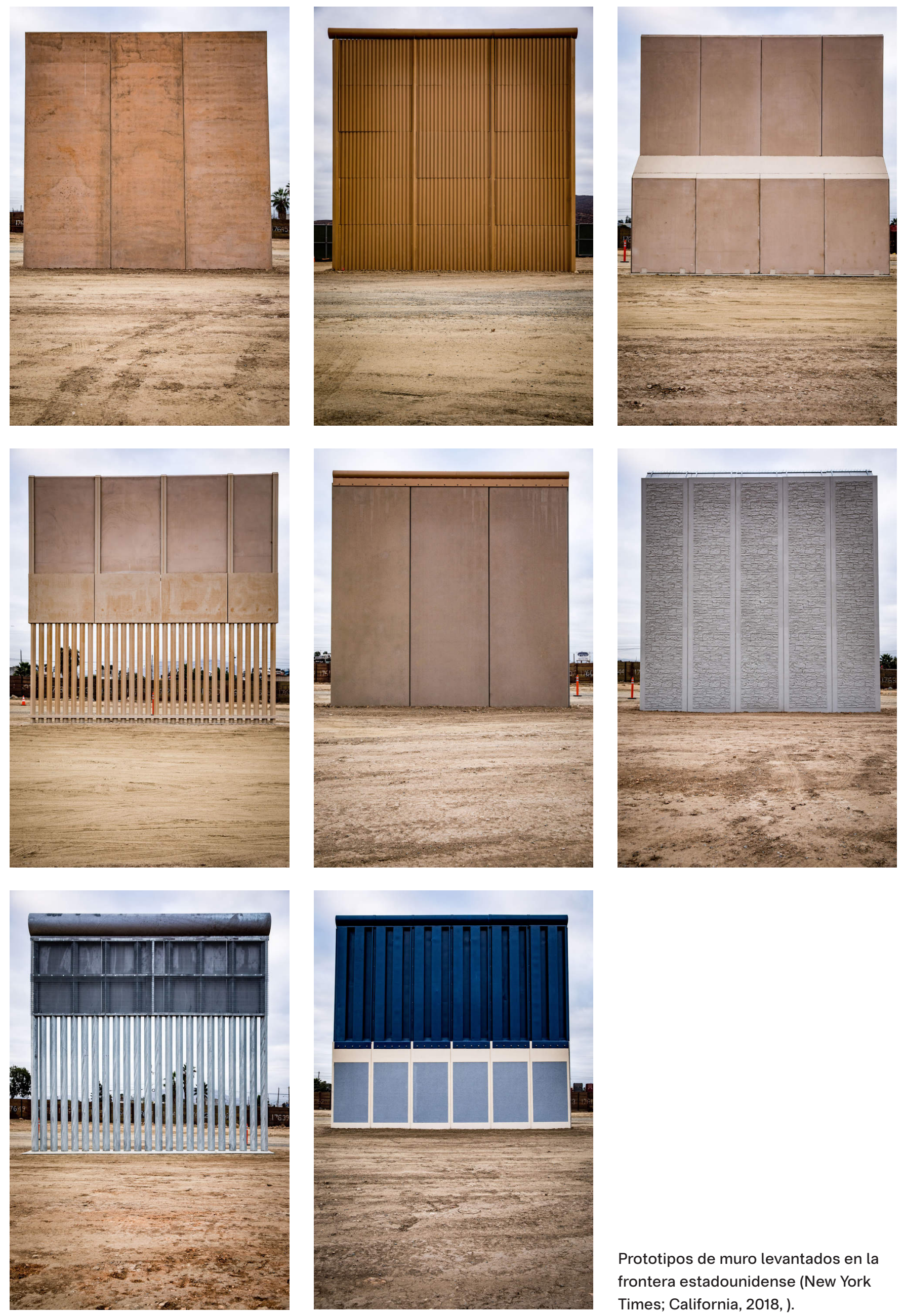

Prototipos de muro levantados en la frontera estadounidense (New York Times; California, 2018, ). 
Caravanas migrantes en su llegada a Estados Unidos

(Mexico, 2017).
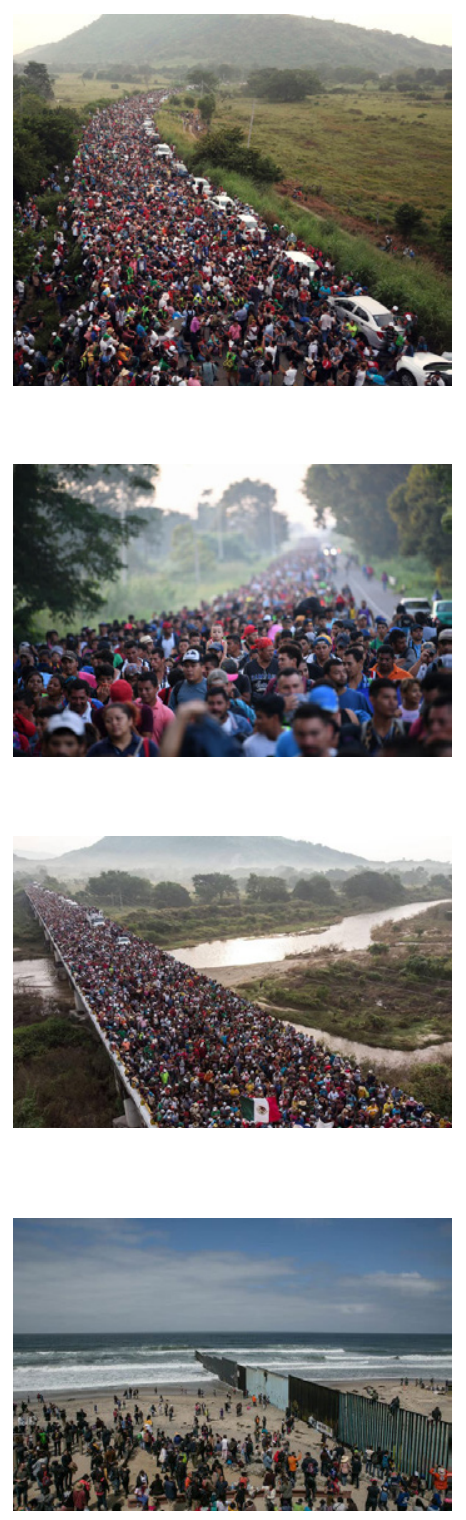

Si, como dijimos antes, la construcción del muro responde más a una intencionalidad política y a la construcción y reafirmación de una soberanía nacional por encima de la función primaria que esta arquitectura encarna -impedir su cruce por todos los medios-; también es importante que nos centremos también en las intenciones no declaradas, en el paralaje entre el funcionamiento simbólico y el operativo. Al aproximarnos a estas fisuras y desplazamientos encontraremos una realidad acerca del funcionamiento de la frontera que poco tiene que ver con el levantamiento de muros y mucho más con el despliegue de arquitecturas y ensamblajes territoriales efímeros. Para ello, como apunta Kafka, no podemos observar la Muralla sin observar a la vez a los Pueblos del Norte. Es decir, entender la construcción de la frontera implica a la vez entender los flujos dinámicas y acciones que el cuerpo migrante lleva a cabo para cruzarla. Un pensamiento estratégico, que no requiere de su finalización para conseguir sus objetivos, frente a un pensamiento táctico que se enfrenta ante cada solución concreta, ante cada materialización de la frontera - sea esta un muro, un mar, un centro de detención o la irregularidad de un sistema de trabajo-.

La muralla, sin embargo, como se divulgó y es conocido por todos, se ideó como protección contra los pueblos del Norte. Pero, ¿cómo puede proteger una muralla inconexa? Una muralla así no sólo no puede proteger, sino que ella misma está en peligro. Fragmentos aislados de muralla en regiones inhóspitas pueden ser destruidos fácilmente por los nómadas, sobre todo porque éstos, en aquel tiempo, asustados por las obras de la muralla, desplazaban sus campamentos con incomprensible rapidez, como si fueran langostas viajeras y, tal vez por esta razón, poseían una visión más completa acerca de los progresos de la obra que nosotros, los constructores ${ }^{54}$.

Así pues, del mismo modo que haremos a lo largo de nuestro ámbito de estudio, observar por un instante las acciones del cuerpo migrante del que el gobierno estadounidense quiere protegerse, permitirá visibilizar el funcionamiento operativo de la frontera y cuan alejado está de los discursos abrazados por diferentes partidos políticos ${ }^{55}$. Por tanto, pese a que la migración desde Centroamérica ha sido una constante durante las últimas décadas, debido a la gran demanda de mano de obra susceptible de ser explotada laboralmente principalmente-desde todas las empresas del cinturón sur estadounidense hasta el servicio doméstico en cualquier vivienda de clase media suburbana-, durante la corta línea temporal que hemos establecido podemos destacar la construcción de un cuerpo migrante. Ha habido un movimiento de especial relevancia mediática donde el cuerpo migrante no sólo cobró una dimensión pública notable, sino también conciencia colectiva: las caravanas migrantes que se sucedieron a lo largo de $2018^{56}$ por toda

\section{Kafka, «La construcción de la muralla china».}

55 En este punto conviene aclarar que este paralaje del que hablamos entre funcionamiento operativo y discurso público no es exclusivo del gobierno de Donald Trump sino que podemos hacerlo extensivo a diferentes ejecutivos de las últimas décadas. No en vano, las dos legislaturas previas encabezadas por Barack Obama fueron aquellas donde más se aumentó el gasto en reforzar la frontera respecto a administraciones anteriores. Del mismo modo que durante el gobierno de Bill Clinton se aprobaron la Illegal Inmigration Reform and Inmigrant Reponsability Act o la Operación Gatekeeper que sentaron las bases para la construcción efectiva del muro en sus fases iniciales.

Para un mayor desarrollo de la implicación de los diferentes gobiernos estadounidenses en la construcción del muro ver: Brown, Estados Amurallados (Madrid: Herder, 2012) 51:57.

56 Es importante señalar que estos flujos migratorios no son tan diferentes a situaciones anteriores, ya que se han usado las mismas rutas y las características sociales del cuerpo migrante presentaban una heterogeneidad similar a cualquier otro movimiento migratorio producido desde Centroamérica a Estados Unidos. Incluso la construcción de un cuerpo colectivo -a través de afectos y lazos de solidaridad- está presente en los flujos migratorios que usan La Bestia -apodo a la red de trenes de carga que usan los migrantes para llegar hasta la frontera-, las redes de cuidados, etc. Sin embargo, si ha sido diferente el tratamiento que tanto desde los 
Centroamérica en su tránsito hacia Estados Unidos. En apenas un mes de duración se sucedieron cinco flujos consecutivos que llegaron a aglutinar entre cinco mil y diez mil personas en la más numerosa -la primera- de diferentes nacionalidades y contextos sociales. Únicamente a través de su desplazamiento colectivo por el territorio buscaban legitimar un derecho que política y espacialmente les estaba siendo negado. Y, precisamente a través de este mismo desplazamiento, de este cuerpo múltiple y creciente que iba ascendiendo de latitud, fue cobrando mayor dimensión, estableciendo nuevos afectos y lazos que aumentaban su poder respecto a la suma de individualidades. Pero, a la vez, este cuerpo colectivo que cada vez tenía mayor capacidad de acción -apoyos mediáticos, políticos...-, también generó una resistencia por parte de una serie de agentes que, ante la supuesta excepcionalidad del desplazamiento, se transformó en un despliegue de una serie de medidas coercitivas a lo largo de la frontera.

Como contramovimiento a este desplazamiento geográfico, el gobierno estadounidense movilizó diferentes unidades del DSNAPF, medios técnicos, tecnológicos y humanos destinados a impermeabilizar una frontera que, pese a estar vallada, dejaba zonas de acceso. Aunque, si bien esta acción no es diferente a cualquier otra intervención, sí lo son los medios auxiliares dispuestos a desplegarse: hasta I5Ooo tropas del ejército para, en palabras de Kevin Mc Aleenan -comisario de la DSNAPF-, asegurar "de manera efectiva y segura" 57 la línea fronteriza. El gobierno estadounidense, como en anteriores ocasiones, recurría a una construcción dinámica y operativa que supliese la ineficacia y lentitud de una arquitectura que no podía detener el avance del cuerpo migrante. Por encima de la frontera arquitectónica que llevaba cerca de dos años levantándose -al menos en el plano discursivo-, la realidad exigía una frontera que no sería construida, sino performada, ensamblada a base de la acción conjunta de agentes de diferente naturaleza - puestos fronterizos móviles, comunicaciones tecnológicas, alambre de espino y concertinas, agentes de la DSNAPF, militares, policías y vigilancia privada, así como de la infraestructura logística necesaria para asegurar su funcionamiento-. Tanques, vehículos militares, y kilómetros lineales de alambre de espino, además de un número de efectivos similar al destinado en Afganistán se mostraban como un mecanismo efectivo de contención y de impermeabilización de la frontera más eficaz que la solidez del muro. Este despliegue demuestra como, a pesar de la grandilocuencia de los prototipos y de todo el aparato discursivo empleado desde el año 2016 por Donald Trump y su gobierno, había plena conciencia del giro dinámico que se produjera en la frontera. Eran conscientes de cómo una gestión operativa del territorio lograba maximizar resultados y reducir esfuerzos y costes, cómo la infraestructura territorial que definía la frontera residía más en estos

medios de comunicación como desde la propia administración estadounidense se le ha dado; y por ello se decide destacar.
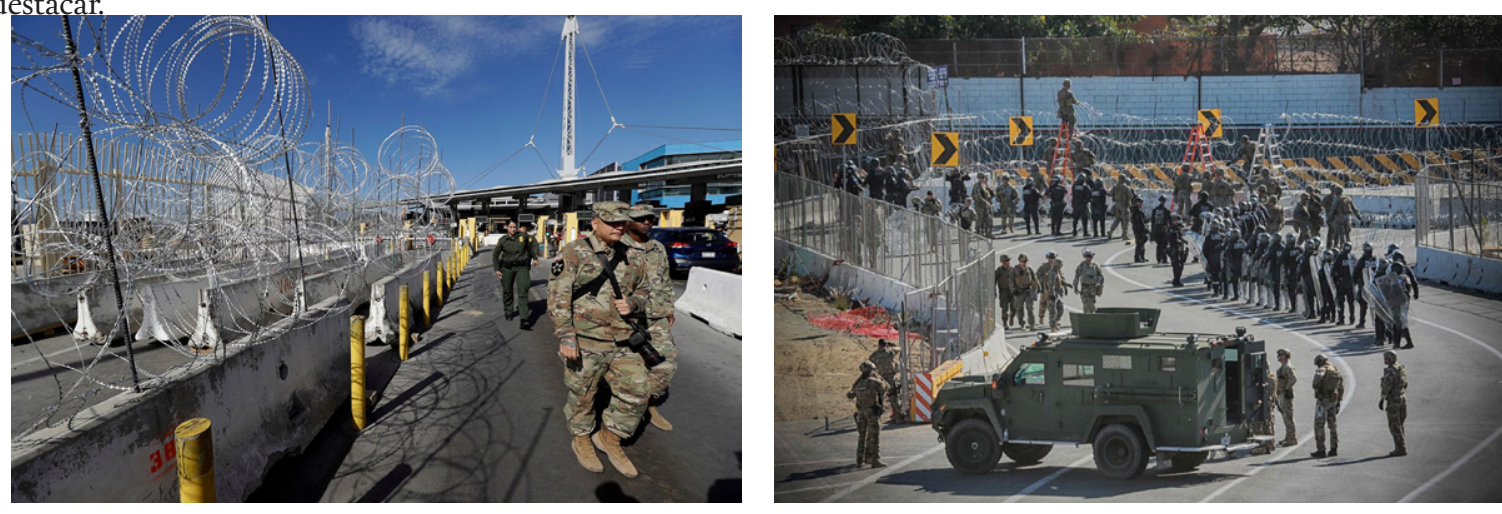

Despliegues militares en el paso fronterizo de Tijuana entre México y Estados Unidos. (Mexico, 2017).

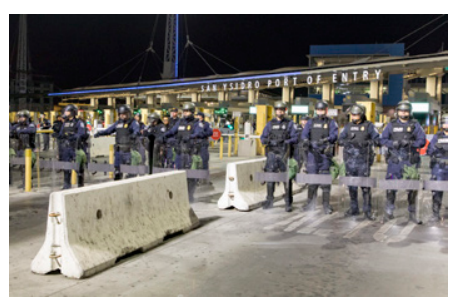

57 Audie Cornish, «Kevin McAleenan Says the Border Patrol Doesn't Make the Laws», New York Times, 7 de agosto de 2018. 
agentes aparentemente no arquitectónicos -que operan bajo lógicas tácticas y de contingencia- que en estructuras rígidas, estables y con baja responsividad -que operan bajo lógicas estratégicas-.

Un giro con profundas implicaciones arquitectónicas, de las formas estáticas a los ensamblajes dinámicos, que lleva funcionando más de una década en esta frontera. Fue durante la administración Bush, al calor de los atentados terroristas del II-S y del consecuente fervor securitario que ha transformado buena parte de las infraestructuras territoriales -así como su correlato a nivel arquitectónico y en el espacio público-, donde este refuerzo fue incrementado con una serie de medidas tecnológicas de supuesta gran efectividad ${ }^{5}$. Bajo el término infraestructuras tácticas se implementó a lo largo de toda la frontera un ensamblaje basado en diagramas de análisis de los condicionantes geográficos, territoriales e infraestructurales de cada tramo diferente. Es decir, se invertía el pensamiento estratégico para mostrar un catálogo de posibilidades infinito y adaptable ante cada situación territorial. A través de una misma serie de agentes técnicos y humanos - sensores, sistemas de vigilancia, unidades radar móviles, satélites, cables Ethernet, radios, vehículos, y agentes de diferentes cuerpos policiales- y las múltiples posibilidades de combinación, a las que hay que sumar los condicionantes geográficos y arquitecturas previas -el muro levantado durante la administración anterior-, la frontera se iba articulando mediante un pensamiento táctico. De esta forma se respondía con precisión a cada ecosistema, en vez de intentar implantar una solución unitaria. Los diagramas del Border Calculus ${ }^{59}$-basados en la combinación de cálculo integral y diferencial, así como en estadística avanzada- establecían una serie de radios de acción de diferente longitud en función de las condiciones de su posición y una serie de variables dinámicas donde no sólo recogía la velocidad de los agentes, sino que incluía, por vez primera, al migrante dentro de este dispositivo.

¿Acaso el cambio de posición gubernamental significa una regresión a posiciones previas respecto a cómo debe funcionar la frontera? No, justo lo contrario, a la vez que la arquitectura como hecho construido se sigue vaciando de funciones en pos de una serie de agentes técnicos desterritorializados que la superan en capacidad de respuesta, efectividad e impregnación en todo el territorio -y no sólo en el área de acción inmediata que la rodea-, su capacidad simbólica y el poder discursivo que se puede depositar en ella va aumentando exponencialmente. Es decir, el gobierno ha encontrado en el muro y la valla una nueva función, en palabras de Wendy Brown, la de encarnar "una modalidad y una ontología del poder soberano, espacialmente limitado y territorial. Parecen expresar un poder

58 Es importante destacar que, si el espacio público y los edificios sufrieron transformaciones fundamentalmente físicas y funcionales - gestión de recorridos, barreras antiimpactos, fortificación de zonas, refuerzos estructurales...-, en las infraestructuras territoriales -y no exclusivamente la frontera- priman los cambios a nivel tecnológico y dinámico por encima de las transformaciones físicas. Podríamos decir que esta diferenciación está sostenida en dos lógicas de operación diferentes basadas en la formulación del orden y la excepcionalidad como ámbitos aparentemente contrapuestos. Esta idea, desarrollada en los capítulos De la ley entendida como línea a las leyes entendidas como espacio y De territorios a cuerpos, se ve con especial lucidez en el contexto norteamericano, en el territorio interior hay un refuerzo de las lógicas del orden, en los territorios exteriores o limítrofes - la frontera sería este último caso-priman las lógicas de la excepcionalidad. E incluso, el orden a través de elementos estáticos fue, poco a poco, sustituyéndose por otra serie de mecanismos mucho más adaptativos y con menor presencia física. Una transformación más importante que la guerra de Afganistan fueron todas las medidas operativas tomadas durante la década siguiente: los ataques con drones, las prisiones extraterritoriales, los controles securitarios, los despliegues de tropas no declarados, son muestras de esta gestión operativa de la soberanía y el territorio nacional, que se amplia, reduce o modifica en función de cada acontecimiento y objetivo a neutralizar. La frontera, en este contexto, pasa de ser una línea reforzada por la administración Clinton, a un ensamblaje múltiple que puede expandirse allí donde sea necesario para asegurar su correcto funcionamiento.

59 Ryan Singel, Border Patrol Calculus, Wired Magazine. 27 de noviembre de 2016. Acceso el I5 de mayo de 2019. https://www.wired.com/2006/II/border-patrol-c/ 
material, visible, centralizado, físicamente ejercido con una fuerza y un control estentóreos" "6o Y, a la vez, "el hecho de amurallar expresa y satisface este deseo de una imago nacional de bondad, un deseo que externaliza totalmente los males de la nación y niega los efectos desagradables sobre los demás" ${ }^{61}$. Su poder simbólico, por más que no debamos obviar la violencia espacial, las heridas, cicatrices y muertes que esta arquitectura es capaz de generar, es la razón principal por la que Donald Trump ha vuelto a levantar el muro.
Diagramas del funcionamiento de Border Calculus (Departamento de Seguridad Nacional, 2005)

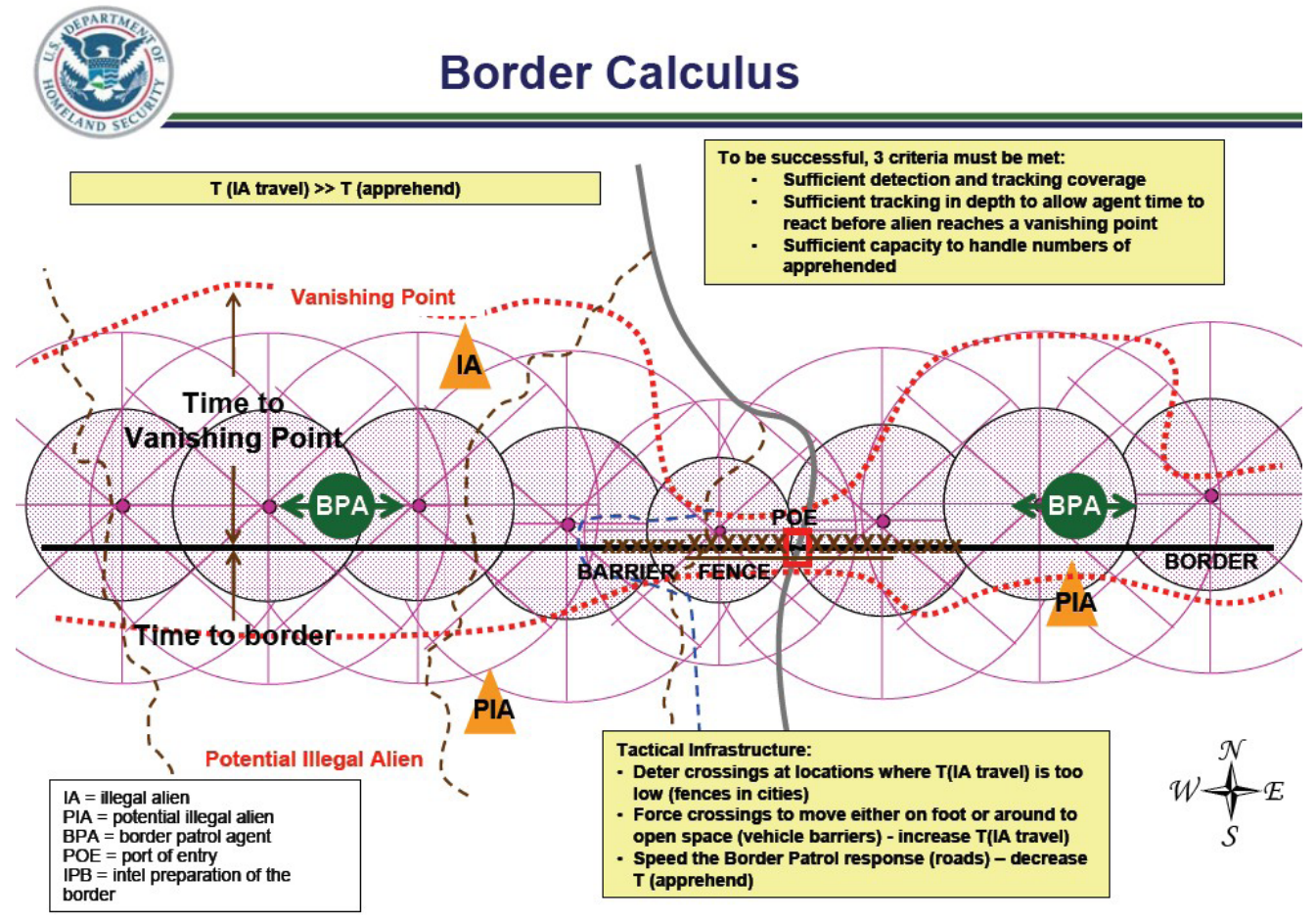

60 Brown, Estados amurallados, $s$

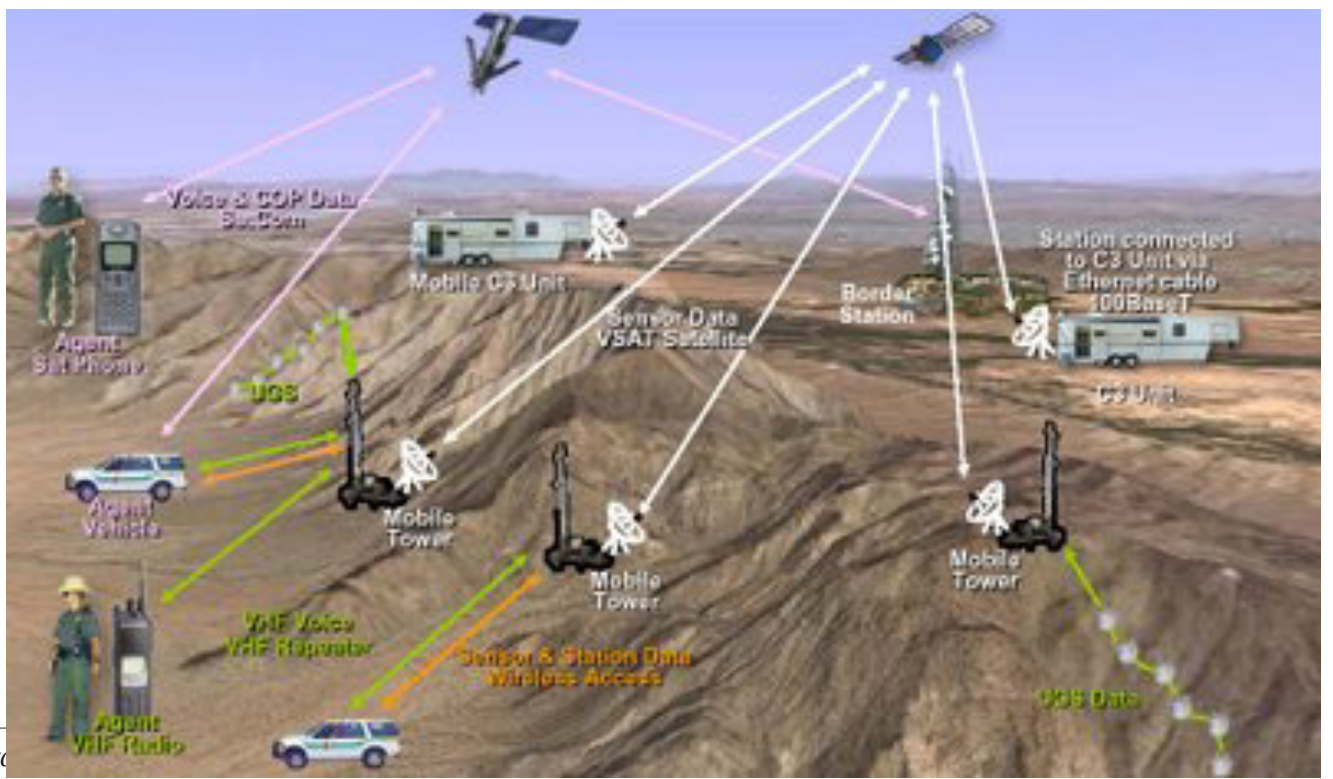

61 Brown, Estados amurallados, soberanía en declive (2015), 36. 



\subsection{LOS OTROS MUROS.}

\subsubsection{EUROPA COMO MURO (1990-2018)}

España tiene una valla desde hace muchos años ${ }^{62}$. Mariano Rajoy Brey.

Si todos estos movimientos, posiciones, declaraciones y arquitecturas han ocurrido durante el lapso temporal en que se desarrolla la presente investigación, no podemos ser ajenos a los movimientos y transformaciones que, durante el mismo período han ocurrido en la Unión Europea, concretamente en su Frontera Sur el mar Mediterráneo- y su Frontera Este -los países balcánicos-. El inicio de este trabajo ha coincidido con el aumento exponencial de la mediáticamente denominada "crisis de los refugiados sirios", causada por el recrudecimiento y duración del conflicto armado de Siria (2011-actualidad) entre el gobierno dictatorial de Bashar Al Assad y la oposición. Esto, sumado a la inestabilidad de Libia y Túnez, rebascularon el peso de la migración a Europa hacia los países del Mediterráneo Oriental -Italia, Grecia y Malta fundamentalmente- así como hacia la ruta balcánica. El resultado, un discurso prácticamente paralelo al de Donald Trump atomizado en el seno de diferentes países limítrofes, y el recrudecimiento en la negación del auxilio y asilo político, así como en la violencia que, a todos los niveles se desplegaba contra este cuerpo migrante múltiple. Un cuerpo en el que se superponían espectros generados desde diferentes discursos ya presentes en toda Europa, que cobraban ahora mayor visibilidad -el extranjero, el terrorista, el musulmán, el pobre; o, lo que es lo mismo, la xenofobia, la intolerancia religiosa, la aporofobia, el clasismo...-. Durante los años 2015 y 2016 pudimos ver la aparición de infinidad de arquitectónicas del internamiento, cómo espacios obsoletos se transformaban en centros de detención o estancia temporal, cómo los puestos fronterizos se fortificaban y militarizaban, y cómo el territorio europeo volvía a generar zonas de exclusión, compartimentándose y transformando las dinámicas de libre circulación que la habían caracterizado. El espacio Schengen, una de las piedras angulares del proyecto europeo, se suprimía, alteraba y modificaba ante la llegada de este cuerpo migrante.

Si el territorio europeo, desde la entrada en vigor del Acervo de Schengen ${ }^{63}$ firmado en 1990 anulaba todas las estriaciones terrestres a la libre circulación dentro del perímetro definido por las soberanías de los diferentes países participantes $^{64}$, en la segunda década del siglo XXI pudimos visibilizar como un espacio aparentemente liso como el mar, estaba en realidad totalmente estriado por una serie de normativas, legislaciones y soberanía. El trabajo de Lorenzo Pezzani y todo el equipo de Forensic Architecture en la Universidad de Goldsmiths lograban visibilizar las estrías y barreras que, incluso en un medio acuático como el

62 Carlos Alsina, "Más de uno” [Entrevista con Mariano Rajoy Brey], Onda Cero, 26 de enero de 2017.

63 Forensic Oceanography es un proyecto independiente que surge en 2011 desde el mencionado grupo de investigación Forensic Architecture. El trabajo de Lorenzo Pezzani -arquitecto- y Charles Heller -cineasta-, junto a un gran número de organizaciones, periodistas y medios, investiga el régimen de frontera militarizado que se ha establecido en el Mediterráneo a través de la reconstrucción forense de acontecimientos concretos.

64 Un perímetro que, por otro lado, se consolidó y reforzó materialmente, dando a conocerse como lo que, coloquialmente se ha denominado "Europa Fortaleza". 
mar Mediterráneo, se levantaban; el caso "Left to Die Boat" ${ }^{65}$, reconstruye a la perfección la superposición de capas legales y negaciones de auxilio en base al análisis forense de una patera a la deriva entre Libia y Malta ${ }^{66}$. Es importante aclarar que lo novedoso del empleo del mar como tecnología de frontera no reside en su uso consciente como barrera natural -algo que se ha cobrado la vida de más de 23.000 personas desde 1998 tal y como registran las plataformas Fortress Europe y Watchthemed-, sino en los contramovimientos para impedir el auxilio que los diferentes gobiernos han desplegado así como un cambio de escala en las embarcaciones empleadas. Este territorio, el Mediterráneo, también había sido tomado por las lógicas de la excepcionalidad y la operatividad, poniendo en suspenso las leyes marítimas al negar el auxilio a las diferentes embarcaciones o directamente saboteando su llegada.

Conforme a la evolución cruda de la respuesta internacional - no tan diferente a momentos anteriores- también se multiplicaron las redes de autogestión y resistencia que, ante esta situación, generaron mecanismos alternativos que, desde un pensamiento táctico, buscaban soluciones espaciales para las personas migrantes; desde los múltiples barcos de auxilio que poblaron el Mediterráneo hasta la proliferación de centros sociales y de acogida por toda Grecia. Los borderscapes, así como las arquitecturas y ensamblajes que los materializan, no sólo se configuran a través de una voluntad punitiva o represiva, sino de un conflicto constante entre diferentes intereses, agencias, tácticas y construcciones que los hacen evolucionar y transformarse con gran rapidez.

\subsection{ESPAÑA COMO LABORATORIO DE PRÁCTICAS DE CONSTRUCCIÓN DE FRONTERA.}

Si hay una imagen que sirve como testigo de esta situación, tan efímera por su rápida obsolescencia como impactante por su crudeza, es la recogida por Nilüfer Demir el 2 de septiembre de 2015. La fotografía muestra la orilla de una playa turca, donde yace el cuerpo sin vida de Aylan Kurdi, de tres años de edad. Una imagen que, pese a la distancia temporal y geográfica, debería resonar en el imaginario popular español por la similitud con las fotografías tomadas veintisiete años antes en Tarifa por Ildefonso Sena. La primera de ellas, otro cuerpo sin vida - este mayor de edad- al lado de una embarcación de madera y las olas rompiendo al fondo. La foto era testigo del naufragio a diez metros de la línea de costa de una patera con dieciocho personas a bordo, de las cuales sólo cinco sobrevivieron. El blanco y negro, el grano de la imagen, y los tricornios lustrosos de la Guardia Civil marcan la diferencia temporal de una realidad que, desde 1988 ha estado presente de manera constante en todo el Mediterráneo Sur.

65 Charles Heller y Lorenzo Pezzani, «"Left-to-die Boat”», en Forensis: The Architecture of public truth, ed. por Forensic Architecture (Berlin: Sternberg Press, 2014), 637: 656.

66 Fortress Europe es el proyecto de archivo web desarrollado por Gabriele del Grande que recoge cada una de las muertes ocurridas en el Mediterráneo de manera cronológica desde 1988, Watchthemed, desarrollado por Forensic Oceanography, empleando esta y otras bases de datos geolocaliza cada uno de los puntos negro en forma de una cartografía dinámica que muestra la evolución del Mediterráneo como tecnología de frontera. 

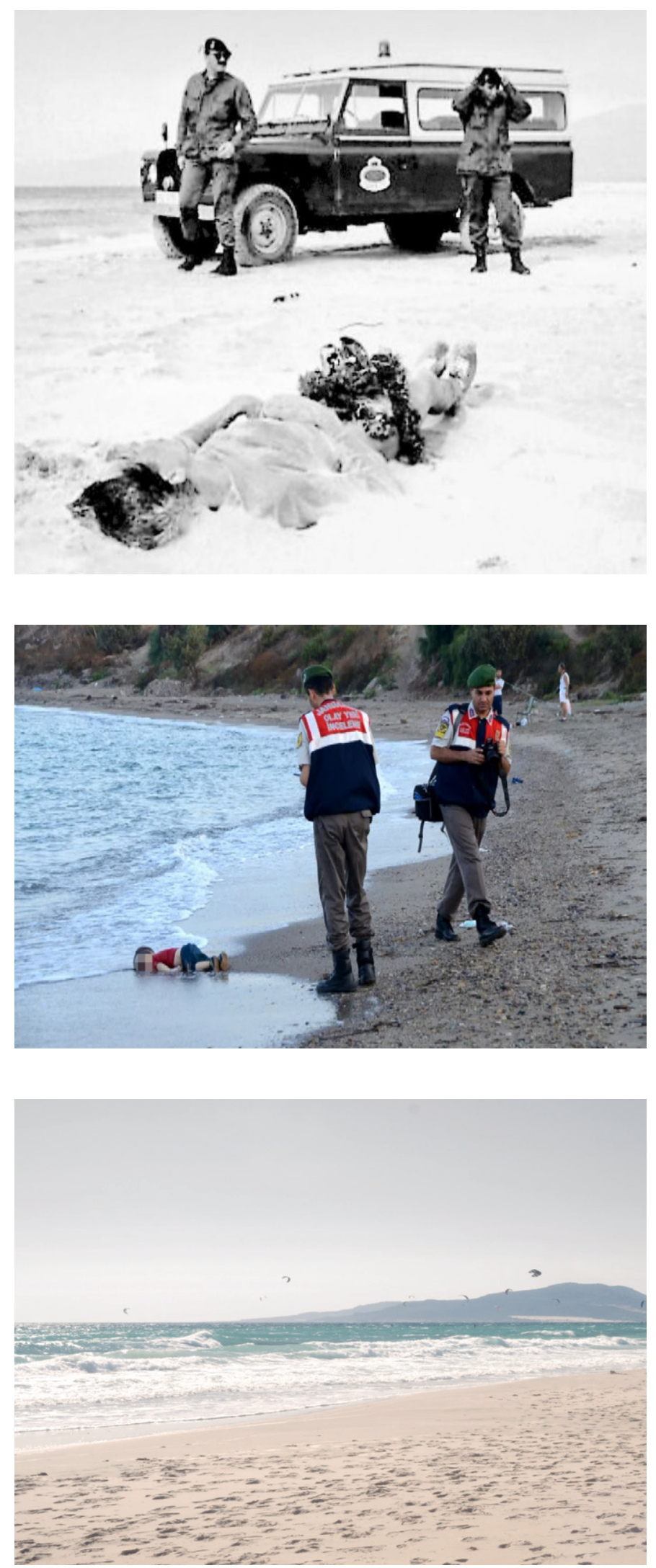

De arriba a abajo:

Migrante muerto en la playa de los Lances (Ildefonso Pena; Tarifa,1988); Aylan muerto en la costa mediterránea (Nilüfer Demir; Turquía, 2015); Playa de los Lances en 2019 (Elaboración propia;Tarifa, 2019). 
Y es que, pese a que la luz del foco mediático reciente ha desplazado a otras geografías el centro de gravedad de los procesos de construcción de frontera más visibles, esta sobreexposición no debería impedirnos ver cómo España ha constituido un laboratorio de vanguardia prácticas espaciales y territoriales en esta línea a nivel europeo desde los años noventa. De manera mucho más silenciosa y en un plazo temporal mucho más dilatado, podemos encontrar en la geografía española antecedentes claros de todas estas arquitecturas y acontecimientos. El gobierno español, como brazo ejecutor de las políticas europeas en un país limítrofe de ese cordón sanitario exterior generado tras el Acervo de Schengen -y como único país con extensión soberana en África-, generó a través de sus acciones un laboratorio de innovación en procesos de bordering La distancia geográfica y temporal a ambos procesos -el muro de Trump y las rutas migratorias en los Balcanes y Mediterráneo Oriental-, así como la visibilización mediática que han tenido, han suscitado una indignación y respuesta crítica mucho más contundente que a un proceso mucho más cercano, imbricado en nuestras costas, ciudades y arquitecturas cotidianas.

La valla de Ceuta y Melilla es un ejemplo paradigmático de una arquitectura militarizada, en cuyas transformaciones, pero también a través de los diferentes discursos encarnados en ella, se podrá ver la creciente securitización dinámica de la frontera. Esta ha multiplicado diez veces su espesor en dos décadas, doblado su altura y complejizado hasta un punto que sólo puede ser considerada un ensamblaje de innovaciones tecnológicas - cámaras de seguridad, sensores de detección de presencia, cámaras térmicas...-, construcciones orientadas explícitamente a impedir su cruce y marcar la carne de aquellos que la hacen, y agentes policiales. Sin embargo, no es la única arquitectura relacionada con el dispositivo frontera, éste va mucho más allá del muro y de la línea soberana que materializa sobre el territorio. Si en los últimos cinco años el concepto de frontera operativa -cuestionado hasta por la propia Unión Europea- ha sido una apuesta clara de maximizar los efectos de la valla, al asumir la ineficacia de una mayor militarización arquitectónica de la misma en pos de despliegues puntuales de soluciones dinámicas, esta gestión "operativa” del territorio ya estaba presente en otra de las principales infraestructuras arquitectónicas ligadas a la frontera: las arquitectónicas del internamiento. Diez años antes que en toda Europa proliferasen los campos de refugiados temporales apropiándose de arquitecturas obsoletas o con usos no ligados a la frontera ${ }^{67}$-desde la estación de trenes de Budapest, el aeropuerto de Tempelhof en Berlín, a los edificios de vivienda ocupados por toda Grecia-, en España cocederos de marisco, restaurantes para boda, sótanos y cocheras de comisarías, barcos, prisiones de alta seguridad, centros hípicos y un sinfín de arquitecturas eran ocupadas de manera temporal para internar a migrantes a través de la transformación mínima del espacio interior. Frente a una red estable de centros de internamiento, el gobierno español había entendido que la solución para responder de manera eficaz, responsiva y con un coste mucho menor a una necesidad voluble de internamiento, pasaba necesariamente por la

67 Por su parte, las empresas y la arquitectura europea colaboraron como cómplices en la capitalización de estas situaciones al realizar prototipos de diversa índole para ordenar y controlar los campos informales que, en muchos lugares de Europa, habían proliferado. Desde el premiado prototipo de Ikea Better Shelter hasta las famosas container city -la materialización distópica de una utopía estética reciente: la creación de edificios y sistemas urbanos empleando exclusivamente contenedores prefabricados como material constructivo-, la arquitectura imponía un orden rígido y aséptico por encima de la informalidad y autogestión presente en campos generados por la agrupación de migrantes. De nuevo, la disciplina arquitectónica imponía un sistema que no sólo aumentaba el control, rigidez y exclusión social sino que además eliminaba un ecosistema mucho más rico y variado ensamblado desde la informalidad y la precariedad. El ejemplo más claro de esta situación lo vemos en la Jungla de Calais, donde como medida profiláctica se arrasó con la práctica totalidad del campamento y se sustituyó por un sumatorio, fácilmente identificable de contenedores prefabricados a los que sólo podían acceder migrantes identificados. 
generación temporal de campos. Incluso hechos tan polémicos y criticados internacionalmente cómo han sido los despliegues militares en diferentes fronteras han sido ya antes puestos en práctica en Ceuta y Melilla, concretamente en el año 2005 cuando la administración de Zapatero en coordinación con el gobierno marroquí desplegó dos mil efectivos para controlar la línea fronteriza. Podemos incluso establecer paralelismos que se centran en cómo la solución empleada deja a la luz la condición menos-que-humana ${ }^{68}$ de que el cuerpo migrante tiene. Bajo esta óptica, el uso de jaulas para retener a migrantes mexicanos en 2018 no es tan distante al empleo de camiones de basura para trasladar migrantes africanos en las Islas Canarias cuatro años antes.

Este giro operativo de la frontera, donde un despliegue militar, un cocedero de marisco o un camión de basura pueden ser capturados instantáneamente para cobrar una nueva función, consigue extender y transformar topológicamente la frontera, ya no es una línea fortificada a través de diferentes medios -sino un plano superpuesto a la totalidad del territorio-. Un tejido de conexiones, lugares y arquitecturas cada vez más tupido y extenso. Y España es también un buen campo de estudio para detectar cómo la línea ha ido ampliándose hasta transformarse por completo en otro sistema, que sólo puede ser enunciado geométricamente como una maraña o, como hemos decidido hacer en esta tesis, un dispositivo.

\subsection{EL MURO ESTADOUNIDENSE COMO REFLEJO}

Este es el contexto cambiante y múltiple en el cual se ha desarrollado la investigación doctoral, cuatro años donde han aparecido y superpuesto multitud de discursos y prácticas espaciales acerca de la frontera. Por ello, para poder analizar con precisión un fenómeno presente a nivel global, donde la arquitectura estática ha dado paso a disposiciones operativas y ésta ha sido relegada a un plano simbólico con una fuerza cada vez mayor, es necesario que miremos más allá del foco mediático de la inmediatez. Porque, si bien esta sobreexposición ha permitido que tanto prácticas espaciales como discursos políticos se mostrasen de manera explícita y mayoritaria que confirman un nuevo modo de entender la soberanía - mucho más líquida y operativa-, también se corre el peligro de dejar en penumbra una serie de transformaciones arquitectónicas que, de manera mucho más silenciosa, dilatada en el tiempo, pero con la misma carga de violencia espacial han estado proliferando en el territorio europeo durante los últimos treinta años. Tomar distancia respecto a la realidad inmediata que rodea a esta investigación permitirá por un lado, contextualizar y situar históricamente estos procesos de construcción de frontera, relativizar su novedad, y por otro lado, poner en relación entre sí situaciones excepcionales aparentemente inconexas que responden a una misma estrategia de fortificación.

Del mismo modo que los paisajistas ingleses usaban un espejo de obsidiana, dando la vuelta al paisaje que intentaban retratar, para ser capaces de trasladarlo al lienzo con la precisión adecuada, hemos de usar nuestros propios artefactos para analizar los paisajes donde se construye la frontera contemporánea. El muro de Trump, sus discursos y despliegues militares no son más que el espejo, deformado

68 Término recogido del libro Habeas Viscus de Alexander G. Weheliye donde argumenta cómo a través de los diferentes dispositivos racializadores la condición humana -en tanto que poseedora de derechos- no es alcanzada por todos los seres humanos.

Ver más en Alexander Weheliye, Habeas Viscus: Racializing Assemblages, Biopolitics and Black Feminist Theories of the Human (Duke: Duke University Press, 2014). 
y acelerado, de una realidad que en el contexto europeo ha sido implementada de manera exitosa, con gran lentitud -y tal vez debido a esto con un ruido mediático, mucho menor y un rechazo disciplinar prácticamente inexistente- y gran contundencia durante las tres últimas décadas. Por ello, por la contundencia de sus declaraciones, la violencia de sus actos y el paralaje que podemos establecer entre ellos, observar este proceso de transformación territorial, permite devolver una mirada nítida a una realidad que, por cercana, nos resulta desconocida. Pero además, esta aceleración respecto al contexto europeo ha logrado suscitar un debate - político y social- donde la disciplina arquitectónica americana se ha sentido directamente interpelada, algo que -salvo contadas excepciones- no ha ocurrido en el contexto europeo. Y viceversa, dar la espalda a la realidad inmediata para centrarse en los acontecimientos y transformaciones espaciales que se han llevado a cabo en los últimos veinte años, permitirá comprender el recorrido trazado hasta llegar a la situación actual. La de una frontera no se conjuga ya como una realidad estable sino que se articula como ensamblajes arquitectónicos múltiples, que responden con precisión a las necesidades de cada acontecimiento concreto. Una frontera donde lo estático ha sido reemplazado por lo dinámico, donde el tiempo ha adquirido mucha mayor relevancia que el espacio, donde el cuerpo ha adquirido la dimensión protagonista que antes poseían los muros y donde la norma ha dado paso a la excepción. 


\section{INTRODUCCIÓN}

2.1. Objetivos e hipótesis de la investigación. Desvelar las implicaciones arquitectónicas de la frontera contemporánea.

2.2. Estrategia de investigación. Entre lo material y lo virtual.

2.3. Estructura y contenidos.

2.4. Metodología. Devenir cartógrafos y forenses.

2.5. Una aproximación al estado de la cuestión. Estudios, paisajes y estéticas fronterizas. 

Trazar una línea es, probablemente, una de las primeras acciones arquitectónicas. A través de la acción violenta de un cuerpo se logra establecer una diferencia sobre un territorio antes neutro. Trazar un límite constituye una operación básica de selección y distinción entre lo Uno y lo Otro, entre lo propio y lo ajeno, lo exterior y lo interior, lo público y lo privado y, a través de dicha operación se establece un posicionamiento dentro de un ámbito más amplio. La línea se convierte en una delimitación que parcela y divide el espacio, lo construye. Sus materializaciones son infinitas, desde las más inmediatas y efímeras hasta las más complejas definidas por una superposición de capas, materiales y agentes involucrados en su construcción. Así pues, una línea no puede entenderse únicamente desde las trazas que deja sobre el territorio, las construcciones que la conforman, ya que esto dificultaría el entendimiento de las razones y objetivos que la dotan de función y sentido. Sin embargo, tampoco es posible hacerlo atendiendo únicamente a las lógicas que la línea encarna, ya que toda arquitectura implica una autonomía respecto a ellas fruto de su materialización. Pero además, su construcción no construye únicamente una territorialidad en base al trazdo de sus bordes o de las lógicas que operan dentro de él, sino que también construye al individuo que incluye $-y$ traza la línea de un modo u otro- como al que excluye. Por tanto, comprender las realidades que esconde una línea supone una serie de idas y venidas entre lo abstracto y lo concreto, entre los elementos que la conforman y las lógicas, leyes y acciones que la dotan de sentido. Sólo así, se puede comprender la verdadera magnitud, las lógicas que hay detrás así como las arquitecturas implicadas en la construcción de una línea.

\subsection{OBJETIVOS E HIPÓTESIS DE LA INVESTIGACIÓN. DESVELAR LAS IMPLICACIONES ARQUITECTÓNICAS DE LA FRONTERA CONTEMPORÁNEA}

La frontera, pese a la simplicidad falaz de los mapas geopolíticos, una línea precisa de espesor ínfimo que delimita el contorno de cada soberanía, esconde una inmensa complejidad ligada a su construcción. Esta tesis se sitúa sobre la construcción de esta línea para analizar las profundas implicaciones arquitectónicas que, la construcción contemporánea de la frontera, acarrea. Este es el objetivo principal de la investigación: desvelar las lógicas de producción espacial de la frontera contemporánea; como se está construyendo así como los agentes, arquitecturas y territorios involucrados en este dispositivo territorial. Para ello situamos el foco en la realidad material que encarna la línea soberana, prestando atención a los diferentes escenarios en los que la frontera se despliega. Unas lógicas que ya no pueden explicarse únicamente a través de las construcciones estables que la conforman, sino que deben incluir en cualquier análisis las acciones dinámicas, los agentes aparentemente no-arquitectónicos que de manera coordinada, cooperan, sustituyen y reemplazan una arquitectura estática y obsoleta. El muro ha dado paso a una serie de ensamblajes territoriales que responden con precisión a las necesidades puntuales de cada momento, lo que ha multiplicado los escenarios, pero también las arquitecturas y agentes involucrados en la misma. Un análisis desde el plano arquitectónico permitirá comprender la dimensión temporal que ésta ha adquirido, por encima de la espacial.
Objetivo: desvelar las lógicas de producción espacial de la frontera. 
Objetivo: comprender el funcionamiento operativo frente a lógicas discursivas
Por lo tanto, al situarnos en la frontera, ni a un lado ni a otro, debemos ser conscientes de la materialidad concreta que construye así como de las conexiones virtuales que potencialmente genera entre arquitecturas y escenarios dispersos. Una mirada detenida a las diferentes construcciones que encarnan la frontera nos permitirá ver como estas no son construcciones autónomas sino que funcionan en relación a una serie de agentes aparentemente no-arquitectónicos a través de las cuales refuerza o amplia su funcionamiento territorial. Por otro lado, una mirada centrada no tanto en los cuerpos, sino en las acciones, leyes y protocolos que estos encarnan, permite entender la disposición de estas arquitecturas dispersas y su funcionamiento conjunto. Si toda línea responde a una decisión previa, y su materialización es la encargada de dotarla de efectividad, es fundamental observar esta serie de decisiones que toman forma de normativas, regulaciones, protocolos, decisiones operativas, tácticas de hackeado y transgresión, acuerdos políticos,...Es decir, por más que la frontera sea un ejemplo paradigmático de una arquitectura que encarna una ley -una soberanía estatal-, no podemos limitar nuestro análisis a la concepción normativa de la misma, sino ir mucho más allá e incluir toda clase de acciones e intereses -contrapuestos, contrarios o antagónicos- que la construyen y actualizan en base a su implementación. Frente a un análisis únicamente centrado en los objetos como forma arquitectónica, primamos las formas activas, es decir, los elementos - materiales o inmateriales- con capacidad de transformación y redisposición de una realidad. Por tanto, se miran con el mismo detenimiento a cada una de las piezas de la frontera como a los enlaces y agencias establecidas entre ellos, al paisaje legal, lawscape, que se superpone y conforma un espacio en tensión y reorganización constante.

A través de esta mirada detenida se intenta comprender el paralaje existente entre el funcionamiento operativo de estas arquitecturas frente a los discursos-arquitectónicos, políticos, sociales- que se generan en torno a ellas. Para detectar este desplazamiento debemos atender a determinados acontecimientos donde se amplia la divergencia entre funcionamiento operativo y discursivo. Pues en ellos se explicita una separación que sólo puede ser formulada como una brecha de paralaje usando la terminología empleada por Zizek: la confrontación de dos realidades que, pese a su cercanía, no comparten una base común -más allá de su propia materialidad, deberíamos añadir-. El cuerpo migrante, a través de su resistencia activa tanto a la materia que conforma la frontera como de las diferentes leyes que encarna, logra explicitar esta brecha, haciendo mucho más fácil la detección de ciertos parámetros que, de otra forma, sería más difícil observar.

Otro de los objetivos principales es entender las transformaciones arquitectónicas derivadas de su giro operativo, que han hecho que las arquitecturas de la frontera ya no se concentren en las inmediaciones de la línea, su perímetro exterior, sino que se superpongan sobre un territorio mucho más amplio. Una tendencia que, en el contexto europeo, coincide con la caída del muro de Berlín y la construcción del espacio Schengen, fecha de arranque de nuestro marco temporal. Así, un territorio tan vasto y aparentemente libre de fronteras o divisiones internas que afecten la movilidad de las personas, es controlado en base a construcciones de otra índole que siguen vinculadas a la regulación del flujo de cuerpos en la totalidad del territorio. Tal y como afirma Ettiene Balibar: "la frontera se está convirtiendo idéntica al territorio al que se suponía tenía que circundar, o en cualquier caso, prácticamente indistinguible, continuamente mezclada con el territorio. Deconstruyendo así el símbolo de una línea que no pertenece ni a un territorio ni a otro" ${ }^{2}$. ¿Es posible detectar esta transformación también a nivel arquitectónico? Profundizar en esta idea resulta clave, no sólo

1 Slavoj Zizek, The Parallax View (Cambridge: The Mit Press, 2006).

2 Etienne Balibar, “Topology: Borders as space of transformation.” (conferencia presentada en la Tate Modern de Londres, noviembre de 2011). 
para entender cómo ha habido un proceso de desterritorialización de una construcción sólida que, por sí misma, ya no resulta eficiente, sino también para arrojar luz sobre las consecuencias que esta traslación tiene al territorio. Si las lógicas excepcionales de la frontera antes se concentraban en el espacio inmediato de la línea construida, su extensión ahora se superpone, impregna y entremezcla en la totalidad del territorio. Por ello, dilucidar de qué forma y hasta qué punto la frontera es ya un dispositivo desterritorializado, permite entender no sólo la dimensión geográfica y territorial que ha adquirido, sino también los mecanismos que posibilitan que siga siendo eficaz.

Profundicemos en esta idea, pues tras esta dispersión territorial subyace una transformación topológica, donde la línea soberana ha dado paso, en todo caso, a un plano o campo. El perímetro se desdibuja, se propaga, no sólo a través de unas arquitecturas dispersas, sino también de las lógicas que antes encarnaba la valla o el muro. Pero ¿a qué responde esta transformación?. Del mismo modo que, con la creación del Estado Nación moderno, la arquitectura que defendía las ciudades -las murallas medievales y barrocas- fue sustituida por un nuevo sistema espacial que respondía a las necesidades operativas del momento33, la arquitectura que define la soberanía nacional en su límite se encuentra también en un proceso de transformación. En un contexto global de tránsito generalizado de cuerpos, divisas y mercancías donde la soberanía del estado nación ha sido sustituida por una red de organismos supranacionales y paranacionales, con capacidad tecnológica para conectar territorios distantes, es lógico que los dispositivos arquitectónicos se adapten a esta realidad. Estamos, por tanto, presenciando los estertores espectaculares de un sistema territorial obsoleto-las vallas y los muros fronterizos-, y la creación incipiente de nuevos dispositivos operativos, presentes en todo el territorio, que lo sustituyen.

Para abordar estas cuestiones, empleamos un concepto que permite conectar realidades materiales específicas con una escala territorial mucho más amplia y sea capaz de explicar su capacidad de acción conjunta a pesar de su dispersión geográfica. Para ello utilizamos la noción de dispositivo la cual plantea la posibilidad de concebir un único software de producción territorial, el cual posibilita la producción de infinidad de acontecimientos, empleando para ello agentes de diferente naturaleza -arquitecturas, medios técnicos, humanos y no-humanos, protocolos, territorios, tiempos...- con capacidad de acción conjunta. Estructurar la tesis alrededor de esta noción no significa exclusivamente emplearla como una herramienta metodológica que conecte realidades aparentemente lejanas o autónomas, sino convertir el método en un objetivo, y ahondar en el concepto mismo de dispositivo desde la disciplina arquitectónica, desplegar toda la potencia que este modelo formulado por Foucault posee para entender las diferentes fuerzas y agentes involucrados en la producción del espacio fronterizo.

Sin embargo, formular el dispositivo frontera obliga a buscar la relación entre partes inconexas, entre una realidad material y unas conexiones virtuales inmateriales entre ellas. Intentar desvelar las lógicas que hay detrás de este concepto filosófico que deviene en un modelo de análisis y producción espacial el dispositivo frontera-, no consiste en agotar todas las posibilidades y escenarios que es capaz de producir. Sería impensable por varios motivos: el primero de ellos la obsolescencia inmediata de todo el trabajo de investigación, convertido en revisión histórica frente al desarrollo de una herramienta operativa y la infinidad
Objetivo: ahondar en el dispositivo como software de producción arquitectónica

3 Es importante señalar que esta disolución de los límites no afectó exclusivamente a la arquitectura sólida que encerraba a la ciudad, sino que la ciudad misma se disolvió en la totalidad del territorio. Sus lógicas de gestión, su manera de concebir el territorio, se superpusieron sobre una nueva extensión de territorio que, sin ser urbana, se iba a ordenar a partir de ese momento, fundamentalmente, en base a los parámetros de la ciudad. 
Hipótesis: el cuerpo construye la frontera. de posibilidades espaciales que, un mismo dispositivo, es capaz de producir. Frente a ello, se pretende visibilizar las lógicas internas que subyacen a esta infinidad de posibilidades, a la vez que se desarrollan las herramientas teóricas y prácticas que permitan analizar nuevas situaciones o extrapolarlo a otros contextos.

¿Hacia donde nos conducen estos horizontes que orientan la investigación? Al configurar una cartografía, lo más compleja posible, de cómo funciona la frontera contemporánea desde la disciplina arquitectónica. Una cartografía que nos permite alcanzar la hipótesis que da sentido a esta investigación doctoral. Pese a lo escurridizo de la misma, debido a la constante transformación de los escenarios y casos de estudio hay una idea que se persigue y que es capaz de conectar todos los escenarios que transita esta investigación. Es el cuerpo, a través de sus acciones y desplazamiento por el territorio, el que está construyendo la frontera contemporánea, una frontera que ya no se presenta como una construcción sino como un dispositivo. El cuerpo, y la norma que lo incluye o excluye políticamente de un territorio en el que está físicamente presente, activa y transforma una serie de arquitecturas mediante sus acciones. Es, en última instancia, el agente capaz de reorientar con extraordinaria rapidez los diferentes elementos que constituyen el dispositivo para impedir, ralentizar o autorizar sus movimientos en cualquier punto del territorio en el que él se sitúe. Frente a arquitecturas estáticas, aparecen ensamblajes precarios, frágiles e instantáneos que, de manera dispersa, se activan y ponen en funcionamiento en función de las acciones que el cuerpo migrante realice. 


\subsection{ESTRATEGIA DE INVESTIGACIÓN. ENTRE LO MATERIAL Y LO VIRTUAL.}

El dispositivo frontera, entendido como un software de construcción territorial -al menos a efectos inmediatos de esta investigación-, es el mecanismo encargado de la regulación de flujos de los cuerpos presentes en un territorio, tantos los autorizados como los no autorizados. A través del estatus político y la posición a cada momento dentro de un espectro que va desde lo legal a lo ilegal, cada cuerpo transita entre una serie de válvulas y sistemas destinados a controlar su desplazamiento y acciones dentro del territorio. Es por ello que los tres escenarios seleccionados para su análisis: la valla, las arquitectónicas del internamiento y la metrópolis componen tres facetas diferentes de un mismo sistema donde los mecanismos de regulación, y por tanto la materialización arquitectónica de la frontera, varía enormemente. Pese a la distancia que los separa, tanto escalar como a efectos de un análisis disciplinar ortodoxo, se ha establecido en cada uno de ellos una estructura interna similar, lo que permite establecer lecturas paralelas. Así pues, los tres arrancan con una aproximación desde una perspectiva histórica centrada en la evolución reciente de cada ensamblaje arquitectónico, donde se introducen variables diferentes en cada caso para centrar el análisis en aspectos específicos de cada uno de ellos. A continuación, en base a acontecimientos concretos y su cartografiado crítico se explica en qué ha consistido y a qué elementos arquitectónicos ha afectado el giro operativo de la frontera. Por último, y desde estos acontecimientos analizados, se visibilizan las resistencias efectuadas por el cuerpo migrante para subvertir la disposición arquitectónica en cada situación, como ejemplo de cómo las acciones de una arquitectónica menor son capaces de alterar una construcción espacial determinada.

Sin embargo, es necesario explicitar las lógicas de funcionamiento que subyacen tras cada uno de los acontecimientos y arquitecturas presentes en nuestro análisis para hacerlas accesibles y contextualizarlas más allá de la concreción de cada situación. Extrapolar a un plano abstracto, desde el análisis simultáneo de los diferentes casos de estudio, permite visibilizar estas lógicas que son, a su vez, aplicables, a otras construcciones espaciales vinculadas a la frontera contemporánea. Pero además, en un contexto arquitectónico más amplio, esta lectura abstracta de cómo se está transformando la frontera contemporánea, permitirá entender la complejidad de una serie de cuestiones que afectan a una arquitectura donde lo material da paso a conexiones puntuales entre agentes dispersos, lo estático a lo dinámico, la construcción de recintos a la generación de campos, la norma a la excepcionalidad, lo territorial a lo disperso, y lo topográfico a lo topológico. Por tanto, esta aproximación a las lógicas de los dispositivos desde una perspectiva arquitectónica, así como a las consecuencias que esto provoca a la hora de concebir y construir el espacio, discurre paralela a los casos de estudio analizados, como única forma de reflejar la complejidad que esconde cada uno de ellos. De manera condensada y claramente diferenciada, tanto en estructura como en contenido, se intercalan entre cada arquitectónica de la frontera estos capítulos que, de nuevo hilvanados por el dispositivo, contienen cuestiones transversales.
Criterios de selección de los casos de estudio. 
Grados de desterritorialización y lecturas no-lineales.
Esta aproximación no es lineal ni unidireccional, sino enmarañada y en bucle, reiterativa, a través de múltiples lecturas sobre un mismo acontecimiento y viceversa, que logran desvelar el cuerpo múltiple de la frontera entendida como un dispositivo territorial, así como construir la mirada necesaria que nos permita analizarlo en toda su complejidad.

Si la sociedad disciplinaria de Foucault ${ }^{4}$ operaba estructurando la sociedad en base a un control aparentemente lineal de la población en base a los grandes centros de encierro, el paso a la sociedad del control enunciada por Deleuze ${ }^{5}$-transforma esta linealidad en una maraña reiterativa de posibles escenarios vinculados de manera frágil, frente a la concatenación de sus predecesores. Esta distinción tiene una relación inmediata con el ámbito que nos compete, ya que la linealidad del formato de la investigación es incapaz de reflejar la simultaneidad de posibilidades que existen en realidad. Es por ello necesario aclarar el orden que se ha establecido para evitar otras lecturas posibles que, desde el marco disciplinar, sería fácil realizar. La más inmediata podría ser una lectura escalar, desde la dimensión más objetual de la valla a la condición urbana de la metrópolis. Sin embargo, en todos los capítulos queda patente la condición transescalar establecida, donde un cuerpo o una pieza de cerámica puede, en un momento dado, adquirir tanta relevancia como una infraestructura territorial. Otra lectura podría atender a la aparente linealidad del proceso de regulación de flujos, pero como acabamos de explicar, sería erróneo ya que es un proceso reiterativo nolineal. Planteamos, ante la necesidad de establecer un orden lineal que no es tal, una aproximación desde el creciente grado de desterritorialización presente en cada capítulo. Es decir, la impregnación de las lógicas excepcionales de la frontera en un territorio cada vez más tupido de elementos susceptibles de ser capturados momentáneamente, donde la línea entre lo ordinario y lo extraordinario se difumina progresivamente.

Sin embargo, nos resistimos a que esta linealidad sea la única forma de lectura posible. Frente a una única dirección posible proponemos múltiples puntos de entrada a la investigación doctoral, escenas independientes cosidas a través de las lógicas virtuales que despliega la frontera; materializaciones diferentes de un mismo dispositivo, inaprensible en su totalidad pero sí reconstruible en base a la observación detenida de fragmentos parciales. Es por ello que, cada capítulo se ha planteado con una autonomía casi total, lo que permite cualquier alteración en el orden o elipsis en su lectura. Los artículos y comunicaciones presentadas durante el desarrollo de la tesis - From Landscapes to Lawscapes; Sistemas de impermeabilización y control de masas; Impermeabilizar, retardar y controlar; Three in-visibilized surfaces outside the CIEs; Between the scanscape and the free-fire zone; El dispositivo frontera- toman cuerpo como parte importante de los capítulos, siendo este formato el espacio y forma adecuada que permite hilvanar conceptos transversales a ellos, poner el foco con detenimiento en cuestiones concretas que las limitaciones o autonomía de los artículos científicos dificultaría. El formato de la investigación se presenta como "un mapa que debe ser producido, construido, siempre desmontable, conectable, modificable, con múltiples entradas y salidas, con sus líneas de fuga" ${ }^{6}$ en base a las evidencias y trazas materiales que dotan de cuerpo a esta tesis.

4 Michel Foucault, Vigilar y Castigar (Madrid: Siglo XXI Editores, 1978).

5 Gilles Deleuze, "Post-Scriptum Sobre Las Sociedades De Control", Polis, Revista Latinoamericana $\mathrm{n}^{\mathrm{o}}$. 13 (2006).

6 Gilles Deleuze y Pierre Felix Guattari, Mil Mesetas (Valencia:Pre-textos, 2004), p.26. 


\subsection{ESTRUCTURA Y CONTENIDO.}

La tesis discurre a dos tempos, diferentes pero simultáneos. El primero de ellos, centrado en el cartografiado crítico de una serie de arquitectónicas ligada de manera directa con la construcción de la frontera. El segundo de ellos enfocado a desvelar las lógicas de producción de un sistema de producción espacial y territorial que ya no requiere de la arquitectura entendida como una realidad estática y estable sino de unos ensamblajes arquitectónicos que puedan desplegarse con inmediatez sobre cualquier lugar.

No obstante, es necesario situar la investigación en un presente inmediato, desplegar de manera instantánea las diferentes claves de navegación que permitirán su orientación a lo largo de todo el documento. Por ello, frente a una aproximación directa a nuestro marco -la frontera contemporánea europea desde España como laboratorio arquitectónico experimental de construcciones ligadas a ella- se decide usar el caso análogo de la frontera estadounidense con Mexico. Esta aproximación externa, condensada en apenas cuatro años de duración desde que Donald Trump la pusiese en el centro de su agenda política, permite recoger tanto las problemáticas que este sistema arquitectónico genera como las inquietudes investigadoras, disciplinares y políticas que nos han interpelado de manera directa en forma de múltiples preguntas - ¿Cuál es la materia arquitectónica que construye la frontera? ¿Cuáles son las respuesta disciplinares que se han dado a este hecho problemático? ¿Cuál es nuestro papel como diseñadores?...-

Una vez anclada la investigación en un aquí y un ahora, en un territorio concreto, es necesario aportar las claves metodológicas que han construido la tesis. Conscientes de la falta de un método científico sólido en la disciplina arquitectónica -y más aún en un campo de estudio que aborda e hibrida necesariamente diferentes saberes y campos de conocimiento-, el presente capítulo sirve para visibilizar la elaboración de un proceso de análisis de la realidad parejo a una de las nociones fundamental que vertebran la investigación: el dispositivo. Se conectan dos medios de análisis de la realidad, la cartografía (crítica) y la arquitectura forense, que permiten analizar y gestionar fuentes documentales de muy diversa índole, a la vez que extraer a la luz pública conexiones entre elementos aparentemente no conectados. Se hace una aproximación, disciplinar y extradisciplinar, a un campo de estudio que aglutina diferentes disciplinas a fin de ampliar la discusión a un marco más amplio.

Es, llegados a este punto, donde la lectura se bifurca, presentándose capítulos alternos que basculan entre el acontecimiento y la abstracción. La valla, las arquitectónicas del internamiento y la post-metropolis constituyen tres capítulos centrados en desvelar las transformaciones hacia una arquitectura operativa que se han dado en las últimas décadas. Entre ellos, a modo de interludios, cuatro capítulos de menor extensión donde se condensan cuatro aspectos claves detectados en la formulación del dispositivo frontera. Una estructura que introduce la pertinencia de la lógica de los dispositivos en la disciplina arquitectónica, explica las características derivadas de este sistema de producción espacial, las consecuencias derivadas de éste y por último un capítulo centrado en la capacidad operativa y de transformación arquitectónica a través de tácticas arquitectónicas menores como herramientas.
\#0. Would not we buid your wall?

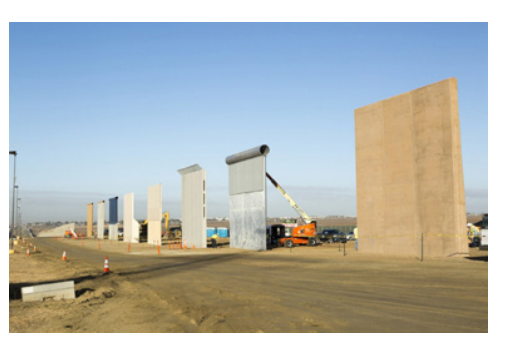

\#1. Introducción: Objetivos, hipótesis, estrategia, estructura, contenidos, metodología y estado de la cuestión. 
\#2. La valla.

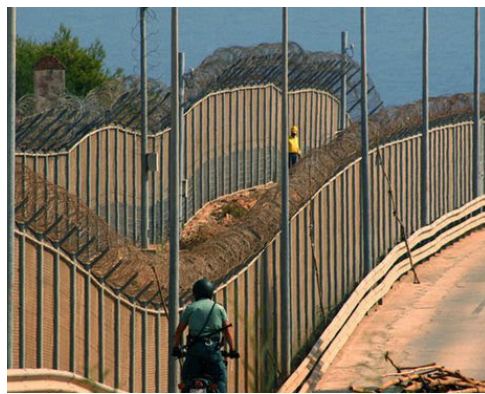

\#3. Arquitectónicas del internamiento.

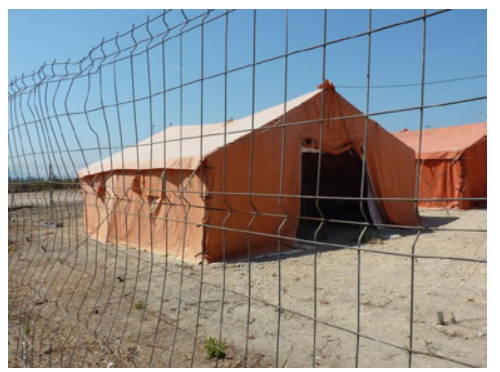

\#4. Post-metrópolis

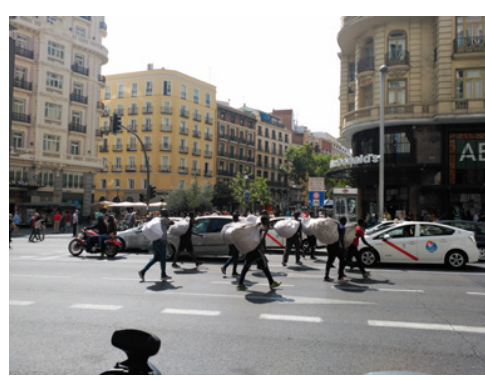

\#a.Una aproximación territorial a las lógicas de los dispositivos.
El primer capítulo se centra en la valla como una arquitectura punitiva, concebida para impedir el cruce del territorio y herir a aquellos que lo hagan, arquitectura que visibiliza de forma paradigmática la violencia inherente a cualquier producción arquitectónica así como la encarnación de una ley. Se inicia el capítulo con la progresiva militarización de la valla de Ceuta y Melilla desde la entrada en vigor del Acervo de Schengen para, a continuación centrarse en una serie de acontecimientos puntuales: las devoluciones en caliente del 2014 en Melilla, la muerte de 14 migrantes en el Tarajal, y el cuerpo encaramado a la valla durante más de 30 horas en el paso fronterizo del Benzú, donde la arquitectura de la valla es sustituida por ensamblajes precarios, móviles, pero con una capacidad de acción inmediata -apenas unas horas- que refuerzan la funcionalidad de una arquitectura obsoleta.

A continuación el foco se sitúa sobre las arquitectónicas del internamiento, término que aglutina las diferentes formulaciones normativas para construcciones donde se retiene a migrantes en diferentes fases del sistema de regulación del flujo migratorio. Se analiza su evolución histórica, explicando la sucesión de diferentes respuestas arquitectónicas $-\mathrm{y}$ los discursos arquitectónicos empleados-, que han derivado a la generación de una tipología interconectada donde cada centro ejecuta una función diferente a nivel nacional. Incluir tipologías menores o diferentes al CIE permite observar la proliferación de una serie de tácticas arquitectónicas para dotar de mayor capacidad o desplegar nuevas arquitectónicas del internamiento en cualquier lugar del territorio sin recurrir a la lentitud y costes derivados de un edificio estable. Finalmente, la opacidad normativa, legal y mediática del CIE, así como las polémicas y resistencia de los migrantes internos en ellos que los han acompañado desde su creación, permite centrar nuestro análisis en las tácticas de resistencia para transformar su realidad material inmediata.

Por último, el tercer caso de estudio se centra en la post-metrópolis como territorio donde se disputa la frontera contemporánea. El área geográfica de análisis es, fundamentalmente, el barrio madrileño de Lavapiés, aunque es fácilmente extrapolable a territorios más amplios ya que, como cuerpo migrante, estudia el caso de los manteros, como figura paradigmática que articula una serie de conflictos, violencias y resistencias espaciales. Del mismo modo que en los capítulos anteriores, se contextualiza históricamente el control urbano ligado a la frontera para reconstruir acontecimientos concretos que demuestran como la excepcionalidad ha transformado el tejido urbano. A través de los manteros se analiza cómo el control urbano ya no efectúa divisiones topográficas de sectores urbanos sino que actúa en base a cuerpos específicos. Además, la organización de los manteros, la resistencia urbana extensible a otros cuerpos migrantes, permiten enriquecer el análisis de cómo a través de tácticas menores se logra subvertir o alterar el espacio.

Entre cada capítulo, la tesis profundiza a través de cuatro aproximaciones en la lógica de los dispositivos y las consecuencias derivadas de las transformaciones arquitectónicas que ha sufrido la frontera. El primer capítulo es una aproximación introductoria a la pertinencia de la inclusión de este modelo espacial como herramienta de análisis y producción en la disciplina arquitectónica. Las diferentes actualizaciones que ha tenido este concepto permiten introducir una serie de variables que permiten ir más allá de limitaciones disciplinares clásicas como la cuestión de la escala o el antropocentrismo - presente tanto en el discurso arquitectónico como en la construcción del paisaje-. 
El siguiente capítulo parte del dispositivo para centrarse en la dimensión espacial que éste adquiere, fundamentalmente a través del lawscape, modelo espacial capaz de explicar la red de relaciones establecida entre cuerpos, deseos, leyes, normas y espacio. Esta apreciación, donde la ley no es exterior al espacio o la materia sino totalmente imbricada en ella, permite comprender una serie de transformaciones arquitectónicas cómo la pérdida de relevancia de ciertas arquitecturas en pos de ensamblajes dinámicos. $\mathrm{O}$, dicho de otro modo, cómo de la construcción de recintos se ha pasado a la construcción de campos.

Del análisis anterior, se deriva una de las consecuencias fundamentales para comprender el funcionamiento operativo del dispositivo frontera, el paso de territorios claramente delimitados a territorialidades definidas por las acciones de los cuerpos a cada instante. Un aspecto que subvierte las lógicas topográficas frente a lógicas topológicas: donde la posición no es tan relevante como la relación variable entre otros elementos presentes dentro de un mismo dispositivo. Se cierra el capítulo cuestionando el papel de la excepción -en tanto que suspensión temporal de las leyes que operan en un espacio determinadodentro de un sistema que no funciona en base a relaciones binarias o estáticas, sino que se modula en base a acciones y cuerpos específicos, proponiendo que, en cualquier caso ésta no se formule como algo unívoco, sino como un gradiente de excepcionalidad

Enfocado al entendimiento operativo de una realidad susceptible de ser transformada, modificada y agenciada, el último capítulo se centra en los efectos inmediatos de tácticas arquitectónicas menores. Frente a un repertorio disciplinar clásico de estrategias para construir un determinado medio, las lógicas del dispositivo plantean repertorios alternativos donde prima un pensamiento material y táctico, que requiere de un cierto grado de violencia espacial para sustraer de la materia funciones previas y dotarla de nuevas posibilidades de uso.

A pesar de esta bifurcación planteada a efectos de organización del contenido, las transferencias entre el plano teórico que analiza las lógicas de los dispositivos y cada uno de los casos de estudio son constantes y no excluyentes. Plantear este doble recorrido permite establecer una mirada detenida sobre cada aspecto que dota de sentido al dispositivo frontera, eludiendo reiteraciones que, de otro modo, serían inevitables. A la vez que, dadas las particularidades que presenta cada acontecimiento, tomar distancia respecto a la idea global del dispositivo frontera para enfocarse en los aspectos materiales específicos que lo construyen, ayuda a desvelar con precisión los agentes y elementos intervinientes en la producción de cada una de estas arquitecturas. \#b. De la ley como línea a las leyes como espacio.

\#c. De territorios a cuerpos.

\#d. Maniobrando el dispositivo. 


\subsection{METODOLOGÍA. \\ DEVENIR CARTÓGRAFOS Y FORENSES.}

Construir una mirada y un paisaje desde las trazas materiales que lo forman
Los estudios de frontera como un campo extradisciplinar
Profundicemos en los mecanismos que se han emplado para aproximarse desde la disciplina arquitectónica a este cuerpo múltiple que hemos definido como dispositivo frontera. Al reconocer en esta construcción la superposición, no sólo de diferentes realidades, sino también de diferentes campos de estudio, resulta imposible abordar su estudio exclusivamente con las herramientas que, tradicionalmente ha usado la disciplina. Requiere, por tanto, la construcción de un método propio que permita situarnos en un territorio complejo, navegar por él comprendiendo las lógicas que lo conforman y, desde ahí construir una mirada que sea capaz de desvelarlas. Una mirada desde la que construir un paisaje, una mirada que no pretende ser personal ni subjetiva por más que toda elección de unas lógicas frente a otras lo implique.

Así pues, el método empleado parte en primer término de esta noción de paisaje para, desde él, desarrollar herramientas específicas -fundamentalmente basadas en la hibridación de la cartografía crítica y el enfoque forense- que permitan construir cartografías, herramientas operativas de navegación que visibilicen realidades presentes -aunque no siempre visibles- basándose en la detección de las trazas materiales presentes en él. Hacemos nuestra la pregunta con la que se interrogaban Darío Gazapo y Concha Lapayese acerca desde donde se construye el paisaje:

La definición de paisaje lleva implícita la idea de construcción y en consecuencia el empleo de una lógica específica que posibilite esa acción de formalización del concepto. Una primera acción supone una elección sobre la actitud referencial desde donde se localiza el constructor de paisajes. Es a partir del análisis de tales situaciones, desde donde es posible la discusión y la crítica. Es desde el origen del proceso de pensamiento, desde donde se establece la especificidad en la forma de la mirada?

Una mirada que no permanece pasiva sobre el territorio, sino que interactúa con él, transformándolo a través de su capacidad de detección de acontecimientos y materialidades que han permanecido subalternas, en el umbral de detectabilidad ${ }^{8}$, bajo otras miradas y discursos. Una mirada que ya no puede ser exclusivamente humana, sino que va más allá, transformándose e hibridándose con el resto de elementos no-humanos del dispositivo para convertirse en un sensor "sin importar si eres un edificio, un territorio, una fotografía, un pixel o una persona, sentir es dejarse impregnar por la realidad que te rodea, internalizar sus campos de fuerza, y transformarte. Y transformarse es sentir dolor".

La frontera obliga a situarse en los márgenes disciplinares para aprehenderla, como un dispositivo a caballo entre arquitectura e infraestructura, capaz de manifestarse como construcciones palpables sin renunciar tampoco a una dimensión geopolítica evidente. En ella las decisiones políticas se desdibujan y se superponen a las de diseño, y la realidad social es clave para entender los movimientos y transformaciones arquitectónicas que tienen lugar. Es por

7 Darío Gazapo y Concha Lapayese, ¿Desde donde...se construye el paisaje?, Revista AUS, nº 7, 2010.

8 Eyal Weizman, Forensic Architecture: Violence at the thresold of detectability (Nueva York: Zone Books, 2017). 
tanto necesario realizar un desplazamiento disciplinar que permita observar con mayor precisión el núcleo del análisis -la arquitectura que configura la frontera- enriquecida con los aportes conceptuales y metodológicos ya realizados desde otras disciplinas. Este desplazamiento extradisciplinar ${ }^{9}$ abre las puertas a un campo de investigación arquitectónica donde la arquitectura no es exclusivamente el objeto de estudio, sino también una metodología que permite explicar acontecimientos y situaciones espaciales más amplias en las que su protagonismo aparece desdibujado. En este sentido, tal y como apunta Céline Condorelli acerca de su participación en el Centre for Research Architecture en la Universidad de Goldsmiths "la arquitectura es mucho más una metodología usada para mirar al mundo, no es un objeto de estudio" ${ }^{\text {เo }}$. Por otro lado, también abre las puertas de la discusión a la inclusión de elementos, agentes y condiciones aparentemente no-arquitectónicas pero que, a través de su observación mediante otros marcos de conocimiento, se revelan fundamentales en la construcción del espacio. Por último, investigar desde los márgenes, en fricción constante con otras disciplinas, permite tomar prestadas herramientas ajenas para validar su utilidad a la hora de ser aplicadas dentro de la investigación arquitectónica.

Markus Miessen introduce en su tesis -y en su tetralogía acerca de la participación- el término crossbencher en la arena arquitectónica extrayéndolo de su origen político, concretamente del parlamento británico. Así, define a esta figura capaz de realizar prácticas espaciales críticas como un personaje que se sitúa en los márgenes disciplinares -"las prácticas espaciales contemporáneas están colonizando los márgenes que el desarrollo espacial genérico ha dejado vacías" "I-, que no está atado a una disciplina en concreto sino que establece alianzas puntuales para alcanzar sus objetivos. Y, precisamente, al posicionarse en los márgenes, es capaz de aportar nuevas miradas sin las ataduras normativas de una posición ortodoxa. Así presenta Miessen este rol:

El crossbencher debe ser entendido como un abogado, alguien que deliberadamente lee y entiende problemáticas situadas a través de un marco espacial -analizando, señalando y comunicando como están organizadas las cosas en el mundo que nos rodea - y, desde ahí proponer mecanismos con los que lidiar y actuar a través de ellos, de maneras y mediante medios que vayan más allá de los establecidos.

Y es precisamente la noción de práctica espacial crítica que articula la obra de Miessen, la que nos permite encuadrar una serie de desplazamientos disciplinares dentro del ámbito del proyecto arquitectónico. Así como incorporar una serie

9 El término extradisciplinar, frente a otras composiciones semánticas, fue acuñado con Brian Holmes y hace referencia a una apertura y retorno crítico que permita ensanchar y enriquecer los límites de una disciplina:

Se pone en funcionamiento aquí un nuevo tropismo y un nuevo tipo de reflexividad que implica tanto a artistas como a teóricos y activistas en un tránsito más allá de los límites que tradicionalmente se asignan a su actividad, con la intención expresa de enfrentarse al desarrollo de una sociedad compleja. El término «tropismo» expresa el deseo o la necesidad de girarse hacia otra cosa, hacia un campo o disciplina exteriores; mientras que la noción de reflexividad indica ahora un regreso crítico al punto de partida, un intento de transformar la disciplina inicial, acabar con su aislamiento, abrir nuevas posibilidades de expresión, análisis, cooperación y compromiso. Este movimiento adelante y atrás, o más bien esta espiral transformadora, es el principio operativo de lo que llamaré investigaciones extradisciplinares.

Ver más en: Brian Holmes, «Investigaciones extradisciplinares. Hacia una nueva crítica de las instituciones». Consultado el 24 de mayo de 2019.

10 Céline Condorelli, «Political, forensic, hi-tech: how 'research architecture' is redefining art», The Guardian, 6 de enero de 2019.

11 Markus Miessen, «Crossbenching: Towards a proactive mode of participation as a Critical Spatial Practice», (Tesis doctoral, Goldsmiths College, Universidad de Londres), I9.
Investigación como práctica espacial crítica y militante 
Vde herramientas surgidas de unos márgenes en fricción con otros ámbitos. Unos desplazamientos que no sólo afectan al objeto de la disciplina, sino también a las acciones y repertorio de tácticas que la arquitectura es capaz de aplicar, así como a nuestro rol como diseñadores. Una cuestión que también vemos presente en la publicación Beyond Patronage: Reconsidering models of practice, de Bohm, Hwang y Printz ${ }^{12}$-que recoge las conclusiones de un evento homónimo- donde se presentan roles alternativos -detective, abogado e iniciador-a las labores de diseño que parten del mismo posicionamiento crítico $^{\mathrm{I} 3}$. Así introduce Miessen el concepto de práctica espacial crítica en su tesis doctoral:

[Las prácticas espaciales críticas] disuelven lo que fue entendido anteriormente como límites formales o disciplinares, las especificidades de contextos culturales particulares conforma sus demandas. La mayor diferencia entre las prácticas espaciales críticas y las prácticas arquitectónicas convencionales es la manera en la que se espacializan las relaciones entre individuos y lugares y, además, que la localización geopolítica y las narrativas se construyen y dirigen consecuentemente por agendas sociales con actitudes políticas claramente demarcadas y comunicables, aunque a veces permanezcan silenciosas.

Desviándose de la mayor parte de producción arquitectónica que persistentemente retorna al arquitecto-como-autor-único un creciente número de profesionales y teóricos se engarzan y participan activamente de campos de conocimiento adyacentes. Debemos reconocer la posibilidad y potencialidades de una "arquitectura del conocimiento": la producción de e intervención activa de las condiciones espaciales y situaciones que se nos presentan con el prerrequisito de identificar, efectuar y afectar a realidades más amplias de lo político mediante la aplicación de estructuras físicas y nofísicas para cambiar y alterar ajustes específicos.

Esta dimensión crítica, que cuestiona una realidad existente para plantear alternativas espaciales, tanto en su construcción como en su relato, lo que nos obliga a cuestionar no sólo el territorio sino también la mirada que establecemos sobre él para comprender los paisajes en los que nos situamos.

Sólo de esta dimensión crítica, habiéndonos situado conscientemente en los márgenes extradisciplinares de la arquitectura y el paisaje, nos han permitido beber de dos herramientas fundamentales para construir un mecanismo propio que nos sirva para analizar la realidad de la frontera contemporánea: la cartografía crítica y la arquitectura forense. A continuación, se vuelve a bifurcar el relato para presentar las bases y desarrollo de una herramienta que, a lo largo de toda la investigación, no se presenta como tal sino hibridada. Unas herramientas que surgen también de esta dimensión crítica, con procesos similares de aproximación al territorio pero orígenes disciplinares distintos: geografía y arquitectura.

12 Martha Bohm, Joyce Hwang, y Gabrielle Printz, Beyond Patronage: Reconsidering models of practice (Nueva York: Actar, 2015).

13 Una dimensión crítica de la que se deriva inmediatamente una consideración y engarce político de la disciplina arquitectónica frente a una formulación autónoma de la misma. Los ejemplos y referencias a esta condición son numerosos, y muchos de ellos pueblan las páginas de esta investigación de manera recurrente. Sin embargo, por ampliar el marco de discusión sin entrar en un detalle excesivo que diluiría el foco que nos atañe, es necesario mencionar la acepción política contemporánea que, con matices muy diferentes, está presente en la obra de Pier Vittorio Aurelli, Keller Easterling, Uriel Fogué Herreros, Lucía García de Jalón, Andrés Jaque, Léopold Lambert, Miguel Mesa del Castillo Clavel, Enrique Nieto, Marina Otero Verzier, José Manuel Pérez de Lama, Felicity Scott entre muchas otras, pero que aquí se refleja de manera explícita. 
En la historia de la invasión colonial, los mapas son siempre dibujados primero por los victoriosos, ya que los mapas son instrumentos de conquista. La geografía es por consiguiente, el arte de la guerra, pero puede ser también el de la resistencia si hay un contra-mapa y una contra-estrategia.

Edward Said.

Si aprehender un territorio a través de un posicionamiento que revele las lógicas y trazas presentes en él es, en cierta medida, la construcción de un paisaje paisajes fronterizos-, debemos elaborar un mapa o cartografía para alcanzar tal posicionamiento. La cartografía, por tanto, aparece como la herramienta metodológica fundamental empleada en el desarrollo de la investigación que permite situarnos sobre un territorio complejo y relacionar entre sí una serie de elementos aparentemente inconexos.

La cartografía, más allá de su función original como tecnología de dominio militar y colonial, se ha convertido en un sistema útil capaz de desvelar y visibilizar otras realidades geográficas o territoriales a través de la superposición y acumulación de información de diferente naturaleza sobre un mismo plano de trabajo. Desposeer a la cartografía de su pretendida objetividad a través de cuestionamiento, como señala Miguel Mesa del Castillo en Víctimas de un mapa, ha permitido entender que:

los mapas no pueden ser entendidos como documentos objetivos sino que son instrumentos llenos de intenciones, engaños, narrativas, omisiones intencionadas, magnificaciones deliberadas... y que la figura del cartógrafo se reserva un enorme poder para intervenir en la realidad, ya sea éste directamente el soberano o un funcionario al servicio de los intereses del estado.

Los mapas pues son dispositivos tecnopolíticos capaces de dar forma al espacio y de condicionar y contribuir a dominar biopolíticamente a los sujetos. ${ }^{14}$

Aparece, por tanto, un concepto ya señalado que no sólo afecta a la producción arquitectónica o territorial, sino también a su representación, las intenciones no declaradas ${ }^{15}$, idea que se recoge en el clásico libro -y exposición- The Power of Maps, de Denis Wood, donde afirma que los mapas expresan intereses a menudo ocultos. De manera pareja al desarrollo cartográfico de los poderes modernos y contemporáneos, se fue generando una cartografia indisciplinada ${ }^{16}$ que, valiéndose de sus mismas herramientas de análisis, invirtió el foco para centrar el foco en las relaciones e intereses políticos detrás de una serie de operaciones -y representaciones- territoriales. Frente a una cartografia positivista, una cartografia crítica surgida del seno de la geografía crítica pero con una rápida apropiación por otras disciplinas dada su operatividad, pues permitía introducir relatos alternativos a los hegemónicos tal y como señala Roger Paez i Blanch en Cartografia Operativa: Usos del mapa al Projecte Arquitectònic ${ }^{17}$. Un

14 Miguel Mesa del Castillo Clavel, «Victimas de un mapa: arquitectura y resistencia en el tiempo de la cultura flexible» (tesis doctoral, Universidad de Alicante, 2012), 32.

15 Keller Easterling, Extrastatecraft, (Londres: Verso, 2014).

16 Gilles Palsky, “Cartographie participative, cartographie indisciplinée”. L'Information géog"” hique. raphique, no 77 , vol. 1o (2013), 10:25. 77. 10. Exte, a flexibleLondres), at the thresold of detectability (Londres: Zone Books, imiento

17 Esta tesis doctoral traza un recorrido historiográfico de los mapas y su vinculación con la práctica arquitectónica, como una herramienta operativa que no sólo sirve para describir la realidad sino para manipularla. Se recomienda la lectura de los capítulos Cartografía operati- 
Cartografía como extensión de la geografía radical ejemplo histórico de cartografía y, con vinculación directa al objeto de estudio de esta tesis, es la Cartografia Crítica del Estrecho realizada por Hackitectura en 2004 donde se despliega de manera gráfica el ecosistema de relaciones afectivas y de poder presentes en el Estrecho de Gibraltar en una época de militarización del mismo. Cobarrubias señala a raíz del trabajo de Hackitectura un binomio antagónico de ideas: las geografias del Imperio frente a las geografias de la multitud ${ }^{18}$, otra formulación más que, desde los márgenes de la disciplina arquitectónica se hace y que contribuye a alimentar el corpus de aproximaciones a la noción de cartografía crítica.

Frente a una idea topográfica de la cartografía, donde la realidad está vinculada directamente a una serie de escalas a través de las cuales se jerarquiza la información, aparecen nuevas formulaciones que trascienden esta idea para presentar una visión topológica. Si bien, la escala de sus análisis se ha centrado especialmente en el marco territorial o geográfico, este carácter topológico hace posible una fácil extrapolación a otros contextos. Más allá de la fascinación por la liberación tecnológica que los sistemas de información geográfica que en la última década del siglo XX e inicios del XXI dominaron buena parte de los horizontes de la cartografía crítica, aparecen otros relatos que son capaces de poner en primer plano del análisis las relaciones entre elementos, territorios y los vínculos de poder o resistencia establecidos entre ellos sin recurrir a un sobredimensionamiento tecnológico. Así pues, encontramos trazas útiles para incorporar a nuestra metodología en la geografía radical o crítica contemporánea, así como en una serie de prácticas artísticas que han empleado el mapa como materia discursiva.

No es casualidad que la cartografía crítica se enmarque dentro de la geografía radical, rama disciplinar de corte marxista que ha efectuado grandes aportes en el análisis del espacio urbano y post-metropolitano fundamentalmente a través de la escuela creada por David Harvey, Mike Davis o Edward Soja entre otros. También ha contribuido, fundamentalmente a través del trabajo de Doreen Massey -la cual se aleja de los principales centros de atención marxistas-, a la elaboración de modelos espaciales propios. En todos ellos, más allá del marco de análisis compartido, se comparte un análisis del espacio urbano y geográfico en base a relaciones de poder de diferente índole -clase social, género, raza, acumulación de capital, gobierno, lógicas policiales...-. Sus investigaciones, a través de áreas de estudio concretas, son capaces de conectar realidades mucho más amplias y dilucidar las responsabilidades o causalidades que de ellas se derivan. Logran, a través de una metodología fundamentalmente textual, generar cartografías precisas de territorios complejos, yendo más allá de su dimensión gráfica para enmarcarla en otros ámbitos.

No obstante, es interesante actualizar esta noción más extendida de geografía radical a través de las críticas que desde la geografía radical de corte anarquista se le han hecho. Fundamentalmente a través de la obra de Simon Springer y las discusiones académicas que ha mantenido con David Harvey ${ }^{19}$, permiten entender las limitaciones de la geografía radical clásica, a la vez que introducen nuevas variables útiles para el desarrollo de nuestra herramienta. En primer lugar,

va y Mapa de un Mapa para comprender esta dimensión operativa que el autor defiende a lo largo de toda la obra así como un recorrido histórico que refleja las diferentes acepciones de mapa, los conflictos y prácticas críticas de manera exhaustiva.

Añadir referencia.

18 José Pérez de Lama se apoya en el binomio Imperio/multitud establecido por Toni Negri y Michael Hardt. Añadir referencia.

19 Harvey, David. “'Listen, Anarchist!' A Personal Response to Simon Springer's 'Why a Radical Geography Must Be Anarchist.” Dialogues in Human Geography 7, n‥ 3 (Noviembre 2017): 233-50. doi:10.1177/2043820617732876. 
la no consideración del Estado como una figura central tanto en el análisis de las relaciones de poder como a la hora de formular herramientas de transformación; frente a ello, una red descentralizada de agentes públicos y privados en interrelación. Esto traslada la capacidad de transformación espacial a cada uno de los agentes involucrados en dicha red de relaciones frente a instituciones $\mathrm{u}$ organismos externos. En segundo lugar, la territorialidad y capacidad afectiva del territorio como una dimensión más de las relaciones establecidas por parte de los propios agentes. Es decir, frente a resistencias enunciadas a nivel general, resistencias y poderes ejercidos desde territorialidades $-\mathrm{y}$ luchasespecíficas. De esto último también se puede extraer la pérdida de relevancia de lo material a la hora de cartografiar la realidad en pos de otras variables. Por ello, reconocer todas estas limitaciones y tenerlas en cuenta nos permitirá abordar la labor cartográfica desde una óptica más próxima a las lógicas de los dispositivos, situando en un mismo plano de análisis agentes y territorios, independientemente de su posición respecto a figuras de poder establecidas.

Más allá de que la arquitectura haya incorporado la cartografía como herramienta de análisis y producción territorial-no sólo en el campo de la investigación sino como práctica cotidiana-, la dimensión geográfica ha tomado relevancia en ciertas prácticas arquitectónicas contemporáneas. En todas ellas se muestra el interés de trascender el sistema de escalas clásicos para conectar arquitecturas dispersas en redes de producción global o, por lo menos, en un territorio expandido. Tal y como afirma David Gissen en Architecture's geographic turns, a través de la incorporación de conceptos geográficos y especialmente la geografía radical, estamos presenciando un "giro peformativo hacia el imaginario y los métodos geográficos en la arquitectura contemporánea. No es tanto una nueva forma de práctica o el abandono del discurso crítico de generaciones previas sino una nueva actualización de los vínculos conceptuales entre la teoría arquitectónica y la geografía" ${ }^{20}$.

La liberación de la cartografía de las formas del poder ha encontrado en el mundo del arte y el activismo un territorio fértil de expansión, alejados de la rigidez académica, incorporando nuevos formatos y material de construcción de mapas que logran traer a la luz las dinámicas de poder. De nuevo, desde los márgenes en fricción entre diferentes campos -el activismo, los medios audiovisuales, la sociología...- una serie de artistas contemporáneos, y movimientos sociales han democratizado estas herramientas, proporcionando mecanismos capaces de incorporar a la arena pública nuevas problemáticas presentes pero no visibles o narrables. Lo inmensurable a través del cartografiado exhaustivo que los nuevos mecanismos digitales no son capaces de datificar, así como lo inaprensible a través de las lentes académicas, tienen cabida en estas expresiones surgidas desde el arte. Aspectos que una dimensión puramente técnica o científica o técnica, como los afectos o la capacidad de agencia entre diferentes cuerpos, sentimientos, sensaciones son también susceptibles de convertirse en materia cartografiable. André Luiz Mesquita desarrolla un recorrido histórico a través de esta práctica contemporánea en Mapas Dissidentes, donde presenta el término contracartografia para denominar una serie de prácticas críticas, a caballo entre el activismo y el arte, exponiendo así su valor operativo:

Un nuevo sentido se le confiere a la cartografía a través de estos mapas, no como una actividad particularizada o un saber restringido, sino como un proyecto posible que disemina al máximo un tipo de información circunscrita a públicos y fuentes específicas. [...] El trabajo con contracartografías puede no sólo revelar sistemas de poder, sino también modificar el enunciado de
La dimensión geográfica de la arquitectura contemporánea 
Contracartografía

Herramienta: El enfoque forense que el "mapa produce territorio". Sea este territorio el lugar donde los mapas son construidos - con sus historias, relatos y vestigios preservados-, hasta la situación en que estos pueden ser consultados y distribuidos. ${ }^{21}$

Es precisamente este término, contracartografia, el que emplea Eyal Weizman para enmarcar el trabajo de investigación que desarrolla Forensic Architecture. Y lo hace desplazando además el material con el que construir la propia cartografía para poder atender también a acontecimientos que, generalmente quedan fuera de la dimensión cartográfica por una escala temporal prácticamente instantánea. Para ello, Forensic Architecture ha construido un repertorio de herramientas técnicas y digitales para enfrentarse a una realidad efímera y cambiante, reconstruida en muchas ocasiones a través de cámaras de videovigilancia, imágenes satélite, declaraciones o testimonios.

Mientras que los mapas son capaces de lidiar con la lenta violencia arquitectónica del planeamiento de asentamientos [israelíes en territorio palestino], el análisis arquitectónico de imágenes proporciona una forma de cartografía acelerada y específica que nos ha ayudado a llevar nuestros análisis a formas eruptivas, kinéticas de violencia y reconstruir incidentes desplegados a un ritmo mucho mayor o a una escala menor ${ }^{22}$.

Así, la contracartografía puede ser entendida desde el enfoque forense como el ejercicio riguroso de superposición en un mismo modelo información de diferente procedencia y formato. El fin último: la dilucidación de responsabilidades entre las diferentes partes involucradas en un conflicto, objetivo para el cual han de reconstruir con precisión la red de relaciones -el ensamblaje- que ha producido una determinada situación espacial o acontecimiento.

Ante una serie de preguntas claras surgidas a lo largo de la investigación: ¿cómo analizar situaciones y construcciones espaciales que se materializan apenas durante unos instantes?, ¿cómo comprender las implicaciones arquitectónicas de una serie de construcciones opacas a nivel político, legal y sin posibilidad de acceso documental a ellas? ¿cómo hacer converger, en un mismo plano de análisis, informes técnicos, croquis a mano, grabaciones amateur de teléfono móvil, declaraciones políticas, trazas materiales...?, encontramos precisamente en la metodología forense, desarrollada desde el Centre for Research Architecture, una herramienta útil a la hora de reconstruir los acontecimientos concretos que conforman la tesis. Un equipo formado por investigadores de diferentes campos, técnicos y artistas audiovisuales han centrado sus esfuerzos en analizar escenarios donde la arquitectura, aparentemente no era el foco de atención, donde a través del enfoque forense han encontrado "un concepto operativo y una práctica crítica, pero entendiendo que "lo crítico” también connota lo vital, lo crucial y lo decisivo. [...] El núcleo de nuestro campo multidisciplinar era la arquitectura, y en la arquitectura encontramos un modo de intervención” ${ }^{23}$. El esfuerzo en aplicar la investigación arquitectónica a escenarios de conflicto ha ido parejo al esfuerzo por abrir los instrumentos de trabajo empleados mediante una serie de publicaciones que, con detalle minucioso, recogen y explican tanto las técnicas como los conceptos fundamentales que sustentan cada uno de las investigaciones realizadas. Dada la multiplicidad de escalas y acontecimientos que han investigado, para un desarrollo mayor de las herramientas de trabajo nos

21 André Luiz Mesquita, "Mapas Dissidentes: proposiçoes sobre un mundo en crise”, (tesis doctoral, Universidad de Sao Paulo, 2014), 183.

22 Weizman, Forensic Architecture... (Zone Books, 2017), 140.

23 Forensic Architecture, Forensis: The architecture of public truth (Berlín: Sternberg Press, 2015), 13. 
remitiremos a las dos publicaciones que recogen el trabajo realizado, Forensis: Architecture of the Public Truth ${ }^{24}$ y Forensic Architecture: Violence at the thresold of detectability $^{25}$, para centrarnos en el desarrollo de varios conceptos transversales a ellas.

El primer concepto desplaza el foco de análisis de los cuerpos a la materia arquitectónica. Hemos de concebir esta materia como materia informada tal y como la enunció Ignacio Borrego ${ }^{26}$, donde más allá de sus cualidades tectónicas, el análisis arquitectónico debe también prestar atención a "los sucesos acontecidos sobre ella, que se registran como información” ${ }^{27}$. Así, cada construcción arquitectónica, cada traza física -independientemente de su escala- es susceptible de transformarse en un sensor que atestigue un determinado acontecimiento. Así, formulan estética material:

La capacidad de percibir y ser afectado, "volverse uno mismo sensible, la capacidad que precede a cualquier distinción entre los instrumentos de la ciencia, del arte o de la política”. Mientras que la estética es generalmente entendida como lo que pertenece a los sentidos y percepción humana, la "estética material" captura el modo en el que la materia absorbe o prehende (en vez de aprehende o comprende) su entorno. [...] La estética, concebida de esta manera, es el modo y los medios a través de las cuales los objetos materiales se relacionan y afectan entre $\mathbf{s i ́}^{28}$.

La relevancia de la materia arquitectónica, desposeída de cualquier función a efectos del análisis, permite comprender su funcionamiento operativo sin interferencias y, por tanto, el verdadero papel que juega en la construcción de cada acontecimiento. Este desplazamiento hacia una dimensión que va más allá de lo humano, establece un plano de observación que no discierne los agentes implicados en función de su origen.

El segundo concepto a señalar, es el término complejo imagen-arquitectónica o complejo imagen-información, la capacidad de síntesis a través de información de diferente naturaleza y origen, fundamentalmente visual, para reconstruir acontecimientos,-en un proceso extensible también a información no visual susceptible de ser espacializada- tal y como explican:

A lo que nos referimos como complejo imagen-arquitectónica es un método de ensamblar evidencias gráficas en un entorno espacial. El complejo imagen-arquitectónica puede funcionar como un dispositivo óptico que permite al observador ver la escena del crimen como una red de relaciones entre imágenes en el tiempo y el espacio. También puede ser usado como un mecanismo de navegación para moverse entre imágenes, explorando un espacio que es a la vez virtual y fotográfico. Esencialmente pone de manifiesto la necesidad de componer evidencias que son simultáneamente materiales, gráficas y testimoniales ${ }^{29}$.
Materia arquitectónica como sensor forense

Arquitectura forense como modelo operativo de análisis

24 Forensic Architecture, Forensis(Sternberg Press, 2015).

25 Weizman, Forensic Architecture... (Zone Books, 2017).

26 Ignacio Borrego, "Materia informada: deformación, conformación y codificación, los tres procedimientos de almacenamiento de información en la materia”, (tesis doctoral: Universidad Politécnica de Madrid, 2012).

27 Borrego, "Materia informada”, (Universidad Politécnica de Madrid, 2012), 383.

28 Weizman, Forensic Architecture... (Zone Books, 2017), 95.

29 Weizman, Forensic Architecture... (Zone Books, 2017), , 100. 
La definición de criterios para manipular, seleccionar y reconstruir la red de relaciones entre imágenes y datos sobre una realidad espacial determinada resulta fundamental, así como cada uno de los relatos presentes en el transcurso de cada grabación o la toma de imágenes -las zonas oscuras, elipsis, o el propio movimiento del observador-.Y es que el tratamiento y análisis de imágenes - capturas de vídeos o fotografías en las redes sociales, imágenes satélite, grabaciones amateurs, cámaras de vídeovigilancia...- permite poner el foco del análisis arquitectónico a realidades que, por efímeras, quedan en los márgenes de los análisis arquitectónicos y que, sin embargo, resultan fundamentales a la hora de comprender la construcción de determinados espacios. Pero además, la liberación o empleo de estas imágenes, al subvertir en muchas ocasiones la función de vigilancia o control en una función testimonial es también muy importante, en nuestro contexto de análisis, pues logra aportar información sobre acontecimientos que, de otra manera, estarían invisibilizados.

Esta idea, que transforma tecnologías de producción de control o de evidencia forense -los sistemas de vídeovigilancia son el ejemplo más claro, pero también la propia cartografía como sistema de ordenación territorial- en tecnologías capaces de atestiguar o construir una versión alternativa del relato, ha sido denominada como investigación contra-forense. Porque, aunque los hechos y evidencias materiales sean claros, los discursos que desde instancias políticas, investigaciones policiales o judiciales, no son neutras sino una versión que debe ser puesta en cuestión en los foros pertinentes:

Mientras que la investigación forense es una herramienta del estado, la investigación contra-forense, tal y como la practicamos, es una práctica civil que pretende interrogar el entorno construido para dejar al descubierto la violencia política llevada a cabo por estados. La llamada a "tomar los medios de producción" significa para nosotros tomar los medios de producción de pruebas. Aquí, la ciencia forense no es únicamente el dominio técnico y neutro de expertos especialistas, ni es la aplicación de ciencia empírica dentro de un sistema judicial bien establecido con sus protocolos correspondientes, sino una práctica civil comprometida que busca articular demandas públicas usando para ello la arquitectura ${ }^{30}$.

Se establecen dos escenarios principales donde es posible un despliegue forense capaz de cuestionar el relato hegemónico o establecido: el campo y el foro. El primero de ellos, el territorio de donde se extraen las trazas materiales y se reconstruye la escena del crimen. El segundo de ellos, el foro, las diferentes arenas de discusión en donde las evidencias extraídas del campo pueden ser expuestas. Esta tesis transita del campo al foro, convirtiéndose el propio documento en un espacio de exposición y discusión, que recoge una serie de acontecimientos analizados de manera independiente para conectarlos a través de sus similitudes y construir una cartografía que evidencie la complejidad arquitectónica de la frontera contemporánea.

Cada campo de nuestro estudio es único, no sólo por las condiciones arquitectónicas particulares que cada uno de ellos presenta sino fundamentalmente por la información de trabajo disponible o, mejor dicho, por todos los puntos ciegos que el sistema deja en completa penumbra. Precisamente, arrojar luz sobre estas zonas opacas, desvelar aquello que estaba pretendidamente oculto, obliga a elaborar una metodología de trabajo que sea capaz de desarrollarse, modularse y adaptarse a cada situación. Hablamos de enfoque forense como una óptica desde la que reconstruir diferentes realidades y, frente a un manual rígido o una concatenación de operaciones, establecer un 
repertorio amplio de posibilidades de análisis espacial. La comparación entre los campos analizados, así como la construcción de relaciones entre ellos, se deriva de este primer enfoque.

Volvamos a la materia, a las trazas presentes en la arquitectura, sensores a través de los cuales extraer la información que nos permita reconstruir una situación espacial que va mucho más allá de la propia construcción, conectándose en un territorio mucho más amplio. Han denominado fetichismo metodológico a la puesta en valor de esta realidad material que permite, desde ella, visibilizar una virtualidad que reconstruye los vínculos presentes entre diferentes arquitecturas, leyes, discursos, poderes políticos y agentes: "el análisis microfísico en donde la parte o detalle supone un punto de entrada desde donde reconstruir procesos mayores, eventos y relaciones sociales, conjunciones de agentes y prácticas, estructuras y tecnologías" ${ }^{31}$. ¿Acaso no es este proceso, enfocado al análisis de arquitecturas específicas, el que nos permite, centrándonos en cada nodo, renderizar la totalidad del dispositivo? Si la frontera es, ante todo, una realidad construida en bases a intereses, discursos políticos, lógicas de gobierno, normativas, resistencias... establecer un contra-relato, una cartografía crítica, centrada en una metodología que sitúe en primer plano "la atribución de poder inherente y agencia a objetos inanimados [...] para entender objetos, edificios, rupturas y sus representaciones como agentes históricos" que permitan narrar el funcionamiento operativo de un sistema de construcción territorial desposeído de las múltiples retóricas en él superpuestas.

El enfoque forense permiten a modo de Aleph borgiano partir desde lo concreto de cada traza detectada para elaborar modelos operativos, artefactos de navegación "modelos espaciales y no espaciales [...] que no sólo representan sino que 'provocan' impacto en el mundo" ${ }^{32}$. Mapas y no calcos que conectan con la noción de cartografía y de construcción de la mirada necesaria para observar cualquier territorio con la que arranca este apartado. Una operación de reconstrucción donde un elemento aparentemente insignificante dentro de un ensamblaje arquitectónico es capaz de explicar, relatar y atestiguar unas condiciones espaciales que, de otro modo, quedarían en la sombra. Así, el enfoque forense busca trazas en la materia, en los testimonios o en el complejo imagen-arquitectura, en elementos situados muchas veces en el umbral de detectabilidad, lo que obliga a afinar nuestra mirada como investigadores. Así pues, debemos plantear una escucha atenta a un territorio donde el impacto de una pelota de goma sobre la superficie del agua, un trozo de revestimiento arrancado de una pared, una fotografía de archivo, las grabaciones de un teléfono particular, o las deformaciones estructurales de una arquitectura pueden ser determinantes para comprender cómo se construye el dispositivo frontera.

31 Forensic Architecture, Forensis (Sternberg Press, 2015), 19.

32 Forensic Architecture, «Operative Models», Acceso el 19 de enero de 2019. https://www. ica.art/learning/a-short-course-in-forensic-architecture/operative-models 


\subsection{UNA APROXIMACIÓN AL ESTADO DE LA CUESTIÓN. DE LOS ESTUDIOS DE FRONTERA A LOS PAISAJES FRONTERIZOS.}

Estudios de frontera como aproximación múltiple.
Sandro Mezzadra y Brett Neilson presentan en La frontera como método un análisis de diferentes realidades territoriales conectadas a través de un mismo concepto: la frontera ha perdido su materialidad en un mundo globalizado a la vez que se produce una heterogeneización del espacio, y la multiplicación de una serie de prácticas espaciales, cuerpos y territorios donde la frontera se materializaba de otras maneras. Un análisis que desbordaba, por la multiplicidad de situaciones recogidas así como por su dispersión geográfica, los compartimentos estancos de sus disciplinas para generar un nuevo territorio híbrido de estudio. Pero además, presentaban una idea fundamental para entender los vínculos entre los diferentes estudios:

Si aceptamos que los métodos tienden a producir (a menudo, en formas contradictorias e inesperadas) los mundos que dicen describir, para nosotros la cuestión de la frontera como método es algo que supera lo metodológico. Es, sobre todas las cosas, una cuestión política acerca del tipo de mundos y subjetividades sociales que se producen en las fronteras y de los modos en los cuales el pensamiento y el conocimiento pueden intervenir en estos procesos de producción. En otras palabras, podemos decir que para nosotros el método supone tanto la acción sobre el mundo como el conocimiento sobre el mismo. Más específicamente, se trata de la relación entre la acción y el conocimiento en una situación en la cual muchos regímenes y prácticas de conocimiento diferentes entran en conflicto. La frontera como método supone negociar los límites entre los distintos tipos de conocimiento que se ven reflejados en la frontera y, al hacerlo, busca arrojar luz sobre las subjetividades que toman cuerpo a través de dichos conflictos ${ }^{33}$.

Este conocimiento, a caballo entre diferentes disciplinas que permite una aproximación múltiple hilvanada en base al campo de estudio, una frontera que deviene método más allá de objeto, ha sido denominado como estudios fronterizos. Para entender las ideas que, bajo diferentes nombres o apreciaciones, aparecen de forma espectral a lo largo de toda la investigación, se recogen a continuación las principales posiciones que nos permiten posicionar esta tesis en su contexto correspondiente. Aquellos conceptos que tienen un desarrollo más detenido a lo largo de la tesis, o los estudios específicos que atañen a casos de estudio concretos, no están aquí incluidos.

La frontera contemporánea, según Mezzadra y Neilson, aparece como un mecanismo espacial y territorial que, por encima de su materialización física y simbólica -tanto en su construcción como en sus representaciones, como nos indica Wendy Brown en Estados Amurallados ${ }^{34}$, , resume en buena medida las posiciones generales presentes en los estudios de frontera contemporáneos. En 
ellos podemos enmarcar a Cutitta ${ }^{35}$, De Geneva ${ }^{36}$, Mezzadra y Pickles ${ }^{37}$, Tazziolli y Garelli $3^{8}$, Andersen, Klatt y Sandberg ${ }^{39}$ entre otros ${ }^{40}$. Estos estudios formulan la frontera como una construcción central a la producción del territorio, su configuración está entendida como un mecanismo de exclusión diferencial que puede ser aplicado en cualquier punto del territorio, la frontera como un dispositivo capaz de configurarse en base a diferentes parámetros y, por último, la frontera como un mecanismo de producción de subjetividades que relaciona indisolublemente el papel del cuerpo con el del dispositivo frontera.

Esta consideración de la frontera como un dispositivo de producción de subjetividades ${ }^{4 I}$ permite introducir la obra de un autor que otorga un enfoque complementario y a través de un relato histórico sobre la construcción de la frontera. Thomas Nail, en sus dos libros complementarios Theory of the border ${ }^{42}$ $\mathrm{y}$ The figure of the migrant ${ }^{43}$ presenta una serie de tecnologías de construcción territorial - la valla, el muro, la celda, el checkpoint, el salvoconducto... - y las liga a cuerpos migrantes que se comportan de una determinada manera. Bajo el término kinopolítica, Thomas Nail plantea un modo de organización del territorio, y de control de los cuerpos, en base a la regulación de flujos dinámicos. En él régimen kinopolítico establecido por la frontera "el migrante es la figura subjetiva cuyo movimiento está definido por esta lógica ${ }^{44 ”}$.

La importancia que ha cobrado el cuerpo migrante como figura central en torno a la cual se produce la frontera es un aspecto clave para entender los estudios de frontera, bien formulado a través del análisis marxista clásico poniendo en primer lugar el valor económico como fuerza de trabajo -Mezzadra y Neilson ${ }^{45}$, Bauman ${ }^{46}$ Brandariz García ${ }^{47}$...- o bien como desplazados por motivos más amplios como recoge Saskia Sassen en Expulsiones: Brutalidad y complejidad en la economía global. Un aspecto compartido por prácticamente la totalidad de autores es la necesidad de formular el cuerpo migrante como un cuerpo

35 Paolo Cuttita, «Territorial and non-territorial: the mobile borders of inmigration control», en Borderities, the mobile border hypothesis. Towards a postmodern conceptualization of space and borders, ed. por Anne-Laure Amilhat Szary y Frédéric Giraut (Basingtoke: Palgrave-McMillan, 2015), 241-255.

36 Nicholas de Geneva, « The Deportation Regime: Sovereignty, Space, and the Freedom of Movement», en The Deportation Regime, ed. por Nicholas de Geneva y Nathalie Peutz, ( Duke: Duke University Press, 2010), 33:68.

Nicholas de Geneva, «The Borders of 〈Europe〉 and the European Question», en The Borders of "Europe": Autonomy of Migration, Tactics of Bordering, ed. por Nicholas de Geneva (Durham, NC: Duke University Press).

37 Nicholas de Geneva, Sandro Mezzadra y John Pickles (eds.), «New keywords: migration and borders», en Cultural Studies vol. 29, nํㅗ (2015).

38 Glenda Garelli y Martina Tazzoli, "Challenging the discipline of migration: militant research in migration studies, an introduction”, en Post-colonial Studies, vol 16, nํㅜㄱ (2013), 245:249.

39 Marie Sandberg, «Introduction to the Border multiple», en Border region series, ed. por Dorte Jagetic, Martin Klatt y Marie Sandberg, (Farham: Ashgate, 2012), 1:19.

40 Se destacan en notas al pie las obras más relacionadas con el eje central de nuestra investigación, haciendo extensible al conjunto de su producción intelectual posiciones similares que también deben ser tomadas en consideración.

41 Mezzadra y Neilson, La frontera como método, (2017), 279:315.

42 Thomas Nail, Theory of the Border (Oxford: Oxford University Press, 2016).

43 Thomas Nail, The Figure of the Migrant (Stanford: Stanford University Press, 2015).

44 Nail, Theory of the Border (2016), 35.

45 Mezzadra y Neilson, La frontera como método, (2017).

46 Zigmunt Bauman, Archipiélago De Excepciones. (Barcelona: Katz editores, 2008).

47 José Ángel Brandariz García, "A lóxica da fronteira flexible e ubicua: sobre o control biopolitico dxs migrantes”, Derritaxes no 4, 2009.
La relevancia del cuerpo migrante 
La transformación topológica de la frontera

Cartografía crítica dentro de los estudios de frontera múltiple, un mínimo denominador común bajo el que se aglutinan realidades heterogéneas, que puede adquirir diferentes nombres en función del marco disciplinar o analítico empleado, o del momento histórico que se analiceMezzadra y Neilson ${ }^{48}$, Genova, Mezzadra y Neilson ${ }^{49}$, Thomas Nail ${ }^{50} . .--$; una figura cambiante que únicamente tiene en común la imposibilidad de estar políticamente en el territorio en el que está físicamente situado. Aspecto que, desde la filosofía política Javier de Lucas ha analizado con profusión, usando los términos “condición infra-política ${ }^{51}$ " o "presencia ausente ${ }^{52}$ " como explicaciones de una realidad con profundas implicaciones espaciales ${ }^{53}$.

Una noción que resulta relevante, también presente en las investigaciones anteriores, es la de "campo extendido" para referirse a la transformación topológica de la frontera, que va mucho más allá del territorio en el que se sitúa sino que crece tanto hacia el exterior como el exterior. Esta idea se presenta en Illegality .Inc, un estudio antropológico llevado a cabo por Ruben Andersson ${ }^{54}$, donde analiza la frontera a través de la red de agentes públicos y privados, cadenas de relaciones, que configuran la frontera. Una idea de transformación topológica, de la línea soberana a otras formas geométricas, móviles y dinámicas que encontramos en Balibar, el cual afirma que la frontera se ha superpuesto en la totalidad del territorio, un punto asociable al del cuerpo migrante -Brandariz ${ }^{55}$-, o una condición líquida o performativa de la frontera en función de las acciones de estos últimos - Soshan $^{56}$.

Los estudios de fronteras no se han limitado a la frontera como objeto o como método sino que han tomado consciencia de la necesidad de elaborar herramientas comunes que permitan conectar esta multiplicación de factores que la conforman así como las disciplinas involucradas en su análisis. La cartografía crítica, en la que enmarcamos las siguientes investigaciones y prácticas, aparece como un instrumento indispensable, transdisciplinar, para analizar la realidad contemporánea de la frontera como señalan Casas Cortes y Cobarrubias en Drawing escape tunnels through Borders ${ }^{57}$.

48 Mezzadra y Neilson, La frontera como método, (2017).

49 Nicholas De Genova, Glenda Garelli, Giorgio Grappi, Charles Heller, Sabine Hess, Bernd Kasparek, Sandro Mezzadra, yBrett Neilson. "New Keywords: Migration and Borders." Cultural Studies 29, no. I (2015): 55-87.

50 Nail, The Figure of the Migrant (2015).

51 Javier de Lucas, «Institutional Xenophobia against Immigrants in Spain»,

52 Javier de Lucas, «Los "otros" de la globalización: sobre la generalización de la presencia ausente», Revista Internacional de Estudios Vascos, $\mathrm{n}{ }^{\circ} \mathrm{7}, 2010$.

53 Aunque los estudios de frontera no son un campo extendido entre la comunidad científica española como tal, sí que hay destacados aportes desde aproximaciones parciales a la realidad de la frontera -motivo por el cual desarrollaremos sus aportaciones en los capítulos correspondientes-. El trabajo del ya mencionado Brandariz García, Iker Barbero, Fernández-Bessa o Christian Orgaz entre otros resulta muy relevante para la comprensión en el contexto específico español. Pero, más allá de la esfera académica, hemos de reconocer el esfuerzo por visibilización y análisis de una realidad compleja que se ha hecho desde diferentes instituciones y plataformas de activismo. Ila realidad de la frontera. la realidad de la frontera.les a la realidad de la frontera, idad del territoriontropolgarse en.

54 Ruben Ardesson, Illegality. Inc: clandestine migration and the business of bordering Europe, (Oakland: California University Press, 2014).

55 José Ángel Brandariz García, "A lóxica da fronteira flexible e ubicua: sobre o control biopolitico dxs migrantes", Derritaxes nํㅜ 4, 2009.

56 Malkit Shoshan, Border Ecologies (Conferencia; Nueva York: CGSAPP, 2017).

57 Maribel Casas Cortes y Sebastián Cobarrubias, «Drawing escape tunnels through Borders», An Atlas of Radical Cartography (Nueva York: Journal of Aesthetic Protest Press, 2007). 
El cartografiado crítico aplicado de manera clara a la frontera se alinea con esta dimensión expandida de la frontera, centrado en desplegar los diferentes agentes que la configuran. Ejemplos históricos son la labor desarrollada por Migreurop y su Atlas of migration in Europe $e^{58}$, que logra recopilar en una serie de cartografías las diferentes fases del régimen de fronteras. $\mathrm{O}$, el trabajo de Fortress Europe que emplea el archivado y catalogado de noticias como herramienta de mapeado de todas las muertes de migrantes vinculadas a la frontera, actualizado recientemente por Forensic Oceanography ${ }^{59}$. Y, a pesar de su especificidad geográfica -El Estrecho de Gibraltar- resulta de vital importancia el trabajo hecho desde Hackitectura, pues en él se mapea claramente la red de agentes públicos y privados que construyen la infraestructura fronteriza del Estrecho, pero se superpone también la red de afectos y relaciones en él presente. $\mathrm{O}$, empleando su propia terminología, a la cartografía del Imperio se superpone la de la multitud, un aspecto que no está claramente localizados en las investigaciones anteriores.

El trabajo del colectivo Hackitectura, Cartografia Crítica del Estrecho, junto con las investigaciones realizadas por An Architektur rastreando y cartografiando las “arquitecturas de la migración” suponen la primera aproximación de la disciplina arquitectónica a los estudios de frontera, enmarcadas en la primera década del siglo XXI. Sin embargo, es necesario señalar la escasez de aproximaciones que se han hecho, desde la investigación arquitectónica, a este campo de estudio ${ }^{60}$. Otra de las aproximaciones contemporáneas a estas dos prácticas cartográficas, es la tesis doctoral realizada por Eyal Weizman sobre el conflicto entre Palestina e Israel donde introduce conceptos fundamentales como la concepción plástica del territorio y, aunque pueda parecer que se aleje del campo de estudio, el impacto que ha tenido en investigaciones posteriores -como Weaponized Architecture, de Léopold Lambert una década más tarde- hace obligatoria su mención. Así como el trabajo desarrollado desde Forensic Architecture, pudiendo destacar Left-todie boat como una investigación directamente relacionada con nuestro ámbito de estudio, cuyo objetivo era la visibilización de las diferentes regulaciones que operan sobre un territorio aparentemente liso y neutral como el mar. Una de las investigaciones herederas de Eyal Weizman, es la de Léopold Lambert, recogida en Weaponized Architecture, donde el autor analiza a través de la misma frontera la violencia inherente a toda producción espacial y, destaca además la dimensión expandida que ésta adquiere dentro del proyecto colonial israelí.

Diego Barajas, primero en solitario y como parte de Husos han hecho una aproximación a las lógicas de la frontera a través de Dispersion ${ }^{61}$ y Urbanismo de Remesas $^{62}$. En estas dos obras, ligadas con la dimensión afectiva construida como consecuencia de la migración, se introduce un concepto fundamental, el de arquitecturas dispersas. Término que se refiere a la capacidad de acción y construcción espacial conjunta de agentes, escenarios y construcciones que pese a su distancia geográfica pueden ser reconectados a través de relaciones instantáneas. Otro aspecto importante de estas investigaciones arquitectónicas, que también vemos presente en el trabajo de Teddy Cruz y su proyecto Cross-

58 Migreurop, Atlas of Migration in Europe: A Critical geography of Migration Policies (Londres: New Internationalist, 2012).

59 Lorenzo Pezzani y Charles Heller, Forensic Oceanography, 2012.

60 Se ha decidido discernir entre propuestas arquitectónicas e investigación arquitectónica, excluyendo de esta breve aproximación aquellas prácticas especulativas o propositivas -fundamentalmente en ámbitos docentes- que, de manera paralela a la relevancia mediática, se han producido de manera reciente.

61 Diego Barajas, Dispersion: A study of global mobility and the dynamics of a fictional urbanism, (Rotterdam: Episode Publishers, 2005).
Aproximaciones arquitectónicas a los paisajes fronterizos. 

que tienen más que ver con la domesticidad o el tejido afectivo que con la dimensión normativa de la misma.

Elena Dell'Agnese y Anne-Laure Amilhat Szary introducen en Borderscapes: From border landscapes to border aesthetics ${ }^{63}$ el término Borderscapes para sustraerlo de su condición exclusivamente artística y ligarlo a los estudios de frontera arrancando con wla siguiente pregunta "¿Puede la producción cultural ser algo más que una cuestión lateral en los estudios de fronteras?”, para a continuación afirmar cómo a través de los artefactos artísticos y determinadas producciones culturales se puede ampliar el marco conceptual desde donde y cómo se analiza la frontera -"Las fronteras y su producción cultural han desarrollado una relación más-querepresentacional que permite revelar un gran número de mecanismos políticos operando en estos espacios afectados por la frontera y por sus cruces"-. Así, lo que se plantea en este texto, y con la formulación actualizada del concepto de paisaje fronterizo o borderscapes, es la introducción de un análisis situado sobre el territorio, no exento de él.

Del mismo modo que la estética forense se concibe como el conjunto de medios y técnicas a través de los cuales extraer información de un territorio o arquitectura, pero también la construcción de artefactos que permitan su comprensión a una determinada audiencia, las estéticas fronterizas nos remiten a esta capacidad que prácticas artísticas, cartográficas, arquitectónicas tienen a la hora de reconstruir las dinámicas y violencias presentes en la frontera. Todo ello, alimentado por las herramientas teóricas ya desplegadas, así como un repertorio de instrumentos de análisis que beben de diferentes disciplinas permiten a nuestra investigación conformar una base sólida sobre la cual construir nuestra propia aproximación a la frontera contemporánea.

63 Elena Dell'Agnese y Anne-Laure Amilhat Szary. "Borderscapes: From Border Landscapes to Border Aesthetics”, en Geopolitics 20, ํㅡㄴ $\mathrm{I}$ (2015). 


\section{UNA APROXIMACIÓN TERRITORIAL A LA LOGICA DE LOS DISPOSITIVOS}

* \#dispositivivo - . [p.266 Michel Foucault

\#del hardware al software

\section{$+$}

¿Qu'é es un dispositivo arquitectónico?

Sistemas de producción espacial y territorial

Convivencia de Lavapiés

[p.260]

1 ' '

Arquitectóniças de la \#redísposición. contingencia

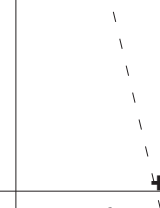

\#microfísica del pooder Michel Foucault [p.204] ,

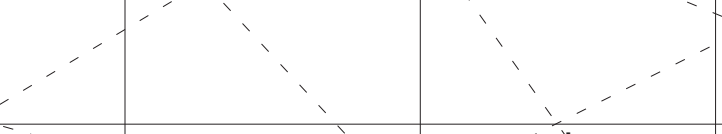

ricault 1
Ensamblaje de Ceuta'y Meli-
lla [p.115] \#ensamblaje \#interrelàción entre niveles, \#diagrama Gilles Deleuze y Felix Gùattari El poder del diagrama Giltes Deleuze y Felix Guattar

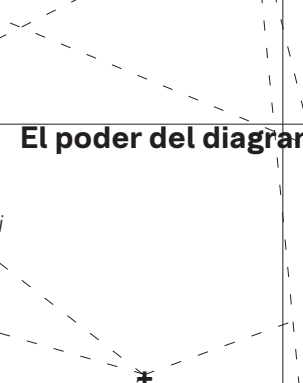
\#capacidad de reorganización Thomas Nail \#relación-entre agentes o sistemaś de diferente naturaleza

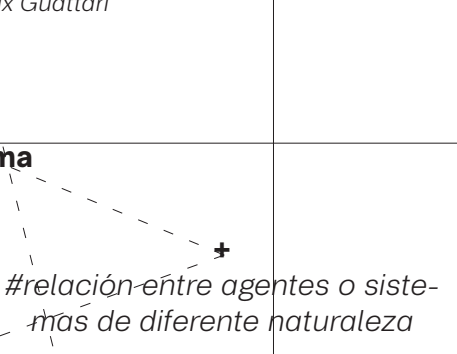

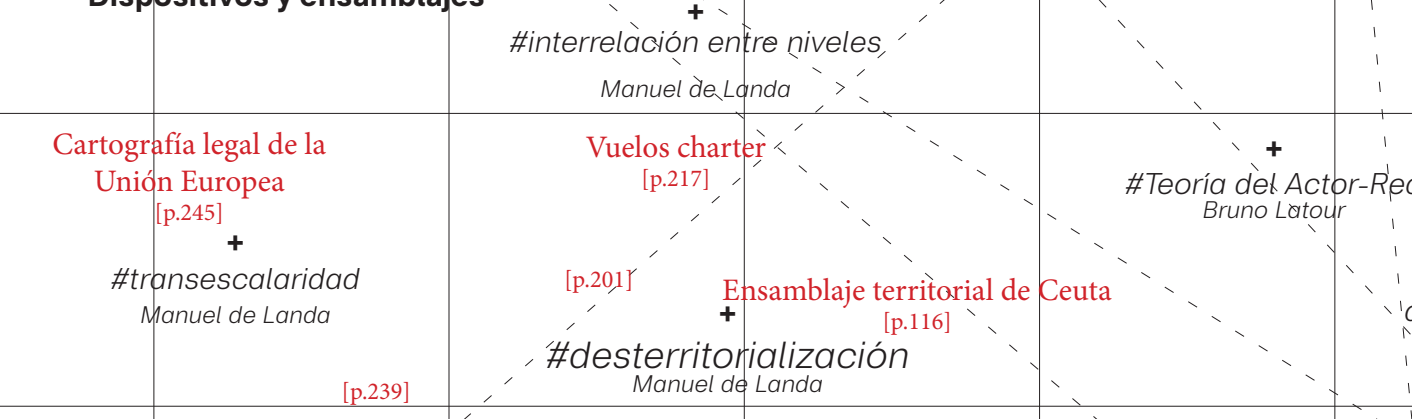

\section{Gilles Deleuze y Felix Guattari

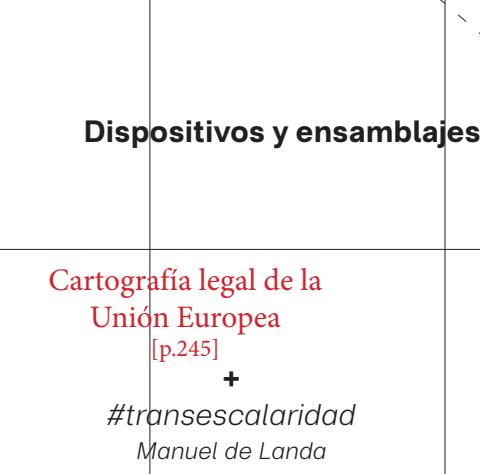

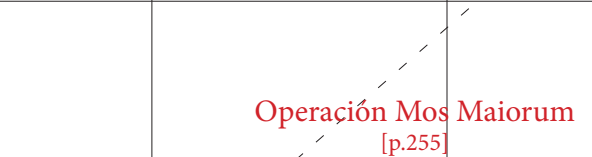 \\ \#relaciones frentè a-agentes

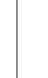

Hacia una lógica de los ensamblajes como modelo de construcción territorial

\section{[p.138]}

$\left[\begin{array}{c}+ \\ \\ \text { \#cuerpo post }\end{array}\right.$ 

Ante una oscuridad absoluta aparecen puntos de luz en movimiento, que vibran y se desplazan de manera constante con cada variable-, interactuando con ellos y alterando su posición de manera más o menos violenta. La disposición de este enjambre de puntos es siempre móvil, apenas conectados por vectores que los ponen en relación. Ante nosotros, un modelo dinámico que responde a todos y cada uno de los inputs que recibe deviniendo formas diferentes en cada ocasión. A veces, cada uno de esos nodos se expande dejando ver la complejidad escalar que se esconde entre la maraña móvil de nodos y conexiones en interrelación constante; otras, esta se reduce mostrando prácticamente como una única forma lo que segundos antes ocupaba todo el espacio. El trabajo audiovisual de Tadej Drolic $^{\mathrm{I}}$ presenta estos espacios responsivos a los estímulos de piezas de arte sonoro, en ellos son las relaciones e información proporcionada por el audio lo que configura y dispone los puntos sobre un espacio vacío; crea un espacio que sólo puede ser representado por las relaciones, información y conexiones que se establecen entre cada uno de los nodos. Así, se construye una performance audiovisual dinámica donde tan sólo en algunas ocasiones, la matriz euclidiana sale a la luz para, al instante, desaparecer convertida de nuevo en una nube borrosa de vectores, nodos e información. Y es esta precisamente, con esta metáfora visual, la mejor forma de introducir el espacio que recorreremos a lo largo de esta tesis: el formado por el dispositivo frontera. Un espacio difuso, variable, que transita entre diferentes territorios y las consecuencias de una acción puntual tienen ecos en la configuración total del dispositivo, que se transforma de manera constante y, con cada nueva disposición, recoloca la ubicación de cada agente y nodo dentro de él ¿Cómo aprehender un espacio que conecta escalas, agentes y escenarios tan diversos, que cambia de manera dinámica con cada acción sino es a través de una formulación de este tipo? Este no está regido por las variables euclidianas, las relaciones entre los objetos no pueden medirse con las unidades habituales ya que la escala y naturaleza de los agentes que la conforman hace imposible que sea mesurable o aprehensible únicamente a través de las dimensiones en las que históricamente se ha desenvuelto la disciplina.

Conectar diferentes realidades territoriales, construcciones, agentes humanos y no-humanos, escenarios, incluso protocolos, normativas, decisiones políticas para entender la formulación contemporánea de la frontera requiere pensar en herramientas específicas que permitan abordar esta complejidad. La frontera ha adquirido la capacidad de impregnarse en la totalidad del territorio, los diferentes casos de estudio y acontecimientos analizados muestran que ésta ya no es contenible exclusivamente en los territorios históricamente asociados a ella, ni a las arquitecturas que la encarnaban. La frontera ya no puede formularse como una suma de objetos -los muros, las vallas, los controles, los centros de internamiento...- sino como una construcción espacial donde no es la suma de objetos, sino las relaciones dinámicas establecidas entre los diferentes agentes que la conforman lo que genera una espacialidad determinada.

Sólo formulando la frontera como un dispositivo se han podido abordar, desvelar y entender el funcionamiento de una herramienta de producción espacial y territorial que ya no puede enunciarse como hardware sino como software. Frente a una realidad material, estática y topográfica, una realidad únicamente aprehensible a través de su virtualidad, su condición dinámica y topológica -la interconexión entre los agentes-. Sin intentar hacer un análisis exhaustivo de las implicaciones que a nivel conceptual tiene el término o las diferencias establecidas entre los diferentes autores que lo han formulado y re-formulado, es importante comprender a grandes rasgos las principales características que lo definen para comprender su operatividad espacial.
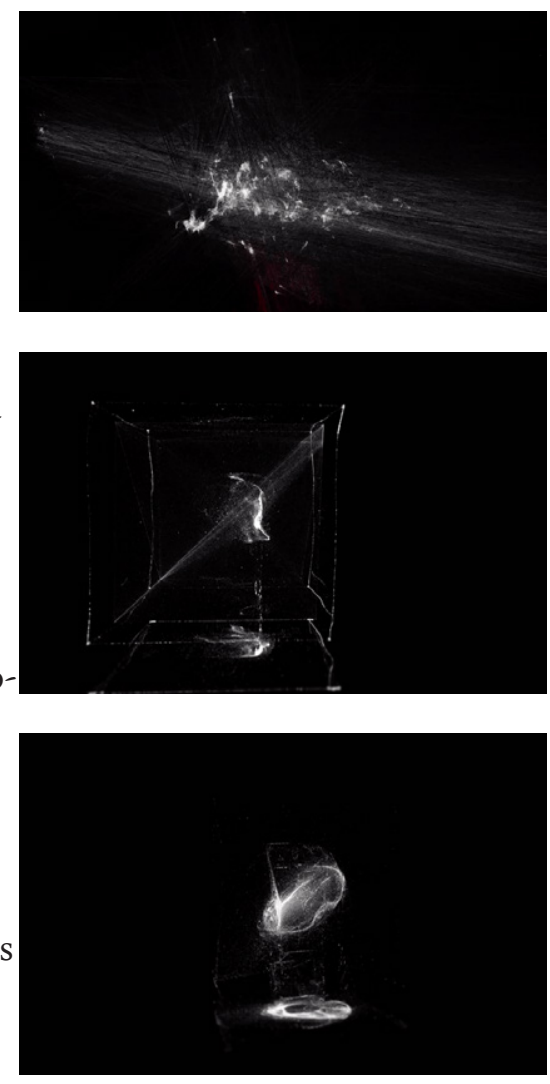

¿Qué es un dispositivo arquitectónico?

Sistemas de producción espacial y territorial 
Expliquemos, por tanto, por qué es importante esta aproximación metodológica a la construcción de la frontera desde este planteamiento ontológico que actualiza la noción de dispositivo - dispositif- formulada por Michel Foucault. Recurramos a ella como punto de partida para, desde ahí, precisar las diferentes actualizaciones y las implicaciones espaciales de estas²:

Lo que trato de indicar con este nombre es, en primer lugar, un conjunto resueltamente heterogéneo que incluye discursos, instituciones, instalaciones arquitectónicas, decisiones reglamentarias, leyes, medidas administrativas, enunciados científicos, proposiciones filosóficas, morales, filantrópicas, brevemente, lo dicho y también lo no-dicho, éstos son los elementos del dispositivo. El dispositivo mismo es la red que se establece entre estos elementos.

...por dispositivo, entiendo una especie -digamos- de formación que tuvo por función mayor responder a una emergencia en un determinado momento. El dispositivo tiene pues una función estratégica dominante.... El dispositivo está siempre inscripto en un juego de poder 3 .

El dispositivo, por tanto, conecta agentes heterogéneos pero, más que la conexión entre los diferentes elementos, es la red establecida entre ellos la que cobra verdadero protagonismo. Las relaciones que posibilitan la conexión entre elementos aparentemente autónomos pero que, en un momento dado, pueden ensamblarse o generar agencias entre ellos para dar una respuesta a una determinada urgencia. Y es que, el carácter de contingencia, emergencia como dice Foucault, o excepcionalidad, es otra de las características diferenciales que lo definen frente a otros planteamientos. Así, el poder se presenta envuelto en esta red de relaciones: cambiantes, efímeras y precarias; como un resultado momentáneo de un equilibrio inestable entre ellas y no como una figura de autoridad independiente de esta realidad material y virtual. Lo que Foucault denominó microfísica del poder ${ }^{4}$ no es más que el reconocimiento de la disolución de éste a través de la amalgama cambiante de relaciones, agentes y tiempos que forma el dispositivo. Sus múltiplices disposiciones y alteraciones no recaen sobre un conjunto amplio sino que cualquier agente involucrado posee esa capacidad de reapropiación y reorientación.

Esta capacidad de reorientación o redisposición es fundamental también para entender, a efectos prácticos, como operar con el dispositivo. Así, el poder se redistribuye recolocándose, alterando la función que cumple cada uno de los agentes dentro del mismo, creando nuevos vínculos -agenciamientos- $\mathrm{y}$ eliminando u omitiendo los existentes; siempre de una manera temporal. Esto es un aspecto fundamental para entender, cómo a lo largo de la tesis, la inclusión de nuevos elementos - una normativa específica, la aplicación de un protocolo policial, la presencia de unos cuerpos en una playa, la instalación de un sistema de vigilancia, ropa ardiendo en una ventana, una denuncia policial, una muerte...-, de variables menores en comparación con el conjunto del dispositivo, tienen efectos inesperados que logran alterar por completo las funciones de cada uno de los agentes involucrados en la construcción del espacio fronterizo.

2 No se pretende una exposición exhaustiva acerca del concepto de dispositivo como tal en la actualidad sino la pertinencia de su elección como herramienta de análisis arquitectónico frente a otras formulaciones similares.

3 Michel Foucault, Dits et écrits vol.III, (París: Bibliotheque des sciences humaines, 1994), 299. 
Deleuze y Guattari parten de este concepto de Foucault y presenta el agenciamiento ${ }^{5}$-agencement $\mathrm{o}$ assemblage- para referirse al acto, a las situaciones concretas que surgen de la conexión de elementos de diferente naturaleza. El ensamblaje, de nuevo recalca la importancia y fragilidad de las conexiones a la hora de construir una determinada situación: conexiones que no se sitúan en un plano -jerárquico- diferente al material, ni pueden ser previstas. Aunque haya una predisposición, estas relaciones son sólo virtuales, expresan una potencia que puede llegar a materializarse -con mayor o menor resistencia-. Así, se introduce un concepto tremendamente operativo en lo que a efectos de análisis se refiere: la idea de diagrama como la visibilización de esta red virtual de relaciones entre los agentes y escenarios involucrados:

¿Qué es un diagrama? Es la exposición de las relaciones de fuerzas que constituyen el poder. [...]

Las relaciones de fuerzas, o de poder, eran microfísicas, estratégicas, multipuntuales, difusas, que determinaban singularidades y constituían funciones puras. El diagrama o la máquina abstracta es el mapa de las relaciones de fuerzas, mapa de densidad, de intensidad, que procede por uniones primarias no localizables, y que en cada instante pasa por cualquier punto, o "más bien en toda relación de un punto a otro" [...] La máquina abstracta como la causa de los agenciamientos concretos que efectúan las relaciones; y esas relaciones de fuerzas se sitúan "no encima", sino en el propio tejido de los agenciamientos que producen ${ }^{6}$.

De esta forma, el diagrama es la herramienta operativa que permite, precisamente, "entender la relación entre sistemas o planos cuyas formas respectivas los harían incongruente" trae a la luz en un mismo plano de análisis y entendimiento cualquier elemento independientemente de su condición y posición jerárquica; así, "al definirse por funcionas y materias abstractas 'ignora cualquier distinción de forma entre un contenido y una expresión, entre una formación discursiva y una formación no discursiva"”. Una formulación que, como nos señala Jalón, es necesario separar de las múltiples acepciones que han cobrado protagonismo mayoritario desde dentro de la disciplina arquitectónica, para evitar caer en la idea de diagrama como modelo previo al proceso de diseño. Precisamente, aclarar esta acepción nos permite plantear una herramienta de análisis arquitectónica que opera a través de la visibilización y alteración de fuerzas que constituyen elłpiadearma

Thomas Nail señala un primer conflicto, en parte derivado de la traducción de agencement por assemblage o, al español, por ensamblaje en vez de agenciamiento, que es la tendencia a poder imaginar los ensamblajes como una unidad o totalidad más que como una heterogeneidad múltiple y transformable. Esta apreciación es importante tenerla en cuenta para comprender la autonomía de cada uno de los escenarios o la inclusión de agentes que no están directamente vinculados a la producción fronteriza. En una misma producción espacial coinciden elementos que pueden formar parte de diferentes ensamblajes o dispositivos - policiales, fronterizos, de deportación, logísticos, informativos...Así, "en contraposición a las unidades orgánicas, para Deleuze y Guattari, los ensamblajes son más como máquinas, definidas únicamente por sus relaciones

5 Gilles Deleuze y Felix Guattari, Mil mesetas: Capitalismo y Esquizofrenia (Valencia: Pretextos, 2005).

6 Gilles Deleuze, “Un nuevo cartógrafo”, Foucault, (Barcelona: Paidós, 2007), p.63.

7 Lucía García de Jalón Oyarzun, «Excepción y cuerpo rebelde: lo político como generador de una arquitectónica menor» (tesis doctoral, Universidad Politécnica de Madrid), 195.

\section{El poder del diagrama}

\#agenciamiento

\#diagrama

\#relación entre agentes o sistemas de diferente naturaleza

8 Deleuze, “Un nuevo cartógrafo”, Foucault, (Barcelona: Paidós, 2007), p.6r. 
\#capacidad de reorganización

Dispositivos y ensamblajes

\#ensamblaje

\#transescalaridad

\#interrelación entre niveles externas de composición, mezcla y agregación”; de nuevo se reconoce la necesidad de comprender las relaciones de conexión entre los agentes que la forman para ser capaces de esbozar el diagrama. Prosigue, por tanto señalando la capacidad de reorganización, adaptación de los ensamblajes "si los elementos de un esamblaje sólo están definidos por sus relaciones externas, entonces es posible que éstas sean añadidas, extraídas y recombinadas entre sí ad infinitum sin crear ni destrozar una unidad orgánica”ı。.

Ante la variedad de formas de enunciación y los diferentes matices que se presentan entre ellas, a lo largo de la investigación utilizaremos el término de dispositivo para referirnos al conjunto de prácticas espaciales, legales y normativas que afectan, contribuyen y construyen la frontera contemporánea. Es el dispositivo frontera, el mecanismo que con una función claramente estratégica y vinculada al poder dispone las construcciones oportunas para regular el flujo de cuerpos entrantes y salientes de un territorio soberano. Así, y atendiendo ahora a la actualización hecha por Agamben, el dispositivo frontera entendido en estos términos mantiene el carácter jurídico, tecnológico y militar y se entiende como "el conjunto de prácticas y mecanismos [...] que tienen por objeto hacer frente a una urgencia y lograr un efecto más o menos inmediato" II. Para cada una de las construcciones concretas y acontecimientos analizados que ponen en relación los diferentes agentes de una construcción espacial en un mismo plano de análisis, emplearemos el término ensamblaje remitiéndonos a la formulación de Deleuze y Guattari y sus posteriores revisiones. De esta manera, la lectura nos permitirá diferenciar de forma clara entre dos escalas de un mismo dispositivo -el dispositivo frontera-, que es analizado a diferentes escalas de abstracción, siendo en realidad un "ensamblaje de ensamblajes"

Es precisamente la idea de "ensamblaje de ensamblajes" a la que se remite Landa en su libro Assemblage Theory la que nos permite adecuar la pertinencia de este marco de análisis de la realidad en un contexto territorial y espacial concreto. Manuel De Landa presenta su teoría del ensamblaje a través de diferentes contextos y ámbitos de estudio diferentes, pero comparten dos cuestiones fundamentales: la transescalaridad y la oscilación en la capacidad de desterritorialización. Estas dos condiciones que señala de manera explícita son tremendamente operativas a la hora de trascender la estratificación por escalas característica de la disciplina para formular modelos transversales que atraviesan en un mismo plano jerárquico desde lo territorial a lo corporal, de lo micro a lo macro, independientemente de su tamaño, relevancia o capacidad de agencia. Pero, además, esta condición transescalar genera una retroalimentación constante del ensamblaje, donde los niveles más concretos generan un impacto directo en aquellos más abstractos y al revés:

Las propiedades de un todo son producidas por las interacciones existentes entre sus partes, mientras que un todo, una vez está estabilizado, reacciona de nuevo a sus partes [...] Si las diferentes partes y conjuntos son ensamblajes, entonces ambos poseen sus propios parámetros, y esto implica que los cambios en alguno de los parámetros de un todo puede afectar a los parámetros en sus partes, y viceversa ${ }^{\mathrm{I} 3}$.

9 Thomas Nail, «What is an assemblage», Substance, volumen 47, ํㅡㄷ, (2017), pág.23.

10 Nail, «What is an assemblage», Substance, volumen 47, n⿳ํㅗ, (2017), pág.23.

11 Giorgio Agamben, ¿Qué es un dispositivo?, (Barcelona: 2015), pág. 17.

12 Manuel de Landa, Assemblage Theory, (Edimburgo: Edinburgh University Press, 2018), 75.

13 de Landa, Assemblage Theory, (Edimburgo: Edinburgh University Press, 2018), 83. 
Respecto a la oscilación en la capacidad de desterritorialización de un mismo ensamblaje es interesante la propuesta hecha por de Landa, al comprender que los grados de territorialización o desterritorialización no son lineales ni asociables a períodos históricos o construcciones concretas sino un parámetro modulable más dentro del ensamblaje. Es decir, a lo largo de la investigación aparecerán construcciones fácilmente asociables a los contornos históricos de la frontera mientras que en otras su silueta se ha diluido tanto que será difícil rastrear, y sólo a través de esta modulación entre lo más territorializado y lo más desterritorializado se podrá conectar una realidad espacial operada a través de las mismas lógicas. Así pues, se desdibuja la dualidad nómada/sedentario, territorializado/desterritorializado como categorías excluyentes en tanto que "el grado de territorialización o desterritorialización debería ser tratado como un parámetro variable que puede cambiar históricamente" ${ }^{{ }^{14}}$.

Otra de las cuestiones operativas que posee la noción de ensamblaje para comprender la realidad espacial a analizar es la capacidad de codificación y descodificación. El dispositivo opera a través de agentes existentes empleando diferentes mecanismos que les otorgan nuevos significados y nuevas funciones. En el proceso de construcción de cada ensamblaje la disposición de los agentes así como las relaciones establecidas entre ellos serán fundamentales para comprender sus funciones y viceversa: las relaciones que se establezcan entre agentes determinará la función y agencia de cada uno de ellos. Esto es, por un lado el dispositivo opera sobre los agentes asignando una función concreta que varía y se modula en base a las necesidades espaciales requeridas; por otro, el dispositivo actúa activando y estableciendo las conexiones, decidiendo qué posibilidades dentro de un amplio arco de variables actúan en cada momento. Cuestión que afecta por tanto a "sus propios componentes, restrigiéndolos y habilitándolos a la vez" ${ }^{15}$.

No es el binomio dispositivo/ensamblaje, ni el filum genealógico claro trazado en los párrafos anteriores, la única aproximación metodológica que permita abordar una realidad compleja desde la disciplina arquitectónica. De hecho, es importante reconocer la afinidad con el pensamiento ecosistémico y la Teoría del Actor-Red a la hora de generar narrativas transescalares y dinámicas que reconocen la complejidad de factores y agentes que intervienen en la dimensión urbana y territorial ${ }^{16}$. Como señala Miguel Mesa del Castillo, el no aislar la realidad urbana o territorial de su dimensión social ha permitido incluir en el análisis espacial una serie de factores y capas de información que históricamente

14 de Landa, Assemblage Theory, (Edimburgo: Edinburgh University Press, 2018), 83 15 de Landa, Assemblage Theory, (Edimburgo: Edinburgh University Press, 2018), 71. 16 Para una mayor profundización en las implicaciones arquitectónicas de la Teoría del Actor-Red de una manera amplia se recomienda la lectura de "Architecture in Action: Traveling with actor-network theory in the land of architectural research", "Learning from Actor-Networtk Theory”, así como la investigación en curso de Micol Rispoli o Daniel Torrego. Ver más en, Kjetil Fallan «Architecture in action: Traveling with actor-network theory in the land of architectural research», Architectural Theory Review, n-13, (2008) 80-96; Simon Bradbury "Learning from Actor-Network Theory", Architecture \& Education Journal, no II, (2014), 453:470. Para comprender el impacto territorial y urbano se recomienda la lectura de la tesis de Uriel Fogué Herreros "Ecología política y economía de la visibilidad de los dispositivos tecnológicos de escala urbana durante el siglo XX Abriendo la caja negra”, quien en términos de ecología política revisa estas implicaciones, así como el mencionado artículo de Miguel Mesa del Castillo "La arquitectura de la ontología orientada a objetos: como poner las prácticas en primer plano”. Ver más en, Uriel Fogué Herreros, «Ecología política y economía de la visibilidad de los dispositivos tecnológicos de escala urbana durante el siglo XX Abriendo la caja negra» (tesis doctoral: Universidad Politécnica de Madrid, 2017); Miguel Mesa del Castillo, «"La arquitectura de la ontología orientada a objetos: como poner las prácticas en primer plano” (artículo, I International Conference on Architectural Design \& Criticism, 2014), 761:771.

\section{Modelos espaciales alterna- tivos}


\#ensamblaje como un objeto dinámico no reducible a su materialidad han sido obviadas por la disciplina. Y esta superposición simultánea de capas sobre un mismo campo de estudio requiere transformar tanto nuestra óptica como las herramientas de aproximación a ella, para reconocer realidades aparentemente no arquitectónicas que pueden ser cruciales:

el materialismo relacional, los edificios y las ciudades no son conjuntos estáticos, por eso los sistemas de representación y las técnicas de diseño convencionales no son suficientes para explicar la enorme complejidad de las entidades arquitectónicas. Un material nuevo, una normativa, una protesta ciudadana, una controversia,un nuevo campo de interés en el estudio, una visita del cliente, una dificultad financiera inesperada... son elementos que intervienen en el diseño. Los edificios no serían, según esta perspectiva, únicamente lo que aparece representado en el espacio euclídeo. Una mirada atenta descubrirá que cualquier ensamblaje arquitectónico está constituido por una multiplicidad de actores que lo convierten en un objeto inestable, dinámico, no reducible a su materialidad y a sus dimensiones geométricas. Esta es la gran ventaja y la propuesta más innovadora de la TAR que debería modificar radicalmente los contextos en los que se produce la ciudad y la arquitectura ${ }^{17}$.

Así pues, a pesar de que terminológicamente los conceptos aquí desplegados respondan fundamentalmente a la primera de las genealogías trazadas, es innegable la vinculación y afectación de los planteamientos conceptuales pero, sobre todo, las aportaciones hechas desde la disciplina arquitectónica a la hora de abordar la realidad desde postulados próximos a la cosmopolítica y la Teoría del Actor-Red. Sin salir del contexto nacional -y reconociendo a éste como pionero a la hora de plantear esta metodología de manera profusa como proyecto tanto arquitectónico como docente/pedagógico- es necesario reconocer la labor de la Escuela de Alicante al plantear metodologías de análisis llevadas luego a la práctica profesional basadas en este modelo de pensamiento.

Sin embargo, y a pesar de que el dispositivo plantee un aplastamiento ontológico o una falta de jerarquía a la hora de establecer relaciones entre las partes, sí es importante reconocer, como elemento de la hipótesis de esta investigación, la preponderancia que tiene el cuerpo en la construcción de la frontera contemporánea. Así, aún frente a análisis humanocéntricos propios de la disciplina, donde es el cuerpo biológico e individual el centro absoluto a partir del cual se construye el espacio -desde los análisis funcionales del cuerpo como medida de todo hasta los planteamientos fenomenológicos-, éste sí que juega un papel fundamental dentro de un ensamblaje mucho mayor. No obstante, el cuerpo de nuestro análisis es necesariamente post-humano, cuyos límites se definen no en función a su contorno sino a su capacidad de agencia. Esta importancia no significa que sea un agente central, sino simplemente que en nuestro marco de análisis ha sido entendido como un elemento de gran relevancia en las diferentes disposiciones operativas de la frontera, que nos permite ampliar la noción de dispositivo frontera a más espacios y lugares que otros elementos del dispositivo. En ese sentido, no se posiciona en el centro, tan solo posee una agencia destacada o mayor relevancia en comparación con otros elementos del dispositivo -a efectos de nuestra investigación- y, por ello, la tradición de pensamiento en la que se inserta el dispositivo foucaultiano y sus actualizaciones -sobre todo la hecha por Deleuze- nos ofrecen mejores herramientas a la hora de comprender la espacialidad que es capaz de generar un cuerpo.

17 Mesa del Castillo, «"La arquitectura de la ontología orientada a objetos” (artículo, I International Conference on Architectural Design \& Criticism, 2014), 764. 
Fruto de estas formulaciones, pero con una génesis radicalmente espacial, debemos mencionar dos aproximaciones ${ }^{18}$ que, desde disciplinas diferentes, permiten entender cómo se construyen, afianzan y manipulan las redes y conexiones entre las partes de un dispositivo. Hablamos del trabajo de Keller Easterling acerca de la disposición y las formas activas, pues, desde la disciplina arquitectónica, traslada el foco de análisis de la construcción de objetos al repertorio de prácticas espaciales con capacidad para manipular, promover, habilitar o prohibir la construcción de un territorio concebido en términos de software y no de hardware -lo que ella ha denominado formas activas-. La segunda referencia, desde la teoría legal, es el modelo espacial presentado por Andreas Philippopoulos-Mihalopoulos en Spatial Fustice: Body, Law, Atmosphere donde el lawscape no es más que el conjunto heterogéneo de cuerpos, leyes y espacio interrelacionado. Un modelo que concibe el espacio como una resultante dinámica y cambiante de esta amalgama en conflicto constante:

El espacio como pliegue es un torbellino de cuerpos generando y deviniendo espacio. Estos cuerpos son humanos y no-humanos físicos, e incluso 'cuerpos humanos ordinarios, tales como el cuerpo humano o el corpus legal que se han transformado en ensamblajes de cuerpos humanos y no-humanos. Cada uno de estos cuerpos emerge con su propia agencia contextual, que he descrito como una agencia material, y siempre espacial ${ }^{19}$.

Ambos enuncian propuestas espaciales consistentes en el desplazamiento parcial del foco de análisis tradicional de cada una de las disciplinas. En el caso de Easterling, de la preponderancia del objeto al conjunto de normas, protocolos y relaciones dinámicas que posibilitan ciertas construcciones mientras que impiden otras. En el caso de Philippopoulos-Mihalopoulos, nos presenta una ley que ya no está exclusivamente encarnada en normativas y textos legales sino encarnada en los cuerpos y las acciones que estos llevan a cabo.

Todos los modelos presentados coinciden, con matices lógicos, en que sólo a través de la visibilización de la red de relaciones se puede operar con ellas y, por tanto, generar resistencias que reorienten el conjunto del dispositivo. Es decir, sólo a través de una comprensión -global (estratégia) o desde la práctica cotidiana (táctica) - y desde un planteamiento que reconozca el carácter microfísico del poder es posible operar en él, no en los objetos y agentes sino en las relaciones entre ellos. Esta operatividad de los dispositivos será analizada con mayor detenimiento en los siguientes capítulos, pero conviene aclarar que se efectúa manipulando -de diferente modo- tanto la materia como las conexiones entre los agentes -activándolas, hackeándolas, interrumpiéndolas, saboteándolas...-, para así generar nuevas construcciones espaciales más favorables a los cuerpos en conflicto. Pero además, el hecho de incorporar en ambos modelos una realidad múltiple generalmente obviada en análisis disciplinares, permite reconocer, analizar y articular tanto modos de resistencia como marcos de acción que generan una agencia que la disciplina arquitectónica históricamente ha contribuido a minimizar. Y, por último, todos los modelos asumen el conflicto, las resistencias y deseos autónomos de las partes, como un mecanismo operativo de evolución, transformación y alteración del status quo del dispositivo.

Así pues, esta aproximación múltiple, que conecta escalas, agentes, territorios atravesados y configurados en base a una realidad social, nos permite construir un discurso ecosistémico que trasciende las escalas tradicionales de

18 Por el peso e importancia dentro de la investigación se desarrollarán de manera pormenorizada en los apartados posteriores.

19 Andreas Philippopoulos-Mihalopoulos. Spatial Fustice: Body, Lawscape, Atmosphere. (Nueva York: Taylor and Francis, 2015), p.59. \#formas activas

\#lawscape

Hacia una lógica de los ensamblajes como modelo de construcción territorial

\#relaciones frente a agentes

\#maniobrar el dispositivo

\#conflicto operativo 
la arquitectura en una red "desordenada" y variable de agentes heterogéneos que conviven con la arquitectura estable que tradicionalmente ha supuesto el foco disciplinar. Una arquitectura que, aparentemente, parece quedar fuera de foco en ciertos momentos de la investigación. Sin embargo, esta aproximación, al situar precisamente en un mismo plano de análisis todos estos agentes y conexiones lo que hace es reconocer cómo los mismos efectos espaciales de la arquitectura pueden ser también construidos y performados por otros agentes aparentemente-no-arquitectónicos. Esta visión ecosistémica, que puede ser común en otras disciplinas, no lo es tanto en la arquitectónica que ha centrado gran parte de los debates exclusivamente en el objeto -forma- así como en la relación establecida con el usuario humano -función-. Al enunciar no como objeto sino como dispositivo las infraestructuras territoriales, podremos comprender la implicación real de una serie de elementos conectados con ellas que van más allá de los límites sólidos de la arquitectura, y así desvelar las prácticas espaciales que la configuran.

Por tanto, al usar esta aproximación, podemos desplazar la discusión arquitectónico del binomio forma/función o arquitectura/cuerpo para proponer nuevos planos relaciones que jamás han de ser duales, sino una red o maraña de relaciones cambiantes y dinámicas entre elementos heterogéneos. $\mathrm{Y}$, al hacer esto, nos aproximamos a una realidad atravesada por múltiples factores, que se replica y reproduce de diferente manera en infinidad de escenarios y territorios sin aparente conexión. Y, desde ahí, sin despreciar ninguna variable independientemente de su condición o (in)significancia, desvelar las relaciones y agentes que configuran cada construcción espacial, así como sus implicaciones reales. 


\section{LA VALLA \\ ARQUITECTÓNICAS DE DELIMITACIÓN E IMPERMEABILIZACIÓN}

3.1. Un cuerpo sobre la línea.

3.1.1. Arquitecturas punitivas. Carne, cuerpos y arquitectura.

3.1.2. Evolución histórica de la materialización arquitectónica de la frontera.

3.2. Ensamblajes territoriales de las líneas fronterizas.

3.2.1. Arquitecturas dispersas.

3.2.2. Ensamblajes territoriales de Ceuta y Melilla. 3.2.2.1 Ceuta. Enclave topográfico.

3.2.2.2 Melilla. Enclave extensivo.

3.2.3. La inoperancia de la arquitectura de la norma. Mecanismos arquitectónicos efímeros en el paso fronterizo del Benzú.

3.3. Fronteras elásticas, arquitecturas operativas y sistemas de impermeabilización de masas.

3.3.1. Introducción.

3.3.2. Fronteras elásticas. 3.3.2.1 Relevancia de cuerpos

3.3.3. Despliegues operativos y sistemas de impermeabilización de masas.

3.4. Subversión de funciones arquitectónicas a través de la operatividad. El papel de la puerta. 
En el tiempo de Kafka, la solidez arquitectónica del muro estaba evaporándose bajo la presión de la burocracia moderna, que requería de múltiples muros, cuya inconsistencia y complejidad era igual de dudosa que los sólidos muros del anticuado despotismo.

Rem Koolhaas.

Las vallas de Ceuta y Melilla no son simplemente la frontera terrestre entre dos países vecinos, están construidas sobre "una compleja amalgama de luchas y alianzas" representando una "línea multi-facetada” entre España y Marruecos. Los dos países representan a un excolonizador y un excolonizado, respectivamente, dos pueblos (español y marroquí), dos naciones (occidental y árabe), dos religiones (cristiana e islámica), dos continentes (Europa y África), y dos regiones (Europa occidental y el Magreb árabe). De hecho, las vallas alrededor de los dos enclaves, como los primeros muros europeos construidos después de la destrucción del muro de Berlín, son "un recordatorio intenso y literal de las barreras culturales, políticas y económicas que permanecen sin ser superadas entre Europa y sus vecinos mediterráneos”.

Said Saddiki.

No entremos en explicaciones esotéricas sobre los límites de España, que parecen elásticos en este momento.

Olabarría Muñoz.

Despliegue policial ante migrantes encaramados a la valla del paso fronterizo del Benzú, entre ellos Star. (Efe; Benzú, 2016).

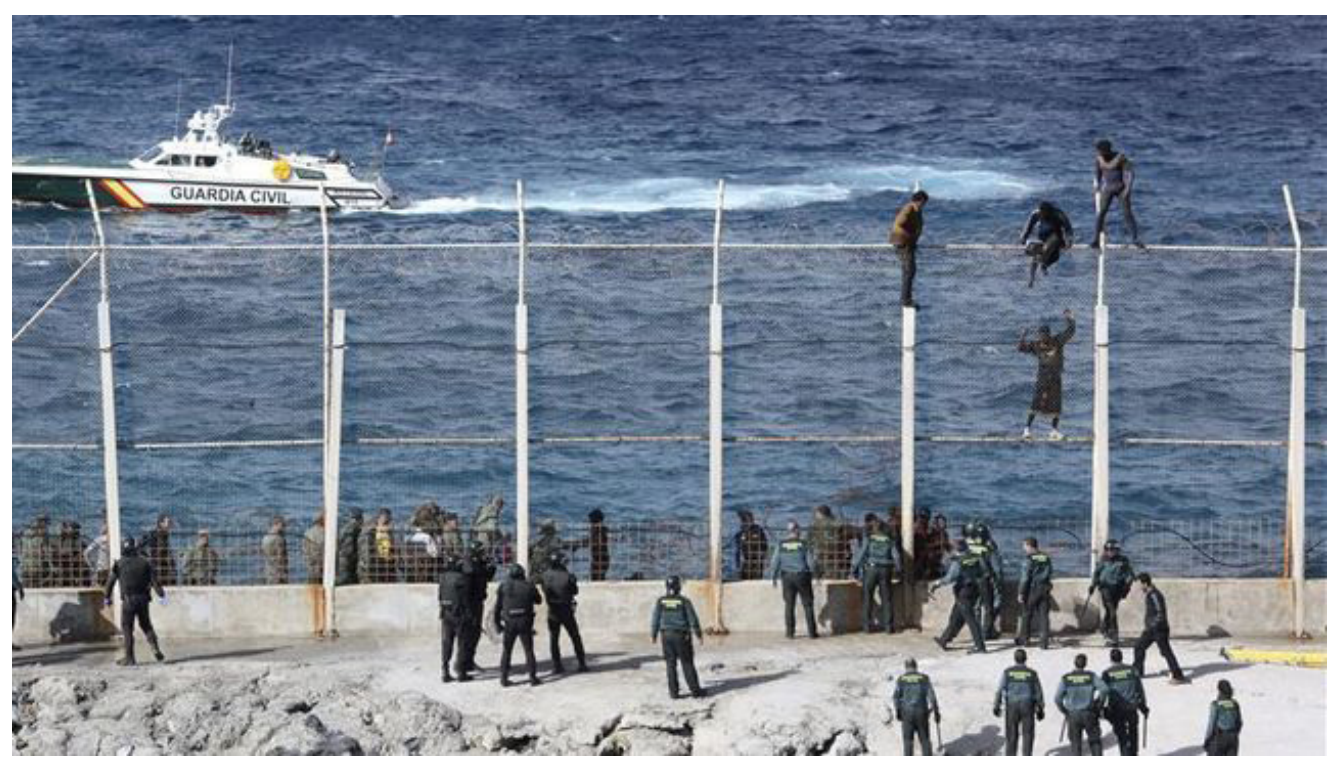




\subsection{UN CUERPO SOBRE LA LÍNEA.}

3.I.I Arquitecturas punitivas.

Carne, cuerpos y arquitectura.

El 23 de junio de 2016, durante treinta horas, un cuerpo situado en el espesor ínfimo de una valla de acero galvanizado de seis metros de alto, con subestructura de malla de acero y remate de alambrada de espino evidenció una paradoja inherente a toda construcción arquitectónica ${ }^{1}$. Evidenció además, de manera explícita, la violencia espacial que toda arquitectura ejerce sobre un cuerpo en la medida que éste se aleje de la norma que la rige; su cuerpo, sus músculos y su carne así lo atestiguaron. Junto a otras cuatro personas, Star permaneció inmóvil sobre el escaso espacio disponible en la estructura metálica de la valla desde las nueve de la mañana del 23 de junio hasta las tres de la tarde del día siguiente. Mientras tanto, cerca de treinta efectivos policiales dotados con material antidisturbios, fuerzas policiales marroquíes y españolas, así como sanitarios de la Cruz Roja esperaban atentamente en las inmediaciones de la línea fronteriza ${ }^{2}$. El paso fronterizo del Benzú (Ceuta), escenario de este acontecimiento constituye, junto al Tarajal, los únicos puntos de comunicación entre Ceuta y Marruecos. Mientras que el Tarajal concentra todo el tráfico entre ambas soberanías, el paso diario en Benzú está sumamente restringido y, por tanto, la formalización arquitectónica del paso fronterizo está mucho menos militarizada: sobre un espigón que penetra veinte metros en el mar se levanta una única valla de acero y una torre de control próxima. Aparentemente, una construcción fácilmente franqueable en comparación con otras materializaciones de la valla ${ }^{3}$. Sin embargo, todos los agentes que también forman parte de este ensamblaje -los medios policiales, técnicos, materiales-...- junto con su propia disposición arquitectónica hacen que un cruce de apenas unas horas se dilate hasta que, el cuerpo extenuado del migrante, decide bajar a territorio español. Una vez allí, es atendido por los servicios médicos e inmediatamente devuelto a Marruecos. La valla no materializaba la línea soberana que separaba un territorio de otro, ni tampoco todas las leyes que rigen el procedimiento de devolución de extranjeros. La línea soberana y la extensión de estas normativas había desaparecido o, por lo menos, se había diluido mientras que la arquitectura permanecía como un elemento falto de función. $\mathrm{O}$, al menos, no con

1 Helena Maleno, "Star, tras 30 horas sobre la valla de Ceuta: "Me devolvieron mientras me arrastraba”, Eldiario.es, 27 de junio de 2016.

2 Una escena prácticamente igual a la que dos años antes había protagonizado otro migrante al permanecer en lo alto de una farola en la frontera de Melilla. Periodistadigital, "El inmigrante que permaneció encaramado a una farola cuatro horas tras saltar la valla de Melillamaerializaza. osee ninguna de estas cargas que sd arquitectd lingra asegurar la eficacia del despliegue. Un elemenro plementario", Periodistadigital, 29 de marzo de 2014.

3 Por economía de lenguaje se utilizará de manera recurrente el término "valla” para referirnos a la compleja construcción arquitectónica que define esta construcción fronteriza. Se es consciente de que, tras esta simplicidad lingüística empleada se oculta una gran violencia simbólica y conceptual que reduce tanto su complejidad arquitectónica, su carácter ofensivo-defensivo así como la crueldad de su diseño presentándola con un término que no posee ninguna de estas cargas, pero que sí materializa. 


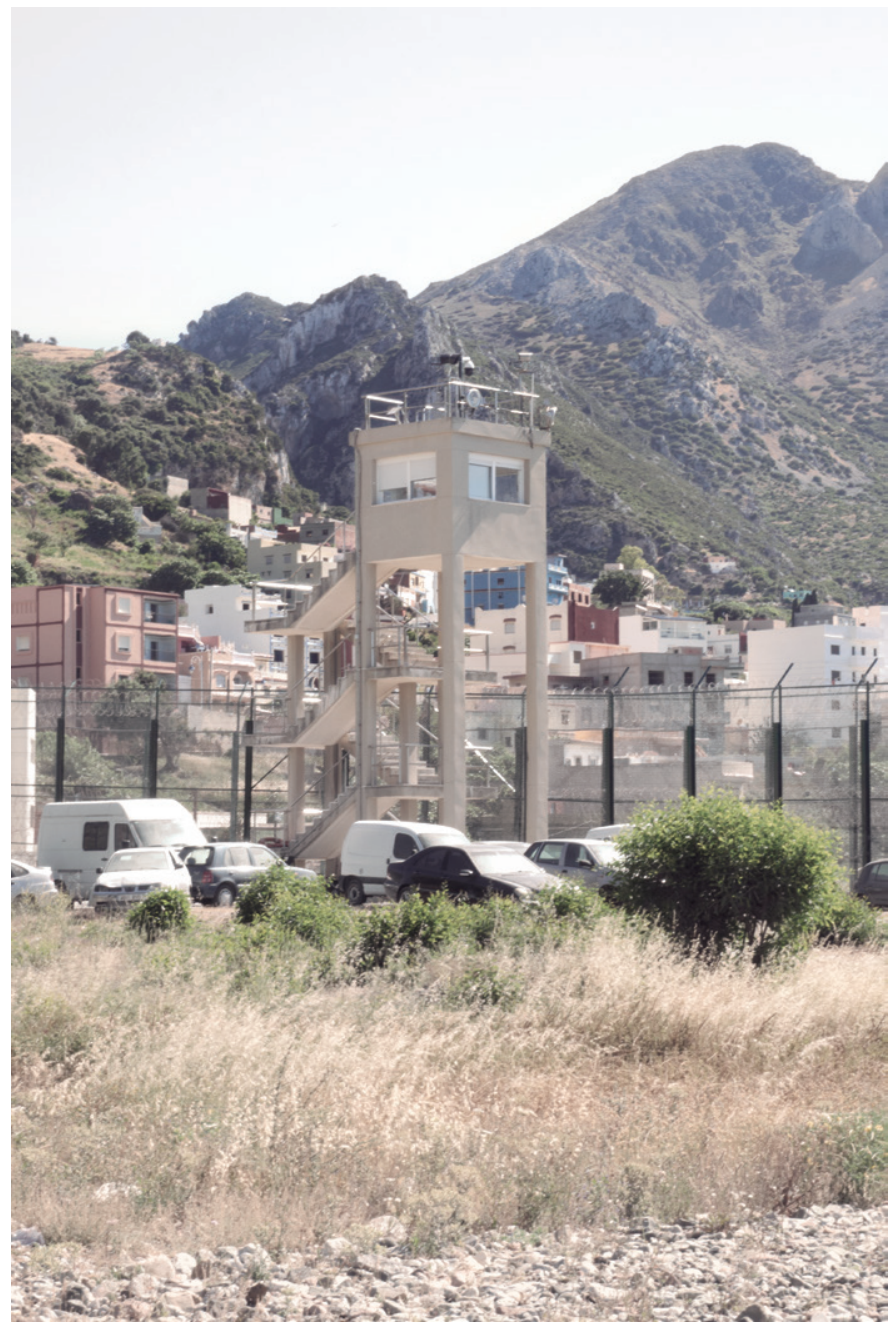

Paso fronterizo del Benzú

(Elaboración propia; Ceuta, 2019).

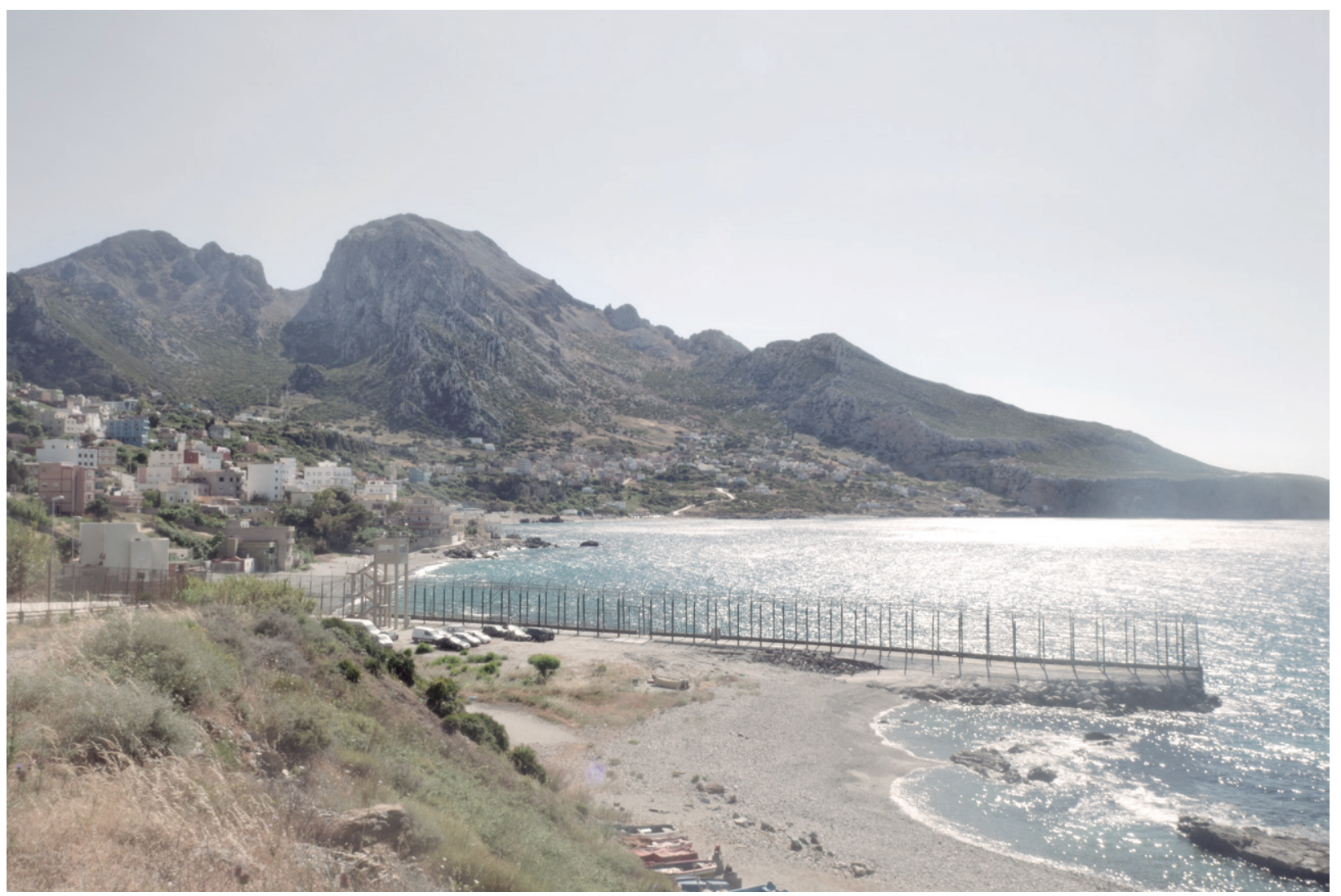


la función que históricamente se le había dado: la construcción de la línea. Simplemente hizo falta una acción, la de un cuerpo no autorizado situándose sobre una figura geométrica sin espesor, la línea, que adquiere el mínimo indispensable para materializarse arquitectónicamente, para que se detonasen las diferentes lógicas de la frontera.Y, así, visibilizar un espacio difuso y dinámico, donde las leyes y normativas adquieren un carácter elástico que se adapta y malea en función de los cuerpos y sus acciones. La línea hecha arquitectura, junto con agentes extraarquitectónicos encarna y defiende la ley, pero desde una nueva posición: la excepción. Esto convierte el territorio en un espacio operativo, retráctil, elástico, con implicaciones arquitectónicas evidentes pese a la aparente simplicidad de una de las figuras arquitectónicas más elementales: una línea construida.

Frente a otros pasos fronterizos entre España y Marruecos, el del Benzú es especialmente significativo por aspectos ya señalados: su relegación a punto auxiliar, únicamente habilitado para habitantes del núcleo transfronterizo, lo convierte en un punto sin apenas tránsito autorizado, pero no por ello exento de vigilancia. Su arquitectura se aleja claramente de los estándares militarizados del resto de localizaciones. Aparentemente podría definirse como un scanscape, un espacio o recinto con un control espacial absoluto tal y como lo definió Mike Davis ${ }^{4}$, donde sólo los cuerpos autorizados tienen la capacidad de acceder e interactuar con él ${ }^{5}$. Un enclave arquitectónico ${ }^{6}$ donde lo específico de su función -regular el movimiento y acciones a través de él o sus inmediaciones-requiere un alto grado de ritualización ; es decir, reducir al mínimo la imprevisibilidad a través de la previsión de todas las posibilidades espaciales posibles. El funcionamiento de cualquier arquitectura, y más las vinculadas de manera explícita a la norma, actúa a través de este esquema independientemente de lo explícito que muestre esta relación. Pero, la frontera es, por encima de otras construcciones, un ejemplo claro de una arquitectura que claramente se muestra como "un espacio ritualizado que demanda un cuerpo disciplinado"8 sea cual sea su formalización arquitectónica. Y el espacio inmediato a la valla es la muestra más elemental de ello. Pero además, su funcionamiento contemporáneo introduce una variable también enunciada por Davis, la free-fire-zone, que se superpone en el mismo espacio físico alterando profundamente las condiciones del mismo: del control regulado absoluto a la excepción absoluta.

Rem Koolhaas ya atestiguó en 1971 la función espacial de una construcción arquitectónica, el muro cuya simplicidad formal contrasta con las consecuencias espaciales que genera. En un curso de verano durante su etapa de estudiante en la Architectural Association centró su trabajo en el minucioso análisis de la realidad del muro de Berlín: una construcción que tomaba diferentes formas a lo largo de la ciudad y que poseía el carácter de "un objeto sin programa", lo que para él representaba la "verdadera naturaleza de la arquitectura"ıo. Al enfrentarse a él descubrió tanto su poder como herramienta de control espacial como su insigni-

4 Mike Davis, Más allá de Blade Runner. Control urbano: la ecología del miedo (Barcelona: Virus Editorial, 200I), 7 .

5 Durante la propia investigación pudimos comprobar esta realidad de primera mano. Pudimos acceder sin problemas a la playa que linda con la arquitectura, situarnos en ella y recorrerla. Tan sólo en el momento de tocar con nuestras manos el acero de la valla, una pareja de efectivos policiales se acercó hasta nuestra posición para desplazarnos hasta otro punto de la playa.

6 Stavros Stavrides, Hacia la ciudad de los umbrales (Madrid: Akal, 2016), 31:81.

7 Tschumi, «Violence on Architecture», en Architecture and Disjunction (1994), 126.

8 Ignacio Mendiola, «La frontera incorporada: espacio, cuerpo y seguridad, Revista mexicana de análisis político y administración pública, Volumen 7, nํㅡ 2 (2018), 26.

9 Lara Schrijver, "OMA as tribute to OMU: exploring the resonances in the work of Koolhaas and Ungers", The Fournal of Architecture 13,3 (2008), 238.

10 Franziska Bollerey, "Rem Koolhaas in conversation with Franziska Bollerey”. 

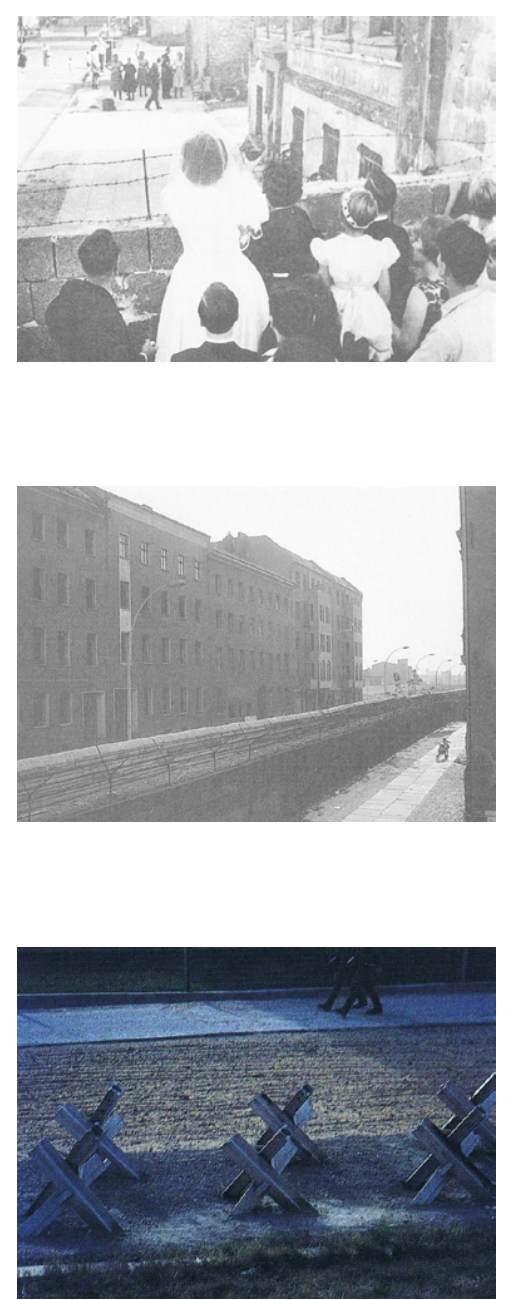

Berlin Wall as Architecture (Rem Koolhaas; Berlín, 1971). ficancia cuando era desafiado por tácticas cotidianas de subversión. En él reconocía el poder de la arquitectura en la configuración del espacio, pero frente a la emancipación promovida por Le Corbusier, Koolhaas atestiguaba su poder como herramienta de separación y exclusión ${ }^{\mathrm{II}}$. Las fotografías y reflexiones mostraban además como la arquitectónica del muro no residía exclusivamente en las piezas de hormigón prefabricado o alambradas de acero, sino que mostraban un ensamblaje que se adecuaba a las necesidades de cada punto, complementándose con instalaciones eléctricas, elementos auxiliares y móviles como las cruces de acero antitanques, o agentes humanos como los dos patrulleros que recoge fugazmente una de las instantáneas. A través de la serie de fotografías que toma muestra materialidad del muro, sus poros y fisuras dejan espacio a usos imprevistos que son aprovechados de forma táctica por los ciudadanos de uno y otro lado para comunicarse o domesticar el espacio. La situación desencadenada por la acción de encaramarse en lo alto de la valla pone de manifiesto estas dos cuestiones: el sistema de control espacial que configura la propia arquitectura junto a todos los agentes así como los usos no previstos que la propia materialidad de la valla permita que ocurran.

Cuestión también planteada por Tschumi en Violence on Architecture $e^{T 2}$ y actualizada por Lámbert ${ }^{13}$ donde en la medida que éste se aleja de los estándares regidos por la norma se acentúa la violencia ejercida por la arquitectura contra él a la vez que se abre un nuevo campo de posibilidades espaciales externas. En el caso de la valla, la malla para impedir el cruce se convierte en un punto de ascenso y el espesor de la perfilería un espacio sobre el que situarse. Star, al encaramarse y permanecer durante más de treinta horas efectúa una transgresión consciente de las normas que encarna la valla, se produce una ruptura del ensamblaje cuidadosamente diseñado que detona un episodio de violencia sobre él al escalar un paramento vertical y herir su cuerpo con el remate de concertinas de acero galvanizado. Y, del mismo modo dota de nuevas posibilidades de uso a la construcción -trepar, ocupar...- que emanan de la materialidad de la misma, y no de su diseño. El paso necesario del proyecto al hecho construido constituye un paralaje ineludible de toda producción arquitectónica: los espesores, dimensiones materiales, simples errores de puesta en obra constituyen un repertorio informal de posibilidades que son leídas por los cuerpos para producir situaciones espaciales a su favor. Así Star se sirve del hueco de la malla de acero convencional ${ }^{14}$ y del dimensionado de los pies derechos para generar un recorrido alternativo que le permita cruzar la línea que separa España de Marruecos. Su carne, como la de tantos otros antes que él sufre la violencia espacial de una ley encarnada en concertina y mallas de acero, del mismo modo que su cuerpo ejerce una violencia contra los materiales que emplea para ascender a lo alto de la valla.

Sin embargo, aunque esta violencia esté presente en toda construcción arquitectónica existen diseños explícitamente orientados a castigar y herir a aquellos que transgreden las normas que su materia encarna. Bajo el término diseños crueles, Lambert introduce una diferenciación entre la violencia inherente a cualquier construcción frente a la violencia explícitamente incluida como premisa de diseño:

11 Schrijver, "OMA as tribute to OMU: exploring the resonances in the work of Koolhaas and Ungers”, 238.

12 Bernard Tschumi, «Violence on Architecture», en Architecture and Disjunction (Londres: The MIT Press, 1994), 121-137.

13 Léopold Lambert y Colon, «Who welcomes this violence?», Colon, volumen 3, no 5 (2015). $14 \mathrm{El}$ paso del Benzú es de los pocos puntos que no posee malla antitrepado. 
La violencia que la arquitectura encarna hacia los cuerpos es la misma sin importar la intención, así el modo en el que es empleada no es exactamente el mismo cuando se manifiesta consecuentemente en vez de deliberadamente. Los diseños crueles son concebidos a propósito para usar esta violencia para ejercer un poder absoluto en uno o múltiples cuerpos. ${ }^{15}$

La valla representa un caso paradigmático de diseño cruel. Y, más aún, si uno atiende a la evolución reciente de esta arquitectura. La simplicidad de la valla esconde una manifestación clara de un poder absoluto que, considera a cualquier cuerpo que la atraviese una nuda vida que puede ser castigada, marcada y herida. Su diseño no responde exclusivamente a un carácter disuasorio ni simbólico, sino que entraña una serie de mecanismos espaciales destinados exclusivamente a lastimar y ejercer una violencia física directa sobre los cuerpos que la transgredan. Va mucho más allá de la persuasión y representa una característica clave de la frontera, como indica Ignacio Mendiola:

la frontera no sólo lee el cuerpo sino que también, en ciertas circunstancias, deja una marca sobre los sujetos. La prohibición de cruzar la frontera que se deriva de la regulación diferenciada de la movilidad comporta situaciones en las que el cuerpo ya no se exhibe para su escrutinio sino que se expone en su propia corporalidad para traspasar de un modo no reglado la línea divisoria alzada. El cuerpo aquí se arriesga, se confronta con la negación, con ese régimen de poder que le excluye, que le expulsa, que no le da paso ni lugar. Aquí la frontera ya no es algo que haya simplemente que atravesar, la frontera, en un sentido mucho más profundo, atraviesa la corporalidad y la rehace: el cuerpo se ve abocado a sentir (la violencia de) lo fronterizo. ${ }^{16}$.

Sin embargo, analizar el papel de las vallas y muros contemporáneos desde la violencia que físicamente son capaces de ejercer a los cuerpos no-autorizados, nos obliga de nuevo a concebirlas como ensamblajes donde las construcciones arquitectónicas son sólo una pequeña parte de un dispositivo mayor. Son una constante los medios dinámicos, las construcciones efímeras y agentes que también encarnan la soberanía de la valla y como, todos ellos, ejercen un carácter claramente punitivo orientado no sólo a impedir el cruce, sino a herir y señalar los cuerpos.

La arquitectura de la valla no resulta suficiente por si misma para regular y neutralizar la situación. Esta singularidad obliga a desplegar una serie de medidas excepcionales que permitan responder con inmediatez a una función - regular el paso y discernir entre cuerpos autorizados y no autorizados-. Y es, precisamente, la importancia que toman estas medidas excepcionales en las prácticas espaciales contemporáneas vinculadas a la frontera las que separan la valla de Ceuta y Melilla del muro analizado por Koolhaas en 1971. Lo más interesante del desarrollo de este acontecimiento es el carácter elástico que adquiere su materialización contemporánea. La función de la valla queda diluida con lo que ocurre inmediatamente después de su cruce: tras cruzar al lado español de la valla fue inmediatamente devuelto a territorio marroquí sin pisar políticamente un territorio que sí había pisado físicamente. La geografía y las soberanías de cada Estado ya no responden a criterios históricos sino que se formulan elásticamente:

La frontera lineal, el imaginario cartográfico heredado de la espacialidad política y militar del Estado Nación ha estallado en multitud de fronteras temporales, transportables, desplegables sinónimos-frontera -'muros de separación', 'barreras', 'bloqueos', 'cierres', 'bloques de carretera', 'puntos

15 Léopold Lambert, Cruel designs, (Nueva York: Punctum Books, 2013), 7.

16 Mendiola, , «La frontera incorporada: espacio, cuerpo y seguridad», Revista mexicana de análisis político y administración pública, (2018), 24-25. 
de control', 'áreas estériles', 'zonas de seguridas especial', 'áreas militares cerradas' y 'zonas de muerte'- que encogen y expanden el territorio a voluntad. Estas fronteras son dinámicas, constantemente evolucionando, menguando y fluyendo. [...] Los diferentes habitantes de esta frontera no operan en las envolventes fijas del espacio -el espacio no es el trasfondo de sus acciones, una malla abstracta donde los eventos tienen lugar- sino el medio que cada una de sus acciones busca desafiar, transformar o apropiar. Además, en este contexto la relación del espacio a la acción no podría entenderse como la de un rígido contenedor o acción 'suave'. La acción política está totalmente absorbida en la organización, transformación, borrado y subversión del

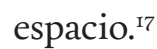

Por tanto, aunque parezca que recae sobre Star únicamente el posicionarse a un lado o a otro - en territorio español o marroquí-; transgredir la línea o no hacerlo, el resultado de los acontecimientos no depende de él. Por más que él catalice el resto de movimientos del ensamblaje y la aparición de nuevos agentes no tiene el control sobre el desarrollo de las acciones. En segundo lugar, no sólo se alteran la relación de fuerzas y cuerpos presentes en el espacio sino también de las normas y leyes que éstos encarnan; durante un tiempo muy limitado se anulan las normas que operan en el paso fronterizo del Benzú, lo que en términos legales se entiende como la declaración (implícita) de un estado de excepción y que, al circunscribirse a un territorio muy definido podríamos expresar como espacio de excepción. A través de protocolos operativos se transforma un territorio estático representado por la rigidez de la línea que materializa la valla en un territorio elástico que se moldea y transforma para impedir que, bajo ninguna condición Star pise suelo español por más que cruce la valla. Bajo el término frontera retráctil o frontera operativa el gobierno español ha desarollado una serie de prácticas cuestionadas legalmente que permiten redibujar de manera instantánea la línea perimetral de la soberanía española. Así pues, a través de la excepción, por más que Star haya cruzado la valla y pisado un suelo, a todas luces, español, no ha cruzado las nuevas líneas y recintos móviles que estos agentes han generado.

\subsubsection{EVOLUCIÓN HISTÓRICA DE LA MATERIALIZACIÓN ARQUITECTÓNICA DE LA FRONTERA.}

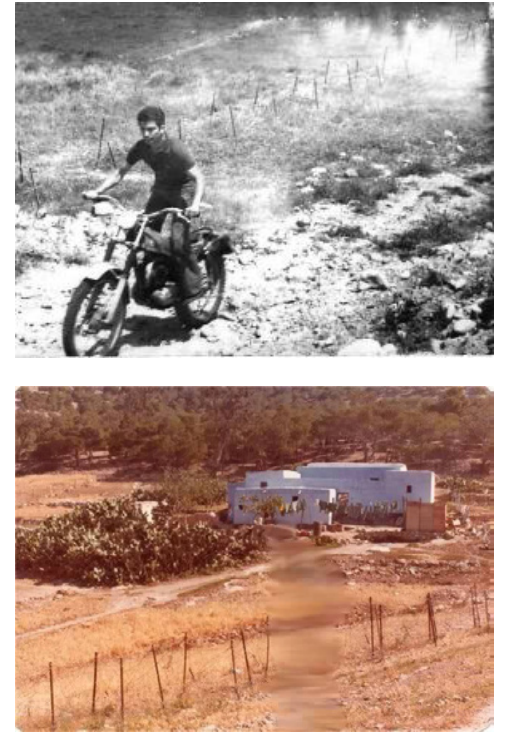

96
Año 1971, la fotografía de un militar de permiso conduciendo una motocicleta y otra instantánea de los montes que rodean la ciudad autónoma dejan ver qué elementos construían la frontera entre Melilla y Marruecos antes de la entrada en vigor del espacio Schengen. Esta únicamente se materializaba exclusivamente a través de un doble línea de varillas de acero corrugado hincadas sobre el terreno con una altura total de sesenta centímetros. Entre ellas, un alambre de espino dando continuidad al sistema de delimitación territorial; una valla que había sido instalada por motivos sanitarios en esa misma fecha a consecuencia de una epidemia de cólera en la provincia de Nador que obligó a la instalación del alambrado siguiendo la delimitación histórica que El Caminante había trazado en 1862. Esta frontera, hasta entonces, había sido totalmente permeable al tránsito de personas tan sólo materializada por una serie de mojones. A través de diecisiete disparos de cañón realizados desde el Fuerte Victoria de la Plaza Mayor española se definió el territorio melillense. El Caminante fue el arma encargada de 
establecer su posición ${ }^{18}$. De nuevo, la arquitectura materializó con construcciones puntuales unos límites que han sido trazados de modo dinámico y violento: a través del impacto de una bola de acero disparada por un cañón militar. Este es el origen de una línea que luego encarnará la arquitectura. Los conflictos con la población afectada por la zona neutral delimitada por esta línea de puntos, las preexistencias territoriales y las disputas de soberanía se tradujeron en modificaciones de su trazado. Pese a estas tensiones, se logró establecer una franja de territorio neutral simétrica para ambas soberanías y no requirió mayor construcción que diecisiete mugas o atalayas en los emplazamientos donde había impactado la bola de acero ${ }^{19}$. Hasta 1970, ningún elemento lineal había definido la frontera en el plano material, aunque sí en el plano soberano. En Ceuta, una fotografía de la localidad del Benzú permite observar el espigón natural que divide en dos pequeñas playas el punto exacto donde en la actualidad se levanta el puesto fronteriza. Ambas imágenes distan bastante de su estado actual.

Cómo se ha producido esta militarización del espacio en los últimos cuarenta años nos permite entender la relevancia que ha cobrado la frontera, pero también diferenciar las diferentes estrategias en la evolución de la materialización de la línea encargada de dividir el territorio, así como impermeabilizarlo frente a entradas no reguladas.

Podemos establecer tres fases claras donde cada una se corresponde además con una estrategia arquitectónica diferenciada. La primera, la emergencia del dispositivo fronterizo ante la demanda de fortificación coincidente con la entrada en la Unión Europea y el espacio Schengen, donde se realiza la primera construcción de la valla en el año 1995. Durante esta etapa de más de diez años, la estrategia es la garantización de la eficacia a través de la dimensión vertical como medida de impenetrabilidad, que se extiende hasta la constitución del ensamblaje actual en el año 2005. Es en este año donde se producen una serie de entradas irregulares que visibilizan por primera vez de manera clara la violencia explícita de una arquitectura militarizada, un diseño cruel complementado con agentes y medios no arquitectónicos. A partir de este momento, con una línea fortificada en su dimensión vertical, la estrategia a seguir es contraria: el aumento en horizontal del grosor de la línea, generando un espesor intermedio cada vez mayor, transformando la línea en una tierra entre soberanías. Esta estrategia se orienta a retardar lo máximo posible el tiempo de cruce por encima de impedir el paso. Así, desde el año 2005 hasta la actualidad la línea será reforzada por su cara marroquí, adquiriendo un espesor mayor de treinta metros en su materialización actual, frente a los cuatro metros escasos, que presentaba en la década de los noventa. Aunque toda esta militarización de la arquitectura de la valla tendrá cada vez un mayor peso simbólico por encima de funcional contrasta con la implementación dinámica de sistemas de control e impermeabilización de masas; ensamblajes operativos destinados a la aseguración efectiva del funcionamiento arquitectónica de la valla. Su arquitectura adquiere en tiempos recientes un carácter cada vez más teatral ${ }^{20}$, mientras que su funcionamiento operativo recae en disposiciones móviles y soluciones efímeras.

18 Miguel Ángel Acosta Sánchez, "Las fronteras terrestres de España en Melilla: delimitación, vallas fronterizas y tierra de nadie”, Revista Electrónica de Estudios Internacionales 28, (2014): 9-14.

19 Señala también Acosta Sánchez como el paso de la línea geométrica precisa establecida entre cada uno de los puntos de impacto a la línea construida por las mugas es el primer punto de conflicto a la hora de establecer la delimitación territorial exacta de Melilla. El paso indispensable de una figura geométrica abstracta, a una soberanía encarnada en una arquitectura provoca esta situación.

Acosta Sánchez, "Las fronteras terrestres de España en Melilla: delimitación, vallas fronterizas y tierra de nadie”, I4.

20 Wendy Brown, Estados amurallados, soberanía en declive (Madrid: Herder Editorial, 2015),
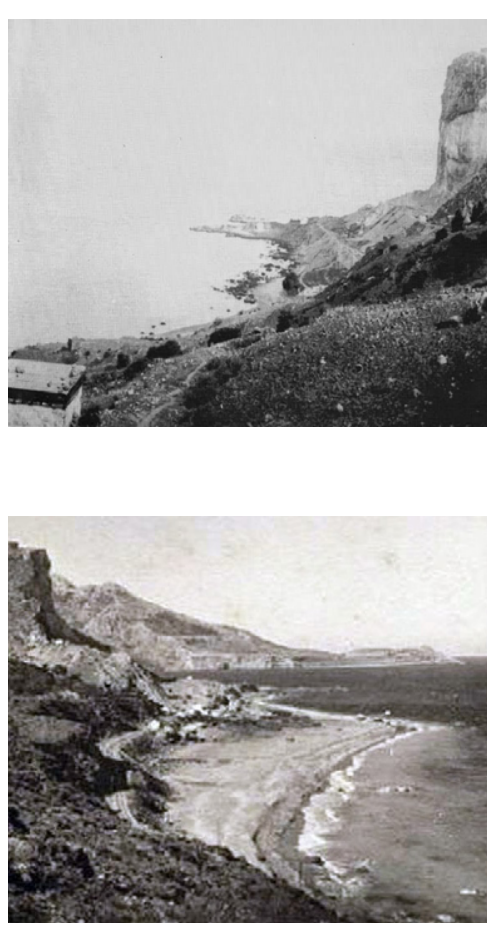

Frontera del Benzú (Ceuta, 1970). 
La entrada en vigor del espacio Schengen en el año 1990 hizo que se comenzase a transformar el carácter fronterizo de Ceuta y Melilla como único territorio español situado en África. Precisamente, la desconexión territorial con el resto del Estado -y por extensión con la Unión Europea- ha hecho que ambos enclaves se hayan convertido en válvulas eficaces de contención y regulación del flujo. Sin embargo, pese a que las obras de sustitución de la valla fronteriza comenzaron en ese mismo año no fue hasta el año 1995 cuando cambió la situación y se acometieron con urgencia las medidas de impermeabilización. En este año suceden una serie de acontecimientos de diferente naturaleza que hacen cristalizar la materialización de la valla. Tanto Ceuta como Melilla adquieren la condición de ciudades autónomas, una formulación jurídica que las independiza de las provincias de Cádiz y Málaga respectivamente, pero que además tiene una implicación fundamental como enclaves fronterizos: esta independencia las excluye del Espacio Schengen y, por tanto, de la libertad de movimiento y tránsito de las personas allí presentes. Decisión política que las convierte, de facto, en territorios excepcionales y transforma por completo la situación respecto a los migrantes que ya no pueden acceder con tanta facilidad a la Península. Hasta el momento, la dificultad de acceso residía más en la falta de infraestructuras y conexión entre Península, Ceuta y Melilla; hecho por el cual se detonaron a lo largo del año 1995 numerosos enfrentamientos entre los migrantes que vivían acampados en las inmediaciones de Ceuta y Melilla. El más numeroso se produjo en Ceuta el once de octubre, hecho que congregó a más de doscientas personas y detonándose una intervención policial saldada con tres heridos de gravedad por disparo de arma, ochenta heridos y más de cientocincuenta detenciones ${ }^{21}$. Tan sólo seis días después, los ecos de este conflicto en el Parlamento Español tuvieron consecuencias arquitectónicas inmediatas en la materialización de la valla; el entonces ministro del Interior Belloch ordenó la "impermeabilización de la frontera" a través de la instalación de alambradas en el perímetro de ambas ciudades así como sistemas de alumbrado y el destacamento de unidades de la Guardia Civil22.

Aparte de los radicales cambios territoriales que supusieron estas decisiones políticas tomadas entre 1990 y 1995, también hubo consecuencias arquitectónicas claras: la materialización de la segunda valla fronteriza que sustituía la doble alambrada de espino construida en el año 1971. Soldados del Regimiento Mixto levantaron una construcción consistente en un doble vallado de estructura de acero de tres metros y medio de alto coronado con un remate superior de alambre de espino que dificultaba el trepado por su disposición oblicua respecto al plano vertical. Junto a ella, un sistema de alumbrado en el lado español y una alambrada superficial en el lado marroquín ${ }^{23}$. Este elemento, que podríamos considerar una primera versión de la sirga tridimensional, consiste en una construcción tejida con alambre de espino con un ancho total de tres metros y altura variable, lo que dificulta considerablemente la capacidad de movimiento a través de ella. Esta constituye la primera formalización de la valla militarizada que, junto con una presencia militar y policial continua en su perímetro, se mantiene hasta el año 2005 con sólo un cambio menor en cuanto a su

36.

21 Chema Lizarralde, "Un policía herido de bala y 150 inmigrantes ilegales detenidos en una batalla campal en Ceuta”, El País, 12 de octubre de 1995.

22 El País, "Belloch anuncia la “impermeabilización” la frontera con Marruecos por Ceuta”, El Pais, 19 de octubre de 1995 .

23 Es importante señalar que toda referencia en estas descripciones respecto a los lados español y marroquí de la valla son exclusivamente a efectos de orientación de la descripción, sin entrar a valorar la posición que ocupa cada elemento de las construcciones dentro de la soberanía de cada uno de los dos países. 

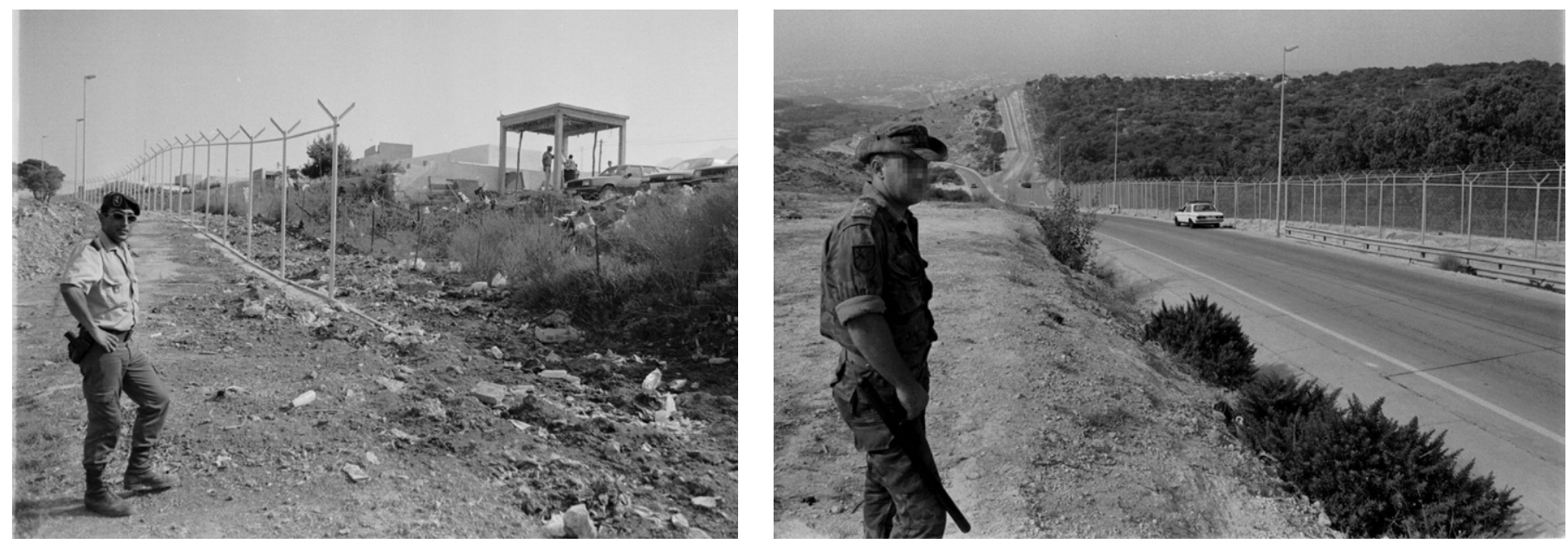

configuración. A finales de la década de los noventa se sustituye el remate de la valla, al menos en ciertos puntos, para reforzar el tendido lineal de alambrada de espino con una bobina superficial que dificulta aún más el cruce de la misma.

A pesar de la situación de la sirga tridimensional como del alumbrado, podemos apreciar una gran simetría en la disposición de elementos arquitectónicos que configuran esta sección constructiva. Algo que cambia radicalmente con la segunda iteración arquitectónica del dispositivo. Es importante señalar las implicaciones soberanas derivadas de esta disposición. Si la frontera es la línea soberana que divide el territorio entre dos Estados de acuerdo a la legislación y convenios internacionales, la materialización arquitectónica así debería materializarlo. Es decir, a efectos prácticos, el funcionamiento de la valla debería ser lo más similar posible en el sentido España-Marruecos que MarruecosEspaña. En esta primera fase nos encontramos con una disposición que responde a estos parámetros de igualdad entre la soberanía marroquí y española. Sin embargo, la actualización de la sección constructiva en 2005 -y sus consecuentes modificaciones hasta la actualidad- anulan esta simetría. La valla funciona con una direccionalidad clara para impedir el paso del lado marroquí al español, no al revés -que de hecho lo mejora-.

El año 2005 supuso un punto de inflexión para la transformación arquitectónica de la valla hasta su estado actual. Durante el verano e inicio del otoño se produjeron una serie de cruces masivos a través de Finca Berrocal - zona limítrofe con el vallado fronterizo - donde se demostró la ineficacia de la valla fácilmente franqueable con escaleras de madera y otra serie de arquitectónicas de la transgresión ${ }^{24}$ construidas por los migrantes en las inmediaciones del perímetro fronterizo. Así narraba El País como, la redisposición de elementos ensamblados dotándolos de nuevas funciones servía para minimizar las restricciones espaciales de la valla:

Con los cuerpos envueltos en cartones, embutidos en gruesos jerseis y con las manos calzadas en guantes de bricolaje para protegerse de las alambradas erizadas de cuchillas que coronan el vallado, los inmigrantes se acercan hasta el perímetro de tres metros de altura al amparo de la oscuridad, apoyan sus escalas artesanales sobre la primera valla y la salvan en sólo 15 segundos.

Una vez en la carretera o camino de ronda que discurre entre ambas vallas, esperan a que sus compañeros les lancen otras escalas, con las que acometen la segunda valla en otros 15 segundos. A pesar de sus precauciones, cuando llegan al lado español están llenos de cortes y cubiertos de sangre.

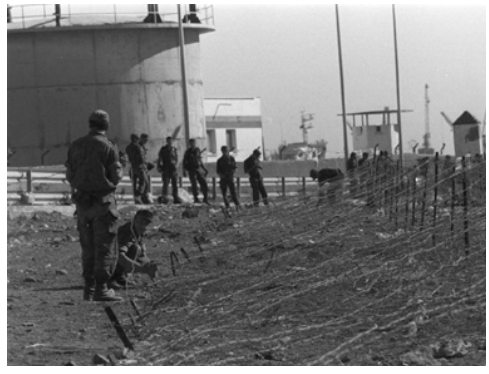

Construcción de la valla de Ceuta y Melilla (Archivo fotográfico de El País; Ceuta y Melilla, 1995-1998) 


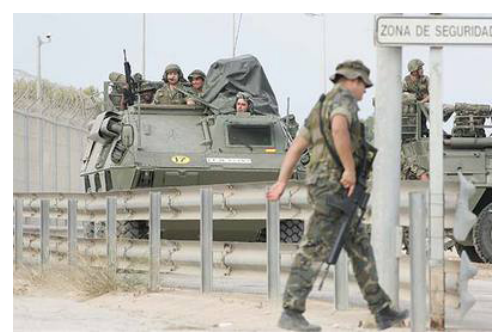

Despliegue militar en la frontera (Melilla, 2005).
En el año 2004, un cuarenta por ciento de los 10,2 $\mathrm{km}$ de vallado ya había sido reforzado duplicando su altura hasta alcanzar los seis metros. Sin embargo, era necesario extenderlo a todo el perímetro fronterizo por lo que se adelantaron los fondos presupuestados para acometer las obras de mejora en el año $2006^{25}$. Esto se debió a la situación de conflicto generada por los cruces y magnificada a través de los medios de comunicación, así como por la violenta respuesta por parte de fuerzas policiales que se saldaron con casi una decena de muertos por hemorragias causadas por los cortes de las concertinas, disparos de pelotas de goma a bocajarro y varios disparos de bala. Las consecuencias del cruce de cuatrocientas personas el 29 de septiembre de 2005 , que se saldó con cinco migrantes asesinados terminó de decantar la necesidad de militarizar aún más el perímetro fronterizo. Sin embargo, las medidas inmediatas tomadas "con carácter disuasorio" por el gobierno español y marroquí visibilizan claramente el giro dinámico que se comienza a producir en la frontera. Se destinan "tres compañías del Ejército a cada ciudad para patrullar por el perímetro fronterizo. Rabat, por su lado, ha reforzado desde ayer el borde de Ceuta con r.ooo soldados y el de Melilla, con 600”. El gobierno socialista de Rodriguez Zapatero replica una lógica ya empleada por el gobierno de Aznar en 1996 - que usó legionarios desarmados para defender la línea fronteriza - sólo que dotándolo de un carácter mucho más militar y teatral al estar equipados con "sus fusiles de reglamento ( $\mathrm{H} \& \mathrm{~K})$ y apoyados por vehículos blindados BMR” que no podrán emplear, pero sí el material antidisturbios de origen militar con los que también se dotó a las diferentes unidades del ejército. El alto grado de violencia explícito de los días anteriores efectuado por agentes dinámicos contrasta con la performance teatral de un ensamblaje arquitectónico -el de una valla patrullada por fuerzas militares y vehículos blindados- que recorre y materializa la línea fronteriza ${ }^{26}$.

¿Qué consecuencias constructivas tiene esta serie de acontecimientos para la valla? Sobre la valla de tres metros y medio de altura se habían acometido las primeras intervenciones para que alcanzase los seis metros. No es la única operación de militarización que se efectúa. La ronda interior se amplia con una dimensión de más de cinco metros lo que optimiza la circulación interna tanto de efectivos a pie como motorizados. La valla exterior no se refuerza sino que se sustituye por otra de sección y posición distinta. Una estructura de acero con una inclinación de cinco grados hacia el exterior que, junto con un mallado metálico de escasa apertura dificultaban su trepado tanto por el efecto de la gravedad -que expulsa al cuerpo del plano de escalada- como por la imposibilidad de agarre. El tramo superior se divide en dos con un remate bífido que acrecenta aún más la inclinación de la estructura y, por tanto, su dificultad para treparla. Toda esta valla, además, está reforzada con el despliegue de concertinas en tres puntos a diferentes alturas para dificultar, disuadir y herir a aquellos cuerpos que la trepen. Aparte de los cambios constructivos, un punto importante de la nueva arquitectura de la valla es la dimensión tecnológica que adquiere, ya que también se incorpora una red de sensores infrarrojos, aerosoloes irritantes autónomos y cámaras de vigilancia situados de manera puntual a lo largo de toda su extensión, lo que desterritorializa la arquitectura de la valla conectándola con las diferentes

25 Las obras de construcción fueron adjudicadas a las empresas Ferrovial y Necso.

26 El patrullado de la frontera no constituye un mecanismo complementario a la construcción física sino que, según Thomas Nail, podemos encontrar en él muestras de las primeras manifestaciones arquitectónicas de la frontera. Se remite en primera instancia a cómo la creación en Sumeria y Akkad de un cuerpo de soldados especializado en defender los límites territoriales fue cuatrocientos años anterior al levantamiento de los primeros muros. Y, recalca, "La primera gran tecnología militar de frontera es la creación de soldados [...] El soldado es el ladrillo humano apilado en el muro militar”. Pero, más adelante señala el limes romano como ejemplo claro de cómo la acción performativa del desplazamiento de soldados marchando a lo largo de los límites territoriales es también parte indisoluble del dispositivo frontera. Ver más en Thomas Nail, Theory of the border, ( Nueva York: Oxford University Press, 2016), 69, 79. 
estancias policiales encargadas de su vigilancia y seguridad ${ }^{27}$. Así, frente a las garitas físicas y puntos de control, una red de agentes no humanos es capaz de detectar con mayor precisión cualquier incursión futura y, así, desplegar los refuerzos operativos necesarios para neutralizarla.

En los años siguientes, esta sección constructiva sufre una serie de transformaciones para mejorar su eficacia; operación que, junto con el aumento de altura de las vallas, asciende a un importe de treinta millones de euros. En primer lugar, la ronda interior que separa las vallas es rápidamente recorrible en decenas de segundos al no haber ningún obstáculo entre ambas. Para ello se instala la ya mencionada sirga tridimensional. Sirga, sinónimo de maroma, y tridimensional por su disposición espacial frente a lineal, es el resumen de un elemento desarrollado específicamente para esta construcción fronteriza. Perfiles IPE de acero levantados a diferentes alturas-de sesenta a ciento ochenta centímetros- entre los que se teje una maraña de cables de acero tensados que impiden el movimiento de los cuerpos. Esta medida, realizada en 2006 se mantiene hasta la actualidad aunque el gobierno socialista ha prometido su retirada dado que ocasionaba daños y lesiones al caer los cuerpos sobre ella desde seis metros de altura. En la actualidad, el remate bífido de la valla exterior también ha sufrido modificaciones debido al mal estado de conservación; en vez de funcionar como un impedimento al trepado, funcionaba justo al revés, como un lugar de estancia más cómodo a la espera de cruzar al otro lado. Las condiciones materiales contradecían a las de diseño y esto era empleado por los migrantes para subvertir a su favor el funcionamiento de todo el conjunto arquitectónico.
Detalle de la disposición actual de la valla fronteriza en Ceuta, apreciándose la sirga tridimensional y los sistemas de videovigilancia (Elaboración propia; Melilla, 2019).

27 "Están equipadas con otro tipo de dispositivos pasivos, como s cámaras de visión nocturna; y activos, como un sistema de aerosol más en Efe Noticias, "El informe de Interior sobre las cuchillas de templa retirarlas", 20 Minutos, 22 de noviembre de 2013.

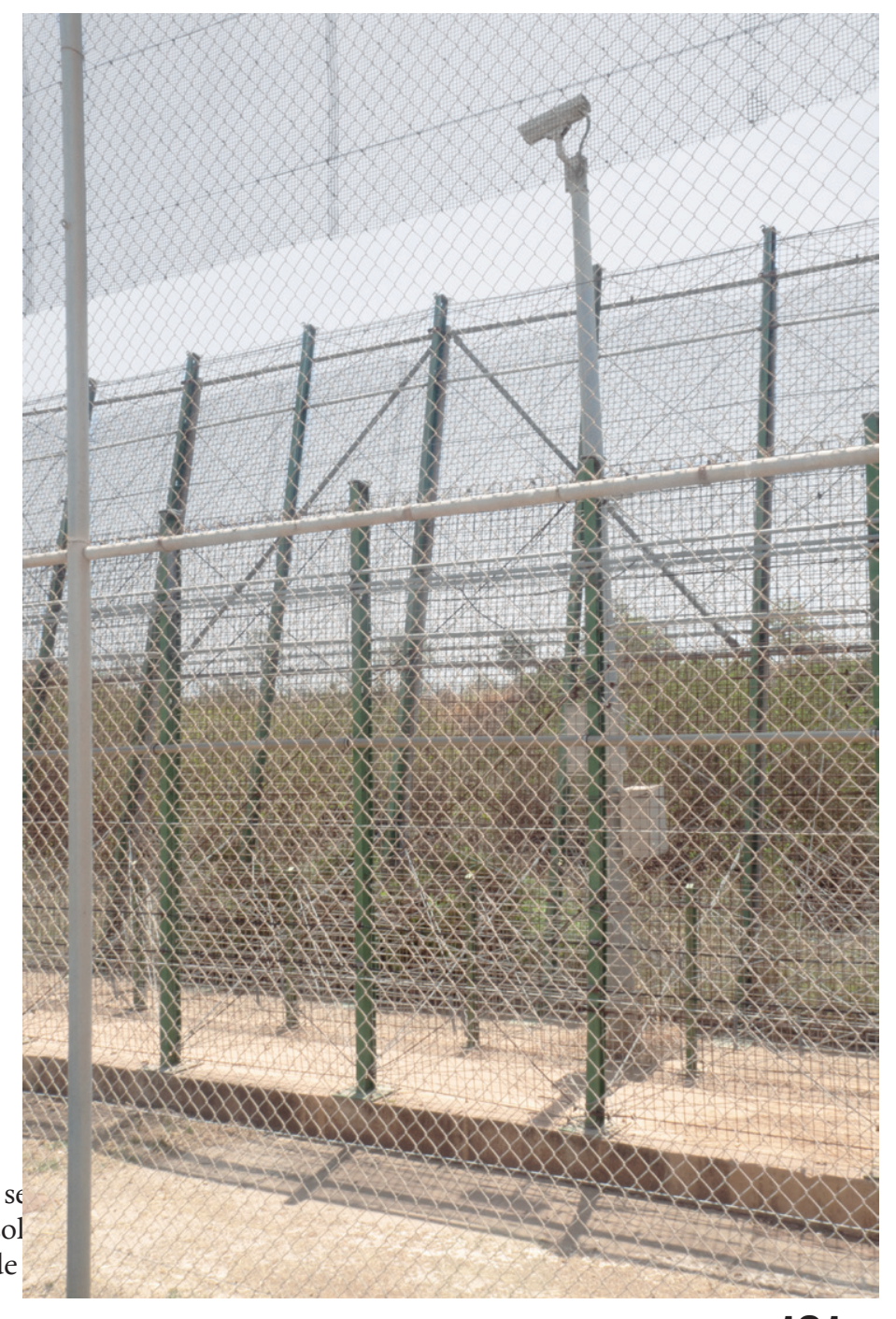




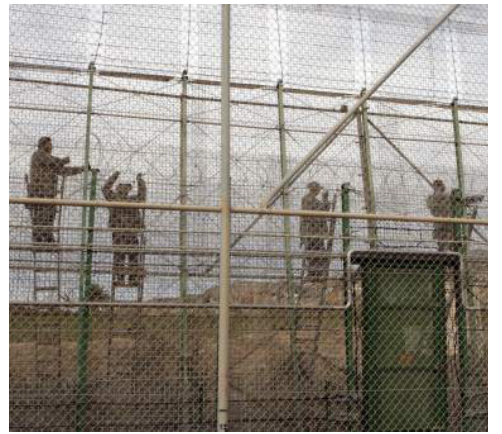

Instalación de concertinas en la valla de Melilla (Melilla, 2006).
Si hay un elemento constructivo del dispositivo fronterizo que ha centrado el foco mediático y la discusión política en la última década han sido las concertinas ${ }^{28}$. Una bobina de acero galvanizado similar al alambre de espino pero que presenta significados avances tecnológicos. En primer lugar, es un elemento mucho más ligero que reduce a un tercio tanto el volumen como el peso del material, haciendo su instalación mucho más económica frente al alambre de espino tradicional. Sin embargo, presenta una aparente desventaja respecto al alambre de espino tradicional: su duración y resistencia a corte o cizallamiento es mucho menor debido a que está formada por un único núcleo de acero frente a los dos núcleos trenzados del alambre de espino. ¿Por qué se escoge un material más fácilmente deteriorable? Por un lado, la facilidad de colocación y economía de medios al tratarse de un elemento más ligero, pero sobre todo porque la forma de los pinchos derivada de su producción industrial resulta mucho más eficaz al agarrar, desgarrar y cortar elementos que la crucen, sean éstos tela o carne. Tal es su eficacia que, pese a que los fabricantes aseguren que este riesgo sólo "depende de la agresividad de la persona. Si te pinchas y te pones agresivo y tiras de la mano, claro, te rajas. En 1999 nos reíamos porque venían las cabras de Marruecos y pasaban la concertina sin rasguño alguno. Y claro, es que muchos animales son mucho más inteligentes y menos agresivos que muchas personas" ${ }^{29}$, causó la muerte en 2009 de un migrante al seccionar una arteria vital durante el trepado de la valla exterior -"El inmigrante falleció en la concertina de la segunda valla, que terminó cortándole una de las arterias, causándole la muerte por pérdida masiva de sangre" ${ }^{30}$-. Pese a ello, declaraciones como la de Fernández Díaz como ministro de Interior minimizan o, mejor dicho, esconden los efectos reales sobre los cuerpos al pronunciar declaraciones hablando de "heridas superficiales" o que son "elementos estandarizados en su uso, son pasivos y no agresivos" ${ }^{\text {I }}$.

Instaladas en el año 2005, las concertinas han supuesto un motivo de crítica constante, así como un elemento simbólico que a lo largo de los años hasta la actualidad ha sido esgrimido como una medida de refuerzo de la valla ${ }^{32}$. De hecho, tan sólo dos años después de su instalación fueron retiradas durante la misma legislatura tan sólo de una parte de la valla. En el año 2013 vuelven a ser reintroducidas en puntos concretos del ensamblaje arquitectónico por parte del gobierno popular amparándose en la necesidad de reforzar el perímetro fronterizo ${ }^{33}$. Junto a esta medida, una nueva malla metálica con huecos de diámetro aún más reducido para dificultar su trepado, un sistema de focos de iluminación orientados hacia el territorio marroquí y cámaras con sensores térmicos a lo largo del perímetro para anticipar el movimiento de los migrantes. En la actualidad, las concertinas siguen instaladas pese al cambio de gobierno, aunque han vuelto a ser empleadas como argumento político por distintas fuerzas

$28 \mathrm{El}$ término concertina nos remite al sistema de repliegue y colocación de este sistema defensivo, que se presenta en bobinas que alcanzan los 400 metros de longitud que son desplegadas. Su capacidad de despliegue y compactación remite al instrumento musical. Aunque este sistema constructivo no diferencia entre el alambre de espino de producción por trenzado del alambre de espino de producción por laminado, se emplea en castellano el término concertina para diferenciarlos.

29 Declaraciones de Clemente Cabero, gerente de una de las empresas comercializadoras de las concertinas. Ángel Cabero, "Así son las heridas que provocan las concertinas en Melilla”. 20 Minutos, 18 de marzo de 2014.

30 Juan Luis Sánchez, "Una persona murió desangrada en 2009 por cortes con el alambre de cuchillas de la valla de Ceuta”, Eldiario.es, 22 de noviembre de 2013.

31 Europapress, "Fernández Díaz: Las cuchillas de la valla causan heridas “superficiales””, Europapress, 25 de noviembre de 2013.

32 Emilio Ordiz, "Las concertinas, recurso extremo en la frontera de Ceuta y Melilla: qué son, dónde se fabrican y quién las instaló”, 20 Minutos, 14 de junio de 2018.

33 Ignacio Cembrero, "El Ministerio del Interior reintroduce las cuchillas en la verja de Melilla". El Pais, 3i de octubre de 2013. 
para su retirada; de hecho el propio gobierno socialista anunció su retirada al entrar en precampaña electoral ${ }^{34}$. La retirada de este elemento, según propuestas hechas por fuerzas policiales, sería reemplazada por dos nuevos mecanismos de carácter menos lesivo: planchas metálicas opacas para impedir el trepado y un remate de cilindros rotatorios que eviten el agarre de cuerpos o ganchos como los que emplean las migrantes como punto de apoyo. Así describe la Guardia Civil su propuesta arquitectónica:

La instalación de unos barrotes elevados, que harían las veces de postes, y entre los cuales se intercalarían planchas metálicas de grandes dimensiones. De este modo, se evitaría que los inmigrantes utilicen ganchos para trepar por la frontera, como lo hacen en la actual malla metálica.

Pero hay más. En lo alto del vallado [...] se instalarían unos cilindros rotatorios. De ese modo, si alguien alcanza el punto más elevado, no podría asirse al extremo, puesto que la rotación del cilindro se lo impediría. ${ }^{35}$

Un simple elemento arquitectónico dentro de un ensamblaje mucho mayor es capaz de focalizar buena parte de la atención mediática, política y simbólica por la violencia que ejerce sobre los cuerpos. Sin embargo, también es importante entender su relevancia en el sentido inverso, la concertina se despliega, ensambla o retira en función de decisiones políticas mediadas durante más de diez años, independientemente de su eficacia. La construcción de la línea fronteriza no se planea dese un proyecto arquitectónico tradicional sino en base a discusiones parlamentarias, programas políticos, así como los esfuerzos de visibilización de las heridas que esta arquitectura causa.

La tercera estrategia de militarización de la valla discurre paralela a estas transformaciones menores del dispositivo fronterizo desde el año 2005. Una estrategia centrada en la componente horizontal como un sistema más eficaz que la fortificación vertical que ralentiza y mejora la eficacia de respuesta del conjunto arquitectónico. Tiene su inicio en el planteamiento original de la sirga como un elemento no destinado a situarse en la ronda interior de las dos vallas sino constituir una tercera valla en sí del lado exterior -marroquí-. Los conflictos con las autoridades del gobierno vecino, que argumentaban la invasión de su territorio ${ }^{36}$ para negarse a la instalación de una estructura de dos metros de alto y tres de ancho que constituiría una tercera valla. La sirga tridimensional iba a ser instalada por Indra a una distancia entre ocho y veinte metros de la valla exterior, lo que triplicaría el espesor total del conjunto ${ }^{37}$. Pero además, detonaría la primera de una serie de decisiones arquitectónicas para engrosar lo máximo posible el ensamblaje fronterizo. La actuación de las autoridades marroquíes, de rechazo frontal al desplegar al ejército para "ocupar el terreno", y "excavado
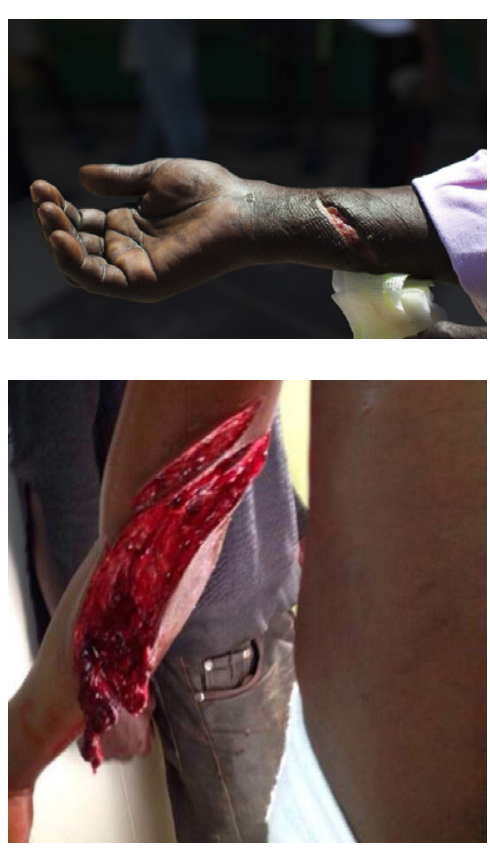

Lesiones causadas por las concertinas.

34 Grande-Marlaska, un defensor de la violencia espacial ejercida por la frontera desde su posición judicial y ahora al frente de la cartera de Interior, se comprometió a su retirada en tramos vulnerables en base a "un estudio muy pormenorizado para tener una posibilidad real y fiable de una frontera segura, pero con medios menos cruentos". Europa Press, "Grande-Marlaska dice que se retirarán las concertinas "con carácter inmediato" y apuesta por "medios menos cruentos””. Europa Press, 26 de julio de 2018.

35 El Pueblo de Ceuta, "La Guardia Civil propone sustituir las concertinas por planchas metálicas y cilindros rotatorios", El pueblo de Ceuta, 19 de febrero de 2019.

36 Situación que confrontaba con la oposición en el Parlamento Español que contraatacaba con que su colocación en la ronda interior era una cesión a Marruecos de territorio español.

37 Roberto Bécares, "El gobierno de Melilla asegura que Marruecos paraliza la construcción de la tercera valla”. El Mundo, 29 de noviembre de 2005. 
allí un foso ancho, ha construido una pista y ha instalado numerosas tiendas de campaña, que dan cobijo a los refuerzos del Ejército marroquí" ${ }^{38}$ contrasta con las decisiones siguientes hasta la fecha.

Precisamente esta primera actuación es la que marca la pauta de unas primeras intervenciones de carácter topográfico que se realizan en una franja de treinta metros de espesor. La finalidad, usar las diferentes pendientes del terreno como elementos de retraso. Así, el foso ancho, los terraplenados y barrancos son las primeras operaciones de esta nueva fase de militarización del fronterizo. Junto a ellas, simplemente dos sistemas básicos ya utilizados: la instalación de una pista de acceso que permita recorrer todo el perímetro fronterizo de manera ágil y un cierre compuesto por una serie de alambras de espino que establecen el límite exterior del ensamblaje. En el 2013, el gobierno marroquí comienza a instalar una tercera valla más allá de este límite exterior consistente en "postes de los que sale una alambrada llena de cuchillas de cinco metros de ancho por tres de alto. Además a ras del suelo se colocará una alfombra de rollos de cuchillas"39. Un foso, situado al pie de esta nueva valla, compensa la altura de tres metros del elemento arquitectónico maximizándolo con una altura negativa de dos metros. Jorge Fernández Díaz confirma un año después la colaboración entre ambos gobiernos para garantizar la defensa de la frontera ${ }^{40}$. Al igual que en otros escenarios del dispositivo frontera la externalización o extraterritorialización que asegure su eficacia y funcionamiento, es un mecanismo que se visibiliza muy bien en este ejemplo concreto. Un ensamblaje fronterizo, la valla, situada en un primer momento exclusivamente en soberanía española es complementada, para mejorar su rendimiento, con construcciones independientes que se sitúan espacialmente más allá de los límites de su soberanía, pero no lo hacen a efectos operativas. Esta misma traslación hacia la inclusión de agentes externos, que ocurre con los elementos constructivos que forman la valla tiene su correlato con las medidas dinámicas y agentes no-arquitectónicos que se emplean a efectos de impermeabilización de la misma. Un mismo mecanismo que permite, no sólo la formación de un ensamblaje arquitectónico, sino despliegues dinámicos y la vinculación con agentes extraarquitectónicos para asegurar su eficacia.
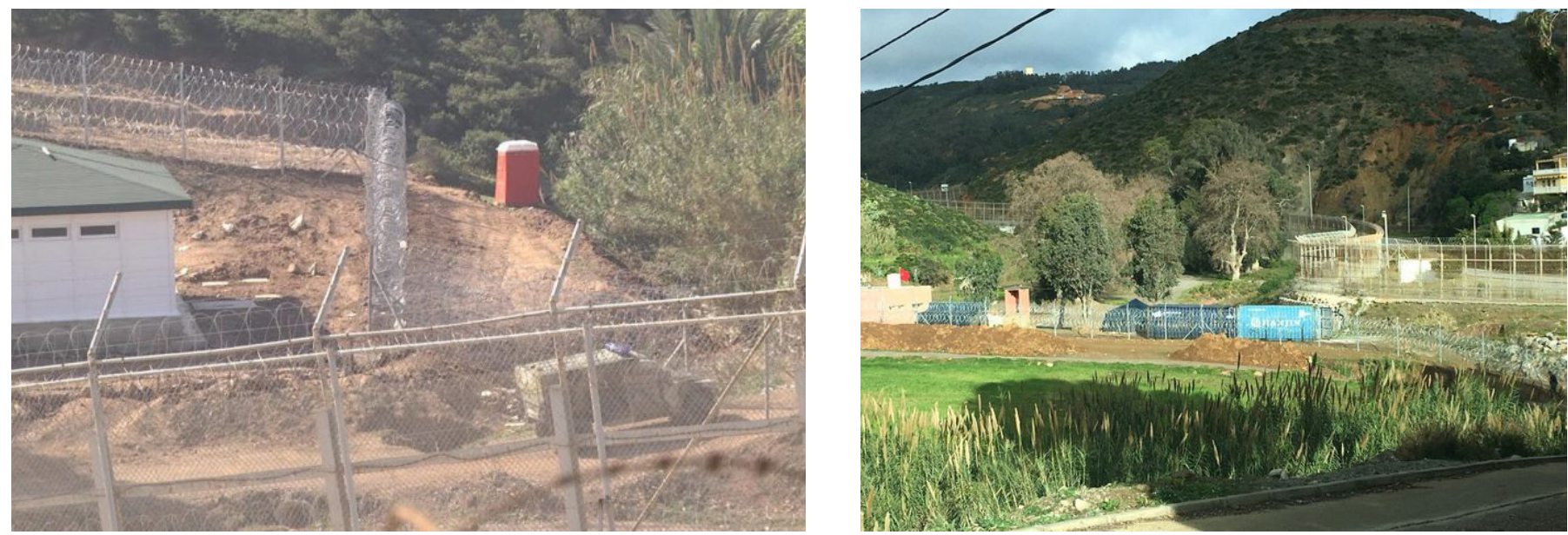

Implementación de nuevos mecanismos arquitectónicos del lado marroquí de la valla. (Melilla, 2015-2018)
38 Bécares, El Mundo, 29 de noviembre de 2005.

39 Sonia Moreno, "Marruecos construye la cuarta valla en la frontera con Melilla", Cadena Ser, https://cadenaser.com/ser/2014/05/19/internacional/1400460319_850215.html (consultada el 30 de marzo de 2019). n: Homo Sacer II (Valencia: Pre-textos, 2010), 59.resencia y desplazamiento de un cuerpo en un espacio $f$ un espacio para el cual

40 Una medida que no sólo se traduce en términos ligados a la arquitectura de la valla sino también en un mayor despliegue policial y militar que asegure el perímetro fronterizo así como la construcción de una valla perimetral en toda la frontera Marruecos-Argelia. 
Entre 1970 y 2019 la valla ha sufrido un proceso claro de militarización. En altura ha pasado de medir menos de un metro a una estructura de acero de seis metros de alto coronada por concertinas. Y, en su dimensión horizontal ha multiplicado por cuarenta su espesor, pero además, se han implementado diferentes mecanismos arquitectónicos para complejizar su sección constructiva. En primer lugar, las diferentes cotas que atraviesa un cuerpo a través de la manipulación permanente de la orografía con socavones, fosos y barrancos generados artificialmente; a lo que hemos de sumar la disposición de las propias vallas -dos de seis metros de altura y una tercera de tres metros- y la sirga tridimensional que, recordemos, es una innovación tecnológica desarrollada específicamente para este ensamblaje fronterizo. La sirga se sitúa a caballo entre el elemento espacial destinado a la ralentización del avance de los cuerpos y el diseño cruel por los daños que puede llegar a causar -motivo de su inminente retirada-; pero son las concertinas, con una misión similar al ralentizar los cuerpos a través de la retención y desgarro de su materia, las que visibilizan más explícitamente el grado de violencia espacial que esta construcción ha adquirido. Sin embargo, reducir este ensamblaje fronterizo únicamente al funcionamiento conjunto de sus elementos constructivos sería obviar que el grado de militarización incluye también una serie de medidas de carácter tecnológico que desterritorializan su arquitectura vinculándola a otros puntos mucho más lejanos de la línea fronteriza. Los más obvios, los sistemas de alumbrado, primero estáticos y en la actualidad móviles capaces de iluminar el territorio mucho antes de que ningún cuerpo entre en contacto con la valla, lo que aumenta la capacidad de acción, respuesta y eficacia de la misma. En segundo lugar, los sistemas de vigilancia ópticos, térmicos, sonoros y detectores de presencia que juegan un mismo papel, vinculando cualquier punto de los más de veinte kilómetros de la valla a las estaciones de vigilancia que los coordinan. Y, por último, la militarización
Extensión actual de la valla y ampliación del lado marroquí (derecha) (Elaboración propia; Melilla, 2019).

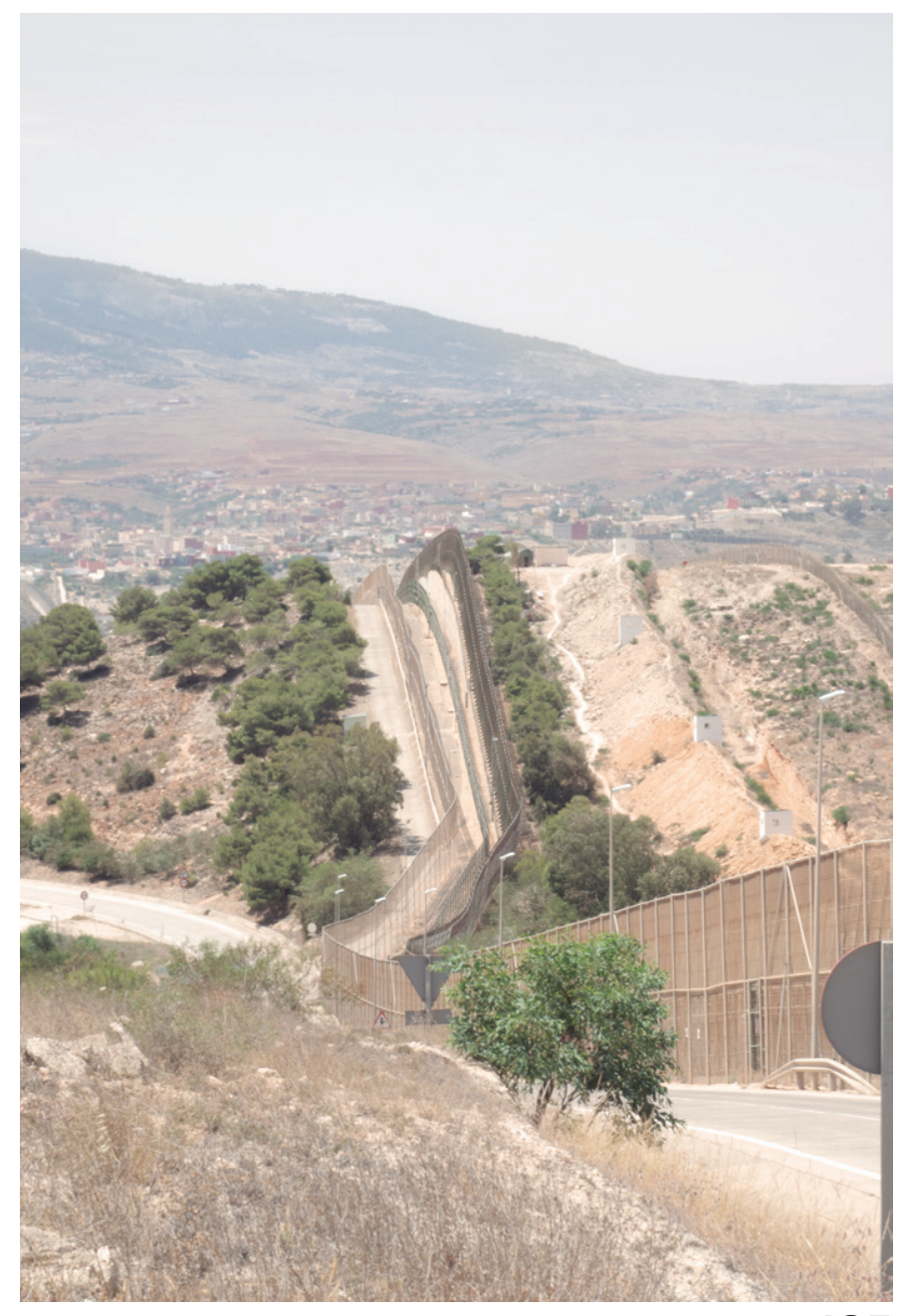




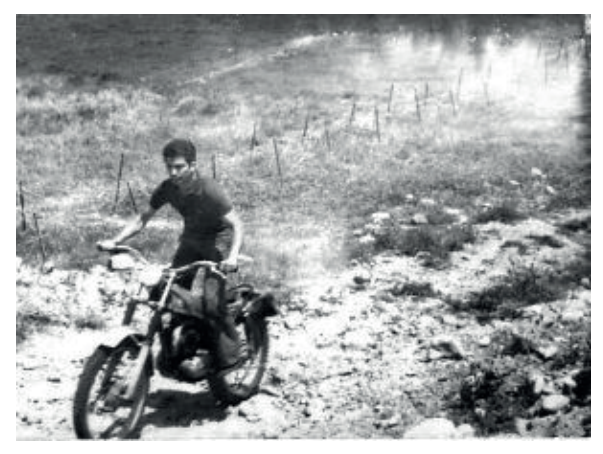

1971

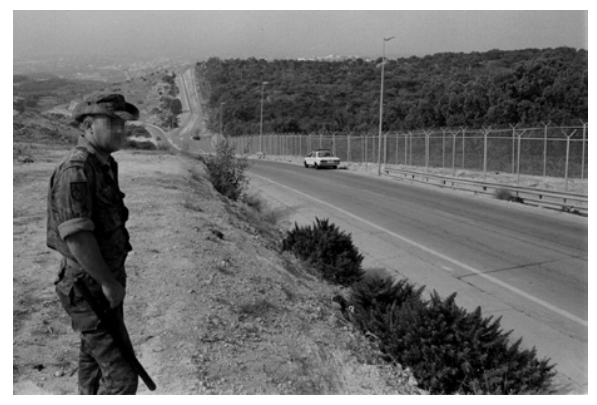

1996
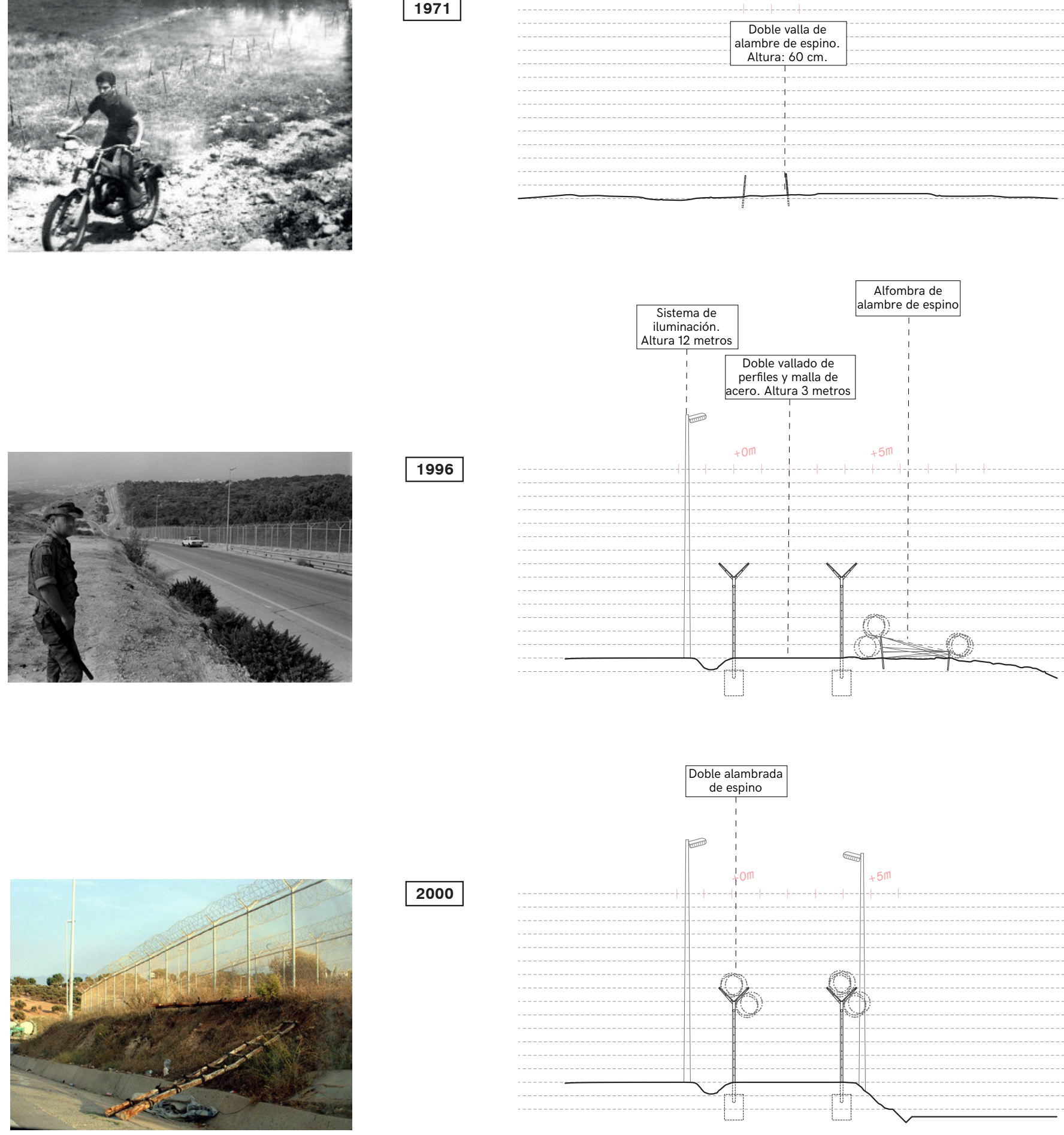

2000

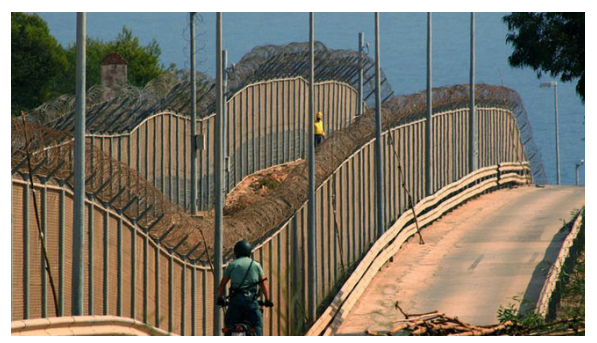

2005
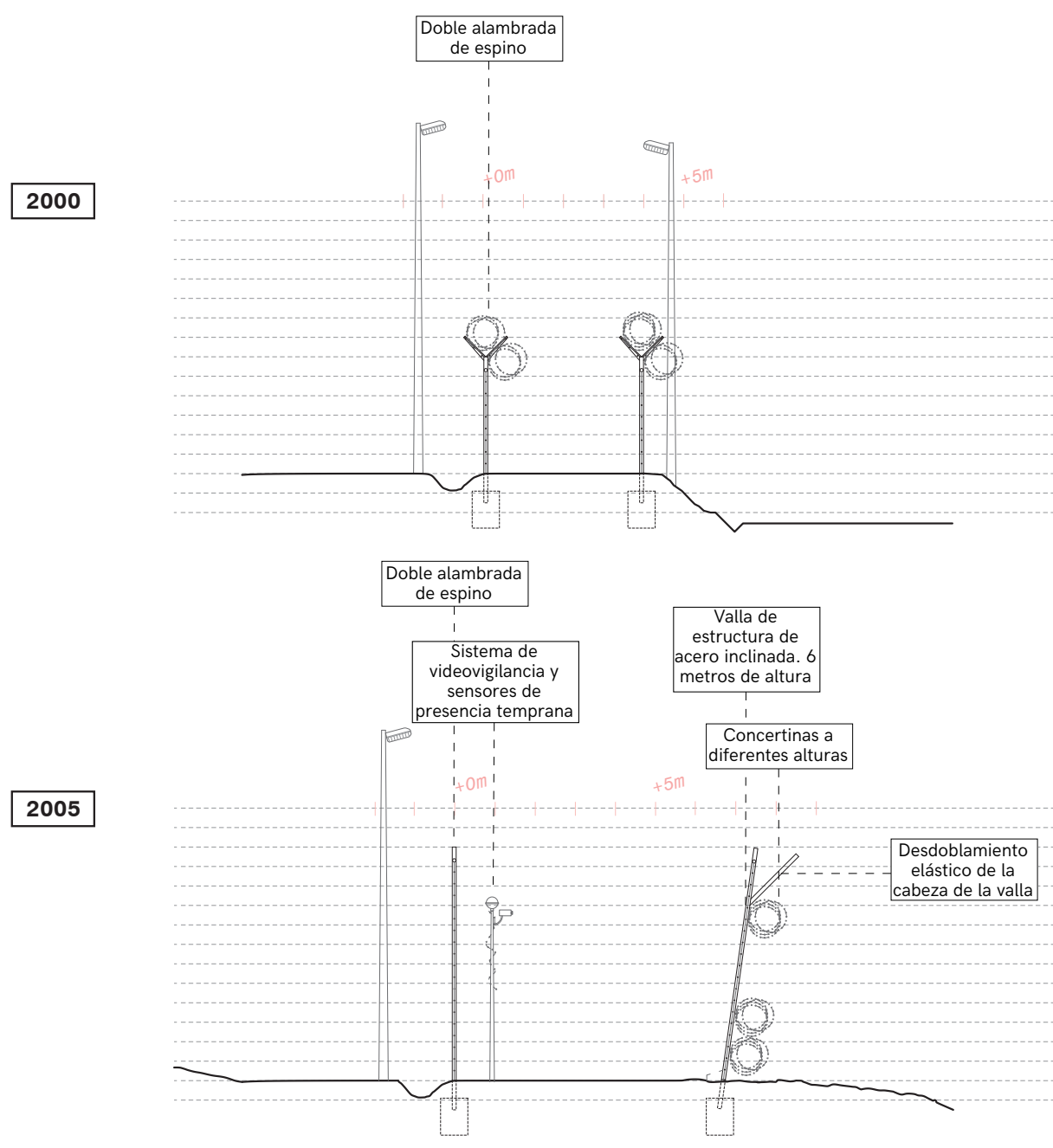
Evolución histórica de la arquitectónica fronteriza 1970-Actualidad

(Elaboración propia). 


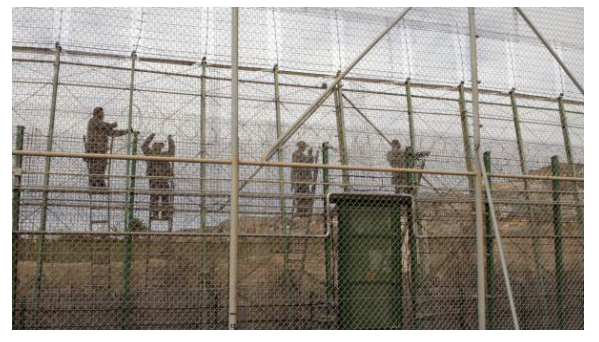

2007
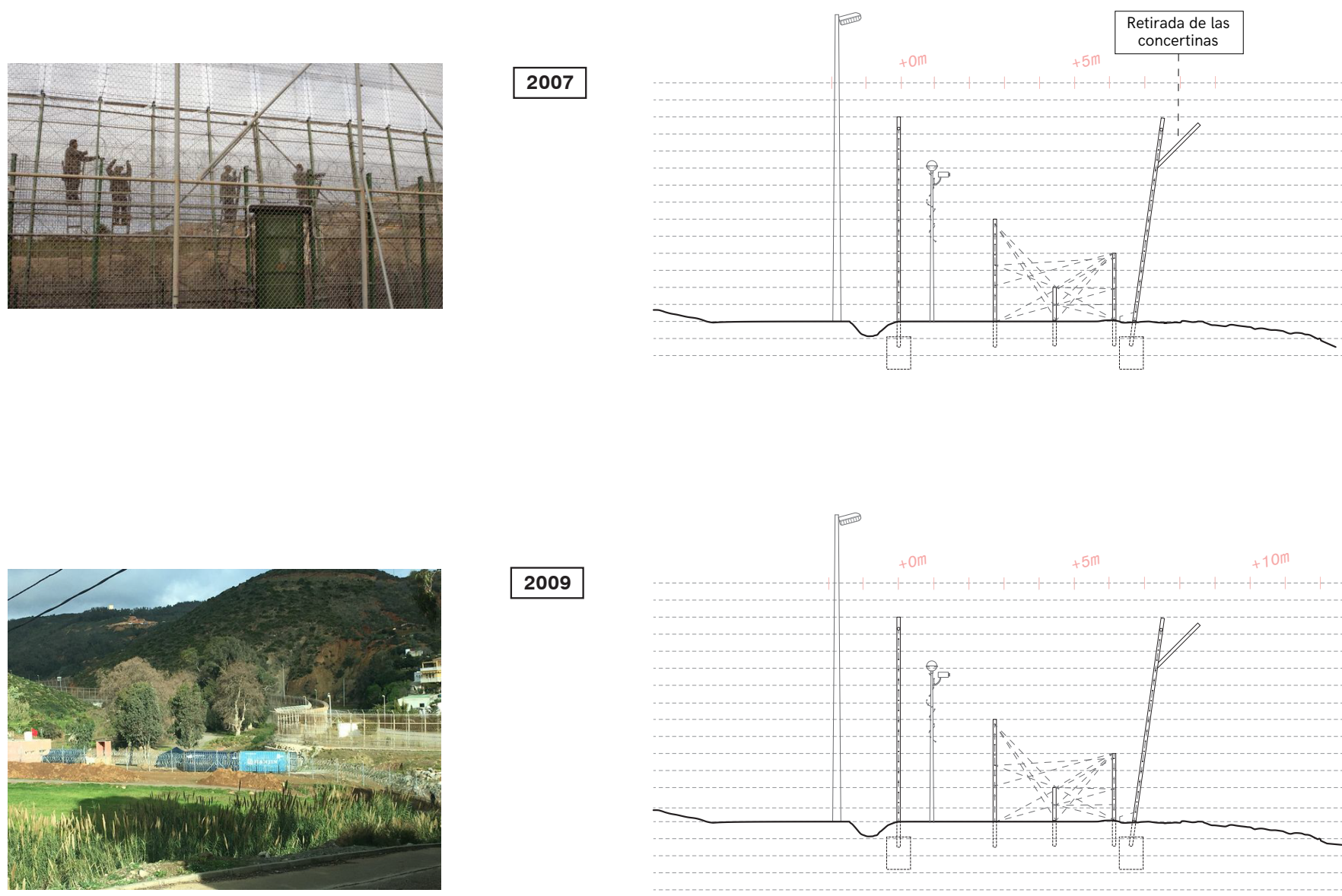

2009
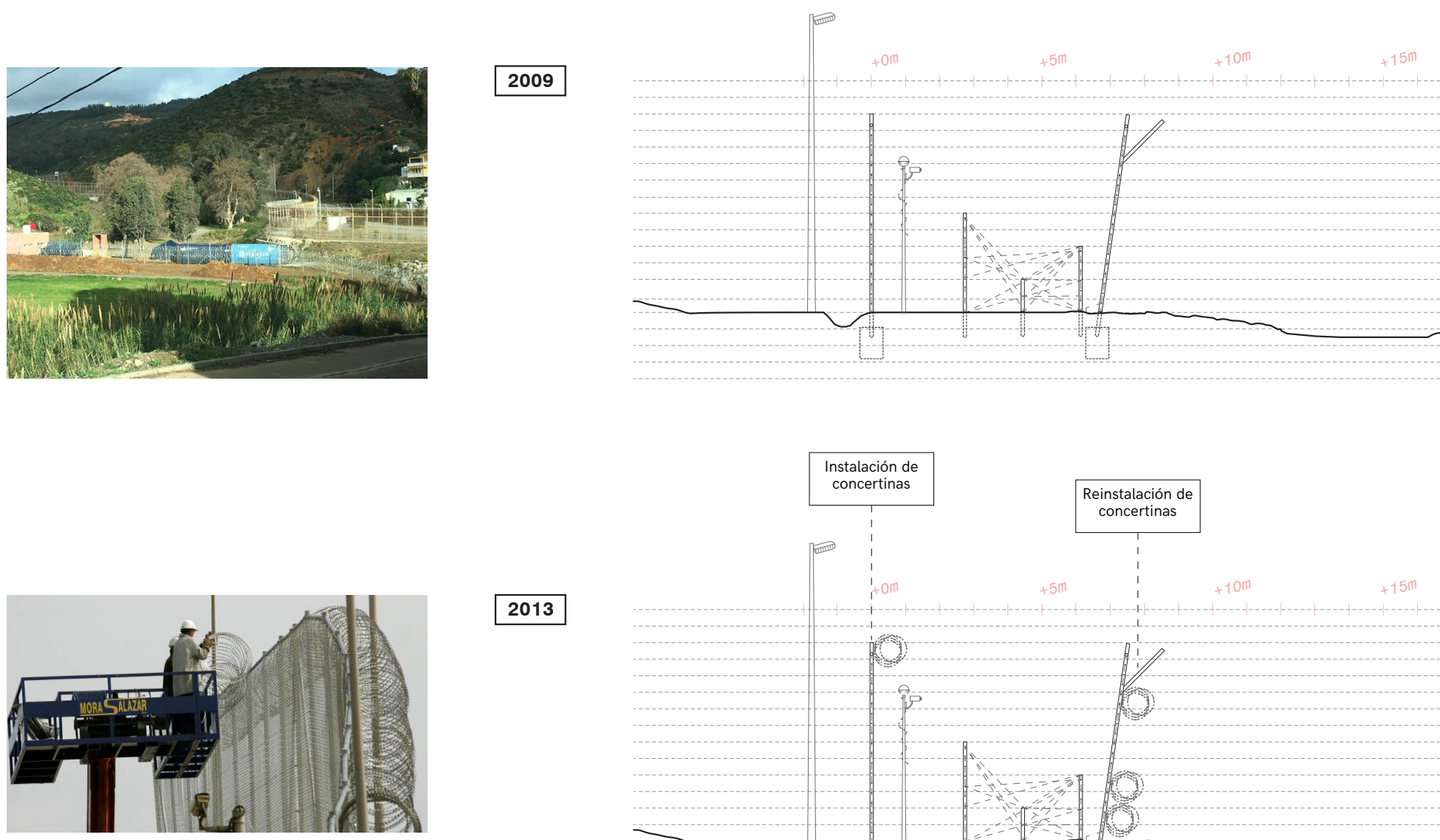

2013
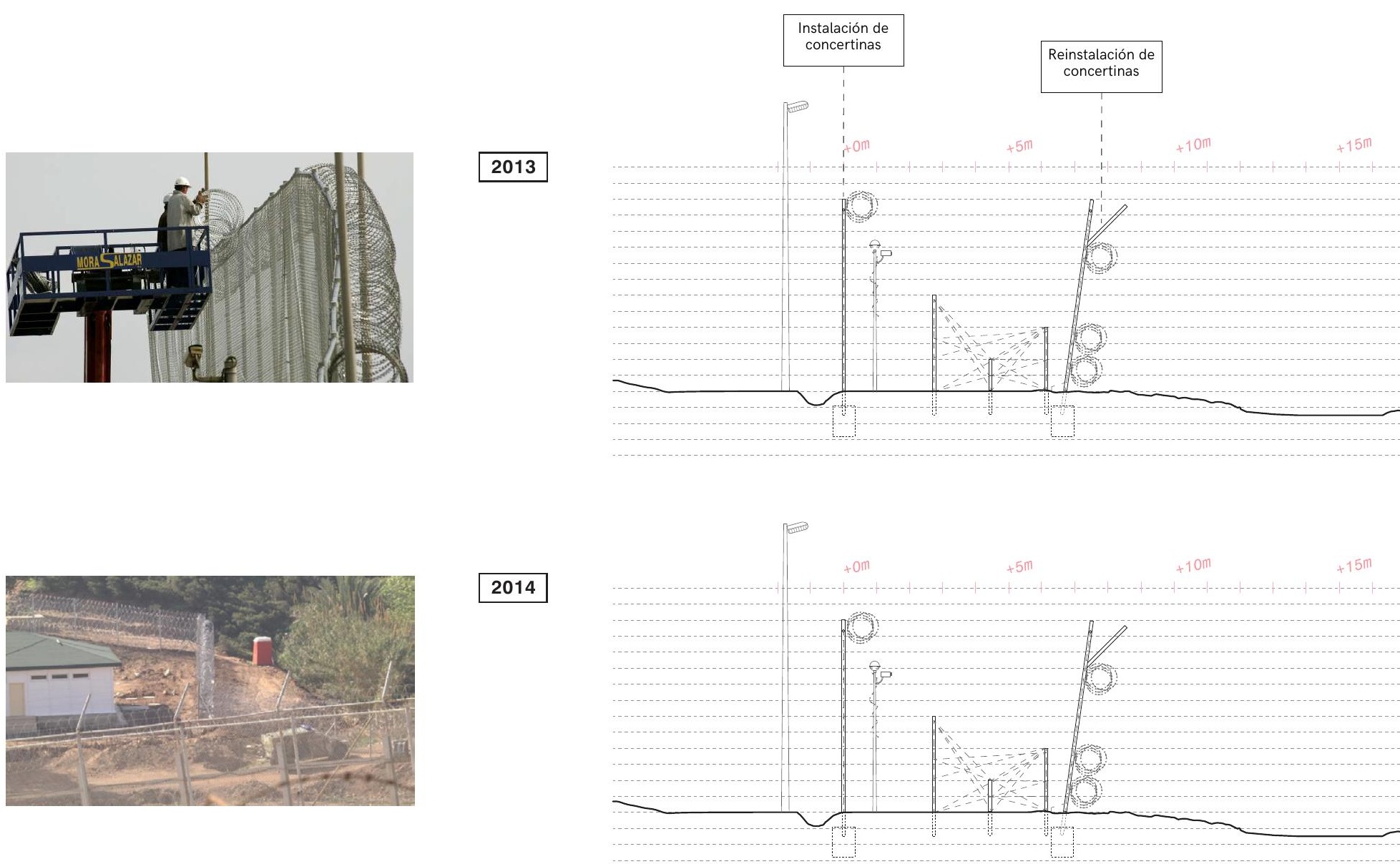


\begin{tabular}{|c|c|}
\hline $\begin{array}{c}\text { Sistema de } \\
\text { iluminación } \\
\text { perimetral con focos } \\
\text { de activación } \\
\text { inmediata }\end{array}$ & $\begin{array}{c}\text { Sistemas de } \\
\text { alarma y } \\
\text { comunicación }\end{array}$ \\
\hline Sistemas de comunicación & $\begin{array}{c}\text { Sistema de cámaras } \\
\text { móviles, alarma sonora } \\
\text { y sensores de detección } \\
\text { de movimiento }\end{array}$ \\
\hline
\end{tabular}

Mecanismos arquitectónicos

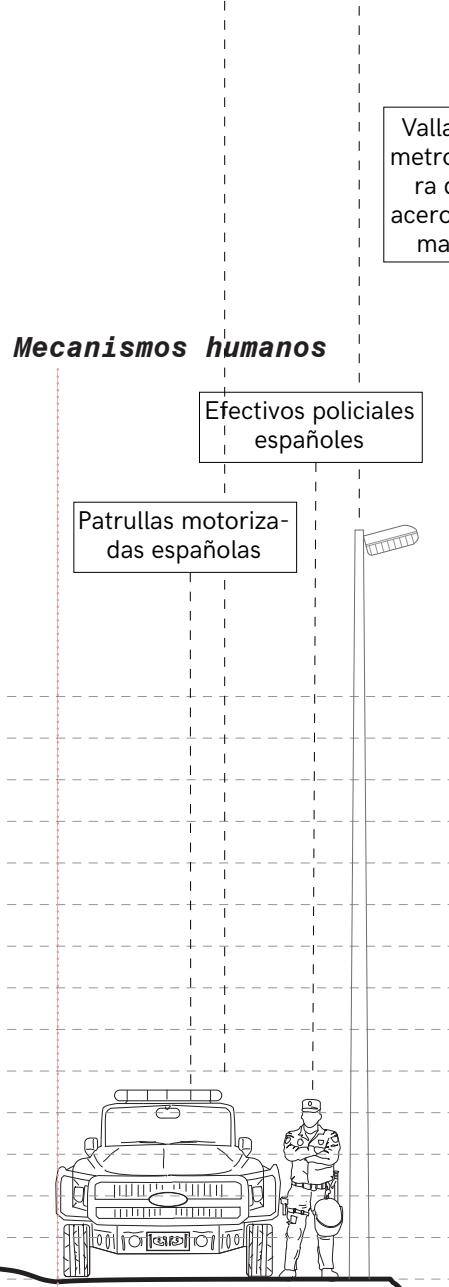

ZONA 1

Perímetro exterior formado por pistas y vías, 10 que posibilita la llegada rápida a cualquier punto.
ZONA 2

Ronda interior con patrullas periódicas, sistemas de alarma y posibilidad de acceso policial.

\begin{tabular}{|c|}
\hline Sensores de \\
movimiento que \\
detonan el sistema de \\
alarma temprana
\end{tabular}

Sistemas de comunicación

Sistemas de comunicación

Valla exterior de 6 metros de

estructura de pilares de acero

galvanizado con inclinación de

$85^{\circ}$, malla antitrepa y

colocación de concertinas a diferentes alturas

de altura variable $1-3$

metros compuesta

por pilares y cables de acero 

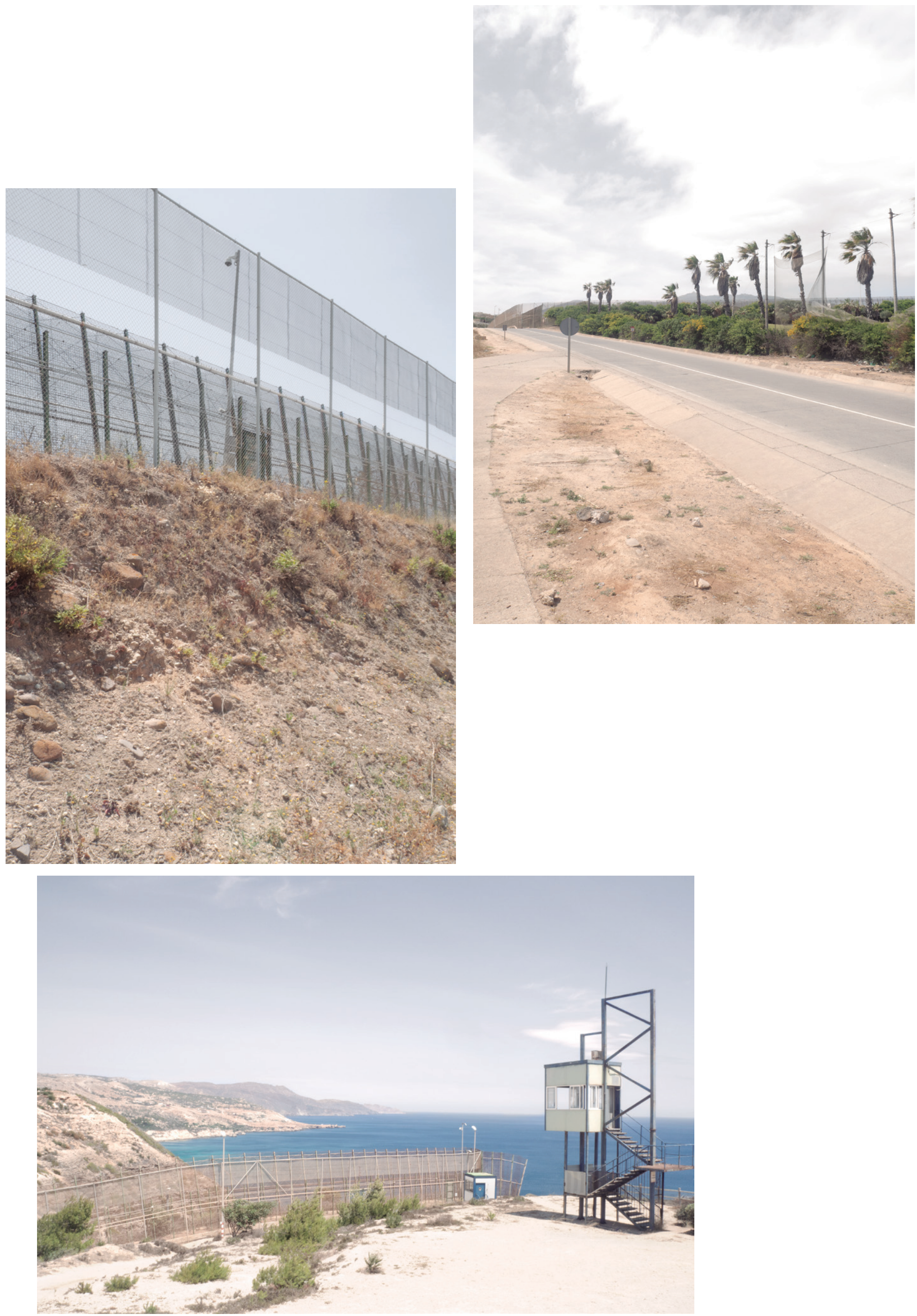

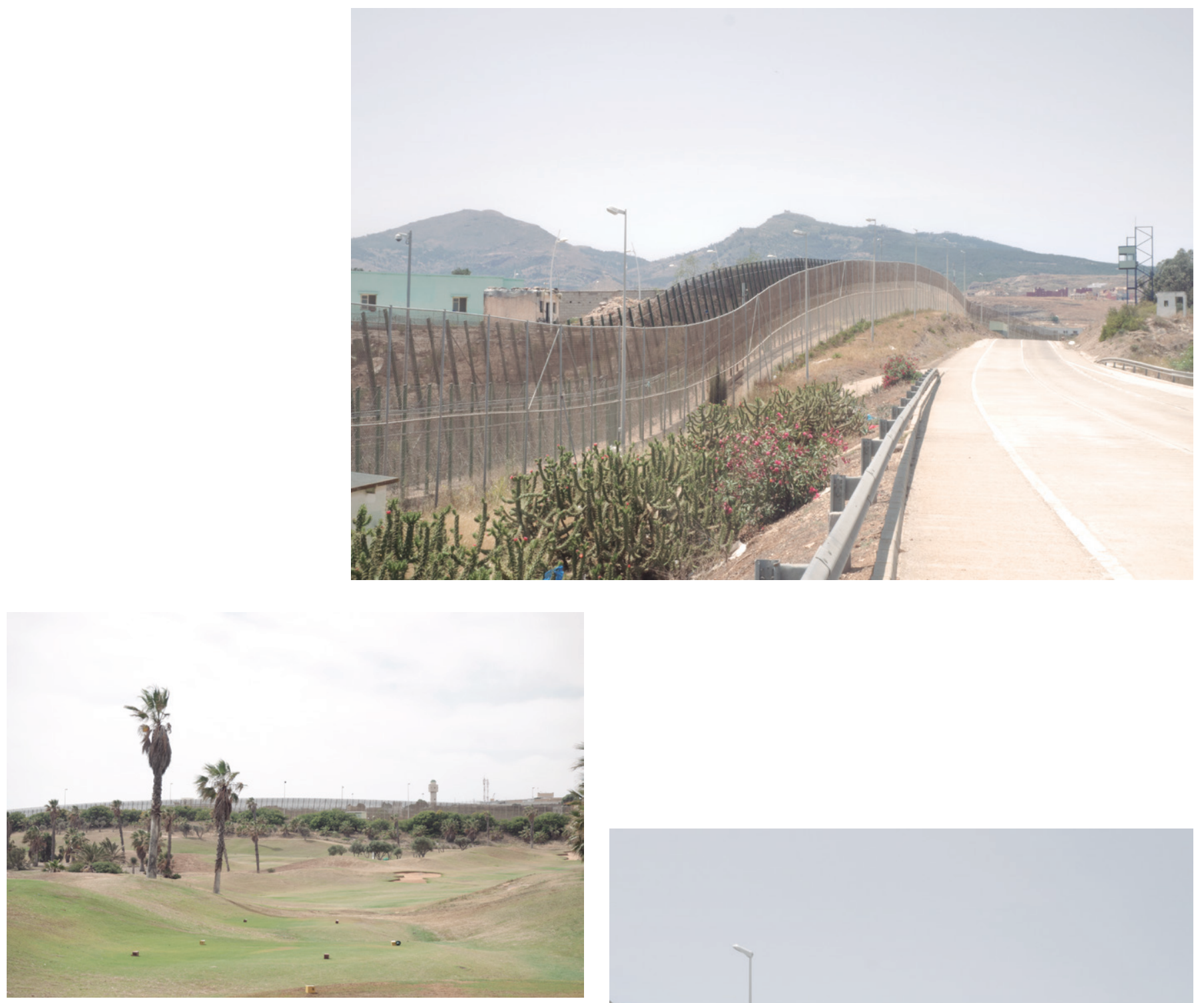

De arriba a abajo e izquierda a

derecha:

Valla fronteriza de Melilla en Sección Oeste, Sección Sur, Sección Sur, Sección Oeste, Sección Sur, Sección Norte (Elaboración Propia; 2019)

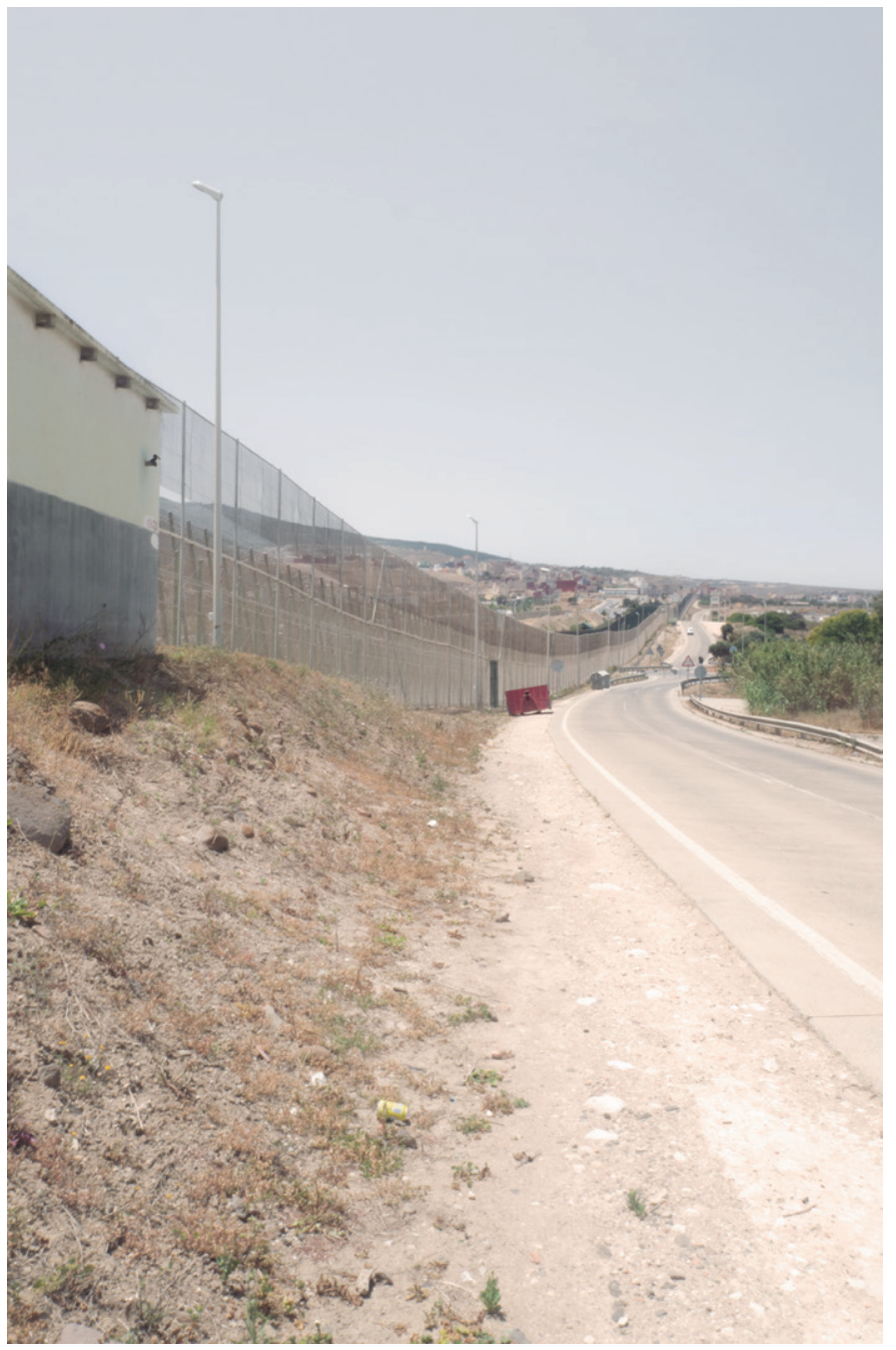


creciente tiene gran importancia en los despliegues operativos, cada vez más frecuentes, realizados por agentes aparentemente no-arquitectónicos pero que resultan cruciales para garantizar la impermeabilización de la valla. Desde el despliegue del ejército en el año 1996, 2005, el uso recurrente de la fuerza por autoridades españolas y marroquís o la implementación de protocolos que ponen en suspensión las normas y leyes establecidas es una herramienta arquitectónica más. Todo ello para desplegar nuevas pautas de actuación que garanticen el funcionamiento de una arquitectura que, por si sola, resulta obsoleta.

A continuación centraremos el análisis en estas dos condiciones: dispersión arquitectónica -desterritorialización- y operatividad, como las grandes transformaciones arquitectónicas de la valla, que se alejan de su condición más estática para presentarse como un ensamblaje capaz de conectar agentes de diferente naturaleza que dan una respuesta eficaz, contundente, y adaptada con singular precisión a necesidades instantáneas. Por tanto, aunque la arquitectónica de la valla sea la que con precisión geométrica más fiel plasme la línea soberana sobre el territorio, vemos como en su materialización arquitectónica este rigor se diluye para dar paso a una condición difusa, dispersa y elástica, que responda con un alto grado de violencia espacial ante cada situación concreta. 


\subsection{ENSAMBLAJES TERRITORIALES DE LAS LÍNEAS FRONTERIZAS.}

\subsubsection{ARQUITECTURAS DISPERSAS}

La eficacia de la línea fronteriza requiere de la acción conjunta de diferentes arquitecturas que, dispersas territorialmente, cumplen funciones diferenciadas, las cuales dotan al ensamblaje arquitectónico de diferentes características que, de otra manera, no poseería. Desde los despliegues policiales a los sistemas de videovigilancia controlados desde dependencias policiales, los puertos españoles y marroquíes de donde parten las patrullas marítimas y embarcaciones, los centros de estancia temporal a donde son enviados los migrantes que logran cruzar, así como los campos y campamentos instalados en las inmediaciones del perímetro fronterizo. A una escala menor, se detectan una serie de operaciones arquitectónicas que, de manera temporal y efímera, modifican la sección constructiva de la valla. Transformaciones topográficas, destacamentos militares y patrullas periódicas por la línea, despliegues temporales de estructuras tridimensionales de alambre de espino... que la dotan de nuevas capacidades técnicas destinadas a retardar, impedir y controlar aún más su cruce irregular.

Abordar el análisis de la construcción de la línea fronteriza desde el reconocimiento de que la dispersión territorial no es un impedimento para que todas estas arquitectónicas formen ensamblajes capaces de generar acciones conjuntas, y así expandir mucho más allá del perímetro fronterizo los espacios y lógicas que esta arquitectura representa. Frente a las conexiones estables, permanentes en el tiempo que los diferentes elementos constructivos de la valla forman -indisolubles en función, tiempo y espacio- es necesario centrarse en agentes de diferente naturaleza que son capturados tan sólo en los momentos necesarios, donde su función habitual no está ligada exclusivamente a la construcción, gestión y protección de la frontera. Incluso en un elemento tan simbólico, simple y que representa sin matices la expresión última del término frontera, la valla, encontramos resonancias claras del Espacio de fronteras temporales que analizan Mezzadra y Neilson. La dimensión geopolítica donde reconocen la "relevancia del tiempo, temporalidad, y procesos temporales en los procesos de regímenes de fronteras, esquemas de migración, y tecnologías de inclusión diferencial" ${ }^{41}$ también puede apreciarse de manera inequívoca en un elemento que posee una escala mucho menor.

Diego Barajas, tanto en solitario como miembro de $\operatorname{Husos}^{42}$, ha introducido el concepto de urbanismos, territorios y arquitecturas dispersas vinculados a las lógicas contemporáneas de la frontera. Con este término define "espacios pequeños y aparentemente aislados en realidad [que] cuentan con la capacidad de funcionar a manera de nodos de territorios más amplios" ${ }^{43}$. En Dispersion, define los terri-

41 Sandro Mezzadra y Breit Neilson, Border as Method or, the multiplication of labour (Londres: Duke University Press, 2013), 131.

42 Diego Barajas y Camilo García, Urbanismos de remesas: viviendas (re)productivas de la dispersión, (Madrid: Caniche Editorial, 2017).

43 Diego Barajas, "Viviendas productivas” (Tesis doctoral, Universidad Politécnica de Madrid, 2016), 44 . 
torios dispersos como aquellos que "ya no están físicamente contenidos en áreas geográficas continuas, pero se han extendido y re-articulado por medios artificiales" ${ }^{44}$. Estas dos acepciones, enunciadas desde lo arquitectónico, nos permiten traer al campo de los paisajes de frontera un concepto fundamental enunciado por la noción que articula esta investigación: la capacidad de desterritorialización que poseen los ensamblajes o dispositivos ${ }^{45}$. Así pues, desde esta perspectiva permitirá reconocer los espacios y construcciones desconectadas del perímetro fronterizo que actúan de manera conjunta y temporal cuando el dispositivo frontera lo requiere.

Entendamos, en primera instancia el funcionamiento de estos urbanismos dispersos en relación a la valla, para posteriormente centrar el foco en otras arquitectónicas ligadas al dispositivo frontera pero ajenas a su realidad territorial. Primero, exclusivamente analizando el resto de construcciones que de manera recurrente forman parte del ensamblaje fronterizo tanto en Ceuta como en Melilla. Y, en segundo lugar a través de las operaciones arquitectónicas llevadas a cabo en el paso fronterizo del Benzú. Todo ello contribuye a desdibujar la línea clara y material que la valla, como frontera construida, materializa, a la vez que comprender las implicaciones espaciales y arquitectónicas de una frontera que sólo puede ser enunciada como un dispositivo.

\subsubsection{ENSAMBLAJES TERRITORIALES DE CEUTA Y MELILLA}

La propia definición de dispositivo incluye la transformación constante de agentes y conexiones entre las partes. Por ello, no resultaría posible establecer una foto fija que fuese fiel a la realidad territorial de los ensamblajes territoriales en Ceuta y Melilla. En vez de esta vía, se ha optado por recurrir a dos acontecimientos concretos, ambos detonados por cuerpos que acceden de manera irregular al perímetro fronterizo desde donde es posible extraer una dimensión territorial mucho más amplia del funcionamiento efectivo de ambas ciudades autónomas. El primer abordaje al ensamblaje territorial lo realizaremos en base a la dimensión expandida de la Tragedia del Tarajal, localizando los nodos principales que durante el desarrollo del acontecimiento y en los días previos y posteriores tuvieron relevancia en la configuración del dispositivo. El segundo abordaje, en Melilla, será realizado en base a los datos obtenidos durante el trabajo de campo ${ }^{46}$ en la ciudad autónoma y la entrevista realizada a José Palazón, donde se detectó la devolución de migrantes procedentes de una patera procedente de Islas Chafarinas.

Es importante comprender la singularidad territorial y normativa que se produce en ambas ciudades autónomas de las cuales se derivan una serie de prácticas espaciales que, de no poseer este carácter excepcional, no serían posibles. Ceuta y Melilla son dos territorios pertenecientes a España situados en el continente africano, que el reino marroquí no reconoce pero que además no están situados dentro del espacio Schengen: es decir, pese a pertenecer a un país que sí está in-

44 Diego Barajas, Dispersion A Study of Global Mobility and the Dynamics of a Fictional Urbanism, (Amsterdam: Episode Publishers, 2003), I.

45 Manuel De Landa, Assemblage Theory, (Edimburgo: Edinburgh Univeristy Press, 2016), 69:85.

46 Este trabajo de campo se desarrolló durante el mes de junio de 2019 a lo largo de todo el 
cluido dentro de un territorio de libre circulación, su condición fronteriza las excluye. Tan sólo las infraestructuras de transporte y conexión con Europa: el puerto por vía marítima y el aeropuerto, se incluyen dentro del espacio Schengen como espacios diferenciales. Así, la excepcionalidad de esta situación produce un decalaje entre Europa-África, Espacio Schengen-España, España-Europa con consecuencias claras para la configuración de ambos enclaves fronterizos. Uno de los aspectos más definitorios de esta situación es la elevada masa de trabajadores migrantes residentes en las ciudades autónomas o en poblaciones aledañas que, sin necesidad de visado ejercen -de manera formal o informal- su vida laboral más allá de la línea fronteriza. Un número, cercano al treinta por ciento respecto al total de la población al que hay que sumar una proporción equivalente que supone la población informal que, sin figurar en los censos oficiales, vive en la ciudad -sin poder acceder a servicios básicos-. Pero, más allá de esto otro aspecto fundamental se deriva de este decalaje donde la superposición de diferentes líneas soberanas no se corresponde con la realidad territorial de las ciudades: la exención de ambas ciudades del espacio Schengen provoca que, aunque los migrantes accedan a territorio español no pueden trasladarse libremente por él más allá de los límites administrativos de Ceuta y Melilla ${ }^{47}$.

\subsubsection{CEUTA. ENCLAVE TOPOGRÁFICO}

La Ciudad Autónoma de Ceuta se sitúa en uno de los puntos más próximos a la península, a quince kilómetros de la costa gaditana, conformando el paso más angosto del Estrecho de Gibraltar. Su situación es próxima al puerto con mayor tráfico marítimo de África, Tanger-Med y de la ciudad de Tánger, metrópolis con más de un millón de habitantes. Por todo ello se constituye como el principal punto de conexión con Marruecos -y por tanto África- de España. Su extensión urbana se acota por la presencia del Monte Hacho y la sierra de Anyera, una formación rocosa escarpada de gran relieve que define una frontera natural respecto a la ciudad autónoma. Esta realidad geográfica hace que la implantación de la valla sea radicalmente diferente a la de Melilla y, por tanto, otros mecanismos de control de acceso han sido implementados.

Si bien este análisis toma como punto de partida las diferentes arquitecturas dispersas involucradas en el desarrollo de los acontecimientos de la Tragedia del Tarajal ocurrida el 6 de febrero de 2014, no se centrará en lo ocurrido en sí, sino en la red territorial construida y dispuesta que permite un control efectivo de la frontera, así como su correcto funcionamiento. Así pues, no es tanto en el desarrollo sino el registro del acontecimiento el que visibiliza la condición dispersa de la frontera: la cámara que registra con mayor precisión el transcurso de los acontecimientos no es ninguna de las presentes en el paso fronterizo del Tarajal sino una cámara de infrarrojos de largo alcance situada en la estación del Sistema Integrado de Vigilancia Exterior [SIVE] del Monte Hacho. Es, a través de su sensor remoto, desde donde se logra captar todas las acciones llevadas a cabo en un escenario situado a más de tres kilómetros frente a un sistema de videovigilancia obsoleto -al producirse la entrada irregular antes de la salida del sol, los sensores de las cámaras ópticas apenas captaron movimiento más allá de las zonas artificialmente iluminadas-.

El SIVE es una infraestructura de vigilancia y control de la Frontera Sur y el Es-

47 Hecho que tiene un impacto arquitectónico claro en una arquitectónica del internamiento implementada únicamente en las ciudades autónomas: los Centros de Estancia Temporal de Inmigrantes. Complejos edificatorios para las personas solicitantes de asilo y migrantes a la espera de resolución donde, a diferencia de los centros peninsulares, tienen libertad de movimiento absoluta. Los migrantes no son recluidos en su interior sino que simplemente pernoctan y habitan en él. 
trecho de Gibraltar desarrollada con tecnología y fondos provistos por la Unión Europea a principios de siglo XXI, datando las primeras construcciones en el año 2002. A través de una serie de estaciones autónomas situadas a lo largo de la costa española -en Europa fundamentalmente en el litoral andaluz y África en las ciudades autónomas y las Islas Canarias- esta red se orienta a la monitorización, control y vigilancia de dos flujos irregulares: el narcotráfico y la migración vía marítima. Estas estaciones consisten fundamentalmente en tres sensores receptores: dos cámaras de vídeo, una de ellas infrarrojas - que es la que registra todo el acontecimiento del Tarajal-, un sensor de radar con un alcance óptimo de cinco y diez kilómetros respectivamente; y una antena de comunicaciones que transmite las señales a un subsistema de comunicaciones. Aquí vemos el primer indicio claro de dispersión territorial que analizamos: este sistema tecnológico no es controlado desde los escenarios donde están sucediendo los acontecimientos sino a través de un entramado de antenas y sensores que remiten toda la información a un único punto: la Comandancia de la Guardia Civil en Algeciras. Es decir, los mecanismos de vigilancia espacial que, en este caso concreto, permiten tener mayor grado de detalle sobre el acontecimiento no están físicamente situados en el terreno sino a más de dos kilómetros de distancia -en el Monte Hacho- pero los agentes que operan los sensores están a más de catorce kilómetros al otro lado del Estrecho de Gibraltar. Este grado de dispersión territorial, que es capaz de conectar de manera simultánea escenarios arquitectónicos tan distantes sólo es posible a través de una infraestructura tecnológica -satélites, comunicaciones, receptores...-que permita no sólo tal grado de desterritorialización sino de coordinación instantánea.

Sin embargo, aunque esta sea la arquitectura dispersa más aclaratoria no es la única que juega un papel relevante en el desarrollo inmediato de los acontecimientos. El propio paso fronterizo constituido por un complejo edificatorio y agentes allí destinados para asegurar su funcionamiento efectivo no resultan suficiente, lo que obligan a conectarse a otros dos nodos policiales: la comisaría de Ceuta, la comandancia de la Guardia Civil y la comisaría de aduanas marroquí. Estos dos nodos proporcionan soporte físico y unidades que serán desplegadas sobre el paso fronterizo durante el desarrollo de la noche. A esto hemos de añadir el puerto de Ceuta donde se localiza la base de las diferentes patrulleras pertenecientes al Servicio Marítimo de la Guardia Civil [SEMAR] -cinco embarcaciones rígidas de diferente eslora y características empleadas para el control aduanero y de las aguas ceutís, más una serie de embarcaciones semirrígidas-. De este puerto salen las embarcaciones que juegan un papel fundamental en la contención de los cuerpos en el agua, condicionando sus posibilidades de desplazamiento en una única dirección ${ }^{48}$. Y, además, es desde estas embarcaciones desde donde se arrojan los botes de gas lacrimógeno a los migrantes en el agua. Así, tanto las embarcaciones como sus lugares de procedencia se suman a la extensa red de arquitecturas interconectadas, agentes y escenarios que conforman este ensamblaje territorial.

Por último, al alargar la línea temporal del acontecimiento aparecen otra serie de infraestructuras relacionadas con los tiempos de espera del cuerpo migrante que, con naturaleza completamente diferente, resultan cruciales para entender que, más allá de la valla, estos enclaves fronterizos poseen una dimensión mucho mayor. Estamos hablando de dos escenarios "domésticos" donde permanecen un tiempo indefinido antes y después del cruce. El primero de ellos, los campamentos informales de los montes perimetrales a la línea fronteriza donde los migrantes esperaban durante varios meses hasta que se produjesen las condiciones idóneas para su entrada. La Foret, situado en el bosque de Beliones, es el nombre de uno de ellos, con cerca de mil subsaharianos ${ }^{49}$. Una red de campamentos que

Siguiente página: Cartografía del ensamblaje territorial de Ceuta durante el acontecimiento del Tarajal (Elaboración Propia)
48 No es el puerto de Ceuta el único punto desde donde salen embarcaciones, también hay constancia de la llegada de, al menos, una embarcación marroquí a la zona sin haberse podido precisar su procedencia exacta.

49 Lucas de la Cal, "Los chicos del bosque que van hacia España”, El Mundo, 27 de noviembre de 2017 . 


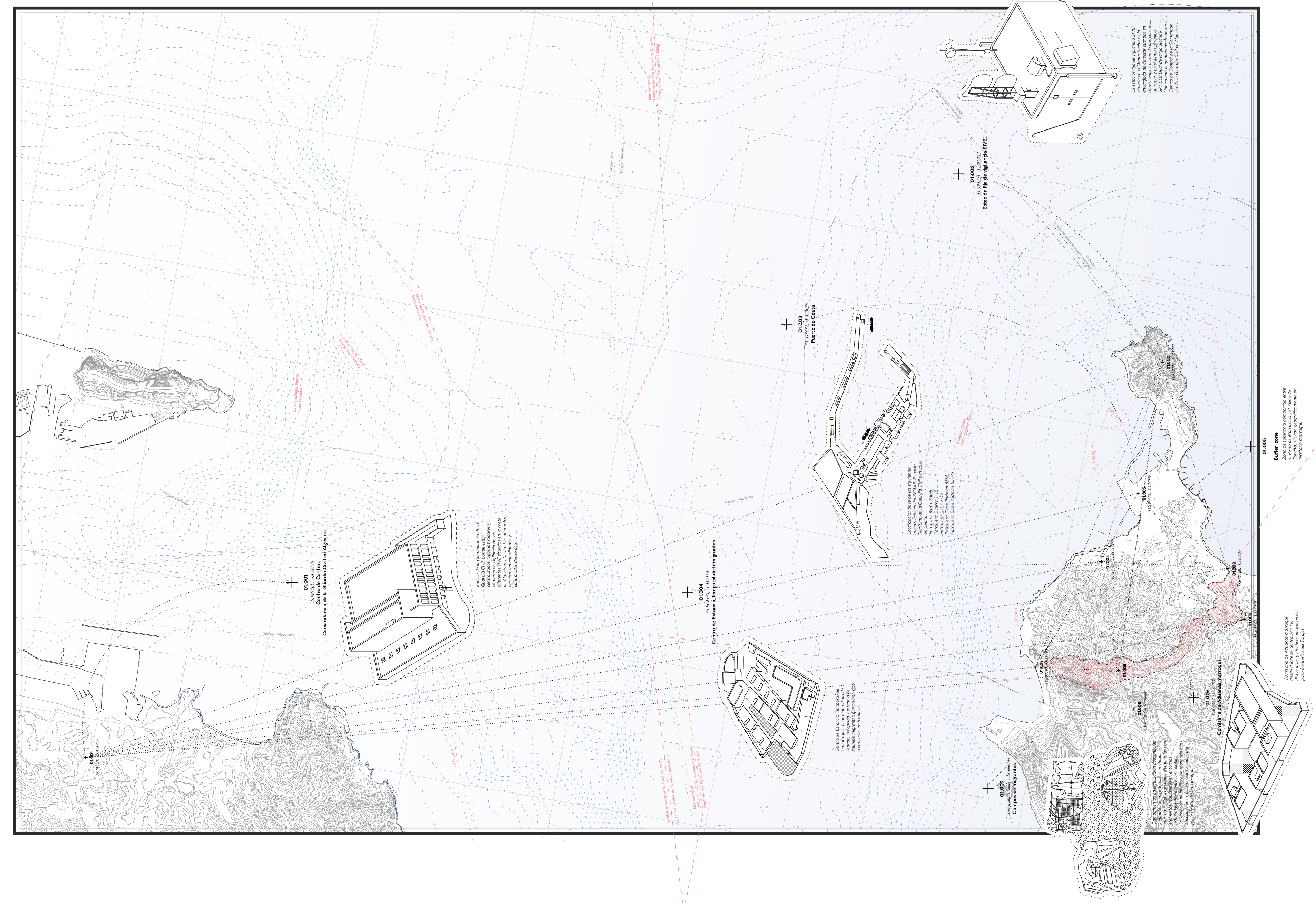


no se localiza exclusivamente en este borde sino que se extiende a otras ciudades como Fez o Casablanca, a donde son trasladados en caso de ser interceptados. En el año 2015, un acuerdo de cooperación entre el gobierno marroquí y el español puso fecha de inicio al desmantelamiento selectivo de estos campos informales, comenzando por aquellos más próximos a las ciudades autónomas y, en julio de 2018 incendiando los de las dos ciudades marroquís ${ }^{50}$. Y, en segundo lugar aparece el lugar de estancia próximo en caso de conseguir permanecer en territorio ceutí una vez cruzada la línea fronteriza: el Centro de Estancia Temporal de Inmigrantes situado en las proximidades de la carretera del Benzú. Es esta arquitectónica del internamiento donde aquellos migrantes con posibilidades de ser acogidos por el sistema han de ser trasladados hasta su canalización a nuevos destinos de internamiento o su traslado a la península. Una situación que no es automática, dada que las devoluciones operativas que se produjeron en el Tarajal -de manera totalmente irregular- impidieron esta posibilidad de asilo. El siguiente caso, centrado en una devolución irregular de migrantes del gobierno español al marroquí, ahondará en este flujo a través de diferentes escenarios.

\subsubsection{MELILLA. ENCLAVE EXTENSIVO}

La realidad territorial de Melilla es completamente diferente a la descrita en el apartado anterior. Si Ceuta se encuentra próxima a grandes núcleos poblaciones, tanto a un lado como a otro del Estrecho de Gibraltar, el aislamiento de Melilla es mucho mayor -sobre todo en lo que respecta a su relación con la España peninsular-. Tampoco es similar la división administrativa respecto a Marruecos, ya que esta no responde a ninguna clase de accidente geográfico sino a un trazado político sobre un territorio continuo a un lado y otro de la línea. Esto hace mucho más permeable la línea fronteriza a la vez que la arquitectura encargada de materializarla ha de garantizar su impenetrabilidad. Por tanto, los pasos fronterizos a lo largo de ella se multiplican hasta alcanzar su máximo histórico en siete puntos de cruce frente a los cuatro actuales: Beni Ensar, Barrio Chino, Farhana y Mari Guari. Cada uno de ellos está especializado con una función diferente : comercio y turismo internacional, comercio ilícito, paso de locales y paso de menores marroquíes a centros educativos melillenses respectivamente ${ }^{51} y$, por tanto, sus características arquitectónicas se adecuan a su función. El paso de Beni Ensar, el segundo con mayor tráfico diario con Europa de toda África, aglutina en su complejo arquitectónico una serie de dependencias policiales y gubernamentales que el resto de pasos, por su condición auxiliar, carecen. Así, en su espesor se localizan aparte de las aduanas correspondientes la Oficina de Asilo y Protección Internacional y dotaciones de Policía Nacional y Guardia Civil, así como sus homólogos marroquís. Entre cada uno de los pasos, la valla discurre inalterable en una sección continua que implementa todas y cada una de las mejoras ya explicadas en un paisaje que varía entre zonas urbanas, rurales y montañosas.

Pese a que el perímetro total de valla hace imposible su vigilancia efectiva en su totalidad, en la actualidad el número de "saltos" a la valla se ha reducido drásticamente respecto a la década anterior: su militarización progresiva, pero sobre todo los esfuerzos represivos del gobierno marroquí han desviado a los migrantes hacia nuevas rutas de acceso a Melilla. Precisamente es una de estos nuevos accesos irregulares a Melilla el que permite establecer la condición arquitectónica dispersa de la frontera, centrándose mucho más en el proceso de devolución de los cuerpos una vez están físicamente situados en territorio español.

50 Esta medida de externalización fronteriza a través de las fuerzas policiales marroquíes permitiría extender aún más la red conformada por nuestro ensamblaje territorial, vinculando nuevos escenarios cada vez más alejados de la línea soberana sino dispersos a lo largo de toda la geografía de Marruecos.

51 Albert Alexandre, "Barrio Chino: cuando la frontera es un buen negocio", Ctxt.es, 28 de marzo de 2018. 
Migrantes detenidos en la entrada de la oficina de Policía de Frontera en el paso fronterizo de Beni Ensar (Elaboración propia; Melilla, 2019)
El suceso que nos ocupa coincide temporalmente con el trabajo de campo desarrollado en Melilla, la observación directa de un hecho aparentemente insignificante detona la reconstrucción de todo este ensamblaje territorial que nos traslada desde el interior de Melilla a las Islas Chafarinas, de soberanía española, situadas en la costa marroquí a más de cincuenta kilómetros de la ciudad -veintisiete millas náuticas-. El martes cuatro de junio de 2019, durante el cruce del paso fronterizo de Beni Ensar de España a Marruecos, una decena de migrantes subsaharianos estaban sentados en una esquina al sol, sentados custodiados por una pareja de policías, con una cartulina atada a su muñeca; en cada cartulina, un número identificativo. Horas más tarde, tras el reingreso en Melilla, los migrantes seguían ahí a la espera bajo el sol. ¿Qué hace posible que en el paso fronterizo más militarizado y dotado de toda la ciudad autónomo estén en esta condición? ¿Qué había llevado hasta esa situación? ${ }^{52}$

La madrugada del tres de junio de 2019, una patera con treinta y siete hombres, diez mujeres y tres menores de edad desembarcaba en la costa de las islas Chafarinas $^{53}$. Estos islotes rocosos, que únicamente cuentan con un pequeño destacamento militar, se encuentran tan sólo a dos millas náuticas de la costa marroquí y, por tanto, hace más factible el cruce en embarcación frente a las diez millas que constituye el Estrecho de Gibraltar. Una ruta cada vez más común debido a la represión marroquí en el perímetro fronterizo y la seguridad respecto al cruce hasta la costa peninsular. Durante el día siguiente, el barco Alcor de Salvamento Marítimo con base en el puerto de Melilla los trasladó hasta la ciudad autónoma. Allí,

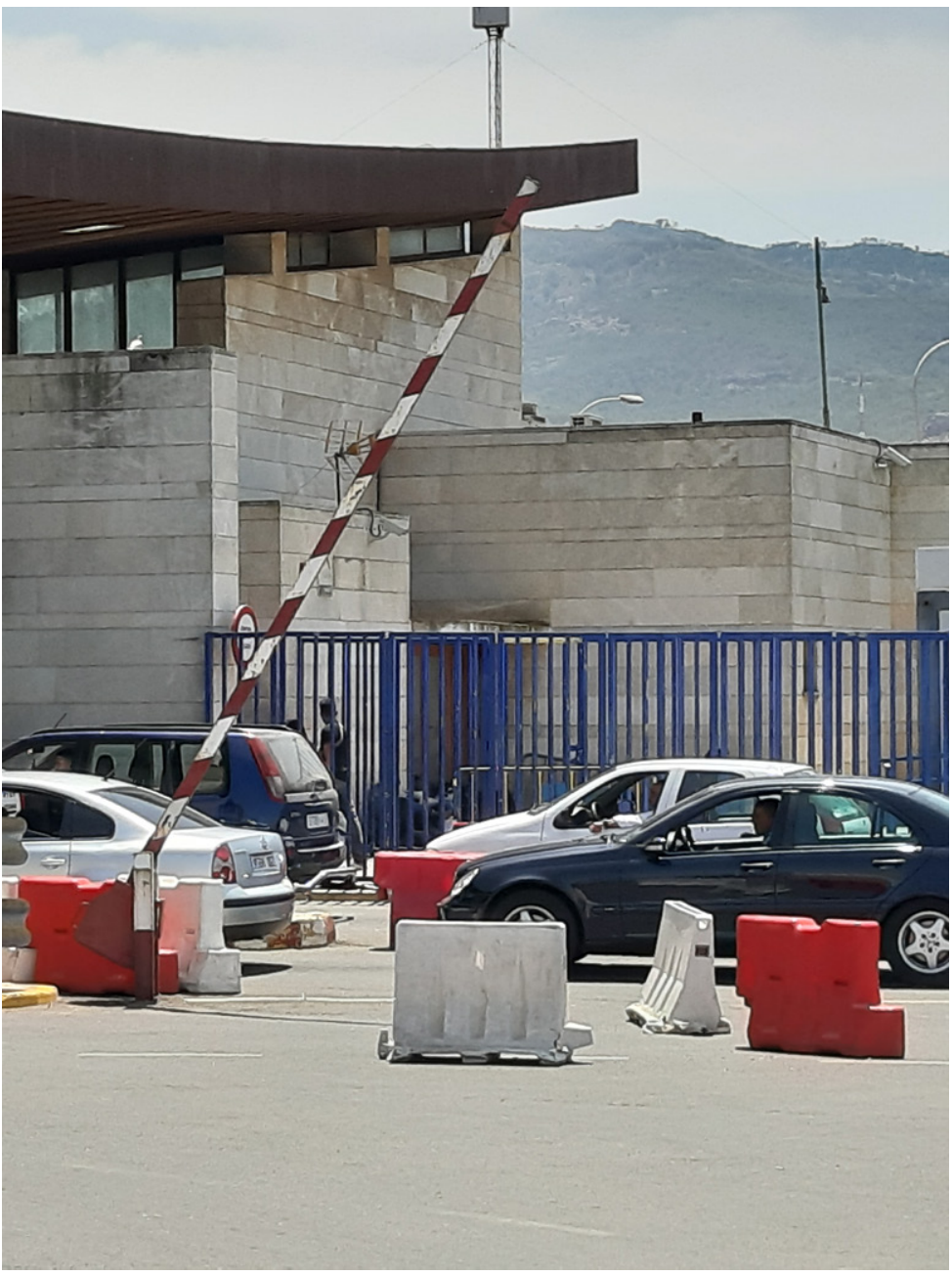

52 La reconstrucción de los hechos desde esta realidad a su dimensión posible ha sido posible, en buena medida, gracias a la entrevista realizada a José Palazón -miembro de Pro.de.in Melilla-. 
antes de bajar a tierra, fueron identificados con un número atado a su muñeca. Y, en función de su sexo y edad trasladados a diferentes arquitecturas de la frontera. Mientras que mujeres y menores fueron directamente enviados al Centro de Estancia Temporal de Inmigrantes próximo al paso de Farhana independientemente de los motivos de su entrada irregular en España. Allí, sus solicitudes de asilo serían evaluadas durante los próximos meses, un proceso administrativo que se puede demorar durante varios meses, en los que permanecerían vinculados al CETI de Melilla, pudiendo deambular con libertad por toda la ciudad autónoma hasta la resolución definitiva. Mientras tanto, los hombres fueron directamente llevados a los calabozos de la comisaría de Melilla, donde permanecieron custodiados hasta la mañana siguiente. Desde allí, sin posibilidad de asistencia, aseo o comida, fueron trasladados hasta la oficina de asilo donde se inicia un proceso de, en palabras de José Palazón, expulsión rápida. A través de los convenios y acuerdos establecidos con las autoridades marroquíes, existe un sistema de cooperación por la cual es posible realizar una devolución de los migrantes deportables, aún habiendo solicitado asilo ante las autoridades españolas, en un plazo inferior a los diez días. Y, una vez puestos en custodia de los efectivos marroquís son deportados a diferentes localizaciones al sur de Marruecos o, directamente a terceros países limítrofes.

Esta expulsión rápida involucra tanto a autoridades policiales españolas como marroquís, y activa una serie de espacios que se ligan inmediatamente a la frontera: las embarcaciones de salvamento marítimo, el puerto, los calabozos, la oficina de asilo y hasta una esquina anodina bajo el sol que sirve como un improvisado lugar de retención que sólo requiere de la presencia de una serie de agentes policiales. Pero, sobre todo, visibiliza también la extensión de un ensamblaje territorial que va mucho más allá de la arquitectura de la valla y el paso fronterizo. Muestra, de manera descarnada la capacidad de desborde y contingencia que el fenómeno migratorio provoca en unas arquitecturas específicamente proyectadas para la impermeabilización, contención y control de los flujos migratorios. Pero además, esta condición de desborde muestra las intenciones no declaradas o la condición ideológica inherente a esta producción territorial: durante el cuidadoso diseño y construcción de una infraestructura arquitectónica que ha recibido inyecciones económicas constantes desde su creación no se ha previsto en ningún momento espacios adecuados para la espera de personas -o grandes grupospendientes de realizar una solicitud de asilo. Frente a ello, únicamente un espacio contingente a la intemperie, donde cuerpos marcados únicamente con un número escrito en una cartulina, esperan su devolución irregular a Marruecos. 


\subsubsection{LA INOPERANCIA DE LA ARQUITECTURA DE LA NORMA. MECANISMOS ARQUITECTONICOS EFÍMEROS EN EL PASO FRONTERIZO DEL BENZÚ.}

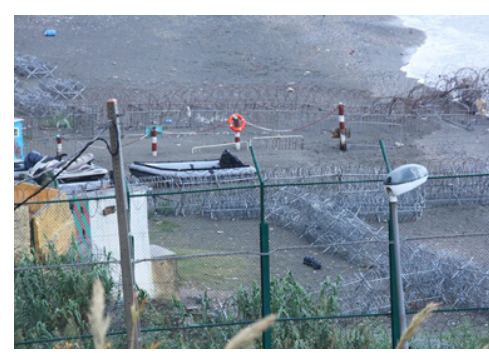

Despliegue de estructura tridimensional de alambre de espino en la playa de Benzú (Ceuta,2016)
A lo largo de la primavera y el verano de 2016 se produjeron numerosos cruces masivos no permitidos a través del paso fronterizo del Benzú, bien escalando o rodeando su perímetro a través del espigón y el mar que, en condiciones de bajamar hacía posible su cruce a pie. Esta repetición constante a lo largo de los meses, una de las cuales tuvo como protagonista a Star ${ }^{54}$, detonando la necesidad de reforzar con una serie de mecanismos arquitectónicos este paso fronterizo.

La valla, mucho menos militarizada que en otros puntos debido a la falta de tránsito regular así como a la propia orografía del terreno, resultaba insuficiente para impedir el cruce de la línea. Así, como también lo era el tiempo de respuesta de los "sistemas de impermeabilización" dado que la falta de un destacamento fijo, un puesto fronterizo de mayor envergadura y su relativa distancia a núcleos principales tanto por parte de Marruecos como de Ceuta hacía que este fuese bastante lento. Se necesitaba desarrollar un sistema que asegurase un tiempo de cruce más dilatado del paso fronterizo para poder interceptar a los migrantes. Para ello, el gobierno marroquí desplegó tres mecanismos arquitectónicos en las inmediaciones del paso fronterizo y en su prolongación hacia el interior de la costa. El Pueblo de Ceuta recoge gráficamente tanto su instalación como las características de estos tres elementos que, junto a la valla, formaban un ensamblaje mucho más eficaz. A diferencia de la naturaleza de la valla, su construcción y despliegue no se concibe desde la permanencia en el territorio, sino de su capacidad de movilización, ensamblaje y repliegue en cualquier punto de la manera más eficiente posible. La primera, la instalación de una superficie tridimensional de alambre de espino de más de cincuenta metros de longitud y veinticinco de ancho según se puede medir desde la fotografía satélite que la capta. La segunda, una alteración topográfica en el perímetro de la valla en el terreno montañoso próximo a Benzú. Y, la última, la asignación de nuevos efectivos policiales, en concreto y según las imágenes al menos nueve vehículos policiales localizados en las dependencias policiales marroquíes para permitir una mayor capacidad de respuesta instantánea sobre el terreno así como un desplazamiento eficaz hasta lugares próximos.

Los tres responden a una misma función: dilatar lo máximo posible el tiempo de cruce de la frontera. Unas intervenciones arquitectónicas que siguen la misma estrategia empleada desde mitad de 2005: el aumentar y complejizar la dimensión horizontal de la sección de la valla. Así pues, tres despliegues de diferente naturaleza ya que el primero añade nuevos elementos a esta sección, el segundo redispone la materia física existente a través de la manipulación topográfico y, un tercero que se basa en dar una mayor importancia a las medidas activas de impermeabilización -operativos policiales-. Tres operaciones aparentemente autónomas, independientes y dispersas territorialmente pero que logran optimizar el funcionamiento de un ensamblaje arquitectónico estable y temporal a la vez.

El primer mecanismo consiste en la construcción de una estructura tridimensional de alambre de espino o concertinas de aproximadamente un metro de altura. De similar composición a las alfombras desplegadas en la valla

54 El cual ocasionó un gran despliegue policial al permanecer en el espesor ínfimo de la valla durante dos días y medio. 
marroquí, pero con una disposición sobre la playa diferente, dado que si las primeras se posicionaban de manera lineal aquí la función es abarcar y densificar toda la superficie posible de la playa. Más de mil metros cuadrados fueron parcelados a través de la colocación de este sistema.

Dada la orografía montañosa del terreno una vez se aleja la línea fronteriza del mar, el despliegue de esta malla resulta ineficaz por la vegetación e irregularidad. Con lo cual se decide emplear un segundo mecanismo que también forma parte de la sección constructiva formal de la valla en otros lugares. Con máquinas retroexcavadoras se generó una nueva topografía entre las diferentes garitas existentes. Un foso de cinco metros de ancho y más de dos metros de profundidad. Esto altera la dureza del terreno durante los primeros días a un firme menos blando, y además multiplica la sección a recorrer así como su dificultad al tener que ascender y descender de manera brusca.

El último mecanismo no tiene una materialización física clara, sin embargo si tiene efectos claros en la eficacia de este ensamblaje. El aumento de patrullas motorizadas por parte del gobierno marroquí confirma el desplazamiento de medidas pasivas a agentes activos a la hora de garantizar la impermeabilización de la frontera. Nueve vehículos policiales de alta capacidad para transportar agentes y material antidisturbios permiten optimizar el tiempo de respuesta tanto en las inmediaciones del paso fronterizo como su desplazamiento a otros puntos.

De todos los mecanismos es posible acreditar el funcionamiento dinámico que poseen las tres por los motivos ya explicados. Sin embargo, sólo hay evidencia fotográfica del carácter temporal de una de ellas: la instalación superficial de alambradas de espino en la playa. Los sucesivos barridos del satélite de Google

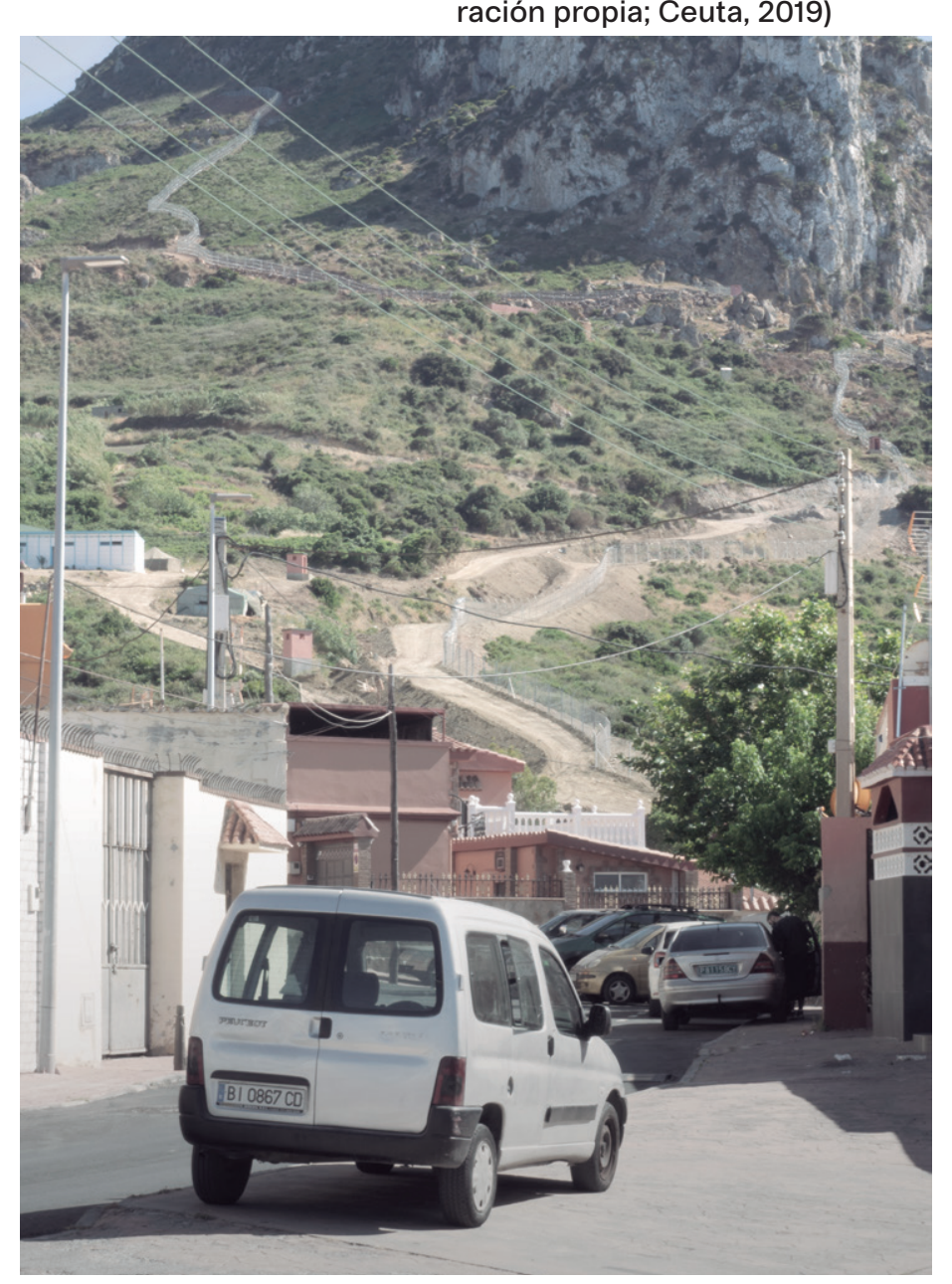



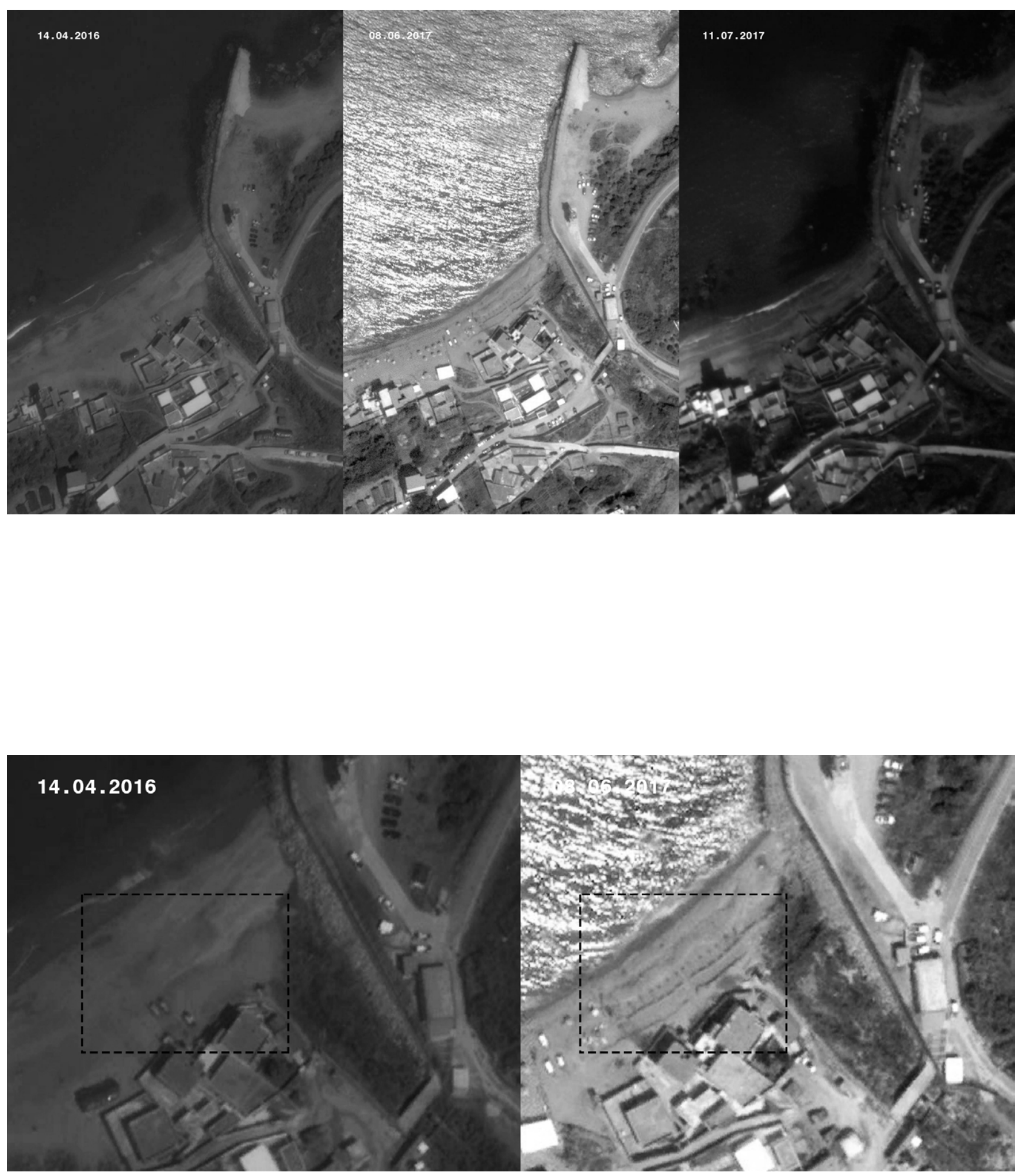

Detección de la instalación y retirada de la estructura tridimensional de alambre de espino en las imágenes satélite (Imágenes de LandSat y elaboración propia; Ceuta, 2016-2017). 
Earth sobre el paso fronterizo del Benzú permiten determinar la duración aproximada de este sistema antes de ser retirado. Al comparar la serie de imágenes se puede apreciar la sombra arrojada del alambre de espino así como las trazas poligonales de su disposición sobre la arena. Trece meses de duración efectiva máxima desde su despliegue hasta su repliegue según las imágenes satélite, algo que no sería posible con una arquitectura construida según las inercias propias de una construcción tradicional. Además, esta ni podría ser mejorada, ni transformada, ni trasladada a otro lugar con la misma facilidad que este ensamblaje arquitectónico, que ya no es sólo el puesto fronterizo regular -la valla, el puesto de control y los agentes- sino también la alfombra superficial de alambre y el resto de elementos.

Y es precisamente este elemento, la alambrada de espino capaz de desplegarse y replegarse con facilidad en horas o días, una de las construcciones que mejor representa la frontera contemporánea. Y, es precisamente esta capacidad de materialización instantánea la que aporta un grado diferencial respecto al mismo elemento que corona la valla. Si en la valla este elemento constructivo tiene una función estática -al menos en una escala temporal amplia comparado con la instalación analizada-, aquí su despliegue dura tan sólo unos meses como atestigua la comparativa de imágenes. Esta facilidad de instalación, así como su aparente fragilidad frente a alternativas más sólidas son, como señala Thomas Nail, indicadores de por qué este material constructivo y no otro evidencia las características espaciales que requiere la frontera a día de hoy:

El alambre de espino puede ser transportado e instalado más rápido que cualquier otra valla, muro o celda en la historia [...] el alambre de espino puede aparecer rápidamente y ser transportado a cualquier punto. Además, el alambre de espino es altamente flexible y adaptable a cualquier situación espacial. Puede ser añadido a una serie de postes de vallado (valla de alambre de espino), puede ser añadido a cualquier supeficie de un muro (el muro de seguridad de alambre de espino), o puede dársele forma rápidamente de celdas de una institución ( las icónicas alambradas de los campos de concentración o de las celdas de retención). No solo puede ser transportado rápidamente a cualquier punto, puede ser desenrolladoe instalado en cualquier punto. Cuarto, el alambre de espino es fino. A cierta distancia apenas es visible, y prácticamente invencible al fuego enemigo, así como su producción es muy barata. Al igual que el puesto de control, es como una tela de araña, una red de pesca o tamiz que deja que la luz, el aire y las balas lo atraviesen mientras que captura los cuerpos de animales y humanos en sus espinas. [...] Su casi invisibilidad invierte el "juego de la visbilidad. Mientras que antes uno podía esconderse para atacar una barrera visibile, ahora es la barrera la que está escondida de la persona que intenta transgredirla ${ }^{55}$.

A través de una inversión de la visibilidad es cómo estos mecanismos arquitectónicos, sumados a la militarización progresiva de una arquitectura que cada vez tiene más peso tecnológico y operativo, es cómo se configura la arquitectura de la frontera. Una suma de elementos independientes, en este ejemplo la alambrada, la topografía, los operativos policiales y la valla construida, que logran maximizar el funcionamiento del ensamblaje fronterizo. Sólo al interactuar con cada uno de los elementos - la alambrada, la topografía alterada, o la propia valla-, al intentar transgredir y cuestionar su función de diseño se visibiliza el esfuerzo añadido que, cada uno de ellos ejerce sobre el cuerpo que lo cruza. 



\subsection{FRONTERAS ELÁSTICAS, ARQUITECTURAS OPERATIVAS Y SISTEMAS DE IMPERMEABILIZACIÓN DE MASAS}

\subsubsection{INTRODUCCIÓN}

En su declaración en sede parlamentaria tras la muerte violenta de catorce migrantes y veintitrés heridos de gravedad como consecuencia del despliegue policial para impedir el cruce no regular en el paso fronterizo del Benzú de dos centenares de migrantes, el entonces ministro del Interior Jorge Fernández Díaz afirmaba lo siguiente: "la impermeabilización de nuestras fronteras significa la seguridad de la Unión Europea”. ¿A qué se refería con el término impermeabilización? El termino impermeabilización y control de masas hace referencia a los despliegues operativos de aparatos de intervención policial comandados por la Guardia Civil destinados a asegurar el correcto funcionamiento de una arquitectura que por si sola resulta ineficaz para impedir la transgresión de la línea geopolítica que separa Europa de Marruecos. Así explicaba, en sus propias palabras, en qué consistía tal sistema de impermeabilización:

A las 05:45 del pasado día 6 del actual mes de febrero, uno de los equipos de vigilancia del perímetro fronterizo, con cámaras térmicas, detectó en los montes próximos al vallado un grupo de inmigrantes de aproximadamente 200 personas acercándose al mismo. Según los protocolos de actuación en vigor, esta incidencia fue comunicada de forma inmediata al Centro de Operaciones Complejas, quien alertó al resto de la fuerza en servicio de la Comandancia de la Guardia Civil, al Módulo de Intervención Rápida, MIR, de la Agrupación de Reserva y Seguridad, que para reforzar los servicios de impermeabilización fronteriza se encuentra comisionado en la comandancia, así como al Servicio Marítimo Provincial y al Grupo Especial de Actividades Subacuáticas, GEAS. La alerta de las unidades anteriormente citadas supuso establecer el máximo nivel de alerta y el empleo de la totalidad del potencial de servicio de la comandancia, todo ello al objeto de garantizar que esa incidencia fuese atendida por un número adecuado de personal propio de la Guardia Civil, cuestión que se produce con mucha frecuencia. Al mismo tiempo, la presencia y ubicación del grupo de inmigrantes fueron comunicadas a las autoridades marroquíes al objeto de impulsar la actuación de las mismas en su territorio, poniendo a su disposición de forma permanente cuanta información sobre los movimientos de los inmigrantes fuera observada por las cámaras térmicas ${ }^{56}$.

El Ministro del Interior se refiere a los sistemas de impermeabilización como el conjunto de "medidas activas de vigilancia, contención y rechazo que la Guardia Civil lleva a cabo (...)mediante el empleo legítimo de la fuerza basado en el uso de medios antidisturbios reglamentarios" frente a las medidas pasivas de contención. Es decir, frente a una arquitectura estable y construida, la impermeabilización de la frontera reside, en 2014, en ensamblajes operativos con un carácter dinámico e instantáneo. Despliegues inmediatos que evalúan la

56 Comparecencia del Señor ministro del Interior (Fernández Díaz) en la Comisión de Interior sesión no 25 celebrada el 13 de febrero de 2014 (Diario de Sesiones del Congreso de los Diputados nํ500, 13 de febrero de 2014), 4 . 
situación a través de diferentes sistemas de vigilancia y coordinan los diferentes agentes -arquitectónicos, técnicos, humanos...- necesarios para neutralizar cualquier posible entrada no autorizada.

Sin embargo, estos sistemas no siempre han tenido este carácter dinámico. Tan sólo hace falta remontarse a la declaración hecha por su homólogo socialista en 1995 para darse cuenta cómo en un lapso temporal de dos décadas esta acepción sufre profundas transformaciones. Juan Alberto Belloch explicaba en el hemiciclo, a raíz de una pregunta parlamentaria, en qué consistían entonces los sistemas de impermeabilización:

Las medidas van a ser las siguientes. En primer lugar, impermeabilización de la frontera. [...] desde mañana mismo se va a proceder a la instalación tanto de unas alambradas alrededor de toda la zona como asimismo de zonas de alumbrado. Se han enviado ya dos unidades básicas de la Guardia Civil, lo que equivale a cien miembros de la misma. Se va a enviar para la zona y para el control de la frontera un helicóptero con misión específica de control57.

Belloch se refiere en primer término a las medidas arquitectónicas concretas que piensa ejecutar sobre la valla en proceso de construcción. El refuerzo de impermeabilización opera en primera instancia a través de la inclusión, refuerzo o transformación de elementos constructivos que mejoren la eficacia del conjunto. Y, en segundo lugar, como medida auxiliar aparecen los agentes humanos y no-humanos que, con carácter operativo, se despliegan sobre la frontera.

Fernández Díaz confirma el giro dinámico que se ha producido en la gestión y construcción de la frontera contemporánea respecto a su antecesor Belloch, empleando además en su discurso una serie de símiles hidráulicos a lo largo de toda su intervención: impermeabilización, flujo, contención, regulación... No presentaba en el relato de los hechos a la frontera como una realidad estable, sino como una serie de ensamblajes arquitectónicos destinados a la contención, redirección o desviación del flujo de personas. Precisamente, las transformaciones arquitectónicas y aparentemente no arquitectónicas de la valla permiten reconocer claramente la realidad de este giro dinámico; un giro que reconoce una realidad en base a las acciones de los agentes, algo que ha estado presente en otras épocas históricas pero que ha ganado gran relevancia en las últimas décadas. La capacidad de desterritorialización mediada a través de la innovación tecnológica, pero sobre todo los criterios de operatividad que trasladan del peso de una ley rígida e histórica a decisiones tácticas encarnadas en agentes, cuerpos y construcciones ha hecho posible la traslación hacia un nuevo modelo de gestión del territorio y de la línea que lo delimita.

\subsubsection{FRONTERAS ELÁSTICAS}

Fernández Díaz fue el que popularizó, al intentar dar cobertura legal a una práctica excepcional, dos términos íntimamente relacionados: frontera elástica -o retráctil-y devolución en caliente. Ambos íntimamente ligados a través del concepto de operatividad o excepción que pone en suspenso la legislación vigente para introducir protocolos policiales y tácticas con un único fin: impedir la entrada de cuerpos en el espacio político europeo por más que sí se sitúen 
físicamente en él. Fernández Díaz explicita en su comparecencia la separación entre el plano político y el plano geográfico que se superponen en una misma realidad espacial:

Es preciso diferenciar el concepto geográfico o topográfico de frontera del concepto jurídico político de frontera, que procede, a su vez, de la exigencia operativa de articular un control eficaz de la frontera y garantizar su impenetrabilidad. Así, en el caso de la frontera terrestre, es bien conocido, y si no lo conocen algunos tengo el deber de informarles, que la línea fronteriza en sentido geográfico estricto llega mucho más allá de las dos vallas ${ }^{58}$.

Este control efectivo de la frontera del que habla Fernández Díaz se traduce en las infames "devoluciones en caliente". Una práctica policial cotidiana que materializa la línea retráctil y elástica, consistente en la inmovilización, retención y devolución de los cuerpos de los migrantes lo más rápido posible a territorio marroquí. Los medios empleados a tales efectos, los necesarios para garantizar su éxito. Una frontera que ya no se erige de manera homogénea sino que se aplica de manera individualizada sobre cada cuerpo con uno, dos o hasta cuatro agentes por cada migrante. Esta práctica espacial aprovecha las fisuras de una frontera basada en la excepcionalidad para operar a través de huecos normativos y espaciales. Uno de los ejemplos más claros registrados es la devolución en 2014 de un cuerpo inconsciente entre varios agentea de Melilla a Marruecos quienes, tras herirlo, lo portan hasta el otro lado de la valla atravesando los diferentes umbrales y puertas presentes en el espesor de la valla. En los minutos de duración de la grabación se vulneran todas las leyes que operan en la frontera, pero además el propio habeas corpus y muestra, de manera descarnada, la rapidez e inmediatez con la que son aplicados estos protocolos policiales. Ni los cauces regulares físicos o normativos son seguidos, sino que cualquier forma de devolución es válida para evitar que ningún cuerpo se sitúe políticamente en suelo español.

La arquitectura de la valla, encargada de materializar tanto la frontera geográfica como política -los límites soberanos del Estado- queda reducida a un símbolo que únicamente encarna la línea de separación geográfica. Esto se debe a la normalización de una práctica excepcional establecida en el año 2005 por el ejecutivo socialista -a consecuencia del aumento repentino de cruces no autorizados de la valla en Ceuta y Melilla- que definía la línea no en base a construcciones sólidas sino a la línea virtual formada por la conexión entre los diferentes agentes que formen el dispositivo de "impermeabilización y control de masas”. Una formulación que, en cierta medida, nos retrotrae a los disparos de El Caminante y los impactos de bala sobre el terreno que, sólo a través de su conexión imaginaria, se delimitaba la soberanía melillense en territorio marroquí. Así explicaba Fernández Díaz como, en base a su criterio, los cuerpos que incluso habiendo atravesado la línea definida por la valla, no llegaron a situarse en territorio español al no haber rebasado la línea retráctil o elástica definida por los cuerpos en movimiento de los agentes:

Este concepto operativo se consolidó en el año 2005, con ocasión de los primeros asaltos masivos a las vallas de Ceuta y Melilla y se ha mantenido inalterable en el tiempo hasta la fecha por la Guardia Civil, a las órdenes de los diferentes gobiernos de la nación. Con arreglo a este concepto operativo, los inmigrantes que son contenidos y rechazados en las líneas de vigilancia antes descritas no son objeto de devolución en caliente, pues este concepto parte de la base de que la devolución es consecuencia inmediata de una

58 Comisión de Interior sesión n⿳⼈ㅡㄴ 25 (Diario de Sesiones del Congreso de los Diputados nº 500 , 2014), 8.
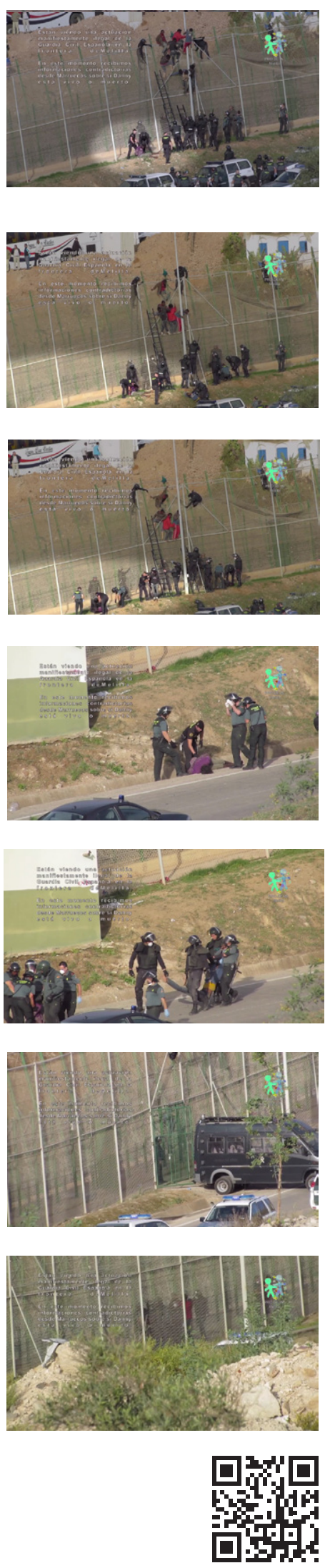

Devolución en caliente producida en la frontera de Melilla de un migrante inconsciente (José Palazón-Prodein; Melilla, 2014). 
entrada en territorio nacional. Por el contrario, en los casos que he descrito no se habría producido la entrada en territorio nacional, que es la que condiciona de forma expresa la producción de efectos del régimen de extranjería 59 .

Precisamente como señala el propio ministro, el giro producido en la gestión y construcción territorial de la frontera no radica en estos despliegues policiales que llevan en vigor desde el año 2005, sino con su normalización y amparo legal frente a la arquitectura de la norma que representa la valla ${ }^{60}$. Si en 2005, la justificación para la construcción de una frontera elástica en base a la posición y características de los cuerpos eran los "asaltos masivos a la valla" y la falta de seguridad de la misma, en la legislatura de 2011 a 2016 se constituyó como un proceso operativo cotidiano al que se intentó dar amparo legal.

Por tanto, incluso desde el propio Estado se reconoce ya en 2014 la realidad dual que se superpone sobre un mismo territorio Y, de nuevo, se nos remite al carácter excepcional de la frontera: aquello que ocurre en o más allá de los límites soberanos de un Estado, como justificación política del despliegue de medidas que van en contra de normativas internacionales. El carácter operativo donde es posible disparar a migrantes, anular las leyes de derecho internacional, los acuerdos soberanos entre España y Marruecos, el Habeas Corpus así como todos los procesos de ingreso y devolución pone en suspenso todas este conjunto normativo a través de unos cuerpos que representan un nuevo paisaje legal a través de sus acciones ${ }^{61}$. Se impone con cada frontera operativa, en términos de Agamben, la fuerza-de-ley por encima de la ley:

Se define así un "estado de la ley" en el que por una parte, la norma está vigente pero no se aplica (no tiene "fuerza") y, por otra, hay actos que no tienen valor de ley pero que adquieren la "fuerza" propia de ella ${ }^{62}$.

La entrada en vigor el 30 de marzo de 2015 de la Ley de Seguridad Ciudadana ${ }^{63}$ lo que hace es intentar invertir la dualidad establecida por Agamben y convertir en ley aquellas prácticas espaciales que, hasta la fecha, sólo era posible justificar desde la fuerza-de-ley o la excepcionalidad. Además, asume el carácter retráctil y elástico de la frontera contemporánea, trasladando a las acciones de los cuerpos una soberanía encarnada, que ya no puede definirse a través de geometrías claras y estables, sino campos difusos. Simplemente con una disposición adicional dentro de la Ley de Seguridad Ciudadana, tan vaga como amplia, se vuelve a intentar regular con una única norma construcciones espaciales mucho más complejas:

59 Comisión de Interior sesión n⿳o 25 (Diario de Sesiones del Congreso de los Diputados nº 500 , 2014), 7 .

60 A estos efectos, resulta muy interesante comprobar como en el año 2005 las palabras de Camacho, representante socialista también en el Parlamento concuerdan, prácticamente en su totalidad, como las pronunciadas una década más tarde por Jorge Fernández Díaz:

No voy a hablar de la frontera geográfica o topográfica, sino de fronteras políticas. Si hablamos de fronteras geográficas o topográficas, seguramente - decían el portavoz del Grupo Parlamentario Socialista y el entonces secretario de Estado, el señor Camacho- la frontera llega mucho más allá de las dos vallas. Si aplicamos esa regla de tres y ese razonamiento - decía el portavoz socialista - todas las personas que ya tocan la primera valla estarían en España y eso es materialmente insostenible. Señorías, no hay forma de detener ese flujo migratorio si hacemos esa interpretación jurídica-geográfica y no política.

61 Debemos englobar en esa amalgama de cuerpos que generan una nueva espacialidad excepcional tanto los cuerpos que atraviesan la construcción fronteriza como los despliegues operativos que intentan neutralizarlos.

62 Giorgio Agamben, Estado de Excepción: Homo Sacer II (Valencia: Pre-textos, 2010), 59. 63 Ley Orgánica 4/2015, de 30 de marzo, de protección de seguridad ciudadana (BOE $n^{\circ} 77$ de 31 de marzo de 2015). 
I. Los extranjeros que sean detectados en la línea fronteriza de la demarcación territorial de Ceuta o Melilla mientras intentan superar los elementos de contención fronterizos para cruzar irregularmente la frontera podrán ser rechazados a fin de impedir su entrada ilegal en España.

2. En todo caso, el rechazo se realizará respetando la normativa internacional de derechos humanos y de protección internacional de la que España es parte ${ }^{64}$.

El modelo espacial del lawscape, una de las bases que construyen esta investigación encuentra en los acontecimientos de fronteras operativas un ejemplo claro que visibiliza la vigencia de sus herramientas de análisis. El paisaje legal que define las potenciales acciones en un espacio no se reduce a la ley escrita o promulgada políticamente, sino que incluye toda una serie de pautas, normas escritas y no escritas, protocolos... encarnados en cuerpos. El uso continuado de las devoluciones en caliente, la construcción de una frontera retráctil y dinámica generada por los cuerpos policiales a voluntad, no es algo que se comience a implementar tras su formulación legal, sino que da cobertura legal, normativiza una práctica que antes se regía por criterios de una excepcionalidad cada vez más cotidiana. Frente a este cuestionado texto legal, la construcción espacial de la frontera sigue haciéndose en base a una violenta coreografía de cuerpos en interacción constante con las leyes que ellos mismos encarnan o a las que se enfrentan.

Sin embargo, por más que esta formulación elástica, retráctil o líquida de la soberanía estatal sea la que mejor se adecue a la construcción territorial de la frontera contemporánea debemos volver a la Ley para dilucidar si realmente es posible -desde el ámbito legal- definir a voluntad la extensión territorial de un estado soberano. Averiguar si es posible que residan los límites de un territorio simplemente en las acciones de unos cuerpos y la línea virtual trazada entre ellos ${ }^{65}$, por más que un gobierno lo plasme en una ley. Es extremadamente importante, dada la encrucijada que nos sitúa como investigadores en la intersección entre norma, cuerpo y espacio, entender esta cuestión, y así dilucidar si el papel de la valla sigue siendo el de encarnar la Ley -al menos en un sentido ortodoxo- o si ni siquiera lo hace al entrar en funcionamiento estos ensamblajes operativos. Detengámonos un momento en las principales críticas y argumentos jurídicos respecto al carácter retráctil de la frontera planteado por Fernández Díaz.

El 27 de junio de 2014, nueve meses antes de la entrada en vigor de la Ley de Seguridad Ciudadana, el informe jurídico 'Expulsiones en caliente': cuando el Estado actúa al margen de la ley visibiliza en primer lugar la condición excepcional o de fuerza-de-ley de esta práctica consistente en el retorno inmediato de migrantes a soberanía marroquí a través del uso de fuerzas policiales y antidisturbios. El propio título del informe establece la relación de la práctica respecto a su encaje jurídico. El segundo capítulo del informe realiza un recorrido a través de todos los aspectos relativos a la Ley de Extranjería que esta construcción operativa infringe o vulnera, ya que es esta ley la encargada de establecer los procedimientos y canales de devolución o negación de entrada de

64 Ley Orgánica 4/2015, (BOE nํㅡ 77, marzo de 2015).

65 Aunque no incumba de manera directa al objeto de estudio de esta investigación, es necesario señalar que al mismo tiempo que este gobierno normativizaba esta noción acerca de la línea fronteriza que residía, en última instancia en la voluntad coordinada de unos cuerpos encarnando una ley, perseguía políticamente un movimiento que reclamaba el ostentar esa misma posición soberana para definir su propio Estado. Las imágenes coincidentes temporalmente de los despliegues de antidisturbios en las playas de Ceuta contrastan con las que Diada tras Diada mostraban cadenas humanas definiendo con su posición tanto la voluntad como los límites geográficos de un nuevo territorio. 
extranjeros ante cualquier supuesto ${ }^{66}$. A continuación se califica de "inadmisible" el concepto operativo o elástico apoyándose en dos conceptos fundamentales, la extensión de la soberanía del territorio español está recogida en acuerdos internacionales y estos no pueden ser vulnerados. Además, precisa:

Las fronteras y los puestos fronterizos se fijan, las primeras por normas internacionales de obligado cumplimiento para todos los países y los segundos por normas de derecho interno con carácter general. A partir de esta normativa es indubitado que cualquier playa española, también la de las ciudades autónomas de Ceuta y Melilla, son territorio nacional, como también son zonas sujetas a la soberanía española las aguas de la orilla de dichas playas, ya que o bien son aguas interiores, al estar dentro de las líneas de base utilizadas para delimitar el mar territorial, o bien son mar territorial. Del mismo modo, también es notorio que la valla externa que delimita en determinadas zonas estas ciudades de Marruecos y que fue levantada en un primer momento por el Gobierno español, está construida sobre territorio español.

[...]no existe ningún tipo de norma jurídica que otorgue cobertura legal a un concepto de frontera que pueda ser determinado de forma caprichosa ad casu violando, entre otros elementales principios, el de la prohibición de la arbitrariedad y el de seguridad jurídica (art. 9.3 CE). No resulta jurídicamente defendible la tesis de que el Gobierno pueda modificar a su libre albedrío, "mediante una decisión libre y soberana" los límites del territorio nacional, aunque fuera, como textualmente se señala, "a los solos efectos de la ley de extranjería" ${ }^{6}$.

Señala un aspecto clave, y es la posición de la valla dentro del territorio español. Existe un imaginario territorial alrededor de la tierra de nadie, una extensión de territorio ajeno a cualquier soberanía delimitada de mutuo acuerdo entre ambos países limítrofes. Sin embargo, este territorio virtual no existe y, de hacerlo, únicamente podría encontrarse en el espesor inexistente de la línea geométrica que traza la división cartográfica entre uno y otro, ya que como afirma Acosta:

El concepto de Tierra de Nadie es desconocido en Derecho Internacional. Por su parte, el concepto de Zona Neutral estaría más vinculado a la existencia de una zona desmilitarizada, creada de mutuo acuerdo por los Estados implicados [...], pero que en ningún caso fuera de la jurisdicción o soberanía de alguna de las partes ${ }^{68}$.

De existir una superficie sin soberanía, únicamente podría localizarse en el espesor geométrico de una figura que, por definición, carece de ella. La línea soberana encarnada por la arquitectura, aún dándose el caso que coincidiese punto por punto con el trazado territorial, requiere una materialización que implica necesariamente un espesor constructivo y, por tanto, la posibilidad de que los cuerpos la habiten ${ }^{69}$ por más que su diseño esté explícitamente orientado a impedirlo. Solo en un espesor inexistente podemos encontrar las características necesarias para construir una tierra de nadie definida en base a sus ausencias: ausencia de normas, ausencia de cuerpos y ausencia de espacio. Pero, ya que

66 Margarita Martínez Escamilla y otros., Informe jurídico 'Expulsiones en caliente': cuando el Estado actúa al margen de la ley, (Proyecto I+D+i IUSMigrante, 2014), 3-5.

67 Escamilla y otros., Informe jurídico 'Expulsiones en caliente': cuando el Estado actúa al margen de la ley, 7 .

68 Acosta Sánchez, "Las fronteras terrestres de España en Melilla: delimitación, vallas fronterizas y tierra de nadie", 24-25. 
incluso en la construcción que ha de encarnar y materializar esta situación encontramos normas encarnadas en un espacio capaz de albergar y ser habitado por cuerpos -como muestra Star en lo alto de la valla- no podemos situar en ella esa tierra de nadie.

Sin embargo, aunque esto no fuese así, la posición de la valla sobre el territorio termina de decantar las dudas acerca de la situación política y territorial de cada uno de los cuerpos que se sitúe sobre la valla o atraviese la línea. Y es que tanto el informe jurídico mencionado como Acosta Sánchez coinciden en determinar la posición de la línea arquitectónica dentro de la soberanía española. Es decir, incluso antes que un cuerpo comience a trepar la valla exterior ya está físicamente en territorio español cedido a control marroquí. Además, y siempre según los argumentos jurídicos esgrimidos, también lo está políticamente por más que el gobierno español se haya empeñado en afirmar lo contrario.

Por otro lado, al reconocer el carácter dinámico y performativo de una línea que el gobierno decide materializar a través de la conexión entre agentes, debemos cuestionar hasta donde el lema “Todo por la patria” de la Guardia Civil -coordinadora de estos despliegues policiales- es realmente aplicable. ¿Acaso ese todo permite incurrir en la infracción manifiesta de leyes, normativas pero incluso protocolos policiales respecto al uso de armas?. Tal vez, no debamos buscar el espesor ínfimo en una arquitectura material como un hecho construido sino en el ensamblaje arquitectónico conformado por las conexiones virtuales entre agentes, la línea imaginaria trazada entre cuerpos policiales que construye la frontera operativa. ¿Podemos encontrar en ella el territorio excepcional -sin soberanía, sin espesor, sin espacio o sin cuerpos que puedan acceder a él- al que se remite Fernández Díaz?.

Aún así, esos cuerpos encarnan una serie de leyes, que no están exclusivamente asociadas a una extensión territorial sino a los agentes del Estado, lo que debería condicionar y limitar su capacidad de acción de acuerdo a una serie de regulaciones:

El sometimiento de la actuación de los poderes públicos a la Constitución y el resto del ordenamiento jurídico (art. 9.I CE) se proyecta no sólo a los supuestos en que la actividad de estos poderes se desarrolla en zona de soberanía territorial española, sino que, también, quedan sometidos al imperio de la ley por la mera circunstancia de ser una actividad desarrollada por empleados públicos españoles en el desempeño de sus cargos.

[...]

Más allá de consideraciones sobre si la actividad desarrollada por las Fuerzas y Cuerpos de Seguridad del Estado en este tipo de supuestos tiene lugar sobre los ciudadanos extranjeros antes o después de que estos se sitúen en zona de soberanía española, es indubitado que lo hacen en su calidad de funcionarios públicos y en el ejercicio de sus funciones. De ese modo, quedan sometidos al estricto cumplimiento de la Constitución y el resto del ordenamiento jurídico y cualquier procedimiento de control migratorio desarrollado debe tener amparo en la legislación de extranjería ${ }^{70}$.

De nuevo, la codificación absoluta del espacio fronterizo que se despliega con cada devolución en caliente da lugar a una frontera dinámica y elástica que no puede reducirse exclusivamente a las leyes escritas que la definen. De hecho, de acuerdo a ellas, los acontecimientos y despliegues espaciales producidos, y su alto grado de violencia, jamás podría producirse. Estamos ante unos acontecimientos donde se provoca una ruptura del conjunto de normas que rige un espacio y

70 Escamilla y otros., Informe jurídico 'Expulsiones en caliente': cuando el Estado actúa al margen de la ley, 8. 
que da paso a una coreografía de cuerpos totalmente codificada que amplia -o reduce $-\mathrm{y}$ finalmente determina sus posibilidades espaciales. Cada uno de ellos, formando parte del mismo ensamblaje, encarnan protocolos, normas, tácticas, estrategias que no tienen cabida en el encaje normativo de un Estado. Ni los cuerpos de los policía que deciden, deviniendo Soberanía, impedir a cualquier coste el cruce de la línea fronteriza aunque esto suponga el infringir leyes al disparar a cuerpos, negar el auxilio de rescate o ignorar los procedimientos de devolución; ni los cuerpos de los migrantes que cruzan la línea fronteriza encaramándose a la valla, exponiendo su carne a la laceración de un diseño cruel o internándose en aguas internacionales responden a estas leyes. Estos conforman una espacialidad propia donde son sus acciones, sus cuerpos en movimiento, la violencia de sus actos los que definen un paisaje legal en tensión y conflicto entre las partes, donde cada desplazamiento tiene una reacción inmediata que intenta neutralizarla. La arquitectura de la norma ha dado paso en la frontera a una concepción del territorio que difumina los los límites haciendo que éstos solo puedan enunciarse a despliegues instantáneos, agentes en movimiento y acciones detonada por la presencia y desplazamiento de un cuerpo en un espacio físico.

\subsubsection{LA RELEVANCIA DE LOS CUERPOS.}

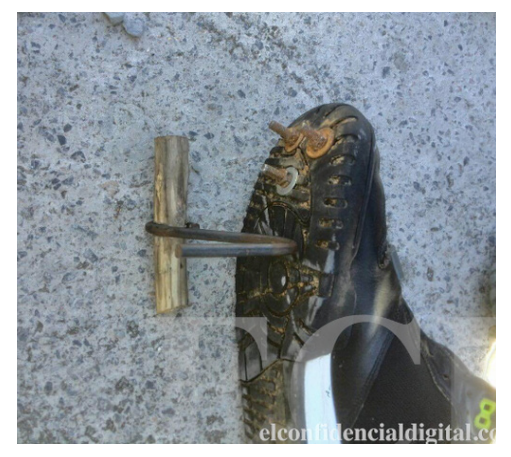

Bota-garfio construida por los migrantes para mejorar el trepado de la valla (El Confidencial Digital; Melilla, 2015).
Es precisamente en esta concepción operativa de la frontera cuando se puede visibilizar, de manera más clara el carácter post-humano de los cuerpos que, a un lado y a otro, conforman el dispositivo frontera. Un cuerpo que es protagonista absoluto de los ensamblajes temporales y efímeros, pero que no puede leerse exclusivamente como el cuerpo humano clásico, sino que sobre él se superponen diferentes capas tecnológicas, políticas, legales que difuminan su condición humana para mostrarnos una serie de prótesis físicas o no físicas pero que, en cualquier caso, tienen un impacto claro en las construcciones espaciales que generan. El cuerpo de los efectivos policiales ha evolucionado a través de una serie de prótesis militarizadas que refuerzan el carácter excepcional de la construcción haciendo que no se pueda desligar el uniforme, casco, botas y material antidisturbios - porras, escopetas con bocachas para lanzar pelotas de goma, esposas...- de sus acciones. Dicho de otro modo, no serían igual de eficaces en la impermeabilización de la frontera si no estuviesen también compuestos por todos estos elementos que amplían sus capacidades de acción. Un cuerpo que evoluciona y se transforma en función de las necesidades que requiere la impermeabilización y seguridad de la frontera. No es el único, pues de manera simultánea a estas transformaciones, el cuerpo migrante también se ha ido modificando para transgredir con eficacia la arquitectura. En un primer momento las escaleras sirvieron para alcanzar lo alto de una valla que, de otra forma dada su formalización sería imposible. Cuando la malla de trepado impidió que entraran sus dedos en los huecos, en sus pies aparecieron cangrejeras con barras de metal que sí permitían generar un soporte precario. Incluso, mediante el empleo de neumáticos hinchados alrededor de su abdomen, transformaron su índice de flotabilidad en caso de cruzar la línea a nado.

Pero además, estos cuerpos que van más allá de lo humano incorporan también la frontera y leyes que la rigen en sus carnes. Una ley "completamente encarnada" ${ }^{71}$, que se superponen también a un cuerpo híbrido. Un cuerpo que extiende sus

71 Andreas Philippopoulos-Mihalopoulos, Spatial Fustice: Body, Lawscape, Atmosphere (London: Routledge, 2014), 74 . 
límites más allá de los de su contorno definido, pero también las diferentes capas que lo conforman. Así, los cuerpos llegan a devenir frontera o exponerse a ser heridos para transgredirla. Situación que se ve claramente en los hechos ocurridos en el paso fronterizo del Tarajal, apenas unos metros separados de la línea de costa que constituye el siguiente apartado, en el interior del paso fronterizo.

El siete de agosto de 2017, en el interior del complejo arquitectónico se porduce una situación que muestra como la arquitectura sólida y estable, a través de situaciones excepcionales que desbordan las lógicas de diseño, hace que un cuerpo - que ya no es humano- encarna la construcción de la frontera. Un nutrido grupo de migrantes, cerca de doscientos, descendió de los montes marroquís pero, en vez de dirigirse a la playa o a la valla, decidió cruzar la frontera a través del paso fronterizo. Los sistemas de vigilancia alertaron del asalto y los sistemas de impermeabilización de masas se desplegaron en los puntos habituales, lo sorprendente fue que emplearon el mismo punto de acceso que, todo el tráfico rodado entre Ceuta y Marruecos emplea de forma diaria. En total, ciento ocheinta y seis migrantes lograron rebasar la línea fronteriza y, ya en territorio español, fueron llevados hasta el Centro de Estancia Temporal. El sistema de cámaras de videovigilancia capta el empleo de tres mecanismos diferentes para impedir su paso, que no resultan efectivos dado el número, velocidad y fuerza de este cuerpo migrante que, gracias a su desplazamiento colectivo, logra superar con éxito cada uno de ellos.

Es importante aclarar aquí la concepción de cuerpo colectivo, pues afecta directamente a la selección y empleo de diferentes tácticas que garanticen una mayor tasa de éxito. Por ejemplo, remitiéndonos a este mismo paso fronterizo, es cruzado de manera irregular habitualmente en el fondo de camiones, bajos de coche y otras cavidades que de manera artesanal se generan en vehículos convencionales. Esta táctica sólo puede emplearse de manera individual. En un número algo superior, no más de diez o doce personas, este mismo paso fue atravesado con coches a gran velocidad que impactaban contra las diferentes barreras, rompiéndolas y con ellas su negativa a situarse en territorio español. Tanto un único migrante como una docena, estarían en clara desventaja si, tan sólo con su cuerpo, intentasen atravesar el complejo arquitectónico; sin embargo, al devenir un cuerpo colectivo sus posibilidades de éxito aumentan exponencialmente. Los contornos de este cuerpo migrante ya no se limitan a cada uno de sus cuerpos sino a una envolvente mucho más difusa, que sólo puede ser enunciada como una suma heterogénea o ensamblaje, que aumenta o disminuye sus posibilidades espaciales.

La primera medida tomada para garantizar la impermeabilizar la frontera es el cierre de los posibles puntos de paso. La puerta y valla exterior que cierra el paso de vehículos, en un momento dado, cede ante la presión exterior de los migrantes. No se consigue cerrar completamente y, ese resquicio genera una fisura a través de la cual penetra el flujo constante de cuerpos a la carrera. Se activa entonces el segundo mecanismo, que consiste en el despliegue de un grupo de agentes policiales dotado de porras y material antidisturbios ligeros desplegados en los diferentes carriles del interior del paso que intenta bloquear el flujo. Sin embargo, el número de efectivos no es suficiente para contener al cuerpo que avanza hacia territorio español. Uno de los agentes, ante el fracaso del resto de medios decide encarnar, no ya en sus acciones, sino en su propio cuerpo, la ley para intentar detener la entrada de migrantes. Así, deviene Ley al extender su pierna y, a patadas, la dirige contra los cuerpos que avanzan a gran velocidad hacia él. Si bien el primer impacto es fructífero, el segundo le causa una rotura de fémur que obliga su traslado al hospital.
Entrada irregular en Ceuta a través del paso fronterizo del Tarajal (Grabación de seguridad; Ceuta, 2017)
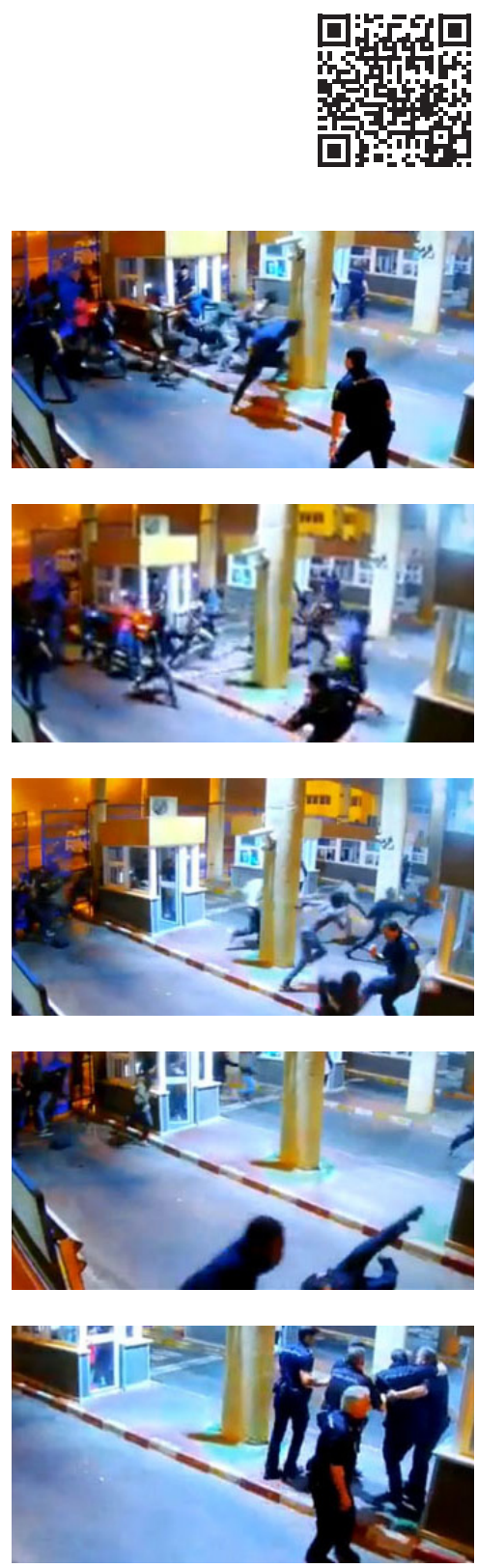
En última instancia, cuando el resto de mecanismos de control espacial fallan, son los cuerpos los que construyen una frontera en movimiento, una confrontación de fuerzas, tácticas y desplazamientos constante. La condición operativa de la frontera bascula este peso de arquitecturas estables a coreografías de cuerpos que ya no son sólo humanos. Pero también es hacia los cuerpos -humanos, no-humanos y materia arquitectónica- a los que se dirige de una manera explícitamente violenta todas las tecnologías necesarias que aseguren su exclusión espacial de un territorio que les es impermeable. Unos cuerpos que devienen ley o transgresión o, mejor dicho, un conflicto y disputa constante entre todos los cuerpos ensamblados. Y, al devenir leyes encarnadas sufren las consecuencias de una violencia espacial dirigida a la materia que los conforma pues, sólo a través de su destrucción o anulación, serán anuladas también las normas que representan.

\title{
3.3.3 DESPLIEGUES OPERATIVOS Y SISTEMAS DE IMPERMEABILIZACIÓN DE MASAS. EL CASO DEL TARAJAL.
}

\author{
El problema esencial vinculado a la suspensión del de- \\ recho es el de los actos cometidos [...] cuya naturaleza \\ parece eludir cualquier definición jurídica. En cuanto no \\ son ni transgresivos, ni ejecutivos, ni legislativos, parecen \\ situarse, con respecto al derecho, en un no-lugar absolu- \\ to $^{72}$. \\ Giorgio Agamben
}

Traslademos esta noción elástica a un acontecimiento concreto para comprender las características y consecuencias espaciales de la frontera operativa que se ejerce en el perímetro fronterizo de manera continuada desde el año 2005. Este análisis espacial podría desarrollarse sobre infinidad de ejemplos y en todos encontraríamos una serie de patrones comunes respecto a las implicaciones arquitectónicas así como a la configuración de un espacio de excepción absoluta en base a las acciones de los cuerpos. Sin embargo, se ha decidido poner el foco sobre los acontecimientos ocurridos en el paso fronterizo del Tarajal (Ceuta) la noche del seis de febrero de 2014 donde murieron catorce migrantes y hubo varias decenas de heridos por dos motivos que le hacen cobrar una relevancia diferencial respecto a otros. El primero de ellos, la dimensión explícitamente política y mediática que cobró el caso a raíz de las muertes que obligó tanto a Guardia Civil como al Ministerio del Interior -e incluso al propio ministro- explicar con todo lujo de detalles desde su óptica como se habían desarrollado los acontecimientos. La extrema violencia desplegada hizo que no sólo desde fuerzas estatales sino también desde organizaciones sociales se elaborasen informes y documentos que contrastasen el discurso único mostrando sus incoherencias; es el caso del informe jurídico al que nos hemos remitido pero también el elaborado por Caminando Fronteras ${ }^{73}$ que recoge los daños sobre los cuerpos, pone cara y nombre a cada una de las personas involucradas. Pero, lo más relevante ocurrido en el Tarajal fue la descajanegrización de una práctica espacial de la que sólo se conocían fragmentos puntuales. ¿Qué produce esta diferenciación respecto a acontecimientos previos o posteriores? Su registro audiovisual es extenso y exhaustivo a raíz de la

72 Agamben, Estado de Excepción (2010), 76.

73 Caminando Fronteras, «Informe de análisis de hechos y recopilación de testimonios de la tragedia que tuvo lugar el 6 de febrero de 2014 en la zona fronteriza de Ceuta», (Informe, 
publicación de los informes y material de las fuerzas policiales. Los mismos medios tecnológicos destinados a supervisar, controlar y mejorar la eficacia del despliegue operativo extraen a la esfera pública una cartografía fragmentada que es necesario recomponer para comprender las acciones llevadas a cabo ${ }^{74}$. Gracias a ello es posible contrastar el discurso político con la reconstrucción forense de los hechos evidenciando la separación o contradicción entre uno y otro. Los sensores no-humanos de las cámaras de videovigilancia, así como el registro forense de las heridas en los cuerpos, desposeídos de su uso original y extraídos a la esfera pública permiten contraponer en igualdad de condiciones las palabras frente a los hechos materiales que han tenido lugar en la playa del Tarajal.

La noche del seis de febrero de 2014, a las 05:45 de la mañana, las cámaras térmicas de vigilancia del perímetro fronterizo detectan a un grupo de migrantes, aproximadamente doscientas personas según cifras gubernamentales y más del doble según ONGs e informes independientes, que descienden del monte marroquí -donde se sitúan los campamentos provisionales donde habitan- en dirección al paso fronterizo del Tarajal. Minutos más tarde, la cámara situada en el complejo edificatorio aduanero corrobora el descenso: los migrantes alcanzan las inmediaciones del paso fronterizo y atraviesan la carretera vallada aprovechando un un paso subterráneo que comunica con la playa marroquí. La playa marroquí está separada de la española por una valla de una única capa y seis metros de alto que se sitúa sobre un espigón que se adentra treinta metros en el mar con marea baja y sesenta con pleamar. Ambas poseen escasa pendiente con lo cual, a pesar de la distancia hasta la línea de costa en el momento de marea alta, se hace pie mucho antes. Además, su emplazamiento dentro de la bahía reduce su exposición al posible oleaje. Una tercera cámara, situada sobre el puesto de vigilancia del espigón -una atalaya de planta cuadrada y nueve metros de alto levantada sobre cuatro pilares de hormigón- registra simultáneamente, según el registro temporal incluido en los vídeos, como se despliega el "sistema de control de masas e impermeabilización de fronteras” en las inmediaciones del espigón.

Este sistema técnico, así denominado por el Ministro de Interior durante su declaración en la comisión de investigación se compone materialmente de trece unidades móviles de la Compañía Rural armadas con material antidisturbios, el módulo de intervención rápida de la Guardia Civil, dos embarcaciones policiales así como los medios técnicos - cámaras de seguridad, sirenas, focos móviles y sistemas de iluminación, sistemas de vigilancia térmica, o el ya mencionado SIVE [Sistema Integrado de Vigilancia Exterior]- correspondientes controlados desde diferentes policiales a ambos lados del Estrecho de Gibraltar. Un inventario de los medios antidisturbios empleados permite visibilizar por un lado el grado de militarización que alcanza este despliegue operativo así como una comprensión en detalle de los medios empleados para reforzar y asegurar la línea fronteriza:

El grupo de la Compañía Rural de Ceuta movilizó 13 vehículos, en cada uno de los cuales había un arma con bocacha (adaptador) para lanzamiento de medios antidisturbios y una bolsa con 20 pelotas de goma, cuatro "botes lacrimógenos" y 40 cartuchos de fogueo.

Además, el personal del módulo de intervención rápida integrado por agentes de la Agrupación de Reserva y Seguridad (ARS) del Grupo de Reserva y Seguridad (GRS), una unidad de apoyo procedente de Sevilla, "hizo uso de 9 bocachas" con otras tantas mochilas en cuyo interior había 20 pelotas de goma, 6 botes de humo "de ocultación" y dos cargadores con 20 cartuchos de fogueo.

74 Es necesario indicar que, aunque la gran parte del material utilizado haya sido el procedente de las diferentes cámaras de videovigilancia y SIVE puestas a disposición pública por el Ministerio del Interior, la grabación ciudadana realizada desde la vía pública también es de suma importancia para ayudar a reconstruir la dimensión espacial del acontecimiento del Tarajal. 


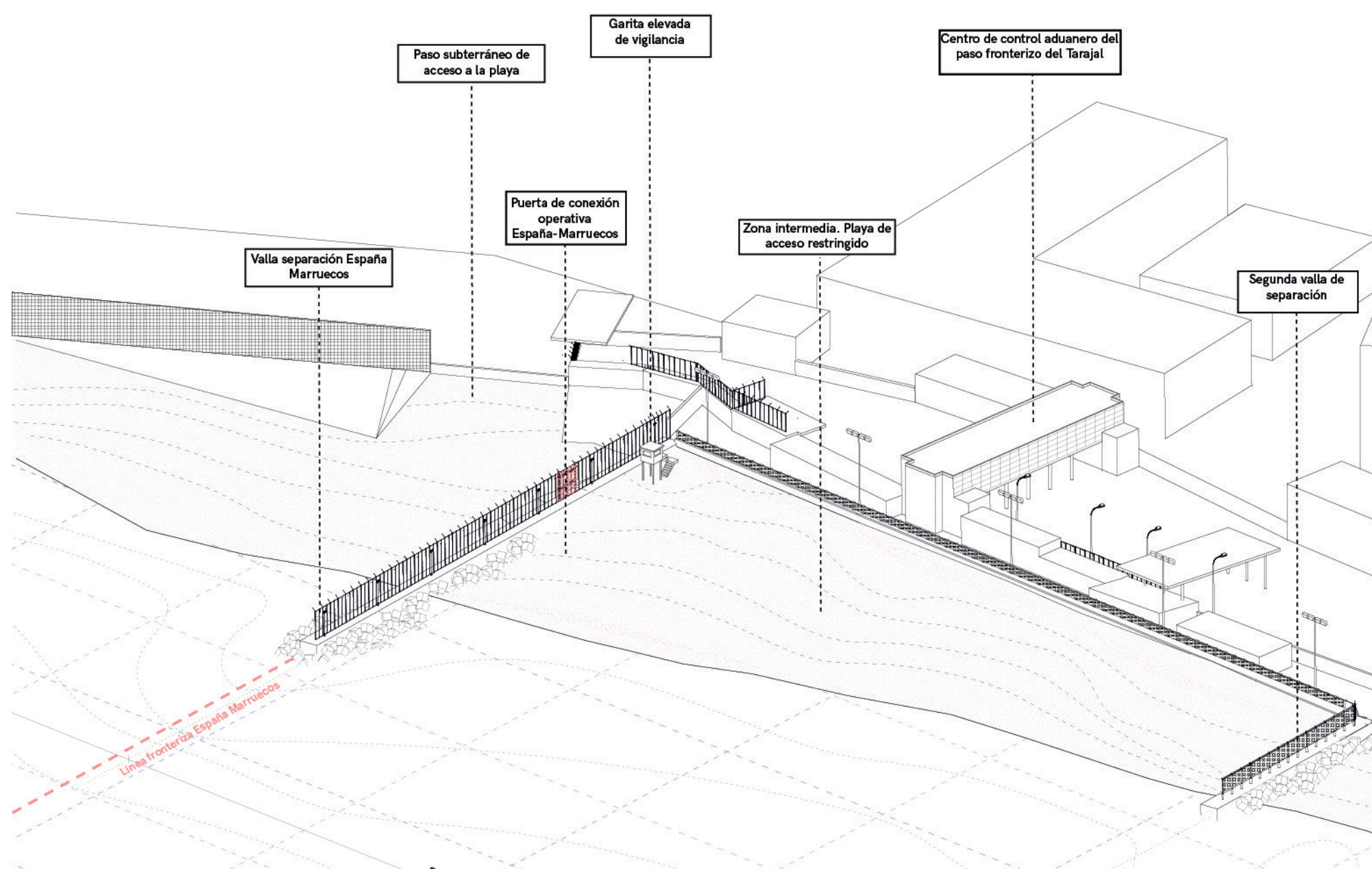

$210 \mathrm{~m}$

$40 \mathrm{~m}$ 

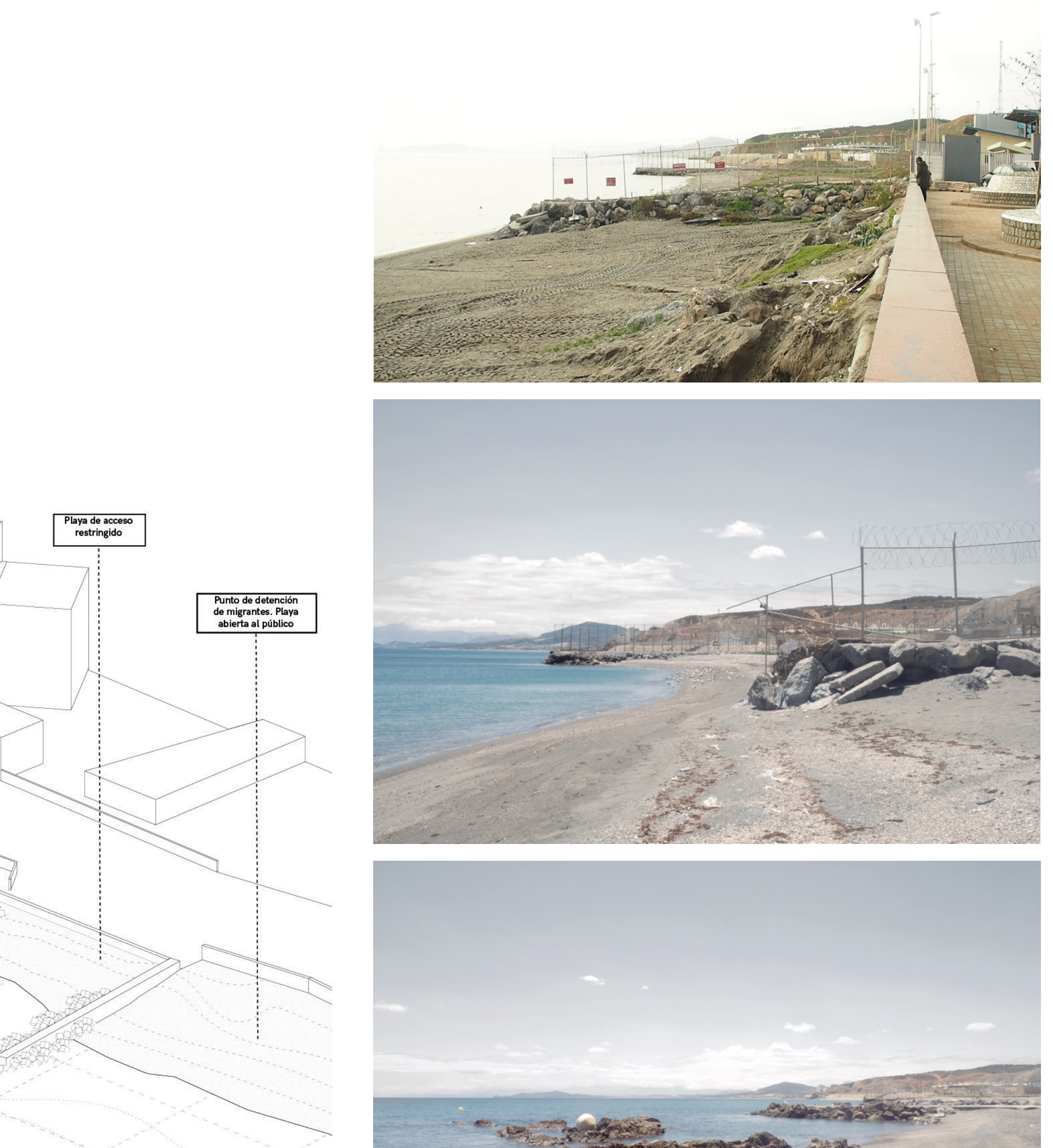

Paso fronterizo del Tarajal. Axonometría (izquierda) Fotografías (arriba) (Elaboración propia; Ceuta, 2014 y 2019)

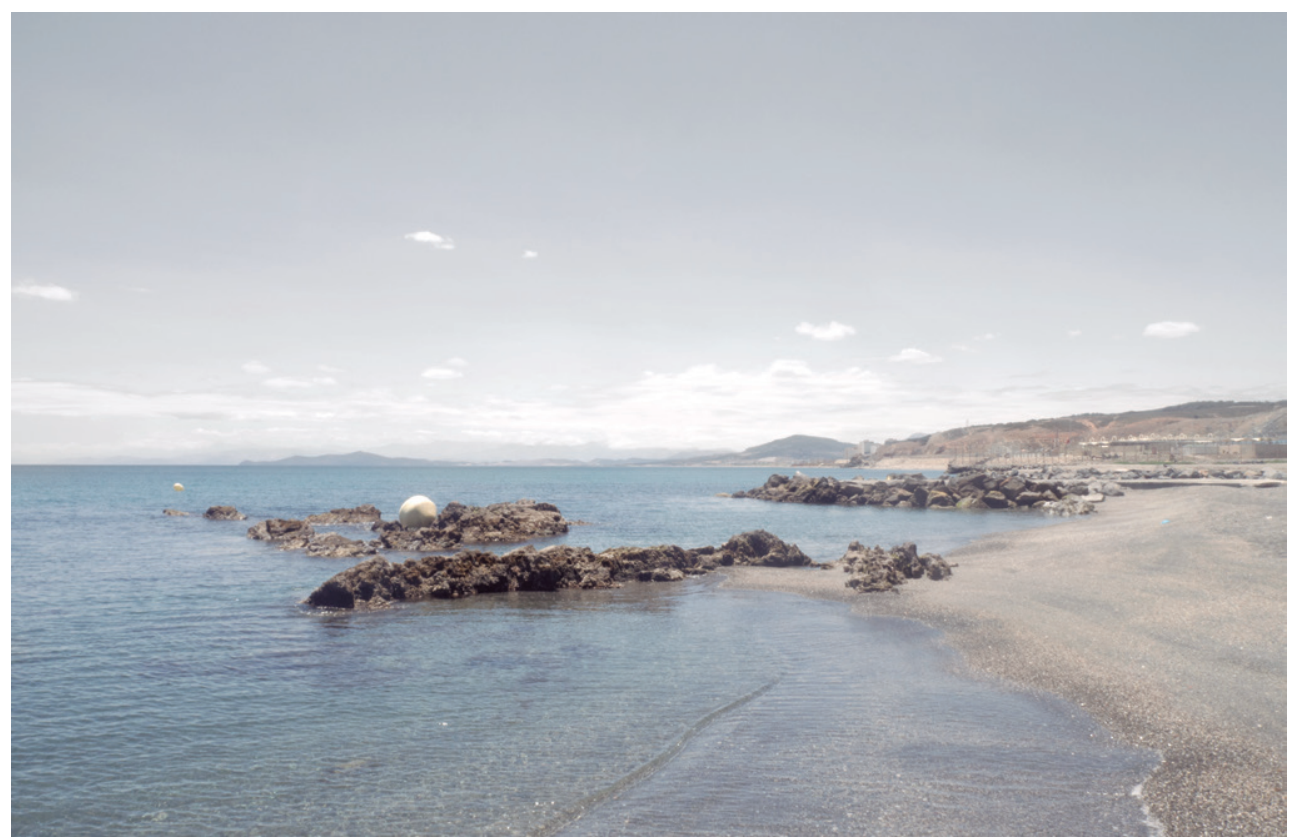


El espigón y la valla, en lo que dura un despliegue de cerca de media hora, pasa a formarse no sólo por los materiales constructivos que la definen, sino por un ensamblaje móvil que también incluye a todos estos agentes.

Un sistema de impermeabilización que, en medios humanos, constaba -por parte española- de dieciséis policías armados con escopetas cargadas con pelotas de goma situados a lo largo del espigón y un número igual o superior dispuesto a lo largo de la playa. A lo que hemos de sumar dos embarcaciones de diferente calado que también ejecutaron maniobras de contención y lanzaron gases lacrimógenos. Y, además, los medios marroquíes, también presentes durante el acontecimiento, pero de los cuales se desconocen los datos técnicos respecto a los medios empleado más allá del empleo de fuerzas policiales, un destacamento del ejército marroquí y una embarcación semirrígida que actuaron antes de que los migrantes tocasen el agua repeliendo las agresiones y "con la intención de embolsar a los inmigrantes" 75 en tierra mientras que la barca efectuaba "maniobras disuasorias para que los migrantes desistieran y regresaran a la playa"76.

A partir de las 07:30 A.M las imágenes de las cámaras de videovigilancia situadas en el perímetro fronterizo resultan más confusas por dos motivos. En primer lugar, la parcialidad del campo visual que impide tener una visión de conjunto debido a su colocación y, en segundo lugar, sus características técnicas impiden un gran detalle en condiciones de baja visibilidad. Las cámaras que registran el espigón apenas se distinguen los fogonazos sucesivos de las escopetas y los cuerpos de los policías en movimiento constante. El resto de ellas, centradas en el perímetro terrestre, apenas registran movimiento. Sin embargo, la cámara térmica y de largo alcance perteneciente al SIVE situada en lo alto del Monte Hacho a más de dos kilómetros del lugar de los hechos permite contrarrestar la parcialidad de las anteriores. Su visión térmica, ángulo de visión y posición alejada permite una precisión de análisis mucho mayor que el resto de cámaras, y permite detectar con claridad tanto los cuerpos de los migrantes en el mar, la localización de los efectivos policiales así como los impactos y deflagraciones de las escopetas de bolas de goma con gran precisión.

El infame resultado es conocido, catorce migrantes muertos a causa de la barrera virtual formada por pelotas de goma disparada directamente contra sus cuerpos o ahogados al no poder alcanzar la playa. Junto a ellos, veintitrés heridos de gravedad y más de un centenar de migrantes devueltos en caliente a territorio marroquí. Sin embargo, el desarrollo de los acontecimientos no es claro. Mientras que la versión defendida niega el uso desmedido de la fuerza y limita su impermeabilización de la frontera física y la "prolongación virtual de la línea en el mar", los vídeos ciudadanos grabados desde la playa, los informes emitidos a posteriori y la reconstrucción forense de los hechos muestra un desarrollo alternativo. La labor de la arquitectura forense, a partir de todos estos datos y versiones contradictorias es re-construir el acontecimiento a través de las evidencias espaciales detectadas.

El análisis espacial llevado a cabo se basa principalmente en las grabaciones de la cámara del SIVE situada en el Monte Hacho y que se controla desde Algeciras a más de catorce kilómetros. La composición digital de los diferentes fotogramas extraídos del vídeo, en movimiento y zoom a lo largo de treinta minutos de grabación permite extraer ciertos datos de gran interés sobre el funcionamiento operativo de la frontera como un dispositivo arquitectónico. Esta reconstrucción confirma no sólo que sí ha existido una situación de espacio de excepción donde se

75 Comisión de Interior sesión no 25 (Diario de Sesiones del Congreso de los Diputados nº 500 , 2014), 5 .

76 Comisión de Interior sesión n⿳o 25 (Diario de Sesiones del Congreso de los Diputados nํ5oo, 
registra la negación del Habeas Corpus, el derecho al auxilio o la infracción de protocolos policiales establecidos como las distancias de seguridad para efectuar disparos, sino que también contrapone una visión alternativa a lo acontecido en la frontera del Tarajal. Por tanto, apoyándonos tanto en declaraciones como en las diapositivas presentadas en rueda de prensa, veamos cual es el relato establecido desde el Ministerio del Interior. A través de un esquema sintético se nos presenta el paso fronterizo del Tarajal señalando claramente la línea fronteriza que éste encarna; la línea se adentra en el mar y junto a ella, se nos señala la posición de las tropas policiales así como dos embarcaciones. El mismo esquema muestra también cómo los disparos producidos se realizan justo sobre la prolongación virtual. Versión que es confirmada de viva voz por el cargo ministerial que indica que tanto la presencia policial como sus acciones se corresponden con "una prolongación virtual en el mar de la línea de la frontera”. Sin embargo, tanto los hechos como la propia declaración de Fernández Díaz muestran un despliegue de la línea que no coincide en absoluto con la trazada sobre el espigón o su prolongación virtual. Una línea materializada a través de las acciones de contención y rechazo, pero que puede adaptarse a las necesidades de cada momento dado el carácter elástico de la misma otorgado a través de la excepcionalidad:

Esta acción de vigilancia, contención y rechazo debería ejercerse en la mar sobre una línea imaginaria, prolongación del espigón, que representaría el límite fronterizo entre las aguas marroquíes y las aguas españolas. Quiero enfatizar que dicha acción descrita anteriormente, basada en el empleo legítimo y razonable de la fuerza, llevada a cabo en el escenario marítimo, supone un grave peligro para la integridad física de los inmigrantes, así como de los propios agentes encargados de esa vigilancia. En estas circunstancias, el Estado, mediante una decisión libre y soberana como la antes descrita, retrotrae la línea de vigilancia y contención hasta un escenario seguro, que no es otro que la tierra firme en la lengua del agua, en la que las legítimas acciones de contención y rechazo pueden llevarse a cabo sin peligro para nadie, ni para los inmigrantes ni para la fuerza actuante. En todo caso, dicha línea no puede quedar materializada mediante obstáculos físicos móviles, dada la aleatoriedad de los incidentes, por lo que solo queda materializada y visibilizada por la línea de agentes de vigilancia que en cada caso y circunstancia se establece desde el espigón hasta el lugar de la playa que se estime necesario ${ }^{77}$.

Es decir, según la versión oficial, por más que la línea fronteriza tenga una condición elástica y retráctil, los medios técnicos y humanos empleados simplemente eran un refuerzo auxiliar de la línea y, por tanto, de la ley materializada. Sin embargo, la cámara de vídeovigilancia muestra una nueva disposición de los hechos ocurridos así como de las acciones policiales llevadas a cabo. Bajo ningún concepto puede la línea, como figura geométrica definir la manifestación del dispositivo frontera ocurrida en el tarajal. Por tanto, nos obliga a buscar y definir nuevas formulaciones que se asemejen más a la realidad forense desvelada.

De los ciento cuarenta y cinco disparos de pelotas de goma confirmados por el Secretario de Estado en el Congreso de los Diputados realizados, y hasta los cuatrocientos veinte disponibles según fuentes policiales ${ }^{78}$, la cámara de vigilancia logra captar con precisión el impacto de treinta y cinco de ellos en el agua. Un número suficientemente significativo como para poder extraer de él los siguientes datos. El análisis de los impactos de los disparos en el agua muestra una realidad diferente ya que, si bien la mayoría de los impactos sí se producen
Diapositivas presentadas por el Ministerio del Interior en rueda de prensa explicando el desarrollo de los acontecimientos del 6 de febrero de 2014 (Ministerio del Interior, 2014)
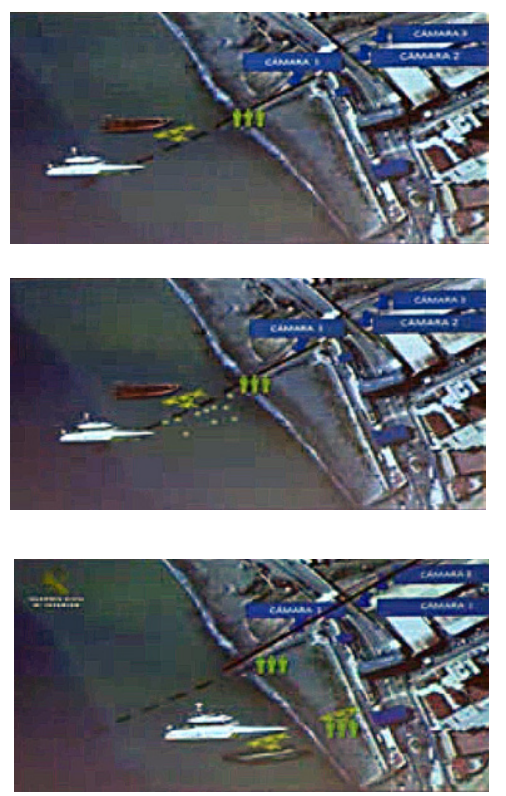

77 Comisión de Interior sesión n⿳o 25 (Diario de Sesiones del Congreso de los Diputados nº 500 , 2014), 7.

78 Europapress, "Los guardias civiles presentes en la tragedia de El Tarajal (Ceuta) defienden que el uso de antidisturbios fue "gradual”", Europapress, 7 de diciembre de 2014. 
Siguientes páginas:

Reconstrucción digital del acontecimiento del Tarajal a través de la cámara térmica de seguridad. Localización de los impactos en el agua (Elaboración propia con frames de vídeo del Ministerio del Interior).

Reconstrucción digital del acontecimiento del Tarajal a través de la cámara térmica de seguridad. Localización de los agentes a lo largo de la costa (Elaboración propia con frames de vídeo del Ministerio del Interior).

Reconstrucción digital del acontecimiento del Tarajal a través de la cámara térmica de seguridad. Localización de las zonas de excepcionalidad generadas por los disparos (Elaboración propia con frames de vídeo del Ministerio del Interior).
Efectivos policiales en la orilla de la playa de acceso libre del Tarajal (Cuatro Cadena de Televisión; Ceuta, 2014).
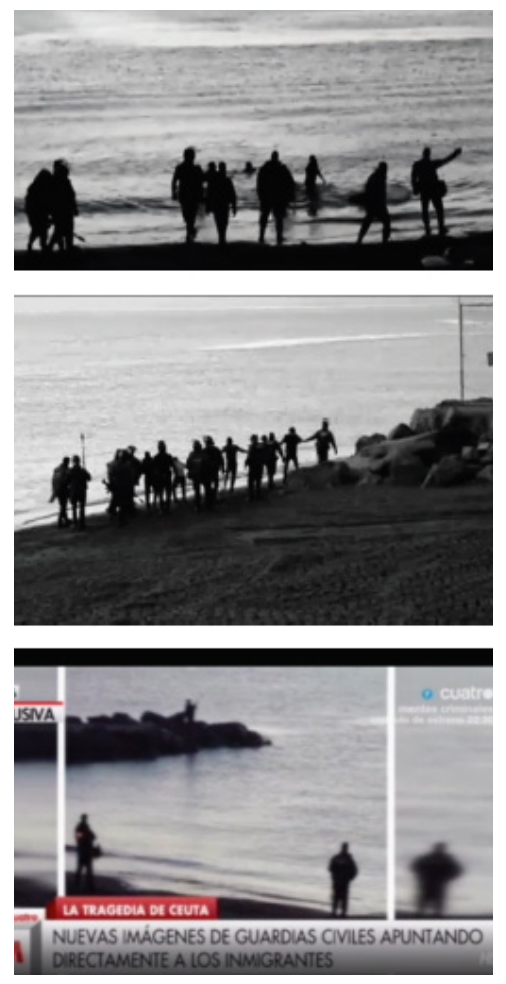

en la prolongación virtual del espigón, existe un número elevado de ellos que se alejan de manera consistente y repetida de la línea tal y como muestra la reconstrucción. Si se descartan los posibles errores de tiro o balas perdidas ${ }^{79}$ más de los quince disparos de los treinta y cinco registrados, un cuarenta por ciento de los impactos, se aleja lo suficiente en trayectoria y área de intervención de la señalada como zona de "prolongación virtual" del espigón. Podemos afirmar que si existía una prolongación de la soberanía, ésta no se ejercía a través de la línea trazada cartográficamente, sino transversal a ella, en paralelo a la costa.

Esto se confirma además con la serie de fotogramas que, tomados desde la cámara que enfoca al espigón, muestran los repetidos disparos de agentes policiales. $\mathrm{Al}$ estar de perfil, con su eje corporal transversal a la valla, y poder verse claramente las deflagraciones de la escopeta, se deduce que el objetivo de sus disparos no era el refuerzo de la prolongación virtual de la línea sino los cuerpos en el mar.

La posición de los disparos que varía en posición a lo largo del desplazamiento de los cuerpos de un lado a otro del espigón, genera un campo de excepción a ambos lados de la valla, variable tanto en localización como en intensidad en función del desplazamiento de los cuerpos. Un campo que se concentra en las inmediaciones del espigón durante los primeros minutos, lo bordea y que luego se desplaza a otros escenarios conforme avanza el acontecimiento. Un segundo análisis nos permite confirmar como mientras que los disparos se concentran en un campo próximo al espigón -aunque se alejan lo suficiente como para admitir que formen parte de su prolongación virtual- el despliegue de agentes policiales en la orilla de la playa se extiende a un arco de más de setecientos metros. Esto es, en palabras de Fernández Díaz una acción que "retrotrae la línea de vigilancia y contención hasta un escenario seguro, que no es otro que la tierra firme”. Una línea soberana virtual que comprende no solo la playa de acceso restringido española y marroquí adyacentes al espigón sino también dos playas de acceso público que, con la presencia de los agentes en ella pasan inmediatamente a convertirse en espacios sometidos a un régimen de excepción.

Podría argumentarse que, si bien esta línea soberana elástica y retráctil no es coherente de acuerdo a la legislación vigente, al menos sí lo es en base a la definición hecha por el Ministerio del Interior en base a su carácter operativo. Fernández Díaz presenta una línea que ya no se encarna en la valla sino en la conexión de agentes policiales dispersos en el terreno y es ésta la que define los límites territoriales de España: "dicha línea no puede quedar materializada mediante obstáculos físicos móviles, dada la aleatoriedad de los incidentes, por lo que solo queda materializada y visibilizada por la línea de agentes de vigilancia que en cada caso y circunstancia se establece desde el espigón hasta el lugar de la playa que se estime necesario". Y hasta que un migrante no rebase esta línea no se hallará en territorio español y, por tanto, sometido a su jurisdicción. Sin embargo, las imágenes muestran una vez más las incoherencias internas y externas entre el discurso y la reconstrucción forense ya que ésta se prolonga aún más allá de la playa a la que el ministro hace referencia y es además rebasada por sucesivos cuerpos. Es a través de estas imágenes, de esta reconstrucción espacial que determina su posición más allá de la línea virtual, donde se ve de manera más clara el paralaje existente entre el discurso y la práctica espacial, abriéndose "un espacio en el que aplicación y norma exhiben su separación"8o.

79 Estos disparos son fácilmente detectables por situarse claramente alejados de los focos de acción definidos en primer lugar por la prolongación de la línea y, en segundo lugar, por la separación respecto a los cuerpos en el agua.

80 Agamben, Estado de Excepción, 61. 


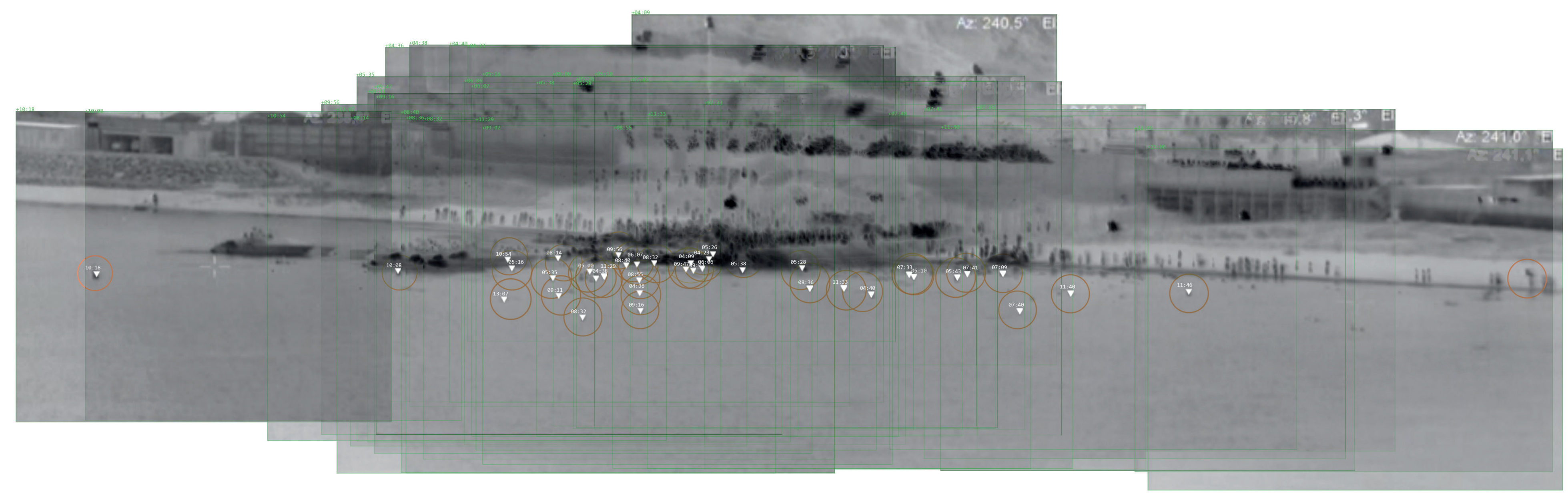




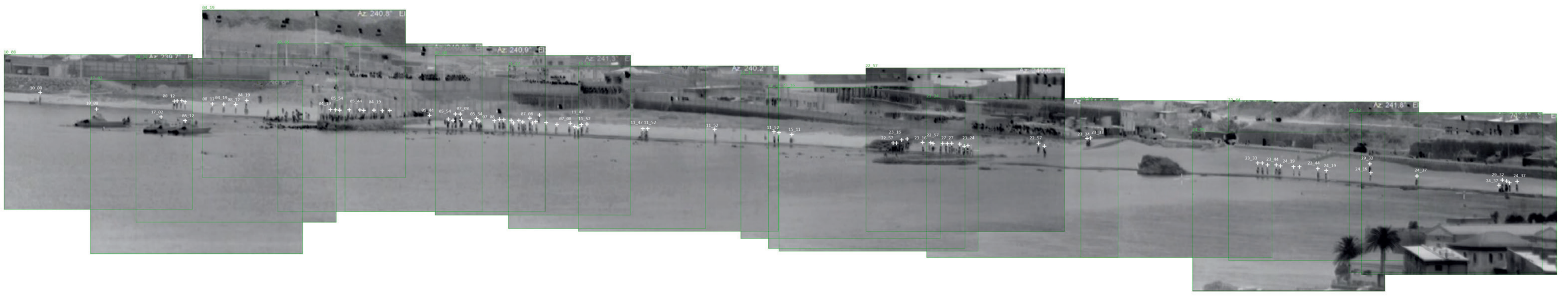




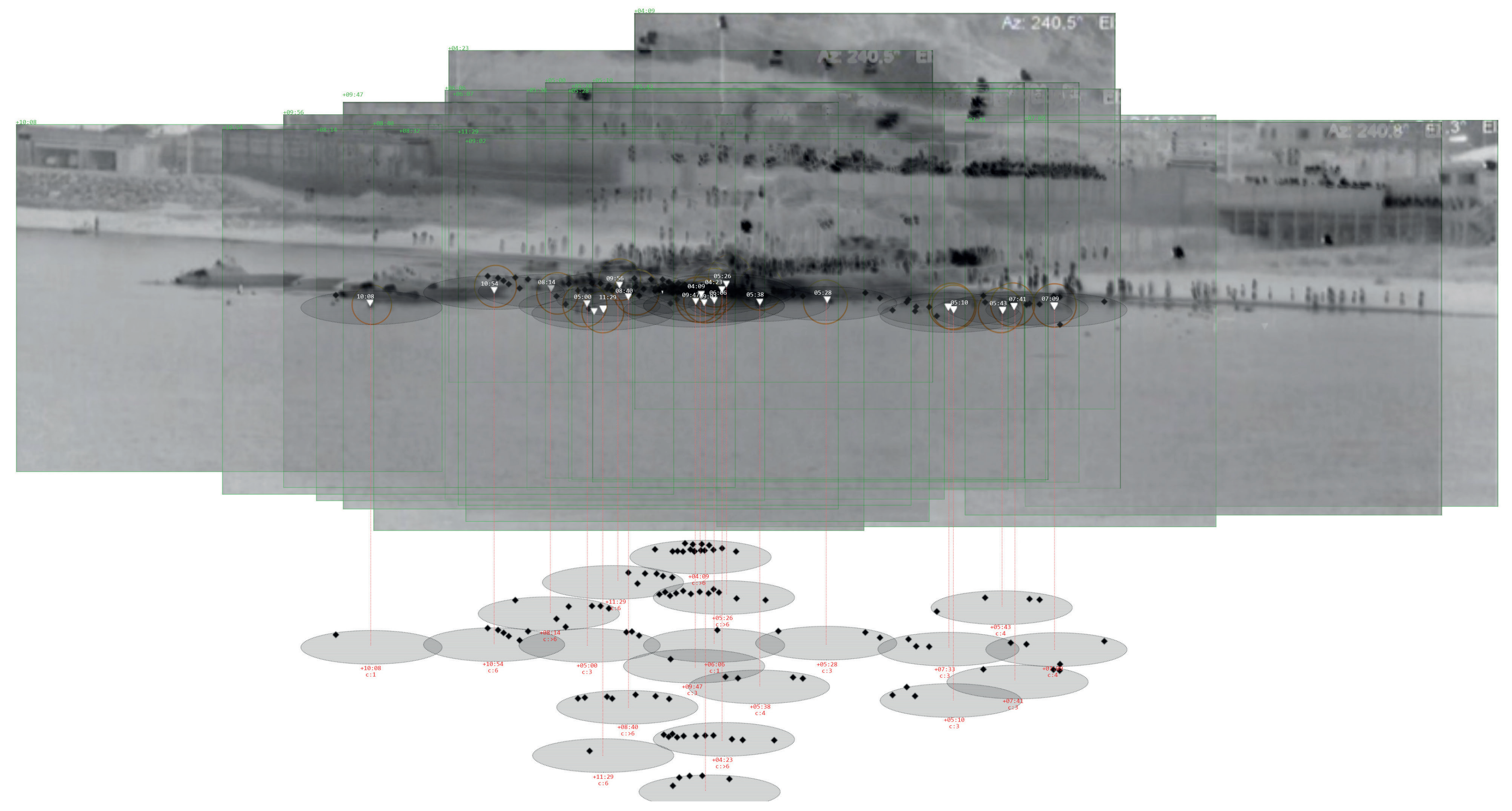


No obstante, ni la posición de los agentes policiales a lo largo de la línea de costa ni los impactos de pelotas de gomas en el agua es capaz de justificar ese desplazamiento líquido de la frontera a lo largo de la costa. Para ello, es necesario poner en relación cada punto -tanto los cuerpos en la playa efectuando los disparos como los impactos sobre el agua- para comprender así el carácter dinámico de este dispositivo arquitectónico. Y, para esto, es necesario incorporar al análisis la posición y desplazamiento de los cuerpos en el agua.

Durante los veintinueve minutos de grabación analizados, desde las 07:34 A.M a las 08.03 A.M se registran en la cámara veinte disparos de pelotas de goma diferentes que impactan a un radio inferior de seis metros de distancia de los cuerpos que se encuentran en el agua. La circular emitida por la Comisión General de la Seguridad Ciudadana establece unas distancias mínimas respecto a las cuales deben establecerse los disparos - cincuenta y setenta y cinco metrospero además la distancia de impacto hasta los cuerpos que se ha de respetar: veinticinco y quince metros en función de cada situación. Además, se hace hincapié en que el uso de estos medios ha de estar limitado a la disuasión de grupos de personas y no debe usarse con carácter lesivo ${ }^{81}$. Si tomamos la variable menos restrictiva, un radio de quince metros ${ }^{82}$. En veinte de los treinta y cinco disparos registrados se invade el espacio de seguridad generado por la ley e torno a cada cuerpo, infringiendo los propios protocolos policiales tal y como se refleja en la reconstrucción. En total, setenta y cinco vulneraciones realizadas en sólo veinte disparos. Su registro en vídeo permite extraer una condición característica de la frontera operativa: la arquitectura de la excepción espacializa una ley que se manifiesta de forma líquida e inestable, elástica en palabras de Fernández Díaz donde son la posición de los cuerpos en movimiento y sus acciones las que activan este ensamblaje fronterizo. Frente a la delimitación clara, el recinto generado por la arquitectura de la norma, representado en este caso por la valla, se evidencia un nuevo modelo de construcción del territorio donde la condición de borde desaparece y se traslada de manera heterogénea y diferenciada a la totalidad de un espacio en situaciones excepcionales. Esto es lo que ocurre en las inmediaciones del espigón durante este acontecimiento: cada cuerpo detona una serie de prácticas espaciales de diferente naturaleza -disparos, retenciones, movimientos, botes de gas...- destinadas a impedir su entrada política en territorio español. De la norma encarnada en el metal de la valla y el hormigón del espigón se pasa a una fuerza-de-ley codificada en múltiples tácticas y protocolos operativos -los que determinan como disponerse, a qué disparar o qué medios usar-, un ensamblaje arquitectónico dinámico que transforma todo el territorio en un campo de intensidades variables. Es precisamente este paisaje legal, que no está fijado de antemano sino que es una interacción variable entre cuerpos y acciones que encarnan leyes y normas, las ejecutan, el que permite una selectividad espacial que, de otro modo, no se podría alcanzar. Una selectividad espacial que permite operar únicamente sobre "puntos calientes" o nodos concretos, en este caso los cuerpos en el mar, a través de un despliegue de todos los agentes posibles destinados a minimizar su capacidad de acción y desplazamiento dentro de territorio español. Del mismo modo que imanes en un campo magnético, cada movimiento de los cuerpos en el agua implica una reacción y un desplazamiento instantáneo del resto de agentes del dispositivo.

81 Circular sobre empleo de material antidisturbios, de 13 de septiembre de 2013, de la Comisión General de la Seguridad Ciudadana (Documento interno, 2013).

82 Este radio ha sido ponderado en la reconstrucción digital a un radio aproximado de diez metros para equilibrar posibles deformaciones o errores de cálculo. Con lo cual, el número total de infracciones es previsiblemente mayor, más aún si considerásemos el radio de seguridad de 25 metros que establece la circular como procedimiento ordinario. 


\subsection{SUBVERSIÓN DE FUNCIONES ARQUITECTÓNICAS A TRAVÉS DE LA OPERATIVIDAD. EL PAPEL DE LA PUERTA.}

Este despliegue operativo en el Tarajal, donde la valla carece absolutamente de protagonismo frente a otros acontecimientos de entrada irregular donde la arquitectura sí supone un elemento principal -tanto los cruces de la valla como a través de los pasos fronterizos-, hace que sea necesario plantear la siguiente pregunta: ¿significa esto que la instauración de espacios de excepción despoja de cualquier función a las arquitecturas de la norma dado que su condición estática les impide responder con rapidez a las exigencias inmediatas que requiere cada acontecimiento? Conviene recordar lo ya enunciado: estos despliegues operativos sólo se despliegan ante acontecimientos determinados y muy acotados en el tiempo que demandan mecanismos espaciales complementario; por tanto las arquitecturas de la norma siguen encarnando funciones fundamentales en la construcción territorial de la frontera. Aclaremos, utilizando de nuevo la reconstrucción espacial de lo ocurrido en el Tarajal si, durante estos despliegues operativos sufren alguna consecuencia arquitectónica más allá de su pérdida absoluta de relevancia como construcción encargada de contener e impermeabilizar la frontera. La respuesta a esta cuestión la da precisamente la valla, que juega un papel secundario pero fundamental para asegurar la eficacia de esta práctica espacial.

Su papel durante todo el acontecimiento, más allá de la redirección del flujo de los migrantes hacia el mar, es registrado por las cámaras de seguridad situadas en el puesto de vigilancia más próxima a ellas. Se compone de un estructura de acero galvanizado de seis metros con soportes verticales cada dos metros, un juego de focos paralelos a ellas dispuestos cada dos metros y una única línea continua de concertinas orientadas hacia el lado marroquí para dificultar su escalada. La valla se levanta sobre un espigón de cien metros de largo que sólo en una zona muy concreta - próxima al puesto de seguridad- está a cota con la pendiente de la playa. En uno de estos paños a nivel con la topografía de la arena se sitúa una puerta que conecta directamente la playa española con la marroquí. El único punto de conexión directa que no se realiza a través del paso fronterizo. Es precisamente este elemento de 2xo,90 metros de superficie el único agujero que se abre en una arquitectura totalmente impermeable y con una función aparentemente accesoria dentro del complejo arquitectónico. Y precisamente esta puerta la que evidencia las transformaciones instantáneas que la excepción es capaz de ejercer sobre cualquier construcción arquitectónica.

Del mismo modo que en Ante la Ley, el cuento de Kafka, la apertura de la puerta no sólo implica la apertura de un umbral o agujero físico, sino también la apertura en las leyes que ésta arquitectura encarna. Así, la aparición de un paño de menos de dos metros cuadrados sobre una arquitectura que ha sido explícitamente diseñada para impedir el paso de cualquier cuerpo a través de ella abre una nueva posibilidad espacial que es inmediatamente aprovechada. Y es que, la ley está embebida en estas construcciones, por tanto las fisuras espaciales se transforman también inmediatamente en fisuras normativas. La misma excepción que anula todas sus funciones - normas de diseño- es la que posibilita que esa arquitectura sea atravesada, poniendo en suspenso tanto los objetivos para los que fue diseñada así como la ley que encarna. Pero, sobre todo, 
Detalle de puerta en Sección Sur de la Valla de Melilla (Elaboración propia; Melilla, 2019)

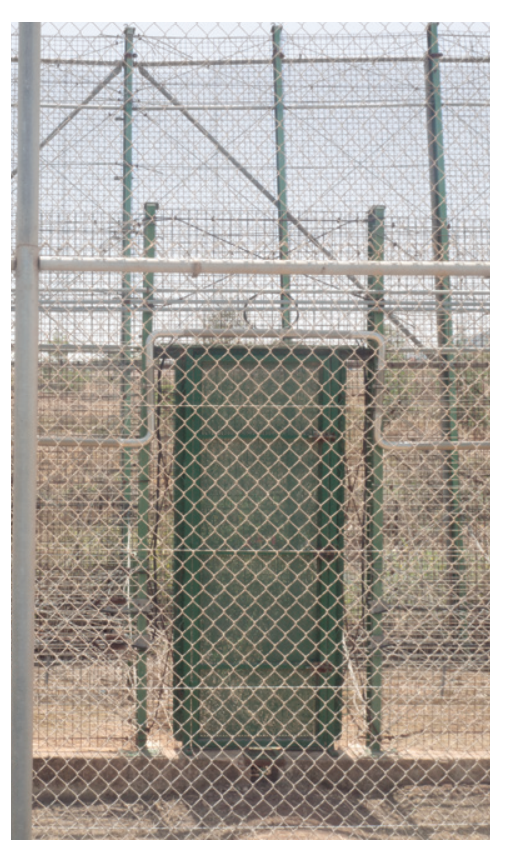

la apertura de ese hueco, pone en suspenso las leyes, derechos y garantías de cada uno de los cuerpos que, de manera forzosa, son atravesados a través de su umbral. Por tanto, y remitiéndonos de nuevo al cuento de Kafka, es importante entender cómo la ley necesita de los cuerpos y espacios para emerger: no es exterior a ellos sino completamente dependiente. Y, precisamente por ello, que residen en los cuerpos y sus acciones la capacidad última de transgredir o ponerla en suspenso, alterar el lawscape, como ocurre en este acontecimiento; lo que en el cuento de Kafka encarna el vingilante que franquea el umbral son, en nuestro caso, los cuerpos policiales que con sus protocolos operativos moldean y adaptan la norma a sus criterios de operatividad. Y, un cambio de disposición tan simple, dos metros cuadrados en una superficie de más de seiscientos, que permiten durante unos instantes una continuidad entre la playa marroquí y la española, altera completamente la función de esa arquitectura así como todo el dispositivo. Un gesto, tan simple como la apertura de un cerrojo, llevada a cabo por un cuerpo policial altera radicalmente la espacialidad de todo el ensamblaje. Una alteración menor en un elemento aparentemente insignificante del dispositivo -a juzgar por el papel secundario que ha desempeñado en todos los acontecimientoscobra, inmediatamente una relevancia central.

Las múltiples devoluciones en caliente realizadas esa mañana, todas ellas franqueando el mismo umbral, implican la transformación temporal de la disposición habitual de los componentes que conforman este ensamblaje arquitectónico, y por tanto una subversión completa de sus funciones y premisas de diseño, ya que permiten la conexión inmediata entre dos territorios que, de cualquier otra manera, deberían realizarse a través de un recorrido mucho más largo y secuenciado. Un recorrido que no es simplemente físico, sino político y legal, ya que al atravesar su umbral se están obviando todos los derechos de asistencia legal, sanitaria o de refugio que cada uno de los migrantes posee de manera individual.

Es la propia arquitectónica de la valla fronteriza, la disposición de los diferentes componentes que la construyen la que permite los mecanismos de una frontera operativa que subvierte y altera temporalmente $-\mathrm{y}$ en condiciones muy determinadas- su funcionamiento cotidiano. Pero esta re-disposición que transita en apenas segundos de lo ordinario a lo excepcional, del scanscape a la free-fire zone, no afecta exclusivamente a elementos construidos sino que también ejerce esta subversión en espacios y territorios, como es el caso de las playas ya señaladas. Durante el despliegue de medios técnicos y humanos en la playa más alejada de la frontera del Tarajal, un espacio de ocio abierto al público totalmente ajeno a las lógicas y arquitecturas de la frontera, se transformó de manera instantánea un espacio de excepción absoluta debido a la presencia de dos cuerpos que habían recorrido a nado la distancia que separaba la playa marroquí hasta esa costa española. Por tanto, no es una cuestión topográfica sino topológica ya que son esos dos cuerpos, y todas las reacciones espaciales que provoca en el dispositivo, los que alteran instantáneamente un espacio o arquitectura. Si bien puede parecer que esta apertura de fisuras sobre la arquitectura y normas encarnadas sólo puede producirse desde una posición de poder estatal; es decir, si formulamos la excepcionalidad desde una concepción clásica y no como un evento o ruptura de un sistema de normas que operan sobre un espacio, esto no ocurre así ya que también puede ser aprovechada por el cuerpo migrante para plantear configuraciones y usos alternativos del espacio. A través de sus acciones, de su transgresión activa que anula espacialmente las leyes que operan sobre un objeto, bien encaramándose a un poste o bien aprovechando los resquicios de la valla para asirse a ella y trepar, pueden reducir, revertir o anular también la violencia espacial de la frontera. Muestra de ello es el caso que introduce este capítulo, donde el cuerpo de Star era capaz de analizar los diferentes componentes constructivos de la valla, hackearlos para improvisar 
un espacio de estancia sobre una superficie minúscula. Y, de este modo, plantear construcciones espaciales alternativas que trascienden las lógicas de diseño, las confrontan.
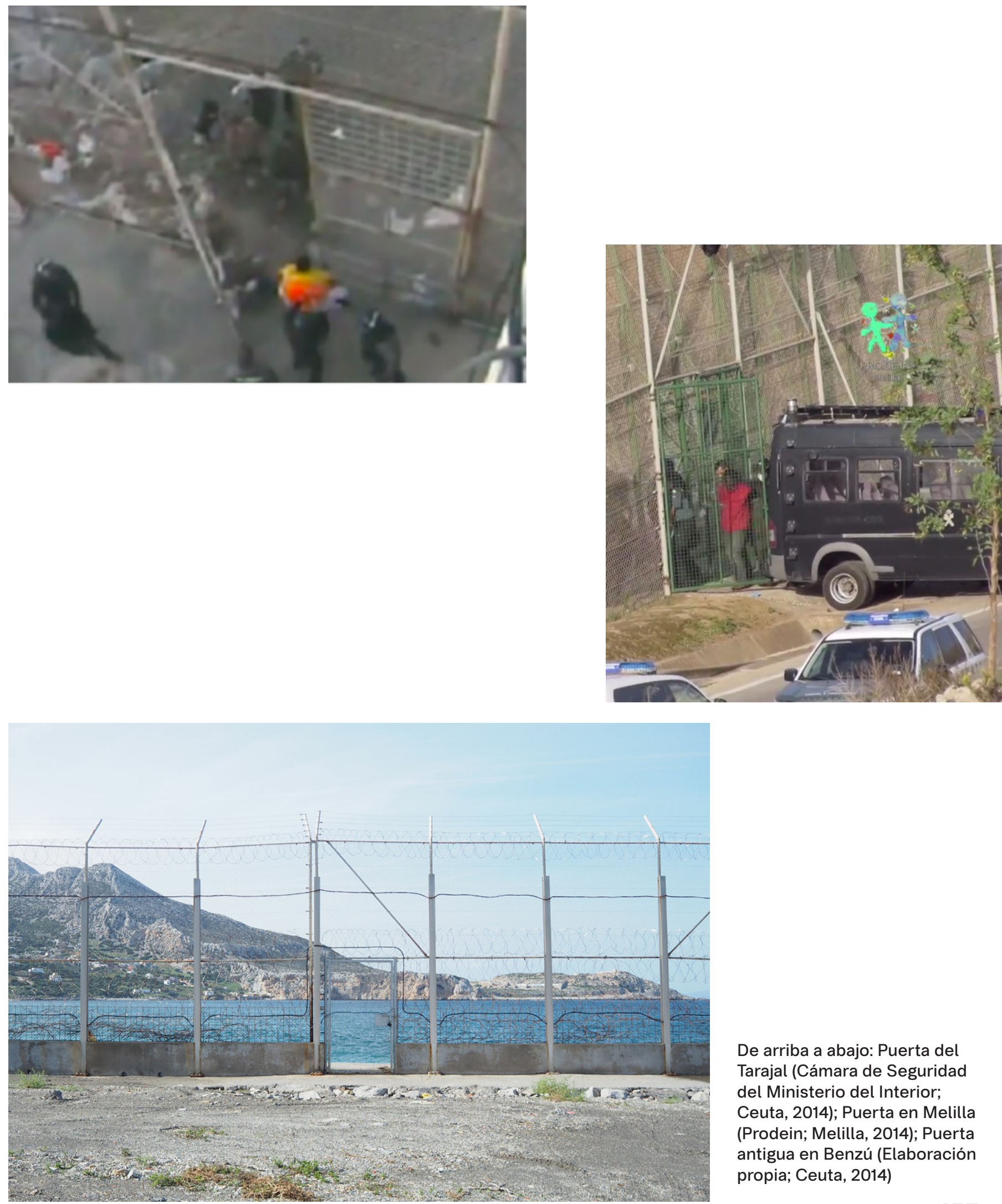

De arriba a abajo: Puerta del Tarajal (Cámara de Seguridad del Ministerio del Interior; Ceuta, 2014); Puerta en Melilla (Prodein; Melilla, 2014); Puerta antigua en Benzú (Elaboración propia; Ceuta, 2014) 
La valla ha representado y representa históricamente la visibilización más clara de la frontera. Su contundencia, la crueldad inherente a su diseño, ha sido un reflejo de discursos políticos explícitos o jamás pronunciados en público pero que logran resumir treinta años de evolución respecto a la construcción de la frontera europea. Una arquitectura aparentemente sencilla, una sección constructiva lineal que recorre todo el perímetro de Ceuta y Melilla que, sin embargo, condensa en su construcción un correlato fidedigno de los mismos movimientos a nivel geopolítico. La progresiva militarización que multiplicado en altura, grosor y complejidad la sección de la valla o su desterritorialización debido a la implementación de sistemas de vigilancia remota evolucionan parejos a la implementación de redes territoriales y programas militares-defensivos de vigilancia y auxilio a lo largo de toda la Frontera Sur y Este. La externalización formalizada en acuerdos internacionales, ayudas a la cooperación e inyecciones financieros a países como Libia, Marruecos, Argelia y países subsaharianos también es posible encontrarla en cómo la gestión de la frontera, desde la constitución del nuevo modelo de valla, ha residido sobre todo en operaciones arquitectónicas marroquíes.

Sin embargo, sí ha habido una transformación reciente de esta construcción con gran relevancia para nuestra investigación, que ha desplazado la estabilidad de las arquitecturas sólidas hacia ensamblajes efímeros e instantáneos. Un desplazamiento que sólo puede explicarse a través de los criterios de operatividad y las condiciones de excepcionalidad a las que, de manera recurrente se alude desde instituciones europeas para legitimar y amparar políticamente una serie de prácticas espaciales que, de cualquier otra forma, carecerían de cualquier base. La suspensión o supresión de leyes, normativas y protocolos por fuerza de ley ante acontecimientos recurrentes -y su normalización a lo largo del tiempo- ha tenido un impacto claro en las funciones que cada arquitectura ligada a la línea fronteriza desempeñaba. Así, la valla ya como mero escenario teatral al no encarnar las leyes que la habían erigido perdió protagonismo frente a ensamblajes móviles que se desplegaban a su alrededor. Y, dentro de estas construcciones móviles y temporales, el gran protagonista ha sido el cuerpo, detonante y a la vez encargado de la impermeabilización efectiva de la línea fronteriza.

En última instancia, cuando el resto de mecanismos de control espacial fallan, son los cuerpos los que construyen una frontera en movimiento, una confrontación de fuerzas, tácticas y desplazamientos constante. Y también, es hacia los cuerpos -humanos, no-humanos y materia arquitectónica- a los que se dirige de una manera explícitamente violenta todas las tecnologías necesarias que aseguren su exclusión espacial de un territorio que les es impermeable. Una frontera que ya no tiene una posición fija sobre el territorio, que no la encarna una única arquitectura, sino que se desplaza con cada cuerpo, una frontera incorporada y desterritorializada al no poderse localizar en un único lugar, capaz de generar una espacialidad selectiva e instantánea que discierne en función de un cuerpo político. Una frontera que se basa en la fuerza-de-ley y la excepción para generar ensamblajes operativos capaces de conseguir una alta responsividad y capacidad de adaptación ante cada acontecimiento. Esto obliga a repensar cual es su posición real en relación al territorio que delimita, haciendo que, al ser los cuerpos los que detonen y generen estas disposiciones espaciales, sea posible encontrar situaciones y arquitecturas análogas en paisajes y territorios físicamente alejados de esta línea perimetral. Una frontera que, a pesar de no poseer una fisicidad tan sólida es capaz de visibilizar igualmente las lógicas contemporáneas de producción territorial así como la relación inherentemente violenta entre norma, materia y espacio. 


\section{DE LA LEY ENTENDIDA COMO LINEA A LAS LEYES ENTENDIDAS COMO ESPACIO \\ \#lawscape \\ Andreas Phillippopoúlos-Mihalopoulos \\ \#el espacio como pliegue de cuerpos y leyes \\ Andreas Philippopoulos-Mihalopoulos}

\section{El lawscape como modelo espacial}

$+$

\#dimensión expandida de la ley \#multiplicidad espaciolegal Andreas Philippopoulos-Mihalopoulos

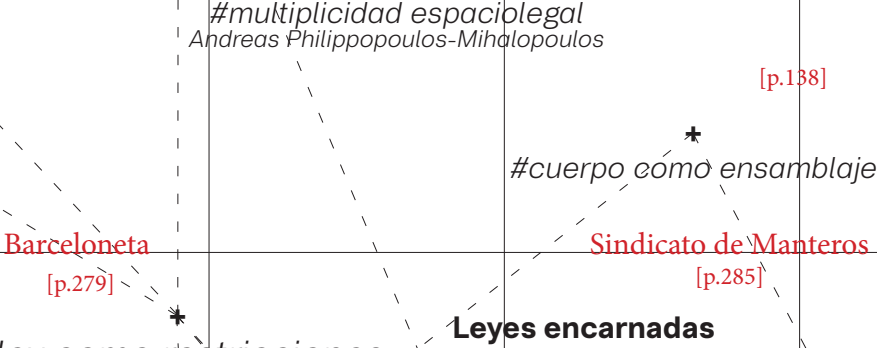

\#ley como restricciones espaciales Bernard ischumi

\section{,}

Leyes encarnadas

Superficies de los CIE $[\mathrm{p} .220]^{\prime} *$

\#pensar el cuerpo desde los afectos a Jalón Oyarzun \#condición dinámica de la árquitectura [p.103] $t$ $+$

Arquitectónicas del Internamiento [p.17,, ] \#violencia espacial t

\#espacióćcomo eventos Bernard Tschumi
Violencia espácial como mediación entre leyés, cuerpos y espacio.

CIEs de primera genéración p.176] ,'

$+$ \#arquitectura y violencia \#la arquitectura

\section{Aarchidona \\ Acrió-} Bernard Tschumi
Star [p.91]

,

,

'Medidas temporales Mótín en Aluche

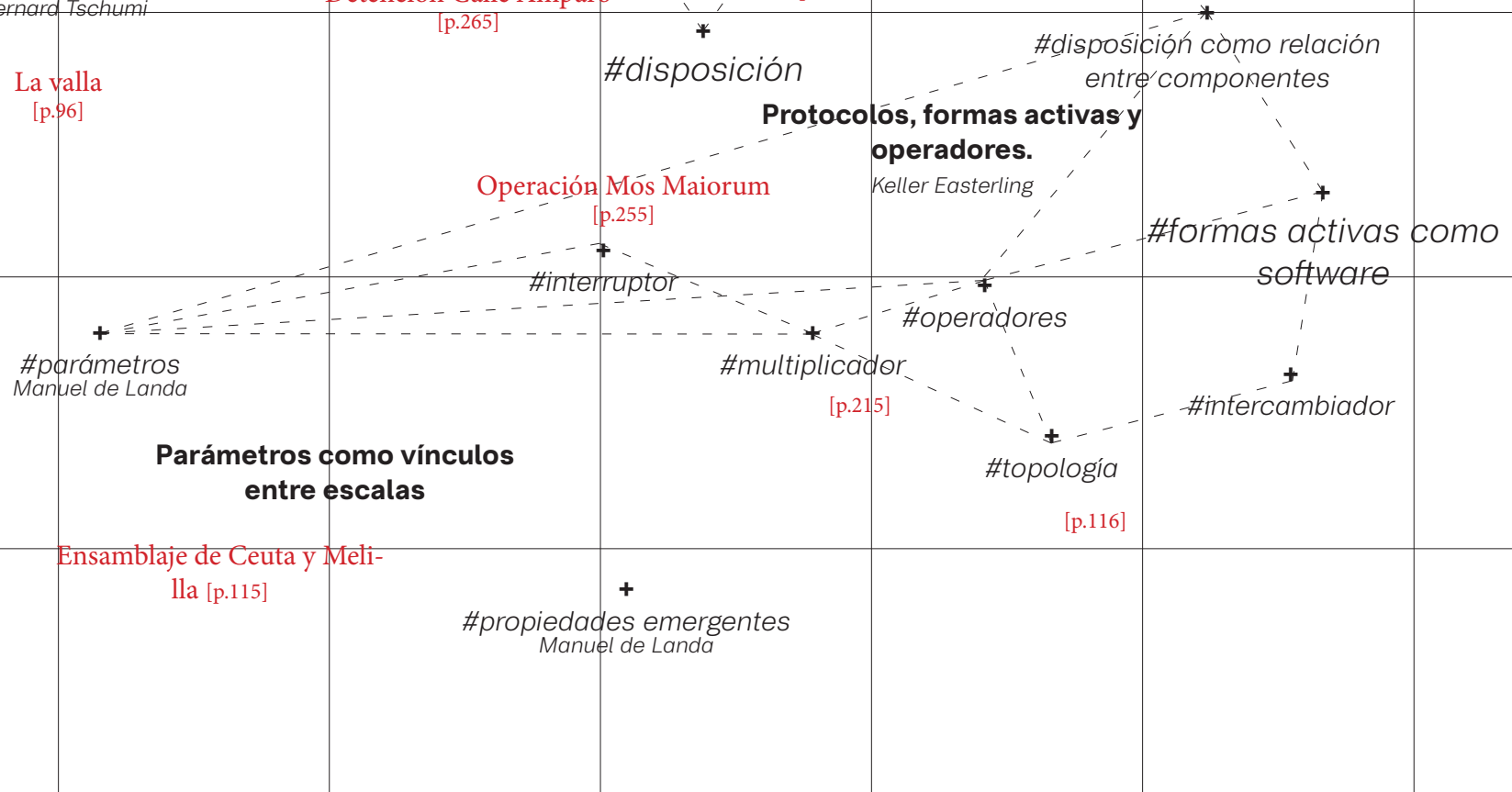



Imaginemos, por un momento, un espacio físico cualquiera y comencemos a superponer e identificar sobre él las diferentes normas que lo configuran como tal. Tal vez no seamos capaces de identificar más que algunas manifestaciones construidas de estas leyes, elementos que claramente respondan en su diseño y construcción a una voluntad específica de materializar una ley -aunque en la práctica siempre exista un paralaje entre creación y funcionamiento operativo-. Una mirada más pausada sobre el territorio hará que de él emerjan las relaciones y condiciones que disponen los elementos en él de una determinada manera, los anchos, distancias, materiales, estructuras, patrones, todo ello responde de un modo u otro a una serie de decisiones que configuran espacialmente el territorio, dotándolo de una estructura compleja. Una estructura donde se comienza a vislumbrar que no sólo el plano normativo, sino la economía, las decisiones políticas, o la propia economía de medios, decisiones intuitivas,..., entre muchos otros parámetros, se entremezclan para conformar algo que sólo puede ser percibido como un todo aparente - un espacio o acontecimiento-. Si continuamos deteniéndonos en este mismo espacio, podremos incluso superponer nuevas capas de realidad intangible: comunicaciones, infraestructuras y toda una serie de acuerdos establecidos que permiten que el espacio funcione según se ha diseñado: un diseño que en ningún momento surge de una voluntad única sino de los acuerdos y conflictos que se establecen entre las diferentes partes que lo forman. Hasta el momento, hemos sido observadores de este espacio, pero situemos en él nuestro cuerpo y desplacémonos por él: lo haremos de una manera concreta, sabiendo por donde sí y por donde no debemos movernos o como debemos hacerlo; nuestro cuerpo incorpora e interpreta normas escritas, pactadas socialmente o simplemente asumidas para generar la mínima fricción posible entre los diferentes cuerpos -humanos o nohumanos, animados o inanimados- que forman el espacio. Y, lo más importante, aunque nuestro desplazamiento sea único, tiene un efecto inmediato en el resto de cuerpos que nos rodean, que adecuan su posición, sienten nuestra presencia o sufren nuestro desplazamiento y acciones; donde los acuerdos y conflictos se actualizan conforme nos seguimos desplazando en el espacio. ¿Qué ocurre si transgredimos alguna de estas normas encarnadas en múltiples cuerpos? Tal vez sea activamente $\mathrm{o}$, tal vez no hayamos sido capaces de hacer visibles aún todas las leyes que forman este espacio. Ese instante, una reorganización inmediata del resto de cuerpos, de las formas activas que construyen el entorno hará visible -de un modo más o menos violento- este conflicto. Y, justo en este preciso instante, esta amalgama de leyes, protocolos, normas, acuerdos y desacuerdos hará más visible cómo nuestro cuerpo -antes autónomo- está ensamblado con el resto, y también cómo esta red de relaciones y leyes tensionan nuestra posibilidad de acción y desplazamiento, permitiendo o impidiendo en función de su disposición. Además, este mismo instante también hará ver cómo el espacio está igualmente construido por el soporte físico y arquitectónico del mismo modo que por un software o conjunto de formas activas y leyes que condiciona absolutamente nuestro comportamiento en él.

Es decir, el espacio no es un elemento independiente de los cuerpos, acciones y leyes, sino un producto imbricado en esta interrelación constante entre norma y materia. Este modelo es el que presenta Andreas PhilippopoulosMihalopoulos bajo el nombre del lawscape, un pliegue constante de cuerpos en movimiento condicionados por las acciones y posibilidades que las leyes otorgan -cuestionándolas, asumiéndolas o transgrediéndolas-. Así enuncia PhilippoulosMihalopoulos esta amalgama múltiple, variable e interrelacionada:

Un continuum de espacio y cuerpos, que se regula así mismo a través de sus propios pliegues y movimientos, mientras que a la vez resiste la uniformidad o la relacionalidad total a través de sus rupturas. [...] En todo esto, la ley tiene una implicación íntima, a la ve logos y nomos, la ley estatal de los límites y las

\section{El lawscape como modelo espacial}

\#lawscape 
\#el espacio como pliegue de cuerpos y leyes

\#multiplicidad espaciolegal

\#dimensión expandida de la ley

Leyes encarnadas leyes nomádicas de paso. La ley también se inscribe en la superficie común entre la lingüística y lo material. Es esta clase de espacio en donde surge el lawscape, donde espacio, cuerpos y ley se pliegan juntos. ${ }^{\mathrm{I}}$

Este modelo, nacido en el seno de la teoría legal, tiene una raíz eminentemente espacial que resulta muy útil a la hora de sentar la óptica con la que analizar nuestros casos de estudio. El punto de partida es claro: existe una retroalimentación constante entre ley y espacio, paradójica y no exenta de fricciones pero de absoluta codependencia entre ambas esferas -"el espacio no es sólo otro parámetro de la ley sino una completa paradoja tautológica, un reflejo de abstracción enterrada"-. Este entendimiento de la ley desde una disciplina que la concibe fundamentalmente de manera geométrica a través de la construcción de recintos y su materialización física -el establecimiento de perímetros, la construcción del límite entre lo público y lo privado, la zonificación urbana, los diagramas de uso y funcionamiento...- permite una aproximación que disuelve esta concepción y extiende sus límites de una manera dinámica y cambiante. Frente a la creación de recintos de límites geométricos claros, este modelo propone entender la ley no en un plano superior o abstracto, sino completamente interrelacionado y dependiente de la materia, acciones y espacio en el que se sitúan: todo ello, sus fricciones, tensiones y transformaciones, configura un espacio. Como él señala, la consideración de la ley como un conjunto de divisiones sólidas, reglas estáticas y recintos no es exclusiva de la disciplina arquitectónica sino también de la perspectiva legal tradicional que plantea un modelo análogo para el espacio-“ desde una perspectiva legal más tradicional, el espacio es lineal, divisible, medible. En una multiplicidad espaciolegal, esto es reemplazado por un laberinto" ${ }^{2}$. Al entrelazar en un mismo plano espacio, cuerpos y ley como parte de un mismo todo - continuum- este modelo renueva las bases sólidas y estáticas para presentar una producción continua del espacio así como de las leyes que emanan de este-. La ley, por tanto, es a la vez producto y resultado del resto de agentes involucrados en ese pliegue continuo denominado lawscape. La ley se inscribe y se materializa a través de esas acciones llevadas a cabo por los cuerpos que la encarnan. La ley pasa del texto al cuerpo y del recinto al espacio: un espacio que no es otra cosa que la amalgama enmarañada de cuerpos interrelacionados a través de afectos, conflictos y formas activas que los predisponen. En definitiva, la ley es una variable más a considerar dentro del dispositivo.

Esto, en primer lugar nos permite centrar la discusión en qué entendemos por leyes o normas, concluyendo que no es útil limitar el concepto de ley únicamente al conjunto de leyes escritas y regulaciones establecidas, códigos penales, tratados internacionales, constituciones, etc... Debemos también incluir en nuestro espectro todos aquellos protocolos, patrones, modos de comportamiento, habitos de conducta, códigos formales e informales. En definitiva, hemos de entender por ley no sólo el logos sino el nomos en el que se inscribe cada cuerpo a analizar, pues todo ello no solo define sino que también posibilita entender el porqué de las acciones, sino el desarrollo llevado a cabo en cada acontecimiento.

Este modelo espacial parte de consideraciones afines al marco presentado en el interludio anterior por dos cuestiones fundamentales: la importancia del cuerpo a la hora de construir la ley -un cuerpo que ya no es el vitrubiano sino posthumano y atravesado por múltiples conexiones, en última instancia ensamblado a través de los afectos- y la proximidad con el concepto de dispositivo y

1 Andreas Philippopoulos-Mihalopoulos. Spatial fustice: Body, Lawscape, Atmosphere. (Nueva York: Taylor and Francis, 2015), p.40.

2 Philippopoulos-Mihalopoulos. Spatial Fustice: Body, Lawscape, Atmosphere. (Nueva York: Taylor and Francis, 2015), p.43. 
ensamblaje que es explícita a lo largo de toda la obra ${ }^{3}$. El cuerpo en este modelo no es simplemente el objeto de la ley, aquel elemento sobre el que ésta opera, coarta, posibilita o imposibilita ciertas prácticas, sino que la ley es encarnada por el cuerpo y las acciones. Apoyándose en la teoría queer, los cuerpos performan la ley con sus acciones y es únicamente a través de estas como la ley emerge en el espacio. Pero, no únicamente es el cuerpo humano quien tiene la capacidad de encarnarlas, ni la autoridad, sino un cuerpo post-humano - una superficie descentrada humana/no humana que ha desestabilizado los estándares legales y el entendimiento político de lo humano como un agente unificado que actúa independientemente ${ }^{4-}$, que tanto puede ser inanimado como animado, un corpus legal, un cuasi-objeto, o un ensamblaje. En definitiva, el cuerpo que se presenta en el lawscape no es sino con otros, relacionándose con ellos, afectando y siendo afectado, difuminando sus límites y enunciándose sin un contorno claro: "un cuerpo no está definido por su contorno. Si fuesen pinturas, los cuerpos serían extensiones de color sin límites dibujados, escenificando con sus fugas expansivas una retirada radical del canon humanista florentino"s. Y esto es fundamental para entender también las implicaciones arquitectónicas que nos permite observar este modelo: a pesar de que el cuerpo humano -incluso aceptando su condición autónoma- sea un agente fundamental en la producción del espacio no es el único con agencia a la hora de modular con sus deseos la orientación del dispositivo -o, lo que es lo mismo, las condiciones del lawscape-. Los muros, los elementos constructivos, la materia arquitectónica también poseen esta capacidad y será su configuración interna en términos estructurales y materiales o de diseño la que determine la capacidad de agencia o resistencia.

Si el cuerpo es en sí mismo un ensamblaje y estos se enlazan de manera constante a través de su capacidad de agencia, sus acciones y su desplazamiento dentro del lawscape, resulta obvio entender que el lawscape posee la misma condición interconectada que anteriormente asociábamos con el dispositivo o ensamblaje. Una agregación transescalar de múltiples realidades interconectadas que generan una disposición específica a todos los niveles y que se retroalimenta constantemente. No obstante, y esto es una diferencia a la hora de plantearlo, según Philippopoulos-Mihalopoulos existe un lawscape para cada cuerpo involucrado dentro de él, cada uno de ellos, su red de afectos, las leyes que emanen de ellos o que los involucren de un gesto u otro, todo eso formará un paisaje propio. Cada cuerpo genera su propio paisaje ${ }^{6}$, atravesado por normas, acciones y desplazamientos. Posición que nos remite al cuerpo que García de Jalón presenta en su tesis doctoral, construido a través de la actualización arquitectónica del cuerpo de Spinoza: "El cuerpo [...] está siempre implicado en el mundo, no puede salirse o aislarse por lo que resulta imprescindible pensarlo desde sus afectos y encuentros, sean estos buenos e intensifiquen su poder de obrar aumentando su espacialidad propia, o malos, y la disminuyan estrechando su mundo"?.

3 En el segundo capítulo "Welcome to the lawscape" se desgrana la relación de este concepto con las principales aportaciones de diferentes autores sobre el dispositivo/ensamblaje, enfocándose fundamentalmente a las implicaciones espaciales y corporales que éste posee. Aunque las referencias a este modelo son constantes en el resto de capítulos. Ver más en Philippopoulos-Mihalopoulos. . Spatial Justice. (Nueva York: Taylor and Francis, 2015), 38:106.

4 Philippopoulos-Mihalopoulos. Spatial Fustice: Body, Lawscape, Atmosphere. (Nueva York: Taylor and Francis, 2015), p.80.

5 Philippopoulos-Mihalopoulos. Spatial Fustice: Body, Lawscape, Atmosphere. (Nueva York: Taylor and Francis, 2015), p.45-46.

6 Philippopoulos-Mihalopoulos. Spatial Fustice: Body, Lawscape, Atmosphere. (Nueva York: Taylor and Francis, 2015), p.71.

7 Lucía García de Jalón Oyarzún, «Excepción y cuerpo rebelde : lo político como generador de una arquitectónica menor», (tesis doctoral, Universidad Politécnica de Madrid, 2017) ,p.36. \#cuerpo como ensamblaje

\#pensar el cuerpo desde los afectos 
\#ley como restricciones espaciales

\#condición dinámica de la arquitectura

\#espacio como eventos

\footnotetext{
Violencia espacial como mediación entre leyes, cuerpos y espacio.
}

El lawscape se presenta, ante nosotros, como una amalgama de cuerpos plegados sobre si mismo, acciones y conexiones entre ellos, leyes que coartan ciertas acciones mientras que posibilitan otras. Una amalgama difícilmente aprehensible sin el ejercicio de escrutinio detenido que permita visibilizar las relaciones, renderizarlas y reconocer los diferentes agentes involucrados en él. Centrándonos en el cuerpo, cartografiar este paisaje permite, en definitiva, entender qué acciones puede llevar a cabo un cuerpo, qué opone resistencia -material o noy qué coarta su capacidad de desplazamiento e interacción con el espacio. Así, cuerpos, normas y espacio se relacionan entre sí de una manera no evidente a priori. Esto nos remite a uno de los Advertisements for Architecture elaborados por Bernard Tschumi en 1976. En él, sobre un fondo negro, se nos presenta una masa, tela y cuerdas. La ausencia de rostro o extremidades completas dificulta en un primer instante reconocer el cuerpo, la disposición de las cuerdas en torno a ellas lo sitúa en una posición extraña. Al menos a priori. Si nos fijamos en ellas, los nudos responden con precisión a la postura del cuerpo, atados con precisión y rotundidad, desapareciendo en la carne allí donde la rodea con mayor presión. Bajo el cuerpo, en letras blancas sobre el mismo fondo negro aparece el siguiente eslogan:

Mirémoslo de la siguiente manera: el juego de la arquitectura es una partida intrincada con reglas que uno puede seguir o aceptar. Estas reglas, como tantos nudos que no pueden ser desatados poseen la significancia erótica del bondage: cuanto más numerosos y sofisticadas las restricciones, mayor es el placer. La pasión más excesiva siempre implica un conjunto de reglas. ¿Por qué no disfrutarlas? ${ }^{8}$

Tschumi desarrolla este planteamiento a lo largo de múltiples textos recogidos en Architecture and Disjunction donde, interesado en profundizar en la condición programática de la arquitectura como afirma al final de la introducción, "no existe arquitectura sin la vida cotidiana, movimiento y acción, y estos son los aspectos más dinámicos de su disociación que sugieren una nueva definición de arquitectura"9. Es decir, cuales eran aquellas variables en la construcción del espacio que, sin materializarse a través de muros, cerramientos, pavimentos, condicionaban los movimientos y acciones de los usuarios en él así como las interacciones entre cuerpos humanos y no-humanos -en su caso diferenciados entre cuerpos y arquitectura- emanaban de una relación inherentemente violenta. Más adelante, en Cuestiones de Espacio se formula algunas preguntas que ilustran hacia donde, según él, debe dirigirse la comprensión de la disciplina arquitectónica: en una de ellas plantea qué conforma el espacio para deducir que son los eventos, acciones y acontecimientos los que lo construyen“ ¿Si el espacio euclídeo está restringido a una concepción tridimensional de la materia, está el espacio no-euclídeo restringido a una serie de eventos en un espacio-tiempo cuatridimensional?" Io. Es decir, plantea un espacio donde son las relaciones entre los cuerpos, su desplazamiento, sus acciones y conflictos de donde emana el espacio y, al plantearse esta posibilidad desplaza el foco de lo material a lo inmaterial. Cuestión que confirma más adelante al preguntarse “es la materialización de la arquitectura necesariamente material?” ${ }^{\text {II }}$.

Tschumi emplea el término violencia de manera rotunda para explicitar estas lógicas de afección entre cuerpos y arquitectura -en nuestro análisis situados en un mismo plano al desplazar al humano del centro de la discusión-, las normas

\footnotetext{
8 Bernard Tschumi, Advertisements for Architecture, 1976.

9 Bernard Tschumi, Architecture and Disjunction, (Londres: MIT Press, 1996), p.23.

10 Tschumi, Architecture and Disjunction, (Londres: MIT Press, 1996), p.56.

11 Tschumi, Architecture and Disjunction, (Londres: MIT Press, 1996), p.58.
} 
que rigen y construyen un espacio y, por tanto, las posibilidades espaciales de uso que van más allá de las planteadas en su diseño. Arranca el texto La violencia de la Arquitectura con la siguiente afirmación:

I. No existe arquitectura sin acción, no existe arquitectura sin eventos, no existe arquitectura sin programa.

2. Por extensión, no existe arquitectura sin violencia ${ }^{\mathrm{I} 2}$.

Tras este axioma inicial recalca cómo la disciplina ha obviado las acciones de los cuerpos como un material igual de importante que la materia que conforma el espacio. Pero lo interesante es comprender qué entiende por violencia: "no me refiero a la brutalidad que destroza física o emocionalmente la integridad sino una metáfora de la intensidad de la relación entre los individuos y el espacio que

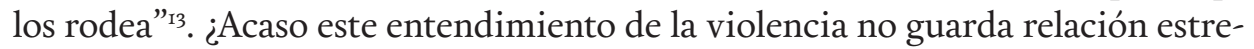
cha con el planteamiento hecho por Jalón y Philippopoulos-Mihalopoulos, capaz de afectar y verse afectado y así construir una espacialidad propia o compartida derivada de esta situación?. Prosigue Tschumi y establece en qué consiste la naturaleza violenta de la arquitectura ligándola a las acciones de los cuerpos en el espacio:

La violencia de la aquitectura es fundamental e inevitable, la arquitectura está ligada a los eventos de la misma manera que el guardia está ligado al prisionero, el policía al criminal y el orden al caos. Esto también sugiere que las acciones cualifican los espacios así como los espacios cualifican las acciones ; así espacio y acción son inseparables y no hay interpretación posible de la arquitectura, dibujo o notación que pueda rehusarse a considerar este hecho ${ }^{\mathrm{I}}$.

Si las acciones de los cuerpos están condicionados por el conjunto de cuerdas y nudos que los rodean y conforman, por todos aquellos códigos -escritos y no escritos- que condicionan sus movimientos, no se puede considerar el espacio y la arquitectura sino como una amalgama resultante de estas tres. Volvamos al cuerpo atado, y veamos cómo éste se nos presenta como una maraña tridimensional en la que cuerpos, norma y espacio no pueden separarse como elementos autónomos sino interrelacionados entre sí de múltiples formas; estas tres variables no son independientes, sino que se producen y reproducen constantemente. Es este medio, donde cada elemento que lo conforma es capaz de tensionar, reconfigurar y alterar el producto resultante $-\mathrm{y}$ así de manera constante y continua-, el que define las posibilidades de acción, los medios empleados y los cuerpos. Es, en definitiva, una formulación que nos recuerda a los planteamientos del dispositivo como un conjunto heterogéneo de múltiples agentes interrelacionados entre sí.

Si la ley ya no puede considerarse exclusivamente como el conjunto de regulaciones escritas o dictados de una autoridad situados en un plano no material, sino que ha de concebirse como una serie de prácticas espaciales que emanan de los cuerpos, a la vez que condicionan las acciones de estos y, a su vez, el espacio es la resultante de las acciones de los cuerpos en el espacio hemos de preguntarnos ¿cómo afecta esto a la disciplina arquitectónica?. Una pregunta que cobra un peso aún mayor en un campo de estudio donde las construcciones analizadas son, a priori, arquitecturas específicamente diseñadas para encarnar la ley. Tal vez ya no sean los muros ni la arquitectura sólida Queda preguntarse qué dimensión operativa tiene esta ley y como funciona para así, desde la disciplina, ser capaces \#arquitectura y violencia

\#la arquitectura como acción

12 Tschumi, Architecture and Disjunction, (Londres: MIT Press, 1996), p.I2I.

13 Tschumi, Architecture and Disjunction, (Londres: MIT Press, 1996), p.122.

14 Tschumi, Architecture and Disjunction, (Londres: MIT Press, 1996), p.122. 


\section{Protocolos, formas activas y operadores.}

\#disposición

\#disposición como relación entre componentes

\#formas activas como software

\#operadores

\#multiplicador \#interruptor no solo de cartografiar sino comprender y manipular también desde la agencia arquitectónica y, por último, entender qué encaje tiene este elemento dentro del dispositivo.

Es necesario preguntarse si las restricciones de acción que toda ley efectúa en función de los cuerpos que afecte se producen de la misma manera, o si es posible categorizarlas en base a diferentes parámetros. Keller Easterling aborda en su trabajo diferentes perspectivas acerca de lo que ella ha denominado formas activas de la arquitectura, es decir elementos o situaciones que sin necesidad de fisicidad son capaces de transformar el espacio. Así, frente al diseño de objetos, Easterling nos habla de la necesidad de resituar el papel de la arquitectura y plantearla en término de diseño de formas activas o, dicho de otro modo, desplazar el foco del hardware al software. Plantea además esta observación apoyándose en el concepto de disposición, que ilustra de la siguiente manera:

Una bola en la cima de un plano inclinado posee una disposición. La geometría de la bola y su posición relativa son simples marcadores de una agenia potencial. Incluso sin rodar por la inclinación, la bola está activamente haciendo algo al ocupar esa posición. Disposición, en otras palabras, describe usualmente una relación de despliegue entre potenciales. Describe una tendencia, actividad, facultad o propiedad de los seres u objetes - una propensión sin un contexto-.

[...]

La bola no tiene que rodar por el plano para que tenga esa capacidad, y los objetos físicos en construcciones espaciales, aunque sean estáticos, también poseen una agencia que reside en su posición relativa. La disposición es inmanente, no en sus partes móviles, sino en las relaciones entre los componentes. [...]

Manipular [este sistema espacial] requiere formas que son como un software. Diferente de las formas objetuales de los edificios emblemáticos o planes generales, estas formas activas operan en otro nivel o registrol, actúan como bits de códigos en el sistema. Las formas activas son marcadores de disposición, y la disposición es el carácter de una organización que resulta de la circulación de estas formas activas en ella ${ }^{15}$.

Así, establece diferentes funciones que estas formas activas pueden ejercer sobre los cuerpos y, por tanto, sobre el espacio resultante de su interacción. Un software espacial donde cada orden "no es una cosa sino un medio para configurar una multitud de secuencias y relaciones interdependientes" ${ }^{16}$. Al igual que en los lenguajes de programación los operadores son fundamentales y pueden categorizarse para entender, a grandes rasgos, como afecta un bloque de código a otro, la identificación en las maneras de proceder de estas formas activas -conexiones, operadores entre agentes del dispositivo- ayuda a expandir esta noción de los efectos espaciales de la ley ${ }^{\mathrm{r}}$. De menor a mayor creciente complejidad, Easterling señala cuatro formas activas fundamentales: el multiplicador, el interruptor, la topología y el intercambiador; ninguna de ellas es excluyente de las demás, pueden agregarse, combinándose de infinidad de maneras para generar una situación espacial determinada, encarnándose en cuerpos, regulaciones o condiciones ambientales. La primera de ellas, el multiplicador, activa el espacio y posibilita la aparición de determinados agentes en él. El interruptor se encarga de regular o intercambiar el flujo y la disposición de los agentes dentro del ensamblaje "modu-

15 Keller Easterling, Extrastatecraft: The power of infrastructure space (Londres: Verso Books, 2014), 136.

16 Easterling, Extrastatecraft (Londres: Verso Books, 2014), p.8o.

17 A diferencia de los operadores en el código, es necesario recordar que la definición de ley de la que estamos hablando no está desligada de los cuerpos que ordena y condiciona, sino que estos cuerpos pueden devenir ley y viceversa. 
lando un flujo de actividades"18 en él. La topología, la tercera forma activa, hace referencia a los vínculos y conexiones más consolidadas dentro de un dispositivo, que funcionan como un indicador de su funcionamiento; aquellas conexiones establecidas de manera regular y constante en un estado "normal" del mismo. Señala además, que esta forma activa, por su complejidad, se construye como un ensamblaje, a su vez, de multiplicadores e interruptores -la materialización visible de agregados sólidos de estas formas-. Y, por último, el intercambiador, que establece los términos y regula el intercambio entre diferentes variables espaciales, constituyéndose como un auténtico software que condiciona la producción del espacio acorde a determinados parámetros ${ }^{19}$.

"Las formas activas establecen un set de parámetros para lo que la organización [espacial] hará a lo largo del tiempo" ${ }^{20}$. Con esta frase, Keller Easterling introduce un concepto que nos lleva de vuelta a la noción de ensamblaje, concretamente a la propuesta por Manuel de Landa. Las formas activas no son necesariamente objetos, ni necesariamente poseen materialidad, o tal vez sí la tengan pero no sean tan fácilmente asociables a un agente, cuerpo, o construcción como tal. Son más difíciles de detectar con análisis arquitectónicos clásicos $\mathrm{y}$, sin embargo, son las responsables del desarrollo de acontecimientos y determinadas organizaciones espaciales. Su encaje dentro de la noción de dispositivo tal vez sea más sencilla, imaginándose como las líneas y conexiones establecidas entre diferentes partes o, mejor dicho, el acto mismo que posibilita dicha conexión.

Estos parámetros no son homogéneos dentro del dispositivo y dependen en buena medida de la naturaleza de los agentes involucrados en cada ensamblaje. Es decir, los parámetros que afectan a cuestiones geopolíticas tal vez no sean mesurables con la misma escala que los parámetros de definición constructiva de la frontera en su materialización física. Lejos de intentar homogeneizar estos parámetros, es necesario reconocer esta especificidad de cada nivel del dispositivo y la condición de cada agente, pues las relaciones, leyes y normas construidas a cada nivel responden a estas dos cuestiones. Sin embargo, esta estratificación en niveles no es estanca sino que cada nivel es capaz de afectar a los superiores o inferiores como explica Manuel de Landa:

Al permitir a cada nivel poseer sus propios parámetros, podemos capturar las interacciones complejas entre niveles. Los cambios en los parámetros en un nivel [...] pueden provocar un efecto cascada en los parámetros de ensamblajes más grandes de los que forman parte [...] que, de hecho afectan a los parámetros de ensamblajes aún mayores.

$$
[\ldots]
$$

Debida a esta causalidad abajo-arriba, las propiedades emergentes y capacidades de un todo son inmanentes, esto es, son irreducibles a sus partes pero no las trascienden, en el sentido que si las partes dejan de interactuar el conjunto cesa de existir, o se convierte en una mera agregación de elementos. Pero por otro lado, en el momento que emerge un todo, puede ejercitar su capacidad de interactuar con otros todos [...] sino también afectar a sus propios componentes $^{21}$.

De este modo, son estas variables espaciales, formas activas y parámetros, la urdimbre inmaterial que cose y dota de capacidad de acción conjunta a un dis- \#topología

\#intercambiador

Parámetros como vínculos entre escalas

\#parámetros

\#propiedades emergentes

18 Easterling, Extrastatecraft (Londres: Verso Books, 2014), p.73:81.

19 Easterling, Extrastatecraft (Londres: Verso Books, 2014), p.73:81.

20 Easterling, Extrastatecraft (Londres: Verso Books, 2014), p.152.

21 Manuel de Landa, Assemblage Theory, (Edimburgo: Edinburgh University Press, 2018), 7 I. 
positivo que puede ser entendido como un todo -en nuestro caso el dispositivo frontera-, pero que acoge en su inmensidad infinidad de ensamblajes. Sin embargo, tanto el todo como las partes pueden afectarse y ser afectadas independientemente de su relevancia o posición dentro del dispositivo. Así, a través de la manipulación y resistencia que los cuerpos ejercen sobre estos parámetros, el dispositivo se transforma del mismo modo que cada uno de los ensamblajes se ve afectado por la reacción en cadena que produce cada alteración en el dispositivo

Volvemos al espacio en el que nos habíamos situado al inicio, las capas de normas y leyes que nos rodean vuelven a invisibilizarse. Sin embargo nuestro desplazamiento por él ya no será el mismo, sabremos que cada acción de nuestro cuerpo provoca una movilización de agentes, de leyes y de conflictos entre ellas que puede ser enunciado de maneras muy diferentes. Nuestro cuerpo genera lawscape en su desplazamiento por él, cambia y modula las formas activas de las que se construye el espacio, se reposiciona, lo altera. A cada paso, a cada movimiento. Y, cada movimiento que demos estará a su vez condicionado por infinidad de normas, protocolos hilos, conexiones más o menos estables, cuerdas que como en el cuerpo atado que presentaba Bernard Tschumi, impide ciertos movimientos, a la vez que posibilita y desencadena otros de un modo inherentemente violento. 


\section{LOS CENTROS DE INTERNAMIENTO DE EXTRANJEROS ARQUITECTÓNICAS DEL INTERNAMIENTO Y LA DEPORTACIÓN}

4.1. Transformación tipológica. Evolución histórica: desde la prisión franquista al CIE contemporáneo.

4.1.1. Origen histórico de los CIEs y su encaje normativo. Evolución y transformación.

4.1.2. El CIE como extensión del calabozo policial. CIEs de primera generación (1985-1989).

4.1.3. El CIE como arquitectura apropiada. CIEs autónomos (1990-2005) .

4.1.4. El CIE de segunda generación. Renovación higienista e institucionalización del internamiento (2005-2011).

4.2. Hacia un CIE desterritorializado. Estado actual de los Centros de Internamiento en funcionamiento y alternativas espaciales.

4.2.1. Infraestructura territorial actual.

4.2.2. Hacia los estándares penitenciarios. El CIE de Algeciras y su visibilización mediática.

4.2.3. Alternativas espaciales.

4.3. CIES interconectados. Del funcionamiento autónomo a dispositivos operativos.

4.3.1. Especialización territorial y funcionamiento en red.

4.3.2. Arquitectónicas de la contingencia.

4.3.3. Arquitectónicas de la deportación y tipologías menores.

4.3.3.1 Arquitectónicas extraterritoriales 4.3.3.2 Arquitectónicas capilarizadas 4.3.3.3 Los vuelos de deportación. El avión como arquitectónica del internamiento

4.4. En el interior del CIE. Motiones, huida y materia arquitectónica 


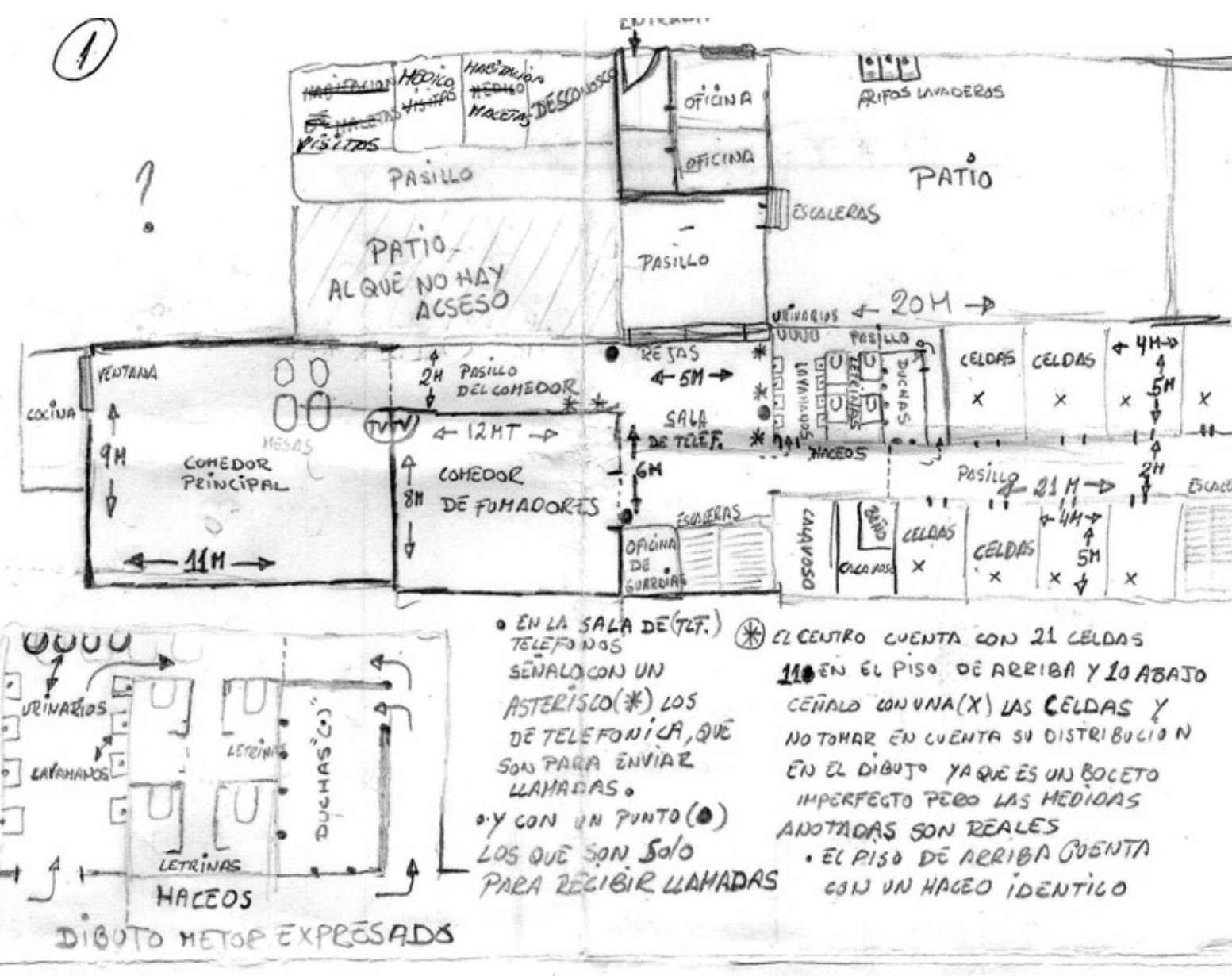

* el miercoles pasado huvo un intento d' suicioio por parte d' un arabe d'nombre saío * dia el misho dia un interno turo un ataque de epicepsia en el patio (nomaet anouimo) la ambulacia taroo has D 15 minutos en llegar y no habia en el centro

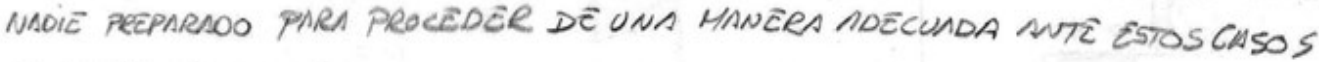
* la misha doche huvo un intento d’ huelga do hambre pero dêvido aupreción Y La intervencion, D los antidisturbios nose levro a cabo, despues d́ comer A LAS 9:00 SE NOS ENNCERRO HASTA LAS 8:00 AM DEL SIGUILNEE DIA (CASi 11 HaraS) LA NOHE O' LA HUELGA A UN,INTERNO QUE ESTAUA CENANDO UN ANTIDISTORBIO LE GOLPEO CON LA PJRRA EN LA GARA SIN MOTIVO ALGUNO, ELL INTERNO STABA CENTADO COMIENDO Y EL AGENTE PASO POE SO LADO Y LO GOLPẼO NOMBRE DEL INTERNO $($ YANCO.CELAA N-2)

* Sos interenos sufrean de una precion deviolo á escaso aspacio oel centro

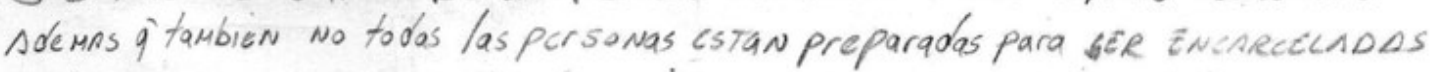
I si mismo se ven casas de depreción, enféemëDADEs, insominio cect. HAY PERSONAS Q' NO PUEDẼN DORMIR SIN TRANKILISANTES

* otro ejemplo de desatención podemos verlo en (murhi nayea) un hombre DEL PAIS DE SENEGAL DE 32 AÑOS N'DE HABITACION 3 , ĊL CUAL SUFRE DESOE HAGE UNA SEMANA unOS DocoRés inTÉNSOS $q$ le provoca la falta de aperito DEPRECION MALESTARES A TAL PUNTO $q$ los AgGNTES TIENÉN $q$ Sacarlo de so CELLOA ARRASTRANDOLO

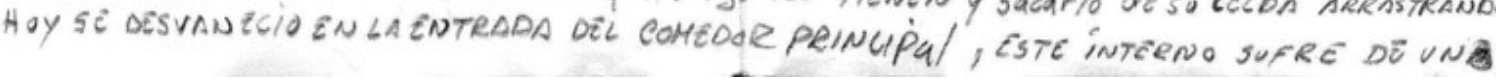

Cartografía del interior del CIE de Zapadores en Valencia realizada por Elvin, migrante boliviano (Elvin; fecha desconocida, Valencia) 


\subsection{EVOLUCIÓN HISTÓRICA Y TRANSFORMACIONES TIPOLÓGICAS. DE LA PRISIÓN FRANQUISTA AL CIE CONTEMPORÁNEO.}

En el año 2012, Elvin, un migrante boliviano retenido en el Centro de Internamiento de Extranjeros de Zapadores (Valencia) a la espera de su expulsión administrativa del país, arrancó un trozo del papel que recubría una de las estancias del CIE para dibujar sobre él la realidad espacial de una construcción opaca, no sólo a nivel arquitectónico y urbano sino también a nivel legislativo y policial'. Durante tres semanas estuvo retenido en un espacio configurado desde las lógicas carcelarias y regulado por protocolos policiales, sin que pesase sobre él ninguna condena o delito más allá de la falta que suponía encontrarse en situación irregular. Este pedazo de papel, convertido en una cartografía menor, recoge una de las primeras representaciones del interior de una de estas arquitectónicas del internamiento. En ella, cada uno de los espacios se acota con precisión, pero se superpone a esta representación física del espacio una serie de anotaciones que visibilizan el grado de violencia espacial presente en el interior de esta arquitectura así como los mecanismos empleados para ejercer dicha violencia. Así, lo que no es capaz de representar en planta se transforma en texto sobre el mismo plano - "intervención de antidisturbios", "le golpeó con la porra en la cara sin motivo aparente", "escaso espacio del centro" ...- que, junto con la declaración a un periodista del diario Latino, re-construía el interior de una excepcionalidad arquitectónicamente materializada. En ella la imposición de ritmos y rutinas -"no nos dejan ir al baño durante las nueve horas en las que estamos encerrados"-y la violencia explícita tanto por los agentes policiales como por las carencias arquitectónicas del centro -"solo hay tres letrinas, tres grifos y seis duchas: estos son los servicios para los más de cien internos”- configura una arquitectónica del internamiento que va más allá de las lógicas de la prisión histórica. Una de las frases que esta misma cartografía recoge, "tienen un Guantánamo dentro de sus propias ciudades" ${ }^{2}$, explicita como las lógicas excepcionales vinculadas a la frontera ya no sólo operan en el limes perimetral sino que son extensibles a un territorio mucho más amplio.

$\mathrm{Al}$ igual que Elvin, más de catorce mil migrantes al año son retenidos de manera forzosa en unas arquitecturas que guardan gran similitud tipológica con arquitecturas clásicas del encierro, las prisiones. Sin embargo, su condición legal -a efectos prácticos su funcionamiento no se rige por los protocolos de prisiones sino como una extensión de un calabozo policial- los exime de cumplir con los estándares espaciales de éstas. Antiguas prisiones, cuarteles en desuso, sótanos de comisarías sin ventilación ni iluminación natural o edificios exnovo han materializado la aplicación de una ley que, entre otras opciones posibles, plantea el encierro de migrantes pendientes de expulsión. Una red de CIEs dispersa en el territorio nacional, que ha ido variando y creciendo en función de las necesidades de regulación desde su implementación efectiva en el año 1985. Aunque el CIE sea el elemento principal de análisis en este capítulo, reducir todas

1 El caso de Elvin está recogido de manera más detallada en la investigación periodística de Toni Martinez.

Ver más: Toni Martinez,. CIE: El Guantánamo Español, (Barcelona: Universitat Oberta de Catalunya, 2016).

2 Martinez,. CIE: El Guantánamo Español, (Universitat Oberta de Catalunya, 2016). 
las arquitectónicas del internamiento a esta red territorial resulta insuficiente, es imprescindible incluir otras arquitecturas que, pese a su distinción normativa o condición efímera, funcionan como contenedores -forzosos o voluntariosde migrantes durante períodos temporales definidos. Así, hemos denominado arquitectónicas del internamiento al conjunto formado por CIE, CETI, CATE, campamentos temporales, calabozos policiales, construcciones ocupadas y una serie de arquitecturas vinculadas a todas ellas. Esta dimensión expandida de la noción del internamiento en relación al control de la migración, atiende a los diferentes estadios y propósitos de una arquitectura que actúa como un sistema de contención y regulación de flujos -tanto de admisión como de expulsión-. Bajo esta óptica, es posible unificarlas bajo un mismo criterio para analizar con precisión las condiciones espaciales y evolución que estas construcciones han tenido en las últimas tres décadas.

Atender a la dimensión expandida de las arquitectónicas del internamiento, que incluye tipologías menores y temporales -o permanentemente temporalespermite comprender como operan las lógicas excepcionales vinculadas a la frontera a un ámbito mucho más amplio. Si bien en un primer momento estas lógicas estaban focalizadas en las inmediaciones de la línea fronteriza y, en un segundo momento, contenidas también en arquitecturas de la excepción como los Centros de Internamiento, a día de hoy han tejido una red mucho más tupida en la totalidad del territorio, una infraestructura territorial de control de cuerpos, con un alto grado de violencia espacial operado por las lógicas operativas y excepcionales de la frontera. Las lógicas dentro del dispositivo de deportación ponen de manifiesto la condición infra-humana, o de nuda vida que adquiere el cuerpo migrante al entrar en este circuito a través de una serie de acciones. La misma violencia que encontramos en las fronteras exteriores, desplegada en las acciones en el perímetro de la valla o más allá de ella, emplea aquí otros mecanismos para ejercerla y, transformar a la persona en un sujeto deportable menos-que-humano o, en palabras de Cristian Orgaz, una no-persona; a la que, por tanto, no se le tienen por qué garantizar los mismos derechos. En este sentido, el CIE, como institución, supone un ejemplo que visibiliza con claridad esta situación:

los procesos de deportación producen no-personas, especialmente mediante la imposición de una realidad administrativa sobe el resto de dimensiones de la vida de las personas extranjeras. Cuando la persona es sometida a los procesos C-I-E pueden operar prácticas de todo tipo, como la dejación del cuidado e incluso, el ejercicio de la fuerza y el maltrato institucionalizado. Precisamente, las vías de fiscalización de este problema son muy limitadas por la opacidad, la arbitariedad y la impunidad que caracterizan a los Centros de Internamiento para Extranjeros y las propias características de la institución y la cultura policial. $^{3}$

Profundizar en este dispositivo territorial nos obliga, nuevamente, a incorporar a nuestra investigación visiones extradisciplinares que permitan, por un lado limitar nuestro análisis a la dimensión arquitectónica de un sistema cuyas ramificaciones son múltiples. Para ello, apoyamos este capítulo fundamentalmente en dos investigaciones doctorales que, desde el contexto español, se han centrado exclusivamente en el dispositivo de deportación, donde el Centro de Internamiento de Extranjeros cobra especial relevancia. Cristian Orgaz en "Emergencia del dispositivo deportador en Europa y su generalización en el caso español" vertebra a través del CIE, un recorrido histórico y análisis social de las prácticas que giran en torno a estos centros; una investigación

3 Christian Orgaz, «Emergencia e Institucionalización Del Encierro De Extranjeros En España: El Caso De Los Cies», (Tesis doctoral, Universidad Complutense de Madrid, 2018), 515. 
exhaustiva que compila y permite comprender la evolución desde diferentes planos -mediáticos, sociales, políticos, normativos... de esta infraestructura de deportación. En El dispositiu de deportació Cristina Fernández Bessa hace una aproximación más amplia a todo el entramado de lógicas de gestión, internamiento y expulsión desde un punto de vista criminológico, centrando el capítulo cuarto -"El cicle de la deportació: detenció, internament i expulsió"en el contexto específico de los CIE. También es importante reseñar los trabajos de Iker Barbero respecto al internamiento de extranjeros. Más allá de estas aproximaciones académicas encontramos diferentes informes y textos críticos que, publicados con cierta periodicidad, permiten a través de su lectura conjunta, extraer información útil para elaborar una panorama de la situación de los CIE. Nos referimos, principalmente, a los sucesivos informes elaborados por el Defensor del Pueblo, por CEAR y SJM así como los diferentes textos publicados desde plataformas activistas como Tanquem Els CIE o CIES no.

\subsubsection{ORIGEN HISTÓRICO DE LOS CIES Y SU ENCAJE NORMATIVO. EVOLUCION Y TRANSFORMACIÓN.}

Analizar las diferentes soluciones arquitectónicas que, desde el Estado, se han dado al encierro de extranjeros implica hacer una aproximación histórica reciente a ellos para comprender la respuesta precisa que, en cada momento, se ha dado a una misma problemática: la regulación, control, absorción y expulsión de flujos no controlados. Frente a otras tipologías arquitectónicas que responden a la necesidad del encierro del cuerpo dentro de sus muros -el monasterio, la prisión, el manicomio...- el Centro de Internamiento presenta una serie de peculiaridades respecto a sus predecesores que emanan de su formulación normativa y que provoca un impacto claro en su materialización arquitectónica. La primera de ellas, la condición temporal de los cuerpos encerrados, de la cual se derivan una serie de carencias espaciales e infraestructurales con gran impacto para los internos. La segunda, es una tipología arquitectónica de nueva creación que responde a la necesidad de respuesta espacial a una interpretación, no exenta de polémica de la Ley 7/1985 donde se establece la posibilidad de creación de Centros de Internamiento de Extranjeros. Frente a tipos históricamente consolidados, aparece un tipo de nueva creación que, si bien el carácter del encierro es radicalmente diferente al de sus antecedentes -la prisión fundamentalmente- se nutre de sus características arquitectónicas y organizativas hasta el punto de replicarlas con precisión, tal y como afirma el Defensor del Pueblo4.

Aproximémonos por tanto al texto de la Ley 7/1985, uno de los textos legales que, junto a otros, pretende actualizar la cuestionada Ley de Vagos y Maleantes, que recoge los derechos y libertades de los extranjeros en España, requisito indispensable para la entrada de España en la Comunidad Económica Europea ${ }^{5}$. El artículo veintiséis recoge las condiciones de la expulsión de extranjeros del territorio nacional de la siguiente manera:

4 Defensor del Pueblo, "Informe Anual 2010 de Prevención de la Tortura», (Defensor del Pueblo, 2010).

5 Orgaz, «Emergencia e Institucionalización Del Encierro De Extranjeros En España », (2018).376. 
I. Los extranjeros podrán ser expulsados de España, por resolución del Director de la Seguridad del Estado, cuando incurran en alguno de los supuestos siguientes:

a) Encontrarse ilegalmente en territorio español, por no haber obtenido la prórroga de estancia o, en su caso, el permiso de residencia, cuando fueran exigibles.

b) No haber obtenido permiso de trabajo y encontrarse trabajando, aunque cuenten con permiso de residencia válido.

c) Estar implicados en actividades contrarias al orden público o a la seguridad interior o exterior del Estado o realizar cualquier tipo de actividades contrarias a los intereses españoles o que puedan perjudicar las relaciones de España con otros países.

d) Haber sido condenados, dentro o fuera de España, por una conducta dolosa que constituya en nuestro país delito sancionado con pena privativa de libertad superior a un año, salvo que sus antecedentes penales hubieran sido cancelados.

e) Incurrir en demora u ocultación dolosa o falsedad grave en la obligación de poner en conocimiento del Ministerio del Interior las circunstancias relativas a su situación, de acuerdo con el artículo 14.

f) Carecer de medios lícitos de vida, ejercer la mendicidad o desarrollar actividades ilegales.

2. En los supuestos a que se refieren los apartados a), c) y f) del número anterior, se podrá proceder a la detención del extranjero con carácter preventivo o cautelar mientras se sustancia el expediente.

La autoridad gubernativa que acuerde tal detención se dirigirá al Juez de Instrucción del lugar en que hubiese sido detenido el extranjero, en el plazo de setenta y dos horas, interesando el internamiento a su disposición en centros de detención o en locales que no tengan carácter penitenciario. De tal medida se dará cuenta al Consulado o Embajada respectivos y al Ministerio de Asuntos Exteriores. El internamiento no podrá prolongarse por más tiempo del imprescindible para la práctica de la expulsión, sin que pueda exceder de cuarenta días. ${ }^{6}$

Precisamente esta formulación legal es la que establece la disposición arquitectónica de un espacio, así como los usuarios que van a estar ligados a él a través de una casuística de potenciales acciones que implican su internamiento. Así recoge el Defensor del Pueblo las contradicciones explícitas entre su formulación normativa y su aplicación operativa a la hora de construir y gestionar los centros de internamiento:

El conjunto de las instalaciones de los CIE tiene una marcada impronta penitenciaria, contraviniéndose con ello un principio básico para este tipo de instalación [...] Se constata una acusada tendencia a priorizar las medidas de seguridad y control policial de los centros, en claro detrimento de las condiciones de vida de los internos y del mantenimiento de sus derechos no afectados por la privación de libertad deambulatorio. El problema principal está en la propia concepción de los CIE en la ley, donde son definidos de manera negativa: es decir, se establece un paradigma que es el penitenciario, para a continuación señalar que debe haber una privación de libertad distinta de esa, pero sin regular cómo ha de ser esta y cuáles han de ser sus límites. ${ }^{7}$

6 Ley Orgánica 7/1985 sobre derechos y libertades de los extranjeros en España (España: Boletín Oficial del Estado), artículo 26.

7 Defensor del Pueblo, "Informe Anual 2010 de Prevención de la Tortura», (Defensor del Pueblo, 2010), 253. 
Esta ambigüedad en la que se sitúa la referencia espacial a las condiciones del encierro ha supuesto diferentes interpretaciones posibles respecto a un paradigma -la cárcel y su carácter penitenciario- en base al cual se sitúan las diferentes materializaciones arquitectónicas. Rodriguez Candela ${ }^{8}$ y Orgaz Alonso $^{9}$ establecen tres interpretaciones posibles respecto al carácter no penitenciario que establece la Ley General Penitenciaria de 1979, a la que nos remite la Ley $7 / 1985$. El CIE como extensión de un calabozo policial o calabozo ampliado, es decir, lugares de internamiento no sometidos a un régimen penitenciario, pese a que sus condiciones espaciales no sean adecuadas para duraciones superiores a las setenta y dos horas estipuladas. En segundo lugar, el carácter no penitenciario establece una situación más garantista respecto al carácter penitenciario en cuanto asistencia y condiciones espaciales de los internos. Por último, una tercera apreciación que abre las puertas a que el encierro no sea obligatorio en caso de no poder asegurar una serie de condiciones espaciales o servicios Sin embargo, en la práctica, el paradigma penitenciario se ha ido superponiendo sobre estos nuevos centros hasta hacerlo casi indistinguibles en la práctica. Sin embargo, al no estar regidos por él y tener que adecuarse espacialmente a sus estándares, a lo que debemos sumar la temporalidad reducida de los internos - hasta los sesenta días actuales-, hace que el CIE se defina por un carácter infrapenitenciario ${ }^{I O}$; algo que tiene su correlato a nivel espacial y arquitectónico.

Esta indefinición o ambigüedad, solo matizada por sentencias judiciales y recursos a la propia ley, ha sido acompañada por una ausencia o falta de definición también de las lógicas internas de funcionamiento de los centros:

La indefinición legal deja a los encargados de aplicar la ley las decisiones sobre cómo hacerlo, de forma que el criterio policial y el imperativo de seguridad primarán por encima de cualquier otro (incluso los propios derechos y la integridad de las personas extranjeras). El criterio securitario determina el plano estratégico, codificado en protocolos de actuación y documentos con resúmenes de interpretación de la ley, donde las complejidades de las sentencias constitucionales se van simplificando. Estas definiciones y prescripciones guiarán los principios de actuación, aunque, ante la falta de mecanismos de control y de medios, en el plano táctico las situaciones padecerán de la arbitrariedad de los agentes de policía que custodian a los extranjeros. ${ }^{\text {II }}$

Hasta pasada más de una década desde su implementación efectiva en el territorio español -y dos décadas hasta la elaboración de un reglamento propio compartido-no existe un cuerpo normativo que establezca y regule las acciones que ocurren en su interior. Por lo tanto, estamos ante un espacio totalmente ritualizado, donde los cuerpos son encerrados y sometidos a unas limitaciones de acción y movimiento muy claras, que no es gestionado desde una ley superior que lo defina, sino de una implementación acumulativa de patrones, protocolos y decisiones policiales de carácter operativo.

8 José Luis Rodriguez Candela, “¿Están justificados los Centros de Internamiento de Extranjeros?”, Transatlantic Student Network n⿳⺈-4, julio-diciembre 2017.

9 Orgaz, «Emergencia e Institucionalización Del Encierro De Extranjeros En España », (2018).

10 Rodriguez Candela, “Están justificados los Centros de Internamiento de Extranjeros?” Transatlantic Student Network nㅜㅜ, julio-diciembre 2017.

11 Rodriguez Candela, “¿Están justificados los Centros de Internamiento de Extranjeros?”, Transatlantic Student Network nํㅜㄴ, julio-diciembre 2017. 
Siguiente página:

Línea histórica de los Centros de Internamiento de Extranjeros 1985-Actualidad (Elaboración propia)
Un recorrido histórico por la corta historia de los CIE nos permite comprender el carácter de contingencia que, en buena medida, los ha acompañado desde su creación. Es decir, la capacidad de resolución, innovación y transformación arquitectónica que tanto el propio tipo - genérico- como cada centro en sí-en función de sus necesidades y características concretas- es capaz de generar. La rápida evolución arquitectónica que esta institución ha tenido -desde los calabozos policiales a los CIE de alta seguridad- se explica en buena medida por la novedad de una función para lo que no había una solución formal arquitectónica definida de antemano - más allá de una no-comparación con el paradigma carcelario-; situación análoga a los procesos de innovación arquitectónica de tipos previos a su consolidación. Para entender estas transformaciones tipológicas es necesario estudiar también los acontecimientos concretos producidos a escala geopolítica -desde la aplicación de determinadas normativas europeas a los períodos temporales donde las rutas migratorios a través de España han sido principales frente a otras- y también a escala de situaciones o acontecimientos específicos - motines, fugas, suicidios, asesinatos...-. De nuevo, sólo es posible un análisis que, como en anteriores ocasiones, entrelace un plano arquitectónico y material con un plano normativo, así como las acciones de los cuerpos internos.

Tracemos una línea temporal desde la entrada en vigor de la Ley 7/1985 hasta la actualidad. Situemos sobre ella, por un lado el marco normativo que se ha ido implementando en todo este tiempo. Como aclaración, conviene recordar que de acuerdo a la idea de lawscape, el impacto de esta Ley no es la única en afectar a la configuración de los Centros de Internamiento, pero sí que tiene la capacidad de modular y operar sobre ciertas decisiones arquitectónicas. Sin embargo, sí que es la Ley, fundamentalmente la que defina, decida y regule el flujo de internos a cada instante. En base a ella se selecciona al usuario potencial de las arquitectónicas del internamiento actuando como una forma activa arquitectónica. Es más, en base a este corpus de normativas, jurisprudencias y leyes vigentes, cada cuerpo es potencialmente asignado a su arquitectónica del internamiento correspondiente dentro del sistema de regulación de flujos. Situemos a continuación los períodos de entrada en vigor, funcionamiento y cierre de cada uno de los CIE, incluyendo tanto su localización geográfica como su procedencia tipológica. El primer resultado que muestra este ejercicio es la falta de correspondencia inmediata entre el paisaje normativo establecido y la creación, inauguración o clausura de cada uno de los centros. La ley, en el caso de los CIE, "ha ido por detrás de su existencia y ha solido dar cobertura a la realidad de los centros" ${ }^{\text {12 }}$, una realidad basada en la contingencia y adecuación instantánea a necesidades varias, o a prácticas implementadas desde protocolos policiales.

Sin embargo, si situásemos sobre esta línea una tercera variable que reflejase tanto una serie de acontecimientos locales -situaciones producidas en el interior de los CIE- como globales - redistribución de los flujos migratorios, cambios en la concepción social de la migración...- podemos observar una correlación mayor entre esta variable y las principales transformaciones arquitectónicas de los centros. Es decir, la visibilización de los cuerpos -internos o libres- en la esfera pública a través de su construcción mediática ${ }^{13}$ que tiene un impacto directo en la transformación de los centros. Visibilización producida en dos líneas divergentes

12 Markus González Beilfuss, "Los CIE: una realidad controvertida y compleja”, Anuario CIDOB de la inmigración 2017, 2017.

13 Orgaz establece una clasificación entre posiciones críticas y posiciones legitimadoras la cual nos permite ubicar los diferentes discursos en torno a la problemática de los CIE, siendo posible extrapolarlos más allá de lo mediático -ámbito al que se limita su análisis- y llevarlo al conjunto de lo social. 
que logra funcionar como un motor de transformación arquitectónica: por un lado la construcción de un cuerpo que debe ser internado y, por otro lado, la denuncia crítica a su internamiento a través del eco en noticias de acontecimientos o protestas acerca de una realidad material concreta. Un ejemplo claro es cómo la fuga de varios internos del CIE existente en los sótanos de la comisaría de La Verneda (Barcelona) a través de una puerta rota y un falso techo en mal estado fue uno de los motivos que aceleraron su cierre e implantación de un modelo que venía a higienizar las carencias espaciales del anterior.

Si aumentamos la escala de esta tercera variable, que contempla el impacto social y la llevamos a una dimensión territorial o incluso geográfica, encontramos otra clave acertada que ayuda a explicar las transformaciones arquitectónicas de los CIEs. Cachón y Orgaz coinciden en establecer cuatro grandes bloques trasladable a las principales propuestas arquitectónicas. Una primera fase de contingencia o emergencia del hecho migratorio que termina en 1985, donde se codifica legalmente ante un aumento de la migración económica a España y se establecen las primeras medidas operativas de internamiento. Una segunda fase hasta el año 2000 donde la inmigración se constituye un hecho social, que reconoce la necesidad de internamiento de manera ordenada, se mantiene la condición operativa de CIE y aparecen construcciones autónomas reutilizadas. La tercera, la institucionalización de la cuestión migratoria, que abarca hasta el año 2011 -a efectos arquitectónicos observamos un decalaje que coincide con la llegada de la crisis económica-; se construyen los CIE de nueva generación, ex novo, que asumen un discurso higienista. Y, por último la crisis del modelo del CIE, debido a la respuesta social crítica cada vez más mayoritaria; una crisis consolidada a nivel arquitectónico por la sustitución de ensamblajes operativos, campamentos y soluciones temporales frente a construcciones específicamente destinadas a CIE.

Profundicemos a continuación en la asignación de una respuesta espacial específica para cada una de estos principales bloques, donde acontecimientos específicos de visibilización de las condiciones interiores de una arquitectura opaca actúan como detonadores o potenciadores de transformaciones arquitectónicas. Porque, realizar en paralelo un recorrido histórico por la evolución de los Centros de Internamiento de Extranjero, permite no sólo asignar e identificar las respuestas espaciales específicas que se han dado en cada momento sino los discursos arquitectónicos, explícitos o implícitos, superpuestos a estas construcciones.

Esquema de configuración territorial actual de los Centros de Internamiento de Extranjeros y CETIs (Elaboración propia)

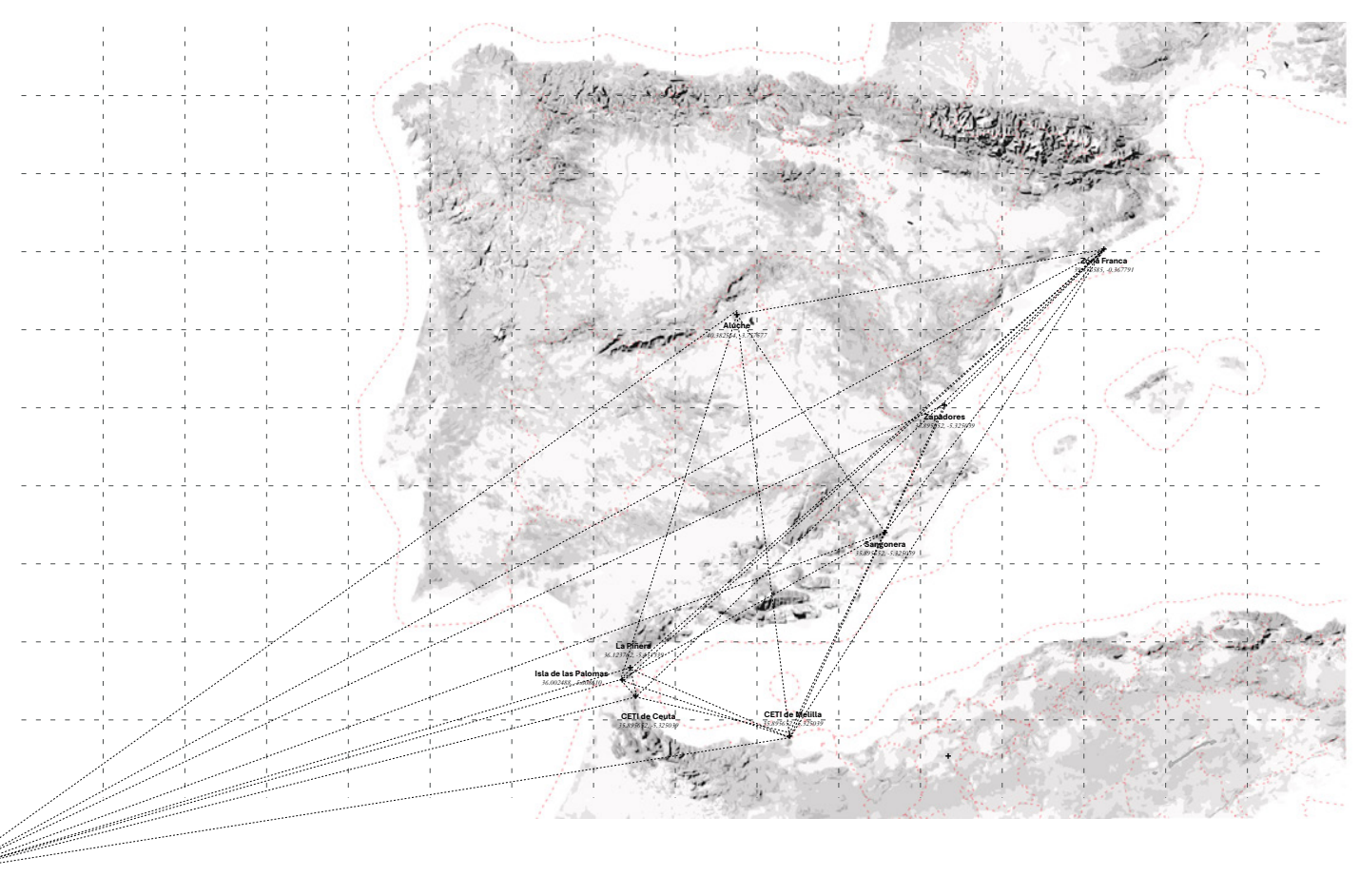




\subsubsection{EL CIE COMO EXTENSIÓN DEL CALABOZO POLICIAL. CIES DE PRIMERA GENERACIÓN (1985-1989)}

El inicio de nuestra línea temporal coincide con la entrada en vigor de la Ley 7/1985, y su implementación efectiva tras una serie de recursos legales que demoraron hasta 1987 su puesta en marcha. En Valencia, Madrid y Barcelona se adecuaron instalaciones policiales existentes para la retención de extranjeros. Por sus características comunes podemos enmarcar en esta primera etapa estos tres centros. El CIE de Zapadores, en Valencia, módulo en desuso del acuartelamiento vinculado a la comisaría, fue el primero en entrar en funcionamiento. Le siguió el pabellón de la comisaría de Moratalaz, en Madrid, inaugurado por Corcuera, entonces ministro del Interior, el quince de noviembre de 1988 en "un pabellón que anteriormente había servido de acuartelamiento de la XIII Bandera Móvil de la policía, en el complejo situado en la calle de Tacona, en el barrio de Moratalaz" ${ }^{14}$; en la práctica, un sótano sin iluminación natural habilitado para una ocupación de ciento veinte personas. Así lo describía la prensa:

Cuando uno entra en el antiguo CIE, se topa con una cruda realidad. Es necesario bajar unas escaleras que conducían a un sótano. El fuerte hedor echa para atrás al visitante. Un pequeño recinto, donde apenas cabe una pequeña mesa y un minúsculo armario, permite a los agentes vigilar la sala de estar. Los desconchones y las humedades son visibles. Los lavabos se rompen cada dos por tres y el agua sale hasta el pasillo, según han denunciado los sindicatos. ${ }^{15}$

El tercer centro se sitúa en las dependencias de la comisaría de La Verneda, Barcelona, con una capacidad máxima para ochenta personas. Comparte con el de Moratalaz su ubicación dentro del complejo policial: un sótano. Estos son los tres primeros centros oficiales reconocidos, que comparten una vinculación directa, funcional y arquitectónica como espacios dependientes de una comisaría o extensiones del calabozo policial. En un primer momento, la traslación de la norma a la materialización arquitectónica es prácticamente literal, siendo espacios habilitados de manera rápida a tales efectos. Sin embargo, se aprecian signos evidentes de la condición infrapenitenciaria al emplear espacios obsoletos o en desuso que no cumplen con unas condiciones espaciales mínimas que sí serían exigidas a un uso penitenciario, el ejemplo más claro la falta de iluminación y ventilación natural al situarse en sótanos.

Es importante señalar la excepción arquitectónica, así como la evolución funcional del edificio, que supone la prisión de Barranco Seco, Gran Canaria. Este edificio fue construido durante la Segunda República como parte de una visión renovadora de las cárceles que garantizase las condiciones higiénicas y espaciales de los reclusos; un edificio con capacidad para cien reclusos, "una cárcel moderna, amplia, higiénica, bien ventilada con los departamentos y servicios que requieren sus fines”. José Luis Aranguren Bourden ${ }^{16}$ proyectó y construyó en 1931 la prisión de Barranco Seco como arquitecto de la Dirección General de Prisiones, edificio que supuso en su momento una actualización de los estándares carcelarios, tal y como refleja en la memoria de construcción:

14 Jesús Duva, "Mañana se abre en Moratalaz un centro de detención para extranjeros en vías de expulsión”, El País, 4 de noviembre de 1988.

15 Francisco Javier Barroso, "Adiós a unas instalaciones que sólo permitían el hacinamiento”, El Pais, 20 de junio de 2005.

16 Arquitecto de tres de los centros de internamiento en uso en la actualidad: Madrid, Algeciras y Barranco Seco. 
Siendo notoria y justificada la construcción de un nuevo edificio para la instalación en el mismo de la Prisión Provincial y de Partido en Las Palmas (Canarias)que sustituya a la actual que no reúne condiciones primordiales de seguridad, capacidad, aislamiento y distribución para la implantación de modernos regímenes penitenciarios no las más precisas de las que se relacionan con la salubridad e higiene de los edificios. ${ }^{17}$

Resulta destacable cómo un edificio que había materializado una visión higienista de la prisión, es considerado obsoleto cuarenta años después pero, aún así, sirve como centro informal para la retención de extranjeros -con constancia hasta diez años antes de la entrada en vigor de los CIEs antes mencionados-. Es decir, en la práctica la detención e internamiento de extranjeros se efectuaba también en edificios penitenciarios. Lo que hace excepcional a este edificio, no sólo es que se mantenga hasta la actualidad como Centro de Internamiento, sino que duplique la capacidad para la que había sido proyectado como cárcel -de nuevo se aprecia el carácter infrapenitenciario al empeorar, de facto, las condiciones espaciales. También, porque es el primer ejemplo de edificio directamente asociado al paradigma penitenciario que, según la ley, no podía vincularse con los centros de internamiento; algo que, anticipa la evolución hacia este paradigma de los nuevos centros en las próximas décadas.

Esta primera etapa se caracteriza fundamentalmente por dos cuestiones: la contingencia de las respuestas arquitectónicas a un escenario nuevo, que bascula entre la informalidad de la retención de extranjeros en espacios no acondicionados para ellos -comisarías, calabozos...- con los primeros intentos de normalizar el CIE como espacio autónomo. Este primer acercamiento a la especificidad del CIE, respecto otras arquitectónicas del internamiento, como calabozo ampliado, introduce el paradigma infrapenitenciario, es decir la precarización de las condiciones espaciales de cada centro. No existen garantías o estándares, ni a nivel arquitectónico pero tampoco a nivel de protocolos o prácticas policiales, lo cual se deriva en una serie de denuncias por torturas, malos tratos, agresiones y protestas en los primeros años de funcionamiento. En la próxima etapa vemos un avance progresivo hacia el paradigma penitenciario, en cuanto a securitización y control del espacio, manteniendo la condición infrapenitenciaria en cuanto a la falta de garantías espaciales y normativas.
De arriba a abajo:

Prisión de Barranco Seco en su estado actual ( Gran Canaria, 2016)

Imágenes de archivo de la prisión de Barranco Seco (Archivo Aranguren; Gran Canaria, década de 1930).

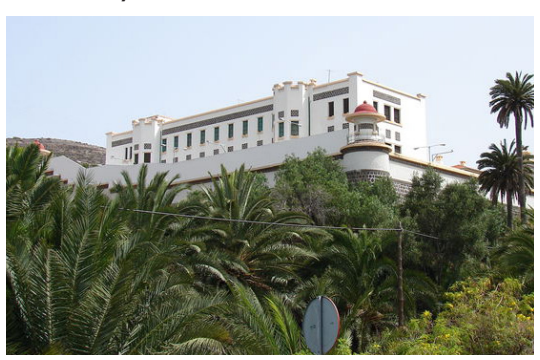

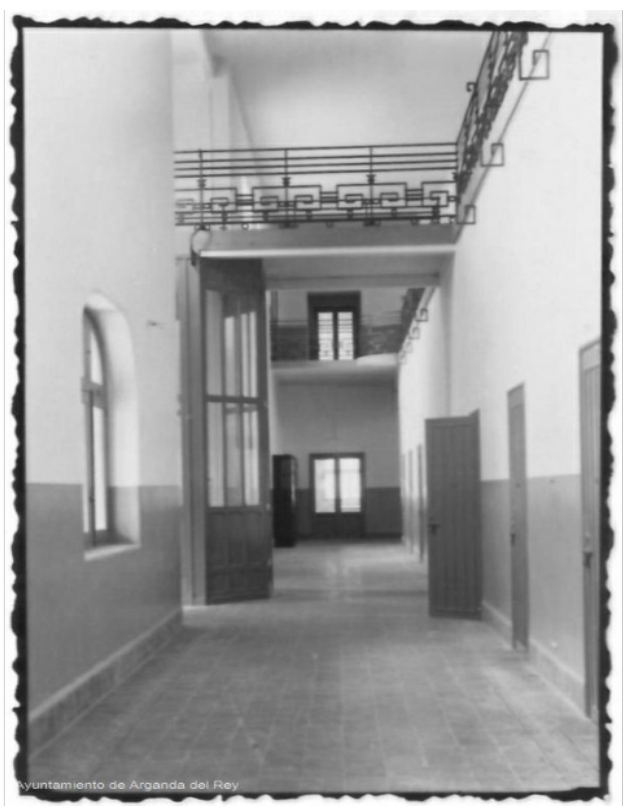

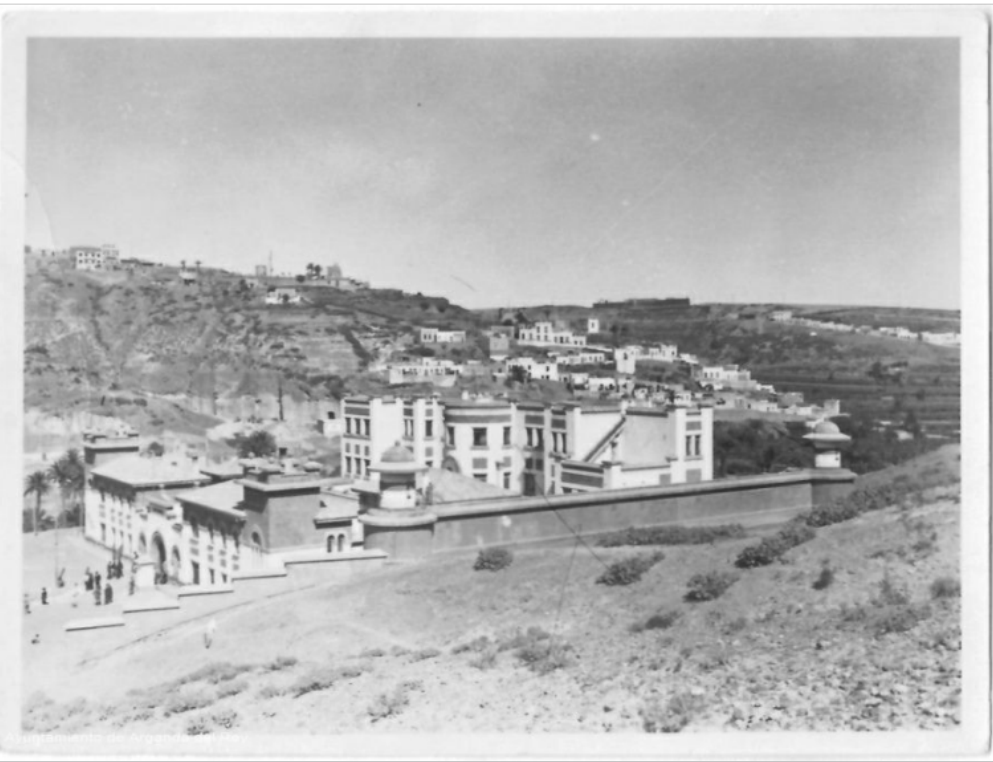

17 José Luis Aranguren Bourden, Memoria descriptiva del proecto de edificación de la Prisión Provincial y de Partido en Las Palmas, (1931). 


\subsubsection{EL CIE COMO ARQUITECTURA APROPIADA. CIES AUTÓNOMOS (1990-2005)}

La segunda gran etapa de nuestra línea temporal, que podríamos denominar de transición entre una primera solución de contingencia a la consolidación normativa de una tipología o CIEs de segunda generación, comprende mayoritariamente la última década del siglo XX. Podríamos asociarla a la fase de transición, establecida por Orgaz, donde la inmigración se constituye como un hecho social. Si la etapa anterior estaba caracterizada por la apropiación de estancias vinculada a un edificio con un funcionamiento no vinculado al internamiento de extranjeros exclusivamente -comisaría o prisión- esta segunda etapa se caracteriza por su funcionamiento independiente. Sin embargo, mantiene la apropiación, captura y reutilización de arquitecturas obsoletas o en desuso con fines originales diferentes. Con intervenciones mínimas en las construcciones existentes, se reutilizan ciertos edificios públicos - vinculados en principio al Ministerio de Defensa o Interior- para acondicionarlos como Centros de Internamiento de manera definitiva. Es en esta etapa donde, a través de la apropiación de arquitecturas en desuso, se establece la red territorial de Centros que existe a día de hoy, apareciendo una serie de localizaciones fundamentalmente localizadas en el Sur de España, que no han variado desde entonces -aunque sí se hayan actualizado los edificios-. Andalucía y Murcia son los nuevos puntos de implementación de esta red, junto con el refuerzo de un segundo centro en las Islas Canarias. El cuartel militar de Capuchinos en Málaga, antiguo convento desamortizado por el Estado en el siglo XIX; la prisión del año 1959 de La Piñera -construida también por Aranguren- y su extensión aprovechando el antiguo cuartel militar en la Isla de las Palomas (Tarifa); la prisión de Sangonera la Verde en Murcia son los nuevos Centros de Internamiento desarrollados en esta segunda etapa y que, siguen en funcionamiento hasta esta última década.

Resulta muy significativo el carácter y función previa de cada uno de los edificios transformados en CIE, ya que se escogen por haber sido arquitectónicas del internamiento - forzosas en el caso de las prisiones y voluntarias en el caso de los cuarteles - y por ostentar la titularidad instituciones involucradas en el dispositivo de internamiento y deportación. Pero, si esta etapa evidencia la violencia simbólica ejercida contra los migrantes a través de la arquitectura, no es tanto por el empleo -ahora sí, sin matices- de tipologías arquitectónicas penitenciarias, sino por emplear arquitecturas obsoletas debido a las carencias y patologías presentes en todos ellos. Es decir, arquitecturas no aptas para el internamiento de personas nacionales - debido a los estándares establecidos por la ley de instituciones penitenciarias- sí resulta apto para migrantes extranjeros. Esta decisión, aplicada de manera general en diferentes centros, evidencia la materialización del Derecho del Enemigo a través de la arquitectura: la supresión o suspensión de derechos y garantías a determinados cuerpos por su simple condición, en este caso, extranjero o migrante. El Derecho del Enemigor ${ }^{18}$, que luego se incrementa a través de una serie de prácticas espaciales en el interior del CIE, toma cuerpo en primera instancia a través de la materia arquitectónica, al permitir el internamiento de cuerpos en arquitecturas obsoletas con deficiencias evidentes, simplemente por el hecho de tener una condición de Enemigo o menos-que-humana, desde el punto de vista del Estado.

Dado que esta solución arquitectónica, la apropiación de arquitecturas obsoletas, constituye el grueso de centros de internamiento en activo, conviene hacer una aproximación a cuales son las características arquitectónicas a través de las cuales

18 El Derecho del Enemigo es un concepto jurídico elaborado por Gunther Jakobs para denominar una categoría de personas acusadas cuyos derechos se ven mermados, por considerarse contrarios a los intereses del Estado, respecto a los de un ciudadano normal. 

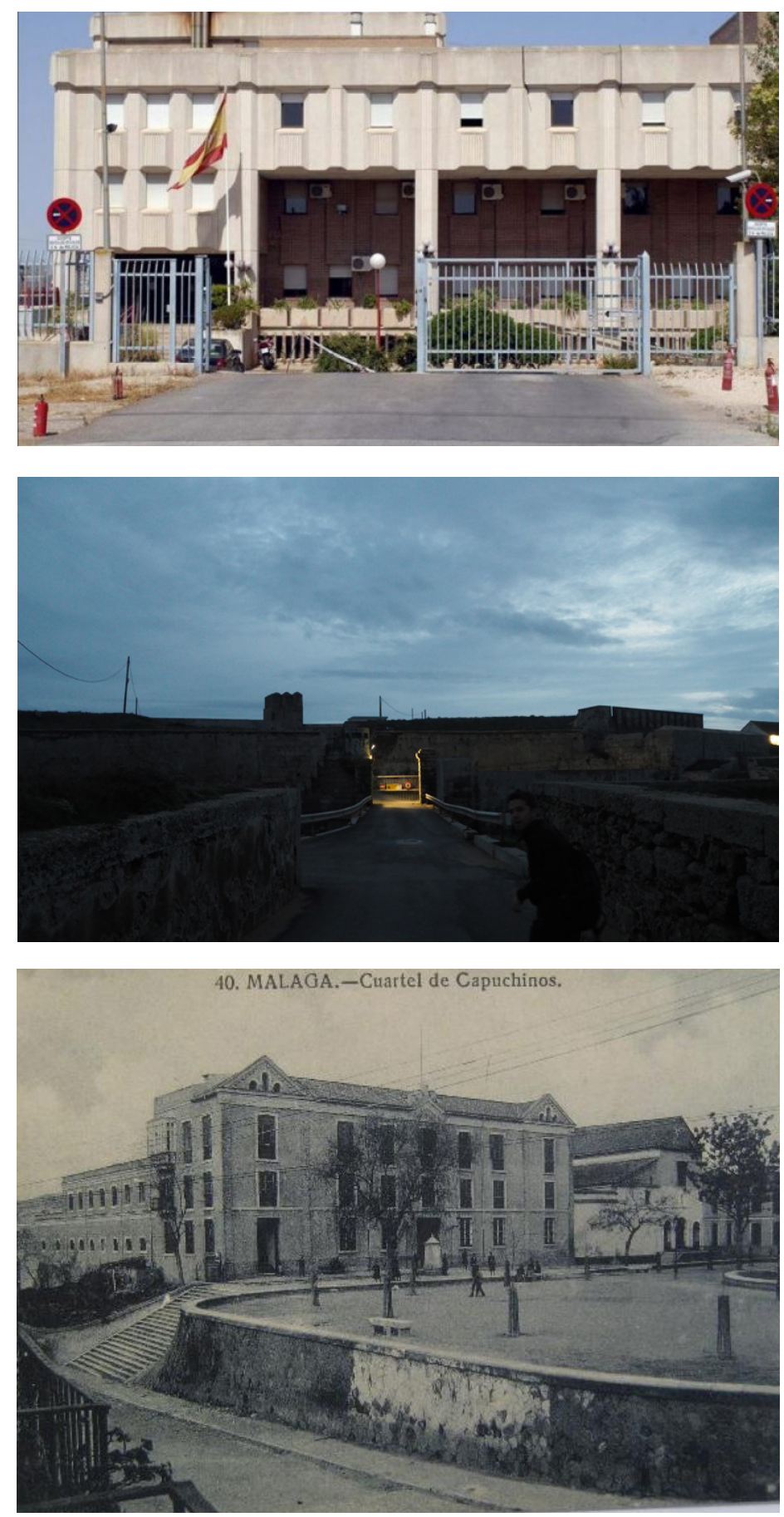

De arriba a abajo:

CIE de Sangonera la Verde (Murcia, Actualidad), Isla Más Palomas (Elaboración propia;Tarifa, 2019), Capuchinos (Málaga, fecha desconocida), La Piñera (Algeciras, Década de 1960).

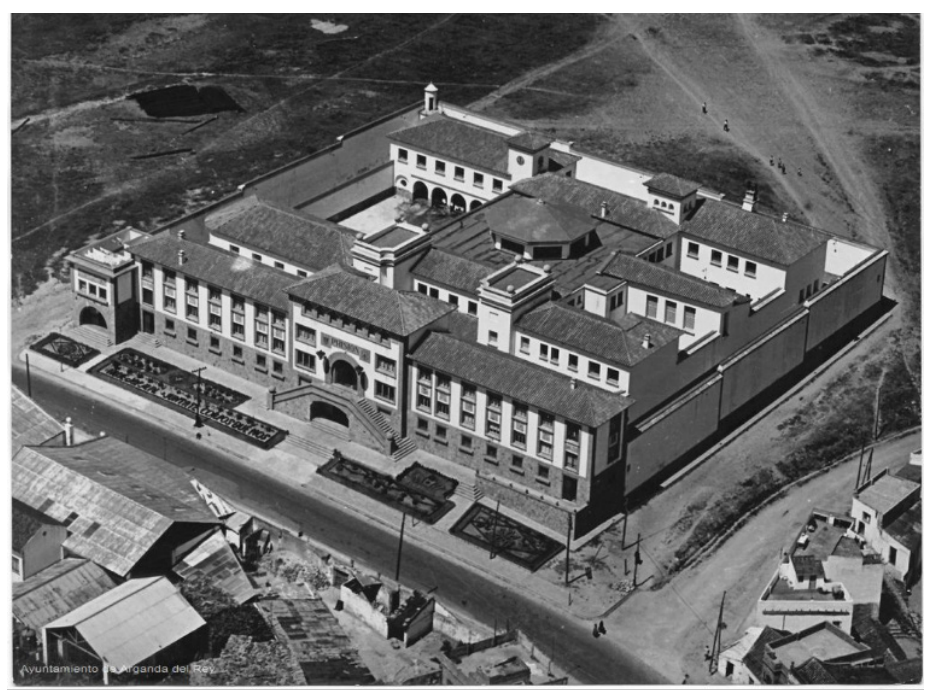



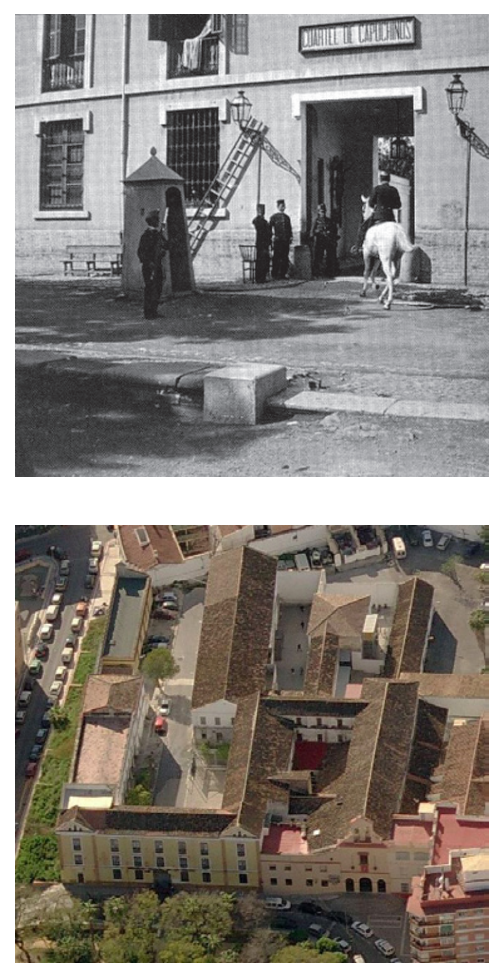

De arriba a abajo:

CIE de Capuchinos en funcionamiento como cuartel y en desuso en la actualidad (Málaga) podemos afirmar que se encuentran en una condición infrapenitenciaria debido a las carencias espaciales que presentan. El CIE de Capuchinos en Málaga, en uso desde 1990 hasta 2012, supone por su longevidad así como por la reutilización de un edificio existente con más de dos siglos de antigüedad, permite un mayor detalle a la hora de explicar carencias generalizadas tanto a nivel funcional como material. Sobre ello conviene señalar que las graves deficiencias arquitectónicas que llevaron a su cierre, han sido acompañadas de una serie de sucesos deleznables cometidos por parte de funcionarios: abusos sexuales prolongados, abortos no socorridos, falta de asistencia sanitaria, plagas de insectos y ratas, comida en mal estado o agresiones físicas. Todo ello evidencia hasta qué punto, la construcción espacial va más allá de los muros y estas situaciones merecen ser tenidas en cuenta en un análisis arquitectónico para comprender el grado de violencia espacial y excepcionalidad que se dio, de manera continuada en el tiempo en cada uno de estos centros.

El "Hotel Capuchinos"19 se adaptó en 1990 de su anterior uso, cuartel militar, para dar cabida a ochenta internos. Una operación que ya había sufrido el edificio en el siglo XIX tras su reconversión de convento capuchino a cuartel. Es reseñable cómo todos los usos desde su construcción -por la disposición espacial de las celdas del convento original- están, en este caso concreto, vinculado a funciones donde a las reglas del propio edificio se superponen con, aún mayor rigidez, las de la vida monástica, militar o policial. Desde prácticamente su puesta en funcionamiento, las carencias espaciales fueron motivo de polémica o controversia. En 1992 el Fiscal General del Estado denunció "las malas condiciones de sus instalaciones" ${ }^{20}$, y dos años después cuarenta y seis migrantes iniciaron una huelga de hambre. Esto nos permite deducir que el deterioro del edificio no fue progresivo debido a las dos décadas de funcionamiento sino que hubo desde el inicio carencias arquitectónicas no resueltas en su adaptación a CIE. Entre medias, dos reformas de las instalaciones interiores, la más cuantiosa de 500.000 euros destinada a duplicar el cupo de internamiento, alcanzado las 175 plazas. Pese a estas reformas en el año 201o los propios funcionarios denunciaron el mal estado del edificio amparándose en un informe del arquitecto de la Dirección General de Policía visibilizando una "situación de grave deterioro de dichas instalaciones con evidente riesgo para la vida y salud de los internos, así como de los propios policías que los custodian” ${ }^{21}$. Era el propio cuerpo policial el que, tras veinte años en un mismo espacio, ponía en evidencia su condición infrapenitenciaria, remitiéndose a la ley para ello "La ley nos obliga a velar por todas las personas que están bajo nuestra custodia y los internos del CIE lo están” ${ }^{22}$. Ese mismo año, el Fiscal General del Estado emitía la siguiente valoración acerca de una situación "sencillamente deplorable, a tal punto de que califique como una inversión a fondo perdido toda la que se encamine a la rehabilitación de una estructura irreparable".

¿En qué aspectos concretos materiales se traduce esta condición infrapenitenciaria? Más allá del deterioro general observado, el Informe sobre los Centros de Internamiento de Extranjeros en España $a^{23}$ elaborado por Migreurop permite un acercamiento mucho más cercano a la realidad espacial del CIE de Capuchinos. En él, elaboran un informe forense acerca de las deficiencias

19 Sobrenombre dado por funcionarios y medios de comunicación.

20 Migreurop, CIE Derechos vulnerados: Informe sobre los Centros de Internamiento de Extranjeros en España, (España: Migreurop, 2011), 4.

21 Europapress, "Piden el cierre del centro de inmigrantes por una plaga de pulgas y por amenaza de ruina”, El Mundo, 3 de febrero de 2010.

22 José Torres, "El CIE de Capuchinos: peligro real para policías e internos”, La Opinión de Málaga, II de febrero de 2010.

23 Migreurop, CIE Derechos vulnerados: Informe sobre los Centros de Internamiento de Extranjeros en España. 
arquitectónicas en función de la legislación vigente en materia penitenciaria y asistencial ${ }^{24}$. Es decir, las evidencias probadas que se recogen ponen de manifiesto el carácter infrapenitenciario al ser un edificio incapaz de asegurar los estándares por los que habría de ser regido una arquitectura penitenciaria.

El Centro de Internamiento presenta carencias claras en cuanto al programa que debería alojar, así como cubrir ciertas necesidades básicas par asegurar un internamiento acorde a la supuesta condición no penitenciaria del centro. El informe señala la falta de funciones básicas como zonas específicas para el lavado de ropa en cada módulo o la posibilidad de almacenamiento seguro de todas sus pertenencias, no encontrando un lugar destinado a tal efecto o, en caso de ser así, sin opción a cerrarlo con llave -o, por el contrario, sin acceso a él durante la totalidad del internamiento-. También destaca la falta de dormitorios destinados a la reagrupación familiar, es decir, habitaciones no separadas por sexos, sino que permitan albergar núcleos familiares pendientes de expulsión. Pero, sobre todo, se pone en evidencia la condición infrapenitenciaria del CIE al hacer la comparativa con el programa que la Ley General Penitenciaria prescribe para cada centro: ni dormitorios individuales, escuelas, bibliotecas, peluquería, instalaciones deportivas o recreativas, locutorios o salas de relaciones familiares existen en el CIE de Capuchinos. El programa arquitectónico del CIE de Capuchinos ha incluido exclusivamente los usos mínimos posibles del esquema penitenciario que asegurasen su correcto funcionamiento. Si nos centramos en cada una de las celdas, la realidad espacial que presenta este informe hace de nuevo patente la precariedad y violencia arquitectónica a la que son sometidos los migrantes internos: celdas de ocho personas con una superficie no superior a los treinta metros cuadrados, donde todos los efectos personales de cada uno de los internos conviven en un mismo espacio, sin apenas luz natural -las ventanas son tapiadas con chapa microperforada- con dos retretes y una ducha dentro de cada habitación. Un espacio reducido, 3,75 metros cuadrados por interno, donde han de pasar la mayor parte de los sesenta días de su estancia dado que no hay funciones secundarias previstas -ocio, esparcimiento...- más allá del internamiento.

Analicemos ahora las carencias materiales detectadas, o amparadas por la regulación, que acompañan a las ya expuestas. Son las instalaciones del edificio: calefacción, iluminación y seguridad contra incendios, las que presentan mayores carencias y que evidencian la falta de preocupación por asegurar, desde la arquitectura como hecho construido, las necesidades básicas de confort y seguridad. El informe contempla la falta de calefacción y climatización de la totalidad de las habitaciones y zonas comunes -o zonas de sombra en los espacios exteriores- que, junto con una construcción tan antigua, nos permite extraer la falta de confort climático tanto en invierno como en verano; señala además como agravante este aspecto "de especial relevancia, ya que los ingresados en un gran número son de países tropicales y ecuatoriales" ${ }^{25}$. El siguiente punto del informe remite a la "deficiente iluminación" de los módulos de habitaciones, sin iluminación eléctrica en los pasillos y con las ventanas tapiadas con chapa microperforada, dejando pasar aproximadamente un diez por ciento de la cantidad de luz exterior. Pero, si estas dos carencias evidencian sobre todo la violencia espacial cotidiana que puede suponer el no garantizar los estándares establecidos de confort lumínico y climático, las carencias detectadas en la seguridad contra incendios del edificio ponen de manifiesto las situaciones

24 La legislación a la que se remiten como base de la inspección forense es: La Orden Ministerial sobre Normas de Funcionamiento y Régimen Interior de los Centros de Internamiento de Extranjeros, La Ley Orgánica I/1979 General Penitenciaria y la Reglamentación Técnica Oficial de Instalaciones.

25 Migreurop, CIE Derechos vulnerados: Informe sobre los Centros de Internamiento de Extranjeros en España, 15 . 
de extrema violencia arquitectónica en casos excepcionales: los incendios, producidos en varias ocasiones -el más numeroso con un saldo de catorce heridos en 1998-. La falta de mecanismos de detección y alarma en varias zonas del edificio, la imposibilidad de los internos de activar los mecanismos de alarma, la ausencia de planes y diagramas de evacuación, el no funcionamiento de aproximadamente el 50\% de detectores de incendios, o la no revisión de BIES y extintores, da cuenta del mal funcionamiento de esta instalación. Podemos pensar, como se ha señalado acerca de otros centros, la grave situación que podría haberse producido en caso de incendio con los internos encerrados en unas celdas cerradas sin posibilidad de apertura remota. Pero, aún estando las puertas abiertas y con todos los sistemas en correcto funcionamiento, los candados que se hallaron en las salidas de emergencia -cuestión también detectada en otros centros- impediría su evacuación.

Si la materialización de frontera, como construcción arquitectónica, es esencialmente punitiva, su dimensión ampliada a otras arquitecturas ligadas a ella, parece no dejar de serlo. Las condiciones espaciales de estas arquitectónicas del internamiento que, como se ha indicado, en mayor o menor grado, siguen estando presentes en la totalidad de los CIEs de primera generación que continúan en funcionamiento-extensibles incluso a los CIEs de segunda generación- hace patente el carácter punitivo al que se somete a los migrantes. El CIE, bajo esta óptica, no es tanto una institución destinada a garantizar la correcta expulsión de migrantes irregulares como una institución que castiga a través de la propia arquitectura a los cuerpos internos en ella. La reclusión en celdas carentes de servicios e instalaciones básicas, falta de zonas de entretenimiento, mal estado de las edificaciones, limitaciones funcionales y de desplazamiento dentro del CIE, y el confinamiento forzado dentro de estas arquitecturas son muestra evidente de la condición punitiva bajo la que se ha construido esta infraestructura territorial. Una arquitectura a todas luces infrapenitenciaria acompañada por la falta absoluta de regulación acerca del comportamiento que los funcionarios - policías- debían tener con los internos que ha hecho que las arquitecturas de esta etapa sean consideradas auténticos espacios de excepción. En ellos, la opacidad arquitectónica, normativa y policial, junto con el silencio de las personas internas que luego son deportadas, ha posibilitado desplegar un altísimo grado de violencia espacial que jamás sería tolerado si este cuerpo migrante fuese considerado, por la sociedad, garante de los mismos derechos que un ciudadano europeo. 


\subsubsection{CIES DE SEGUNDA GENERACIÓN. RENOVACIÓN HIGIENISTA E INSTITUCIONALIZACIÓN DEL INTERNAMIENTO COMO UN PROBLEMA SOCIAL.}

Esta tercera etapa, donde el planteamiento arquitectónico del CIE evoluciona tipológicamente hasta su consolidación actual, coincide a mediados de la primera década del siglo XXI que podemos asociar a la institucionalización de la migración como un problema social enunciada por Orgaz ${ }^{26}$. Es decir, la migración irregular es ya vista socialmente como un problema que debe ser gestionado y, por otro lado, aparece una mayor presencia crítica a través de plataformas ciudadanas, activistas y migrantes que denuncian la precariedad y violencia espacial a la que son sometidos los migrantes. La coincidencia de tres acontecimientos fundamentales permite comprender la profusión y evolución de estas arquitecturas: la entrada en vigor de la Ley de Extranjería -que regula el acceso y permanencia de los migrantes en territorio español y, por tanto, define los potenciales usuarios del CIE- el aumento de migración irregular a mediados de década y el boom de la construcción que convirtió a España en un país demandante de mano de obra barata. Una etapa concentrada en muy poco años, de 2005 a 2007 donde se construyen los principales Centros de Internamiento de nueva generación. Fundamentalmente, destacan por el impacto mediático y, por la sustitución de CIEs existentes envueltos en múltiples polémicas, la construcción del CIE de Aluche (Madrid) y el CIE de Zona Franca (Barcelona), que reemplazan los degradados centros de la comisaría de Moratalaz y La Verneda, respectivamente. El CIE de Zapadores, uno de los primeros en entrar en funcionamiento, también efectúa una renovación completa, construyendo nuevas instalaciones dentro de un complejo policial con capacidad para 156 personas; aunque, el siguiente testimonio evidencia cómo, pese a la reforma, el carácter securitario se agudiza:

Cuando digo celdas hablo de barrotes de hierro, de llaves que las cierran y las abren, no existen mecanismos automáticos de apertura. (...) Las camas se organizan en literas, no tienen baño, únicamente hay una pila que la tienen que utilizar para hacer sus necesidades dado que en la noche no hay posibilidad de ir al servicio. ${ }^{27}$

Alejado de los epicentros mediáticos, se inauguraba en noviembre de 2003 un proyecto desarrollado con gran discreción a ocho kilómetros de Santa Cruz de Tenerife, en un terreno montañoso desconectado de núcleos de población y próximo a un cuartel militar: el centro de Hoya Fría. El primero de los CIEs construidos en Canarias en esta época, junto con el complejo arquitectónico de El Matorral (Fuerteventura), y una serie de instalaciones de carácter temporal. El proyecto inicial propuesto por el delegado del gobierno, que consistía en la reconversión de la antigua cárcel de Santa Cruz de Tenerife obtuvo el rechazo de toda la oposición. Con lo cual, de manera fortuita, el gobierno se vio obligado a realizar una construcción de nueva planta en terrenos cedidos por el Ministerio de Defensa. Este imprevisto, sin embargo, constituyó el inicio de complejos arquitectónicos con un carácter cada vez más securitario, aproximándose todavía más al paradigma carcelario respecto a sus antedecesores, tanto a nivel de garantías espaciales para los internos -en lo que a efectos arquitectónicos

26 Orgaz, «Emergencia e Institucionalización Del Encierro De Extranjeros En España », 2018), 344 .

27 Adriana Jarrín Morán, "La Construcción De La Persona Inmigrante En El Limbo Jurídico: Ni Expulsables Ni Regularizables En España”, Cadernos De Campo (São Paulo, 1991) 21, no. 21 (2012): 301-318. 
se refiere- como por el grado cada vez mayor de control sobre los cuerpos. La descripción en prensa no da pie al equívoco, estamos ante una construcción de máxima seguridad con un claro carácter penitenciario en lo que a sistemas de seguridad se refiere:

El perímetro interior del muro está dotado con sensores de movimiento, focos y cámaras de vídeo, que dan a un camino de ronda de unos dos metros de ancho. A un lado, el muro; al otro, una verja de seis metros de altura con cinco sensores, que discurren paralelos al suelo a una distancia de un metro unos de otros. Tras la verja está el patio de recreo de los internos; su longitud es equivalente a dos canchas de baloncesto. Más allá hay otros dos patios. En uno de ellos, destinado en principio a las mujeres, hay varias pilas para lavar la ropa. El otro, más pequeño, servirá para aislar a los huéspedes más conflictivos o a los enfermos contagiosos.

Hay tres grandes construcciones, a las que se accede por la misma puerta. A la izquierda de la entrada principal, en un edificio alargado de una sola planta, están los comedores, la sala de máquinas (extracción de olores, aire acondicionado, calefacción), las salas de ocio y un oratorio. No está prevista la cocina, por lo que se supone que los internos recibirán alimentos de cátering. A la derecha, en un bloque de dos plantas, están las dependencias policiales, los despachos para los abogados y la consulta médica. Sus amplios ventanales con persianas blancas contrastan con los del tercer edificio, también de dos pisos, al que se accede por un pasillo cubierto. Allí, en el pabellón de los internos, las ventanas son horizontales y estrechas, y están cubiertas con planchas de hierro azul con pequeños agujeros que sólo dejan pasar hilos de luz. Detrás de las planchas hay rejas ${ }^{28}$.

La construcción de Hoya Fría coincide con un momento álgido de alarma social debido al aumento de llegada de migrantes a las costas canarias, la conocida "crisis de los cayucos". El discurso político se traduce a hechos arquitectónicos concretos, que incorpora medidas arquitectónicas securitarias sin precedentes en la construcción de estos centros para "calmar" la sensación de amenaza existente. $\mathrm{Al}$ igual que en la valla que, de manera paralela se levanta en Ceuta y Melilla, los sensores de movimiento, focos, cámaras de vídeo, módulos de aislamiento, ventanas tapiadas con planchas de hierro y rejas, son parte del discurso político que encarna esta arquitectura.
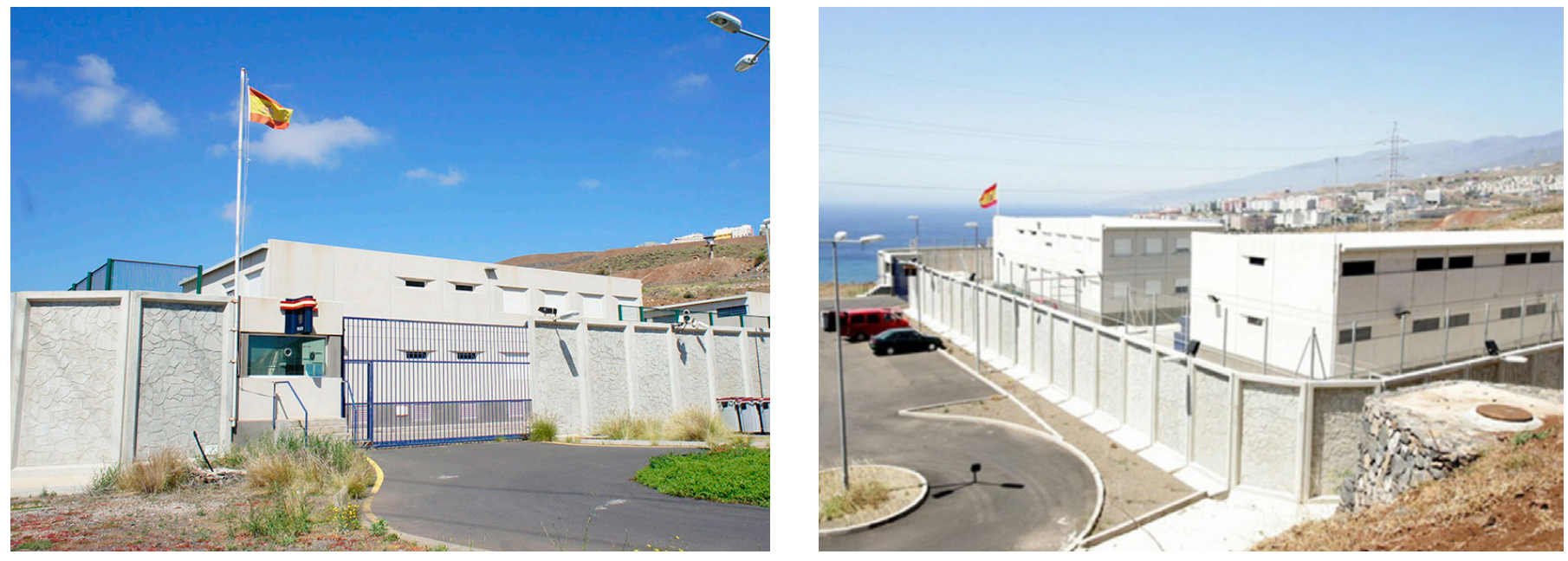

28 Tomás Barbulo, "Interior abre en Tenerife un Centro de Internamiento para 250 inmigrantes”, El País, 24 de noviembre de 2003. 
Si Canarias ha sido en estos años un motor de innovación arquitectónica en materia de internamiento, los otros territorios extrapeninsulares de Ceuta y Melilla también han anticipado esta urgencia social del internamiento de la inmigración. Las características particulares de las ciudades autónomas, territorio español físicamente aislado del resto del Estado, posibilitaron la construcción de una nueva tipología de arquitectónicas del internamiento, cuyo fin no era punitivo sino asistencial. Si el CIE funciona, en teoría, como una válvula de regulación del flujo migratorio de detención y expulsión, el CETI -Centro de Estancia Temporal de Inmigrantes- funciona en el sentido opuesto, una válvula de regulación del flujo migratorio de entrada. Aunque, en la práctica, las funciones del CIE se han ampliado al constituirse como una infraestructura territorialmente dispersa con capacidad de acción conjunta. Es importante, a efectos de entender cómo debido a la institucionalización de la inmigración como un problema social, se comienzan a generar en esta época las primeras arquitecturas pensadas en claves de infraestructura territorial. Ambas construcciones datan de inicios de década y la tipología arquitectónica poco tiene que ver con las arquitecturas del internamiento descritas, son arquitecturas mucho más extensivas, con pabellones, módulos amplios capaces de acoger durante temporadas indefinidas a un gran número de migrantes y con libertad de deambulación absoluta. El carácter asistencial se superpone al internamiento establecido por la propia extensión territorial de cada ciudad. La arquitectura del CETI supone una garantía espacial innovadora respecto a épocas previas y, a la vez, resulta eficaz para retener de manera ordenada a una población controlada durante temporadas indefinidas -de meses a años- en un recinto ya no establecido por los muros de un edificio, sino por los límites administrativos de Ceuta y Melilla.

Los CIE de Aluche y Zona Franca son la cara más visible de una renovación higienista llevada a cabo tras la salida a la luz pública de una serie de prácticas excepcionales llevadas a cabo por funcionarios -torturas, abusos sexuales, palizas...-.La inmigración y su internamiento ya habían alcanzado la esfera pública, y eso implicaba un posicionamiento político que formalizase la necesidad de internamiento a la vez que garantizase unas condiciones para los internos que habían quedado manifiestamente en entredicho durante la década anterior. ¿Cómo se intentó responder a esta situación? A través de un posicionamiento arquitectónico claro: la construcción de dos centros que pusiesen el punto final a los protoCIEs que llevaban cerca de quince años en funcionamiento: los sótanos de las comisarías de Moratalaz y La Verneda. Ya no resultaba admisible que un gobierno recluyese en un sótano sin luz a migrantes pendientes de expulsión o, al menos no que lo hiciese formalmente. Además, la construcción de estos nuevos centros multiplicaba el número de plazas, cuadriplicando en Madrid - al pasar de sesenta a doscientas cuarenta- y triplicando en Barcelona - de ochenta a doscientas veinticuatro- en un entorno mucho más controlado y con alto grado de securitización. El CIE de Zona Franca es una edificación situada en el polígono industrial homónimo, de gran extensión y dos plantas constituida por una retícula modular clara donde se sitúan las diferentes dependencias organizadas en torno a grandes patios. El CIE de Aluche, sin embargo, aprovecha el antiguo módulo del hospital de la prisión de Carabanchel -también proyectado por Aranguren- que rehabilita para alojar, por su disposición, las celdas de internamiento; son las edificaciones anexas -la comisaría y dependencias de extranjería- en las que se centra el esfuerzo de visibilización arquitectónica.

Las mejoras respecto a ciertas instalaciones de los centros son evidentes, pero es interesante como el director del centro de Barcelona señala cómo esta renovación higiénica del CIE va acompañada de un incremento securitario claro: 
De izda a dcha: Brigada de Extranjería y módulos de internamiento del CIE de Aluche (Madrid)
El nuevo CIE aúna instalaciones dignas con máximos niveles de seguridad y cuenta con detalles pioneros como un sistema de cierre de puertas electromágnético para sus habitaciones que permite abrir o cerrar sólo una de ellas o todas a la vez desde una sala de control.

Instalaciones básicas como locutorios, taquillas, sistemas de control y apertura de puertas automáticas en caso de incendio -aspecto solamente implementado hasta la fecha en el CIE de Barcelona ${ }^{29}-$, acceso a espacios exteriores, sistemas de calefacción y aire acondicionado, inclusión de sistemas de vídeovigilancia para evitar abusos policiales en zonas comunes, son incorporados en estas nuevas instalaciones.

Más allá de las mejoras evidentes en cuanto a dotación espacial e instalaciones de cada centro, hay también un esfuerzo simbólico en transmitir a través de la propia arquitectura la entrada de luz dentro de una institución que había permanecido opaca durante más de una década. La luz, materia arquitectónica que ha ocupado infinidad de discursos, era una de las grandes protagonistas de sendas campañas mediáticas de legitimización de los edificios. En el caso de Barcelona, se hace especial hincapié durante la inauguración en cómo la luz iba a llegar a todas las estancias del centro: "El nuevo CIE no está ubicado en un sótano, como su antecesor, sino en un edificio de una sola planta toda ella a pie de calle. Es mucho más amplio y luminoso"30. En el caso del CIE de Aluche, definido como "sacado de una película. Se trata de un edificio moderno, pintado en un vistoso color crema y con ventanas y parasoles azules" ${ }^{31}$ en su inauguración es la propia arquitectura la que encarna esta necesidad. Curiosamente, no es el módulo donde van a estar internos los migrantes sino el destinado a comisaría el que materializa esta necesidad. Adolfo Morán Ortega es el arquitecto encargado de proyectar un símbolo que represente estos nuevos valores y esta nueva relación con los extranjeros. Su respuesta es una pieza que sirve de fachada a un complejo arquitectónico mucho mayor que incluye el antiguo hospital de la cárcel de Carabanchel y parte de sus terrenos. El edificio, de base cuadrada, está dividido en nueve módulos y dos plantas de altura, los cuatro módulos de las esquinas son cilíndricos, mientras que el resto son prismáticos. Las referencias a Rossi, por las geometrías rotundas son claras, y se completan con la coronación en cubierta de un cono en espiral que incluye los colores de la Policía Nacional. Es precisamente la compleja construcción de esta cubierta, junto con la envolvente exterior realizada en parte con ladrillos de vidrio, la que traduce esta necesidad de transparencia y luz en términos arquitectónicos, a través de un sistema hidráulico capaz de elevar el cono transformando el vestíbulo central del edificio a doble altura en un espacio al aire libre.
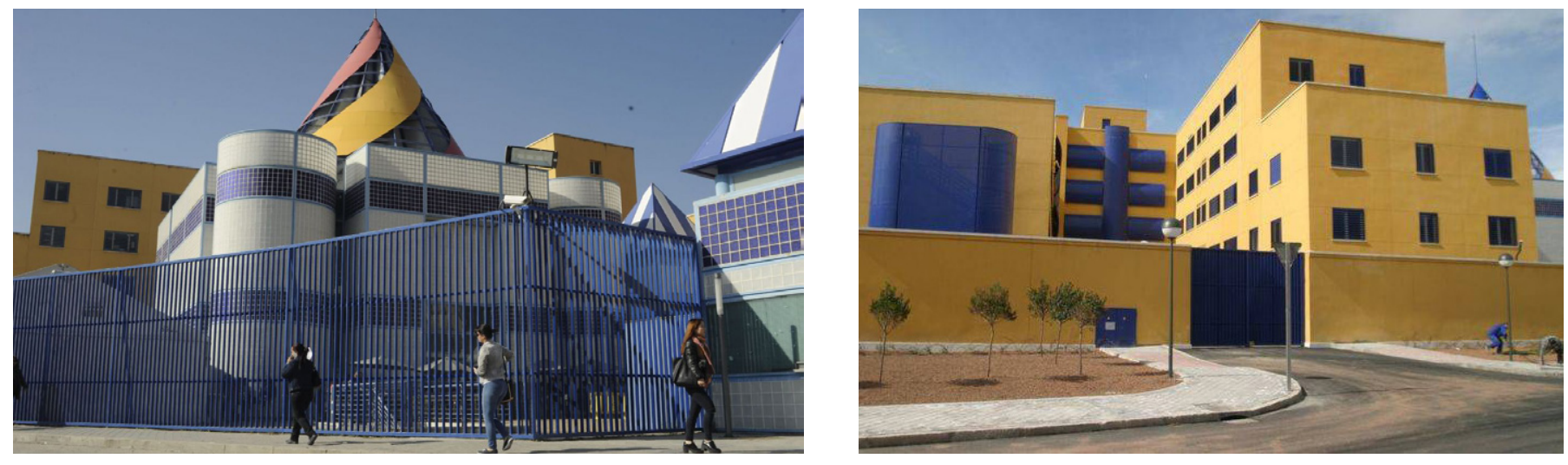

29 Defensor del Pueblo, Informe anual 20Io: Mecanismo nacional de prevención de la tortura, (España: Defensor del Pueblo, 20ir), ı16.

30 Janot Guil, "La nueva Verneda de los inmigrantes”, $A B C$, 12 de agosto de 2006.

31 Barroso, "Adiós a unas instalaciones que sólo permitían el hacinamiento", El País, 20 de junio de 2005 . 


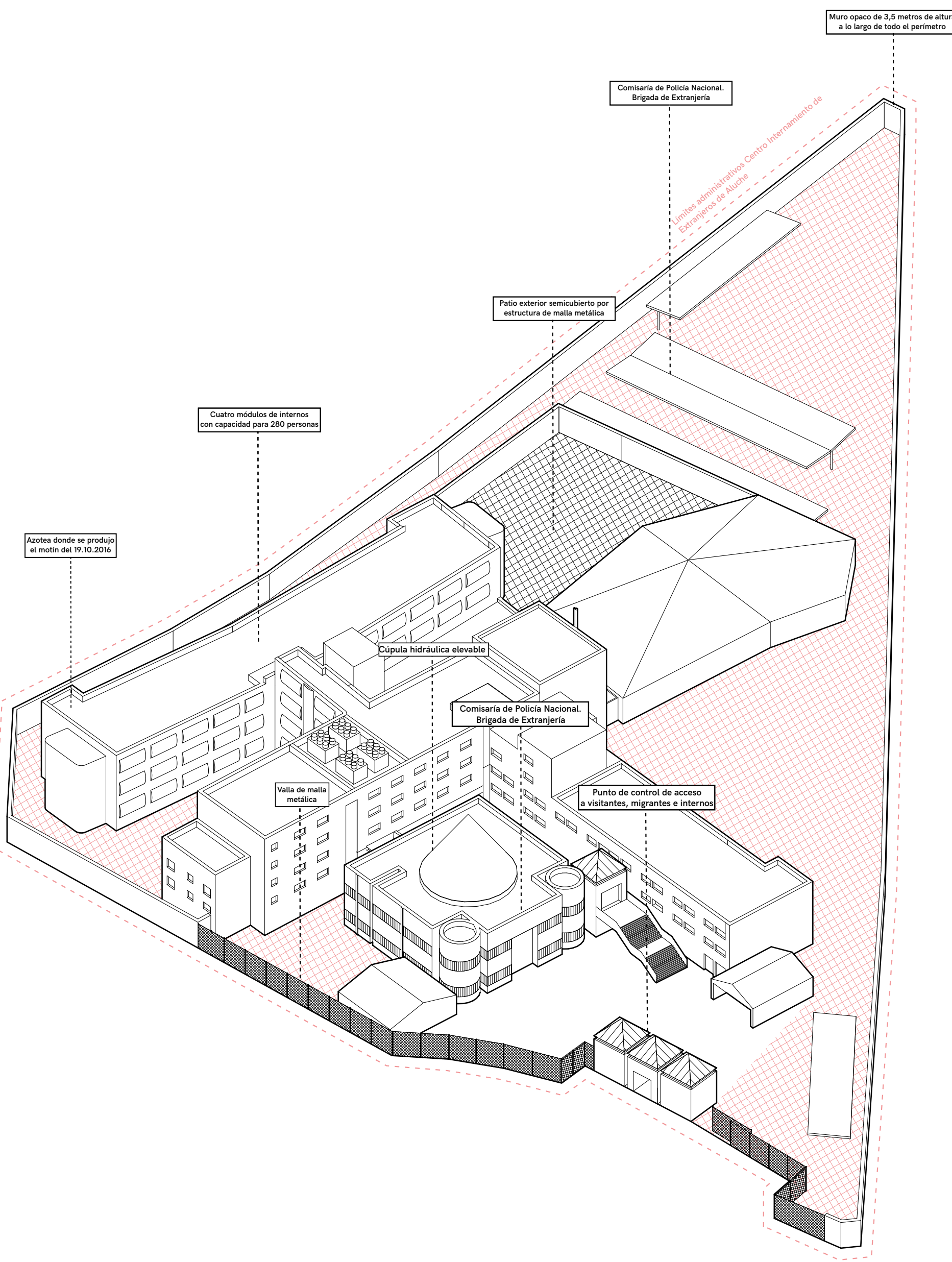

Axonometría del CIE de Alu-

che (Elaboración propia) 


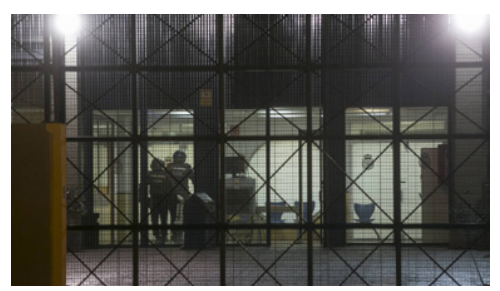

Interior del CIE de Zona Franca,

Barcelona (Imágenes de archivo)
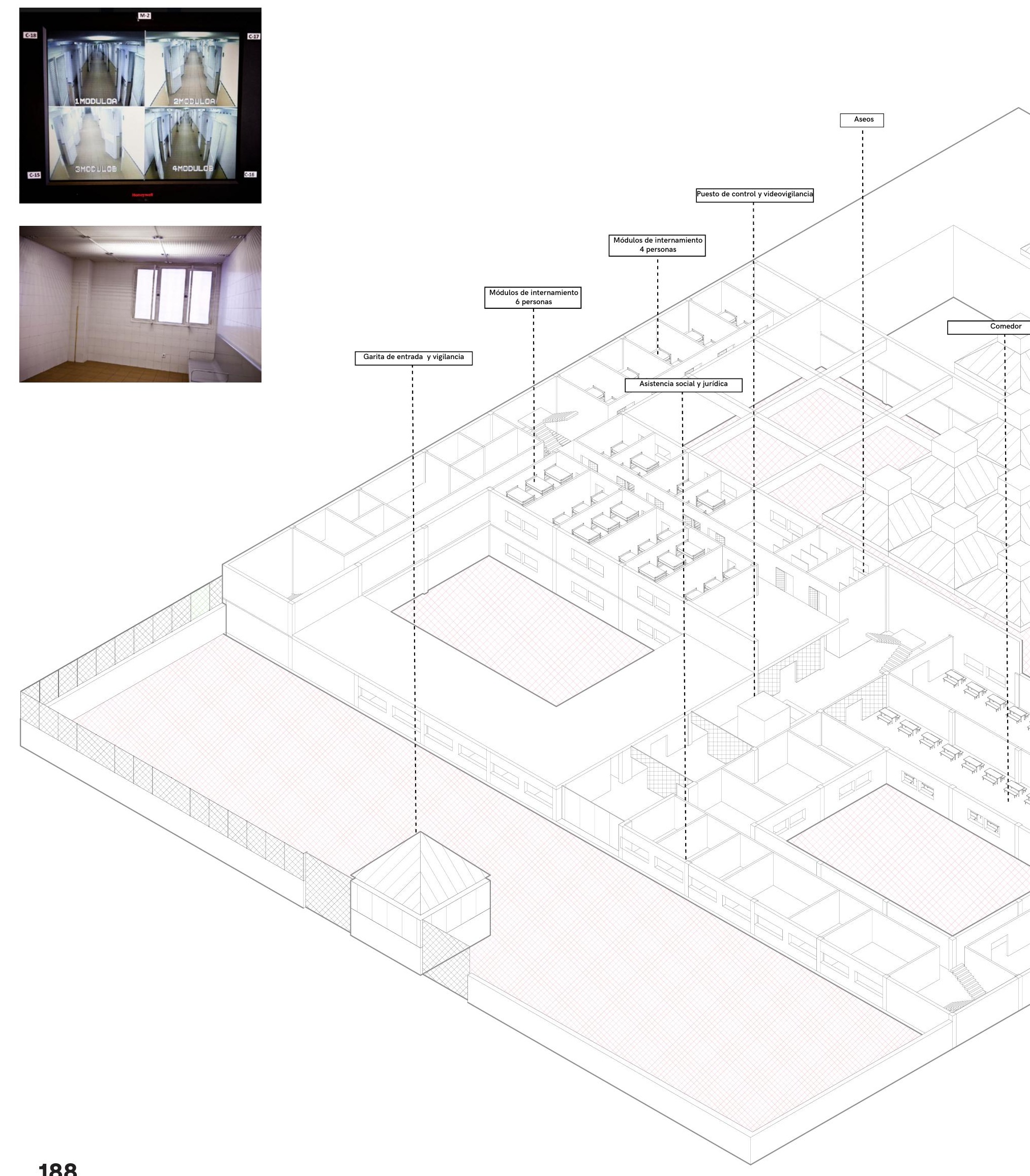
Aluche y Zapadores. También la localización de los propios CIE a nivel urbano aleja el problema de los centros de las ciudades para llevarlo a distritos periféricos (Madrid), zonas industriales (Barcelona), o directamente expulsándolos de la ciudad (Hoya Fría o el Matorral). Esta situación produce, en primer lugar una violencia derivada de su implementación en el territorio: la desconexión territorial con la red afectiva de cada interno, que dificulta su acceso hasta él; pero en segundo lugar, invisibiliza socialmente la presencia -cada vez más profusa- de CIEs.

Si las carencias en las instalaciones del edificio eran una denuncia constante en los diferentes informes emitidos sobre los CIE anteriores, estos implementan cambios que, no pueden considerarse suficientes y cuyas ausencias visibilizan de nuevo la violencia espacial implícita en un diseño arquitectónico: tan sólo el CIE de Barcelona cuenta con mecanismos de liberación de las celdas en caso de incendio, algo fundamental en caso de evacuación. Pero, es aún más llamativa la ausencia selectiva de cámaras de seguridad en zonas del centro, cuestión reiteradamente denunciada: los constantes casos de violencia policial, abusos y agresiones físicas a internos ocurren en puntos ciegos de los centros. Si esta nueva generación de edificios se caracteriza por una alta securitización arquitectónica y la implementación de toda clase de mecanismos de vigilancia resulta contradictoria esta falta de interés ${ }^{32}$. Más allá de la solución arquitectónica concreta, cada vez más cercana al paradigma carcelario, las medidas de seguridad - por presencia o por ausencia selectiva-, los agentes aparentemente no-arquitectónicos, la opacidad del propio dispositivo de deportación... hace que el CIE siga siendo un espacio donde puedan desplegarse altos grados de violencia hacia los internos. Las muertes, suicidios, motines, fugas y denuncias interpuestas desde diferentes plataformas sirven como testigo de las carencias espaciales que aún siguen presente, así como el carácter punitivo que aún mantienen. 


\subsection{HACIA UN CIE DESTERRITORIALIZADO. ESTADOACTUALDELOSCENTROSDEINTERNAMIENTO EN FUNCIONAMIENTO Y ALTERNATIVAS ESPACIALES.}

\subsubsection{INFRAESTRUCTURA TERRITORIAL ACTUAL.}

Han pasado más de diez años desde el gran período de construcción de Centros de Internamiento que, en menos de cinco años, llegó a duplicar el número de centros existentes. Los centros formales, construcciones de obra nueva con la única función de internar migrantes -tanto recién llegados como pendientes de expulsión- ha convivido con la profusión de arquitecturas temporales que, apropiándose de instalaciones obsoletas, solventaban los picos de flujo. ¿Qué ha quedado de esta infraestructura territorial una década después? Fundamentalmente, si nos remitimos a los porcentajes de ocupación de la última década podemos observar una caída clara ${ }^{33}$ por escasez de internos que incluso llevó al cierre de varios de ellos (El Matorral, Las Raíces o La Isleta); muestra del sobredimensionamiento de un dispositivo arquitectónico de deportación que tuvo que responder durante un período muy concreto a un incremento de la migración ${ }^{34}$. Pero, además, la puesta en crisis de un modelo de internamiento frente a soluciones gerenciales que requieren tanto una inversión económica mucho menor para su puesta en funcionamiento como los gastos de mantenimiento de internos e instalaciones. En la actualidad, buena parte del flujo de migrantes pendientes de inserción o expulsión ya no se canaliza a través de los CIEs sino desde arquitecturas temporales o directamente desde comisarías y calabozos policiales. Junto a esto, el cierre debido al mal estado, de manera definitiva o temporal para efectuar reformas de diferentes centros (Capuchinos, Zapadores, Zona Franca...) hace que en la actualidad la red territorial esté formada por un número mucho menor. Aparentemente, una contracción de la red territorial que, sin embargo, supone una evolución de la misma, donde aparecen menos nodos estables que, en momentos determinados, son reforzados de manera dinámica a través del despliegue temporal de arquitectónicas del internamiento en focos localizados.

En este lapso temporal es necesario reseñar un cambio que, si bien no se produce a nivel arquitectónico, ya que en ninguno de los centros se efectúan reformas ni modificaciones programáticas, sí tiene profundas implicaciones espaciales. La reforma del Código Penal hacía que los CIE fuesen lugares de internamiento de extranjeros, pendientes de expulsión, sobre los que pesaban condenas penales. El límite entre la condición carcelaria y la no-carcelaria se ha vuelto cada vez más difuso en el interior de los CIE:

Cuando entró en vigor la reforma del Código penal introducida por la Ley Orgánica 5/2010, los CIE tienen la función -declarada- de operar como lugares de privación de libertad para la preparación de la ejecución no solo de la expulsión administrativa (arts. 6i y ss. Ley Orgánica de Extranjería), sino también de la expulsión penal, prevista para personas condenadas por delito (art. 89.6 Código penal). 
[...] La reforma que permite desde hace seis años y medio internar en los CIE a personas extranjeras con condenas penales supone una innovación, al menos en términos formales. Implica privar de libertad en el mismo establecimiento, y sin ningún género de separación modular, a hombres y mujeres con situaciones jurídicas claramente diferentes: una minoría de extranjeros convictos que generalmente han estado encarcelados, junto a una amplia mayoría de personas, frecuentemente recién llegadas, que simplemente carecen de documentación habilitante para estar en territorio español.

Esa diferenciación formal, no obstante, oculta algunas homologías materiales que son aún más relevantes. Por una parte, más allá de sus estatus jurídico, las personas que se encuentran en los CIE presentan rasgos socio-demográficos muy semejantes. Los datos publicados en los últimos años por el Mecanismo Nacional de Prevención de la Tortura (MNP) desvelan que las personas que están en los CIE son, de forma muy mayoritaria, negras o pertenecientes a minorías étnicas. En segundo lugar, son personas pobres provenientes del Sur global, que tienen una posición social notablemente vulnerable. A mayor abundamiento, y en esto no cabe confusión alguna, no están en los CIE por haber cometido un delito, lo cual es puramente adjetivo, sino porque son personas extranjeras, en la amplísima mayoría de los casos sin papeles. ${ }^{35}$

En este contexto son ocho los Centros de Internamiento formales en funcionamiento a día de hoy: Zapadores (Valencia), Sangonera la verde (Murcia), Barranco Seco (Tenerife), Aluche (Madrid), Zona Franca (Barcelona), Hoya Fría (Santa Cruz de Tenerife), La Piñera (Algeciras) y su extensión en la Isla de las Palomas (Tarifa). A día de hoy, aparece una realidad arquitectónica híbrida constituida por CIEs de segunda generación y una serie de arquitecturas apropiadas que, en el mejor de los casos -como Zapadores- actualiza sus instalaciones para adaptarlas a las demandas espaciales establecidas. Demandas que siguen situándose por debajo del umbral penitenciario, mantienen el carácter infrapenitenciario al no ser capaces de garantizar una serie de estándares mínimos que aseguren las necesidades mínimas de confort y seguridad para los internos. Mientras que la Ley Penitenciaria establece un estándar -no cumplidode un único preso por celda, aquí las habitaciones son múltiples en todos los CIE, cuatro, seis y hasta ocho personas conviviendo en un único espacio que no está dotado con los mismos equipamientos -ni sanitarios ni de esparcimiento-. Si a continuación analizamos la ratio de metros cuadrados/persona dentro de cada una de ellas, vemos como si el estándar español supera los cinco metros cuadrados/recluso en el caso de las prisiones, estándar que sólo es alcanzado en el CIE de Aluche, pero que contrasta con los 3,75 de La Piñera o los apenas 2 del CIE de Zapadores. A pesar de la evolución discursiva, los ejercicios de modernización y mejora de las condiciones espaciales de cada centro siguen lejos de alcanzar la condición penitenciaria que, sin duda alguna, supondría una mejora clara de las condiciones de los internos. Pero, sobre todo, las constantes denuncias, motines y protestas sirven como un indicador claro de la disfuncionalidad de un modelo arquitectónico del encierro en crisis.

La cuarta etapa establecida por Orgaz, a partir del año 2011, supone la puesta en crisis de la legitimidad del CIE coincidente con una inversión del saldo migratorio ${ }^{36}$. A esto hemos de sumar la drástica reducción en inversión pública para el cierre de los CIE: del reformismo a la abolición, ed. por OCSPI, (Málaga: Universidad de Málaga, 2017) , 30. 
desde el año 2008, un giro gerencial de la frontera ${ }^{37}$ que cuestiona la necesidad de arquitecturas manifiestamente obsoletas -con una vida útil inferior a una década-. En esta etapa los discursos críticos cobran cada vez más fuerza, alcanzado incluso las instituciones; varios son los ayuntamientos que, desde 2015 - Barcelona, Valencia y Madrid- cuestionan la legitimidad de estas arquitecturas dentro de sus ciudades. El gobierno de Colau inicia en 2016 acciones legales y burocráticas para intentar cerrar el CIE de Zona Franca arguyendo una serie de motivos que van desde cuestiones humanitarias a la falta de licencias urbanísticas o permisos de obras; mientras que el ejecutivo de Carmena plantea posibilidades alternativas al encierro haciéndose eco de demandas ya realizadas desde plataformas activistas.

Debemos preguntarnos si se han estabilizado las iteraciones y transformaciones tipológicas sobre estas arquitecturas o si aún es posible detectar indicios de transformaciones futuras. Si bien, como refleja el siguiente epígrafe, se ha detectado que la apropiación temporal de arquitecturas en desuso y la generación de campos es la táctica que, con mayor profusión, se ha mantenido estable durante la última década, aunque también hay propuestas de transformación de los Centros de Internamiento. Sobre el horizonte próximo del CIE aparecen dos modelos alternativos vinculados a polos opuestos del espectro político. Ambas propuestas vienen a confirmar un cierto agotamiento respecto a los modelos en funcionamiento y reclaman la garantización de mejores condiciones espaciales de los internos. Es obvio que determinadas visibilizaciones recientes del interior de los CIE han podido ser detonantes de esta nueva iteración de transformaciones arquitectónicas: la muerte de Samba Martine en el CIE de Aluche, los motines y fugas reiteradas en Aluche y Zona Franca, así como el acceso parlamentario al interior de esta institución, han puesto en evidencia cómo incluso arquitecturas diseñadas bajo parámetros supuestamente higienistas y garantistas, eran en la práctica arquitecturas marcadamente punitivas por las prácticas espaciales desarrolladas en su interior.

37 Cristina Fernández Bessa y José Angel Brandáriz García. “Transformaciones De La Penalidad Migratoria En El Contexto De La Crisis Económica: El Giro Gerencial Del Dispositivo De Deportación.” InDret.Revista Para El Análisis Del Derecho, , Num.4 (2016), 1:25. 
La primera propuesta es la futura construcción del CIE de Algeciras presentado por el Ministo del Interior Zoido como prototipo de tres nuevos centros destinados a reforzar o sustituir nodos existentes de la infraestructura actual. Una medida que Grande-Marlaska, su sucesor en el cargo, confirmó añadiendo además una partida presupuestaria destinada a las obras de mejora de los ocho CIE existentes; incluyendo el CIE de La Piñera que el ejecutivo popular pretendía clausurar en base a los informes de control que señalaban la falta de garantías y mal estado del edificio ${ }^{38}$. Tres nuevas infraestructuras que no concuerdan ni con los datos reales de internamiento, ni con los de deportación desde los CIE, pero que responde a demandas de la Unión Europea por el refuerzo material del dispositivo de deportación ${ }^{39}$. Esta solución es, a todas luces, continuista con el modelo consolidado en la primera década de siglo. Reconoce las principales características arquitectónicas de los tipos previos y los actualiza al contexto actual. Asume en su diseño el aislamiento urbano, la condición carcelaria, la estructura modular y la securitización del espacio. El dimensionado del edificio permite el internamiento de un número cada vez mayor de internos respecto a los modelos anteriores, quinientas plazas, lo que dobla prácticamente la capacidad de Aluche y Zona Franca. Llama la atención que, en un período donde la ocupación media de los CIE ha descendido considerablemente, se decida construir un edificio de semejante capacidad; por ello es interesante comprender su posición estratégica -Algeciras- para preguntarse si realmente se construye como una arquitectura previa a la expulsión o, si por el contrario, como una arquitectura de retención en el inicio del flujo regulador de migrantes. Incluye en su programa usos reclamados como las dependencias policiales, sanitarias o de esparcimiento a la vez que también implementa los principales puntos críticos señalados a los centros anteriores, incluye sistema de calefacción, mejora clara de las condiciones espaciales de las celdas que incluyen funciones complementarias al internamiento, espacios al aire libre con vegetación y sin cubrición. Abre incluso la puerta a que no sean policías sino funcionarios civiles los que se encarguen de la gestión del centro. Esta transformación tipológica mantiene el reconocimiento del edificio como un instrumento eficaz de internamiento pese a que sean cada vez más las instancias que señalan la búsqueda de alternativas. Del mismo modo que Aluche y Zona Franca sustituyeron, en su día, a la primera generación de CIEs, la construcción de loss tres nuevos centros aspira a largo plazo la sustitución total de arquitecturas no específicamente construidas como Centro de Internamiento.

Lo que resulta sorprendente, y permite establecer una evolución clara respecto a como los discursos tanto arquitectónicos como políticos sobre las arquitectónicas del internamiento, es la presentación que se hace del proyecto del Centro. En rueda de prensa, dos pantallas de televisión muestran un vídeo promocional de I:I5 minutos de duración. En él, una melodía de piano introduce una serie de imágenes virtuales estáticas del CIE, las primeras muestran el exterior del CIE, un edificio totalmente aislado en medio de colinas verdes, sin vallas perimetrales que lo rodeen sino exclusivamente una garita de acceso. El siguiente fotograma

38 Icíar Gutierrez y Gabriela Sánchez, "El Gobierno aprueba la construcción del nuevo CIE de Algeciras ideada en la etapa de Rajoy”, Eldiario.es, I8 de enero de 2019.

39 Fernández Bessa y Brandáriz García. “Transformaciones De La Penalidad Migratoria En El Contexto De La Crisis Económica” InDret.Revista Para El Análisis Del Derecho, (2016), 1:25. 

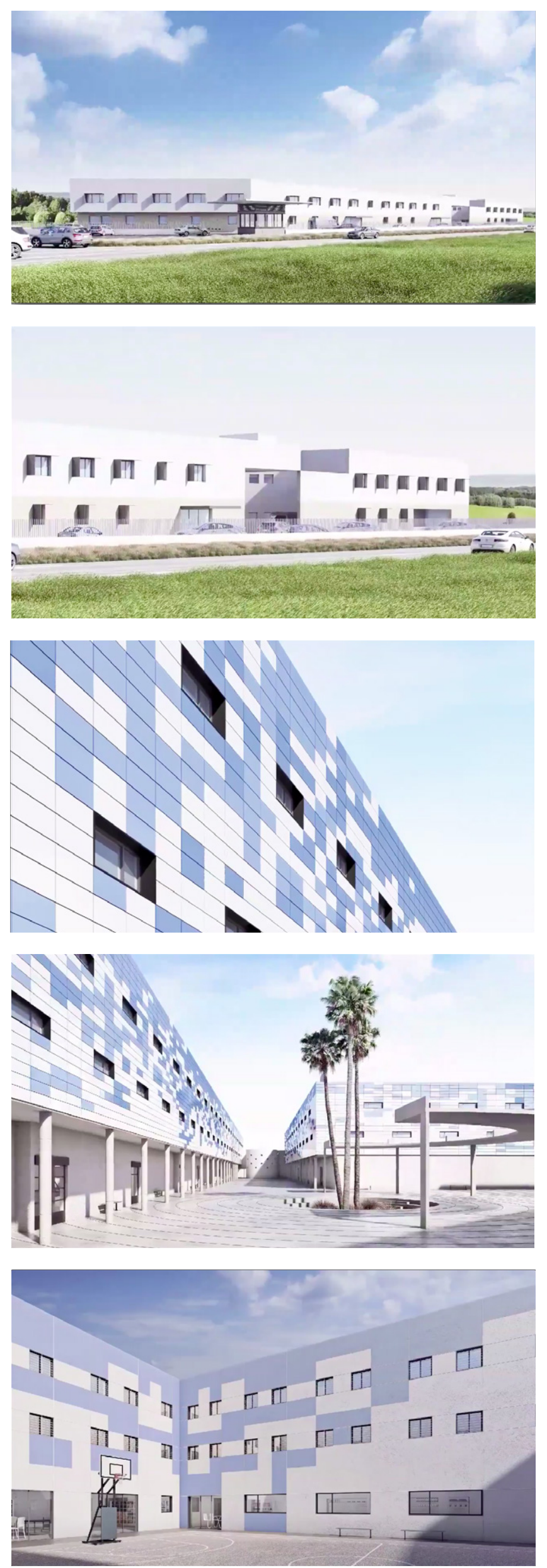
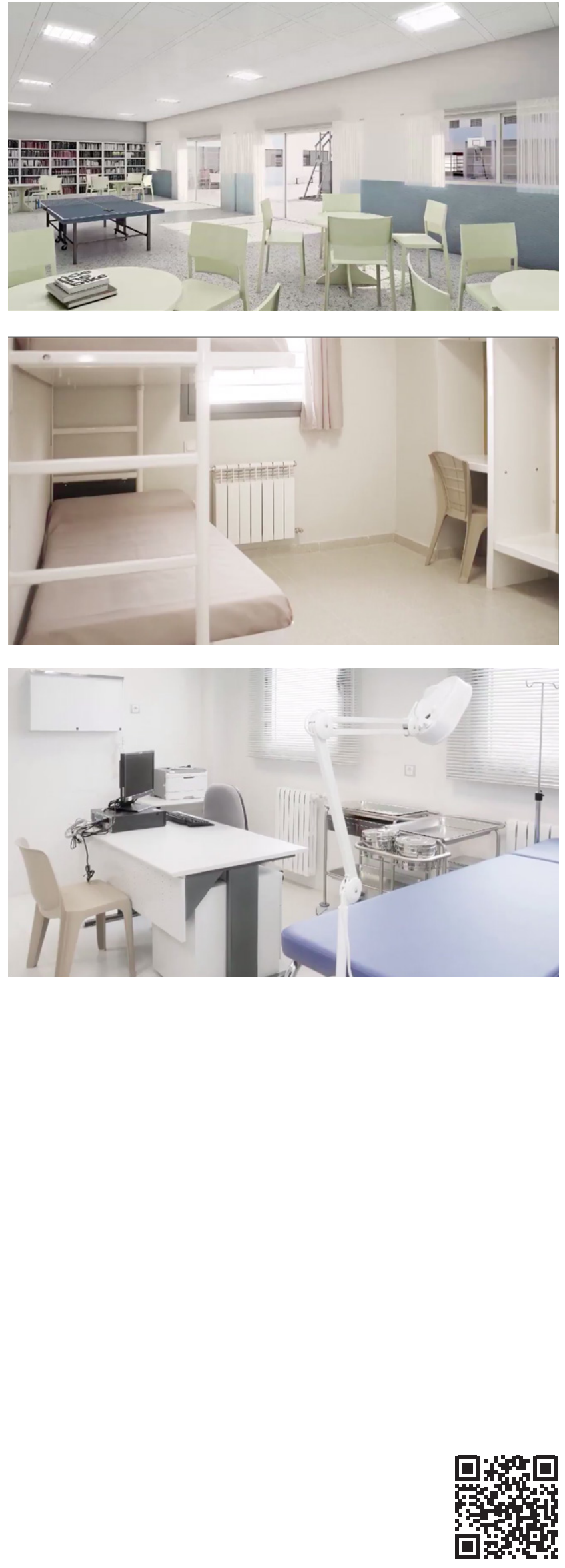

Presentación del Ministerio del Interior del nuevo modelo de CIE de Algeciras (Ministerio del Interior; Render, 2017). 
encuadra los espacios exteriores arbolados, e instalaciones deportivas -una pista polideportiva con canastas de baloncesto-, con posibilidad de situarse bajo un espacio porticado e incluso bajo una pérgola de hormigón. El plano siguiente, se centra únicamente en la fachada, dejando ver en él una modulación clara donde aparecen ventanas con visión directa al exterior, carentes de barrotes y de las infames chapas de acero perforado.

A continuación, el vídeo nos introduce por vez primera en el interior de un $\mathrm{CIE}^{40}$. Este es un aspecto clave, pues en cada uno de los renders hay un esfuerzo por mostrar aquellas carencias denunciadas reiteradamente. El primero, una biblioteca repleta de publicaciones es el telón de fondo de un espacio donde conviven mesas de lectura con tableros de ping-pong; tres grandes puertas establecen una conexión directa con el patio exterior donde, de nuevo aparecen dos canastas de baloncesto. El ocio y esparcimiento habían sido cuestiones pendientes en absolutamente todos los CIE y, aquí decide mostrarse como primer fotograma del interior. A continuación, el interior de una habitación donde el brillo de la iluminación que entra a través de la ventana desdibuja sus contornos, junto a ella una cortina como sistema de oscurecimiento. Ni rastro de barrotes o paños cegados con chapa; bajo ella, un radiador indicando la presencia de instalaciones de calefacción. Pero, sin duda alguna, el motivo más destacable del render es el número de plazas de cada celda: únicamente dos. Frente a ellas, ocupando todo el largo de la habitación, un escritorio y espacio de almacenaje. Una celda prácticamente idéntica, en disposición y dimensiones al modelo desarrollado por la Secretaría General de Instituciones Penitenciarias lo que, por un lado confirma las mejoras evidentes en comparación con las celdas de otros CIE, nunca inferiores a las cuatro plazas, y por otro lado confirma la superposición clara -hasta en disposición espacial- de la arquitectura penitenciaria a las arquitecturas del internamiento de extranjeros. El siguiente fotograma al igual que los anteriores recoge a través del modelado virtual, atestigua la incorporación de servicios sanitarios al interior del centro, una consulta totalmente equipada, con camilla, lupas de observación y material médico con la que se cierra el recorrido por el centro.

El vídeo promocional, junto a los planos del centro difundidos en twitter por el ministro, supone un esfuerzo higiénico por renovar la imagen de una institución en crisis. Cada elemento dispuesto en el espacio virtual del render no responde tanto a una exigencia arquitectónica sino a una exigencia política. Por muy realista que sea el modelado, es habitual no incluir elementos accesorios como las instalaciones de calefacción o el material médico de una consulta. Sin embargo aquí parece haber, por el minucioso detalle de cada plano, un esfuerzo de utilizar la materia arquitectónica como herramienta de comunicación y legitimación. Por ello, resulta tan llamativa una ausencia entre tantas presencias: las cámaras de seguridad una de las demandas hechas por los propios internos para poder usarse como evidencia forense en caso de numerosos abusos policiales, no aparece en ninguno de los planos. Puede deberse, tanto a una ausencia consciente del propio diseño arquitectónico, como a, si se lee en clave simbólica, un borrado selectivo que permita disminuir la sensación de control sobre los internos.

Tan sólo cinco días antes que el ministro convocase esta rueda de prensa, el Ministerio del Interior trasladaba a medio millar de migrantes argelinos llegados a las costas andaluzas a una cárcel de máxima seguridad pendiente de inaugurar, la cárcel de Archidona (Málaga). Las irregularidades durante los dos meses que duró su uso como arquitectónica del internamiento son destacables y contrastan con la visión ejemplar que mostraba el nuevo modelo arquitectónico

40 Recordemos que la inauguración del CIE de Aluche no se enfocó a las cualidades espaciales del interior, sino a los grandes gestos del exterior y de una pieza arquitectónica que ni siquiera 
a implementar. La superposición entre CIE y cárcel era absoluta. El Estado, a la vez que se esforzaba en mostrar una realidad que pretendía alejarse de este paradigma carcelario que había acompañado al CIE desde su creación, recluía a migrantes en un edificio que tan sólo lo distinguía de una cárcel su entrada en funcionamiento. Pero la arquitectura había sido explícitamente diseñada a tales efectos. Sin embargo, al no estar aún completado, el edificio no contaba ni con instalaciones climáticas ni tampoco ninguna clase de medida contra incendios devolviéndolo a la condición infrapenitenciaria debido a esta precariedad espacial. A estas irregularidades espaciales, se le sumaron como en otras ocasiones las irregularidades funcionales, donde la operatividad de esta apropiación arquitectónico hizo por ejemplo que se recluyesen también a menores en el centro. Pero, sin ninguna duda, para entender la excepcionalidad imperante tras los muros de estas arquitecturas, debemos remitirnos a los vídeos grabados el veintisiete de diciembre de 2017, un día antes de la cuestionada muerte por suicidio de uno de los internos, Mohamed Mouderbala ${ }^{41}$. Un vídeo tomado con un móvil desde una ventana exterior a lo que parece una sala de espera muestra como yace en el suelo el cuerpo de uno de los internos mientras una decena de antidisturbios avanza por el interior de la estancia, la cámara se mueve a continuación para mostrarnos a otro migrante retenido en el suelo, rodeado por cuatro agentes también totalmente equipados. La grabación de este vídeo, realizado durante una de las múltiples protestas por falta de comida y difundida a medios argelinos, muestra cómo la excepción y violencia espacial que impera dentro de estos centros va mucho más allá de la que ejercen sus propios muros.

Esta coincidencia temporal resume a la perfección el horizonte establecido por este primer modelo futuro: la convivencia de arquitecturas del internamiento estables formando una infraestructura territorial consolidada, renovada bajo los estándares penitenciario, que es complementada en momentos puntuales con despliegues operativos de bajo coste y duración acotada en los que, la violencia y condiciones de excepcionalidad son justificadas ante la contingencia de cada situación. Algeciras y Archidona son dos caras de un mismo modelo que, si bien renovado, lleva en funcionamiento efectivo durante más de una década. Un modelo en crisis, tanto por la falta de eficacia efectiva dentro del dispositivo deportados -las deportaciones hechas desde el CIE son inferiores al cincuenta por ciento, con lo cual más de la mitad de los internos simplemente son retenidos allí hasta expirar el plazo máximo- como por la crítica social a una institución marcadamente punitiva. Esta crisis ha hecho que cobrase voz a nivel institucional un modelo alternativo defendido desde múltiples instancias y que, en la práctica, supone el traslado de la arquitectura del encierro al interior del espacio doméstico.

41 Néstor Cenizo, "Encuentran ahorcado en la cárcel-CIE de Archidona a uno de los inmigrantes internos", Eldiario.es, aremos Los Vuelos." 6. los CIEmigrantes a quienes se ficacies s lity (Londres: Zone Books, imiento29 de diciembre de 2017. 

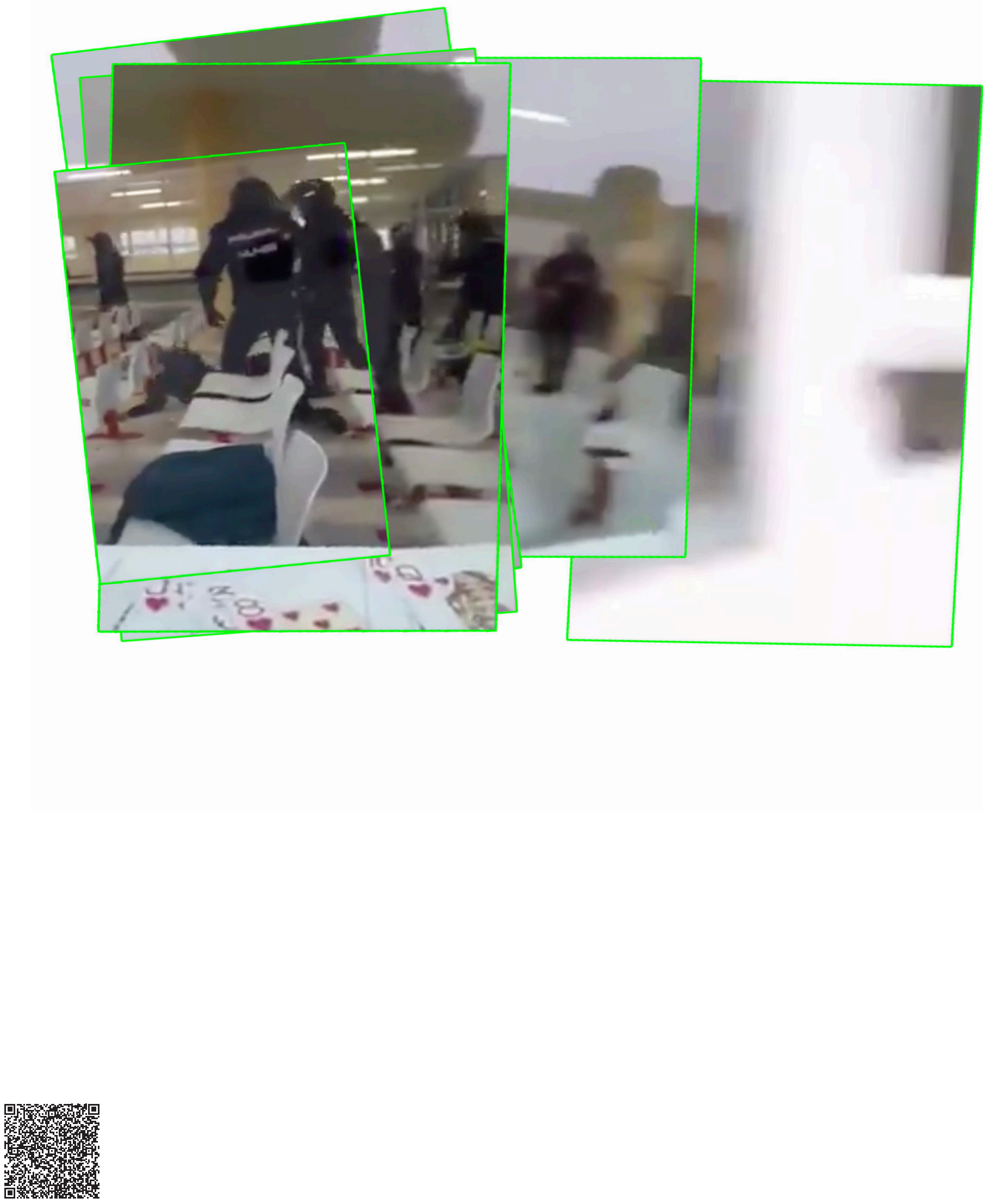

Composición digital del vídeo de Intervención Policial en el interior de la prisión de Archidona (Elaboración propia con imágenes extraídas de vídeo; Archidona, 2017). 


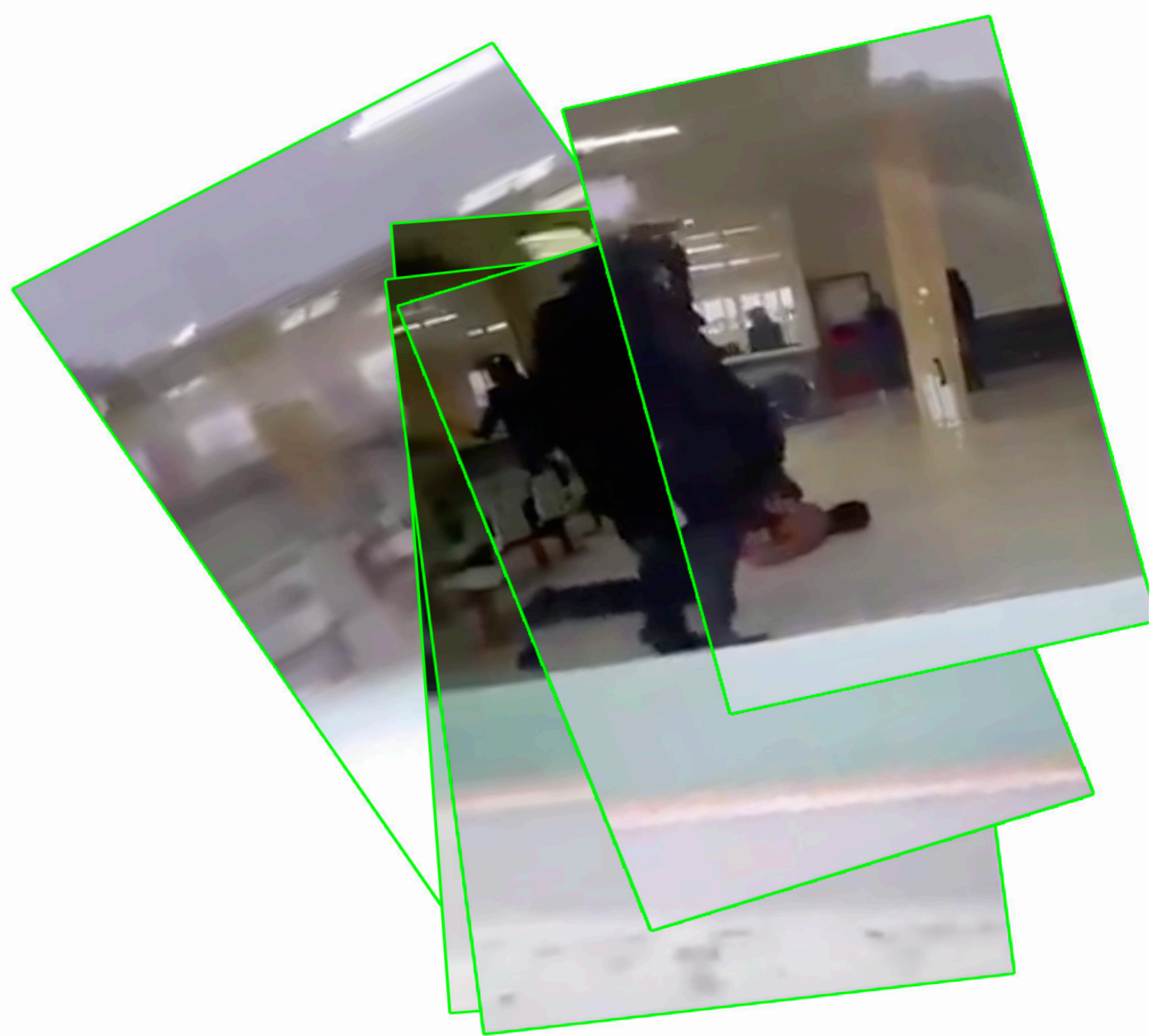

4.2.3. ALTERNATIVAS ESPACIALES.

Este segundo modelo supone una ruptura tipológica clara, que afecta a la arquitectura del internamiento a causa de una interpretación mucho más garantista de la Ley de Extranjería, donde la privación de libertad se contempla como solución excepcional y no como norma. Basándose en los diferentes mecanismos recogidos por la propia ley, pero no implementados de manera efectiva se presentan diferentes alternativas:

el marco legal contempla de forma nítida algunas de estas alternativas. [...] Junto con ella, el artículo contempla la presentación periódica ante las autoridades competentes, la residencia obligatoria en determinado lugar o la retirada del pasaporte o documento acreditativo de su nacionalidad, previa entrega al interesado del resguardo acreditativo de tal medida. Se trata de medidas mucho menos invasivas y restrictivas que el internamiento pero que podrían también garantizar niveles de ejecución de la expulsión similares a los que, en estos momentos, asegura el internamiento. Es más, el propio artículo 6I.I, en su letra f) contempla la posibilidad de que el juez adopte cualquier otra medida cautelar que estime adecuada y suficiente ${ }^{42}$. 
A grandes rasgos, las diferentes propuestas concuerdan en la abolición del CIE como arquitectura ineficaz que debe ser sustituida por la prisión, para aquellos migrantes sobre los que pese una condena penal, y una serie de mecanismos desterritorializados de diferente índole que controlen el movimiento y acciones de los migrantes pendientes de expulsión, pero que no los desconecte de su entorno físico y afectivo. El control sobre los movimientos de los cuerpos se traslada, de los muros sólidos de los CIE a

dispositivos burocráticos -comparecencias periódicas en determinados lugares- o tecnológicos - geolocalización continuada-. Si la capacidad de desterritorialización de la frontera ha aumentado considerablemente en las últimas décadas es lógico que se refleje en los sistemas de deportación. Es decir, la imbricación de las lógicas (excepcionales) de la frontera en el tejido cotidiano del territorio, de la misma forma que las lógicas de control y privación del movimiento que producían los CIEs se actualizan a una formalización mucho más cotidiana; sin negar el reconocimiento de la mejora espacial evidente que esta propuesta espacial propone.

¿Dónde está aquí la transformación arquitectónica más allá de su destrucción? El consistorio madrileño presentó al gobierno estatal, en 2017, un documento con un plan de actuación que sustituyese al CIE de Aluche. Entre las propuestas concretas aparece la creación de una red de "vivienda municipal o perteneciente a alguna asociación con la que exista convenio, en la que la persona extranjera podrá permanecer teniendo cubiertas sus necesidades básicas, hasta que se resuelva sobre su expulsión o no del territorio nacional”33. La propuesta, a pesar de todo, transforma el espacio doméstico en una arquitectónica del internamiento. Una arquitectura que, de nuevo, busca alejarse del paradigma carcelario pero que en última instancia está concebida desde la restricción de libertad de movimientos de cada migrante -a lo que habría que superponer el resto de medidas burocráticas y tecnológicas que asegurasen su control efectivo-. Frente a un control centralizado, un control disperso en la totalidad del territorio, ni siquiera ya en edificios sino en unidades habitacionales seleccionadas por cada comunidad autónoma. Esta propuesta reconoce la condición dinámica de la frontera, siendo una red que pueda crecer con facilidad en función de las necesidades de internamiento a cada instante, tan solo mediada por la disponibilidad de vivienda pública del gobierno. Además, al igual que en otros casos analizados, se parte de una apropiación temporal de arquitecturas existentes cuya función es reemplazada a través de mecanismos no arquitectónicos; lo único que diferencia un piso tutelado de una vivienda de protección oficial son exclusivamente los cuerpos y acciones -de formación, de control, de vigilancia...- que ocurren dentro de sus muros.

La propuesta, claramente, se hace tanto política como ideológicamente como una manera de revertir a un estado previo toda la evolución arquitectónica de una institución que parte de una interpretación sesgada de la ley. Sin embargo, lo que en realidad actualiza a las lógicas contemporáneas de la construcción de la frontera una tipología arquitectónica ineficaz a todas luces, falta de la responsividad arquitectónica necesaria de un modelo que demanda inmediatez, capacidad de adaptación y eficiencia en la gestión de recursos. Estas propuestas alternativas, tal vez no de forma consciente, ayudan a tejer un dispositivo cada vez más tupido, con capacidad de presencia en lugares de manera prácticamente inmediata y a muy bajo coste que con infraestructuras anteriores sería imposible de gestionar; mientras que esta propuesta lo consigue al descentralizar el encierro de cada una de las celdas del CIE en una ubicación diferente. Y, de nuevo, el cuerpo aparece como un agente central en la producción de estos ensamblajes que ya no son exclusivamente arquitectónicos sino que requieren de la disciplina de un cuerpo migrante que vaya y atestigüe su presencia bien física o virtualmente. 


\subsection{CIES INTERCONECTADOS. DEL FUNCIONAMIENTO AUTÓNOMO A DISPOSITIVOS OPERATIVOS.}

Hasta ahora, hemos analizado las arquitectónicas del internamiento de manera autónoma, nos hemos adentrado en su configuración espacial y en las diferentes violencias que, sobre un mismo edificio, se superponían a través de las decisiones arquitectónicas que las habían construido durante los últimos treinta años. Sin embargo, si analizamos el funcionamiento en conjunto de las diferentes arquitecturas vinculadas al internamiento de extranjeros, es fácil observar cómo se ha construido una infraestructura territorial que logra maximizar la capacidad de regulación de migrantes. Un ensamblaje territorial tiene la capacidad de conectar agentes arquitectónicos autónomos durante un tiempo determinado -o mantener este ensamblaje de manera prolongada-y así ser capaz de realizar funciones que, de otro modo, quedarían limitadas. Es esta conexión virtual entre construcciones autónomas la que evidencia de manera clara cómo los CIE, CETI, CATE y toda solución temporal de internamiento de migrantes son, en realidad válvulas reguladoras del flujo de migrantes no-deseados dentro del territorio español. Para ello, hay que explicar en primer lugar cómo se ha construido esta infraestructura territorial y qué efectos tiene sobre las arquitecturas. Es necesario entender cómo esta red de arquitectónicas del internamiento se nutre de una serie de construcciones o despliegues temporales que logran hacer un ensamblaje con presencia mayor en el territorio, y que además tiene capacidad de adaptación en función de las necesidades instantáneas o en un plazo temporal corto. Por último, para comprender su funcionamiento efectivo hemos de mirar a los diferentes espacios, agentes e instituciones públicas o privadas que median y posibilitan su capacidad de acción conjunta.

\subsubsection{ESPECIALIZACIÓN TERRITORIAL Y FUNCIONAMIENTO EN RED.}

Thomas Nail define las tecnologías de frontera como las políticas y construcciones encargadas de gestionar el flujo de personas a través del territorio. Es precisamente en este apartado -que concierne a las arquitectónicas del internamiento- donde esta acepción cobra mayor fuerza, tanto porque a través de esta serie de arquitecturas circulan más de quince mil personas al año - una cifra que aumenta considerablemente en períodos puntuales- como por el carácter molecular que estos cuerpos adquieren al entrar dentro del circuito de regulación de flujo no deseado. Dentro de los circuitos que establece el dispositivo frontera, establece el circuito de detención como aquel donde "en vez de ser rápidamente deportados son atados un empalme diferente - la prisión, detención o campo-. El flujo de migrantes es expandido en el centro de detención. Este, como empalme, es también un vehículo que ata y extrae movilidad de los migrantes a través de su trabajo, ocupación y consumo generado por su propia encarcelación” 44 . Una de las funciones claves en la concepción contemporánea de las arquitectónicas del internamiento es la retención, la disminución absoluta de capacidad de acción y desplazamiento sobre el territorio a la espera de su regularización ${ }^{45}$, bien como sujetos aptos o bien como sujetos

44 Thomas Nail, Theory of the Border (p. 30). Oxford University Press.

$45 \mathrm{El}$ término regularización no hace aquí referencia a su regularización normativa o admi- 
deportables. Las arquitectónicas del internamiento analizadas operan en buena medida como buffer zones o, por seguir con el símil hidráulico, como válvulas de regulación de flujo capaces de acoger el exceso, contenerlo a través de la retención temporal y posteriormente redirigirlo de manera ordenada hacia la expulsión o inclusión dentro del territorio nacional. Esta devolución al territorio, sin embargo, no es neutra sino que sirve como un instrumento que marca y controla en primer término a los migrantes recién llegados.

Dado que esta institución juega un papel fundamental a la hora de convertir personas en sujetos deportables, es necesario comprender su funcionamiento no únicamente como arquitectura vinculada a la deportación sino como una arquitectura, cada vez más, destinada a castigar, marcar e introducir en el circuito de deportabilidad a toda una serie de cuerpos no controlados. Es importante entender la transformación de estas arquitecturas, no tanto por los efectos que ha tenido este cambio programático sobre ellas, sino por las consecuencias que tiene sobre el tercer escenario de nuestro dispositivo frontera: un territorio, como la ciudad, sin aparente presencia de fronteras físicas, pero que sin embargo puede reconocer a unos cuerpos marcados como sujetos deportables. El CIE actúa reduciendo a objetos burocráticos deportables las vidas de los migrantes que interna, bien a través de la cristalización de su irregularización -en caso de llegada- o bien a través de un proceso de muerte social -en caso de ser un sujeto deportable $-{ }^{46}$. Todo esto ocurre en el interior de unos muros que no han variado en todo este tiempo pese a que sí haya sufrido profundos cambios a nivel funcional. Es decir, si en el momento de su formulación normativa (1985) y sus primeras materializaciones arquitectónicas el CIE funcionaba fundamentalmente como una arquitectura exclusivamente vinculada a la deportación, el funcionamiento operativo del CIE en la actualidad funciona en un alto grado como punto de entrada, retención y regularización de migrantes, pese a que no haya cambiado su condición normativa. Así explica Fernández-Bessa su funcionamiento territorial conjunto:

Los CIE han sido utilizados para "almacenar" y después "distribuir" por los CIE de la peníncula recién llegadas que no podían ser expulsadas, y que eran puestos en libertad con una orden de salida, que impedía regularizar su situación. Así como indica Hector Silveira, como consecuencia de que la administración no podía ejecutar todas las órdenes de expulsión que dictaba, los CIE cumplían dos funciones: en primer lugar actuaban como "centros de identificación y de comprobación de datos de extranjeros" retenidos " $\mathrm{y}$, en segundo lugar, como instituciones creadoras de extranjeros a-legales y marginales" 47 .

Este hecho se explica muy bien con el traslado del centro de gravedad de la red territorial formada por el conjunto de los CIE en el estado español durante el inicio de la primera década del siglo XXI. La instalación de los primeros centros se produjo en las grandes metrópolis que aglutinaban gran número de población migrante: Madrid, Barcelona y Valencia. A continuación, se construyeron en la costa sur del Mediterráneo los primeros centros de internamiento, Sangonera la Verde y Capuchinos, que luego fueron reforzaron al otro lado con la presencia en Ceuta y Melilla de dos CETI -arquitectónicas del internamiento ya explícitamente orientadas a la fase de llegada y no de expulsión-. A continuación La Piñera en Algeciras, su extensión en Tarifa, junto con el CIE de Hoya Fría

nistrativa -permisos de residencia, solicitud de asilo...- sino a su canalización dentro de los diferentes circuitos normativos del dispositivo frontera.

46 Orgaz, «Emergencia e Institucionalización Del Encierro De Extranjeros En España », (2018), 471 . 
y el Matorral en las Islas Canarias suponen el gran desplazamiento territorial del peso de esta infraestructura. Los CIE se construyeron respondiendo a los focos principales de llegada a través de las dos grandes rutas de llegada a España: la Mediterránea Occidental y la Africana Occidental ${ }^{48}$. ¿ Responden estas construcciones territorialmente a una mejora de la eficiciencia del sistema de deportación? Al analizar la situación del CIE de Isla Palomas, en Tarifa, extensión autónoma del CIE de Algeciras, es fácil detectar por su posición desconectada a una hora de trayecto del centro matriz, situado a pie de playa y desconectado del núcleo urbano, que la rapidez en el traslado a un centro o lugar con capacidad efectiva de deportación es francamente costosa. Sin embargo, la localización de este espacio en pleno mar de Alborán, lugar que ha registrado más llegadas de pateras en las últimas dos décadas, lo hace un emplazamiento idóneo para trasladar inmediatamente a los migrantes una vez desembarcados. Esta situación se refuerza con el despliegue múltiple de arquitecturas operativas que multiplican varias veces la capacidad de internamiento de esta red territorial y que, también se sitúan exclusivamente en los puntos de llegada: Algeciras, el mar de Alborán e Islas Canarias son los epicentros de estos ensamblajes temporales durante los años 2005, 2006 y 2007.

En la actualidad, esta infraestructura territorial juega un papel crucial en la identificación, control, regulación y expulsión del flujo de migrantes en territorio español, concretamente en lo que a migración irregular africana se refiere. Para este cuerpo migrante a diferencia de otros, el paso por las arquitectónicas del internamiento es el punto de entrada al territorio nacional, y también el de salida en caso que sea deportado. Sin embargo, para convertirse en piezas claves del dispositivo frontera, y no sólo como contenedores de sujetos deportables como sí lo fueron en su inicio, ha debido producirse un cambio respecto a su autonomía. Aunque cada centro funcione a efectos logísticos de manera independiente, su coordinación territorial es la que hace efectiva su gran eficacia y omnipresencia dentro del dispositivo frontera. Esta coordinación consiste en que el CIE de Aluche, fundamentalmente -y de manera complementaria el de Zona Franca en Barcelona- centralizan todo el flujo de migrantes en procesos de deportación, por su proximidad a los principales aeropuertos del estado, junto con las cada vez más numerosas deportaciones exprés desde comisarías. A través de ellas, a modo de embudo, se canalizan los sujetos deportables desde todas las partes del estado y desde el resto de CIEs en funcionamiento; a la vez que asumen la llegada de migrantes detenidos en regiones geográficas que carecen de centros de internamiento. El resto, junto con la multiplicidad de arquitectónicas del internamiento actúan de manera operativa como válvulas de identificación, ingreso, internamiento e inclusión o exclusión.

La selectividad espacial de arquitecturas diseñadas y configuradas para asumir una función única y compartida resulta muy relevante si lo analizamos desde la lógica de los dispositivos. Las arquitectónicas del internamiento no poseen una función previa, sino que son las necesidades demandadas por el dispositivo, el cual construye la red territorial que opera entre ellos como arquitecturas dispersas que asignan el funcionamiento operativo de cada nodo. Y, si llegado el caso, la infraestructura generada no tuviese la capacidad suficiente de acción sobre el territorio, el dispositivo es capaz de desplegar, apropiarse y generar nuevos espacios de internamiento que logren suplir de manera prácticamente instantánea las carencias detectadas. Así pues, la pérdida de autonomía operativa de cada centro y el desplazamiento de su función primaria debe leerse como consecuencia lógica de un funcionamiento que sólo puede ser visibilizado a nivel territorial.

48 Frontex, «Migratory map», acceso el 1o de marzo de 2019. https://frontex.europa.eu/alongeu-borders/migratory-map/ 


\subsubsection{ARQUITECTÓNICAS DE LA CONTINGENCIA}

De manera constante se han desplegado desde la década anterior una serie de arquitecturas destinadas a internar, de manera rápida y eficaz a los migrantes recién llegados. Estas arquitecturas están localizadas en el perímetro español del Mediterráneo Sur. Muchas de ellas son ensamblajes dependientes de Centros de Internamiento o Centros de Estancia Temporal, pero muchas otras son instalaciones temporales autónomas que funcionan en la práctica sustituyendo a estas dos categorías. Estas construcciones se entienden únicamente en función de requerir una capacidad de respuesta de esta infraestructura territorial en los momentos que, la existente no es capaz. Cuando el flujo de migrantes llegados a través de las rutas africanas aumenta de manera explosiva -en un corto período de tiempo-, se plantean soluciones excepcionales que poseen un carácter aparentemente temporal pero sostenidas a lo largo del tiempo o tácticas de implantación repetidas a lo largo de una década ${ }^{49}$. Es especialmente destacable el período de 2005-2007 como laboratorio arquitectónico en las Islas Canarias y el Mediterráneo Sur donde, como recoge el informe presentado por Migreurop:

A lo largo de todo el año 2006 y de forma improvisada se fueron habilitando espacios para "amontonar" africanos, las más de las veces en condiciones más que lamentables. Llegó a haber en septiembre de ese año hasta 14.000 inmigrantes en los CIE: 4.00o en la Gomera, I.500 en El Hierro, I.80o en la Comisaría Tenerife Sur, 3.000 en las Ríces, I.400 en Hoya Fría y unos 1.600 en El Matorral ${ }^{50}$.

Esta red de centros informales, únicamente en Canarias fue capaz de internar a tantos migrantes en un único mes casi quince mil, el total de internos en el CIE de todo el estado español a lo largo de un año. Multiplicó catorce veces la ocupación teórica de toda la infraestructura territorial a través del despliegue de ensamblajes temporales para lograr tal efecto. El carácter de contingencia de estos ensamblajes arquitectónicos - ante un aumento localizado y repentino del flujo- provoca la no consideración de una serie de estándares espaciales que convierten estas arquitectónicas en espacios de excepcionalidad, donde la condición infrapenitenciaria se agudiza hasta niveles muy altos. El mismo informe señala cómo estas arquitecturas presentan graves carencias higiénicas, condiciones de hacinamiento, alta precariedad en las instalaciones, falta de condiciones de salubridad e higiene, ausencia total de servicios complementarios al internamiento -asistencia legal, sanitaria o intérpretes- a la vez que presente la misma opacidad que ha caracterizado los CIE formales ${ }^{51}$. Sin embargo, dada la recurrencia del gobierno a efectuar esta clase de despliegues temporales durante la última década, el carácter de excepcionalidad que pretende justificar esta ausencia deliberada de servicios en base a una emergencia puntual, se difumina cada vez más con una excepción permanente que no los tiene en cuenta como parte del programa arquitectónico necesario que debe ser desplegado pese a su temporalidad.

Frente a un modelo de construcción que posee unas inercias de ejecución, gasto y mantenimiento muy elevado ${ }^{52}$, estas medidas operativas dotan al dispositivo territorial de una responsividad mucho mayor que no necesita apenas tiempo

49 Este carácter constante pero muy acotado en el tiempo es posible asociarlo con el concepto de temporalidad permanente enunciado por Alessandro Petti para referirse a la situación de ciertas arquitectónicas del internamiento -campos de refugiados-cuya función temporal parece obviarse. Añadir referencia.

50 Migreurop, «Centros de Internamiento y retención en España: octubre 2008», 13.

51 Migreurop, «Centros de Internamiento y retención en España», 7:15 .

52 Tan sólo el importe de mantenimiento de los Centros de Internamiento asciende a los ocho millones de euros, y la construcción de cada uno oscila en torno al millón y medio, con refor- 
de despliegue ni costes, tanto de construcción como de mantenimiento, más allá de los imprescindibles. El giro gerencial de la frontera afecta no sólo a nivel de funcionamiento interno -repatriaciones, sistemas de mantenimiento, devoluciones exprés...- sino también tiene su correlato en el plano arquitectónico.

Se han detectado, fundamentalmente, dos estrategias de actuación que, en la práctica, se combinan también con una serie de mecanismos arquitectónicos dando como resultado un agregado de posibilidades espaciales. Esta hibridación que, por efectos de análisis hemos separado, supone una selectividad mucho mayor del dispositivo frontera, que permite dar una respuesta contextual en función de múltiples variables: disponibilidad en centros existentes, cercanía a ellos, arquitecturas apropiables, materiales para la construcción de campos disponibles..., frente a la solución estándar del Centro de Internamiento ya analizada. Así pues, la primera estrategia consiste en la apertura temporal de centros autónomos a través de la generación de campos con arquitecturas efímeras, tiendas textiles o a través de la apropiación de arquitecturas en desuso de todo tipo y función previa. Mientras que, la segunda estrategia aplica las mismas operaciones arquitectónicas sobre centros existentes a fin de aumentar su capacidad, aún a costa del riesgo de malfuncionamiento.

Existe en todos estos ensamblajes arquitectónicos una clara dimensión temporal en la configuración de estas arquitecturas. Desde las instalaciones hasta la materialización de los módulos de internamiento, absolutamente todo en ellas está íntimamente ligado a su uso y demanda a cada instante. El empleo de tiendas -tanto en interior como en exterior- para compartimentar los espacios, la instalación de aseos portátiles, las divisiones únicamente hechas con vallas metálicas, junto con la señalada despreocupación por las carencias espaciales fácilmente detectables en algunas construcciones, nos remiten a esta condición de precariedad asociada a la temporalidad del propio ensamblaje. Hasta los constructores cambian: si en los CIE eran empresas constructoras las que se encargaban de su edificación, ahora toman el relevo el ejército, unidades de protección civil o de emergencias; hecho que explica el despliegue inmediato y los materiales empleados frente a las inercias propias de la industria de la construcción. Pero esta dimensión temporal está sobre todo mediada por los usuarios potenciales que van a ser ahí internados, son ellos los que modulan la arquitectura a cada instante, ampliándola, reduciéndola, o incluso haciéndola desaparecer. Se podría afirmar que en cierta medida son ellos, el cuerpo migrante, los que activan, desactivan y producen -de manera no voluntaria, eso sí- estas arquitectónicas del encierro. Esta condición dinámica marcada por la necesidad de cuerpos que habiten las arquitecturas para sostenerlas, aparentemente reservada exclusivamente a arquitecturas temporales o efímeras, es trasladable fácilmente a los Centros consolidados, que también se ven afectados por esta necesidad ${ }^{53}$.

A través de tres mecanismos estas estrategias se trasladan a propuestas arquitectónicas concretas. Las podemos identificar de manera independiente, aunque en muchos casos se presentan combinados entre ellas, complementándose o hibridadas con las arquitectónicas del internamiento ya analizadas. Esta capacidad de hibridación permite aumentar de manera notable las posibles respuestas espaciales ante cada acontecimiento; sin embargo, a efectos de

\footnotetext{
mas en los existentes cercanas al medio millón
}

53 En un período muy corto de tiempo, debido a la falta de migrantes internos, el CIE de El Matorral cerró sus puertas, una vida útil de tan sólo diez años; pero incluso más ilustrativa es la apertura en 2005 de los CIE de Las Raíces y La Isleta, que sólo permanecieron dos años activos hasta su cierre definitivo en 2007 
De arriba a abajo:

Aumento de la capacidad de internamiento a través del despliegue de carpas dentro del CETI de Melilla (Melilla, 2014) y del CIE de Hoya Fría (Tenerife, 2012). diferenciar las actuaciones, se presentan a continuación de forma aislada, en función del grado de autonomía que cada uno presenta respecto a la dependencia de centros formales o instituciones cercanas para asegurar su funcionamiento.

El primer mecanismo, modulación de la capacidad, consiste en la regulación de la capacidad teórica de cada habitación o módulo dentro de un centro existente para adecuarlo a las necesidades operativas de internamiento real, lo que afecta a la ratio de espacio disponible por persona. De nuevo, las regulaciones establecidas son puestas en suspenso en base a las necesidades excepcionales a las que tiene que dar respuesta la arquitectura. Esta actuación no afecta exclusivamente a las áreas del edificio destinadas a tales efectos sino que, en caso de resultar insostenible por cuestiones de hacinamiento se llega a convertir espacios del centro - exteriores, zonas comunes, comedores...-, con funciones diferentes para la instalación de nuevos módulos que permitan aliviar la presión. Un ejemplo claro de esta situación lo encontramos en el CETI de Melilla durante el año 2013, que vió como su capacidad teórica de 480 plazas era duplicada para albergar a 900 migrantes durante un período indefinido, teniendo que ocupar servicios complementarios al internamiento, como denunció la Defensora del Pueblo en su momento: "dado el alto grado de ocupación y la necesidad de habilitar todas las dependencias posibles para alojar a los residentes, ya no se prestan los servicios de guardería, educativos y formativos, que se habían puesto en marcha”. Este mecanismo permite mejorar la eficiencia real del centro en materia de internamiento -aumento considerable de la capacidad- a costa de la sobreexplotación de los módulos logísticos - aseos, comedores, vigilancia- que no se ven alterados, o la supresión de servicios complementarios como los ya señalados.
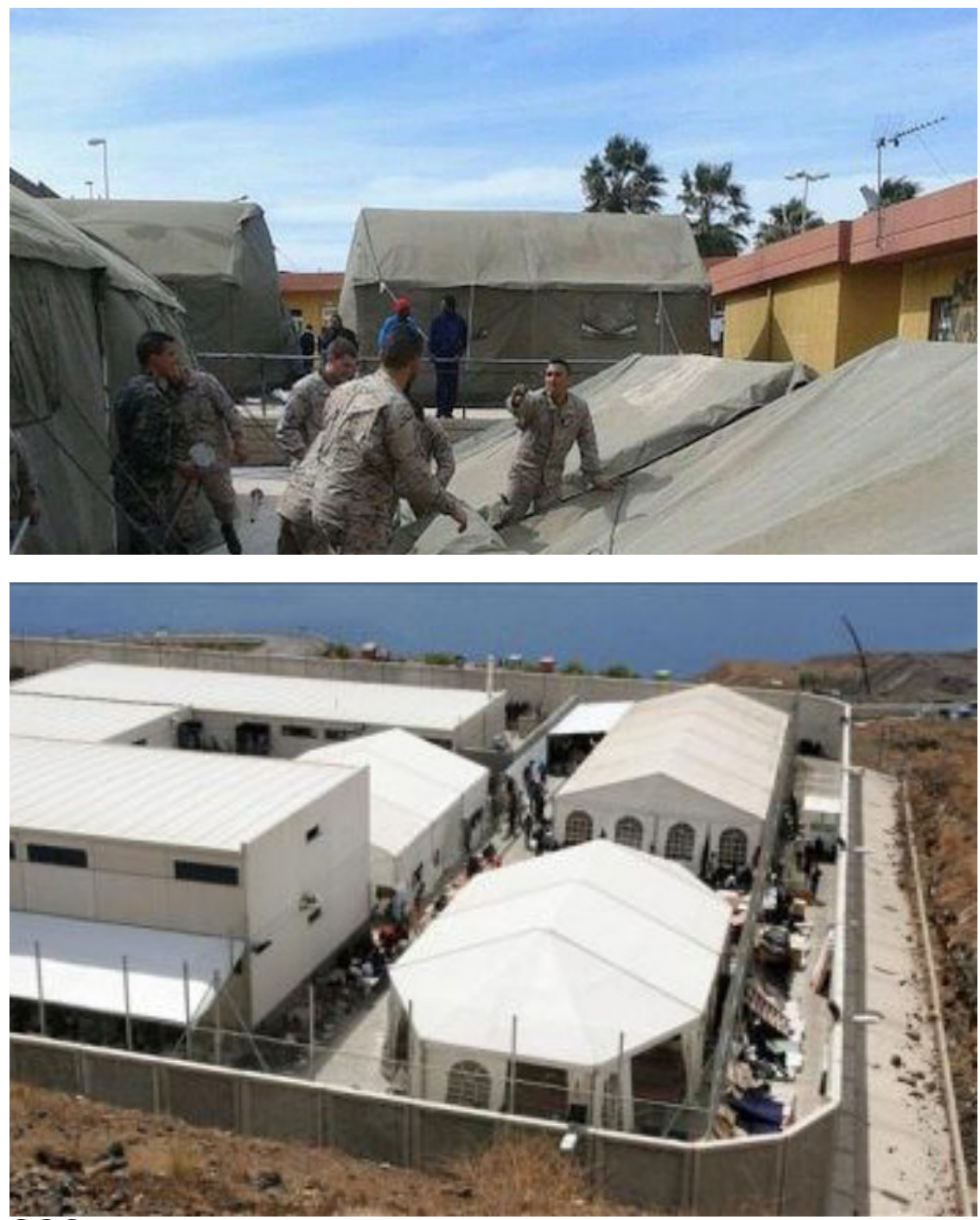
El segundo recurso, apropiaciones de arquitecturas, consiste en la localización, selección y apropiación de un serie de construcciones disponibles, sin uso, que responden a las dimensiones y características espaciales para instalar en su interior o en sus inmediaciones el programa de internamiento requerido. Convierten la arquitectura en un contenedor de programa, donde la disposición espacial no ha de responder con precisión a las necesidades del internamiento sino simplemente dar cobertura material para que en su interior se desplieguen sistemas efímeros de alojamiento. A través de actuaciones menores sobre el esqueleto construido -las cuales dependen del grado de temporalidad esperadose instalan los servicios mínimos que garanticen las condiciones mínimas para su funcionamiento. Sistemas de literas, tiendas portátiles, vallas, aseos móviles, servicios de cátering así como la externalización de otros servicios, permiten una autonomía prácticamente total respecto del resto de nodos de la red. Si la apropiación de arquitecturas obsoletas ya formaba parte de las estrategias espaciales para la construcción de Centros de Internamiento, es necesario señalar que éstas se limitaban a propiedades de titularidad vinculada al Ministerio de Defensa o de Interior, con programas similares - alojamiento forzoso o voluntario de personas-, cárceles, cuarteles, prisiones o comisarías de policía se transformaban en CIE. Sin embargo, la apropiación de estas construcciones en desuso ya no responde a esas lógicas, sino que responde aún más a las de la inmediatez. Restaurantes (La Gomera), cocederos de marisco (Algeciras), garajes de comisarías (Tenerife), polideportivos (El Hierro), centros hípicos (Ceuta), barcos, espacios portuarios (Algeciras), junto con cuarteles militares(Tenerife, Gran Canaria) o terrenos anexos a ellos; todos ellos son espacios que han sido apropiados de manera temporal para construir en ellos arquitectónicas del internamiento.

El Restaurante "El Camello" representa uno de los ejemplos más claros de esta solución espacial. En el kilómetro 8.3 de la carretera GM-3, en la Isla de la Gomera, una discoteca y salón de bodas, bautizos y comuniones fue transformado en un centro de internamiento cuya actividad cesó en 2007. En un primer momento se instalaron veinticuatro carpas militares para internar a los migrantes en la extensión de terreno anexa al salón de bodas, donde se centralizaban los servicios logísticos. Tras una reforma de 760.000 euros, las tiendas dieron paso a dos filas de contenedores de obra levantadas sobre zapatas corridas de bloque de hormigón con capacidad para internar a doscientas personas. Su funcionamiento osciló desde una primera necesidad puntual de acogida hasta adquirir un carácter más permanente con una intervención destinada a hacer permanente lo que antes era temporal.

Este recurso permite generar nuevos nodos dentro de la infraestructura territorial, totalmente independientes y próximos a los principales puntos de llegada de migrantes. La cuestión fundamental es que esta respuesta espacial no requiere de la creación de nuevos edificios sino apropiándose de edificaciones existentes, donde las intervenciones arquitectónicas que sufren los edificios se reducen a las mínimas necesarias.

En función de la proximidad a otros centros, este mecanismo puede funcionar como una extensión o ampliación externa a arquitectónicas del internamiento consolidadas. Esta variación supone que se puede aumentar la capacidad de un centro sin comprometer las funciones complementarias del mismo. Y, a la vez, las apropiaciones de arquitecturas, se benefician de que requieren un gasto de inversión mucho menor para entrar en funcionamiento. La única limitación es la distancia efectiva entre un centro y construcciones susceptibles de ser apropiadas. Esta situación se ha dado en el CETI de Ceuta, situado inmediatamente al lado del Centro Hípico; esta proximidad ha hecho que en numerosas ocasiones se haya llegado a expandir el CETI invadiendo los espacios 

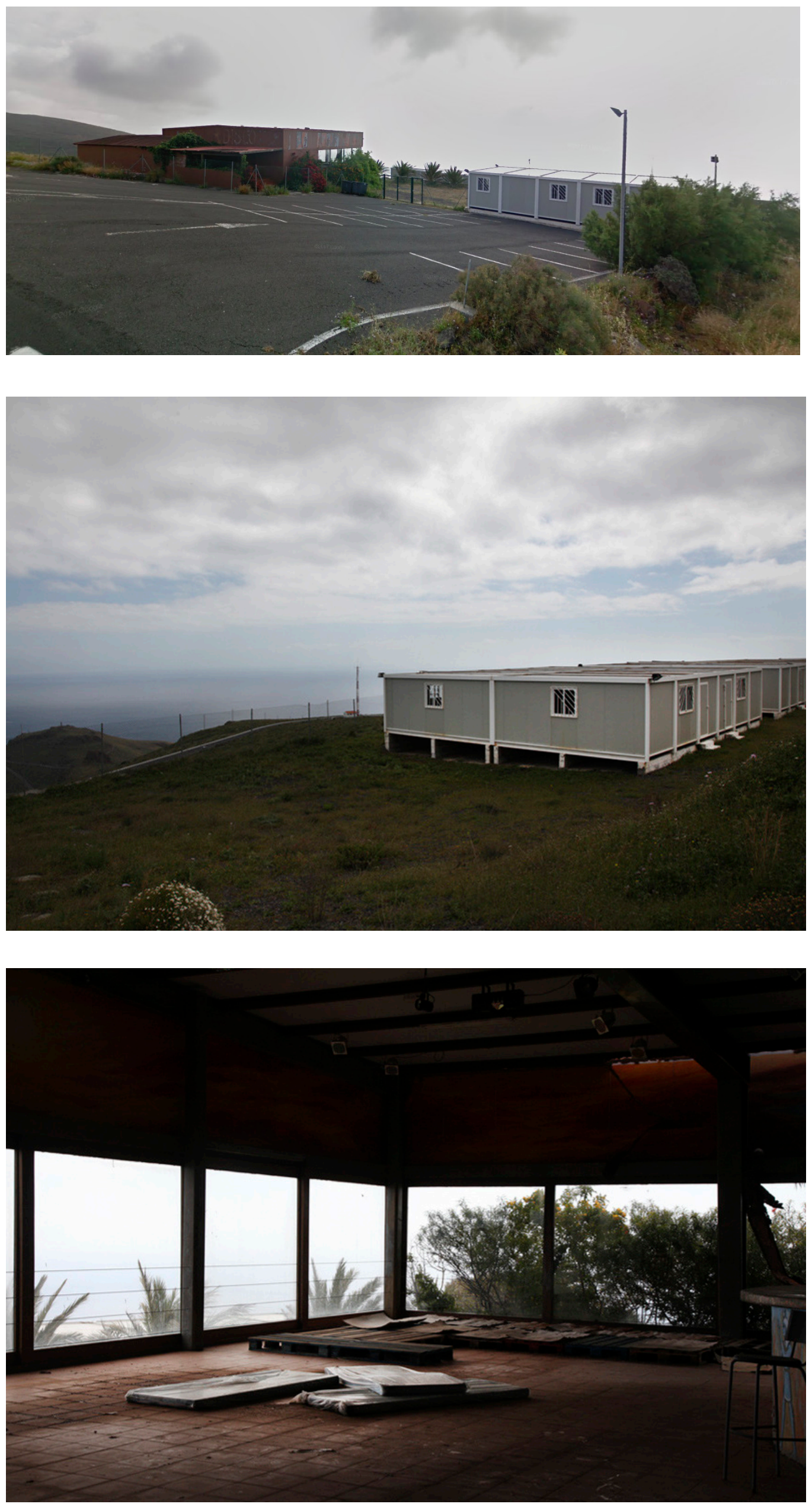

Restaurante El Camello, edificación original, módulos prefabricados añadidos e interior. (Google Street VPatricia Gómez y María Jesús González; Tenerife, 2014 ). 
de los aparcamientos del Centro Hípico donde se instala un número de carpas capaz de aliviar la sobreocupación del centro. El verano de 2018 se produjo la última actuación de este tipo, con un sistema de piezas de acero prefabricadas, piezas textiles la unidad ULOG 23 del ejército levantó carpas y literas únicamente una tela tensionada entre dos perfiles tubulares de acero- para dar cabida al exceso de flujo de migrantes que había entrado en Ceuta a través de la valla.

El tercer recurso, construcción de campos -en el sentido más concreto del término-; es aquel que presenta un grado de autonomía mayor tanto de independencia respecto a nodos existentes como a las necesidades contextuales que requería el recurso anterior -la presencia de arquitecturas disponibles-. Este recurso consiste en la instalación efímera de unidades autónomas cuyo despliegue es casi inmediato debido a los materiales empleados. Aunque suele aparecer en combinación con los recursos anteriores puede alcanzar una autonomía casi absoluta al no depender de instalaciones de terceros para su subsistencia. El despliegue de unidades habitacionales, el uso de tiendas militares o heredadas de las arquitecturas del refugio y cooperación son una constante que logra dar cabida prácticamente inmediata a grandes cantidades de migrantes. Sin embargo, esta inmediatez de construcción que proporciona el sistema constructivo hace que sea un recurso mucho más contenido en el tiempo. Un buen ejemplo es la instalación del CATE [Centro de Atención Temporal de Extranjeros] en el puerto de Motril en 2018, con capacidad para acoger a 200 personas en carpas, transformado en permanente a través de la instalación de barracones en 2019,. Una actuación que hemos visto repetirse, de manera constante, durante la última década y que fue especialmente útil en Canarias, donde el campamento de La Isleta y Las Raíces llegaron a albergar 1300 y 2700 personas respectivamente.

Se han presentado tres recursos arquitectónicos capaces de dar respuesta espacial de manera dinámica, táctica y responsiva a cada situación concreta. La combinatoria que podemos establecer entre cada uno de los centros consolidados que forman la infraestructura territorial de arquitectónicas del internamiento, junto con estos recursos dinámicos hace que, ante cada acontecimiento, se pueda generar una disposición específica. Un despliegue arquitectónico que responde a las demandas contextuales a cada instante, con facilidad para expandirse, adaptarse o contraerse en función de las variaciones que existan durante su funcionamiento, de manera rápida y eficaz. Además logran, con la menor cantidad de recursos infraestructurales y logísticos, maximizar la capacidad de respuesta de un centro existente o generar uno nuevo autónomo con un grado de independencia prácticamente absoluto. La coexistencia de una red sólida -formal- de arquitectónicas del internamiento estables a lo largo de todo el territorio estatal, junto con un número de nodos en estado latente, indefinido y adaptable ante cada acontecimiento hace que la infraestructura territorial se refuerce, a la vez que sea mucho más tupida y continua, y sólo se manifieste en ocasiones de excepcionalidad. Si se obviasen estos recursos arquitectónicos, por la informalidad que presentan estas construcciones, su carácter efímero, o se atendiese a la división normativa entre las diferentes instituciones que forma esta infraestructura, se estaría excluyendo una gran variedad de respuestas espaciales que, con la misma o mayor eficacia, logran articular espacios de control e internamiento.

Podríamos pensar que por su condición temporal están siempre subordinados a centros formales. Eso no es así, este conjunto de arquitectónicas del internamiento genera una red de jerarquías débiles y variables entre ellas, que fluctúa en función de necesidades puntuales. El ensamblaje se desterritorializa todavía más y localizaciones periféricas pasan, en un instante determinado, a 

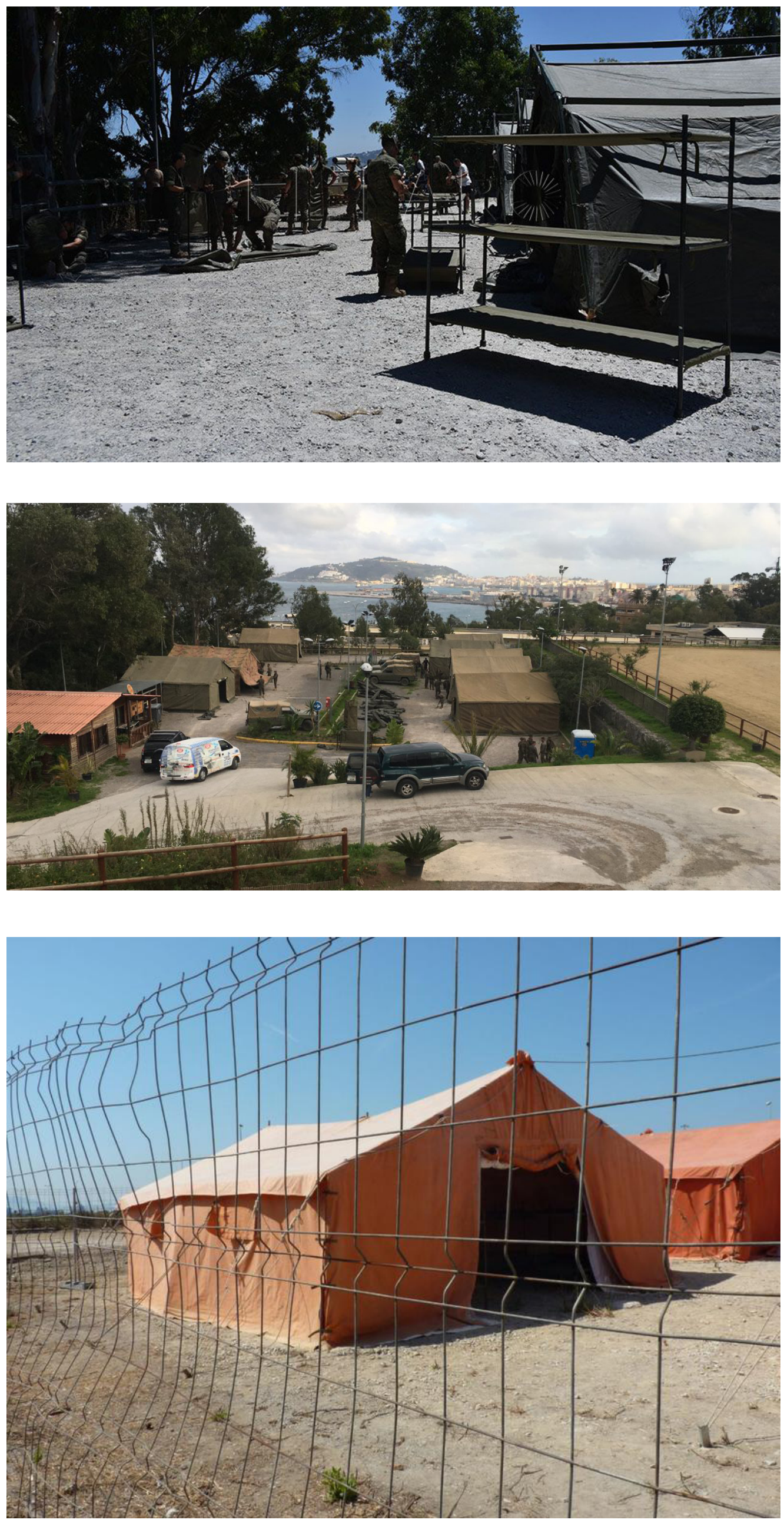

De arriba a abajo:

Instalación de campamentos

militares en Ceuta (Ceuta,

2014) y Motril (El Salto; Granada, 2018). 
cobrar un peso fundamental dentro del dispositivo de regulación del flujo de migrantes. No hay una cadena o jerarquía clara entre ellos, la precariedad de los mismos no establece un eslabón inferior en el proceso de expulsión ya que este no es lineal sino enmarañado y reiterativo. La red que dibujamos en el primer apartado, con una serie de centros ensamblados territorialmente, claramente especializados en función de su localización, da paso a una red tupida y variable, interdependiente entre sí a cada momento, reconfigurable, y donde las funciones no son asignadas a priori por su posición territorial estática sino por las características de cada acontecimiento. Es decir, un nodo periférico o inexistente, como la cárcel de Archidona o los terrenos del Centro Hípico anexos al CETI de Melilla, puede cobrar en un momento una función equivalente a la de un CIE oficial si las necesidades así lo requieren.

Estos recursos dinámicos, contingentes, temporales y precarios, que se apropian de materia arquitectónica existente y la reconfiguran para generar nuevas soluciones espaciales, son los que con mayor profusión se han mantenido constantes a lo largo de la última década. Desde el período de 2005-2007 en las Islas Canarias donde hubo apropiaciones de campamentos militares, antiguas prisiones, garajes de comisarías, restaurantes, carpas en puertos y estancias de aeropuerto..., hasta el repunte migratorio en la frontera Sur durante el verano de 2018, son las arquitectónicas más demandadas en primera instancia. Recursos que, de manera instantánea, lograron igualar la capacidad de internamiento de todo el estado y que, una vez dejaron de resultar eficaces, fueron desmanteladas con la misma inmediatez con la que fueron ensamblados. Por ello, si pensamos más allá de la solidez de los muros como única posibilidad de internamiento, encontramos que estas construcciones dinámicas son la tipología más eficaz consolidada en el presente inmediato. Un modelo, con sus múltiples variantes, no basada en la solidez de un recinto, sino en el ensamblaje de una serie de recursos materiales y una disposición sobre el territorio para conseguir generar un campo dinámico.

Mientras que la evolución tipológica formal a largo plazo parece clara y enfocada hacia un modelo cada vez más securitario y carcelario -recinto-, la evolución que atiende a estas construcciones contingentes e informales, apunta hacia la noción de campo en cuanto a su temporalidad. Puede que sea éste, dada la profusión y repetición a lo largo de la última década de estas soluciones espaciales, el modelo que defina el internamiento de migrantes en años futuros. Cualquier arquitectónica del internamiento estará definida, en su dimensión operativa, por la noción de campo más allá que la del recinto: un espacio indefinido configurado por relaciones móviles y acciones frente a un espacio definido de antemano. 
Hemos visto cómo la aparente centralización de todas las arquitectónicas del internamiento ha dado paso a una red mucho más capilar, que fluctúa, crece y desaparece en función de las necesidades puntuales de internamiento. Sin embargo, esta serie de arquitecturas dispersas, un ensamblaje territorial con presencia en prácticamente todo el territorio español, requiere de una serie de agentes, espacios e instituciones que aseguren su funcionamiento efectivo. No poseen la entidad arquitectónica, en términos ortodoxos, de las construcciones anteriores, ya que muchos de ellos son simplemente estancias o espacios mínimos dentro de complejos mucho mayores. A caballo entre el nodo y la conexión, estos espacios resultan fundamentales para comprender la eficacia de un sistema capaz de conectar arquitecturas independientes pero con capacidad de acción conjunta. $\mathrm{Su}$ análisis evidencia hasta que punto las lógicas de la frontera no se reproducen exclusivamente en los espacios destinados a tal efecto sino que son capaces de desplegarse en cualquier punto del territorio, difuminando aún más la línea que separa lo cotidiano de lo excepcional.

Tres son las aproximaciones que, con una escala arquitectónica muy diferente, nos permiten complejizar la visión de las arquitectónicas del internamiento, y terminar de trazar así la cartografía de esta infraestructura territorial que regula buena parte del flujo migratorio. La primera de ellas muestra cómo el perímetro de la frontera no tiene su correlato en la extensión del dispositivo, que es capaz de ir mucho más allá de los límites soberanos para asegurar su funcionamiento; en concreto con la construcción de un centro de internamiento en la costa mauritana, situado a $750 \mathrm{~km}$ de la costa canaria y $2000 \mathrm{~km}$ de la península ibérica. La segunda de ellas, la red capilar de diferentes espacios públicos y privados que actúan de manera operativa como arquitectónicas del internamiento, y reemplazan la centralización de los CIE en un sistema disperso territorialmente que responde a las demandas del giro gerencial de la frontera. Por último, la concatenación de espacios que se produce en un proceso de deportación donde el avión cobra un protagonismo absoluto, capaz de desplegar un control individualizado sobre cada cuerpo y donde mecanismos no arquitectónicos son los encargados de ejercer tal control a través de un alto grado de violencia espacial. Es este último el que evidencia el carácter dinámico de la frontera, donde el control no se aplica de manera generalizada sobre conjuntos de población -el cuerpo migrante en su dimensión colectiva- sino que responde con soluciones espaciales individualizadas en función de las acciones y resistencias de cada cuerpo.

\subsubsection{ARQUITECTÓNICAS EXTRATERRITORIALES.}

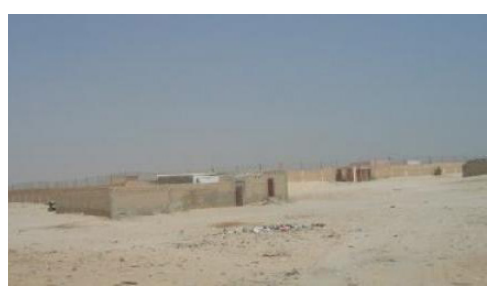

Centro de Internamiento de Extranjeros en Nuadibú (Mauritania, 2008)

212 arquitectónica para transformar los pabellones de una escuela abandonada y los patios exteriores que la rodeaban en un centro informal de internamiento. Los mecanismos, los habituales: intervenciones mínimas para suministrar electricidad y agua corriente al interior, despliegue de material textil para formar barracones con trescientas cincuenta literas y dieciséis tiendas de campaña en el exterior. Los militares solo necesitaron tres días para habilitar la construcción que internase a los migrantes procedentes de las llegadas irregulares a costas canarias. Hasta aquí, la operación es idéntica a tantas otras que ocurrieron en ese año (La Isleta, Las Raíces, El Camello...), la única diferencia: su localización. 
Esta arquitectónica del internamiento, supervisada por la Agencia Española de Cooperación Internacional, se desplegó en la costa mauritana, en Nuadibú, la segunda mayor ciudad del país como centro de acogida para los migrantes deportados a su llegada a territorio español; entre 200 y 300 personas mensuales eran internadas en él. "Guantanamito", a falta de un nombre oficial, es la denominación popular de un espacio arquitectónico excepcional, ya que sobre él no regían ni los estándares establecidos por España para centros de este tipo, ni los de Mauritania. Una visita realizada en marzo de 2008 por Amnistía Internacional evidencia la realidad espacial de esta infraestructura que, situándose fuera del territorio español, contribuye a la eficacia del dispositivo frontera:

Apenas las autoridades mauritanas comenzaron a utilizar el edificio como centro de detención, las tiendas y el comedor desaparecieron y sólo quedaron las aulas, que se convirtieron de hecho en "celdas". Actualmente hay 216 literas distribuidas en varias aulas, pero cuando la delegación de Amnistía Internacional visitó el centro a principios de marzo de 2008 sólo se estaban utilizando tres aulas, lo que causaba un grave problema de hacinamiento y deplorables condiciones higiénicas. El centro lo gestionan las autoridades mauritanas, pero las comidas las pagan y distribuyen la Cruz Roja española y la Media Luna Roja mauritana ${ }^{54}$.

Este edificio supone un caso sin precedentes, ya que materializa arquitectónicamente una práctica política desarrollada desde los años noventa, donde cooperación internacional y externalización de fronteras se superponen con un mismo objetivo: trasladar la gestión del flujo de migrantes a terceros países. Sin embargo, a nivel español, no se conoce otro caso de este tipo donde hasta la construcción y parte de la gestión del edificio sea realizada por instituciones dependientes del estado. Así pues, tanto la Unión Europea como España han financiado acuerdos de cooperación con países africanos del Mediterráneo como estrategia de externalización y contención ${ }^{55}$. Este trasvase de responsabilidades a terceros países, con la consecuente falta de acuerdo en cuanto a los estándares espaciales y garantías de los internos se ve claramente también a nivel arquitectónico: la disposición espacial del centro de internamiento cambia pasando a usar sólo tres aulas como zona de internamiento, se aumenta la altura del muro perimetral e instalan concertinas en su tramo superior para impedir su cruce; demandas hechas por las autoridades mauritanas en el momento de su construcción que fueron rechazadas por los responsables españoles ${ }^{56}$.

Se emplea el término externalización de fronteras para señalar este hecho, sin embargo teniendo en cuenta que el dispositivo frontera no está vinculado de manera unívoca a un único territorio -como sí lo está la frontera histórica-, sino que fluctúa desplegándose en diferentes escenarios, creemos más apropiada el concepto de extra-territorialización. Este término define aquellas prácticas no tanto en función de quien las ejecute, sino de la localización de las prácticas espaciales respecto a los límites territoriales definidos por su soberanía en un sentido clásico del término. Trauttmansdorf explica así el concepto aplicado

54 Amnistía Internacional, «Mauritania, "Nadie quiere tener nada que ver con nosotros”: arrestos y expulsiones colectivas de migrantes a quienes se ha negado la entrada en Europa”, (Amnistía Internacional, 2008), 20.

$55 \mathrm{El}$ acuerdo de Cotonou (2000), las conferencias de Rabat (2006, 2008), el tratado de cooperación entre Italia y Libia (2008), el acuerdo entre Grecía y Turquía (2010), la cumbre Europa-África celebrada en Libia, que en el marco español tienen un correlato estrecho con las relaciones e inversiones hechas por España con el gobierno de Marruecos y, en este caso, Mauritania.

56 Tomás Barbulo, “El fiasco de 'Guantanimito”, El País, ro de julio de 2008. 
Centro de Internamiento de Extranjeros en Nuadibú ( Patricia Gómez y María Jesus González; Mauritania, 2015). a las capacidades tecnológicas y digitales del funcionamiento de la frontera remitiéndose a este mismo término, al que rápidamente podemos establecer un correlato claro en el plano espacial que nos atañe:

Estrategias y técnicas del gobierno de la movilidad que pueden ser encontradas mucho más allá de las fronteras territoriales, lo que indica la "multiplicidad de situaciones" donde la producción de frontera tiene como objetivo el gobierno de la movilidad, donde "detectores y efectores” operan. [...] Prácticas que extienden el funcionamiento de la frontera más allá del territorio Schengen, indicando la así llamada extraterritorialización del control migratorio ${ }^{57}$.

Del mismo modo que la cooperación con las autoridades marroquíes ha supuesto un aumento de la efectividad de las construcciones fronterizas en Ceuta y Melilla, la cooperación con terceros países, con agentes públicos pero también con instituciones no gubernamentales -la Cruz y Media Luna Roja- ha permitido generar un nodo de gran relevancia fuera de sus límites territoriales. La excepcionalidad de Guantanamito no sólo la rigen las condiciones espaciales ocurridas en su interior que, a todas luces, serían denunciadas de producirse en territorio español. Viene también definida por cómo un gobierno es capaz de instalar un recinto autónomo en un territorio no soberano, y operar desde él a efectos prácticos como un nodo más dentro de la infraestructura territorial.
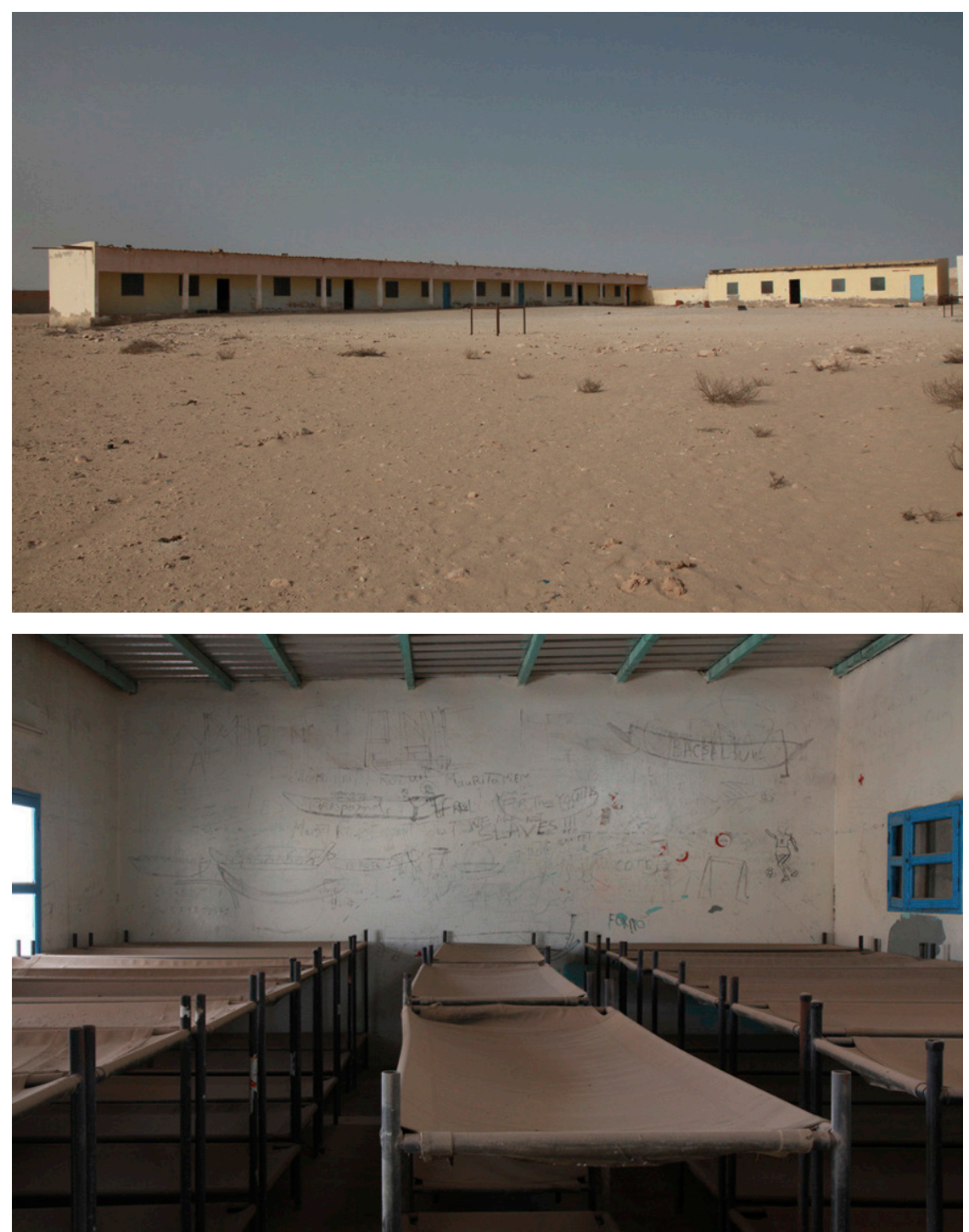


\subsubsection{ARQUITECTÓNICAS CAPILARIZADAS}

Las deportaciones exprés ejecutadas, con el giro gerencial de la frontera española producido en la última década a raíz de la Gran Recesión ${ }^{58}$, han visibilizado la capilarización de esta infraestructura, que no se localiza exclusivamente en los nodos materializados por los CIE sino que presenta una infinidad de nodos menores que funcionan como arquitectónicas del internamiento. Los calabozos policiales, no ya como la extensión a la que nos remitía la primera arquitectura de los CIE sino como hecho arquitectónico y programático. Frente a una red fuertemente centralizada, el dispositivo frontera teje una red con unas jerarquías mucho más débiles, con capacidad de manifestación absoluta en el territorio ya que sólo requiere una comisaría del Cuerpo Nacional de Policía para que, a efectos prácticos, sus dependencias sean capturadas por el dispositivo frontera. Esto incrementa la eficacia de un sistema de internamiento que no requiere los gastos de manutención ni derivados de su construcción en comparación a los de un CIE. Junto a la capilaridad operativa, presenta además una característica fundamental que se alinea con los mecanismos arquitectónicos contemporáneos del dispositivo frontera: la performatividad arquitectónica. Los espacios no tienen una función unívoca, sino que se activan en función de la demanda de internamiento de cuerpos. Durante las 72 horas máximas de retención, en una misma dependencia policial conviven dos regímenes de internamiento que responden a demandas muy diferentes: el calabozo y el internamiento de migrantes pendientes de expulsión.

Esta red está formada por un conjunto mucho mayor de nodos latentes en todo el territorio que no se focalizan únicamente en aquellas zonas con mayor demanda de internamiento -el Sur, Madrid y Barcelona-. A través de su activación, se genera una red de jerarquías débiles que, apoyadas en los protocolos orientados a mejorar la eficiencia del dispositivo frontera -el giro gerencial-, logran redistribuir la importancia de cada uno de las arquitectónicas del internamiento que la forman, haciendo que un espacio de apenas una veintena de metros cuadrados tenga la misma relevancia, en un momento dado, que una construcción como el CIE de Aluche o Barcelona a la hora de garantizar la deportación efectiva de migrantes.

Sin embargo, los calabozos no son la única manifestación de esta red de espacios latentes que actúan como vehículos o sustitutos dentro del esquema de deportación. Las salas de rechazados, o inadmitidos, en aeropuerto suponen también otra serie de dependencias que es necesario ligar al dispositivo frontera. Ellas replican el mismo esquema de funcionamiento como reguladoras de flujo que los CIE, pero incluyendo además los migrantes que acceden a territorio español por avión y cuya entrada es denegada. Aquí pueden llegar a ser retenidas durante un plazo indefinido -muy superior a las 72 horas en algunos casos concretos- migrantes que no cumplan los requisitos establecidos por los agentes para su acceso a territorio español. De nuevo, se produce una situación infrapenitenciaria, pues a nivel arquitectónico el internamiento no presenta los estándares exigidos, en este caso a un CIE o prisión, espacios sin iluminación o ventilación natural, sin posibilidad de acceder a zonas exteriores son algunas de las características señaladas tanto por migrantes allí retenidos como por la Defensora del Pueblo ${ }^{59}$. Los aeropuertos no funcionan únicamente como un filtro de acceso para prevenir migración que no cumpla los estándares exigidos

58 Fernández Bessa y Brandáriz García. "Transformaciones De La Penalidad Migratoria En El Contexto De La Crisis Económica.” InDret.Revista Para El Análisis Del Derecho, (2016), 1:25.

59 Laura Galup, “Salas de inadmitidos de Barajas: viajeros retenidos durante días sin sus enseres personales",

Eldiario.es, 9 de mayo de 2015 . 
de permanencia en el territorio, sino que es el cuello de botella, el último espacio arquitectónico antes de producirse la deportación efectiva. Allí, migrantes llegados a través de diferentes mecanismos de deportación y procedencia de todo el Estado confluyen en un mismo espacio, una dependencia del aeropuerto que funciona como el penúltimo espacio de internamiento temporal.

La Ruta contra'l racismu y la represión elaboró una serie de crónicas acerca de los vuelos de deportación y así describen la cristalización efectiva de esta red capilar presente en todo el Estado:

Víctimas de esta persecución planificada, fueron detenidos -en las 72 horas previas a la salida del avión- dos inmigrantes senegaleses residentes en Asturies. A uno de ellos -que la semana anterior había presentado la solicitud de permiso de residencia y trabajo por arraigo social- le convocaron en las oficinas de la Brigada Policial de Extranjería de Oviedo porque «había unos datos que aclarar». De allí fue llevado a los calabozos, donde fue retenido durante dos noches. (...) Los dos detenidos fueron llevados a Madrid por una escolta policial. Cuando llegaron a Barajas comprobaron la magnitud de la operación. Decenas de compatriotas esperaban allí, retenidos por la fuerza en una sala del aeropuerto. Una veintena aproximadamente procedía del cie de Aluche; otros habían sido trasladados desde el cie de Zona Franca (Barcelona) y de Zapadores (Valencia). Sin embargo, también había otros casos de inmigrantes detenidos en los últimos días, y que por tanto venían directamente de los calabozos. Serigne relata desde Dakar que uno de sus compañeros fue detenido en Valencia por la calle, junto a su casa, mientras caminaba a comprar el pan. Mbacke nos cuenta su propio drama: fue capturado, justo después de haber enviado dinero a su madre desde el locutorio, cuando salía, en bicicleta, camino de su trabajo de recolección de pepinos y pimientos en El Ejido. Otros senegaleses fueron detenidos en Málaga, Zaragoza, Alicante, Mallorca, Almería, Salou... Hay más casos similares al de Asturies- de personas deportadas que llegaron a presentar su solicitud de residencia ${ }^{60}$.

Ni en Asturias, El Ejido, Zaragoza, Alicante, Mallorca o Salou existen centros de internamiento. Sin embargo, esto no excluye la capacidad del dispositivo frontera para operar en ellos. Se vale de agentes no arquitectónicos y arquitecturas que no son autónomas, al igual que las dependencias policiales dentro del aeropuerto, que son capturadas para producir espacios vinculados a las lógicas de la frontera. Junto a ellos, debemos incluir en nuestra cartografía nodos incluso menores: los vehículos donde son trasladados, las estancias intermedias y toda la red externalizada que asegura el funcionamiento eficaz de cada uno de ellos. Una amalgama de agentes humanos y no-humanos, protocolos, arquitecturas y acciones cuyo carácter no posee la excepcionalidad vinculada a las arquitectónicas del internamiento, pero que sin embargo replica sus mismas lógicas. Este hecho difumina hasta hacer prácticamente invisible la línea que separa las arquitecturas y agentes cotidianos de aquellos excepcionales donde opera la frontera, y esto se debe a la performatividad que poseen estas construcciones arquitectónicas, que ya no están localizadas en un único punto del territorio sino que se activan en el momento preciso que el dispositivo frontera lo demanda.

60 Campaña Estatal por el Cierre de los CIE. «Paremos Los Vuelos.» Las Deportaciones De Inmigrantes y El Boicot a Air Europa», (Oviedo: Cambalache, 2014), 9. aremos Los Vuelos.»6. los CIEmigrantes a quienes se ficacies s lity (Londres: Zone Books, imiento 9. «de mayo de 2015. io.es, los CIEmigrantes a quienes se ficacies s lity (Londres: Zone Books, imiento 


\subsubsection{LOS VUELOS DE DEPORTACIÓN. EL AVIÓN COMO ARQUITECTONICA DEL INTERNAMIENTO}

Migrantes procedentes de CIEs, calabozos, comisarías policiales y salas de rechazados en aeropuertos se agrupan en una única ruta de salida forzosa del país: el avión ${ }^{61}$. El escenario arquitectónico que materializa el final del ciclo migratorio se reduce al fuselaje de un avión de línea comercial. Sin embargo, los mecanismos aplicados sobre los cuerpos para asegurar el control sobre ellos, así como el alto grado de violencia que se puede desplegar en el interior de este espacio, hace que diste mucho del interior de cualquier vuelo regular pese a que compartan espacio físico. Espacios donde los viajes de ocio y trabajo coinciden, apenas separadas por unas filas de asientos, con lugares de excepción donde la sedación forzosa, el uso de fuerza policial, instrumentos de inmovilización, e incluso la muerte tienen lugar.

Esta práctica se remonta, como primer caso que salió a la luz pública en el contexto español, al 22 de junio de $1996^{62}$. El ministerio del Interior del recién conformado ejecutivo del PP decidió, fletar cinco aviones militares con "cincuenta y dos agentes de las fuerzas especiales de la Unidad Policial de Intervención de Granada y Málaga y seis inspectores de la Brigada de Documentación y Extranjería [...] para escoltar hasta Mali, Camerún, y Senegal a los I03 inmigrantes expulsados de Melilla" ${ }^{3}$. Más allá de este hecho, lo relevante del caso es que a los migrantes "se les droga con haloperidol para anular su voluntad, se les maniata con bridas de plástico y se les vendan los ojos". La sedación forzosa, la inmovilización, y la anulación de la vista, o el uso de mordazas junto con la proporción entre agentes y sujetos deportados son características espaciales que serán, desde entonces, empleadas habitualmente para asegurar la eficacia del vuelo. La muerte de Osamuyi Aikpitanyi en 2007, producida en el interior de un vuelo comercial a consecuencia de las condiciones espaciales sufridas, atestigua el alto grado de violencia que se produce. La mordaza, inmovilización del cuerpo y alto grado de estrés provocó en Aikpitanyi:

Un aumento de catecolaminas, neurotransmisores relacionados con el estrés, el miedo, el pánico y el instinto de huida. A ello se añadió, según los expertos, un déficit de oxígeno debido a la altura a la que volaba el avión, y en lo que también pudo influir la mordaza (cinta adhesiva) que el fallecido llevaba en la boca y que había sido colocada por los agentes.

El caso de Austin Johnson en 2012, también nigeriano evidencia cómo a la violencia por inmovilización y amordazamiento se superpone la violencia física ejercida por los propios agentes que custodian a los migrantes. De acuerdo a la denuncia presentada en el juzgado de Valencia, a consecuencia de la deportación Austin tuvo que ser inmediatamente hospitalizado a consecuencia de las "agresiones directas con medios contundentes", que le causaron múltiples hematomas, molestias generales en todo el cuerpo y dificultad de movimientos cervicales. Junto a estos casos, los numerosos documentos audiovisuales

61 Las deportaciones forzosas también se producen, de manera muy minoritaria, a través de barcos o autobuses.

62 Sin embargo, Miguel Ángel Rodriguez, secretario de Estado de Comunicación durante el conflicto que produjo este vuelo declaró que el gobierno "no ha hecho nada especial que no se viniera haciendo antes”. Con lo cual, se deduce que ya era una práctica corriente en el momento de los hechos.

Jesús Duva, "Interior admite que los policías drogaron a los 103 inmigrantes y abre una investigación”. El Pais

63 Campaña Estatal por el Cierre de los CIE. «Paremos Los Vuelos », (Cambalache, 2014), I3. aremos Los Vuelos.»6.
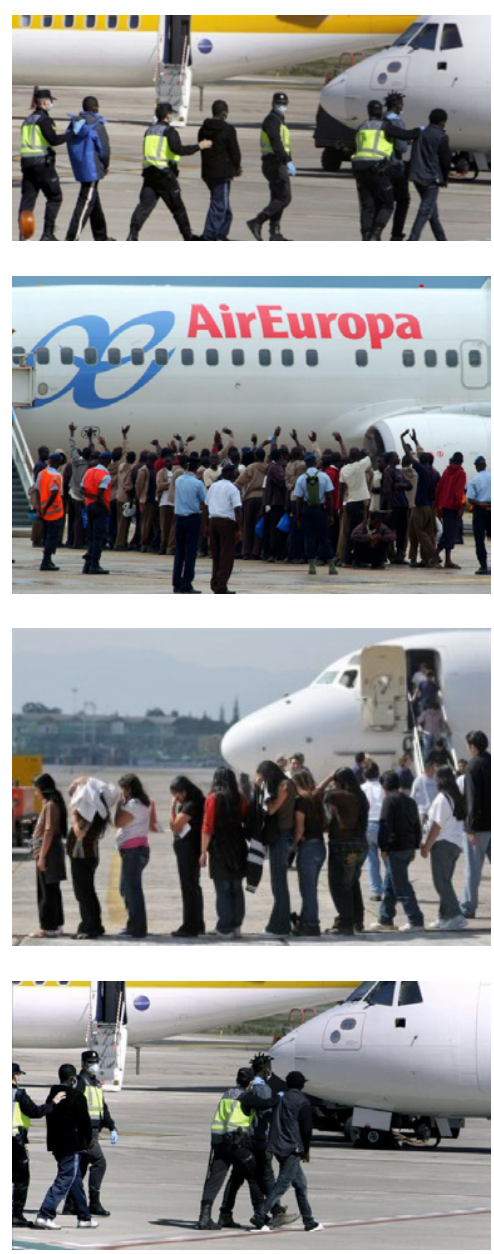

Vuelos de deportación en el Aeropuerto Adolfo Suárez-Barajas (Madrid). 

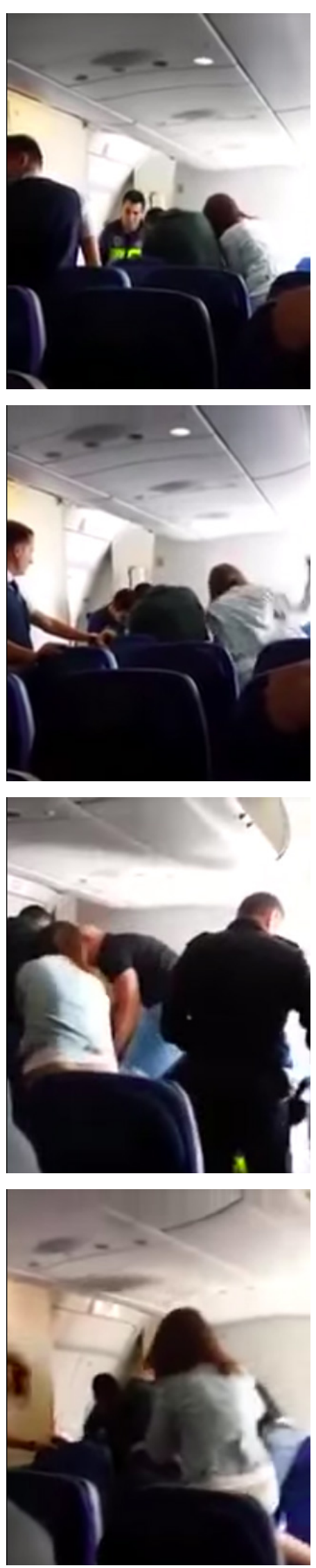

Grabación de una agresión a un migrante dominicano durante la deportación en un vuelo comercial (Youtube; Madrid, 2015). que recogen prácticas recurrentes, algunos de ellos tan llamativos como la intervención de unidades de antidisturbios dentro de un vuelo comercial antes de su despegue. Todas estas prácticas no guardan demasiada diferencia a las denunciadas que ocurrían en el interior de los CIE y que ejemplifican el carácter excepcional que marca las arquitectónicas del internamiento y, en general, las lógicas de la frontera contemporánea.

Las deportaciones forzosas se realizan en la actualidad a través de convenios con aerolíneas comerciales. Air Europa, Barceló Viajes, Spanair o Air Maroc son algunas de las empresas que, con financiación pública se encargan de fletar vuelos a diferentes países. Podemos señalar dos tipos de deportaciones con diferencias significativas, tanto por la configuración espacial del propio vuelo como por las consecuencias que esto tiene a la hora de gestionar el flujo de migrantes que deben ser deportados. Cuando el número de sujetos a deportar es bajo, se realiza una deportación dentro de un vuelo comercial, donde se reservan un número de asientos igual a tantas deportaciones se vayan a efectuar más dos asientos, que ocupará cada policía, que custodie a cada uno de estos sujetos. Esto, implica que convivan en el mismo escenario, a ojos de un viajero, sea un vuelo comercial al uso, mientras que a ojos de un migrante deportado siga siendo una arquitectónica del internamiento, ya no materializada por elementos arquitectónicos sino por una serie de mecanismos que impidan su capacidad de movimiento dentro del fuselaje del avión e incluso del propio asiento. Sin embargo, esta situación es capaz de provocar la resistencia o rechazo del resto del pasaje, llegando a provocar la cancelación del vuelo y la visibilización pública de unas prácticas que distan de los estándares requeridos, así como permiten visibilizar las fisuras y el paralaje entre el discurso político y la práctica operativa respecto al tratamiento del internamiento. Sin embargo, resulta más eficaz tanto a nivel económico como por evitar resistencias o testimonios públicos de los vuelos el empleo de vuelos comerciales exclusivamente destinados a la deportación. Los así conocidos como macrovuelos de deportación supusieron, sólo en 2013, más de dos millones y medios de euros por nueve vuelos organizados desde España a diferentes países donde participó no sólo el gobierno español, sino más de una decena de países europeo; cifras que nos permiten contextualizar la magnitud de este dispositivo territorial y las condiciones espaciales en las que éstos se producen. Una práctica que nos devuelve a la realidad europea donde se inserta nuestro caso de estudio, pero que supone una difuminación clara entre la línea que marca la gestión pública y privada de la frontera, y que además evidencia cómo el dispositivo frontera es capaz de apropiarse y dotar de capacidad de acción tanto a agentes públicos como privados.

Estamos ante una característica que vuelve a evidenciar la performatividad de los espacios arquitectónicos a través de la frontera. El avión, por tanto, no requiere más que de la presencia de un cuerpo migrante -custodiado y controlado- para que sea capaz de transformarse en un espacio de excepción absoluta donde no rija ninguna de las normas de seguridad exigidas sino que pueda llegar incluso a producirse la muerte de este cuerpo. Un espacio, con una función previa clara y definida -el vuelo comercial- que puede sustituirse por otra función en su totalidad -en el caso de los macrovuelo- o que puede incluso limitarse a apenas una fila de asientos. Frente a las arquitectónicas del internamiento, sólidas y que gestionaban el control de los cuerpos en un número muy elevado - decenas o centenas de internos- las nuevas tecnologías de la frontera efectúan un control altamente individualizado de los mismos, llegando a ser, en este caso uno a uno. Esta individualización, además evidencia cómo son las acciones del cuerpo migrante, la resistencia que oponga a su deportación -es decir al espacio arquitectónico construido a través del fuselaje del avión, el asiento, los agentes policiales así como los métodos de control empleados por éstos- la que medie y detone el grado de violencia espacial que será sufrido por ese cuerpo. 


\subsection{EN EL INTERIOR DEL CIE MOTINES, HUIDA Y MATERIA ARQUITECTÓNICA}

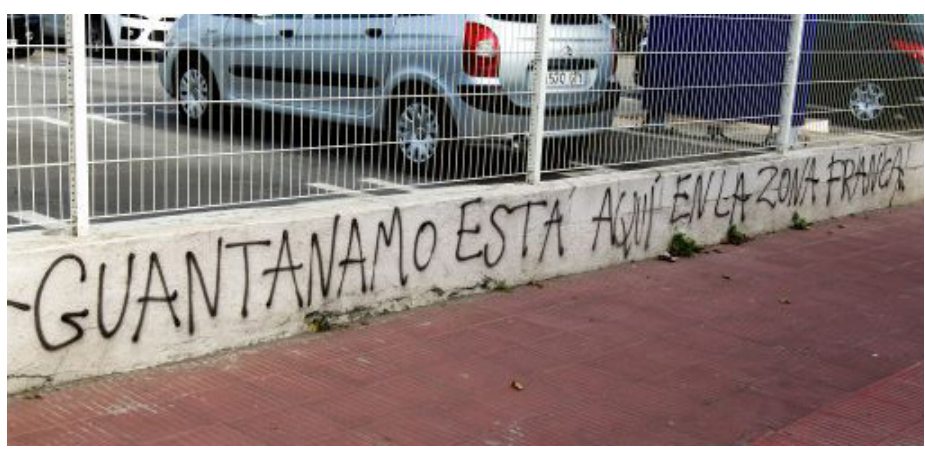

Una pintada hecha con spray sobre el hormigón en la puerta del CIE de Barcelona, junto con otra similar en los alrededores del CIE de Málaga nos advierten de las condiciones internas que uno puede encontrarse tras cruzar -como migrante- el umbral del CIE. La primera reza: "Guantánamo está aquî" ${ }^{64}$, mientras que la segunda simplemente indica "Centro de Exterminación" ${ }^{65}$. Estas dos declaraciones pintadas sobre el telón urbano nos permiten la primera aproximación al interior de una construcción absolutamente opaca, donde la visibilización de las condiciones exteriores ha requerido de acciones concretas que lograron arrojar luz al interior de una arquitectura opaca en todos los sentidos. A través de tácticas arquitectónicas menores, de una manipulación directa de la materia, muros y superficies que conforman los diferentes CIEs podemos hacer un recorrido no sólo por las -ya mencionadas- condiciones infrapenitenciarias a las que se exponen los internos sino también a las agencias espaciales que estos crean para revertir o denunciar su situación. Este recorrido presenta diferentes grados de destrucción operativa sobre la materia que conforman las arquitectónicas del internamiento, acciones que invierten la violencia espacial de cuerpos a arquitectura-en el binomio planteado por Tschumi- para, a través de ella, subvertir también sus condiciones espaciales. Desde su manipulación superficial hasta su destrucción parcial o total, operaciones realizadas directamente sobre los muros que de una forma u otra logran atravesarlo y, con cada acción, hacer visible la oscuridad normativa y arquitectónica del interior de los CIE.

La primera serie de operaciones arquitectónicas arrojan luz a través de la superposición de nuevos significados sobre las superficies de los CIE, o que los rodean. Las pintadas mencionadas, de una manera totalmente gráficam lograban asociar a edificios silenciosos y anodinos dentro del espacio urbano con ejemplos históricos de la excepcionalidad; destacando del tejido edificatorio la relevancia de unos muros tras los cuales se encierran prácticas y cuerpos excepcionales. Esta misma práctica, de escritura sobre las superficies es detectada también en el interior de algunas de estas arquitecturas; sin embargo, una misma operación de transformación arquitectónica cobra significados completamente diferentes.

64 Jesús García, "La Muerte De Un Guineano Evidencia Las Carencias Del CIE De Barcelona”, El País, 2018.

65 La Opinión de Málaga, "Suspenden La Expulsión de testigos en la muerte del interno en la cárcel”. La Opinión de Málaga, 2018. 

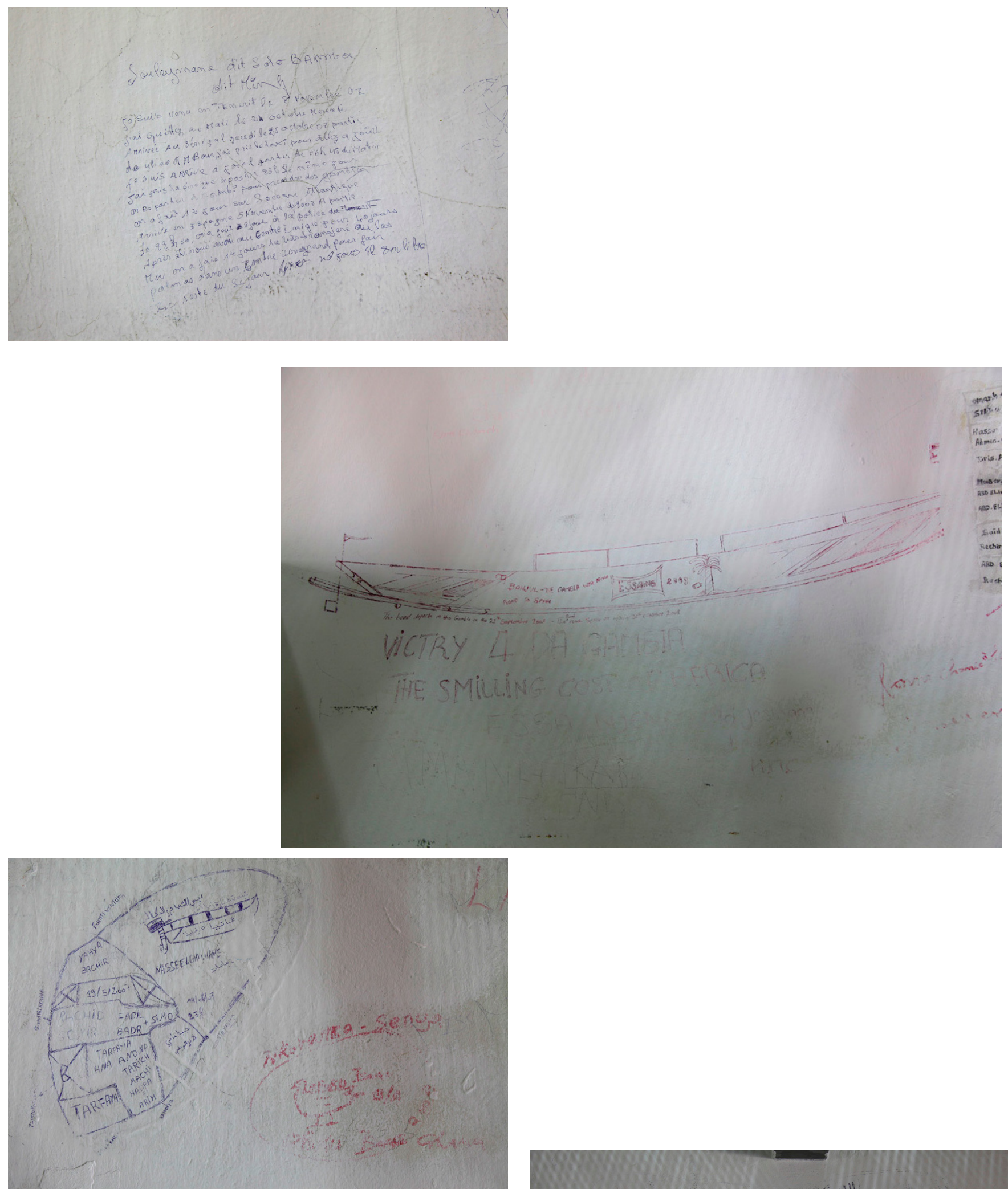

Dibujos en los paramentos verticales del CIE de Fuer-

teventura (Patricia Gómez y

Maria Jesús González; Fuerteventura, 2014-2016).

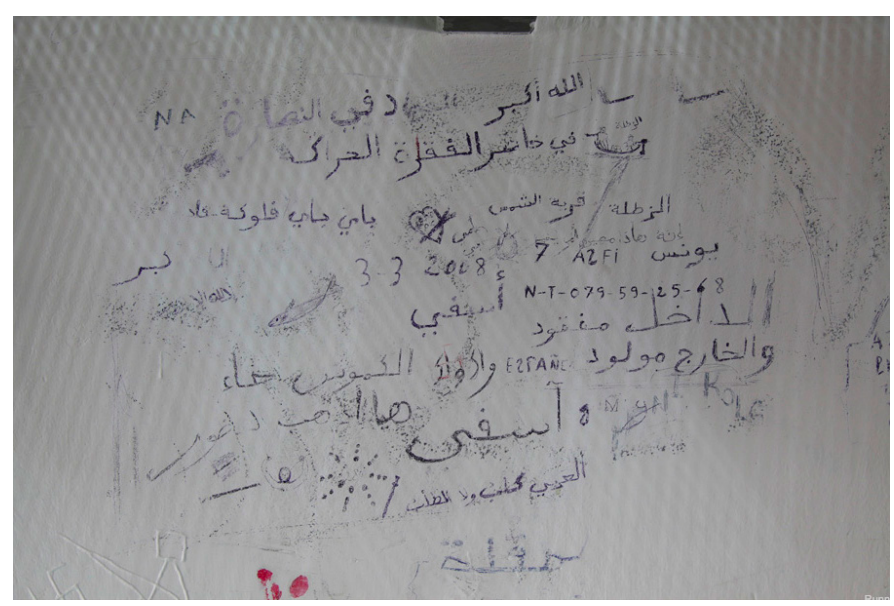


Las paredes del CIE de Fuerteventura, ya en desuso, atesoran sobre su superficie blanca una cartografía colectiva de afectos, deseos y miedos construidos por los centenares de migrantes que, a su llegada en cayuco o patera a las Islas Canarias, eran retenidos allí antes de ser redirigidos por los canales habituales. Patricia Gómez y María Jesús González, en su proyecto Please don't paint the wall ${ }^{66}$ documentan más de seiscientas anotaciones hechas con lápiz o bolígrafo sobre la pintura blanca de los barracones. En ellas se superponen dibujos de cayucos, plegarias religiosas -"Que Dios nos libre de las cárceles de España"- y no religiosas -"Buena suerte a todos los clandestinos"-, nombres y lugares de procedencia, retratos, rutas de viajes - "El barco partió de Gambia el 21 de septiembre de 2008- El barco llegó a España el lunes 30 de octubre de 2008”- calendarios con los días tachados, pero también anotaciones con carácter operativo:

Si la policía española te detiene solo y no acompañado con un grupo de marroquíes y el tribunal ha sentenciado tu expulsión, pero no han encontrado contigo un pasaporte ni otro documento que acredite tu nacionalidad marroquí, tienes la solución: cuando te devuelve la policía a Marruecos, tienes que negar totalmente que eres marroquí y tienes que decir que eres de nacionalidad mauritana. Aunque te pegue la policía marroquí de la frontera con Melilla tienes que negar rotundamente que eres marroquí, y de esta manera te van a devolver otra vez a la policía española, que te va a dejar libre, porque los marroquíes no aceptan a los mauritanos, diez días en la cárcel y ya estás fuera ${ }^{6}$.

Una de las pocas imágenes que se tiene del CIE de Aluche muestra el punto de acceso desde el interior de una de las habitaciones. En la fotografía, tanto la pared como la puerta y la litera están conformadas por un mismo material metálico y lacados en el mismo tono de azul corporativo. Sin embargo este detalle constructivo se nos presenta como una acumulación de múltiples estratos temporales y materiales. Una yuxtaposición de sucesivas capas de pintura azul rascadas hasta conformar una constelación de nombres y lugares. Marruecos, Mali, Pakistan,
Dibujos en los paramentos verticales del CIE de Aluche (Imágenes cedidas a Eldiario. es; Madrid, 2016).

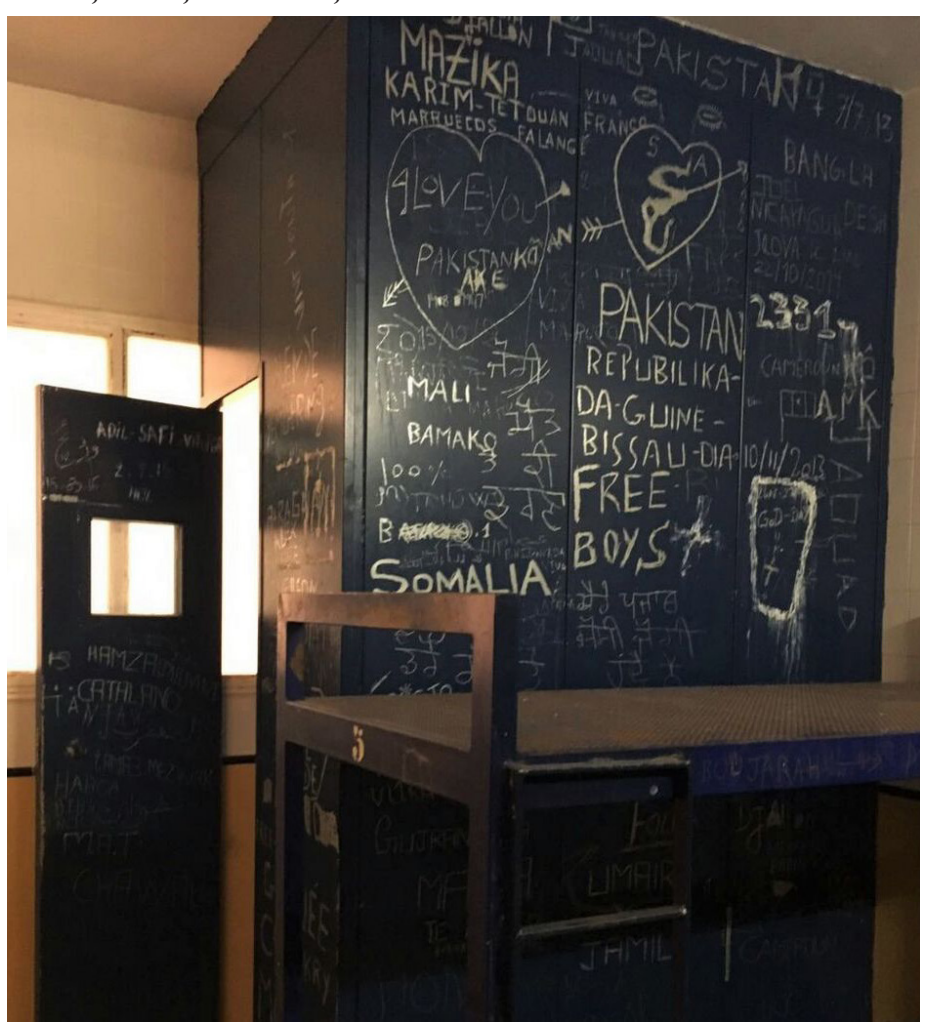

66 Patricia Gómez y María Jesús González, Please don't paint the wall 2014-2016 (Serie fotográfica documental, 2016).

67 Patricia Gómez y María Jesús González, Please don't paint the wall 2014-2016 (Serie fotográfica documental, 2016). 
Guinea Bissau, Somalia, Camerún junto con múltiples fechas y nombres propios transforman la homogeneidad del pigmento corporativo del Ministerio del Interior -el mismo del que están lacadas las chapas de acero galvanizado que cubren las ventanas- para hacer emerger una nueva cartografía que funciona igual que en Fuerteventura: conectando diferentes tiempos, espacios y lugares, resignificando una celda anónima en un lugar habitado por diferentes cuerpos a lo largo del tiempo. La única diferencia, las condiciones materiales de la construcción que obligan a alterar la táctica para alcanzar un mismo resultado, mientras que la laca azul oscuro impide cualquier pintado sobre ella obligando a sustraer la materia superficial que la conforma, el blanco del encalado en Fuerteventura facilita que, simplemente con tinta, se puedan obtener resultados mucho más elaborados. Estas acciones funcionan en un sentido inverso a las pintadas realizadas en el exterior, desde un interior aislado logran conectar, a través de una única acción y una única superficie, múltiples exteriores dispersos. Logran transformar las paredes en un palimpsesto sobre el que se deposita información a través de la adición o sustracción de materia en ella que acumula información sobre los tiempos, cuerpos, deseos, afectos y lugares que han habitado ese espacio.

Dos acciones son efectuadas de manera simultánea en esta superficie, la primera el acto de dibujar o escribir como un acto rebelde de significación individual dentro de un cuerpo colectivo. Es decir, si el dispositivo de deportación y la frontera logran convertir en números y cuerpos despojando las historias de vida que hay detrás, el recuperar el nombre, la voz, el deseo y la procedencia logra reindividualizar aquello que había sido forzado a desaparecer o comportarse de manera homogénea y colectiva dentro de los engranajes de las arquitecturas de la deportación. Y, durante esta acción, tanto la superficie como el cuerpo que la inscribe adquieren un mayor potencial político al enfrentarse deliberadamente a las discontinuidades espaciales ejercidas por el poder y reconstruir un nuevo espacio común, virtual y disperso, a través de las inscripciones en la pared. Así, a través de una reinterpretación libre por parte del lector que aprehende las superficie intervenida de su encierro se logra "liberar la memoria material de la propia celda" ${ }^{68}$. Unas inscripciones que reconectan, en primer lugar, a cada interno con las comunidades a las que pertenecen y, en segundo lugar que conecta a los internos entre sí, que han habitado un mismo espacio en diferentes tiempos y sólo permanecen como evidencia en forma de rascazo en una pared. En esta acción es posible ampliar los afectos virtuales entre los internos de diferentes tiempos y procedencias, a través de la manipulación, transformación y destrucción operativa de la materia que lo forma. El poder de dibujar -rascar- una línea sobre la pared desnuda abre un nuevo espacio como afirma Jill Stoner "el acto de dibujar una línea a través de un objeto es politizado por la fuerza del dibujo. Esto proporciona una nueva agencia constructiva" ${ }^{69}$. Cuando la superficie es leída en vez de dibujada provoca un desplazamiento contrario haciendo que la suma de diferentes cuerpos que habitan -han habitado y habitarán- ese espacio devengan en un cuerpo colectivo. La acción de leer la yuxtaposición de localizaciones, fechas y nombres desterritorializa una superficie ordinaria para, en su lugar, emerger no sólo un registro emocional o censo de los cuerpos encerrados, sino para crear afectos comunes entre ellos, sin importar la distancia geográfica o temporal que los separe. Tal vez esta manipulación superficial sea la que requiera una mayor complejidad en tanto que sólo puede ser conformada a través de una acción colectiva: una secuencia de adición y sustracción repetitiva de materia, significados e historias de vida que son material e inmaterialmente acumuladas sobre el muro original. Una superficie que, sin atravesar el muro opaco del CIE, es capaz de difuminar interior y exterior a través del depositar capas de memorias en él. 
La segunda serie de operaciones arquitectónicas implica la destrucción material del muro y de los elementos que lo forman que permitan la aparición de poros y fisuras en él, que lo atraviesen y socaven su rotundidad para alcanzar el exterior de manera corporal -en el caso de las fugas-o mediática -en el caso de motines. En el caso de las fugas es paradigmático el caso del CIE de la Verneda (Barcelona) pues pone de relevancia la importancia material del propio muro, su configuración interna, para posibilitar o imposibilitar ciertas prácticas; en esta ocasión el mal estado de las instalaciones -en concreto de las puertas- hizo que fuese sencillo romperlas y escapar al exterior ${ }^{70}$. Así, la anulación -no del muro- sino de las fisuras y puntos débiles que aparecen en él, su lectura y consecuente destrucción operativa permiten reorganizar las funciones, durante unos instante, las funciones y diseños que encarnan. No obstante, la complejidad y estado constructivo de los nuevos centros de internamiento hace que los mecanismos para alcanzar ese exterior de manera corporal o mediática sean más complejos. La sábana, un elemento auxiliar y de aparente fragilidad ha sido la facilitadora de diversas tácticas menores para alcanzar el exterior de diferentes maneras. La primera, como articuladora de una fuga: su ensamblaje con varios nudos, contrapesos y un mueble al que ser atada hizo que diez internos fuesen capaces de escapar. Una táctica que no sólo requirió del empleo de material sino también de un conocimiento de los espacios, tiempos y agentes involucrados en las rutinas del centro de internamiento:

Los internos aprovecharon un descanso tras el recuento matutino, cuando se estaba dando el desayuno, para descolgarse con las sábanas previamente enrolladas y con una botella de agua en el borde para hacer de contrapeso. Una vez en el patio, han saltado la valla perimetral para llegar al a calle y han huido a la carrera ${ }^{71}$.

No sólo la operación directa con el muro, sino con otros elementos, puede también alcanzar estos objetivos. El CIE de Aluche, y su fachada que ha sido cuidadosamente diseñada para impedir que cualquier observador exterior pueda ver qué ocurre en su interior con el cegado de todos los huecos con placas curvas de acero microperforado,permite entender estas tácticas arquitectónicas menores. En 2010 ${ }^{72}$, esta fachada completamente aséptica se transformó violentamente cuando, tras varias de las chapas comenzaron a salir el humo y las llamas procedentes del interior de las habitaciones interiores. Los colchones
Fuego en el interior de una de las celdas durante un motín (Santi Carneri; Madrid, 2010).

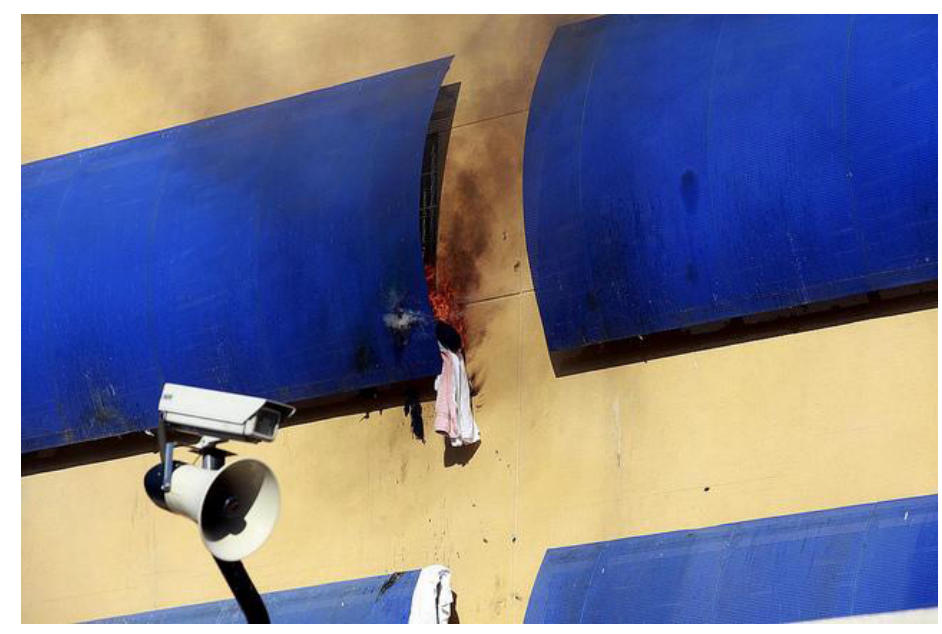

70 Adrián Foncillas, “23 inmigrantes que esperaban su expulsión se escapan de La Verneda por una puerta rota”, El País, 18 de mayo de 2005.

71 Europa Press, Diez internos del CIE de Aluche (Madrid) se fugan por una ventana), El Periódico, ro de septiembre de 2019.

72 Santiago Carneri, "Motín en el Centro de Inmigrantes de Aluche”, La Razón, 28 de noviembre de 2010 . 


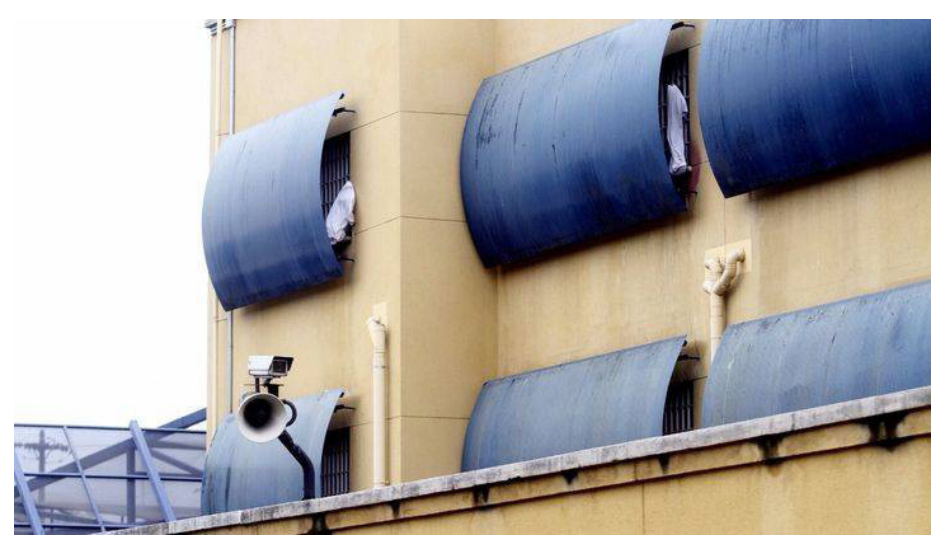

Sábanas blancas extendidas en el exterior durante un motín en el CIE de Aluche (Madrid)
Internos en la azotea del CIE de Aluche durante un motín (El Confidencial; Madrid, 2016)

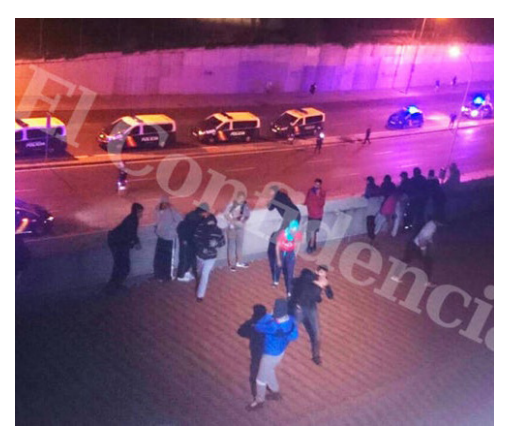

quemados, el mobiliario incendiado y los cristales rotos habían conseguido atravesar las diferentes capas materiales del muro para alcanzar la esfera pública y los migrantes, a través de una destrucción operativa lograron alterar su invisibilidad consiguiendo centrar los focos en su protesta y, por tanto, alterar su condición. Con menor intensidad, pero de forma mucho más constante a lo largo de los años estas protestas también han salido al exterior del CIE usando las sábanas blancas como elemento de conexión entre un interior y un exterior: simplemente su descuelgue desde una ventana abierta o rota logra señalar que, detrás de la chapa opaca, está ocurriendo algo. Aunque Herman Melville afirmase que sólo se puede alcanzar el exterior a través del muro, aquí no es necesario. No se necesitan los cuerpos físicamente en el exterior del CIE para que se sepa lo que ocurre en su interior ya que es una pieza de tela colgando en el exterior de la fachada o las partículas en suspensión tras un incendio que, convertidas en humo, salen por los poros de la misma los que conforman un ensamblaje o cuerpo post-humano y con él la presencia de los migrantes recluidos que, operando con la materia logran visibilizarse.

En otras ocasiones son los propios cuerpos los que, sin salir del CIE, ocupan espacios que sí son visibles desde el exterior. Es el caso de los sucesivos motines en Aluche donde, simplemente rompiendo los candados, desbloqueando las puertas de acceso lograban ocupar un espacio no previsto: las azoteas ${ }^{73}$. De nuevo una presencia extraña, en este caso plenamente humana, es la que altera el paisaje homogéneo que se aprecia desde el exterior del CIE. Durante horas, los cuerpos son capaces de atraer presencia de todo tipo al entorno: policial, mediática, activista y ciudadana que pone en el foco su situación. Subvierten el uso y prohibiciones de los elementos arquitectónicos para llegar hasta ahí, rompiendo las puertas bloqueadas y convirtiendo en un lugar accesible lo que antes no lo era; y, con esta acción resignifican el espacio momentáneamente. De nuevo las sábanas, convertidas antes en soga y fuego, aparecen en estas construcciones espaciales, esta vez en forma de lienzo. En la revuelta de 2016, donde treinta y

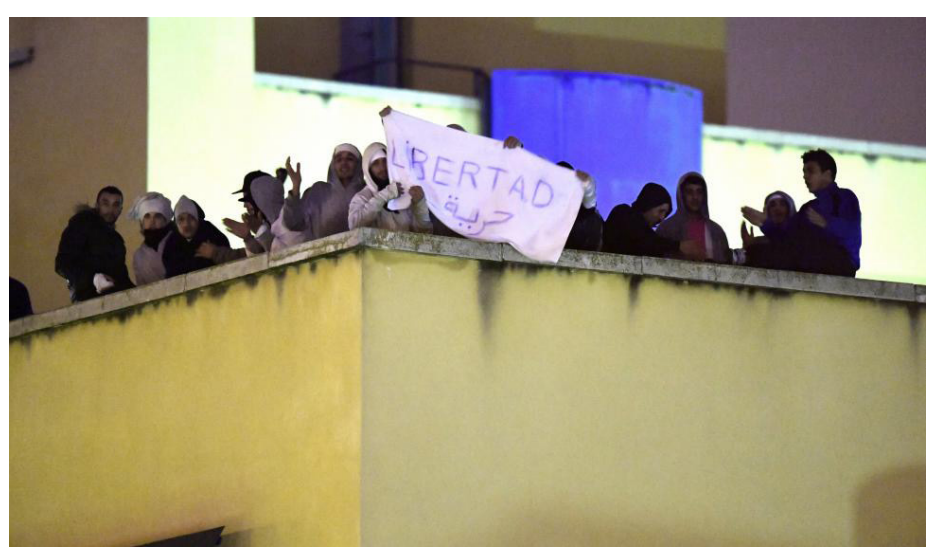


nueve migrantes argelinos ocuparon este espacio, emplearon estas tácticas como amplificadores de lo que allí ocurría desplegando pancartas ensambladas con el material de las propias habitaciones mostrando "libertad" y "dignidad" sobre la tela blanca. Este caso nos muestra la posibilidad de apertura y subversión de las disposiciones específicas aunque sea de manera temporal, conectando y yendo más allá de los muros opacos del CIE a través de acciones efímeras, que duran tan solo una noche antes de ser sofocadas por los funcionarios del centro.

La sábana, desposeída ya de toda función, anudada, garabateada o incendiada cobra una nueva función previa destrucción de las funciones previas para las que, por diseño, había sido construida. Así la sábana se vuelve una materia sobre la que se depositan nuevas capas de información, que habilita posibilidades espaciales no previstas y que es capaz de permitir a los migrantes ir más allá de los confines de los centros de internamiento a través de manipulaciones creativas de la materia que tienen a su alrededor. Al igual que la sábana se convierte en un vehículo de un mensaje al ser enarbolada por migrantes en lo alto de la azotea del CIE de Aluche, el espesor ínfimo de papel de pared arrancado por Elvin en el CIE de Zapadores, que ya no es un paramento o revestimiento superficial sino un papel sobre el que trazar una cartografía del interior del centro, la materia cobra nuevos significados a través de una manipulación directa. Es esta materia, estas superficies alteradas y reorganizadas las que logran revertir la invisibilización de un interior arquitectónico.

Volvamos al punto de partida y observemos de nuevo estos materiales y superficies invisibilizadas. Prestemos atención al proceso violento, temporal y precario de conformación de cada una de ellas; conformados por tácticas menores que surgen del conflicto explícito, como un mecanismo de revertir la violencia espacial que encarna el propio centro de internamiento y que lo explicitan a través de una destrucción, parcial o total, de la forma previa de la materia así como de los significados asociados a ella. Estas acciones catalizan espacios de disputa a través de la intervención directa de la materialidad previa que los rodea; y que generan una nueva materia -y por tanto espacialidadque no está concebida para durar -lo justo hasta que el motín sea reprimido o la fuga se haya completado-. Y, que sin embargo contienen en su aparente in-significancia una agencia política y espacial de gran valor que cuestiona y visibiliza las condiciones espaciales existentes que de otro modo permanecen ocultas. Probablemente, el éxito de conformar estas superficie resida en la habilidad de leer la materia y el entorno que los rodea desde un punto de vista operativo; esto es, que la información ambiental no sólo pueda ser leída y asumida sino afectada y transformado. Sólo a través de este entendimiento de la carne arquitectónica desde una dimensión operativa y menor permitirá ser consciente de las posibilidades creativas y transformar una sábana en un sistema de fuga o un trozo de papel pintado en una precaria cartografía. 


La frontera se presenta aparentemente ante nosotros como una construcción estática, firme y rotunda que delimita con precisión la soberanía de un territorio, en nuestro caso la Unión Europea. Su materialidad, sus pliegues y edificaciones, su implantación a lo largo de una línea soberana o en función de cuestiones tecnológicas y logísticas -si atendemos al dispositivo de deportación- encarnan una ley que emana de la concepción misma de la Unión Europea. Su definición arquitectónica responde, sin lugar a dudas, a una voluntad regulada a través de múltiples normativas que la frontera -como entidad arquitectónica encarna-. La frontera encarna la ley, la materializa y la construye con rotundidad, al menos en apariencia. Pero ¿es únicamente esta voluntad suficiente para que un diseño arquitectónico sea capaz de recoger en su ínfimo espesor todas estas realidades?. La realidad nos demuestra lo contrario, los acontecimientos que se producen en estas construcciones evidencian una realidad espacial donde la frontera no se limita únicamente a las edificaciones estables sino que construcciones espaciales dinámicas y efímeras reemplazan o complementan las funciones de los muros y vallas. Es en estas construcciones operativas donde se desborda la capacidad de la arquitectura, es decir, donde el hecho construido no sólo resulta insuficiente sino ineficaz, y se requiere la participación de nuevos agentes aparentemente no arquitectónicos.

Las imágenes del acontecimiento del Tarajal muestran una masa de cuerpos en movimiento, constelaciones de puntos que a lo largo de la media hora de vídeo se desplazan a través del territorio, tanto en la costa como en el mar. El movimiento constante e interrelacionado entre unos policías que encarnan la frontera y los cuerpos de los migrantes que cruzan desde la costa marroquí a la española desdibujan la claridad de la línea geopolítica encarnada en la valla y las construcciones anexas a esta. El paso fronterizo, el espigón de bloques de hormigón, el vallado de acero galvanizado, las torres de vigilancia pasan a un segundo plano, absolutamente difuminado por las acciones que performan los cuerpos en su desplazamiento a través del espacio. No es la excepcionalidad del acontecimiento la que bascula el peso y las responsabilidades de la ley hacia los agentes de policía desplegados sobre la línea ni hacia los migrantes que intentan alcanzar sino simplemente que en dichos acontecimientos es más fácil vislumbrar una transformación en el modo en el que las leyes son encarnadas. Tanto el planteamiento microfísico del poder hecho por Foucault, la noción de dispositivo y el lawscape de Andreas Philippopoulos-Mihalopoulos coinciden en una cuestión: la autoridad -en este caso el ejercicio soberano de la frontera de Europa- no reside en una única construcción, sino en un aglomerado de agentes con capacidad de acción conjunta. En este dispositivo los cuerpos han adquirido una relevancia fundamental a la hora de ser capaces de movilizar con su presencia no autorizada o con sus acciones las disposiciones para intentar neutralizarlos. Y es el cuerpo migrante, aquel que no está autorizado a acceder a un espacio y que transgrede las normas que lo regulan con su mera presencia en él, aquel que de manera más clara evidencia la relevancia que han adquirido los cuerpos. Es una consecuencia lógica que, en tiempos de una soberanía líquida y escurridiza -formulada bajo el paraguas de la excepcionalidad y la operatividad- donde ya no es una protección entre Estados sino contra individuos concretos que tanto las leyes como las arquitecturas que las encarnan den paso a nuevas formulaciones espaciales.

Es este cuerpo, un cuerpo post-humano y ensamblado, el que ha catalizado las transformaciones fundamentales de la frontera en las últimas décadas. El cuerpo migrante -y aquí explotamos la ambivalencia de su formulación tanto individual como colectiva - que desde la escala i:I se dota de prótesis para escalar mejor la valla, flotar en el mar, protegerse de las agresiones policiales... a la escala geopolítica, al modificar las rutas y métodos de llegada a Europa, con sus acciones genera reacciones inmediatas en un dispositivo que a todos los niveles se orienta para
Arquitectura desbordada. Limitaciones del diseño y su ejecución

La relevancia del cuerpo en la construcción del espacio contemporáneo 


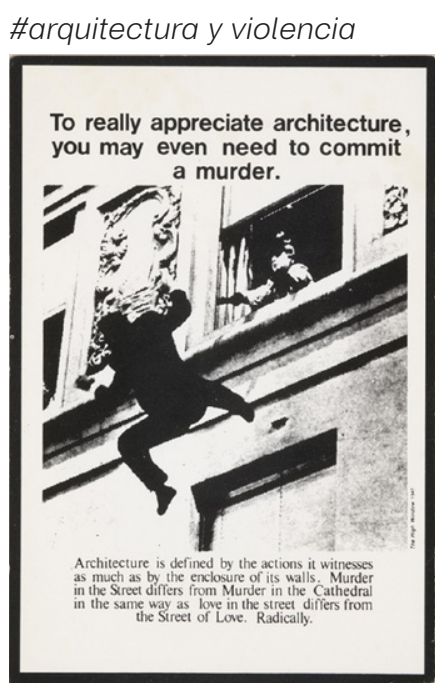

\#separación de la norma

\#exposición a la violencia espacial

La relevancia de la acción

\#territorialidades

\#espacio como lugar practicado intentar neutralizarlas. Y, precisamente es a través de ese conflicto donde apreciamos la verdadera configuración operativa de la frontera así como la naturaleza inherentemente violenta de la arquitectura.

Retomemos otro de los anuncios de Bernard Tschumi, en el que un texto reza: "para realmente apreciar la arquitectura tal vez necesites cometer un crimen"; a continuación la silueta de un hombre cayendo al vacío se proyecta contra un edificio mientras que una mujer, asomada a una ventana, lo acaba de tirar. Esto nos señala, en primera instancia hacia donde hemos de enfocar nuestros análisis para "realmente apreciar" el funcionamiento, magnitud y agentes involucrados en la producción arquitectónica de la frontera: no en los símbolos que con rotundidad y grandes partidas presupuestarias han sido erigidos. Y, en segundo lugar, cómo la violencia inherente a toda producción arquitectónica requiere acontecimientos extremos para ser más fácilmente detectable. Así pues, del mismo modo que no todas las personas que se acerquen al perímetro fronterizo ni todos los agentes involucrados tienen la misma capacidad de decisión, no todos los cuerpos son capaces de verse afectados por dicha violencia espacial. Léopold Lambert actualiza la afirmación hecha por Tschumi al considerar también que toda arquitectura es inherentemente violenta y añade que "la violencia que los cuerpos tienen que experimentar es proporcional a su grado de separación de la norma” ${ }^{2}$. Debemos puntualizar aquí que, lo que Lambert entiende por norma es a su vez -de acuerdo al modelo espacial ya explicado- un conjunto heterogéneo de restricciones, protocolos de acción, etc, en constante disputa o, dicho de otro modo, la orientación principal del dispositivo. Por tanto, el cuerpo migrante en cuanto se aleje de los estándares que regulan su inclusión dentro del flujo migratorio regular - en tanto que sea rentable como fuerza de trabajo, como capital intelectual o de acuerdo a los estándares de asilo y acogida- y decida, aún así, situarse en un espacio que políticamente le es negado, se expondrá a una mayor violencia espacial.

Si las leyes no son el resultado de una aplicación directa sobre el territorio sino una disputa que requiere que éstas se encarnen en cuerpos para hacerlas efectivas -del mismo modo que la valla deviene ley en su trazado a lo largo del perímetro fronterizo, los muros de los CIE, o los cuerpos de los policías dispuestos en la costa ceutí...- y son los cuerpos, sus acciones y conflictos los que accionan, reaccionan, movilizan y activan estas leyes y el espacio resultante de las mismas ¿podemos hablar con rotundidad de territorios o debemos buscar nuevas fórmulas espaciales que se adecuen a este planteamiento dinámico y rápidamente transformable? Frente al territorio de límites precisos debemos hablar de territorialidades, un espacio cuya extensión no está prefijada de antemano sino que es la capacidad de afección de los cuerpos y ensamblajes la que la define a cada instante. Como señala Miguel García Cortés, es preciso desde un planteamiento que bebe de una espacialidad queer y que por tanto se resiste a la categorización estática sino que la condiciona a las acciones producidas en él:

El espacio no es un mero escenario donde suceden las más diversas situaciones, sino un resultado constituido por la acción concreta y el discurso específico. El espacio, sea público o privado, es ante todo un lugar practicado que aparece -se constituye en la acción- con los individuos y sus movimientos, ellos lo dotan de significado, no sobrevive a ellos y desaparece con la dispersión de los protagonistas 3 .

1 Bernard Tschumi, Advertisements for Architecture, 1976.

2 Léopold Lambert, «The political», Colon III, (2015).

3 José Miguel García Cortés, Politicas del espacio: Arquitectura, género y control social (Barcelona: Actar, 2006), p.57. 
Es a través de las acciones de los cuerpos, la extensión de su capacidad de afección a la realidad que los rodea, cómo podemos entender la extensión de un territorio o una soberanía. La acción de los policías como extensión operativa de la valla fronteriza se extiende mucho más allá del trazado geopolítico definido por la ley. La frontera se extiende allá donde las prácticas excepcionales ligadas a esta sean capaces de desplegarse independientemente de su posición territorial y son los cuerpos -tanto los cuerpos policiales y burocráticos como los migrantes- los que llevan la frontera consigo. Al desplazar el modo en el que analizamos las construcciones espaciales, no en base a los recintos establecidos a priori, sino por el límite escurridizo y en constante cambio que generan los cuerpos y a donde estos lleguen, veremos el verdadero funcionamiento de la arquitectura y de un espacio que no es sólo construido sino fundamentalmente performado. Un espacio que sólo puede ser entendido "sin uso, amoral y sensual que sólo existe por y para la experiencia"4 -donde sensual ha de ser entendido como la capacidad de expandir la espacialidad propia a través de los afectos-. Se nos presenta, por tanto, un modo de entender el espacio que es contextual y no establecido de antemano, una forma de entender las construcciones arquitectónicas que no se pueden desligar de los eventos que ocurren en ella. Y, si esto ocurre con los contornos de cada construcción, lo mismo ocurre con las funciones asignadas a ellas y a cada cuerpo. Todo proceso de diseño arquitectónico requiere una cristalización, una ritualización del espacio que defina con precisión y anticipe cualquier posibilidad espacial, cualquier interacción entre los cuerpos, asignando a cada uno funciones -normas, leyes, protocolos, reglamentos, modos de acción...- y diseñando una jerarquía precisa entre las partes.

Sin embargo, al aproximarnos a la construcción del espacio desde las lógicas de los dispositivos y del lawscape encontramos que resulta imposible abordar la realidad desde planteamientos que no emanen desde la propia realidad material que los configura. $\mathrm{O}$, dicho de otro modo, estos planteamientos de diseño se ven desbordados por la autonomía material de cada agente involucrado, que posee sus propios deseos, su propios afectos y una espacialidad propia independiente de la asignada dentro del proyecto:

El ámbito material presenta una complejidad de relaciones que ningún sistema humano puede comprender completamente y, por consiguiente, constituye una barrera a la traslación literal del diagrama a lo arquitectónico. Lo que significa que en la práctica, todo sistema de poder, a través de su materialización, crea las formas de resistencia a ese poder gracias a la fricción garantizada en la traducción de lo abstracto a lo material. [...] la resistencia es producida oculta en los pliegues del mapa[...] Debemos usar lo arquitectónico contra lo arquitectónico5.

Esto puede manifestarse de infinidad de maneras, desde resistencias no contempladas en su fase inicial, situaciones insospechadas, a la propia composición de los cuerpos y ensamblajes, hasta elaborar en ella fisuras que pueden ser aprovechadas para desplegar tácticas arquitectónicas menores que permitan reorientar el dispositivo y, por tanto, la implicación y funciones de los agentes involucrados en él. Se hace especial hincapié en el plano material pues, al hablar de cuerpo con capacidad de agencia y resistencia, no lo hacemos enfocados al cuerpo humano, sino que cualquier objeto animado o inanimado entra dentro de esta categoría. Y este matiz tiene profundas implicaciones, al entender cómo el éxito o el fracaso, la alteración del dispositivo reside en objetos \#espacialidad queer

\#ritualización

\section{Autonomía material}

\#complejidad del ámbito material

\#arquitecturas menores

\footnotetext{
4 Aaron Betsky, Queer Space: Architecture and same sex desire (William and Morrow: Nueva York, 1997), p.7.

5 Léopold Lambert, The Funambulist Papers (Nueva York: Punctum Books, 2013), p.21.
} 
\#materia vibrante

Recintos frente a campos

\#espacio frontón

\#espacio esgrima

\#espacios y cuerpos no codificados inanimados, materia arquitectónica que facilita o impide ciertas prácticas por su propia configuración material. Como señala Jane Bennet estamos ante una materia vibrante que nos obliga a considerar los cuerpos desposeídos de toda jerarquía:

los cuerpos aumentan su poder en o como ensamblajes heterogéneos. Lo que sugiero para la capacidad de agencia es que la eficacia o efectividad con la que se ha referido tradicionalmente a este término está distribuida a través de un campo ontológico heterogéneo, más que una capacidad localizada en un cuerpo humano o en un cuerpo colectivo producido (sólo) por esfuerzos humanos $^{6}$.

Este agregado de cuerpos con su propia voluntad -tanto propia como compartida-, que escapa de todo principio de diseño para responder con su propio deseo, pudiendo ser este contradictorio, incoherente y en constante cambio, construye el espacio de un modo que sólo puede ser contextual. Frente al recinto delimitado de antemano con precisión sobre el plano, el contorno geopolítico trazado sobre el mapa, la normativa urbana especificada en la planificación, este espacio se construye en acciones y campos de intensidad variables, donde los contornos no son fácilmente dibujables pues los cuerpos en movimiento lo impiden. Federico Soriano ${ }^{7}$ contrapone dos formas de abordar el entendimiento del espacio en base a dos juegos, el frontón y el esgrima. En el primero, el campo de juego está definido con precisión, del mismo modo que las posiciones de los pelotaris que se sitúan en él y donde tan sólo la física de la bola rebotando contra los paramentos tiene un margen de acción. Frente a ello, el esgrima se configura únicamente en base a los movimientos de los dos espadachines y, concretamente, la punta de los floretes que empuña cada uno de ellos; todo, absolutamente todo el espacio es una coreografía entre ambos cuerpos para tocar al rival. No existe campo de juego sino un movimiento constante. Esta contraposición surgida desde la arquitectura tiene su correlato, también desde dos juegos de estrategia, en la lectura que hacen Deleuze y Guattari del ajedrez y el go, tremendamente ilustrativa para explicar cómo, frente a un espacio regido por jerarquías y posiciones estables donde cada agente reproduce sin cuestionarse su función, también es posible concebir un espacio donde sólo la posición de cada cuerpo y la relación con su entorno inmediato determina su capacidad de agencia:

Veamos, por ejemplo, el ajedrez y el go, desde el punto de vista de las piezas, de las relaciones entre las piezas y del espacio concernido. [...] Las piezas del ajedrez están codificadas, tienen una naturaleza interna o propiedad intrínsecas, de las que derivan sus movimientos, sus posiciones, sus enfrentamientos. Están cualificadas, el caballo siempre es un caballo, el alfil un alfil, el peón un peón. Cada una es como un sujeto de enunciado, dotado de un poder relativo; y esos poderes relativos se combinan en un sujeto de enunciación, el propio jugador de ajedrez o la forma de interioridad del juego. Los peones del go, por el contrario, son bolas, fichas, simples unidades aritméticas cuya única función es anónima, colectiva o de tercera persona: "El” avanza, puede ser un hombre, una mujer, una pulga o un elefante. Los peones del go son los elementos de un agenciamiento maquínico no subjetivado, sin propiedades intrínsecas , sino únicamente de situación. También las relaciones son muy diferentes en los dos casos. En su medio de interioridad, las piezas de ajedrez mantienen relaciones biunívocas entre sí, y con las del adversario: sus funciones son estructurales. Un peón del go, por el

6 Jane Bennet, Vibrant matter: a political ecology of things, (Durham: Duke University Press, 2010), 37.

7 Federico Soriano, Ioo Hipermínimos: Escritos de Arquitectura (Zaragoza: Lampreave Ediciones, 2009). 
contrario, sólo tiene un medio de exterioridad, o relaciones extrínsecas con nebulosas, constelaciones, según las cuales desempeña funciones de inserción o de situación, como bordear, rodear, romper. Un solo peón de go puede aniquilar sincrónicamente toda una constelación, mientras que una pieza de ajedrez no puede hacerlo (o sólo puede hacerlo diacrónicamente) ${ }^{8}$.

Es en esta constelación de piezas, agentes y formas activas donde los límites de los acontecimientos se definen por la interacción de los cuerpos y el alcance de sus afectos. El espacio y las construcciones, rígidas si se dibujan desde lógicas estáticas se vuelven dinámicas y volubles y, del mismo modo, las funciones asignadas a cada una de sus partes. Y el territorio se transforma en territorialidad; esto es, la extensión de las acciones de un grupo de cuerpos en él. Podemos, por tanto, definir estos despliegues espaciales como un campo, a caballo entre el campo -camp- estudiado por Agamben y el campo -field- enunciado por Stan Allen. Si el campo de Agamben se remite a la excepcionalidad como requisito indispensable para su conformación, Stan Allen sienta las bases en Field Conditions de una espacialidad no definida por objetos concretos sino por las relaciones dinámicas establecidas entre ellos. Y es, precisamente, esta condición dinámica la que dota de sentido al campo -siempre precario, siempre temporal, siempre fácilmente alterable-. Así, este campo se define en primer lugar "por los complejos y dinámicos comportamientos de sus usarios"9 y "especula con nuevas

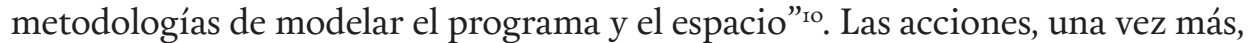
de cuerpos en movimiento son la precondición para que se produzca lo siguiente:

Una condición de campo podría ser cualquier matriz formal o espacial capaz de unificar diversos elementos a la vez que respeta la identidad de cada uno. Las configuraciones de campo son cúmulos débilmente unidos caracterizados por su porosidad y la interconectividad local. La forma resultante y su extensión son altamente fluidos y menos importantes que las relaciones internas entre las partes, las cuales determinan el comportamiento del campo $^{\text {II }}$.

El giro dinámico, producido al variar el entendimiento de una arquitectura construida mayoritariamente a través de objetos a una arquitectura donde son las acciones y los cuerpos las que construyen el campo, tiene un eco importante en la construcción de la frontera contemporánea. Los procesos de construcción de la frontera no son ajenos a esta condición dinámica y efímera, pero es fundamental leerla también a través del campo de Agamben, donde es la excepcionalidad y no la norma la que rige este espacio ${ }^{12}$. Este espacio, que denomina anómico,

8 Gilles Deleuze y Felix Guattari, Mil mesetas: Capitalismo y Esquizofrenia (Valencia: Pre-textos, 2005), 360-361.

9 Stan Allen, «Field Conditions», Architectural Design (1996), 2.

10 Allen, «Field Conditions», Architectural Design (1996), 2.

11 Allen, «Field Conditions», Architectural Design (1996), 2.

12 Es importante explicitar aquí una llamada de atención respecto a la cuestión de la excepcionalidad dentro del modelo espacio-legal empleado durante la investigación. La excepción, en términos clásicos, se formula como una alternativa a la legalidad vigente que se aplica sobre un espacio determinado,con una duración determinada y sobre unos determinados cuerpos que es ejecutada por una autoridad que "declara" este estado frente a la normalidad. Este planteamiento choca de manera frontal con una concepción de lo que entendemos por ley y de los gradientes que esta genera: la ley -y la excepción no deja de ser un corpus de medidas, protocolos y acciones destinadas a suspender la legalidad vigente- no puede formularse de manera binaria. Por tanto, aunque se hable de excepcionalidad para introducir el planteamiento de Agamben y otros autores y analizar sus implicaciones espaciales, de acuerdo a las lógicas del dispositivo que hemos establecido como marco de referencia esta no será más que una disposición específica dentro de un amplio rango de posibilidades. Es decir, la excepcionalidad no es una imposición superior a un sistema establecido - una afirmación o negación de la existencia \#territorios frente a

territorialidades

\#condiciones de campo

La excepción como materia arquitectónica

\#excepcionalidad 
presenta una singularidad, se produce una inversión fáctica entre ley y la fuerzade-ley, una condición donde "la norma está vigente pero no se aplica (no tiene 'fuerza') y, por otra, hay actos que no tienen valor de ley pero que adquieren la 'fuerza' propia de ella”' ${ }^{\text {I3 }}$. Es esta excepcionalidad, matizada o de baja intensidad en determinadas ocasiones lo que permite y, es por ello pertinente su ligazón a las prácticas espaciales, lo que posibilita "la apertura de un espacio en la que aplicación y norma exhiben su separación” ${ }^{14}$. Es decir, la condición dinámica del espacio contemporáneo pone de manifiesto el paralaje entre construcciones diseñadas para encarnar la ley y los cuerpos - de naturaleza heterogénea- que, de manera contingente, la encarnan en la práctica.

Una excepcionalidad que podemos detectar a través de otros términos que aparecen constantemente asociados a la frontera -"contingencia", "desborde", "emergencia"...-, pero sin duda el concepto "operativo" es aquel que mejor representa esta condición contemporánea. El término "frontera operativa” popularizada durante la primera legislatura de Mariano Rajoy por su ministro del Interior Fernández Díaz ponía en tela de juicio, al omitir de manera consciente la aplicación de ciertas leyes - no sólo españolas sino europeas e internacionales- que tenían un efecto inmediato sobre el territorio en el que se aplicaban: ya no era la línea fronteriza la que construía la soberanía europea sino los cuerpos de los agentes y las acciones que, con amparo político, podían devolver los cuerpos llegados a territorio español físicamente pero nunca políticamente. Esta operatividad se corresponde con lo que Brandariz García y Fernández Bessa han denominado "giro gerencial" de la frontera: una gestión eficiente de los recursos desencadenados desde la crisis económica de 2008 donde "forzado por el actual contexto de austeridad en el gasto público, no ha asumido exactamente el objetivo de 'hacer menos con menos' [...], se han guiado por un lema más eficiente y gerencial que el anterior: "hacerlo mejor con menos". El hacerlo "mejor con menos" se traduce a una reducción selectiva de las construcciones estables y al desarrollo táctico de mecanismos espaciales que logren esta elasticidad y operatividad espacial que estiran y modulan de manera dinámica los contornos del territorio a proteger. La condición operativa ya no se entiende como un recurso excepcional -muy limitado y controlado en el tiempo- sino que se convierte en un recurso espacial más pese a que los conflictos que genere -en términos de protestas, denuncias y procesos judiciales- sean importantes: el pensamiento táctico a la hora de construir el territorio se antepone al estratégico.

De este modo, el territorio se presenta a la vez como potencialmente seguro, ritualizado e hipervigilado a través de mecanismos tecnológicos, donde sólo determinados cuerpos pueden acceder a él pero también, cualquier punto del mismo puede albergar situaciones de excepcionalidad absoluta, donde la violencia espacial llega a niveles que jamás serían tolerados de manera regular. Mike Davis, en Más allá de Blade Runner: Control urbano y la ecología del miedo $^{15}$, contraponía estos dos polos opuestos del espacio metropolitano como realidades excluyentes, archipiélagos en el territorio entre los que se establecía un gradiente geográfico de áreas urbanas que las separaba. Así, el espacio era dividido y categorizado de manera clara según el control espacial ejercido, donde destacaban fragmentos hipervigilados contrapuestos a zonas aparentemente

del Estado de Derecho sobre un espacio y un tiempo- sino una configuración específica de los agentes, escenarios y formas activas. [En el último conector se analizará con mayor detenimiento las causas, consecuencias y efectos operativos de esta configuración excepcional].

13 Giorgio Agamben, Homo Sacer II: Estado de Excepción (Valencia: Pre-textos, 2010), p.59.

14 Agamben, Homo Sacer II (Valencia: Pre-textos, 2010), p.61.

15 Mike Davis, Más allá de Blade Runner: Control urbano y la ecología del miedo, (Barcelona: Virus, 200I). 
reguladas “al margen de la ley”. Al primero lo denominó paisajes vigilados, territorios autónomos perfectamente controlados a través de una "visibilidad protectora”, donde el control espacial se ejerce por mecanismos de naturaleza heterogénea -sistemas de videovigilancia, privatización del espacio, cuerpos de seguridad, aplicación de protocolos específicos...-. Frente a ellos, el segundo término, las free-fire zones, o zonas de libre disparo, donde la ley se pone en suspenso y se presentan como espacios de excepción absoluta. Los "barrios de control social" son el resto de fragmentos territoriales que median entre un polo y el otro. Mike Davis plantea un modelo rígido, estático y planteado bajo criterios geográficos claros; sin embargo termina el texto -escrito en 1992con una incógnita, preguntándose si es este modelo el que definirá la ciudad del siglo XXI. Casi tres décadas después podemos concluir que, efectivamente la construcción del espacio post-urbano se modela en base a estos dos polos, no puede plantearse en términos topográficos sino topológicos. Tres décadas más tarde los paisajes hipervigilados se han superpuesto, a través de diferentes tecnologías, a la totalidad del territorio, pero en el mismo grado que la condición de excepcionalidad se ha vuelto cotidiana o permanente. Así, ya no es posible discernir recintos que respondan a unas u otras lógicas, sino que tan sólo las acciones de los cuerpos, la alteración y manipulación que éstos hagan dentro del dispositivo hará que éste responda convirtiendo el espacio en un scanscape o una free-fire zone. En definitiva, respondiendo a la pregunta de Mike Davis, efectivamente el modelo territorial planteado por él tiene, si cabe, más vigencia que en la fecha de su publicación, sin embargo ambas realidades coexisten en perfecta superposición, alternando entre una y otra de manera instantánea, temporal y con alta selectividad espacial en función de las acciones que se lleven a cabo.

Todo esto nos lleva a afirmar que los límites trazados con precisión sobre el territorio en el mapa no son ya reconocibles. Tampoco son límites válidos, dado que sólo la materialidad y la configuración concreta de cada diseño abstracto determinará su funcionamiento real. La importancia adquirida de los cuerpos en la construcción del espacio han hecho que frente a los recintos de límites claros, aparezcan campos de intensidades construidas en base a sus acciones y condiciones materiales. Esto, claramente, genera un territorio que es dinámico, donde en cualquier lugar puede ser desplegada cualquier construcción. Leer el territorio desde esta óptica nos hace ver que las lógicas excepcionales de la frontera pueden ser desplegadas en cualquier punto, independientemente de su vinculación aparente. Son los cuerpos los que cargan a cuestas con ella, desplazando y detonando las lógicas espaciales vinculadas a ella en cualquier punto, moviéndose en una relación inestable con infinidad de leyes que condicionan y coartan su movimientos. 



\section{LA POST-METRÓPOLIS ARQUITECTONICAS DEL CONTROL EN ESPACIOS URBANOS}

5.1. Llevar la frontera a cuestas.

5.2. Fronteras extensivas. Normativas, operaciones policiales y espacio público.

5.2.1. El paisaje legal de la Unión Europea

5.2.2. Operación Mos Maiorum. Protocolos y espacio público

5.3. Dispositivos espaciales de control en entornos urbanos. Lavapiés como caso de estudio.

5.3.1. Características y consecuencias urbanas del Plan Integral de Mejora de la Seguridad y Convivencia de Lavapiés

5.3.2. Sistemas de vigilancia pasiva y activa

5.3.3 Arquitecturas cómplices. El papel de la arquitectura urbana en el control espacial

5.3.4 Enclaves urbanos y espacio público ritualizado

5.4. Los manteros como paradigma de la frontera encarnada.

5.4.1. Ocupaciones temporales y criminalización de la venta ambulante. El caso del ayuntamiento de Barcelona

5.4.2. Tácticas de resistencia. Devenir un cuerpo público 



\subsection{LLEVAR LA FRONTERA A CUESTAS.}

Solo la muerte es innegable, todo lo demás puede ser reescrito al gusto del consumidor. Y así, entretenidos en el debate de los hechos, en la disputa narrativa, desenfocamos el transfondo: la vida hecha miedo, la abolición del descanso y la serenidad para quienes no tienen cabida en una ciudad que acoge mimosa a especuladores, multinacionales y fondos de inversión.

Normalizaremos de nuevo a los cientos de Mames de pie, durante horas, sobre las aceras, en el metro, observando pasar a las turistas, a los ciudadanos de pleno derecho que van al trabajo o a ver a sus familias, a las personas precarias que temen no llegar a fin de mes, pero no ser detenidas y deportadas, a jóvenes despreocupados que se dirigen a las terrazas. No adquirir el derecho a la despreocupación en toda tu vida, siempre alerta, siempre en vilo. El miedo te roba tus mejores años, cercena tu felicidad, te enferma. Tener miedo por ser, por estar, por intentar sobrevivir, en una ciudad segura como Madrid, es una de las peores desigualdades posibles. ${ }^{\mathrm{I}}$

Sarah Babiker

Somos X no tenemos derechos, no tenemos derecho a trabajar, ni de comer, por lo que no tenemos derecho siquiera a existir ${ }^{2}$ Gillets Noir

A las cinco de la tarde del quince de marzo de 2018 un cuerpo caía al suelo de la calle del Oso en su intersección con Mesón de Paredes, cruce situado en el madrileño barrio de Lavapiés - muy próximo a las zonas con mayor afluencia turística-. Una patología en uno de los ventrículos del corazón provocó que en cuestión de minutos falleciese sin que los servicios de Urgencias lograsen reanimarlo. Su nombre era Mame Mbaye, de treinta y cinco años y nacionalidad senegalesa pese a llevar catorce años viviendo en España de manera irregular. Su muerte, controvertida por los hechos que la precedieron así como por los que la prosiguieron, puso de manifiesto una condición a la que de manera diaria se enfrenta el cuerpo migrante en el espacio público. Un espacio totalmente accesible en apariencia, democrático al permitir su empleo y disfrute a cualquier persona por igual, pero lo más importante supuestamente desposeído en apariencia de cualquier vinculación con la frontera. Y, sin embargo, este acontecimiento ilustra con gran claridad cómo el dispositivo frontera se ha imbrincado hasta tal punto en la totalidad del territorio que ya no requiere de arquitecturas específicamente diseñadas para que ésta se materialice sino que pueda hacerse en cualquier espacio. De la línea perimetral encarnada en la valla -y en los múltiples ensamblajes territoriales en los que ésta se ha materializado-

1 Sarah Babiker, "Cinco reflexiones tras la muerte de Mame Mbaye”, El Salto, i8 de marzo de 2018.

2 Declaración de los Gillets Noir en su encierro en el panteón de París. Citado en Carolina Meloni González, "Los Gillets Noir y el devenir negro del mundo", El Salto, 20 de septiembre de 2019. 
al kilómetro cero de la capital española, la puerta del Sol, lugar donde se inició el acontecimiento que terminó con la vida de Mame Mbaye a tan sólo un kilómetro de distancia del epicentro geográfico y administrativo de España.

Más allá de la patología congénita detectada en el informe forense, no hay certezas claras sobre qué provocó el fallo de su cuerpo ¿Qué ocurrió en los minutos previos a su muerte para que este ventrículo dejase de funcionar con normalidad? Mame Mbaye se dedicaba a la venta ambulante en la vía pública, era mantero de profesión aunque no se haya certificado que la estuviese ejerciendo esa misma tarde. Sí se certificó su presencia en la Puerta del Sol quince minutos antes de su desfallecimiento a un kilómetro y medio desde su posición original. Una redada realizada por la Policía Municipal en los alrededores de la plaza hizo que tanto Mame como un compañero escapasen a pie en dirección al barrio de Lavapiés. Aunque las cámaras de seguridad no hayan detectado persecución explícita hacia la pareja de migrantes 3 , la violencia desplegada por la policía, así descrita por algunos testigos: "fue una redada muy bestia y fuerte en Sol, dando golpes a varios chicos. Uno de los chicos que nos lo cuentan recibió un golpe en la rodilla. Han detenido a dos y otro ha salido corriendo" ${ }^{4}$. Más allá de la violencia directa presenciada, es necesario superponer a esta coreografía policial las posibles consecuencias de una identificación o detención, dada su condición irregular. Todo ello forzó, hubiese persecución directa o no, una huida apresurada en la que el kilómetro y medio de separación entre un punto y otro se recorrió en menos de doce minutos. Javier Barbero, concejal de Seguridad, describía así lo sucedido en una rueda de prensa a los pocos días del acontecimiento - cuando el Ayuntamiento de Madrid se posicionaba claramente del lado de la policía ante lo ocurrido-:

Esa tarde, Mame Mbaye se encontraba en la Puerta del Sol con su manta, se produjo una intervención policial como las que ejecuta de forma regular, él corre por la calle postas hacia la Plaza Mayor» [...] «Venía huyendo desde la Puerta del Sol, corriendo hasta la Plaza Mayor y andando desde la Plaza Mayor hasta calle del Oso, pero huyendo. Es cierto no hubo persecución directa desde Plaza Mayor hasta calle del $\mathrm{Oso}^{5}$.

Pese al corporativismo asumido en su posición pública, hay una frase que nos permite entender parte de las causas que detonaron la muerte de Mame Mbaye así como los disturbios subisiguientes. Apenas unos segundos dentro de una extensa declaración ante los medios que ponían el foco sobre cómo la frontera que estamos analizando no se limita al perímetro del territorio, sino que cada cuerpo la porta con ella. Javier Barbero pronunciaba simplemente lo siguiente: "Mame Mbaye llevaba catorce años huyendo" ", huyendo de un dispositivo que sistemáticamente les niega el espacio público -en todas sus dimensiones- y que aquellos cuerpos que se exponen a aparecer en él sufren la violencia espacial, política, judicial de este ensamblaje. Un ensamblaje que ha encontrado en las dinámicas contemporáneas de la arquitectura, en el diseño del espacio urbano, pero también en una serie de agentes cuasi-arquitectónicos, un escenario cómplice para producir esta exclusión y violencia de un modo altamente

3 El juicio para dirimir las responsabilidades tras la muerte de Mame Mbaye ha archivado la causa contra la Policía Local de Madrid por no hallar evidencias explícitas que mostrasen una persecución directa. Sin embargo, la asociación SOS Racismo ha reclamado la reapertura de la investigación al hallar indicios de posible trato inhumano o delito de torturas.

4 Redacción El Salto, "Un vendedor ambulante muere en Lavapiés tras ser perseguido por la Policía”, El Salto, 15 de marzo de 2018.

5 Luca Constanini, "Barbero insiste en que Mbaye falleció a raíz de una operación policial", $E l$ País, 23 de marzo de 2018. 
selectivo. Un modo de construir la frontera que dista mucho de la arquitectura de la valla, ya que no genera recintos unívocos ni construcciones específicamente ligadas a ella, sino que se apropia de disposiciones urbanas, superpone a ellas un complejo entramado normativo y legal, generando un lawscape a través del cual el cuerpo migrante se desplaza. Un dispositivo que transforma con inmediatez espacios cotidianos como la Puerta del Sol o una calle en Lavapiés en espacios de excepción absoluta, donde somos capaces de encontrar la misma violencia espacial señalada en capítulos anteriores, pero también las mismas características y mecanismos para aplicarla.

La muerte de Mame Mbaye sólo fue el detonante de un acontecimiento que transformó la realidad de uno de los barrios más turísticos de Madrid en un campo de batalla, donde la reclamación legítima de justicia por parte de sus compañeros migrantes tuvo como respuesta un despliegue policial que tomó las inmediaciones del cruce donde Mame Mbaye había fallecido. Del scanscape configurado a través de la implementación de medidas espaciales claramente securitarias, sistemas de vigilancia y la necesidad de minimización del riesgo en una de las zonas más céntricas de la ciudad, a una free-fire zone que puso en suspenso el funcionamiento normal del barrio con persecuciones, contenedores en llamas, disparos de bolas de goma, detenciones irregulares y agresiones. Una excepcionalidad que no es exclusiva, que comparte características comunes con muchos otros acontecimientos de naturaleza diferente pero que, indudablemente, estaba ligada a la condición fronteriza de un cuerpo migrante -múltiple, una multitud- que con independencia de la fecha de su llegada al territorio español sigue constantemente atravesado por la frontera.

Al mismo tiempo que el SAMUR levantaba una carpa móvil para intentar reanimar el cuerpo sin vida de Mame Mbaye, un cordón policial de agentes antidisturbios bloqueaba los accesos estableciendo un perímetro de seguridad en torno a él. Al otro lado del perímetro se comenzó a congregar una multitud, un grupo heterogéneo formado en un primer momento por compañeros de Mame, migrantes pero que fue aglutinando a más y más gente que reclamaba su derecho a saber qué estaba pasando. Esta multitud generó una serie de lazos afectivos con la muerte de Mame Mbaye a través de su presencia física en el espacio público -y virtual a través de su prolongación en redes-, generando un cuerpo múltiple y, por tanto, una espacialidad común de resistencia que cobraba mayor y mayor dimensión. Cuatro horas más tarde, los técnicos del SAMUR y los empleados de la funeraria se llevaron el cuerpo inerte de Mame Mbaye. Una hora después, antes de las diez de la noche, comenzaron los disturbios en Lavapiés al producirse las primeras cargas policiales. El escenario urbano controlado dio paso a una coreografía de furgones de las Unidades de Intervención Policial descendiendo por las calles, a decenas de antidisturbios en formación disparando pelotas de
Disturbios en Lavapiés tras la muerte de Mame Mbaye (El Salto; Madrid, 2018)

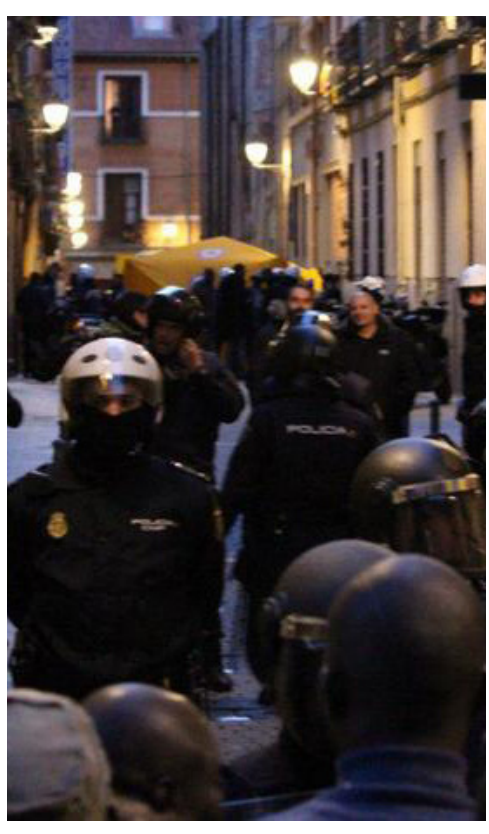

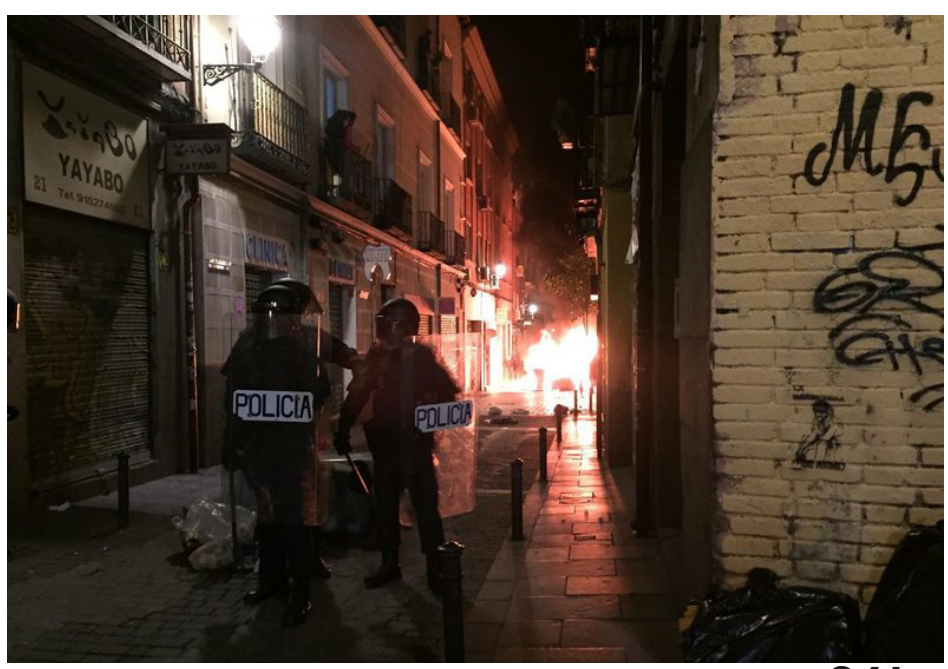



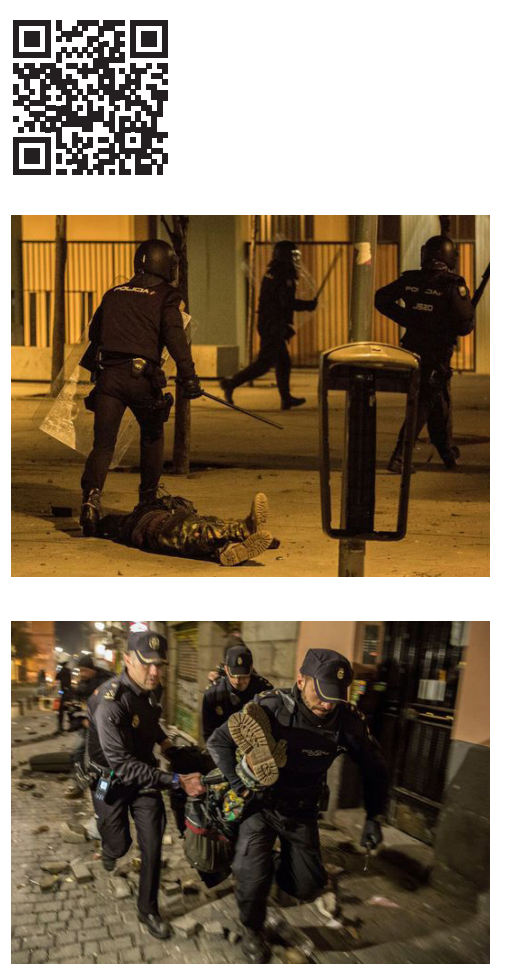

Agresión y retirada del cuerpo de Arona Diakhate (Olmo Calvo; Madrid, 2018) goma o replegándose en las esquinas para evitar el impacto de los adoquines que les lanzaban. El pavimento de algunas calles fue levantado y se prendió fuego a numerosos contenedores como medida de contención, pero también de visibilización ante los medios de lo que había ocurrido cinco horas antes. Este escenario excepcional, donde los portales se convirtieron en improvisados centros de detención irregular, el pavimento y mobiliario urbano en barricadas y las esquinas en lugares de protección provocaba una suspensión de las funciones arquitectónica básicas que definen el espacio público. Todo, absolutamente todo, era susceptible de ser transformado y dotado de nuevas funciones.

Se abría, dentro de una zona excepcional, un momento de ruptura donde las leyes, normas y códigos superpuestos al espacio público eran puestas en suspenso, obviadas por cada uno de los cuerpos en acción. Por un lado, un cuerpo policial que había instaurado la excepción tanto por su presencia como por sus lógicas que derivaban en un altísimo grado de violencia espacial. Por otro lado, un cuerpo colectivo, heterogéneo, una multitud irreductible que logró visibilizar la violencia cotidiana que sufrían en forma de redadas racistas, detenciones y persecuciones policiales; reclamaban con sus acciones no sólo justicia para Mame Mbaye, sino que también ponían en evidencia cómo seguían siendo el foco del dispositivo frontera y las consecuencias que éste era capaz de ejercer cada vez que sus cuerpos hacían presencia en el espacio público de manera consciente y resistente.

El caso del portal es aquel que mejor permite entender el grado de violencia espacial detonado tras la muerte de Mame Mbaye. Arona Diakhate se encontraba en la Plaza Nelson Mandela, contigua al lugar del fallecimiento del mantero, cuando se produjeron las cargas policiales; dos porrazos directamente a la cabeza -contraviniendo los protocolos de actuación policial- sin mostrar resistencia en ningún momento fueron suficientes para que cayese inconsciente al suelo. Inmediatamente, cuatro agentes de policía lo transportaron en volandas hasta el interior de un portal de la calle del Oso, donde se produjo a su detención irregular antes de ser transportado a la comisaría de Leganitos. Y, desde allí al hospital de la Fundación Jiménez Díaz, donde fue ingresado con un traumatismo craneoencefálico tal y como recoge el informe médico - "quince puntos en la cabeza, dos contusiones. Traumatismo craneoencefálico, con hematomas internos, pero sin riesgo de lesión neuronal"7-. Es importante entender como sólo a través de este grado de violencia espacial en el que se sume Lavapiés la noche del quince de marzo de 2018, lo que se ponen en suspenso no son las funciones arquitectónicas o los usos del espacio, sino las normas que rigen sobre ellos y el resto de normas: sólo así, en esta complicidad entre función, espacio y excepción se explica esta actuación irregular de la policía. Una actuación que, pese a estar documentada de manera forense por diferentes observadores y medios -tanto la agresión como su detención en el portal-, no figura como tal: "según la versión oficial de los hechos, no fue detenido o herido en la noche de los disturbios en Lavapiés"8.

Exactamente un año más tarde, el quince de marzo de 2019, los contenedores habían sido sustituidos, el mobiliario urbano destrozado reparado y las sillas metálicas y adoquines con los que se improvisaron barricadas y armas arrojadizas habían vuelto a su sitio correspondiente. El barrio de Lavapiés prácticamente de forma inmediata había vuelto a convertirse en una de las zonas más turísticas de la ciudad. En el mismo punto donde había fallecido por una cardiopatía un año antes, sus compañeros colocaron una placa idéntica en forma a las empleadas

7 Juan Luis Sánchez, Qué pasó con el hombre desplomado en Lavapiés por un porrazo de la Policía, Eldiario.es, 16 de marzo de 2018.

8 Sánchez, Qué pasó con el hombre desplomado en Lavapiés por un porrazo de la Policía, Eldiario.es, 16 de marzo de 2018. 
por el ayuntamiento de Madrid para significar enclaves urbanos. Su texto rezaba lo siguiente: "En esta calle murió el 15 de marzo de 2019 Mame Mbaye víctima del racismo institucional del Estado español”. Tras la inauguración de la placa, promovida por el Sindicato de manteros de Madrid, éste, junto a colectivos antirracistas y vecinos del barrio, se concentraron sosteniendo una pancarta donde se reflejaba otro aspecto clave que nos señala como estos conflictos, aparentemente no vinculados a la realidad inmediata de la frontera, sí son atravesados de lleno por las lógicas creadas por el dispositivo. El texto, lema empleado por el Sindicato en numerosos actos, es el siguiente: "El racismo institucional nos condena a la manta" 9 . La placa fue retirada a demanda de los grupos políticos de derecha del consistorio madrileño, pero, pese al poco tiempo que permaneció en el espacio público, este acto infra-arquitectónico, temporal de nuevo hacía que cobrase visibilidad una realidad que, por cotidiana, no se puede apreciar. Por un lado, al señalar que no era un problema concreto, una singularidad dentro de una casuística mucho más amplia, sino las consecuencias excepcionales de un sistema de organización del espacio público y, en

definitiva, de gestión del territorio, donde el cuerpo migrante era perseguido y criminalizado a través de diferentes mecanismos que, como ellos mismos señalan, forman parte de las propias instituciones. Así, las lógicas de la frontera de regulación, canalización y control del flujo de migrantes regulares y no regulares,
Concentración para la colocación de placa conmemorativa en honor a Mame Mbaye (El Salto; Madrid, 2018)
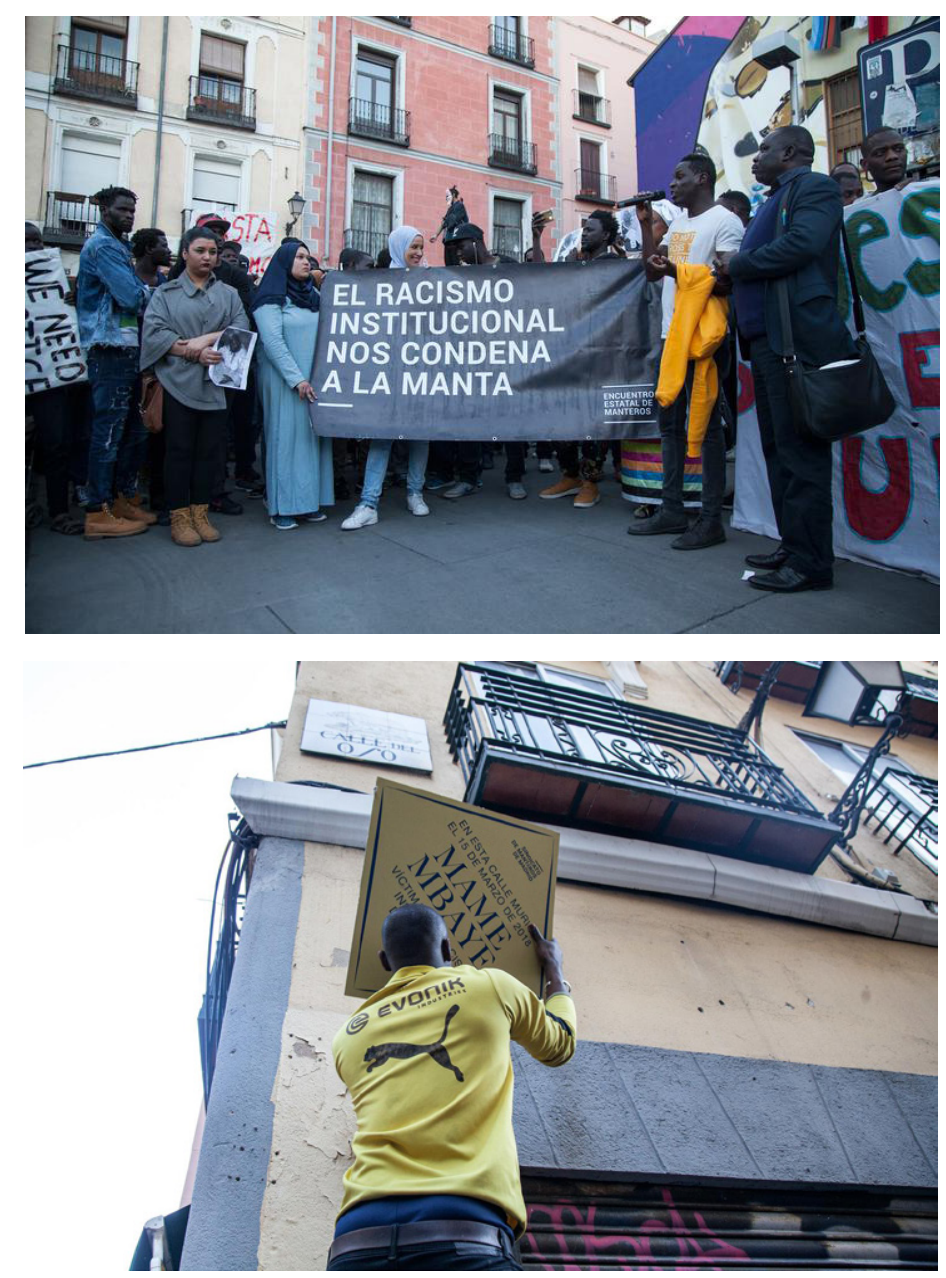

se extienden más allá de los perímetros de los muros, estallan en mil pedazos para imbrincarse en todos los aspectos del tejido urbano y político ${ }^{\mathrm{To}}$. Pero, por otro

9 Redacción El Salto Diario, Una placa para que la muerte de Mame Mbaye no caiga en el olvido, El Salto, 15 de marzo de 2019.

10 Este término, racismo institucional, nos devuelve al dilema de la Banalidad del mal planteado por Hannah Harendt, donde permite cuestionarse si, dentro de un dispositivo formado por infinidad de agentes, arquitecturas y escenarios reside en ellos un racismo inherente o es su 
lado, el hecho de que la placa fuese colocada por el Sindicato de Manteros de Madrid nos permite entender que esta disputa por el acceso a un espacio público que les es negado políticamente está presente y se le debe prestar atención para entender cómo se construye desde el conflicto entre intereses divergentes. La dimensión colectiva del conflicto, la autoorganización, y sobre todo, la agencia colectiva que el cuerpo de manteros posee nos permite comprender qué mecanismos se emplean contra ellos, pero también las tácticas de resistencia y auto-organización. A través del apoyo muto y la organización colectiva, el cuerpo migrante ha ido disputando su derecho a entrar y desplazarse por el espacio público. Un derecho reclamado desde acciones cotidianas e infraordinarias, basadas en una lectura inmediata de las diferentes variables del medio urbano, pero también un derecho reclamado a través de acciones extraordinarias, protestas y manifestaciones que resignifican un espacio - el que les es negado- o la simple instalación de una placa metálica en el encuentro entre dos calles en el barrio de Lavapiés.

orientación dentro del ensamblaje a través del cual realizan prácticas claramente enmarcables como racistas. Así, si en el primer momento se culpó exclusivamente a la policía municipal de lo ocurrido a Mame Mbaye, un año más tarde la posición de los manteros y el movimiento antirracista señalaba a los problemas estructurales, de negación del espacio público, que habían desembocado -en su conjunto- en la muerte del migrante. 


\subsection{FRONTERAS EXTENSIVAS. NORMATIVAS, OPERACIONES POLICIALES Y ESPACIO PÚBLICO.}

\subsubsection{EL PAISAJE LEGAL DE LA UNIÓN EUROPEA}

La transformación topológica del dispositivo frontera -de una posición marginal a su superposición sobre la totalidad del territorio- cobra en las ciudades su máxima expresión: un ensamblaje de baja intensidad impregnado en el tejido urbano. Este es capaz de desplegarse con especial efectividad y de manera instantánea. Para entender cuales son los mecanismos de gestión y producción territorial que posibilitan la aparición de estos espacios excepcionales independientemente de su proximidad o vinculación aparente con la frontera, es necesario recurrir una vez más a su dimensión política. A priori, una esfera que por su escala geopolítica difícilmente puede tener un impacto directo sobre la configuración urbana y los agentes que la conforman; y sin embargo, la realidad es que ha permitido, condicionado y promovido una serie de dinámicas que devienen en una frontera totalmente desterritorializada, capaz de localizar, neutralizar y controlar el exceso de población migrante. Por tanto, entender a través del cartografiado de las principales leyes que han definido y definen la frontera de la Unión Europea en sus diferentes aspectos nos permite comprender la transescalaridad del dispositivo; es decir, como el paisaje legal que conforma la experiencia urbana de cada cuerpo está mediado no sólo por las normas inmediatas vinculadas a la ciudad -ordenanzas, protocolos policiales, planes urbanos...-, sino que también tienen su eco en decisiones aplicadas a un conjunto territorial muchísimo mayor.

Desde el limes romano hasta la actualidad, toda soberanía de un territorio ha sido la traslación directa al plano material de una serie de textos abstractos en apariencia que lo configuran y moldean a través de diferentes operaciones materiales e inmateriales. La Unión Europea también requiere de esta necesidad, donde los diferentes intereses entre las partes involucradas hace que sea imposible pensarlas como una sucesión lógica de diferentes textos, sino como un conjunto heterogéneo donde cada texto posee una autonomía que les hace entrar en conflicto, desalinearse o contradecir intereses entre sí. De este modo, frente a un proyecto unitario - al igual que en sus materializaciones físicas- la frontera europea funciona como un agregado o ensamblaje de normas con capacidad de acción conjunta que sólo puede ser cartografiado como una deriva y no como una sucesión ordenada ${ }^{\text {II }}$. Una deriva en la que podemos establecer un punto

11 La cartografía legislativa de la Unión Europea desarrollada permite realizar un seguimiento cronológico de los principales textos legales implementados hasta el año 2015 en materia de fronteras de la Unión Europea. Se superponen en un mismo plano textos de diferente entidad y calado territorial independientemente del impacto o consideración normativa que puedan tener, sino únicamente en base al impacto territorial que éstas puedan generar. Su posición polar dentro de la brújula generada atiende a dos factores fundamentales: su vinculación a determinados aspectos claves y su fecha de implementación efectiva. Así, su situación radial depende del arco de aspectos contemplados en el texto de la misma mientras que su distancia respecto al centro se ha establecido en función de su fecha de redacción. Es conveniente aclarar que no existe una incorporación de normativas exhaustiva respecto a la construcción de la frontera, sino sólo de aquellas relativas al tránsito de personas, su control, seguridad y militarización. Para ello, se ha usado como fuente fundamental la investigación realizada por Migreurop en Atlas of Migration in Europe, que ha sido complementada con la búsqueda de textos 
de partida claro con la creación del Acervo de Schengen firmado en 1985, que disuelve las fronteras internas entre los países adheridos al tratado internacional. Esta supresión tiene una consecuencia inmediata a nivel espacial: una serie de construcciones perimetrales a cada Estado se vuelven instantáneamente obsoletas con la entrada en vigor de este nuevo régimen territorial. Sin embargo, la transformación principal no reside ahí, sino en la necesidad de generar nuevos mecanismos espaciales que logren monitorizar, controlar y restituir en caso de que sea necesario la frontera. Una frontera con capacidad de materializarse en cualquier punto del territorio. En definitiva, elaborar un sistema de regulación del flujo de migrantes que, con mayor efectividad y en un territorio mucho más amplio, sea capaz de tener mayor precisión, selectividad y rapide ${ }^{12}$.

Una de las principales líneas de actuación respecto a la frontera guarda relación directa con la consideración del cuerpo biológico como un agente fundamental en la construcción de la misma. Una serie de medidas centradas en cómo los parámetros biométricos de cada individuo pueden mediar en su integración o expulsión del territorio. A esta transformación Giorgio Agamben la ha denominado como "tatuaje biopolítico", un sistema de identificación que no requiere ser marcados físicamente, sino que es su propio cuerpo el que los identifica. Así enunciaba esta condición implementada ya en Estados Unidos a raíz del escenario securitario post-IIS y que, más de una década más tarde, son moneda común a la hora de ejercer un control espacial altamente efectivo:

El fichaje electrónico de las huellas digitales y de la retina, el tatuaje subcutáneo y otras prácticas de la misma especie son elementos que contribuyen a definir ese umbral. [...] La historia nos enseña cómo las prácticas en principio reservadas a los extranjeros terminan pronto por aplicarse al conjunto de los ciudadanos. [...]

De esta manera, al aplicarle técnicas y dispositivos inventados para las clases peligrosas, los Estados, que deberían constituir el lugar mismo de la vida política, han hecho del ciudadano, o más bien del ser humano como tal, el sospechoso por excelencia, al punto de haber transformado en clase peligrosa a la humanidad misma. [...] indudablemente el tatuaje apareció en Auschwitz como la manera más normal y económica de regular la inscripción y el registro de deportados en los campos de concentración. El tatuaje biopolítico que los Estados Unidos nos imponen ahora para entrar en su territorio bien podría ser el precursor de lo que más tarde se nos pedirá que aceptemos como registro normal del buen ciudadano en los mecanismos y engranajes del Estado $^{\mathrm{I3}}$.

En el año 200o, cuatro años antes de la publicación de este artículo, la Unión Europea había aprobado el sistema Eurodac ${ }^{14}$, la primera ley que obligaba a la identificación mediante huella dactilar de todos los ciudadanos extranjeros presentes o con intención de entrar en el territorio Schengen para su inclusión en un registro centralizado. Esta ley fue la primera de una serie de medidas políticas y territoriales destinadas a recabar un conjunto cada vez mayor de datos biométricos registrados a nivel europeo. $\mathrm{Al}$ amparo de un hipotético refuerzo securitario de los estados miembros ante la amenaza terrorista -de nuevo un

específicos en los boletines del Parlamento Europeo.

Ver más en: Migreurop, Atlas of Migration in Europe: A Critical geography of migration policies, (Londres: New Internationalist Publications STD, 2012).

12 A efectos del texto que a continuación se presenta desglosando las principales tendencias de la frontera europea contemporánea, se han descrito con mayor detalle aquellos que han establecido una relación clara respecto a la componente espacial que articula el presente capítulo.

13 Giorgio Agamben, "No al tatuaje biopolítico”, Le Monde, 22 de enero de 2004.

14 Regulación 603/2013, del 26 de junio de 2013, establecimiento de EURODAC para la comparación de huellas dactilares de solicitantes de asilo. 
cuerpo extranjero, amplio y vago, como catalizador de una serie de medidas aplicables al conjunto general de la población, -estas políticas han configurado el que hoy es uno de los registros más sutiles de control espacial donde están presentes rasgos faciales, altura, apariencia, huellas dactilares, etc. Cada entrada al país, cada pasaporte escaneado en el aeropuerto, más allá de la insignificancia del acto, quedan registrados en sistemas que conectan partes del dispositivo frontera. Junto al Eurodac podemos incluir el Sistema VIS - sistema integrado para compartir información de visados emitidos entre países-, el Entry/Exit Programme aprobado en 2016 o el Registered Traveller Programme. Tods ellos proporcionan y centralizan, en una infraestructura desterritorializada pero compartida por todos los países de la Unión Europea, una cantidad ingente de información a través de operaciones rutinarias en los puntos fronterizos de acceso a Europa. Un sistema que, de nuevo, no sólo se circunscribe al territorio europeo, sino que es extraterritorializable, al monitorizar también a todas aquellas personas a las que, por cualquier motivo, se ha denegado su visado de entrada pero no por ello su inclusión en el registro centralizado.

Otro aspecto que conviene señalar son dos dinámicas aparentemente contrarias pero que logran aumentar la eficacia espacial del dispositivo frontera. Por un lado, una centralización y homogeneización de instituciones capaces de actuar de manera supraestatal con el único objetivo de generar una fortificación operativa que supla la ineficacia de los muros físicos. Y, por otro lado, una extraterritorialización y externalización de las dinámicas fronterizas, a través de un grupo de acuerdos internacionales o con terceros países que mejoren las condiciones económicas mediante inversión en cooperación y desarrollo a cambio del establecimiento de políticas que obliguen a aquellos a asumir los migrantes deportados o el control directo de las fronteras - tal es el caso de los países perimetrales al Mediterráneo, siendo Libia y Marruecos los ejemplos más claros-.

La creación en el año 2004 de la agencia Frontex, la institución europea encargada de la "ayuda a los Estados miembros de la UE y los países asociados al espacio Schengen a gestionar sus fronteras exteriores y contribuye a armonizar los controles fronterizos entre los países de la UE. La Agencia facilita la cooperación entre las autoridades fronterizas de cada país de la UE, ofreciendo apoyo técnico y experiencia" ${ }^{15}$ es un cambio paradigmático que centraliza en un único cuerpo de nueva creación las tareas desarrolladas independientemente por cada uno de los estados miembro. Con sede central en Varsovia y un presupuesto anual de doscientos cincuenta millones de euros, Frontex coordina los servicios de frontera financiados por el conjunto de estados europeos, donde sólo hacen uso de sus efectivos y recursos aquellos con perímetro fronterizo exterior. Más allá de esto, también son los encargados de coordinar los diferentes operativos en las áreas de interés, así como de coordinar y organizar los vuelos de deportación a terceros países, los así denominados chárter ${ }^{16}$. Esta medida no es la única política implementada de cara a la fortificación del espacio Schengen, pero sí la más significativa en términos espaciales, junto a ella, una serie de medidas con impacto territorial: la activación y desactivación de las fronteras nacionales o los protocolos de aplicación del espacio Schengen. Frontex destaca, más allá de su labor policial en la gestión y control de fronteras, porque nos permite entender cómo la Unión Europea genera a través de esta agencia un

15 «Agencia Europea de la Guardia de Fronteras y Costas», Unión Europea, acceso el 23 de julio de 2019, https://europa.eu/european-union/about-eu/agencies/frontex_

16 Los vuelos masivos de deportación son coordinados por la agencia Frontex junto a dos estados miembro. El vuelo, a través de un convenio de deportación con un país extranjero, realiza recogidas de migrantes en diferentes puntos geográficos de la Unión Europea antes de partir definitivamente al país de destino. Ver más en Campaña Estatal por el Cierre de los CIE. «Paremos Los Vuelos », (Cambalache, 2014). 
Siguiente página:

Cartografía del paisaje legal de la frontera de la Unión Europea en función de las principales normativas generadas 1990-2015 (Elaboración propia)
De arriba a abajo:

Mapa de las rutas migratorias elaborado por Frontex (Frontex; 2012); Mapa de las operaciones policiales de Frontex y países miembros involucrados (Migreurop; 2012) sistema de monitorización y cartografiado en tiempo real de las principales rutas migratorias y dinámicas a lo largo de todo su territorio. Por primera vez, y de manera transnacional, se abordan estudios periódicos con una función fundamentalmente estratégica: la detección, innovación y mejora de la eficacia de los recursos que es necesario desplegar en los diferentes focos. En su propia descripción explica cómo opera estratégicamente a través de un cartografiado operativo:

El análisis de riesgos es el punto de partida de todas las actividades de Frontex, desde el alto nivel estratégico de toma de decisiones a la planificación e implementación de operativos.

Frontex recoge una gran cantidad de información de los Estados Miembro, los cuerpos de la Unión Europea, los países colaboradores y organizaciones así como de fuentes abiertas sobre el campo y más allá de las fronteras de la Unión Europea. Estos datos son analizados con la intención de crear una imagen del estado de las fronteras exteriores europeas así como los factores claves que las influencian y alteran.

Más allá de establecer tendencias e identificar los riesgos, Frontex también proporciona consejo sobre la adecuación de respuestas operativas a diferentes retos, incluidos el crimen transfronterizo en las fronteras exteriores de la Unión Europea. Esto ayuda a optimizar el uso de los recursos disponibles y mazimizar la efectividad de las acciones llevadas a cabo. El análisis de riesgo de la agencia es usado para asesorar a un alto nivel de toma de decisiones así como para la coordinación diaria de operaciones conjuntas ${ }^{17}$.
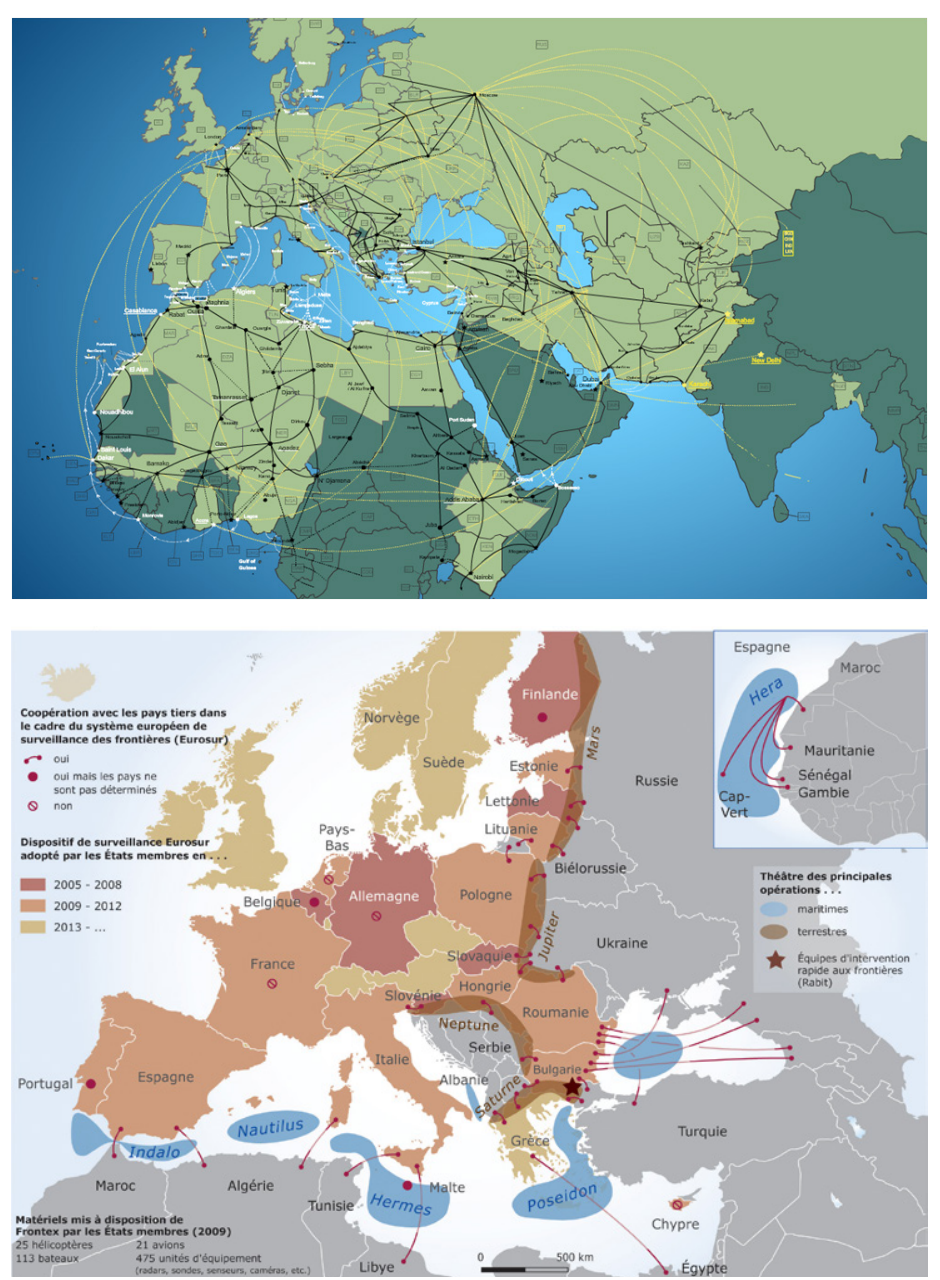

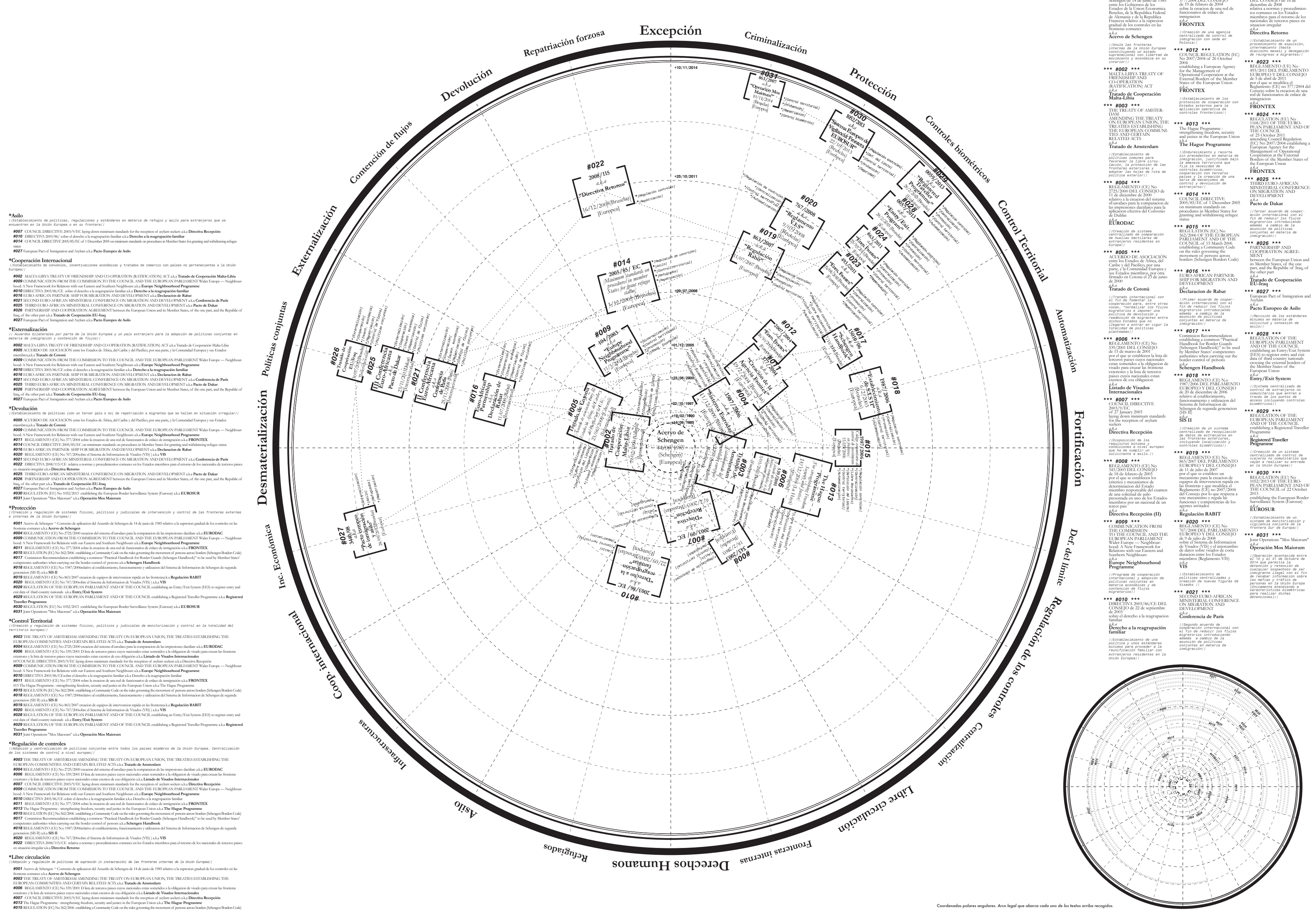
Este texto señala dos cuestiones fundamentales para entender el impacto de estas políticas de fortificación y centralización. La primera de ellas, la transescalaridad asociada al dispositivo-frontera a la que nos remite la última parte. Frontex actúa a través de dinámicas en escalas aparentemente no vinculadas pero con una relación directa: por un lado la detección y actuación a nivel geopolítico en los principales focos y, por otro, a través de despliegues operativos concretos que afectan no a grandes dinámicas migratorios sino a cada cuerpo -como el caso de los ya estudiados vuelos de deportación y todo el ensamblaje asociado a cada uno de ellos-. Para asegurar la eficacia territorial de esta agencia, su labor de cartógrafos, es necesario disponer de un conjunto, lo más vasto posible, de datos de diferente naturaleza acerca de la situación de los migrantes dentro del territorio. No sólo sus características físicas o biométricas, sino una posición actualizada, lo que requiere un acceso y control mucho más permeable y cotidiano: los controles policiales, los registros municipales, sanitarios... Todo ello actualiza una cartografía potencial de un cuerpo migrante que ya no es un flujo sino una multitud de puntos presentes en el territorio. Si hacia dentro queda claro como una serie de regulaciones han centralizado y generado una base común de datos entre estados, queda preguntarse cuales han sido los motivos para que países exteriores también colaboren en la construcción de este dispositivo.

Si la fortificación entendida como una centralización común de los cuerpos y políticas en materia de fronteras - no ya una centralización física sino desterritorializada- permite la implementación de este sistema de control territorial, la extraterritorialización es la segunda pieza clave. El tratado de Cotonú, firmado en el año 200o, supone el punto inicial de una serie de tratados y acuerdos internacionales para fomentar la cooperación en inversiones con los Estados de África, Caribe y del Pacífico, y a la vez establecer una política de agilización a la hora de tramitar las devoluciones de migrantes a los países exteriores a la Unión Europea. A la ratificación de este tratado le siguieron, desde el 2006 hasta el 2012, una serie de conferencias internacionales destinadas a estrechar lazos de colaboración entre estados africanos y europeos, que además ahondaba en la facilitación de devolución y deportación. Es decir, en términos de flujos migratorios, a estrechar lazos entre potenciales emisores y receptores de migrantes. La Declaración de Rabat, en el año 2006, La II Conferencia Euroafricana - o conferencia de París-, en el 2008, o la III Conferencia Euro-aficana Pacto de Dakar- son los esfuerzos comunes para expandir, más allá del perímetro del espacio Schengen, las lógicas fronterizas de producción territorial ${ }^{18}$.

La Unión Europea establecía así, no de una manera intencionada -o estratégicamente prevista- pero sí en base a tendencias muy claras qué prioridades definían su política territorial. Por un lado, una consolidación de un sistema de control sin presencia física en el territorio pero eficaz al ensamblar infinidad de material de archivo de diferente procedencia, haciendo una cartografía a tiempo real de la posición y características de los migrantes dentro de la Unión Europea. Y, por otro, el establecimiento de una alianza que agilizase o ralentizase el flujo de los migrantes antes y después de acceder al espacio Schengen. La Directiva Retorno ${ }^{19}$ - aprobada en diciembre de 2008 en

18 Una estrategia que, no debemos olvidar replica en buena medida las lógicas coloniales y geopolíticas presentes hasta medio siglo antes. Los países africanos sirven en primer lugar como foco de producción de una mano de obra que puede aceptar unas condiciones laborales mucho inferiores dada su condición de irregularidad y, en el momento que no son necesarios, el país africano sirve además de receptor forzoso de los mismos -o de externalización de unas prácticas policiales que no serían toleradas por el marco institucional y legal de la Unión Europea- a cambio de un aporte económico.

19 Cuyo nombre completo es la DIRECTIVA 2008/I15/CE relativa a normas y procedimientos comunes en los Estados miembros para el retorno de los nacionales de terceros países en situación irregular. 
el parlamento europeo, tal vez ha sido la política capaz de conectar este esfuerzo de centralización desterritorializada de la Unión Europea con la externalización creciente a terceros países. Pero, más aún, la Directiva Retorno conecta una realidad geopolítica con una serie de procedimientos con un impacto claro a nivel territorial y espacial para cada migrante, al establecer los tiempos, espacios arquitectónicos y flujos a los que serán sometidos desde la fecha de su aprobación en su deportación. Si la externalización queda clara a través de la obligación y tratados firmados ya con terceros países, esta norma establece una serie de criterios comunes en materia de deportación y devolución de migrantes, tanto voluntariamente como de manera forzosa. Las arquitectónicas del internamiento adquieren un marco común donde los migrantes pueden ser internados en función de cada Estado- hasta un máximo de dieciocho meses hasta su deportación en caso de que el país no coopere en la agilización del trámite. Junto a esto, establecimiento de garantías y derechos fundamentales mínimos que todos los estados han de asumir.

En definitiva, la Directiva Retorno como consecuencia inmediata de la suma de una serie de políticas no intencionadas a priori, al igual que Frontex, ensamblan en sus procedimientos una serie de mecanismos de diferente naturaleza con un impacto territorial tan claro que sobrepasa la condición escalar del marco de actuación geopolítica desde donde se enuncia. Su afectación a la construcción espacial de la totalidad del territorio europeo media, en el primer caso desde los protocolos y condiciones de deportación y, en el segundo, del control monitorización y dispositivos policiales, a una escala que sólo puede ser concebida desde el cuerpo que se enfrenta a ella por su situación irregular. Una frontera ya totalmente desterritorializada, que opera apoyándose en infraestructuras políticas, policiales y económicas tanto hacia fuera como hacia dentro del territorio que delimita. Una frontera que ya no establece una distinción geográfica para su operación sino que se superpone en su totalidad y que, como afirma Balibar, "se está convirtiendo idéntica al territorio al que se suponía tenía que circundar, o en cualquier caso, prácticamente indistinguible, continuamente mezclada con el territorio. Deconstruyendo así el símbolo de una línea que no pertenece ni a un territorio ni a otro" ${ }^{20}$. Una frontera que homogeneiza el espacio al superponer las lógicas de la frontera a la vez que es capaz de hiper-especializarlo al ser cada cuerpo -monitorizado en tiempo real- el que active estas lógicas en función de su situación, sus acciones y su desplazamiento.

\subsubsection{OPERACIÓN MOS MAIORUM. PROTOCOLOS Y ESPACIO PÚBLICO.}

Es importante entender como esta concepción geopolítica del territorio, la centralización de la gestión de fronteras de un sistema nacional a otro supranacional, es capaz de afectar a cada cuerpo de manera individualizada. No son los flujos migratorios -enunciados a nivel global- sino cuerpos concretos muy específicos los que encarnan y sufren estas lógicas del dispositivo frontera. Pero también lo es un espacio público y unas arquitecturas que, sin estar vinculadas a la frontera se vuelven parte del dispositivo de manera momentánea. Así, de la valla y los centros de internamiento, la frontera contemporánea es capaz de materializarse también en locutorios, estaciones de tren, paradas de autobús o incluso en pistas polideportivas de cualquier centro urbano. Esto es lo que ocurrió en el parque Casino de la Reina en el barrio madrileño de Lavapiés, 
donde de manera momentánea un espacio público deportivo se convirtió en una arquitectura ligada al dispositivo frontera. ¿Qué mecanismos espaciales habían permitido esta transformación efímera pero radical de un espacio cotidiano?

Entre el trece y el veinticuatro de octubre de 2014, un único texto de carácter policial, un protocolo operativo, convirtió la totalidad del espacio Schengen en un espacio de excepción, en tanto que -según su definición- se suspendían de manera temporal las leyes existentes en un territorio para superponer un nuevo orden operativo. Sin embargo, frente a la noción clásica de excepcionalidad homogénea y de alta intensidad, se ejecuta un espacio de excepción de baja intensidad y altamente selectiva en cuanto a sus objetivos. La Operación conjunta Mos Maiorum $^{21}$ activó durante dos semanas esta excepcionalidad en la totalidad del espacio Schengen donde a cada migrante irregular se le impidió su acceso al espacio público o, al menos, al acceder a él era susceptible de ser identificado, detenido e interrogado por su mera apariencia física. La operación, coordinada por el ejecutivo italiano -el Ministerio de Interior- con el apoyo de Frontex, se saldó con la detención de diecinueve mil trescientas veinticuatro migrantes en seis mil actuaciones tanto en el perímetro exterior como, fundamentalmente, en el interior del espacio Schengen. En el caso español, la cifra asciende a trescientas cuarenta y seis, donde sólo cuarenta y dos se detienen en el perímetro exterior ${ }^{22}$. Es la operación más exitosa en términos de cifras absolutas realizada, precedida por las operaciones Aphrodita y Perkunas. Las lógicas de la frontera se extendían a la totalidad del territorio a través de una operación policial cuyo objetivo declarado- consistía en generar una cartografía en tiempo real de los flujos de migración irregular. Así lo explicaba el propio texto:

La operación conjunta "MOS MAIRORUM" será una operación cuyo objetivo es debilitar la capacidad de grupos criminales organizados que faciliten la inmigración ilegal a la Unión Europea y se centrará en los cruces ilegales de fronteras. Otra meta de esta operación es recabar información, con propósitos de inteligencia e investigación, centrada en las principales rutas seguidas por los migrantes para entrar en el área común y el modus operandi usado por las redes criminales para traficar con gente hacia territorio europeo, centrándose también en movimientos secundarios ${ }^{23}$.

Sin embargo, es la manera de llevar a cabo este objetivo policial el que conecta la realidad geopolítica de los flujos migratorios globales -y las llamadas redes de tráfico de migrantes- con la concreción física de cada cuerpo. Para alcanzarlo, se desglosan una serie de protocolos, donde el primer punto de los objetivos explicita claramente los modos, así como la dimensión transescalar que este proceder adquiere: "aprehender migrantes irregulares y extraer información relevante a efectos de investigación e inteligencia”. El proceso de extracción de información, a través de un interrogatorio en dependencias policiales, está estructurado de manera que también sea posible cartografiar no el flujo global como una cuestión asbtracta sino con datos actualizados de cada cuerpo que lo conforman, las escalas se obvian al incluir datos tales como el lugar y hora de detención, rasgos físicos, nacionalidad, documentación falsa, trabajo... junto con una serie de ítems que hacen referencia explícita a su proceso de llegada. La operación policial opera tanto para generar una cartografía del flujo migratorio previo a su llegada al espacio Schengen, como una monitorización

21 Operación Conjunta Mos Maiorum, del ro de julio, Consejo de la Unión Europa (Nota presidencial, I1671/14, Io de julio de 2014).

22 Informe final de la Operación Conjunta Mos Maiorum, del 22 de enero, Consejo de la Unión Europea (Nota de la Delegación Italiana ST 5474 2015, 22 de enero de 2015).

23 Informe final de la Operación Conjunta Mos Maiorum, del 22 de enero, Consejo de la Unión Europea (Nota de la Delegación Italiana ST 5474 2015, 22 de enero de 2015). 
extraordinariamente precisa de cada uno de los detenidos en su posición actual incorporando una nueva capa de información que, de otra manera, sería imposible obtener.

A pesar de que la única indicación sea la extracción de información para elaborar una cartografía en tiempo real, como señala State Watch, no existen garantías que, una vez detenidos no sean incorporados al ciclo de deportación por encontrarse en situación irregular ${ }^{24}$. La cartografía elaborada por Mapping Mos Maiorum, así como los informes de State Watch, nos permite visibilizar como se habían transformado los escenarios y trasladado de la periferia -territorial y urbana- a espacios e infraestructuras centrales, barrios céntricos y nodos de transporte como estaciones de tren o autobús ${ }^{25}$. Las consecuencias espaciales eran claras, las detenciones se extendieron durante dos semanas en diferentes puntos estratégicos, pero también espacios cotidianos que se hibridaban de manera instantánea con las lógicas de producción del espacio fronterizo. Un espacio que ya no era articulado en primera instancia a través del tatuaje biopolítico -el conjunto de capas de información superpuestas al cuerpo como entidad física-, sino simplemente su apariencia era lo que determinaba el grado de exposición a una mayor o menor violencia espacial.

La cartografía Map the Mos Maiorum! pone de manifiesto la posibilidad de divergencia entre un protocolo policial enunciado en abstracto y su materialización real, señalando cómo es no ya el cuerpo, sino su apariencia la que primaba en buena parte de las identificaciones. $\mathrm{O}$, dicho de otro modo, cómo la apariencia física era el primer vector que activaba un espacio fronterizo independientemente de que se correspondiese con el cuerpo específico migrante irregular- que se pretendía localizar. Así, frente al "evitar usar tratamiento discriminatorio en base a ningún parámetro como sexo, raza, origen social o étnico, religión" ${ }^{26}$ aparecen una serie de casos registrados donde precisamente la apariencia es el detonante fundamental. En Zaragoza "La policía nacional paraba a la gente sólo por el color de su piel (siempre negra)” ${ }^{27}$ reza una de las entradas, mientras que otra indica la presencia de "Policía Especial en la Estación Central. Cuando fueron preguntados contestaron que estaban bucando refugiados ilegales con 'color oscuro de piel"' 2829 .

$24 \mathrm{Al}$ pensar en esta situación desde las lógicas del dispositivo, no tiene porque haber una intencionalidad directa o relación lineal entre una acción y la siguiente, sino tan solo una disposición proclive a que esto suceda. Esto claramente permite entender cómo a pesar de que la intención sea únicamente recabar información, al exponer a los migrantes irregulares a una detención policial es altamente probable que se altere su situación dentro del flujo migratorio, haciendo mucho más probable el inicio de su proceso de expulsión.

25 Del mismo modo que la Operación Mos Maiorum se articula bajo un intento de actualizar la cartografía de los flujos migratorios dentro y fuera del Espacio Schengen, este ejercicio de contracartografía visibiliza las consecuencias espaciales del dispositivo policial para una audiencia que, de otra manera no accedería al texto legal. Así, organizaciones de la sociedad civil a través de un ejercicio de mapeado colectivo, de recabar información a través de diferentes fuentes, se lograron mapear localizaciones, obtener cifras y extraer a la luz pública la otra cara de un ejercicio cartográfico basado en el ejercicio de la violencia espacial y policial.

26 Informe final de la Operación Conjunta Mos Maiorum, del 22 de enero, del Consejo de la Unión Europeo (Nota de la Delegación Italiana ST 5474 2015, 22 de enero de 2015).

27 Nadir.org , entrada en mapa, "La policía nacional paraba a la gente sólo por el color de su piel (siempre negra)”, Map Mos Maiorum!, acceso el I5 de noviembre de 2017.

28 Nadir.org , entrada en mapa, "Policía Especial en la Estación Central. Cuando fueron preguntados contestaron que estaban bucando refugiados ilegales con 'color oscuro de piel”, Map Mos Maiorum!, acceso el I5 de noviembre de 2017.

29 A pesar de que no es posible validar la información presente en esta cartografía colectiva, la repetición de entradas similares hace viable pensar que sí existió un patrón reiterado de identificación en función de la apariencia física. 


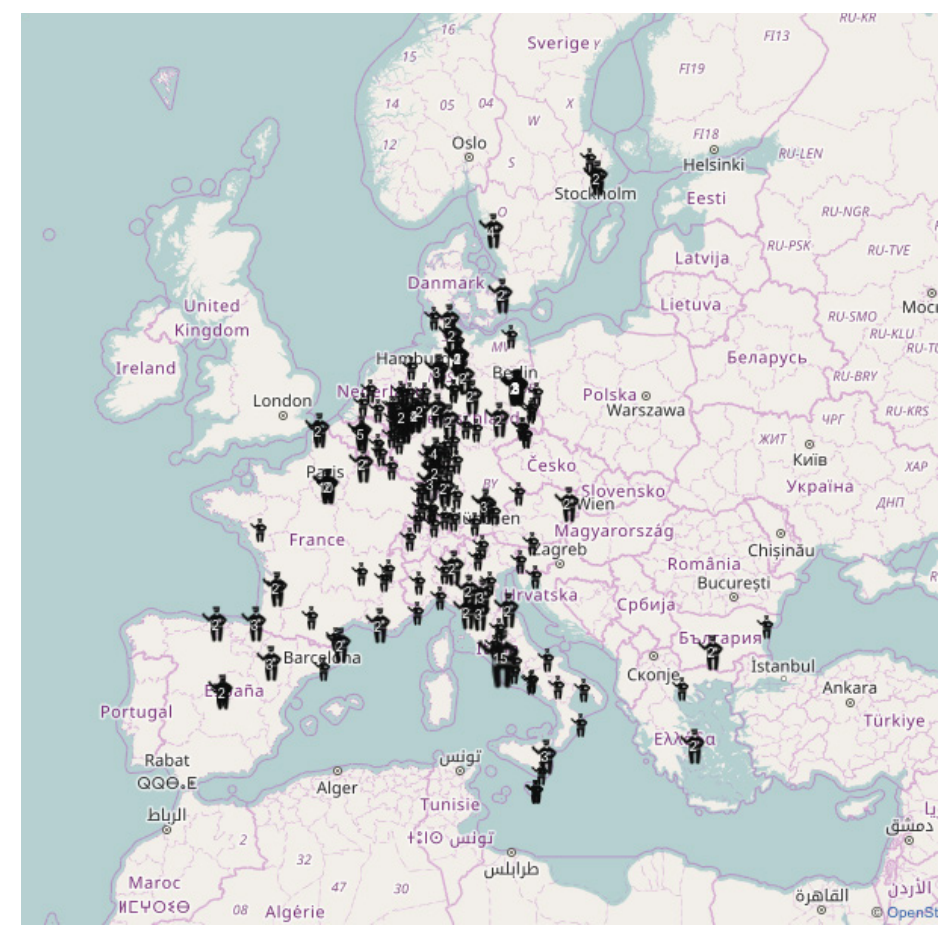

Este es el marco operativo donde se sitúa nuestro caso de estudio. Un paisaje legal completamente atravesado por multitud de normas y protocolos y al que se le superpone una nueva norma que no hace más que elevar el grado de excepcionalidad y violencia espacial sobre un cuerpo. Este hecho tiene una afectación inmediata en cómo se vive y utiliza el espacio público; utilizar el término negación del espacio público no es en este ejemplo una referencia metafórica sino una realidad incontestable, una reclusión voluntaria en localizaciones a salvo de esta violencia espacial. El ejemplo que utiliza Pepa Torres para definir la atmósfera percibida por parte de la comunidad migrante es muy reveladora:

Desde que en Lavapiés se informó del inicio de la operación «Mos Maiorum», las clases de español impartidas por el colectivo están «medio vacías». «Hemos organizado a los inmigrantes para que vayan en parejas estos días, hay mucho miedo a salir a la calle" ${ }^{30}$.

Sin embargo, cuando los cuerpos se exponen consciente o inconscientemente a esta excepcionalidad que no es reconocible o explícita -recordemos que esta operación policial se hizo pública a través de la filtración parcial del documento por parte de State Watch sino de baja intensidad, son víctimas de un paisaje legal que les es absolutamente hostil. Esto ocurrió en la pista polideportiva del parque Casino de la Reina en Lavapiés. Un hecho que explica de forma paradigmática el funcionamiento de esta operación policial pero también cómo el dispositivo es capaz de afectar a una realidad espacial concreta a través de elementos arquitectónicos que sólo se vinculan a la frontera durante unos instantes.

En el interior de la pista polideportiva ocurrió lo siguiente: "ocho policías encubiertos en una pista pública de baloncesto, frecuentada por jóvenes inmigrantes". Alli "les pidieron la documentación y se llevaron a dos en una furgoneta" ${ }^{31}$. La disposición de los elementos constructivos y el diseño del parque hizo que en el momento de la redada las posibilidades de acción fuesen tan limitadas que el resultado de la situación viene determinada, prácticamente en exclusiva por la disposición arquitectónica de la pista. Un espacio que, sin ser visualización online de Map Mos Maiorum! (Nadir.org; 2014) 
Siguiente página:

Cartografía de la detención en el Parque Casino de la Reina, diferentes fases y agentes involucrados (Elaboración propia)

Pista polideportiva en el Parque Casino de La Reina, Lavapiés (Elaboración propia; Madrid, 2015)

específicamente diseñado para eso, alcanzaba un alto grado de ritualización que descartaba cualquier alternativa que no desembocase en la detención de los migrantes. La cancha de baloncesto se hallaba, en 2014, rodeada perimetralmente por una valla de aproximadamente seis metros de alto con un único punto de acceso operativo -el resto habían sido bloqueados- de un metro de ancho. La valla, a su vez, estaba rodeada por un seto tupido que impedía cualquier visión del exterior, lo que dificultaba la visión de una posible aproximación a la puerta hasta que estuviesen prácticamente en ella. Esta decisión de diseño, que no recae exclusivamente en los arquitectos que la diseñaron sino en la suma de decisiones logísticas que conformaron el estado actual de la pista polideportiva, convirtió la cancha en un embudo. $\mathrm{O}$, dicho de otro modo, un gran espacio fácilmente controlable desde un único punto por parte de un número reducido de agentes.

La operación Mos Maiorum era el agente que provocaba una redistribución entre las relaciones del resto de agentes del dispositivo frontera. Era el detonante que alteraba las condiciones, las funciones y también el grado de violencia espacial permisible y detectable en un territorio extremadamente amplio. Un protocolo policial, enunciado a miles de kilómetros de distancia de la pista polideportiva, transformaba el espacio, pero solamente lo hacía para aquellos cuerpos que desafiasen las normas presentes entre el trece y el veinticuatro de octubre. La excepción se hacía selectiva, y mucho más difícil de detectar, pero no por ello con un grado de violencia menor. No obstante, más allá de este acontecimiento excepcional o de alta intensidad donde la hostilidad del entorno es absolutamente explícita, el espacio cotidiano donde se desarrolla la actividad de miles de migrantes posee una serie de mecanismos espaciales que lo convierten en un entorrno . Agentes, arquitecturas, elementos de diseño que no están específicamente vinculados al dispositivo frontera pero que pueden ser fácilmente apropiables si las condiciones así lo requieren y que colaboran a la construcción de ensamblajes efímeros, fácilmente desplegables en cualquier situación o escenario urbano que sea necesario. Una redada policial, un altercado, una identificación rutinaria en el metro son situaciones en las que pueden verse inmersos y donde la configuración urbana y tanto elementos arquitectónicos como elementos aparentemente no arquitectónicos, desempeñan una labor fundamental a la hora de construir mecanismos capaces de desplegar en cualquier punto las lógicas de la frontera.

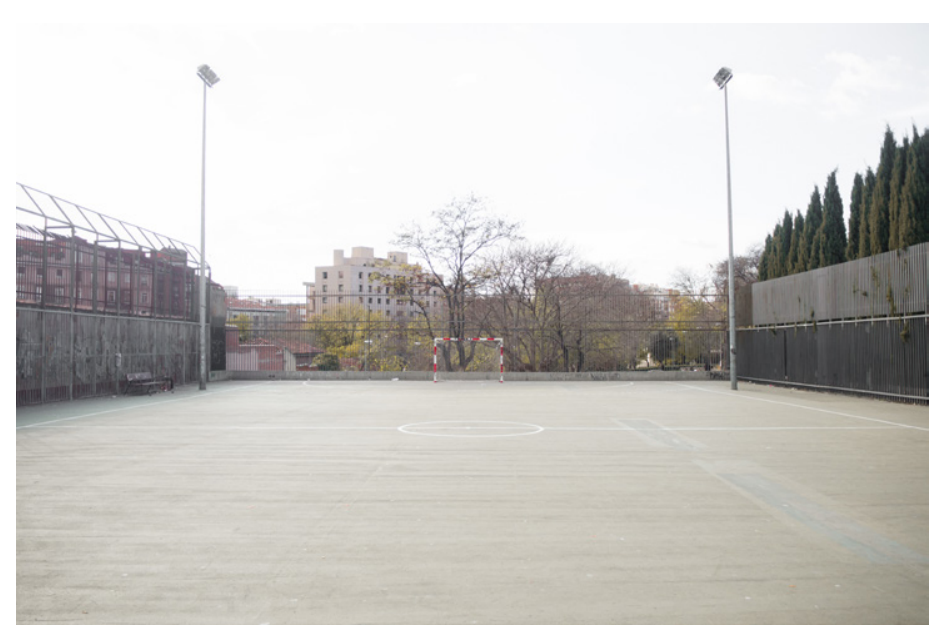




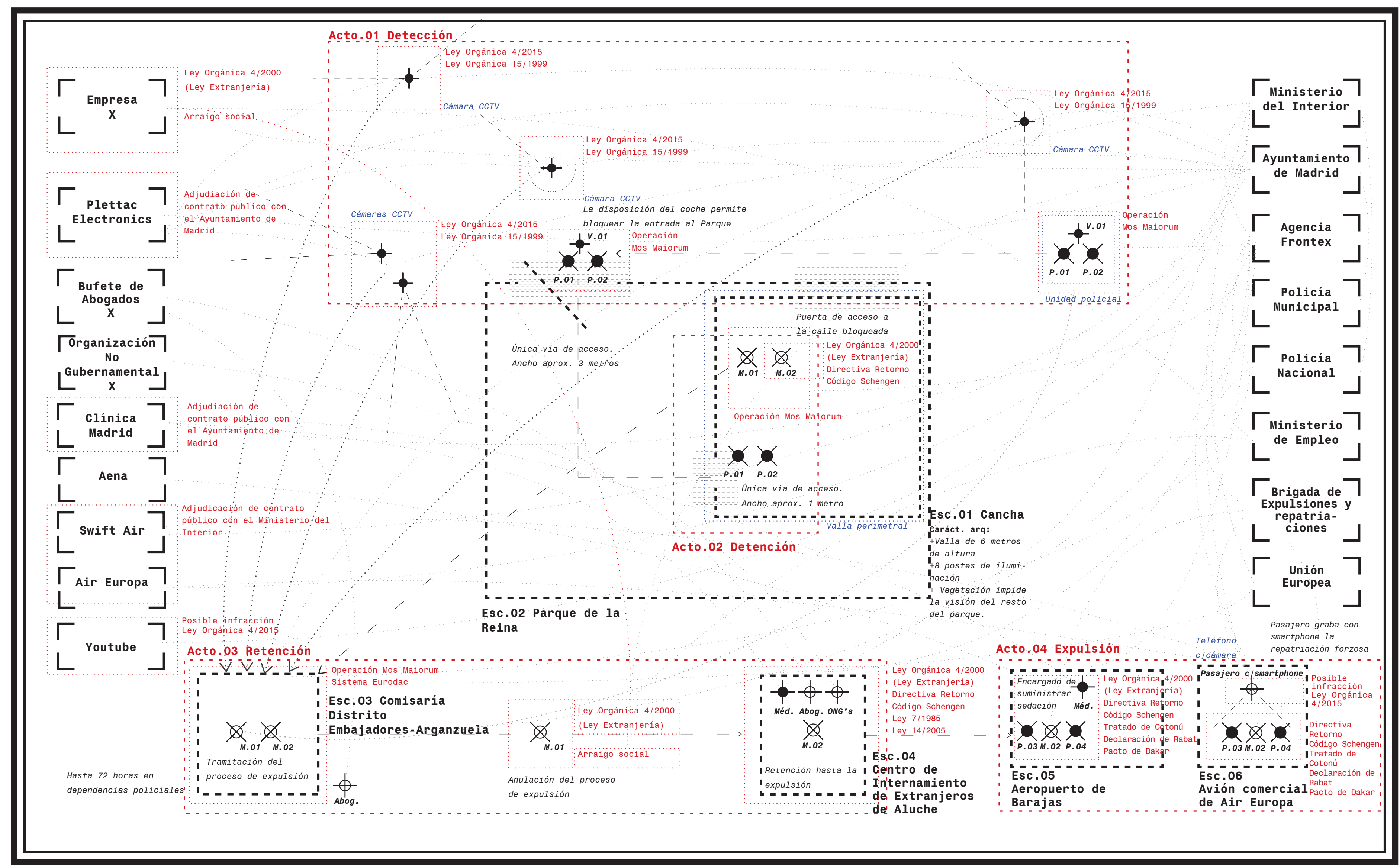




\subsection{DISPOSITIVOS ESPACIALES DE CONTROL EN ENTORNOS URBANOS. LAVAPIÉS COMO CASO DE ESTUDIO.}

La ciudad sigue siendo el gran laboratorio para la ley, su altavoz y tablero de juego. Y, por hecho, la ley es la medida de la ciudad, la (in)flexible, (in) cuestionable regla metálica que hace notar su presencia a través de pulgadas y centímetros de propincuidad y distancia, determinando la identidad y la diferencia. La ley es la reguladora de espacios entre lugares, conectando y cortando seres urbanos, objetos urbanos, deseos urbanos y miedos, entre ellos y con cualquier cosa que sea imaginada para estar fuera de lo urbano ${ }^{32}$. Andreas Philippopoulos-Mihalopoulos

En septiembre de 2018, entre más de cincuenta candidatos, la publicación digital Time Out nombraba a Lavapiés como el "barrio más cool del mundo", apelando a su identidad como un "lugar de convivencia de gente de todas partes". Esta apreciación es el eslabón final de un controvertido proceso de gentrificación y transformación urbana de más de una década de duración. Es necesario entender su situación actual para comprender bien las diferentes dinámicas urbanas que en el se están produciendo. Ubicado en el centro histórico de la ciudad, con una gran presión inmobiliaria dado el envejecimiento del parque de vivienda así como por el auge de los pisos turísticos, posee una población migrante superior al $\mathbf{2 0} \%$, según figura en el censo, más un número bastante mayor de migración irregular que vive, transita y realiza en Lavapiés su vida en común. Se está produciendo un desplazamiento entre un conjunto amplio potencialmente expulsable con la entrada de nuevos sectores permanentes - clase creativa- y puntuales - turismo- que demandan un nivel de seguridad ciudadana mucho mayor. Alcanzar el título de barrio más cool había obligado a implementar una serie de medidas encaminadas a minimizar los potenciales problemas de informalidad -política, social y migratoria- de un barrio situado en el epicentro de la ciudad. Para ello hemos de situar un punto de partida claro que recoge buena parte de las medidas llevabas a cabo a nivel urbano en la zona en la última década: el Plan Integral de Mejora de la Seguridad y la Convivencia de Lavapiés del año 2012.

Si, según Deleuze y Guattari, la actualidad se regía por parámetros de control frente a parámetros de vigilancia, esto desplaza el foco desde mecanismos explícitos y fácilmente detectables para cualquier observado a mecanismos con una impregnación mucho mayor en el tejido cotidiano, que pasan desapercibidos y sólo revelan su verdadera función en caso de necesidad.

Para entender como se ha producido este desplazamiento, y cuales han sido estas transformaciones urbanas, nos remitiremos a tres fuentes fundamentales a través de las cuales iremos hilando los diferentes agentes y mecanismos que articulan este ensamblaje. En primer lugar, el ya mencionado Plan Intengral de Mejora de la Seguridad y la Convivencia de Lavapiés, como un documento que establece una hoja de ruta prospectiva pero que, a la vez, señala las causas y medidas pasadas. En segundo lugar, el trabajo de campo desarrollado en el propio barrio. Y, por último, la labor investigadora de Santiago Ruiz Chasco que, desde la sociología urbana, ha centrado su trabajo en los diferentes modos de construcción de la 
seguridad ciudadana, tomando Lavapiés como caso de estudio ${ }^{33}$. De nuevo, los acontecimientos concretos detectados en el barrio nos permitirán abordar no sólo desde la generalidad sino desde una concreción muy específica las consecuencias espaciales de cada mecanismo analizado.

El análisis de cuatro agentes, que operan bien como un hardware o bien como software de producción espacial, nos permite comparar las diferencias entre mecanismos de naturaleza y características muy diferentes. El primero de ellos, el documento del Plan Integral de Mejora de la Seguridad y la Convivencia de Lavapiés, un conjunto de protocolos y políticas que propiciará la aparición e inclusión de nuevos agentes en el tejido del barrio, a la vez que condicionará el espectro de acciones y cuerpos que pueden estar en él -a través de la gestión de su exclusión-. El segundo, la instalación de cincuenta cámaras de seguridad en diferentes espacios públicos de Lavapiés nos permitirá cuestionar la vigencia de la vigilancia, centralizada o descentralizada en este caso, en el espacio público contemporáneo, así como la contra-vigilancia también puede ser empleada a la hora de gestionar las acciones permitidas en él. En tercero, el papel de la policía y en concreto del policía de paisano a la hora de ejercer una vigilancia, control y capacidad de acción mucho más inmediata. Y, por último, cómo el diseño urbano y la superposición de modificaciones realizadas en él a lo largo del tiempo constituyen también un entorno propicio a la disposición de ciertas construcciones espaciales mientras que impiden otras o, lo que es igual, cómo el espacio público es fácilmente controlable al incluir en su diseño ciertos parámetros. Todos ellos, en conjunto y sin una vinculación directa a las arquitecturas ni lógicas del dispositivo frontera, se desvelarán, en mayor o menor medida, fundamentales a la hora de construir un espacio urbano con capacidad para desplegar en él situaciones de excepcionalidad.

\subsubsection{CARACTERÍSTICAS Y CONSECUENCIAS URBANAS DEL PLAN INTEGRAL DE MEJORA DE LA SEGURIDAD Y CONVIVENCIA DE LAVAPIES}

En diciembre de 2012 se presenta el Plan Integral de Mejora de la Seguridad y la Convivencia de Lavapiés ${ }^{34}$, documento elaborado entre la Delegación de Gobierno, la Comunidad de Madrid, el Ayuntamiento y asociaciones vecinales con intereses económicos en el barrio. Al calor de la descentralización del 15-M en los diferentes barrios, la fuerte movilización social, vecinal y política en el barrio -además de una característica trama urbana- hacen que la Subdelegación del Gobierno, representada por Cristina Cifuentes en dicha fecha, promuevan un plan integral que aborde de manera específica la cuestión de la inseguridad dentro de Lavapiés ${ }^{35}$. El documento plantea una doble vía de transformación urbana: por un lado la mejora infraestructural del espacio público y privado

33 Santiago Ruiz Chasco, «Madrid de Norte a Sur: Análisis sociológico de las desigualdades sociales y la inseguridad ciudadana en los barrios de Lavapiés y Salamanca» (tesis doctoral, Universidad Complutense de Madrid, 2017).

34 Plan Integral de Mejora de la Seguridad y Convivencia del Barrio de Lavapiés de Madrid. (Ayuntamiento de Madrid, 2012).

35 Sí se habían implementado medidas parciales en la década previa a su publicación destinadas a la mejora y pacificación del barrio a través de diferentes aspectos: desde la instalación de cámaras de videovigilancia, la rehabilitación de viviendas, reformas del espacio público hasta la instalación de infraestructuras artísticas y educativas. Toda esta suma de operaciones urbanas ayuda a modificar sustancialmente el sustrato social del barrio a la vez que permanece inalterable una situación de infravivienda a la que migrantes sin recursos económicos pueden acceder. Así, esta pacificación del barrio a través de la inclusión de nuevas clases sociales en él, demanda medidas securitarias acordes a un nuevo imaginario, multicultural pero no conflictivo, de Lavapiés. 
pero, por otro, la mejora ambiental del espacio público en términos de seguridad. Dicho de otro modo, una mejora en términos no estrictamente arquitectónicos pero sí espaciales, para homogeneizar a grupos de población difícilmente capitalizables o concordantes con la nueva imagen urbana que se pretendía proyectar del barrio, usando la inseguridad como herramienta. La introducción aclara, en términos generales, cual es el objetivo prioritario del paquete de medidas a implementar en los próximos años:

Lavapiés es un Barrio importante por el espacio físico al que se extiende (el $28 \%$ del distrito Centro), y de la población que reside en él (en torno a los 40.000 habitantes con un origen multicultural). Se aprecian, en la actualidad, problemas de convivencia e integración, así como la existencia de actividades delictivas que generan un clima de inseguridad para los vecinos y comerciantes de la zona.

Dadas estas circunstancias, a día de hoy se requiere no sólo profundizar en la rehabilitación arquitectónica mediante actuaciones innovadoras que permitan hacer frente al problema de la infravivienda vertical, aún persistente pese a las fuertes inversiones realizadas, sino también avanzar en el desarrollo de un Plan de Mejora de la Seguridad y la Convivencia ${ }^{36}$.

El documento, tras este posicionamiento claro sobre la situación actual del barrio, desgrana las actuaciones, aportando para ello estadísticas y gráficas que validen la necesidad del mismo. Sin embargo, entra en franca contradicción al mostrar que las cifras de criminalidad - uno de los pocos criterios objetivos y mesurables a la hora de evaluar la inseguridad urbana- no es más alta que en zonas urbanas próximas. Así, a la vez que se señala la inseguridad existente se puede leer la siguiente aclaración: "Hay que recalcar que no existe en el Barrio de Lavapiés un problema delincuencial específico; la Tasa de Criminalidad (TCR) está muy por debajo de la media del Distrito". ${ }^{37}$ No es la primera ocasión que se apela a la inseguridad como mecanismo mediático, social y político de transformación urbana del barrio. De hecho, durante las últimas décadas, se ha apelado a diferentes figuras genéricas o concretas como focos fundamentales de inseguridad y conflicto social. En los años ochenta la drogadicción y crímenes derivados de ella pusieron a Lavapiés en la agenda mediática y, una década más tarde, un grupo de magrebíes menores de edad conocidos como la banda del pegamento acaparó titulares por la violencia y reiteración de sus crímenes. Es decir, la inseguridad en todo momento aparece ligada a Otro, un peligro potencial que es foco de una conflictividad social que debe ser eliminada a

Ver más en: Ruiz Chasco «Madrid de Norte a Sur: Análisis sociológico de las desigualdades sociales y la inseguridad ciudadana en los barrios de Lavapiés y Salamanca» (tesis doctoral, 2017), 287:294.

36 Plan Integral de Mejora de la Seguridad y Convivencia del Barrio de Lavapiés de Madrid. (Ayuntamiento de Madrid, 2012).

37 Sergio García señala cual es el verdadero objetivo del plan en términos urbanos, la consolidación urbana del centro de Madrid como un espacio seguro y turistificable:

Aunque el texto apenas introduzca medidas novedosas, sirve para reforzar la presencia policial y el dispositivo de videovigilancia que funciona desde 2010 con el fin de producir la "revitalización del barrio", esto es, abrir definitivamente el único melón gentrificable que queda en el centro de la ciudad -y que además resulta cada vez más incómodo por su vitalidad social y política- a base de hacer la vida imposible a sus vecinos de menor renta; si pensamos que estos actores sociales también son seres racionales que calculan costes y beneficios, el acoso policial debería conducirles al desplazamiento a otros espacios de la ciudad o del planeta. 
través de la expulsión o transformación del Otro. Como señala Ruiz Chasco, la inseguridad es usada como un motor de transformación social y urbana para Lavapiés:

la cuestión de la inseguridad en Lavapiés irá mutando su propia naturaleza a través de las últimas décadas, sin dejar de ser "el problema por antonomasia" de esta zona. Y como veremos, esa evolución tendrá poco que ver con las cifras oficiales de criminalidad del barrio, configurándose como un dispositivo a través del cual pacificar determinas relaciones conflictivas fruto de la mezcla social creciente del barrio ${ }^{38}$.

De las cuatro líneas estratégicas que establece el plan, tan sólo una hace referencia explícita a la actualización del parque de vivienda y el espacio público como posibles dinamizadores de la zona. El resto son medidas que, sin ninguna fisicidad o aparentemente sin arquitectura, tienen un impacto fundamental a la hora de configurar el paisaje legal del barrio bajo parámetros securitarios. Así, se plantean los siguientes ejes: "mejorar la seguridad ciudadana mediante el incremento de la vigilancia a pie y motorizada, tanto a cargo de agentes uniformados como de paisano", "potenciar la participación ciudadana para definir las actuaciones necesarias" como medida de prevención de actos delictivos, "impulsar la revitalización del barrio de Lavapiés mediante iniciativas" que no solo incluyan la "rehabilitación arquitectónica" sino la "mejora de la integración social y la dinamización económica” y, por último, la necesidad de "modificaciones normativas que permitan hacer frente a actividades generadoras de altos niveles de inseguridad ciudadana". El cuarto punto articula, dispone y decide qué cuerpos y acciones son admitidas en el espacio público y cuales han de ser expulsados, sancionados y perseguidos.

Es interesante además entender cómo el concepto de seguridad mismo se pretende imbricar en el tejido ciudadano de una manera mucho más sutil que en experiencias previas. En primer lugar, al aplicar nuevas regulaciones sobre el barrio, segundo, a través de la vinculación del tejido social como parte de los agentes responsables de la seguridad y, tercero, el incremento de agentes policiales -humanos y no-humanos-. Frente a la vigilancia entendida como un poder autoritario siempre presente, un control que se impregna y hace latente de una manera mucho más silenciosa y que sólo se manifiesta cuando es necesario. Esta idea de una seguridad ciudadana, donde la figura y responsabilidades del policía se implique y diluya en el tejido asociativo, pero también educativo como señala el Plan, posee además un alto grado de desterritorialización en el mismo sentido que plantea el dispositivo frontera. Ya no son exclusivamente las arquitecturas y figuras directamente asociadas a ella las que ejercen este control, sino que la inclusión de otras nuevas diluye esta diferenciación al amparo de la seguridad ciudadana, tal como señala Sergio García:

La seguridad es, entonces, ciudadana, construida por todos y cada uno de los miembros de la ciudadanía, pero de una ciudadanía que está individualizada y diferenciada en infinitas categorías sociales, cada una de las cuales porta derechos desiguales. Todos esos agentes individualizados y diferenciados $-\mathrm{y}$ si se des-cuidan, puestos a competir-co-producen la seguridad, aunque algunos se verán más perjudicados que otros en el funcionamiento del dispositivo securitario que lleva aparejada. Este dispositivo lo conforman arquitecturas, normativas, instituciones, imaginarios, discursos, prácticas, gestos y 
emociones, y es producido al mismo tiempo por multitud de agentes, desde el ministro del Interior a la igualmente famosa entre los movimientos sociales "vecina del quinto"39.

El plan establece puntos prioritarios del barrio, lo lee en términos que jerarquizan en cierta medida los espacios como enclaves a conquistar. Pero también señala ciertos cuerpos que suponen un mayor grado de conflicto o peligrosidad. Se ve de manera clara en el apartado que el plan dedica a la venta de droga ilegal, donde se señala tanto la nacionalidad de los supuestos vendedores -magrebíes y subsaharianos-como los espacios donde estos operan- Plaza de la Corrala, Plaza de Lavapiés, bocas de metro- e indica la necesidad de fortalecer operaciones en estos lugares ${ }^{40}$. Sin embargo, el enfoque del plan no está exento de asociaciones mucho más generales entre ciertos cuerpos y los problemas de convivencia que generan. Situación que se recoge de manera explícita en la siguiente afirmación:

En el Barrio de Lavapiés hay que tener en cuenta, como factor muy importante, el problema que se genera y que no podemos obviar, relacionado con la convivencia. Es de todos conocida la diversidad de ciudadanos, de diferentes características, que residen en este pequeño espacio, donde conviven: ciudadanos nacionales, muchos de ellos mayores y de edades avanzadas, que han nacido y crecido en el barrio; grupos de jóvenes, bastante relacionados con grupos antisistema de todo tipo [...] Por último, ciudadanos inmigrantes de multitud de países y culturas: asiáticos, países caribeños, etcétera.

Amalgamar esas distintas formas de ver y actuar de grupos tan heterogéneos crea tensiones y problemas de convivencia, es decir conductas incívicas, la mayoría de ellas de difícil encaje sancionador ${ }^{4}$.

El Plan, en definitiva propone tanto una serie de cuerpos como una serie de acciones que son directamente señaladas, expulsadas y sancionadas en caso de que se manifiesten en el espacio público. Bajo términos tan vagos como 'sensación de seguridad', 'orden público', 'salud pública' y 'convivencia' se establecen y discriminan qué y quien puede acceder al espacio público de Lavapiés y quien se expone a una violencia espacial ejercida a través de diferentes herramientas -sanciones, multas, detenciones, patrullas, agentes antidisturbios...-. 15M, grupos antisistema, magrebíes, subsaharianos, inmigrantes de multitud de países y culturas, son cuerpos señalados como problemáticos, pero también acciones específicas como la venta de droga, la ocupación de viviendas, delitos relacionados con el ocio, el consumo de sustancias estupefacientes... Todo ello se contrasta a su vez con la inclusión de cuerpos de policía, sistemas de vídeo-vigilancia, vehículos policiales... y acciones: patrullas, reuniones, control..., que se despliegan por el espacio público negándoselo o expulsando a aquellos cuerpos no autorizados.

Nada de esto guarda, a priori, relación directa con el dispositivo frontera y, sin embargo, logra exponer a un nivel de violencia espacial mucho mayor a cualquier migrante que resida en Lavapiés por una serie de condiciones donde su cuerpo puede ser señalado. Este documento altera a diferentes niveles el paisaje urbano, incluyendo nuevos agentes, agregando al dispositivo securitario nuevas variables

39 García, «Policías Cotidianas», en Enclaves de riesgo: gobierno neoliberal, desigualdad y control social (Madrid: Traficantes de Sueños, 2015), 57.

40 Plan Integral de Mejora de la Seguridad y Convivencia del Barrio de Lavapiés de Madrid. (Ayuntamiento de Madrid, 2012), p.12.

41 Plan Integral de Mejora de la Seguridad y Convivencia del Barrio de Lavapiés de Madrid. (Ayuntamiento de Madrid, 2012), p.13. 
y estableciendo un nuevo paisaje legal. Es este, en última instancia, el primer mecanismo que autoriza y regula un área urbana bajo unos parámetros claros, un algoritmo de producción espacial que ha de ser materializado a través de cuerpos que devienen ley y se encargan de hacer cumplir estas directrices. Son los agentes concretos los que dan soporte físico a este software, donde sus acciones, su desplazamiento a través de las calles del barrio, las asociaciones de comerciantes, los acontecimientos en las plazas los que harán patente -a través de la afirmación o el conflicto- este paisaje legal donde el Plan Integral de Mejora de la Seguridad y de la Convivencia del Barrio de Lavapiés es tan sólo una capa más.

\subsubsection{SISTEMAS DE VIGILANCIA PASIVA Y ACTIVA}

Situación de la videovigilancia en el barrio de Lavapiés (CNT; 2009)
En el año 2009 el Ayuntamiento de Madrid instaló una red de cuarenta y ocho cámaras de vigilancia con visión de $360^{\circ}$. Se generaba así una red de monitorización en tiempo real de prácticamente la totalidad del espacio público del barrio. Lavapiés se convertía, a través de esta infraestructura de control, en el barrio más videovigilado del centro de Madrid. Esta transformación responde a un plan coordinado iniciado en el año 2005 con la instalación de las primeras cámaras en el entorno de la Plaza Mayor, hasta alcanzar las ciento cuarenta y siete en todo el centro de la ciudad. Una infraestructura cuyo control no reside exclusivamente en agentes públicos sino que es mediada y actualizada a través de agentes privados o con diferentes intereses. Las cámaras instaladas por la empresa municipal de transporte, los sistemas de vigilancia del tráfico así como las cámaras instaladas por comercios privados, hacen del espacio público un territorio modulado a través de la exposición, presencia y ausencia de estos dispositivos independientes pero centralizados a través de un único sistema de monitorización. El sindicato CNT realiza una cartografía que localiza cada uno de los dispositivos, un mapa de densidades donde se acumula un mayor número de cámaras en función de la visibilidad y optimización de los recursos, así como de la jerarquía que establece sobre el espacio público al priorizar ciertas vías y áreas sobre otras.

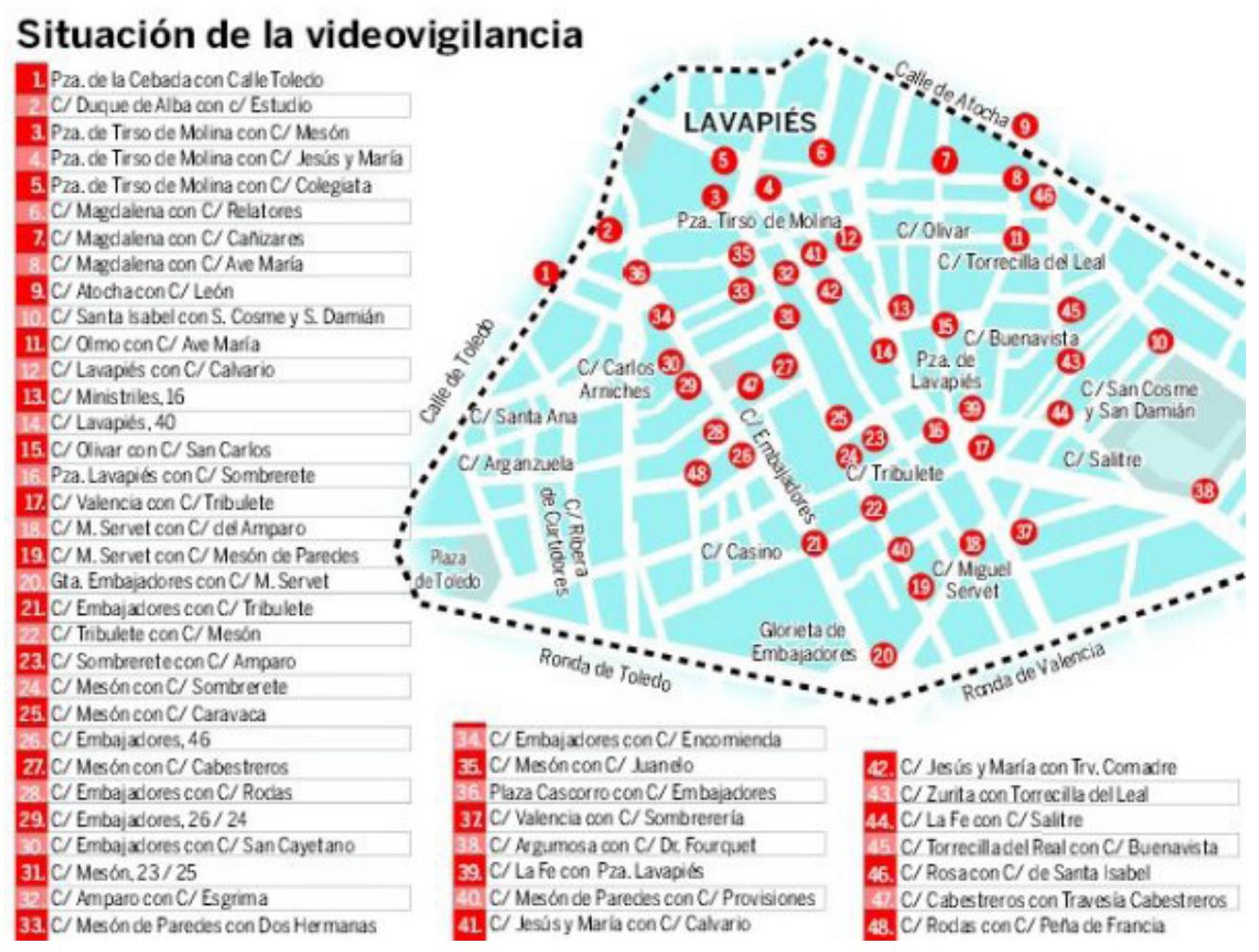


Lejos de ser la utopía tecnológica de múltiples dispositivos conectados la idea de paisaje vigilado enunciado por Mike Davis en Más allá de Blade Runner guarda relación con la construcción de una "vigilancia extensiva que rea un scanscape virtual, un espacio de visibilidad protectora que delimita cada vez más la zona en la que los oficinistas y turistas de clase media se sienten seguros" ${ }^{42}$. Es decir, la transformación urbana que se da en el centro de Madrid -en correlación con la práctica totalidad de centros metropolitanos occidentales al calor del fervor securitario- pasa por bascular "de un modelo territorial y temporal de la seguridad (algunos espacios y tiempos controlados) a un modelo extensivo del espacio e intensivo del tiempo, en el que las ciudades están bajo vigilancia permanente" ${ }^{\prime 3}$. De este modo, frente a un escenario altamente controlado, la implementación masiva de cámaras de seguridad convive con una cotidianidad que las asume y las sumerge de una manera prácticamente silenciosa en el tejido urbano del barrio. Sin embargo, las cámaras siguen ejerciendo su control sobre determinados cuerpos y acciones.

Frente a otros sistemas de vigilancia, las cámaras actúan como un panóptico difuso o electrónico que no requiere necesariamente una persona observando al otro lado para afectar al comportamiento del espacio público. Su sencilla instalación, su funcionamiento autónomo y su rápida identificación acentuada con señaléctica explícita que indica su presencia- hacen que sean un elemento urbano altamente preciado. Sin embargo, al igual que la función principal del muro había dado paso a nuevas connotaciones y usos, la cámara de vídeovigilancia también ha sufrido este proceso de transformación. Así, no es la vigilancia óptica de la cámara lo que se busca con su proliferación en el espacio público sino, como indica Deleuze, "la fórmula abstracta del Panoptismo ya no es, pues, "ver sin ser visto" sino imponer una conducta cualquiera a una multiplicidad cualquiera" 44 . Esta multiplicidad no es homogénea ni única, sino que afecta a cuerpos y acciones concretas que han sido calificables como no autorizadas dentro del espacio público. Esta selectividad espacial lo que implica son dos efectos antagónicos en la construcción espacial en función de qué cuerpos detecten la presencia de las cámaras de vídeovigilancia: para unos supondrá una herramienta de control e incluso violencia mientras que para otros aumentará su sensación de seguridad subjetiva.

En primer lugar, esta infraestructura urbana afecta a los cuerpos que excluye bajo su radio de acción en función de las acciones indeseables que realicen: "la mirada de la cámara no se enfoca a todo usuario de la calle de igual manera sino a aquellos quienes están predeterminados como descaminados - de forma estereotipo -, a través de sus aparienciaso maneras de ser, están marcados como no respetables" 45 . Una afirmación que una década después del auge de esta tecnología es matizable, como indica Varona ${ }^{46}$ en un estudio realizado sobre el impacto real de las cámaras de seguridad, dado que si bien su presencia es disuasoria, el ensamblaje urbano es rápidamente reconfigurable para encontrar nuevos espacios fuera del alcance de estos dispositivos. En segundo lugar, ese mismo dispositivo cualifica el espacio urbano como seguro o inseguro para la percepción de otro conjunto de cuerpos autorizados a transitar en él,

42 Mike Davis, Más allá de Blade Runner: La ecología del miedo, (Barcelona: Virus Editorial, 200I), 9.

43 José Miguel García Cortés, La Ciudad Cautiva: Control y vigilancia en el espacio urbano (Madrid: Akal, 2010), p.44.

44 Gilles Deleuze, Foucault (Barcelona: Paidós, 2015), p.60.

45 Gary Armstrong y Clive Norris, The Maximum Surveillance Society: The rise of CCTV, (Berg Publishers, 1999).

46 Gema Varona Martínez, Estudio exploratorio sobre los efectos del uso policial de la videovigilancia en lugares públicos (Donostia: Instituto Vasco de Criminología, 2012).
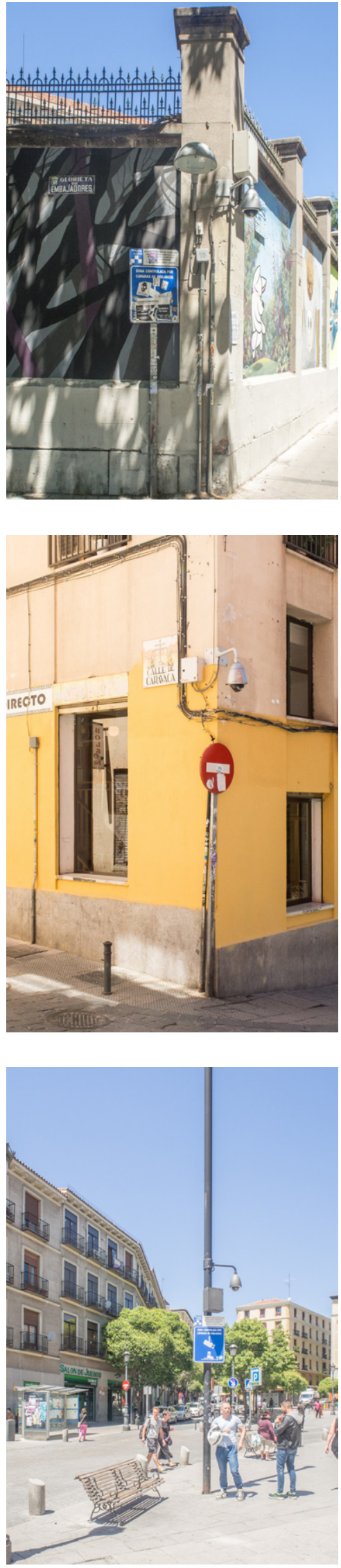

Cámaras de vídeovigilancia en el espacio público de Lavapiés (Elaboración propia; Madrid, 2015) 
Composición digital de la detención en Calle Amparo (Elaboración propia; Madrid, 2012)

a través de un aumento de la seguridad subjetiva: el área abarcable por una cámara de seguridad hace que la percepción de que se cometa un crimen sean, aparentemente, mucho menores.

Así, los cuerpos no autorizados han elaborado una serie de tácticas arquitectónicas que se valen del entorno inmediato, de las protecciones que ofrece el espacio público para reconfigurar en base a sus posibilidades de acción. De una lectura pormenorizada del entorno urbano, de la localización precisa de cada cámara, de su asunción como un elemento cotidiano más, extraen información para desplazar sus acciones a otras zonas ciegas. Pese a la cotidianeidad de estos actos, de una superación inmediata de la vídeovigilancia, no se puede negar la violencia espacial de baja intensidad que esta

infraestructura es capaz de ejercer sobre los cuerpos. Una violencia que niega el derecho a todo el espacio público expuesto a su radio de acción.

Con todo, es necesario cuestionarse si esta infraestructura urbana, distribuida, descentralizada y conectada en red sigue siendo un mecanismo eficaz en términos absolutos o si, por el contrario aún es heredero del paradigma de la vigilancia y no tanto del paradigma del control que define la espacialidad contemporánea. Frente a una presencia constante en el espacio público, pasiva, sin capacidad de respuesta inmediata ante un acontecimiento, aparecen respuestas dinámicas que se activan exclusivamente en el momento que sea necesaria en prácticamente cualquier punto del espacio público.

El Plan Integral de Mejora de la Seguridad y la Convivencia de Lavapiés señalaba que, además de las cámaras de vídeovigilancia ya instalada y el incremento de patrullas policiales a pie y motorizadas, era también necesario reforzar el número de patrullas de agentes de paisano en todo el barrio. Ni las cámaras ni las patrullas son capaces de obervar una realidad mucho más menuda y compleja. Su visibilidad les impide en cierta medida no ser reconocibles y, ante

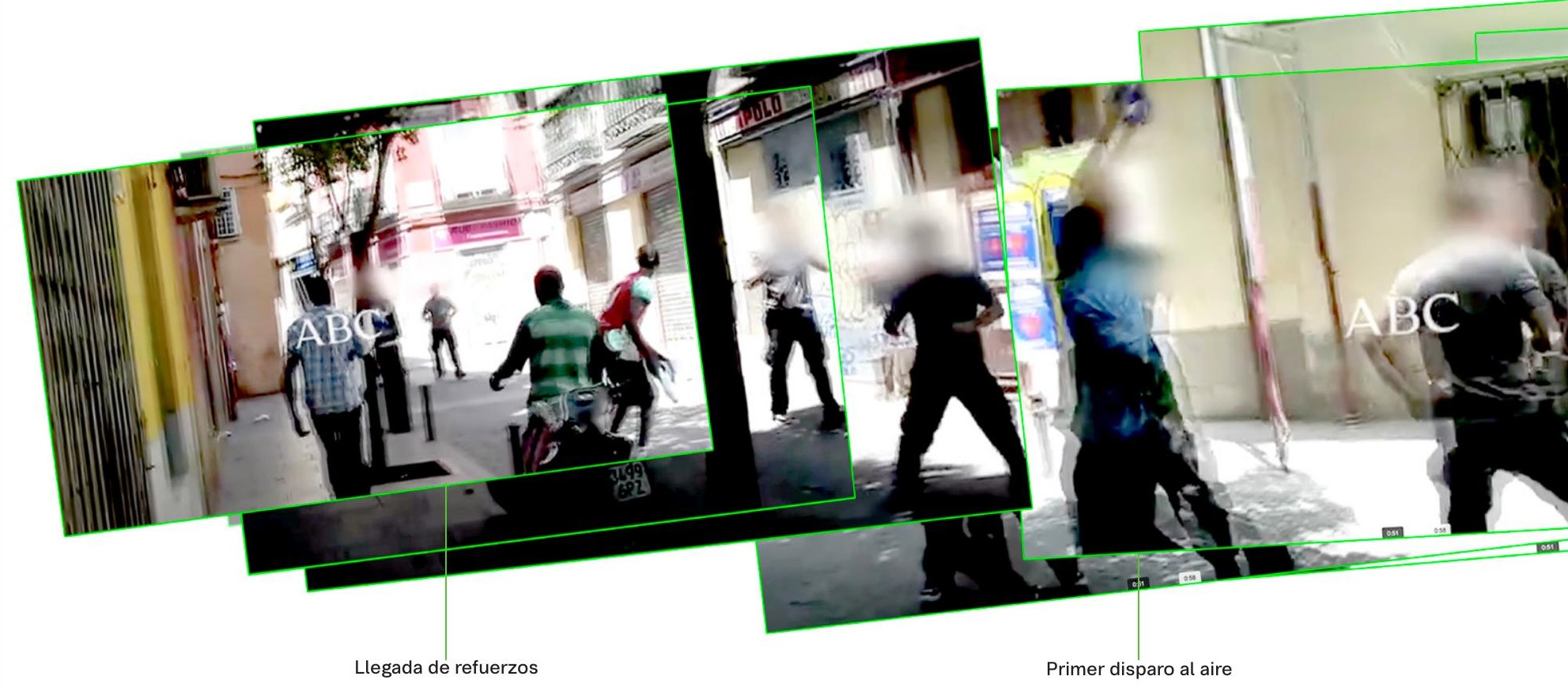




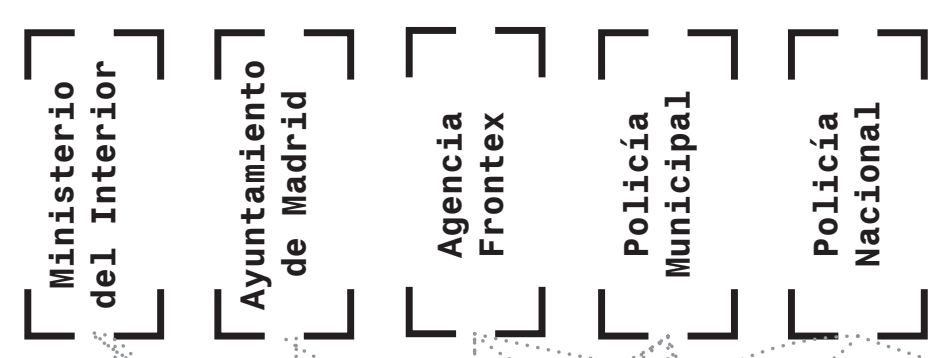
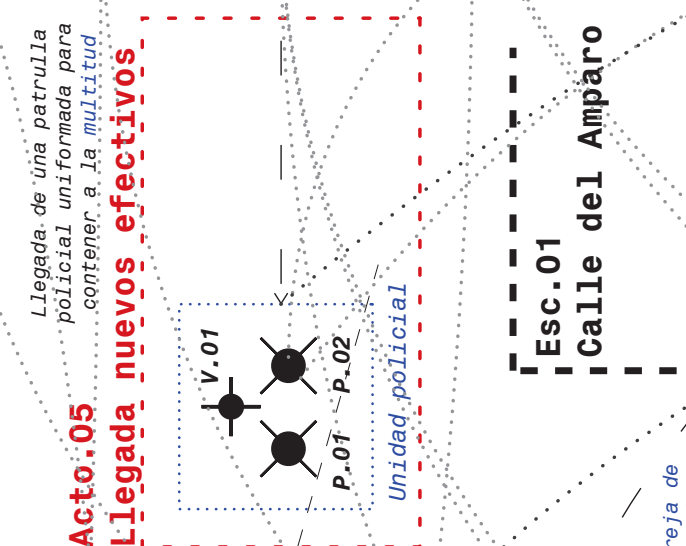

申:

일
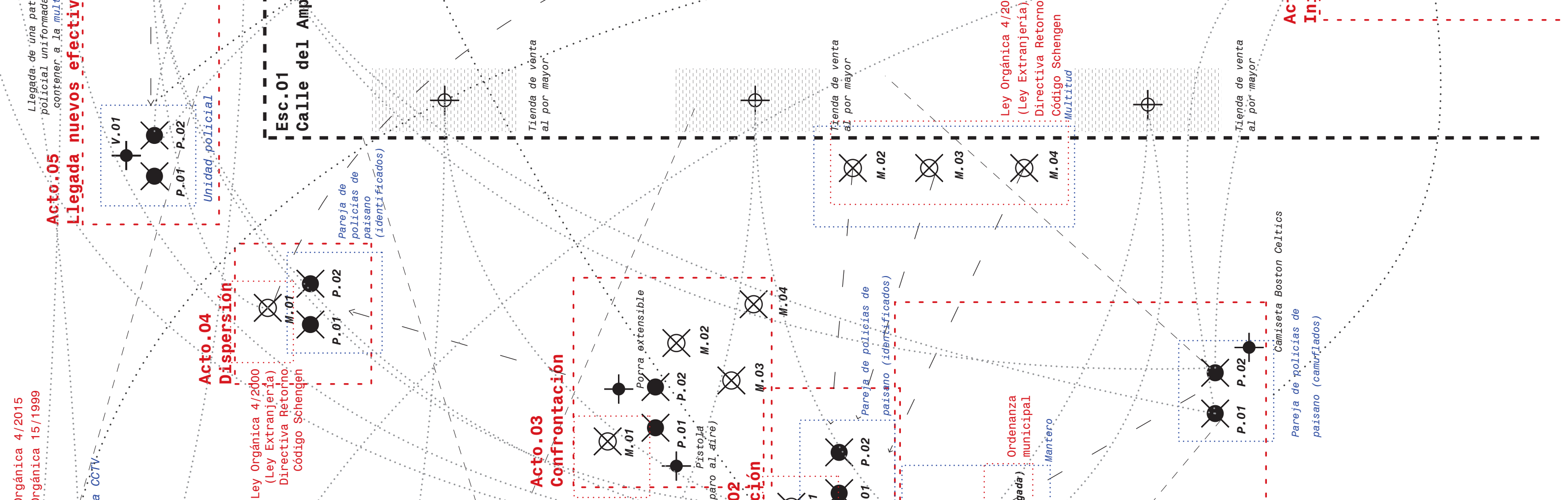

100
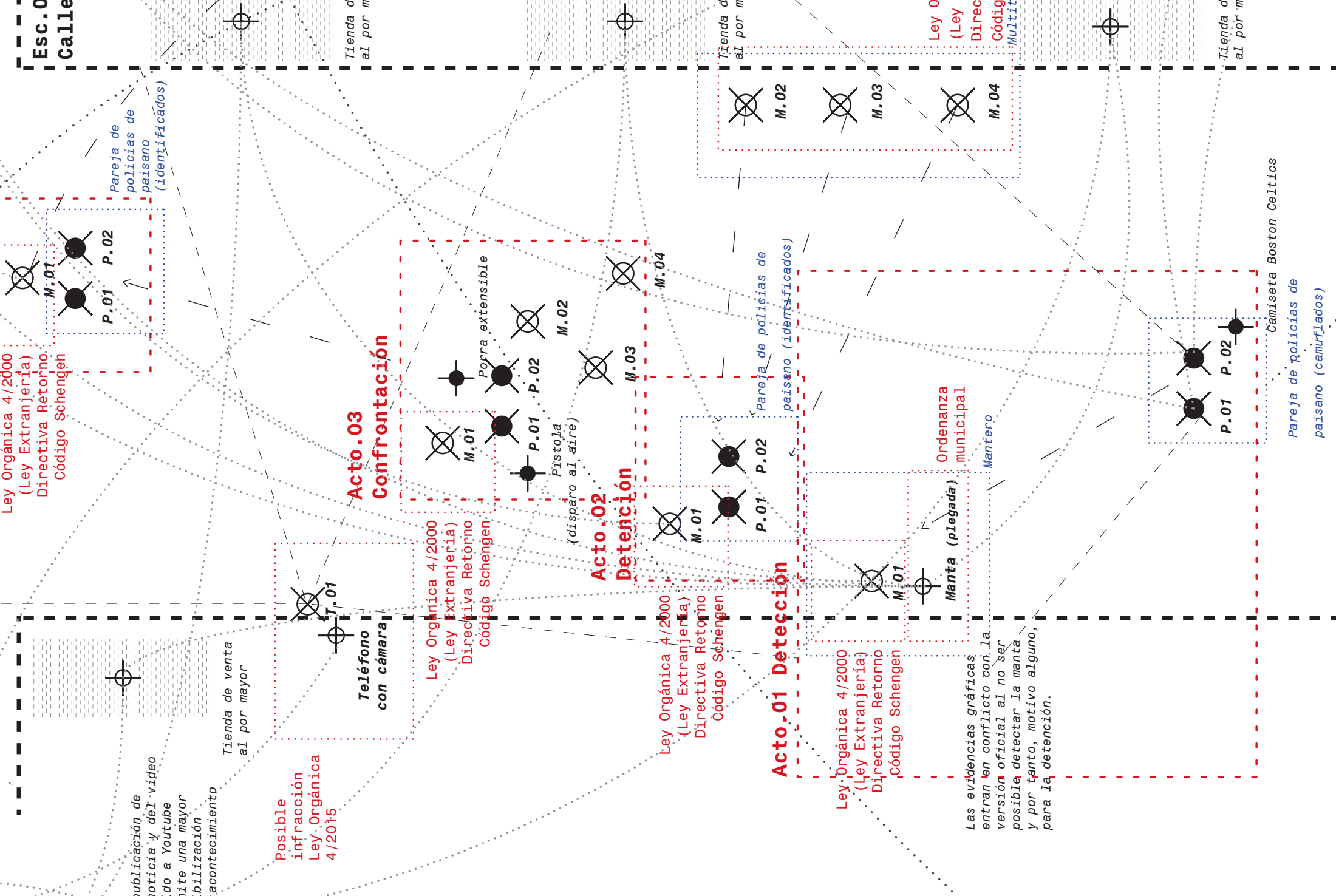

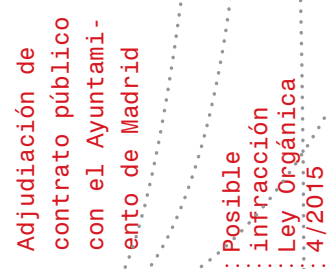

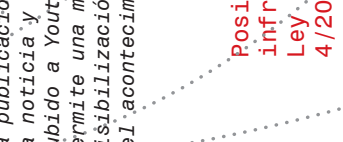

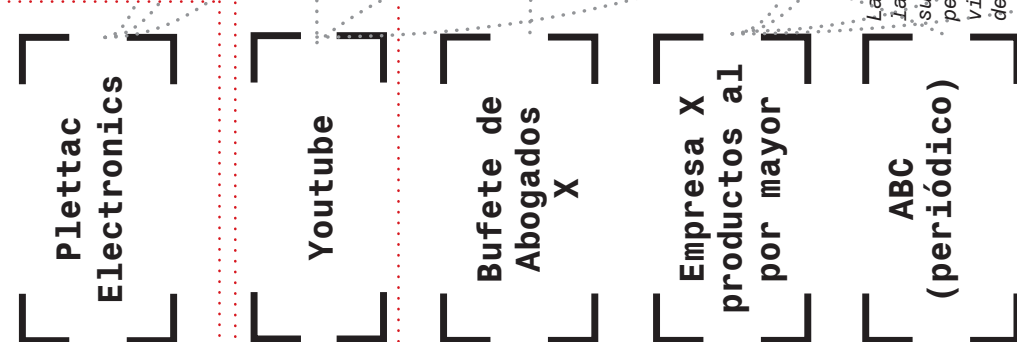


no penado por la Ley de Seguridad Ciudadana en el momento de su registro- el que permite contraponer una versión oficial con una reconstrucción forense de los hechos que evidencia un desarrollo alternativo. El vídeo muestra en primer plano tres hombres, dos de ellos con ropa deportiva y un tercero bajo la rodilla de uno de ellos, tumbado en el suelo mientras es esposado. Los dos hombres de pie son policías vestidos de paisano, el tercero supuestamente un mantero de procedencia subsahariana. Mientras lo incorporan, otro migrante increpa a la pareja cada vez con mayor virulencia. Como respuesta, el policía que retiene al mantero desenfunda su pistola mientras que el otro agrede al protestante con una porra extensible en reiteradas ocasiones. En apenas cincuenta metros, se congrega un pequeño grupo de vecinos del barrio que entre gritos avanza hacia la pareja de policías mientras ésta se retira a la espera de refuerzos. Durante este trayecto son varios los disparos al aire que ejecuta uno de ellos. Al llegar a la intersección entre Calle del Amparo y Travesía Comadre, una segunda pareja de policías de paisano aparece para disolver a la multitud que protesta y llama racistas a la policía por la actuación que acaba de realizar. De nuevo, ni una sola identificación más allá de la porra extensible y de las acciones que realiza distingue a estos nuevos agentes de cualquier transeúnte y, sin embargo, la transformación que su sola presencia provoca en el espacio es evidente. Únicamente al final del metraje, aparecen dos patrullas motorizadas para controlar la situación. Según la plataforma vecinal del barrio, cuatro personas en total fueron detenidas por estos hechos.

$\mathrm{Al}$ igual que la porra extensible del policía se despliega en fracciones de segundo antes de ser plenamente operativa, este ensamblaje policial no requiere más que una visibilización inmediata de una serie de agentes para alterar las relaciones entre ellas y, por tanto, la construcción del espacio público. En el momento que, por la identificación o por la acción de detener al mantero, dejan de ser transeúntes para devenir policías, el espacio se transforma convirtiéndose en un lugar de excepción absoluta donde las normativas habituales son puestas en suspenso. El ejemplo más claro de esta excepcionalidad es el uso de armas no reglamentarias -la porra extensible- así como los disparos efectuados al aire en el espacio público $4^{8}$. Nada de esto se rige por los protocolos policiales establecidos y, sin embargo, nada cuestiona su legitimidad. Y es esta excepcionalidad, instantánea y de baja intensidad la que mejor explica las lógicas contemporáneas de la frontera: solamente la presencia de un cuerpo no autorizado realizando una acción no autorizada en el espacio público es capaz de detonar una serie de mecanismos espaciales que generen un grado de violencia espacial tal que, de tornarse constante, jamás sería tolerado dentro del espacio público. Solo un cuerpo, como el migrante, que es considerado como no autorizado y que no posee los mismos derechos y garantías que un ciudadano -aquel que tiene pleno derecho al espacio público-

En este acontecimiento es importante entender como cada cuerpo físico que se enfrenta a la pareja de policías lo hace deviniendo un cuerpo múltiple o multitud. Este espacio de excepción también posibilita que, ante la falta de otros recursos o alternativas espaciales, los compañeros del mantero detenido decidan exponer su cuerpo y su carne a la violencia policial como medida disuasoria -con efecto nulo-. Pero es esta exposición a la violencia, a ser heridos por una porra metálica o alcanzados por una bala, también la única manera de visibilizar la violencia de una realidad espacial para comunicar, afectar y solidarizar a otros cuerpos allí presentes. Así, esta visibilización crítica que también se consigue en otro tiempo más dilatado y con otro alcance es la que permite generar posiciones críticas más allá de la esfera del cuerpo migrante. 
El papel de la policía resulta fundamental para entender cómo funciona el dispositivo frontera en espacios con una ligazón menos directa a ella. A diferencia de la valla y el centro de internamiento, donde el papel policial es el de reforzar una arquitectura explícitamente orientada a restringir el movimiento y acciones del cuerpo migrante, en la post-metrópolis se altera esta función. La diferencia fundamental es el grado de relación o de visibilización de las normas presente en cada uno de ellos y lo tolerable que éstas sean a ojos de la sociedad. Si en los dos primeros casos, se asumían como espacios más allá de la norma geográfica o funcionalmente, la ciudad es precisamente lo diametralmente opuesto. Y es precisamente en la metrópolis moderna y contemporánea donde surge la policía como un mecanismo de control espacial que luego será extrapolado a espacios de excepción -como la valla o las arquitectónicas del internamiento-. Un control espacial que ha de ser de baja intensidad, y regular a través de la hiperpresencia y la hiperactividad cualquier posible desviación de la norma. Como señala Thomas Nail, esta tecnología de frontera netamente metropolitana, dentro de la ciudad un mecanismo altamente efectivo de vigilancia, control y ritualización del espacio público al que atribuye las siguientes funciones: " tiene cuatro funciones kinéticas: una función preventiva, una función kinóptica, una función kinográfica y una función circulatoria”49. Sin embargo, en la época moderna estas cuatro funciones se basan en la visibilidad que los agentes, en su desplazamiento por el espacio público generan: son una tecnología de frontera construida para evitar el crimen -función preventivay que se desplaza con el movimiento de sus cuerpos haciéndose visible a cada instante - función kinóptica- a través de rutas establecidas - función kinográfica- y que es capaz de regular los flujos del resto de cuerpos -función circulatoria-.

Así, en la modernidad se establece esta tecnología de una frontera que ya se traslada al interior de las ciudades y que frente a construcciones estáticas vallados, fortalezas...- actúa como un desplazamiento dinámico, periódico y visible por el espacio público. Sin embargo, la visibilidad posee unas limitaciones obvias que son subsanadas por un nuevo modelo policial contrario al anterior, la policía secreta; la cual es capaz de aproximarse, aprehender y controlar un territorio sin, aparentemente, alterarlo:

El espía es el lado oculto de la patrulla y es el reverso de las tres funciones sociales kinéticas encontradas en la patrulla: kinóptica, kinográfica y circulativa. La policía secreta funciona como una frontera en el mismo sentido que lo hace la patrulla: establece una división móvil social entre buena y mala circulación, legal e ilegal, ciudadano y extranjero, patriota y traidor, ocioso y caminante, etcétera. Pero la policía secreta también divide el movimiento social y define un nuevo sistema de puntos de control invisibles específicos: inspecciones autónomas que pueden ocurrir en cualquier punto y momento. [...] Mientras que la labor de la patrulla policial es la de ser capaz de aparecer en cualquier punto y lugar, la de la policía secreta es precisamente ser capaz de desaparecer en cualquier momento. [...] De este modo, la policía secreta hace explícito lo que ya estaba implícito en la patrulla: que las condiciones de libre circulación y libertad son precisamente el control absoluto e iliberal sobre la totalidad del entorno. La libertad de movimiento, como la patrulla, es sólo apariencia ${ }^{50}$

La patrulla policial, tanto la visible como la invisible operan y afectan al espacio público que recorren. El espacio se gestiona a través de los ritmos, la zonificación y las actuaciones policiales en base a parámetros de prevención del crimen.

49 Thomas Nail, Theory of the Border (Oxford: Oxford University Press, 2016), I16:117.

50 Nail, Theory of the Border (Oxford: Oxford University Press, 2016), 134:135. 
O, dicho de otro modo, a través de la exclusión espacial de cuerpos y acciones potenciales catalogadas como no autorizadas. Así, este control espacial emplea la prevención "mediante la hiperpresencia y la hiperactividad [que] juega un papel fundamental en la gestión policial del espacio urbano" ${ }^{1}$. Una presencia y actividad que, del mismo modo que ocurría con las cámaras de vídeovigilancia, no se aplica de manera homogénea sino selectiva sobre la población en función de diferentes aspectos. Y, precisamente el cuerpo migrante, como un sujeto, a todas luces, infra-político, es un ejemplo paradigmático de esta diferenciación cualitativa de sus posibilidades de acción y desplazamiento dentro del espacio público. "Se lleva hasta el extremo la vigilancia policial sobre quienes encarnan los riesgos: la tolerancia cero se aplica solo sobre ellos, pues otros grupos sociales, en función de su legitimidad, contarán con una tolerancia uno, dos, tres... según su posición en la prolongada segmentación suave" ${ }^{52}$. En este sentido, no existe ninguna diferencia entre la condición humana o no-humana de los agentes del dispositivo policial. Las cámaras, los vehículos, los sistemas de seguridad forman un conjunto de agentes post-humanos han complementado la labor policial, extendiendo a un coste mucho menor la capacidad de vigilancia. La hiperpresencia de cámaras de videovigilancia, del mismo modo que la hiperpresencia de patrullas policiales en determinados enclaves urbanos modula los patrones, los tiempos y la movilidad de los cuerpos presentes en él.

\subsubsection{ARQUITECTURAS CÓMPLICES. EL PAPEL DE LA ARQUITECTURA URBANA EN EL CONTROL ESPACIAL}

El control de la ciudad aparece, tras este análisis, como un conjunto de elementos desterritorializados y dinámicos donde lo estrictamente construido puede parecer simplemente un escenario teatral que acoge las diferentes coreografías y ritmos que en él tienen lugar. Sin embargo, es necesario cuestionarse hasta qué punto las diferentes construcciones presentes en el espacio público no son también agentes activos a la hora de determinar ciertas disposiciones o limitar las posibilidades espaciales de los cuerpos que lo transitan. Así pues, el espacio urbano es diseñado siguiendo unas lógicas que replican las relaciones de poder, dominación y control existentes en la sociedad como afirma Stavrides:

«El espacio es fundamental para todo ejercicio de poder" (Foucault). Esta afirmación parece expresar la idea de la relevancia del espacio, así como las disposiciones materiales específicas que lo definen, como receptáculo de las relaciones de poder. Esta afirmación puede interpretarse de un modo algo distinto: la lógica de la organización del espacio no sólo nos permite descubrir los resultados de la articulación de las relaciones de poder, sino las precondiciones que resultan para que se produzca dicha articulación ${ }^{53}$.

En esta formulación respecto a las posiciones de Foucault, el espacio público contemporáneo no está explícitamente orientado a replicar estructuras de poder, pero sí a orientar su disposición a maximizar ciertas prácticas espaciales a la vez que minimizar otras ${ }^{54}$. La pregunta, por tanto, una vez entendidos cuales

51 García, «Policías Cotidianas», en Enclaves de riesgo (Madrid: Traficantes de Sueños, 2015), 78 .

52 García, «Policías Cotidianas», en Enclaves de riesgo (Madrid: Traficantes de Sueños, 2015), 78.

53 Stavros Stavrides, Hacia la ciudad de umbrales, (Madrid: Akal, 2016), 160.

54 Esta precondición a la que hace referencia encuentra su eco en el concepto de disposición de Keller Easterling. 
son los agentes -humanos y no-humanos- que de manera explícita ejercen este control, es la función de las construcciones urbanas y los diferentes elementos arquitectónicos que conforman el espacio público.

Sin embargo, es importante entender que esta predisposición no es absoluta ni estática, sino que los elementos urbanos pueden ser capturados, apropiados y su función de diseño verse alterada a través del conflicto y los diferentes acontecimientos que tengan lugar. Los escenarios urbanos siguen siendo campos de batalla de baja intensidad. Así, mientras el espacio público - desde el orden y las lógicas policiales- es leído en términos estables y estáticos que responden a estrategias de diseño, las tácticas de resistencia permiten leer el espacio público de una manera contingente ante cada situación. Esto permite plantear subversiones funcionales y alterar el espacio público de manera efímera. Situación que se ejemplifica de manera clara en situaciones concretas como los disturbios tras la muerte de Mame Mbaye donde cada elemento urbano cobraba una nueva función, pero también en el día a día de los cuerpos no autorizados que usan los elementos del espacio público a su favor.

El diseño del espacio donde tuvo lugar la detención de migrantes en la cancha polideportiva del parque Casino de la Reina deja claro que el entorno construido sí es un agente más que modula, dirige e impide los flujos y ritmos de los cuerpos. El proyecto arquitectónico diseñado por Matos y Castillo, de manera no consciente respondía a un encapsulamiento progresivo de los espacios que facilitaba su control por parte de un número muy reducido de efectivos policiales. Del mismo modo, los principales enclaves de Lavapiés respondían a estas mismas lógicas: la plaza de Nelson Mandela, la plaza de Lavapiés, la plaza de la Corrala, y la plaza de Agustín de Lara. En todas ellas, el diseño arquitectónico repetía una serie de parámetros comunes, áreas extensas con puntos de entrada muy controlados y el resto del perímetro delimitado por barreras físicas de diversa índole.

Es importante aclarar el carácter palimpséstico que se le da en este contexto al diseño arquitectónico. El espacio público como obra arquitectónica sólo puede ser entendida, desde el presente, como la superposición acumulativa y simultánea de actuaciones no conectadas pero que actúan y definen el espacio en su conjunto. Las necesidades infraestructurales, viales, policiales, de accesibilidad confluyen en una única disposición temporal. Por tanto, entender esta condición nos ayuda a comprender que esta precondición del espacio no tiene una autoría único sino que funciona como un ensamblaje y, de la combinación concreta de diferentes elementos - bolardos, escaleras, puntos de acceso, vegetación, pavimentos, iluminación topografía...- cada espacio urbano posee una diferente. Atendiendo exclusivamente a este aspecto, la plaza de Agustín de Lara diseñada por Ignacio Linazasoro, o el ya parque del Casino de la Reina por Matos y Castillo suponen excepciones en tanto que es un proceso mucho más acotado en el tiempo con responsables claros. Y, sin embargo, todas ellas comparten una serie de patrones comunes que definen un modo específico de control urbano.

En 2009, David Piqué i Batallé -entonces comisario general de coordinación territorial de los Mossos d'Esquadra- publicaba su trabajo fin de máster centrado en las políticas públicas de seguridad y tácticas policiales contra el movimiento okupa y los movimientos antisistema de la ciudad de Barcelona ${ }^{55}$. Más allá de la relevancia académica que pueda tener, este texto supone una oportunidad

55 Es importante señalar cómo el autor toma como cuerpo a neutralizar el movimiento okupa o antisistema de un barrio muy concreto y politizado de Barcelona. Del mismo modo, el Plan Integral de Mejora de la Seguridad y la Convivencia de Lavapiés se pone en funcionamiento al calor de los movimientos del $15-\mathrm{M}$, y se señala específicamente como motivo de conflictividad social el mismo cuerpo vinculado a los movimientos sociales. 

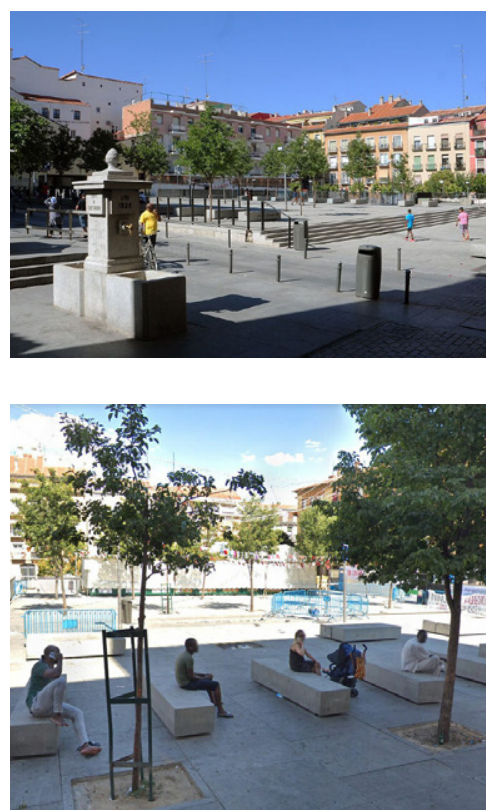

Plaza de Nelson Mandela (Madrid, 2018)
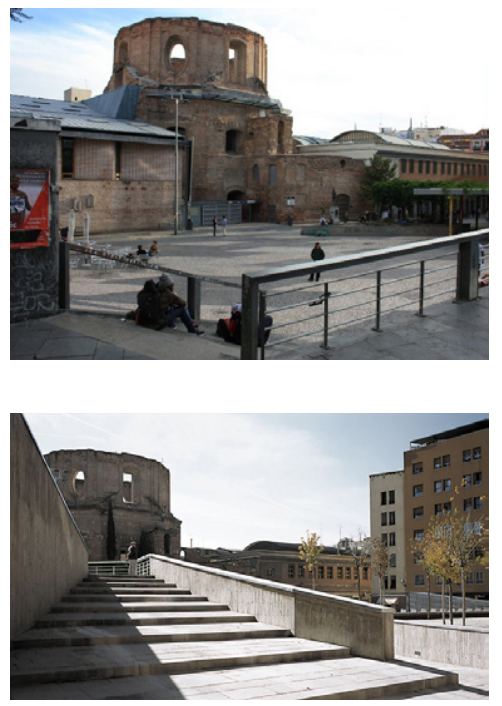

Plaza de Agustín de Lara (Madrid, 2018) única de comprender de primera mano una serie de tácticas de control espacial de grupos grandes de población a través de la optimización de los recursos disponibles. Como coordinador de unidades de intervención policial su materia arquitectónica no son los cuerpos inmóviles del mobiliario urbano sino los agentes policiales y, sin embargo, ilustra eficazmente los principales sistemas de control eficaz en el espacio público. Un control que no es evidente ni explícito, a todas luces tolerable por la totalidad de la población pero que consigue una contención inmediata de los flujos. Así, los espacios de aglomeración -en su caso leídos a través de las manifestaciones- son controlados a través de un fortalecimiento del perímetro que sólo es franqueable a través de "filtros muy sólidos a los lugares de paso obligados" ${ }^{66}$ donde se sitúan los "refuerzos que se necesitan" en caso de intervención según una de las tácticas policiales propuestas. En otra de ellas, se limita "la capacidad de movimiento de los manifestantes rodeándolos totalmente [...] con un filtro de malla fina en los puntos de paso obligados" ${ }^{57}$. Pique i Batallé nos remite constantemente a la necesidad de construir un recinto infranqueable o difícilmente franqueable al que sólo es posible acceder a través de puntos muy concretos que fácilmente pueden ser tomados por un número reducido de agentes.

Las plazas responden, desde la colocación del mobiliario urbano y su diseño, a estos esquemas en mayor o menor medida, siendo lugares cercados por diferentes elementos -vallas, barandillas, bolardos, vegetación, muretes de contención...donde los puntos de acceso son una interrupción de un perímetro continuo. Un perímetro con una altura que limite las posibilidades de escape mientras que mantiene la posibilidad de contacto visual con el exterior; es decir, se genera un espacio continuo visualmente pero estriado a través de elementos lineales. Y, dentro de este espacio delimitado de manera sólida, un área construida con el menor número de impedimentos visuales posible combinado con un alto grado de iluminación artificial. El desnivel topográfico del barrio de Lavapiés, en altura decreciente del norte al sur al situarse en la ladera del Río Manzanares acentúa además las medidas de contención por motivos de accesibilidad y cambio de cota entre los diferentes puntos de la plaza. Una descripción rápida de los principales espacios públicos del barrio de Lavapiés ${ }^{8}$ ayudará a comprender las líneas comunes seguidas.

La plaza de Agustín de Lara tiene tres puntos de entrada, cerrada por un desnivel considerable en uno de los lados y bloques de edificios con soportales en los otros dos; hasta su reciente reforma, el espacio diseñado por Linazasoro contaba con unas pérgolas metálicas que generaban un espacio de sombra a las que sólo era posible acceder desde dos puntos. Dentro de un espacio mucho más amplio, se delimitaba a través de la sombra y el asiento un área de congregación de gente a la que sólo era posible acceder desde dos únicos puntos. Adyacente a esta plaza, la plaza de la Corrala tiene una delimitación continua de vallado metálico en dos de sus lados mientras que en los otros dos la diferencia de cota genera un muro de

56 David Piqué i Batalle, «El fenómeno okupa / antisistema circunscrito al distrito de Gràcia (Barcelona), como factor de riesgo para la convivencia y potencial foco de percepción de inseguridad. Políticas públicas de seguridad aplicables para evitar que se convierta en un problema de orden público o delincuencial y consecuentemente de solución únicamente policial» (tesina, Universidad de Barcelona, 2009), 15.

57 Piqué i Batalle, «El fenómeno okupa / antisistema circunscrito al distrito de Gràcia (Barcelona), como factor de riesgo para la convivencia y potencial foco de percepción de inseguridad. Políticas públicas de seguridad aplicables para evitar que se convierta en un problema de orden público o delincuencial y consecuentemente de solución únicamente policial» (tesina, Universidad de Barcelona, 2009), 15 .

58 Es importante que la selección de estos espacios responde a la presencia de acontecimientos vinculados al dispositivo frontera en cada uno de ellos de diferente tipo -detenciones, cargas policiales, manifestaciones, redadas...-. Más allá de eso, por no extender el análisis a todos los espacios públicos del barrio, los patrones detectados no son exclusivos de las plazas señaladas. 
más de tres metros de altura bajo el nivel de la calle. La plaza de Nelson Mandela, punto de reunión habitual de la comunidad migrante, debido a la diferencia de cota en cada uno de los lado, presenta de nuevo una estratificación absoluta a diferentes niveles rematada con vallas de protección; sin embargo, en el único punto de contacto continuo -en su encuentro con la calle Mesón de Paredeses también delimitado a través de la colocación de bancos no desplazables y bolardos metálicos que filtran de manera permeable el acceso al recinto. El Parque del Casino de la Reina, por su extensión y complejidad funcional presenta diferencias considerables respecto al resto: es un espacio que se abre y cierra el público, de ahí que su perímetro adquiera una mayor dimensión y robustez a través de un vallado de lamas metálicas de más de tres metros de altura. De nuevo, esta envolvente continua es perforada en diferentes puntos de acceso de dimensiones bastante reducidas siendo la principal una puerta pivotante de cinco metros de ancho. El espacio interior de nuevo es compartimentado de manera dura -a través de nuevos recintos vallados como la cancha polideportiva- o de manera blanda -a través de cambios de cota o elementos discontinuos-.

Junto a este diseño acumulativo y procesual que ha determinado la condición del espacio público, es innegable la presencia de otros factores estrictamente arquitectónicos que causan una afección clara sobre el acceso al espacio público y la estancia en determinadas zonas de la ciudad. Tal y como recoge el Plan que articula la estrategia a seguir en la transformación urbana de Lavapiés, la necesidad de renovación del parque inmobiliario debido a la existencia de infravivienda - heredada de la tipología de corralas madrileñas aún presente en buena parte del tejido del barrio- es una prioridad. Tanto a nivel de equipamientos públicos - dotaciones culturales, espacios sociales, adecuación y creación de espacio pública- como de vivienda colectiva, las inyecciones económicas realizadas en el barrio de Lavapiés en las últimas dos décadas han sido considerables. Por otro lado, este proceso público se acompañó de una serie de condiciones de carácter privado que transformaron el hábitat del barrio, siendo una de ellas es el aumento de demanda de alquiler en un mercado cada vez más tensionado y, por otro lado, la aparición de plataformas colaborativas de alquiler de vivienda. Así, aquellas viviendas consideradas infrahabitables por su condición tipológica heredada se vuelven, sin embargo, deseables para pernoctar con un plus de independencia, amplitud y menos coste que un hotel. Viviendas que, precisamente por su condición infrahabitable -sin iluminación natural, instalaciones actualizadas, no accesibles...-eran fácilmente rentabilizables en un mercado informal donde el cuerpo migrante era el principal demandante: los conocidos pisos patera ${ }^{59}$. Esta realidad habitacional es la única posibilidad de acceso a una vivienda al carecer ninguno de los requisitos habituales nómina, contrato, recursos económicos...- que el mercado exige. La negación del espacio público se extiende a la necesidad de recurrir a ilegalismos o vacíos legales para acceder a ciertos servicios que, de otra manera, sería imposible. Así, es esta lectura del espacio y de los mecanismos que lo regulan -en definitiva,

59 Así describía El País uno de estos espacios de cincuenta metros cuadrados habitado de manera constante por once migrantes - diez de ellos en situación irregular y el undécimo con permiso de residencia-:

El piso patera tiene unos cinco metros cuadrados por habitante. No hay zonas privadas. Las dos habitaciones, a las que se pasa desde la sala, son minúsculas y no tienen ventanas. En una hay una litera y un colchón; en la otra, dos colchones. Entre ambas duermen siete personas, y otras cuatro pasan la noche en la sala. [...]La cocina está al otro lado de la sala. Es corta, estrecha y tiene un cráter horroroso en el techo. El espacio es reducido, para un solo chef, pero también funciona como pasillo para ir al baño -un cubículo con un lavabo, un retrete y una ducha- o acceder a un patio interior, al aire libre, en el que está instalado el calentador del gas, rodeado de tres bombonas de butano 

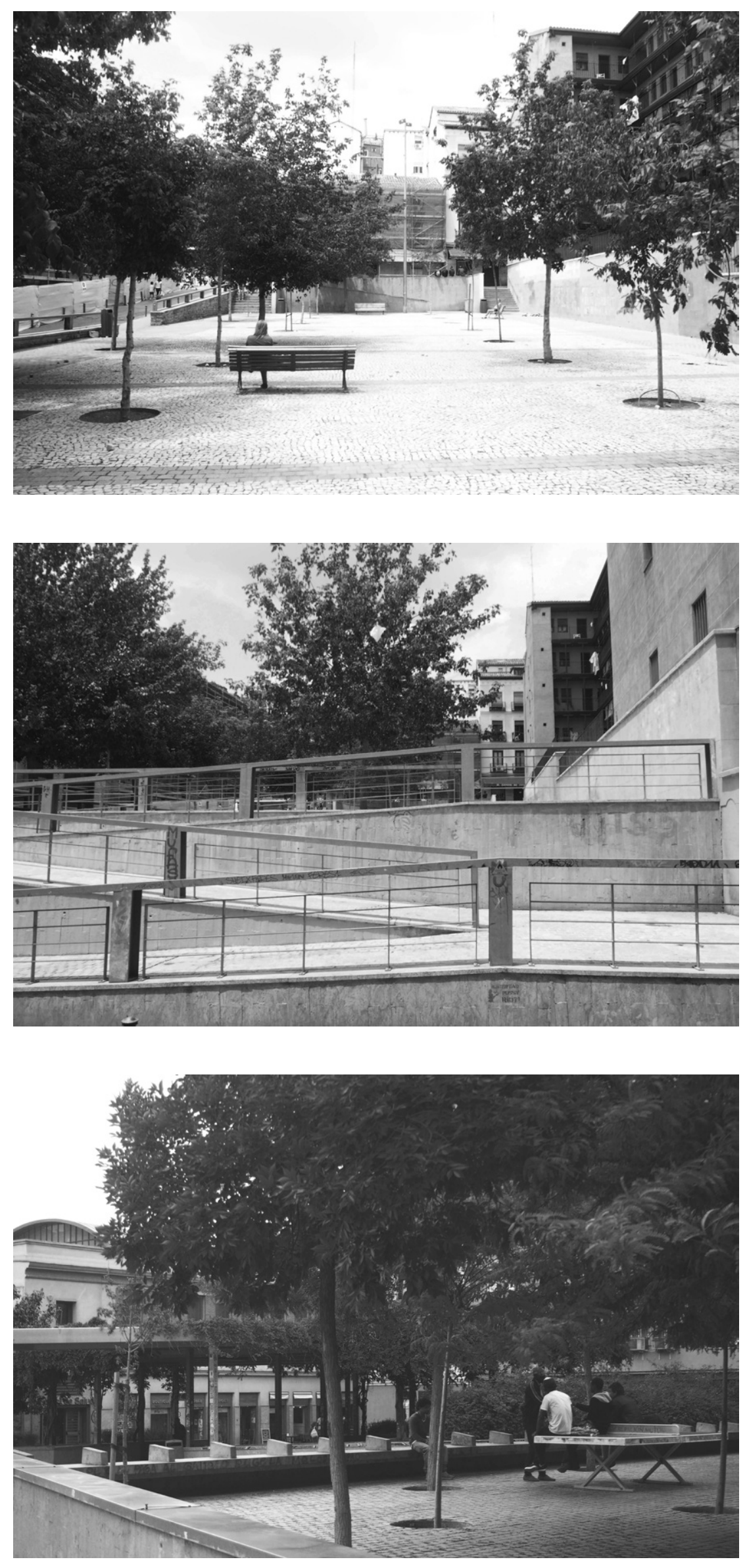

De arriba a abajo:

Limitaciones y barreras arquitectónicas

Plaza de la Corrala (Elabo-

ración propia; Madrid, 2015);

Plaza de Agustín de Lara (Ela-

boración propia; Madrid, 2015) 
de su paisaje legal- lo que construye una serie de tácticas de resistencia ante la hostilidad de un medio -la ciudad- que les niega el acceso tanto al espacio público como al privado, donde la vivienda es la extensión fundamental de éste.

Es innegable la situación de violencia espacial derivada de esta exclusión consciente del mercado inmobiliario, que desplaza a la informalidad la posibilidad de establecerse vitalmente en un espacio. En primer lugar, por los estándares espaciales - menores a cinco metros cuadrados por persona- que se pueden generar por la sobreocupación de viviendas no previstas para ello, así como por la falta de adecuación a los estándares actuales. Pero, por otro lado, el desplazamiento de población -tanto saliente como entrante-que suponía del barrio de Lavapiés provocado por todos los factores ya señalados es otra cara de la violencia que sufren. Lavapiés suponía, por el envejecido parque de vivienda disponible, las características de las mismas, el alto porcentaje de población migrante y la proximidad al centro un caldo de cultivo fértil para la aparición de pisos patera y viviendas informales. Pero suponía también una oportunidad de vinculación afectiva comunitaria así como de acceso a una serie de servicios, lugares y oportunidades de trabajo que no se dan con la misma fluidez en la periferia urbana.

\subsubsection{ENCLAVES URBANOS Y ESPACIO PÚBLICO RITUALIZADO}

La planificación urbana -donde esta dimensión no atañe exclusivamente al urbanismo entendido como tal sino a la acumulación de intervenciones, operaciones con intencionalidad y origen muy diferente- ha convertido el centro de Madrid en un enclave urbano de baja intensidad a través de la sucesión y superposición no causal de todas estas transformaciones y acciones. Diferentes mecanismos conforman un dispositivo inevitablemente ligado al control espacial, a la definición y autorización de desplazamiento de ciertos cuerpos a través de la ciudad: las leyes, las ordenanzas municipales, los planes de seguridad, los agentes humanos y no-humanos vinculados al dispositivo policial y la propia arquitectura que da soporte material a este ensamblaje. Pese a que seamos conscientes de que la diferenciación entre paisajes vigilados y free-fire zones no es ya geográfica sino topológica, modulable y dinámica, la fortificación de determinadas regiones urbanas es una realidad. Una fortificación que eleva el grado de seguridad a través de mecanismos y ensamblajes pero que, sobre todo ritualiza el espacio definiendo muy bien qué cuerpos pueden acceder e interactuar con él con total normalidad y cuales no. Así, la planificación del barrio de Lavapiés -como señala Sergio García- tiende a convertirlo progresivamente en un enclave domesticado frente a una serie de cuerpos resistentes. Es decir, un fragmento urbano que se puede definir de la siguiente manera:

Los enclaves metropolitanos se caracterizan más por los puestos de control que por la existencia de muros. Uno ha de pasar por el control, probar su inocencia por anticipado, antes de ser usuario de tales enclaves. [...]

Los puestos de control son los elementos que modulan el ritmo predominante, que producen una nueva expriencia dominante de "estar en público". Los puestos de control marcan las rutinas cotidianas y definen a la vez rutas distintivas de acceso a distintas categorías de habitantes dentro de las ciudades parceladas [...] 
Asistimos a una proliferación de puestos de control que se extienden en forma de metástasis; nuestro modelo de ciudad está salpicado de comisarías, de cámaras de vigilancia en los lugares públicos, con controles de inmigrantes por todas partes.[...] Los puestos de control siempre estarán ahí para identificar, separar y someter a personas ${ }^{60}$.

La excepcionalidad que se despliega sin ambages en los territorios y arquitecturas explícitamente vinculados a la frontera sirve como laboratorio de prácticas espaciales de vanguardia que, en mayor o menor medida, son después trasladables al espacio urbano, asegurándose un nivel de intensidad tolerable. Los límites de la soberanía nacional ya no se conjugan a través de la condición exterior o interior, sino que se trasladan al conjunto del territorio y, como afirma Stephen Graham, al interior de las ciudades a través de "fronteras ubicuas", capaces de desplegarse en cualquier zona o lugar. Y, en concreto, señala la inmigración ilegal como uno de los cuerpos paradigmáticos que encarnan esta frontera:

La idea de la ciudadanía nacional, más que oponerse a la idea del exterior y el extranjero, están siendo cada vez más rehechas contra otros que son consierados fuera o más allá de la ciudadanía, independencia de que se sitúen dentro o más allá de las fronteras geográficas de los estados nacionales. Esta reconfiguración en la naturaleza de las fronteras está alimentada por lo que Allen Feldman llama 'guerras securocráticas' - guerras (a las drogas, crimen, terror, inmigración ilegal, amenazas biológicas) deterritorializadas y sin final organizadas en torno a nociones vagas y amplias de seguridad públicas más que al dominio territorial. Su propósito es mantener la soberanía estata, no a través de la guerra exterior combinada con la política interior, sino al aumentar el espectro de movilidades y flujos destinados a a contaminar sociedades y amenazar el orden social, interna y externamente. [...] Estos daños desconocidos y desconocibles están concebidos para acechar dentro de los insterticios de la vida urbana y social, fusionándose invisiblemente con ellas ${ }^{61}$.

Todos estos mecanismos son el grado cero de una realidad espacial con capacidad de operar para todos los ciudadanos por igual en función de su nivel de separación respecto a la norma que autoriza y rige el espacio urbano. Es esta separación de la norma la que modula los cuerpos, los discrimina y detona el grado de violencia espacial al que son sometidos atendiendo a su condición pero también a las acciones que lleven a cabo. Y el cuerpo migrante aparece aquí como un potencial Así, la superposición simultánea de todos estos elementos -arquitectónicos, humanos y tecnológicos- da como resultado el mencionado aumento de espectro de movilidad. Esto significa que un espacio aparentemente libre de cualquier fragmentación o restricción específica por el que circulan a la vez cuerpos constantemente categorizados en función de sus acciones y, en la medida en que éstas transgredan el paisaje legal establecido. La ritualización de las circulaciones ya no es explícita ni unívoca, ni requiere de la declaración explícita del estado de excepción como en períodos históricos previos para actuar con inmediatez sobre un área o fragmento urbano. Nada de eso es necesario ya que la imbricación del tejido urbano con tácticas y mecanismos propios de la excepción ha hecho que ésta se superponga y diluya aún más la distinción entre lo cotidiano y lo excepcional, extendiéndola a cualquier espacio y cualquier tiempo, de manera instantánea. 


\subsection{LOS MANTEROS COMO PARADIGMA DE LA FRONTERA ENCARNADA.}

En verano de 2015, en la localidad catalana de Salou el cuerpo de Mor Silla se precipitaba por la ventana a las seis de la mañana. Minutos antes, los Mossos d'Esquadra habían irrumpido en su piso en el marco de una operación contra el "top manta”. Según las declaraciones policiales, el hombre saltó por su propia voluntad "al detectar presencia policial"; sin embargo esta opinión no es compartida por los dos cententares de compatriotas que, al verse afectados - con toda la potencia del término- por la muerte de un compañero tomaron el espacio público en señal de protesta. El anuncio de Tschumi retorna en forma de premonición trágica, siendo esta vez el espacio público -y las extensiones de este hasta el interior mismo de la vivienda con la presencia policial- el que podemos apreciar realmente cuando se comete un crimen: su exposición al espacio público al desarrollar una actividad ilegal, la venta ambulante, y las consecuencias que tiene cuando no estás autorizado a interactuar con él. El desarrollo del juicio no despejó dudas sobre si Mor Silla cayó por su propia iniciativa, fue empujado o qué le llevó a tomar dicha decisión, siendo archivada la causa en 2018 sin involucrar a la policía. Independientemente del papel real de la policía, al igual que con la muerte de Mame Mbaye en Lavapiés tres años después, es innegable la exposición a una violencia espacial de tal calibre -la ejercida por el dispositivo frontera- que llevan a un hombre a precipitarse al vacío y perder la vida durante dicha acción. Así lo entendió la comunidad migrante de Salou -una localidad que demanda los servicios de los vendedores ambulantes en temporada estiva-, fueron capaces de conectar con el terror de Mor Silla y la violencia que rodeó su muerte. La rabia colectiva se transformó en unos disturbios de un día de duración, donde las vías del tren fueron cortadas y se confrontó de manera directa a la misma policía que horas antes provocaba la muerte de su compañero. Entre las proclamas y pancartas se reclamaba justicia, pero una frase en concreto evidenciaba de manera clara la construcción de un cuerpo migrante colectivo, atravesado por violencias compartidas, que se ponía frente a los efectivos de antidisturbios "A nosotros nos es igual; si morimos, morimos todos". Esa confrontación, esas violencias y afectos compartidos que atravesaban en diferente grado a cada una de las personas que ese día tomaron la villa de Salou, nos muestra las diferentes dimensiones que tornan un cuerpo individual en un cuerpo colectivo.

Todo intento de representar al cuerpo migrante como una unidad está predestinado al fracaso, este es irrepresentable - al menos si no se atienden a cuestiones mediáticas ni agendas políticas-, ya que éste se nos presenta como una multiplicidad conformada por infinidad de historias de vida que resuenan entre sí con menor o mayor fuerza en función de cada situación. Y, asociada a esta multiplicidad las violencias espaciales que, de forma diferencial sufre cada cuerpo en función de su condición racializada, su precariedad o la irregularidad en la que se sitúen. Así, intentar reducir la experiencia urbana del cuerpo migrante a una única figura resultaría estéril: las violencias a las que se enfrenta una cuidadora doméstica -sin habitación propia, sin jornada laboral fija...en nada se parecen a las que se ve forzada a convivir una trabajadora sexual 
Disturbios en Salou tras la muerte de Mor Silla (Salou, 2015) migrante ${ }^{62}$ a pesar de que ambas sean atravesadas por condiciones de género, raza y precariedad. Sin embargo, hay una figura que sí ha hecho del espacio público netamente su espacio de trabajo, que desarrolla la totalidad de su práctica profesional recorriendo sus calles y plazas, habitándolo pero que, además, ha tomado conciencia de su condición -laboral y migrante- para organizarse colectivamente. Es simplemente este hecho diferencial, su capacidad de articular una resistencia desde el mismo espacio que les es políticamente negado, $\mathrm{y}$ haciéndolo aún por encima desde un ilegalismo como es la venta ambulante no regulada, lo que ofrece aspectos de interés para entender a qué se expone el cuerpo migrante en el espacio público, pero también cómo es capaz de subvertir y alterar esta situación a través de tácticas espaciales.
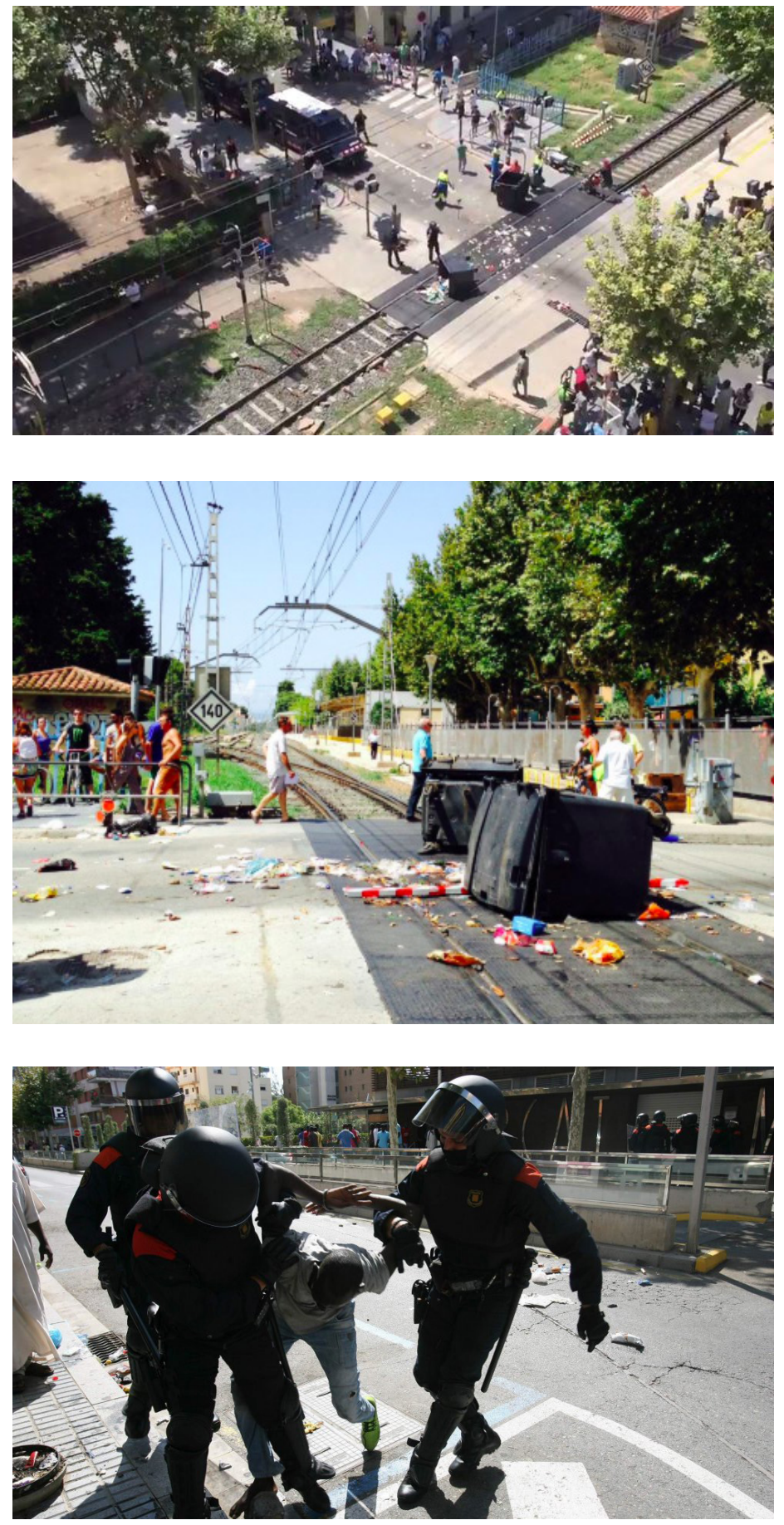

62 Esta es una de las pocas figuras femeninas que, de manera recurrente es internada en los 


\subsubsection{OCUPACIONES TEMPORALES Y CRIMINALIZACIÓN DE LA VENTA AMBULANTE. EL CASO DEL AYUNTAMIENTO DE BARCELONA}

La práctica de la venta ambulante asociada a la migración irregular durante la década de los 200o, el famoso "top manta", una sábana blanca con películas y discos musicales grabados, enfundados en bolsas de vinilo con carátulas impresas a bajo coste fueron la primera manifestación de una táctica de supervivencia que visibilizó la situación de, fundamentalmente, migrantes varones subsaharianos. Esta práctica al margen de la legalidad representa una paradoja espacial: requiere situarse en espacios de máxima visibilidad para generar ventas pero a la vez tener una posición esquiva en caso de que se presente la policía ya que dicha acción acarrea consecuencias legales -variables desde la aparición del fenómeno hasta la actualidad-. Esto genera una tensión evidente entre un cuerpo que accede a un espacio público a través de prácticas irregulares ${ }^{63}$-un cuerpo que, además también lo es- y que debe mostrarse claramente en su acción, y un cuerpo policial que trata de neutralizarlos a través de diferentes medios. En como se resuelve esta tensión, como ha ido variando y manifestándose de diferente forma hasta el día de hoy, nos permite entender cómo esta práctica está atravesada por las mismas condiciones del dispositivo frontera y como replica las mismas características estando totalmente deslocalizada de los territorios de frontera.

Un manifiesto a favor de la despenalización del top manta emitido por el Sindicato Popular de Vendedores Ambulantes señala como, frente al intento de estigmatización mediático y político de asociarlos con mafias organizadas y redes criminales, es un modo de supervivencia autogestionado frente a un espacio que les niega sistemáticamente acceder a él:

Si repudiamos el muro de Trump no podemos permitir que existan muros visibles e invisibles que impiden que muchos de nuestros vecinos y vecinas no dispongan de un estatus jurídico que les permita acceder, no solo a derechos básicos como la salud o la educación, sino simplemente a vivir. Ante la imposibilidad de obtener un contrato de trabajo -a la situación de falta de empleo en general se suma, en el caso de la población migrante, el estatus de irregularidad administrativa o de "sin papeles" a causa de la Ley de extranjería-, muchas personas inmigrantes han de buscarse la vida, como sabemos, vendiendo en las calles. La venta ambulante siempre ha sido una vía de obtención de ingresos para las capas de población más empobrecidas. En la Europa de la austeridad y el neoliberalismo, esta es una situación a la que se ve abocada un porcentaje de población cada vez mayor. Para los inmigrantes de origen subsahariano, muchos de ellos residentes en nuestras ciudades desde hace más de ro años, esta ha sido y sigue siendo una vía de salida que les permite ir sobreviviendo ${ }^{64}$.

63 Los ilegalismos, como prácticas espaciales en el ámbito público son generalmente asociados a una visibilidad baja o prácticamente nula. Si pensamos en prácticas que necesariamente requieren la presencia del cuerpo en el espacio público, como puede ser la prostitución callejera, la venta de droga al por menor o en su día los encuentros sexuales, en estas la detección del sujeto y la mercancía aparece camuflada u oculta. Tan solo los códigos explícitos en el momento preciso de la interacción desvelan la práctica que se desarrolla-al ofrecer un servicio sexual, una transacción comercial o el acuerdo mutuo- y, por tanto, el ilegalismo. Sin embargo, el caso de los manteros invierte esta relación ya que la mercancía a la venta es imposible de camuflar sino que se expone abiertamente.

64 Sindicato Popular de Vendedores Ambulantes, «Manifiesto por la despenalización del Top Manta», acceso el I de octubre de 2019, https://manteros.org/comunicados/\#1488655372018-0124eear-2boa 
Manteros en la Barceloneta (Barcelona, 2016)
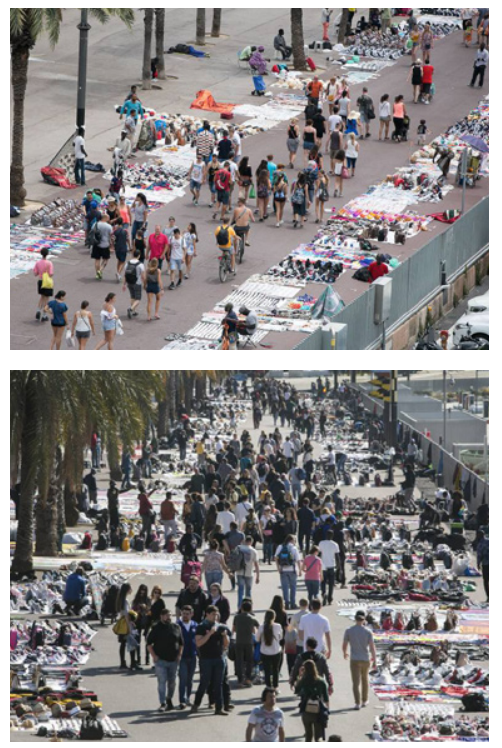

La entrada en vigor de la Ley de Seguridad Ciudadana en $2015^{65}$, promulgada por el entonces gobierno del Partido Popular supuso una medida destinada a coartar y limitar una serie de ilegalismos y prácticas no consentidas, entre ellas la venta ambulante llegando a penarla con penas de prisión; tipificación penal había sido reducida notablemente en 2010 a través de una gran campaña de sensibilización. Ese mismo año, se producía un giro político radical en las dos principales metrópolis españolas hacia una nueva política de izquierdas, aparentemente sensible a las problemáticas de la comunidad migrante: Ada Colau llegaba al consistorio barcelonés y Manuela Carmena lo hacía en el de Madrid. Sin embargo, a pesar de una orientación política con una agenda alineada a los derechos y protección de la población migrante, la relación entre los ejecutivos locales y la comunidad de vendedores ambulantes ha sido ampliamente cuestionada. Esto señala dos cuestiones fundamentales: el carácter infraestructural del dispositivo frontera -y policial- que trasciende los colores políticos para actuar con unas lógicas propias y, por otro lado, el escaso peso político que una comunidad sin derecho a voto -que en ningún momento son ciudadanos de pleno derecho sino que simplemente poseen phoné pero no $\log _{0} s^{66}$ tiene en las agendas políticas de los gobiernos del cambio. Los conflictos que tensionaron esta relación a lo largo de ambas legislatura, la respuesta policial que han empleado en cada caso, y las tácticas de control y expulsión del espacio público permiten entender la frontera encarnada que cada mantero porta a sus espaldas, y que tan sólo al desplegar una manta cambia radicalmente su relación con el espacio que la rodea. Una acción leve, minúscula, un despliegue textil sobre el pavimento urbano que logra alterar el status quo convirtiéndose en un cuerpo que necesita ser neutralizado.

El puerto de la Barceloneta y el paseo marítimo que lo recorre es uno de las localizaciones habituales en la disposición de la mercancía por parte de los vendedores ambulantes en época estival, junto con el Passeig de Grácia o La Rambla. Las actuaciones que el gobierno municipal llevó a cabo a lo largo del verano de 2016 condensan, en decisiones de pocos meses, las características señaladas a lo largo del capítulo a la vez que muestran como los vendedores ambulantes despliegan tácticas de resistencia efectivas durante estas disputas por el espacio público. Tras la "ofensiva policial para acabar con el 'top manta' en Barcelona" ${ }^{67}$ se encontraban por un lado actuaciones policiales agresivas destinadas al desalojo de los vendedores, actuaciones arquitectónicas efímeras de ocupación del espacio público y aplicación de reglas excepcionales vinculadas a la temporalidad. Las dos primeras medidas operaban de manera indistinta al reemplazar un cuerpo por otro, imposibilitando que los manteros ocupasen ese espacio; en la primera eran los cuerpos de policía mientras que en la segunda era una construcción estable. La tercera medida poseía un carácter completamente diferente al operar con las normas de uso del espacio; simplemente regulaba los tiempos asociados al espacio, activando la posibilidad de que los vendedores ambulantes vendiesen su mercancía tan solo a horas de baja afluencia de público. Todos estas operaciones, de carácter fuertemente represivo y con una ejecución fundamentalmente policial, se combinaron con la creación de un plan de empleo y atención social para mejorar las condiciones de vida de los manteros -medida que fue calificada de insuficiente por parte del sindicato y asociaciones

65 Recordemos que esta misma normativa ha afectado también a otros casos de estudio de esta investigación, entre otras cosas, al dar cobertura legal a las devoluciones operativas.

66 José Luis Pardo, Políticas de la intimidad (ensayo sobre la falta de excepciones), (Madrid: Escolar y Mayo, 2012), 57.

67 Javier Oms, “Ofensiva policial para acabar con el 'top manta' en Barcelona”, El Mundo, 15 de julio de 2016. 
vinculadas-; el Plan Transversal para evitar la venta ambulante no autorizada en la calle mostraba en la práctica las incoherencias entre un discurso aperturista con medidas represivas continuistas con ejecutivos anteriores.

La primera decisión del consultorio de Ada Colau fue aumentar la presencia policial en la zona de venta -el puerto de la Barceloneta- para "disolver a los vendedores ocupando la zona con agentes de la policía de la Generalitat”68, pero también evitar su reubicación en otros puntos de la ciudad con patrullas policiales específicas de la Guardia Urbana. Esto generaba un mayor control de las zonas conflictivas y, a la vez, expulsaba a los manteros al impedirles acceder al espacio.

La segunda medida utilizaba la arquitectura como mecanismo de expulsión con una construcción, aparentemente efímera, cuya función no era el skatepark anunciado por el ayuntamiento, sino un programa capaz de ocupar con un coste mínimo la mayor superficie posible de espacio público. La arquitectura aparece de nuevo como un mecanismo exclusivamente al servicio del poder, y en este caso no importa el discurso, programa o demandas sociales previas sino que el equipamiento deportivo se concibe desde las lógicas de ocupación y expulsión ${ }^{69}$. Una arquitectura que, además responde a las mismas lógicas de la inmediatez y despliegue efímero que aparecían en los territorios de frontera y que, en ningún caso sigue las lógicas e inercias de la industria arquitectónica, sino a la rapidez y necesidad de respuesta inmediata ante un problema determinado. Tan solo dos días tardó el consistorio en construir 600 metros cuadrados de skatepark modular desde su anuncio público el i3 de julio de 2016. Y, al igual que ocurría con otros despliegues arquitectónicos, su duración únicamente se limita a la emergencia del problema, siendo desmantelado a finales de verano cuando la afluencia de turistas es mucho menor. Es destacable una diferencia en el modo de desplegar las arquitecturas, al tratarse de un entorno urbano donde el foco mediático son mucho mayores que en los terrenos excepcionales analizados en los anteriores casos de estudio, este despliegue arquitectónico se hace de manera oficial con una inauguración: "este mismo viernes a las nueve de la mañana cerrarán el recinto de 600 metros cuadrados para instalar las rampas y no lo abrirán hasta las seis de la tarde, cuando harán «la inauguración» con una multitud de skaters"7o. De nuevo, las lógicas del espacio postmetropolitano, que siguen sin responder plenamente a la excepcionalidad inherente a los territorios de frontera requiere que medidas de este tipo sean amparadas y soportadas por discursos políticos.

La tercera medida consiste en transformar un mismo espacio a lo largo del día, del paisaje hipervigilado por la policía local y la portuaria a la zona de tiro libre, pero en este caso, las leyes que se suspenden no son aquellas que impiden castigar al cuerpo migrante -como sí ocurría en la valla- sino precisamente una "suspensión" de aquellas normativas que penan la venta ambulante irregular:

$68 \mathrm{Oms}$, El Mundo, 15 de julio de 2016.

69 Es posible encontrar ecos de estas funciones encubiertas de la arquitectura, a una escala incomparable -así como las condiciones que genera- con las arquitecturas de ocupación israelí analizadas por Eyal Weizman y Léopold Lambert. Bajo el paraguas de la inocencia de viviendas unifamiliares y agregaciones de urbanizaciones se esconde un discurso no declarado de utilización de la arquitectura como una herramienta de ocupación del espacio y legitimización -por la praxis- de los discursos del poder. Ver más en: Eyal Weizman, Hollow Land (Londres: Verso Books, 2007); Léopold Lambert, Weaponized Architecture (Barcelona: Dpr-editorial, 2012).

70 El Patín, «Aprueban la construcción de un skatepark en la Barceloneta», Elpatín.com, acceso el I de octubre de 2019, http://elpatin.com/aprueban-la-construccion-de-un-skateparken-la-barceloneta/ 
Siguiente página:

Operación policial contra manteros en la Calle Preciados de Madrid (Elaboración propia)
A las nueve y media de la noche acababa el turno de la policía portuaria, que trabajaba respaldada por los Mossos d`Esquadra, la policía catalana. Entonces se abría una especie de barrera policial y los vendedores, que habían estado esperando a esa apertura, salían a la carrera para colocarse en los mejores sitios.

Era una especie de pacto tácito que les permitía vender unas horas. Hacia medianoche recogían sus mantas y se marchaban para tomar el metro y regresar a sus casas. Muchos de ellos viven fuera de Barcelona, en lugares como Sant Adrià del Besós ${ }^{71}$.

Un "pacto tácito" que se basa en una cuestión logística - un cambio de turno en la policía portuaria - para "activar" nuevos protocolos de regulación del espacio, y que a su vez coincide con las horas de menor afluencia de compradores. Esto, junto a la gestión policial condiciona y limita el uso del espacio público por parte de los manteros pero pone en evidencia cómo las leyes han de ser encarnadas para que sean realmente efectivas; en este caso la ausencia de policía portuaria durante unas horas y la connivencia de los Mossos d'Esquadra abría una vía de ocupación consensuada únicamente por una de las partes.
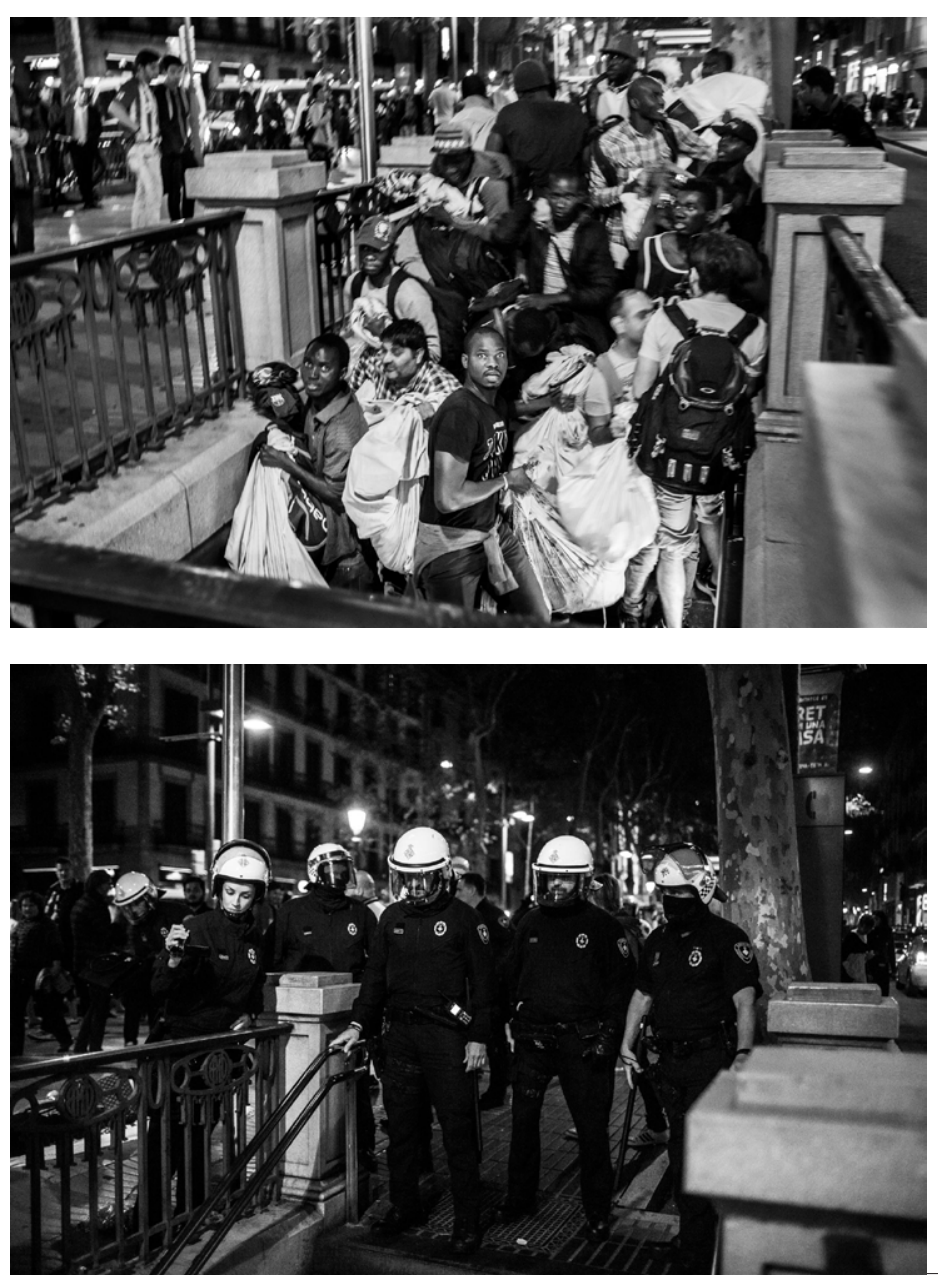

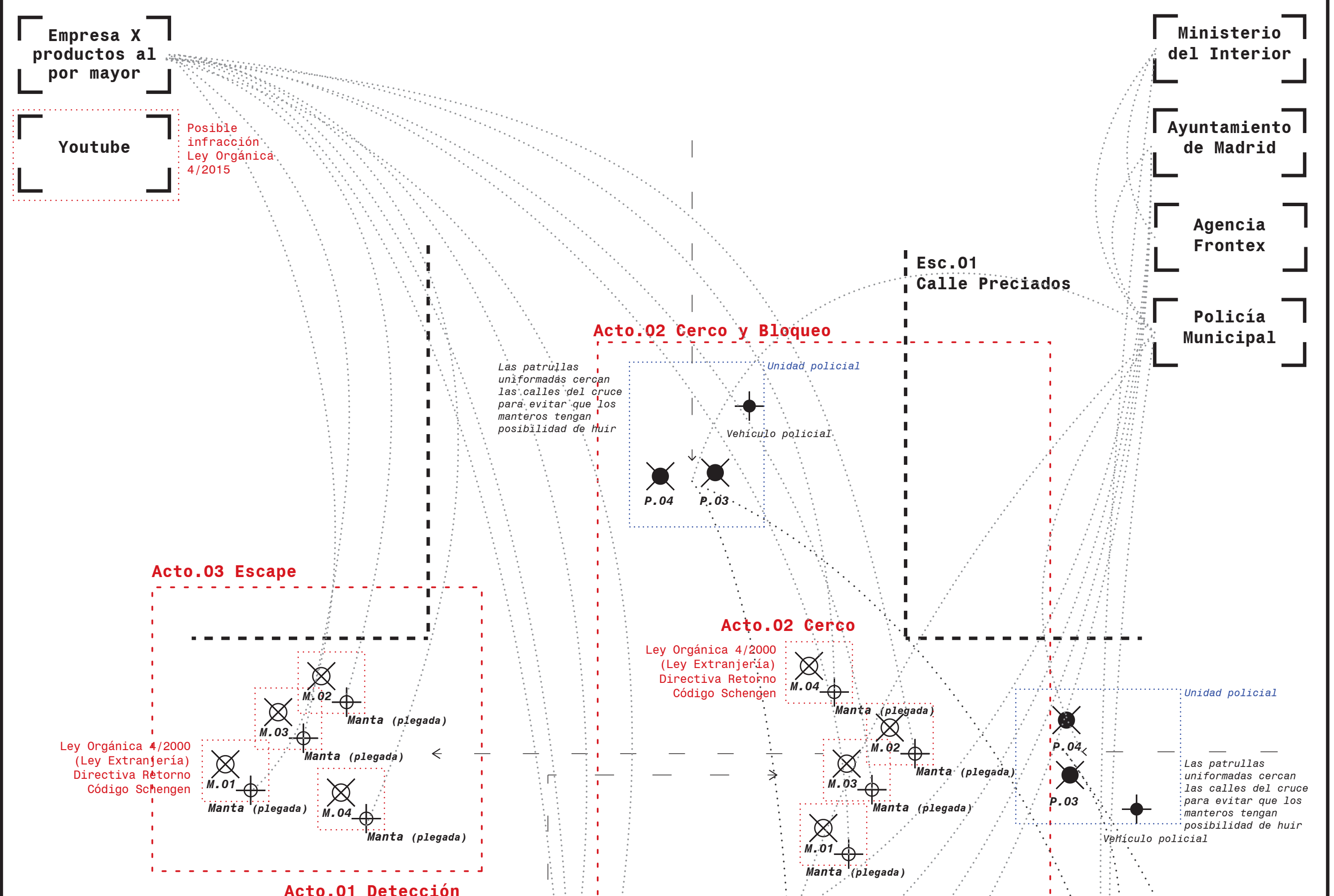

Acto.01 Detección

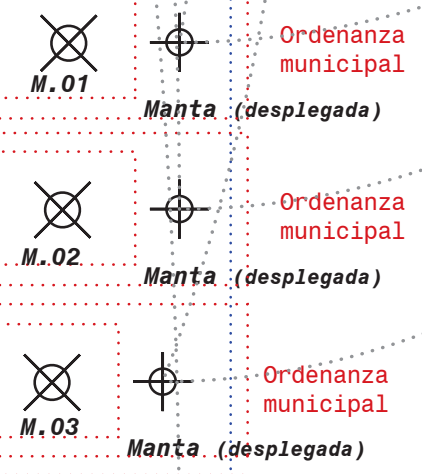
'Ley Orgánica 4/2000
(Ley Extranje
irectiva Retorno $\mathbf{I}$
\& $\phi$ ordenanza
Manta (desplegada)

Uno de los manteros detecta

a laipareja de policías de

antelación como para recogel

las manta y yalir corriegno

ellos.
ane lleguen junto

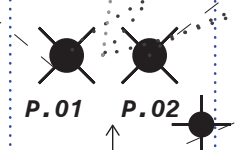

Waikie talkie

- El testigo toma

- Pareja de policías de

- viods de los policías, Posible

'de ser puestos en 


\subsubsection{TÁCTICAS DE RESISTENCIA. DEVENIR UN CUERPO PÚBLICO.}

A pesar de este dispositivo policial, los vendedores ambulantes -ya organizadosse enfrentaron a lo largo de ese verano a la policía, reinvindicando su acceso al espacio público. La misma lectura operativa del espacio público que habían hecho de manera cotidiana se repetía ahora para ser capaces de desplegar su manta en el suelo sin que la policía los detuviese o, qué puntos eran más seguros para esconderse. Los andenes de metro se convirtieron, durante estos meses, en lugares seguros ya que, dada la especial configuración espacial de estos hacía muy peligroso para la policía intervenir en la proximidad de las vías con lo cual aprovecharon esta situación ambiental para convertirlos en un espacio seguro, práctica ya consolidada ${ }^{72}$. Y es precisamente esta confrontación directa con el entorno, el trabajo conjunto entre ellos para evitar ser detenidos o identificados -cuestión que les puede costar su internamiento en un CIE o la imposibilidad de acceder en el futuro a la regularización de su situación-, lo que les proporciona una capacidad de entendimiento operativo del espacio público y, por tanto, aprovechable en su beneficio propio. Este es el mismo mecanismo de supervivencia que utilizan de manera cotidiana en el espacio público y, como muestra la cartografía del intento de detención en Calle Preciados no funcionan como una mera suma de individualidades sino que, de manera conjunta son capaces de avisarse y así prever los movimientos y acciones del cuerpo de policía para minimizar los efectos que puedan causarles: desde la pérdida de la mercancía, la identificación, las agresiones policiales o incluso el internamiento en el CIE que puede detonar el proceso de expulsión. Allí, ante la detección ocular por parte de los manteros de dos policías vestidos de paisano que aún no se habían identificado como tales, el grupo al completo de vendedores ambulantes recogió sus cosas y escapó segundos antes que otra patrulla policial - motorizada- cerrase una de las vías de escape.

Esta organización grupal que ha sido posible al compartir un mismo espacio de trabajo, así como la visibilidad adquirida por desarrollar su actividad en el espacio público les ha otorgado una gran capacidad de organización. Pero estas relaciones no se limitan al trabajo como señala Ángel García "la vida en comunidad es uno de los pilares fundamentales para la auto-organización de este colectivo. El compañerismo y la convivencia son su sustento emocional"73. Esta organización más allá del espacio de trabajo y del doméstico -o, dicho de otro modo, que no diferencia entre espacio público y privado ni entre trabajo y forma de vida- les ha permitido adquirir una voz pública cada vez con mayor fuerza y, a la vez, ir construyendo medidas que mejoren sus condiciones como vendedores ambulantes pero también como migrantes y personas racializadas. A consecuencia de estos encuentros espaciales, de este devenir forzoso que les impide acceder al circuito laboral, pero también de vivienda,

Una imagen que, por simbólica es capaz de reflejar muy bien la situación en la que se situaron estos ejecutivos locales respecto a la venta ambulante irregular tuvo lugar el 14 de diciembre de 2018. La portavoz municipal, Rita Maestre, daba una conferencia cuando integrantes del Sindicato de Manteros y del Movimiento de Acción Política Antirracista desplegaron una pancarta -en una sábana similar a las que usan para llevar con ellos la mercancía- donde se podía leer "Ayuntamiento Racista", junto a ella el famoso lema "El racismo institucional nos

72 Pau Esparch, "El top manta entra a les andanes del metro per esquivar la policía”, Diario Ara, 12 de febrero de 2018.

73 Angel García, “Tras las mantas”, 5W, 16 de agosto de 2018.
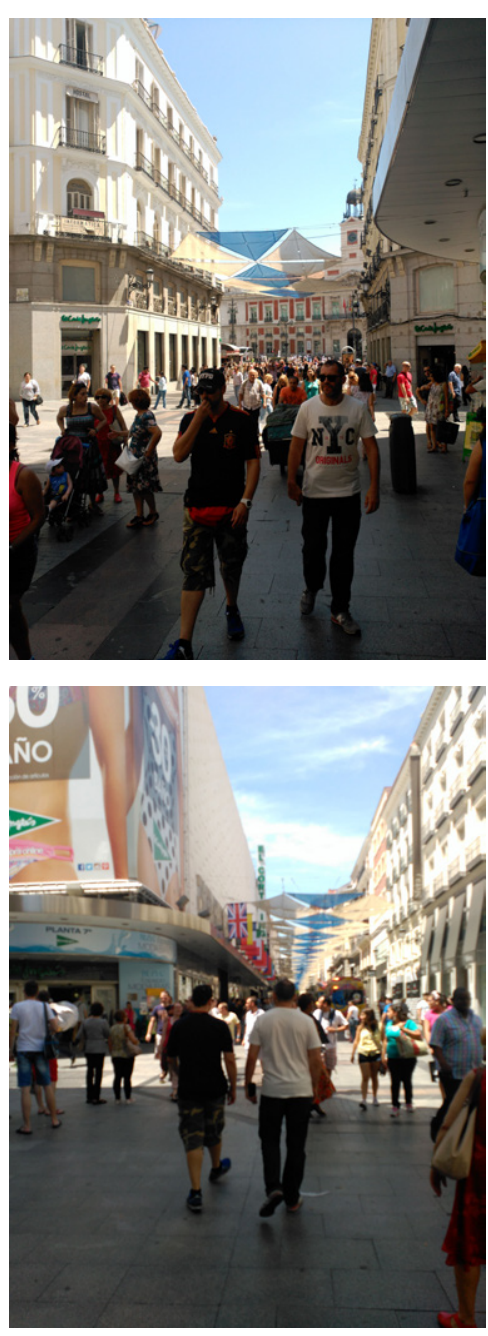

Pareja de policías de paisano previos a actuación policial en la calle de Callao (Elaboración propia; Madrid, 2015) 


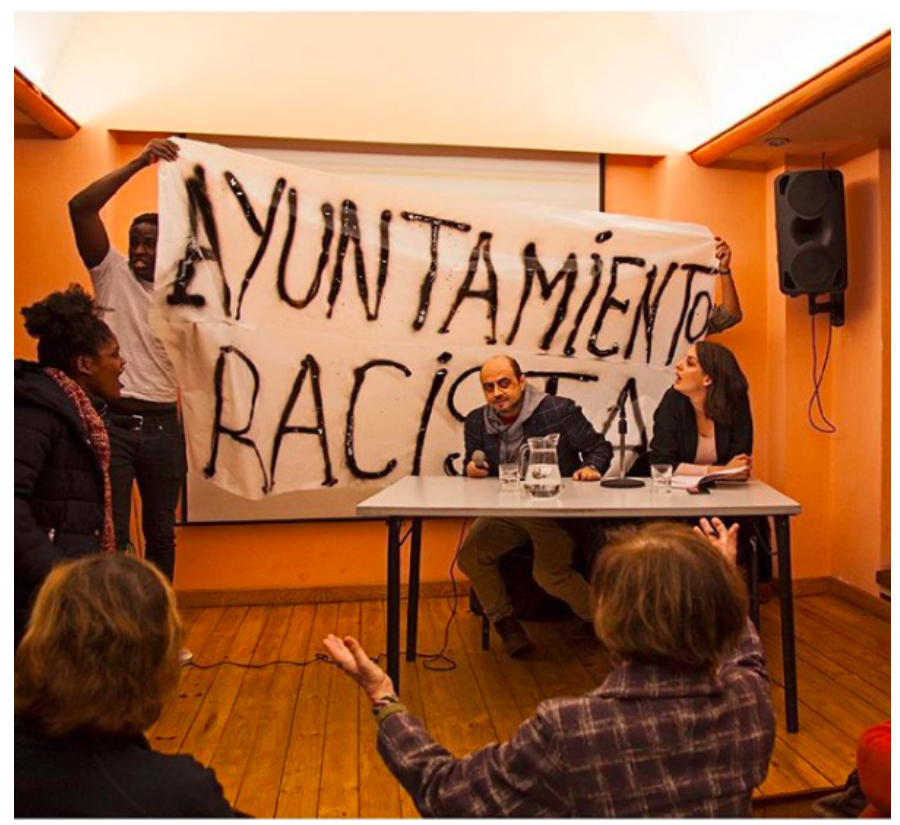

Protesta contra el Ayuntamiento de Madrid por el Sindicato de Manteros (El Salto; Madrid, 2018) condena a la manta"74. Mientras tomaban la palabra y hacían uso del micrófono para denunciar las incoherencias entre discurso y praxis, la estupefacción de la edil madrileña reflejaba muy bien la posición de una izquierda incapaz de comprometerse, o incapaz de no verse afectada por otras partes del dispositivo de gobierno ciudadano -comerciales, policiales...-, con las necesidades de un colectivo extremadamente vulnerable y criminalizado. Y es precisamente a través de estas incoherencias donde, hasta las posiciones políticas ideológicamente más próximas y sensibles a su problemática, se ve más clara la necesidad de alzar su propia voz y no mediada por terceros no conscientes de su realidad cotidiana es necesaria.

Esta organización sindical, que es necesariamente interseccional -ya que son personas atravesadas por múltiples opresiones y realidades como la precariedad laboral, la condición de migrante y la racialización-no se construye tomando como ejemplo el sindicato histórico laboral sino desde la base y el afecto compartido. Y así lo hacen saber en uno de sus comunicados "Somos manteros, trabajadores migrantes y luchadores, que ante el racismo y la violencia institucional que sufrimos cotidianamente hemos decidido organizarnos para luchar por nuestros derechos"75. Este distanciamiento les ha permitido abordar problemáticas de manera directa -como ante la muerte de compañeros- pero también pensar medidas que subviertan las lógicas que los condenan a la venta ambulante; por ejemplo, la creación de sus propios productos -la marca Top Manta- o vías de financiación y cajas de resistencia para las comunidades. No son la única organización sindical que reconoce las realidades múltiples que las atraviesan: Territorio Doméstico, una asociación laboral de empleadas migrantes del hogar, es otro buen ejemplo de cómo a través de maneras creativas de asociarse es posible devenir un cuerpo múltiple para mejorar las condiciones espaciales a las que se enfrentan y las violencias cotidianas que sufren al grito de "Levántate empleada del hogar, lucha por tus derechos y tu visibilidad" 76 , "queremos currar en condiciones, y el paro poder cobrar, basta

74 Redacción El Salto, "El Sindicato de Manteros protesta por la criminalización en una charla de Rita Maestre”, El Salto, I5 de diciembre de 2018.

75 Sindicato Popular de Vendedores Ambulantes, «Comunicados», acceso el I de octubre de 2019, https://manteros.org/comunicados

76 Territorio Doméstico, «Levántate empleada del hogar», acceso el 2 de octubre de 2019, https://soundcloud.com/territoriodomestico/5-levantate-empleada-del-hogar 
de invisibilidad" 7 . Es importante señalar como, el trabajo doméstico, la figura por antonomasia de la migración global contemporánea -pero mediáticamente invisibilizada al ser constantemente absorbida y demandada por el sistema-, genera un sistema de violencias inherentes al propio espacio donde se desarrolla que se suma a las sufridas como migrantes, precarias, racializadas y mujeres: al ser el espacio de trabajo individual y atomizado dentro de cada casa, las posibilidades de encuentro y establecimiento de lazos es mucho menor y, por tanto, las de asociación.

Esta es su manera de devenir un cuerpo múltiple, pero también público al tener voz y reconocimiento en espacios en los que, de otra forma, estarían sistemáticamente excluidos - programas de televisión, ruedas de prensa, foros...- que expande los afectos más allá de la propia comunidad, generando lazos de solidaridad. Reconocen su posición "condenados a la inmaterialidad de la existencia, llevando sobre sus espaldas, sin embargo, toda la materialidad que carga un cuerpo explotado: miseria, dolor, sudor, miedos e incertidumbre. Underclass espectral, imposibilitada incluso para constituirse como sujeto de clase" 78 . Y es precisamente, desde este reconocimiento espectral, desde donde operan para mejorar sus condiciones en el espacio público, entendiendo que "al pobre no le permiten ocupar el espacio público"79 ya que no sólo portan la manta, ni la precariedad sino la propia frontera encarnada en su cuerpo y sus acciones. Y, por ello es fundamental trascender la idea moderna del espacio público como un espacio accesible por todas las personas, sino como un espacio al que sólo pueden acceder aquellas que tienen derecho a él, es decir, ciudadanos de pleno derecho -en el sentido clásico del término-. Por lo tanto, es importante entender que son estos cuerpos que de manera activa lo ocupan, se visibilizan y exponen para obtener una voz que por otros canales es anulada, que la frontera se desplaza con ello y que, como dice Lamine Assar - portavoz del Sindicato Popular de Vendedores Ambulantes- "el problema no es el espacio público, es quién lo ocupa"8o.

77 Territorio Doméstico, «Me duele to», acceso el 2 de octubre de 2019, https://soundcloud. com/territoriodomestico/8-me-duele-to

78 Meloni González, "Los Gillets Noir y el devenir negro del mundo”, El Salto, 20 de septiembre de 2019.

79 Efe, "Sindicato de manteros: "Al pobre no le permiten ocupar el espacio público"”, Público, 13 de agosto de 2019.

80 Efe, "Sindicato de manteros: "Al pobre no le permiten ocupar el espacio público””, Público, 13 de agosto de 2019 . 

\#perpetuación de la atmósfera + \#gestión preventiva de los riesgos Unión Europea \#gestión preventiva de los riesgos \#, \# \#normalización [p.245]

Ritualización y atmósfera

Limitaciones de la condición dinámica del dispositivo,

\begin{tabular}{c|c|c} 
- & Plan Integral de Mejora de la Seguridad y \\
\hline & Convivencia de Lavapiés
\end{tabular} [p.260]

\section{$+\ldots \ldots+\ldots \ldots-$ - \#relación congelada entre espacio y evento \\ \#estabilización \#atmósfera

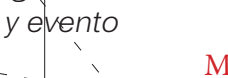
Andreas Philippopoulos-Mihalopoulos

Arquitecturas en el espacio público [p.270] \#anulación dé, las posibilidadés dé transformación,

dade's ',

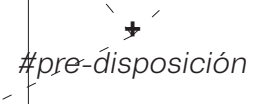

\#ho-lawscape

Andreas Philippopoulos-Mihalopoutos

$+$

\#normalización de los afectos Andreas Philippopoulos-Mihalopoulos

(1)

Tres condiciones sobre la violencia espacial y la apertura de nuevas posibilidades espaciales.

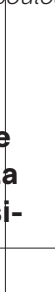

Motín en Aluche

\#rituálización Beŕnard Tschumi

\section{\#desactivación de díspositivos}

\#profanación Giórgio Agamben
Barceloneta $\begin{gathered}\text { de poder } \\ \text { Giorgio Agamben }\end{gathered}$ [p.281] dé la sustracción [p.137]$$
+
$$

\#restitución de la manipulación Giorgio Agamben \#apertura de nuevas posibilidades espaciales
Transgresión, prơłạnación y

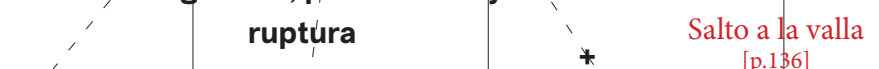
\begin{tabular}{c|ccc} 
ruptura & ', & Salto a la valla \\
[p.136]
\end{tabular}

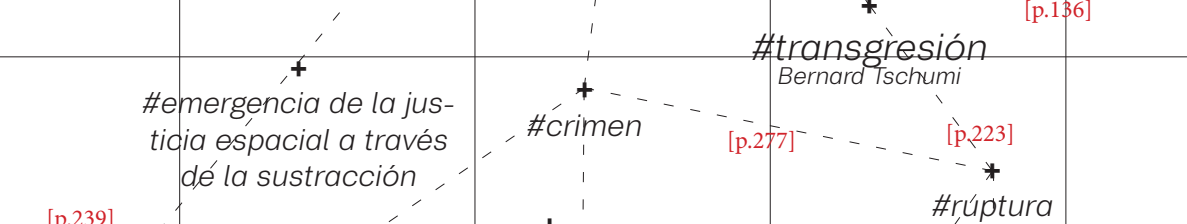



A lo largo de diferentes casos de estudio hemos recorrido espacios construidos a través de las acciones de los cuerpos, despliegues arquitectónicos basados en la operatividad, que respondían con precisión a los movimientos -tanto macro como micro- de un cuerpo migrante en acción. Su desplazamiento, sus decisiones y transgresiones activaban un espacio, lo reorientaban y explicitaban la violencia espacial inherente a la frontera contemporánea. En escenarios cotidianos donde "aparentemente nunca pasa nada" se desarrollaban acontecimientos que, en cuestión de segundos, devenían espacios regidos por la excepción. Independientemente de su naturaleza, tanto calles, plazas, edificaciones en desuso, playas o espacios directamente vinculados a la frontera, alteraban su status quo de manera instantánea y temporal. Las normas que regían en ellos hasta el momento eran puestas en suspenso, emergían otras, y la función habitual que desarrollaba cada agente era sustituida por acciones inesperadas que sólo podían ser explicadas desde la contingencia del momento. En definitiva, la disposición habitual del ensamblaje era violentamente modificada a través de un detonante que activaba, reorientaba y establecía conexiones instantáneas entre las partes involucradas en el transcurso del acontecimiento y, por tanto, en la construcción del espacio. Es hora de preguntarse de donde emergen estas nuevas configuraciones del dispositivo y qué consecuencias tienen tanto sobre la norma, los cuerpos y los escenarios donde estos acontecimientos se desarrollan.

Aunque el dispositivo posea una condición dinámica, es innegable que el desarrollo cotidiano o la propia disposición de los agentes hace que se estabilicen las relaciones entre las partes, lo que facilita ciertas disposiciones, mientras que la aparición de otras presenta una resistencia mucho mayor. El orden natural de las cosas no es más que esto, lo que propicia que los cuerpos actúen de una determinada manera en el espacio aunque las posibilidades espaciales sean infinitamente mayores. Este estatismo -que aparentemente invisibiliza la condición dinámica de los ensamblajes arquitectónicos- se presenta como una ritualización del espacio, es decir, "una relación casi congelada entre espacio

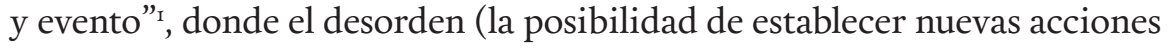
o relaciones) es evitado y "nada extraño o inesperado debe pasar. El control debe ser absoluto" ${ }^{2}$. Esta ritualización de la que nos habla Bernard Tschumi es ejercida precisamente a través de un corpus de normas que son asumidas para canalizar los movimientos de los cuerpos, haciendo que "la interacción original, espontánea del cuerpo con un espacio sea purificada a menudo por rituales"'3. Es, por tanto, el conjunto de leyes -las cuerdas que atan a los cuerpos y condicionan sus movimientos en el espacio- y su espacialización cotidiana las que generan esta normalización del espacio. Una normalización que hace que todo aquel individuo que no se adapte a ella, sea expulsado, castigado o violentado espacialmente. De la misma manera que el dispositivo adopta disposiciones con más frecuencia que otras, igual ocurre con el lawscape: existen situaciones donde la interacción entre las normas se cristaliza y agarrota, dando paso a lo que Philippopoulos-Mihalopoulos ha denominado atmósfera.

Antes de entrar a analizar las implicaciones espaciales de este concepto es importante entender cómo la ley procura una estabilización de las normas: "La ley opera con normas, y a través de esto la ley vincula el tiempo en la forma de estabilización de las expectativas" ${ }^{4}$. La ley estabiliza las expectativas regulando las prácticas que pueden o no realizarse mediante normas explícitas o implícitas, materiales o inmateriales. Esto construye un espacio ritualizado, donde cada

\section{Ritualización y atmósfera}

Limitaciones de la condición

dinámica del dispositivo

\#ritualización

\#relación congelada entre

espacio y evento

\#normalización

\#atmósfera

\#estabilización

1 Bernard Tschumi, Architecture and Disjunction, (Londres: MIT Press, 1996), p.126.

2 Tschumi, Architecture and Disjunction, (Londres: MIT Press, 1996), p.126.

3 Tschumi, Architecture and Disjunction, (Londres: MIT Press, 1996), p.126.

4 Andreas Philippopoulos-Mihalopoulos. Absent Environments: Theorising environmental

Law and the city, (Oxford: Routledge Cavendish, 2007), p.129. 
\#perpetuación de la atmósfera

\#gestión preventiva de los riesgos

\#anulación de las posibilidades de transformación

\#predisposición

\#no-lawscape

\#normalización de los afectos movimiento está planeado de antemano y cada acción, cada cuerpo juega un papel preciso para perpetuar el funcionamiento establecido - "los cuerpos capturados en una atmósfera están ahí con un único propósito: la perpetuación de esta atmósfera" ${ }_{-}$. . El objetivo de este espacio es claro, minimizar los riesgos existentes de que algo no planeado ocurra y materializar la disposición específica del ensamblaje del modo más duradero posible, a través de la expulsión o reconducción de aquellos cuerpos que se alejen de la norma.

La gestión del riesgo, su minimización y control a través de diferentes dispositivos técnicos, arquitectónicos, legales y humanos es una constante en la producción de la frontera que también podemos extender al conjunto del espacio urbano. La prevención es una idea cada vez más presente en los estudios contemporáneos sobre el control de fronteras, destinada a evitar la entrada irregular de cuerpos en el espacio europeo o a expulsarlos una vez han entrado a través de las actuales lógicas de deportabilidad y securitización -basadas directamente en la gestión del riesgo-. Sin embargo, es fácil entender las implicaciones del diseño de un espacio -sea arquitectónico o geopolítico- con una tendencia al riesgo cero. Ante un presente determinado se despliegan una serie de mecanismos espaciales de diferente naturaleza que no sólo pretenden estabilizar una situación (de riesgo) actual sino también impedir que esta se produzca o reproduzca en un futuro determinado. Por ilustrarlo con un ejemplo concreto, tras los saltos a la valla en el paso fronterizo del Benzú (Ceuta) tanto la policía marroquí como la española desplegaron una serie de mecanismos aparentemente no arquitectónicos para intentar estabilizar una situación determinada. Si observamos este mismo acontecimiento desde las lógicas de los ensamblajes, veremos la relevancia arquitectónica del despliegue de alambrada a lo largo de la playa, la generación de zanjas a lo largo de la línea fronteriza y la incorporación de nuevos agentes al destacamento. Pero, si además lo analizamos desde el punto de vista de la gestión del riesgo - un nuevo salto a la valla-veremos como su diseño responde a una función: estabilizar una situación determinada e impedir un futuro concreto. El riesgo aparece, por tanto, como una forma de relacionarse con el tiempo, pero también con el espacio

¿Qué es un espacio donde el riesgo se minimiza a través de un control absoluto? La atmósfera, o espacio ritualizado, se presenta ante nosotros como un espacio donde la interacción entre normas, cuerpo y espacio no es posible más que en una determinada dirección; esto es, los cuerpos y sus acciones están predefinidos. Se diferencia del lawscape, precisamente por "ser un lawscape que ha logrado alcanzar su 'perfecta' disimulación como un no-lawscape", es decir, un espacio donde (aparentemente) no es posible establecer nuevas disposiciones. La atmósfera aparece como una disposición específica capaz de "absorber el exceso de afecto, que barre los restos contingentes, ordena cualquier cosa que pueda ir diferente y diseñar la dirección ya dada de los afectos de una manera colectiva"6. Mientras que los afectos entre cuerpos son capaces de disponer y construir determinadas situaciones arquitectónicas, la atmósfera congela, ritualiza y cristaliza determinadas situaciones, "la atmósfera es el afecto castrado, deexcesificado, normalizado" . Así, aunque es posible diferenciar la naturaleza de las atmósferas, hemos de hablar de atmósferas diseñadas como resultados específicos y muy concretos provocados por la inercia del dispositivo, en nuestro caso la frontera contemporánea. ¿Cuál es la diferencia por tanto entre un espacio cotidiano y un espacio ritualizado? Que mientras en los primeros siempre hay un margen de maniobra, adaptación o alteración de ellos sin exponerse a una

5 Andreas Philippopoulos-Mihalopoulos. Spatial Fustice: Body, Lawscape, Atmosphere. (Nueva York: Taylor and Francis, 2015), p.108.

6 Philippopoulos-Mihalopoulos. Spatial Fustice. (Nueva York: Taylor and Francis, 2015), p.130. 7 Philippopoulos-Mihalopoulos. Spatial Fustice. (Nueva York: Taylor and Francis, 2015), p.130. 
violencia explícita o sin que implique el desmonoramiento de la misma, en las segundas toda acción no reglada implica necesariamente una transgresión y una expulsión de ella. Esta expulsión no es necesariamiente física, pero sí tiene efectos espaciales concretos sobre los cuerpos expulsados.

Sin embargo, esta construcción de atmósferas o espacios ritualizados puede ser revertida a través de la restitución de su condición dinámica e interactiva, donde los cuerpos sean capaces de nuevo de operar en el lawscape a través de sus acciones y desplazamiento. Los casos de estudio muestran como en determinados acontecimientos los cuerpos logran anular, durante un tiempo determinado, la cristalización del espacio y operar con los elementos que lo configuran de maneras totalmente imprevistas: las vallas se convierten en puntos de escalada, las playas pasan a ser territorios de excepción, los restaurantes se transforman en improvisados centros de detención... Para entender estas situaciones resulta interesante traer al ámbito arquitectónico el concepto de profanación que presenta Giorgio Agamben como aquella acción que logra traer de vuelta al uso común lo que había sido sustraído. Es decir, el mecanismo mediante el cual es posible volver a usar -del mismo modo pero también de forma diferente- los agentes y escenarios que antes sólo era posible emplear de una única manera posible. $\mathrm{O}$, dicho de otro modo, la realidad que nos rodea, las construcciones y escenarios dejan de ser una realidad "no ya observada, sino jugada [que] abre la puerta del uso"». Así, si la esfera de lo sagrado es aquella en la que una institución -en nuestro sustituyamos este concepto por el de dispositivosustrae ciertos elementos del uso público, el rito de la profanación restituye esta posibilidad. Agamben pone el foco en dos aspectos de la profanación que cobran especial relevancia a la hora de extrapolar esta lectura al campo arquitectónico: la relevancia de la materia y de los usos no previstos. Así, en primer lugar señala como la manipulación directa de la materia, "un tocar que desencanta y restituye al uso lo que lo sagrado había separado y petrificado"9, permite revertir la ritualización del espacio; es decir, son en primera instancia las condiciones materiales y su capacidad de manipulación las que abren la puerta a la operatividad del espacio y no las posibilidades fijadas por diseño-algo que nos remite a los planteamientos de Jane Bennet-. Y, en segundo lugar como "el pasaje de lo sagrado a lo profano puede, de hecho, darse también a través de un uso (o, más bien, un reuso) completamente incongruente de lo sagrado" "о ; lo que señala como el cuestionamiento activo de los usos, funciones y programas asignados a cada elemento arquitectónico permite una exploración de nuevas posibilidades espaciales. Estas dos manipulaciones son precondiciones que ayudan a desmantelar los espacios ritualizados, bien cuestionando la propia materia o las normas, funciones y usos que les han sido asignados. Aunque Agamben exponga de manera diferenciada estas dos situaciones es necesario precisar que, si son los cuerpos los que encarnan la ley y que la ley, a su vez, deviene materia, esta diferenciación es tan sólo un matiz en un proceso que indistintamente opera tanto sobre los cuerpos como las normas que estos encarnan.

La profanación va más allá de la mera restitución a un estado previo, al retorno a una condición dinámica del uso del espacio -que también se alcanza- sino que abre la puerta a la construcción de nuevas posibilidades espaciales. No es, por tanto, un retroceso a un estado previo sino un movimiento imprevisible donde las inercias y conexiones entre los agentes del ensamblaje están por producirse. Señala Agamben este matiz diferenciando la secularización -el simple retornofrente al acto de la profanación:

\section{Transgresión, profanación y ruptura}

\#profanación

\#restitución de la manipulación

\#apertura de nuevas posibilidades espaciales

8 Giorgio Agamben, Profanaciones (Buenos Aires, Adriana Hidalgo Editora, 2005 ), 101.

9 Agamben, Profanaciones (Buenos Aires, Adriana Hidalgo Editora, 2005 ), 99.

10 Agamben, Profanaciones (Buenos Aires, Adriana Hidalgo Editora, 2005 ), 99. 
\#desactivación de dispositivos de poder

\#transgresión

\#crimen

\#ruptura

\#sustracción

\#emergencia de la justicia espacial a través de la sustracción
Una vez profanado, lo que era indisponible y separado pierde su aura y es restituido al uso. Ambas son operaciones políticas: pero la primera tiene que ver con el ejercicio del poder, garantizándolo mediante la referencia a un modelo sagrado; la segunda, desactiva los dispositivos del poder y restituye al uso común los espacios que el poder había confiscado ${ }^{\text {II }}$.

Es fácil asociar esta idea con la transgresión que plantea Tschumi como el mecanismo que, a través de la violencia entre cuerpos y arquitectura, se produce como condición previa al planteamiento de usos alternativos dentro de un espacio ritualizado. La afirmación "para realmente apreciar la arquitectura, puede que sea necesario cometer un crimen" cobra ahora una nueva dimensión, pues aparece la violencia entendida como una condición de manipulación operativa del espacio, tanto de sus cuerpos como de sus leyes. Es la transgresión, la violencia ejercida contra cuerpos, espacios y normas, que se produce en momentos específicos la que permite explorar nuevas posibilidades de uso del espacio y relación entre las partes que lo conforman. Podemos reconocer, por tanto, que existen acontecimientos concretos, eventos que sobrepasan el simple transitar por una atmósfera o espacio ritualizado sino que sus actos plantean una atmósfera diferente precedida de la ruptura de la existente. Cuando estos eventos ocurren, al igual que indicaba Agamben al distinguir entre secularización y profanación, pueden ocurrir dos situaciones: que dicha ruptura sea absorbida por la propia atmósfera ${ }^{12}$, tal vez con una disposición o configuración ligeramente diferente o que la propia atmósfera colapse y de paso, aunque sea por unos instantes, a otra configuración que no guarda ninguna relación con la situación previa. A este momento específico, un instante donde las conexiones cristalizadas entre agentes son liberadas y aún no han sido materializadas las nuevas relaciones Philippopoulos-Mihalopoulos lo ha denominado como sustracción. La sustracción ocurrida en estos momentos de ruptura hace que la violencia espacial encarnada en los cuerpos y construcciones se vuelva mucho más explícita que en otros acontecimientos. Los cuerpos, por deseo propio o por la disposición específica del ensamblaje, pueden ser heridos, destruidos parcial o totalmente a través de diferentes mecanismos para desplazarse a un nuevo régimen. Sin embargo, pongamos el foco en qué ocurre durante esos acontecimientos extraordinarios estudiados durante la tesis para entender qué consecuencias espaciales genera este evento cuando un cuerpo se retira de la atmósfera:

Aterriza en el lawscape, a la vez el mismo que permitió la construcción de la atmósfera y uno diferente; parte de un continuum todavía roto con capacidad de crear diferencia. Este lawscape puede ser el lugar de esperanza de emergencia de la justicia espacial, entendiendo que en el acto de la sustracción uno reorienta el lawscape, y así cambia el registro del conficto. La justicia espacial emerge cuando un cuerpo que se sustrae pasa a un espacio orientado diferentemente en el cual el registro del conflicto puede cambiar.

11 Agamben, Profanaciones (Buenos Aires, Adriana Hidalgo Editora, 2005 ), 102.

12 Philippopoulos-Mihalopoulos señala la capacidad que poseen las propias atmósferas para absorber y canalizar los conflictos internos y disensos que puedan existir en su seno a través de adaptaciones y nuevas configuraciones:

El disenso y las diferencias pueden ser parte de la economía atmosférica, ya construidas en los materiales del proyecto diseñado. Esto significa que cualquier diferencia está ya atmosféricamente incluida. Por simplificar, ontológicamente no pueden existir dos atmósferas al mismo tiempo. Lo que ocurre es que una atmósfera deviene otra-atmósfera, a través de acomodar el cambio, la pluralidad y el conflicto. La atmósfera mueve su topología mientras cambia.

Ver más en. Andreas Philippopoulos-Mihalopoulos. Spatial Fustice: Body, Lawscape, Atmosphere. (Nueva York: Taylor and Francis, 2015), p.164. 
Por tanto, son estos momentos de ruptura la precondición necesaria para que, de ellos, de la visibilización nítida de los conflictos y violencias existentes entre los cuerpos, emerja la justicia espacial. Una justicia espacial que se aleja de los postulados enunciados por la geografía radical sino que emana de la propia relación entre los agentes. Sin embargo, antes de entender las implicaciones arquitectónicas de esta situación es necesario recapitular tres apreciaciones respecto a este desplazamiento desde el lawscape a la atmósfera y desde ella a su ruptura.

Volvamos por tanto al crimen perpetrado en el anuncio de Tschumi ¿en qué consiste exactamente? ¿Qué operaciones y situaciones desvelan la violencia espacial inherente a toda producción arquitectónica de manera explícita y, a su vez, abren la posibilidad de nuevas configuraciones espaciales no planteadas en su diseño? Intentemos recopilar ciertas condiciones o características comunes para averiguar no tanto quién o qué comete el crimen sino en qué consiste exactamente. La primera de las condiciones, por la especial relevancia que cobra en este pasaje es la violencia espacial, ya que se manifiesta a través de la destrucción parcial o total de determinados cuerpos y objetos -sean estos materiales o no-. Es necesario un cierto grado de destrucción para lograr alterar la disposición existente y retirarse de la atmósfera o transformarla en una nueva. Un grado de destrucción que no afecta exclusivamente a objetos arquitectónicos - un motín en un CIE que, para adquirir visibilidad pública, requiere de la destrucción e incendio de cierto mobiliario- sino también cuerpos humanos -la carne desgarrada por las concertinas al intentar cruzar el perímetro fronterizo, la pierna rota de un agente, las heridas por impacto de pelota de goma...-. Pero también aquello que, generalmente no es puesto en un mismo plano de relevancia: la destrucción parcial o total de las leyes que estos cuerpos encarnan y las hacen manifestarse en un determinado espacio. Una destrucción constructiva en tanto que reorganiza la configuración del dispositivo para alterar o subvertir sus resultados espaciales.

Esta destrucción constructiva, capaz de reequilibrar las fuerzas y afectos entre las partes requiere de un entendimiento de la situación concreta, de la materialidad de los cuerpos pero también de las normas que encarna cada uno de ellos -así como el cuerpo propio-, y en este proceso donde lo que nos rodea pasa a ser aprehensible y transformable, cada cuerpo deviene un arquitecto menor. A través del desarrollo acciones y tácticas que aparentemente no poseen la entidad suficiente para ser consideradas como procesos arquitectónicos desde la ortodoxia disciplinar, pero que al operar con la materia arquitectónica de manera directa logran revertir y proponer alternativas espaciales a situaciones concretas. En definitiva, logran alterar las condiciones espaciales generadas por los ensamblajes en los que están inmersos haciendo que "obras que parecían terminadas son devueltas al fluir de los procesos" ${ }^{\text {"3 }}$, a un estado de potencia creativa. Frente a las lógicas de construcción del muro -estrategias, abstracción, permanencia, solidez, estatismo- las arquitecturas menores se definen por poseer las lógicas de la barricada -contingencia, inmediatez, reapropiación, temporalidad, precariedad-y, por ello, su detección y visibilidad es mucho más esquiva, resistiéndose a su captura o sistematización. Así, el repertorio de tácticas espaciales que logra operar y maniobrar desde las atmósferas, transformándolas o anulándolas sólo puede entenderse en un espacio donde "lo menor aparece como una potencia de variación, definido por su poder de invención continua de nuevas prácticas” ${ }^{14}$. Nos apoyamos, para ampliar esta noción de arquitectónica

13 Jill Stoner, Hacia una arquitectura menor (Madrid: Bartlebooth, 2018), I15.

14 Es importante entender como las nuevas prácticas y arquitectónicas menores, las acciones desarrolladas por los cuerpos no necesariamente generan situaciones de ruptura, pero si de transformación y alteración de las dinámicas internas del dispositivo. Es claro cómo, en el caso concreto del dispositivo frontera, las acciones del cuerpo migrante, la invención de nuevas

\section{Tres condiciones sobre la violencia espacial y la aper- tura de nuevas posibilidades espaciales.}

Destrucción constructiva y arquitectónica menor. Operar a través de tácticas arquitectónicas menores

\#retornar al proceso

\#arquitectónica menor

\#invención continua de nuevas prácticas espaciales 
\#potencia arquitectónica de

los cuerpos

\#espacialidad propia

\#condición subalterna

\#potencial político

\#dimensión colectiva

\#repertorio no rastreable de acciones

\#experimentación y circunstacialidad

\#carácter destructivo menor

\#conocimiento profundo del entorno material menor, en el trabajo de Jalón Oyarzún que diferencia entre arquitectura y arquitectónica para expandir el concepto, que la entiende como una "expresión libre (o rebelde) de la potencia arquitectónica de los cuerpos" donde son los que poseen la capacidad de "aumentar su potencia a través de una estrategia vital que potencia la razón y favorece los encuentros alegres” generando así una "espacialidad propia nacida de las acciones" ${ }^{15}$. Lo menor, que toma su punto de partida de La literatura menor presentada por Deleuze y Guattari se define en base a tres ejes que podemos trasladar a los procesos arquitectónicos que estamos analizando: su condición subalterna, su potencial político y su dimensión colectiva. Su condición subalterna en tanto que opera en los márgenes de una arquitectónica mayor, codificada y ejecutada desde el poder, a la que se resiste; su potencial político porque, como indica Agamben, la profanación que estas arquitectónicas produce en la materia arquitectónica desactiva los dispositivos de poder; y su dimensión colectiva. En definitiva, este modo menor puede concebirse como "una producción espacial que emerge de la potencia de los cuerpos y al margen de los poderes", precisando aquí que los poderes en nuestro caso son las disposiciones específicas consolidadas dentro del dispositivo, "producción que es siempre política, múltiple y la que, en tanto afecta a una potencia que es estrategia de supervivencia está siempre en juego la vida”"ז6.

Las tácticas arquitectónicas menores aparecen por tanto como un repertorio no rastreable de acciones y operaciones dirigidas contra la materia arquitectónica y las leyes encarnadas en ella realizadas por los cuerpos. Los conocimientos y saberes empleados no surgen de la academia o la disciplina sino de la realidad material a la que se han de enfrentar de manera constante, lo que hace "que no pueda ser codificado y que, frente a la generalidad, [se] reinvidica la experimentación y lo circunstancial” "ז7. Sólo del encuentro directo con la realidad, del contacto y confrontación de los cuerpos en espacios, arquitecturas y condiciones que les son hostiles y ejercen violencia se pueden desplegar estos mecanismos espaciales orientados a revertir o alterar la situación existente. Jill Stoner recoge esta multiplicidad de roles, técnicas y saberes asociadas al arquitecto menor apoyándose en el carácter destructivo de Walter Benjamin:

Un arquitecto menor es un carácter destructivo menor, manitas y hacker, periodista y editor, alter ego y subalterno. Quien es hábil arreglando, también puede sabotear, y sabe desmantelar tanto como ensamblar. Un hacker puede codificar un mensaje o descifrarlo, y los editores, para salvarnos de nuestra palabrería, cortan sin piedad cualquier exceso ${ }^{18}$.

Sólo un conocimiento en profundidad de la realidad material, de los componentes y agentes que la forman permite su alteración y manipulación a pesar de que el espacio se encuentre ritualizado o se haya convertido en una atmósfera. En este sentido, las figuras bajo las que un arquitecto menor puede desarrollar su actividad variarán en función del contexto, adoptando diferentes roles y tácticas. Esta es la idea que presenta Keller Easterling a modo de conclusión de su obra Extrastecraft, cuando reclama un repertorio activista

tácticas y agencias para subvertir los efectos de la frontera, tienen una reacción más o menos inmediata que intenta revertir la nueva situación provocada por las arquitectónicas menores construidas.

Stoner, Hacia una arquitectura menor (Madrid: Bartlebooth, 2018), I15.

15 García de Jalón Oyarzun, «Excepción y cuerpo rebelde: lo político como generador de una arquitectónica menor» (tesis doctoral, Universidad Politécnica de Madrid, 2016), I81.

16 García de Jalón Oyarzun, «Excepción y cuerpo rebelde: lo político como generador de una arquitectónica menor» (tesis doctoral, Universidad Politécnica de Madrid, 2016), 366.

17 García de Jalón Oyarzun, «Excepción y cuerpo rebelde: lo político como generador de una arquitectónica menor» (tesis doctoral, Universidad Politécnica de Madrid, 2016), 366.

18 Stoner, Hacia una arquitectura menor (Madrid: Bartlebooth, 2018), 136. 
alternativo, donde frente a las enmiendas a la totalidad aparecen una serie de figuras y agentes que, de manera silenciosa, reconfiguran las relaciones del dispositivo de manera muy precisa y táctica. Así el potencial político del arquitecto menor aparece de nuevo reflejado en esta idea donde es desde la praxis y no desde el discurso desde el que revierte su situación, alumbrando, denunciando o modificando su situación y, en base a ello adquiriendo alterando las disposiciones a su favor:

Rediseñar la disposición en el espacio infraestructural no es un duelo. Dado que los cimientos amplios de este espacio, las formas activas que generan disposiciones son capaces de efectuar cambios significativos al sistema operativo. Los activistas no necesitan enfrentarse a cada hierba en el campo sino, sin anunciarlo, alterar la química del suelo. Estas capacidades dispositivas proponen una aproximación tanto a la construcción como el activismo que es más performativa que prescriptiva. Mientras que ciertas tradiciones políticas llaman a revoluciones o a la absoluta aniquilación del viejo sistema, un cambio en la disposición puede promover la actual redisposición o revolución de un determinado clima espacio-político. Estos ajustes pueden reducir las tensiones y la violencia y, al no estar declarados, no necesitan invocar los dogmas prevalecientes que harían falta, de ser nombrados, enunciar para una pelea simétrica.

Se reconoce aquí la asimetría de fuerzas existente en la reorientación de un dispositivo entre cuerpos que, por su condición, carecen de la inercia necesaria para alterar su disposición. Y que, sin embargo, al operar a través de las fisuras detectadas exclusivamente del reconocimiento físico y material de la realidad, son capaces de redisponer en buena medida para subvertir la violencia espacial, o al menos reducir en buena medida su grado, ejercida contra ellos.

Si la materia arquitectónica ha dejado de estar conformada exclusivamente por los materiales que levantaban muros y construcciones para incluir también a normas, regulaciones y condiciones infraestructurales es necesario plantear qué otras figuras puede adoptar el arquitecto menor más allá del carácter destructivo Si la forma-objeto ha dado paso al entendimiento de que las formas activas son también parte del corpus arquitectónico, si ley, materia y espacio están íntimamente ligados, el manipulado de una o de otra las afecta indistintamente. Y es precisamente esta manipulación la que introduce la segunda característica común que podemos detectar, la cual podría relacionarse con la carne arquitectónica de la que se componen los diferentes cuerpos en acción. Pues es a través de su exposición y destrucción -aunque no necesariamente en todos los casos haya de ocurrir- como se pueden operar, invertir, alterar o suprimir las leyes encarnadas en la materia que las conforman. No obstante, es en estos momentos específicos de ruptura, donde el grado de violencia espacial desplegado es mucho mayor que en otros acontecimientos, las carnes y materias de los agentes involucrados en él se exponen a almacenar en su superficie los resultados de estas operaciones en formas de cicatrices. La materia aparece como una materia informada, que incorpora en su transformación temporal las acciones sufridas, generando así una memoria material de los acontecimientos, haciéndolos visibles y públicos. "La información se acumula y el protagonismo de la materia se desvanece" al hacerse visibles las cicatrices y exponer los resultados de los acontecimientos atesorados en ella, "la materia se convierte en información [...] deja de ser una colección de propiedades intrínsecas genéricas para convertirse en información acumulada específica” ${ }^{19}$. Así, tanto la materia arquitectónica dura como la blanda sirven como testigo material de \#carácter performativo frente a prescriptivo

\#ausencia de discurso explícito

Relevancia material. Materia informada y evidencia forense.

\#carne arquitectónica

\#cicatrices

\#materia informada

\#testigo material

19 Ignacio Borrego Gómez-Pallete, «Materia informada: deformación, conformación y codificación. Los tres procedimientos de almacenamiento de información en la materia», (Tesis doctoral, Universidad Politécnica de Madrid, 2012) 382 


\section{In-significancia}

Alteración y subversión de los pesos y roles dentro del dispositivo

\#reorganización no convencional los acontecimientos excepcionales que han registrado. Por ejemplo, la acción de cruzar la alambrada deja tras de sí las cicatrices sobre el cuerpo humano de la misma manera que el peso de este cuerpo deforma la valla de acero galvanizado mediante el acto de trepar por ella; o las cicatrices causadas por los impactos de pelotas de goma en los cuerpos que cruzaron a nado el paso del Tarajal. O en el interior del CIE como los paramentos con el papel arrancado para elaborar una cartografía precaria, con cartografías grabadas en ellas sirven para registrar y visibilizar ciertas condiciones espaciales allí ocurridas del mismo modo que las lesiones físicas de los migrantes encerrados. E incluso como el propio barrio de Lavapiés sufrió las consecuencias en forma de contenedores quemados y adoquines levantados tras la muerte del mantero Mame Mbaye en esas mismas calles. Podemos afirmar que, aunque la violencia espacial sea siempre gradual y proporcional a la desviación que cada cuerpo tenga respecto a la norma, pocas veces ésta llega a afectar a los cuerpos en una dimensión material, dañando su carne y materia, sino que fundamentalmente lo hace coartando o redirigiendo sus posibilidades de acción, funciones y desplazamientos. Al igual que se preguntaba Herman Melville en Moby Dick, “¿cómo puede salir el prisionero sino es a través del muro?" en estos momentos de ruptura la única salida posible es precisamente a través del muro, de la materia arquitectónica y la carne, que ha de exponerse a ser dañada, o destruida si es necesario, como precondición para establecer nuevas configuraciones espaciales radicalmente diferentes a las existentes.

La tercera apreciación respecto a estos acontecimientos de ruptura hemos de hacerla en relación a la condición de dispositivo de la que parte todo nuestro análisis. ¿Cómo afectan estos acontecimientos a las dinámicas y lógicas internas del dispositivo? Si partimos de las ideas alcanzadas, una ruptura o acontecimiento no es más que una reorganización violenta y específica de los agentes que componen un ensamblaje. Es decir, durante el acontecimiento se produce una reorganización no convencional ni cristalizada - diseñada- de las conexiones, pesos y agencias que cada uno de los cuerpos involucrados en la producción del espacio posee en relación al resto. Esto tiene como traducción directa un nuevo reparto en la relevancia que cada agente tiene en la configuración, así como en la capacidad de orientación del dispositivo. Por lo tanto existe un desplazamiento temporal de los pesos dentro del ensamblaje donde aquellos elementos que tenían un peso fundamental son reemplazados o directamente descartados, poniendo de manifiesto la in/significancia de ciertos objetos arquitectónicos ante ciertas condiciones. E, incluso una completa alteración de su papel y funciones dentro del dispositivo. Un ejemplo claro es cómo durante el acontecimiento del Tarajal la valla subvierte por completo sus funciones dentro del dispositivo y es un elemento auxiliar dentro de una estructura de cien metros de largo, una puerta de acero que conecta la playa ceutí con la marroquí, la que altera las funciones y parámetros de diseño habituales de esta construcción. Así, la construcción que separaba e impedía el cruce de la línea geopolítica entre Europa y Marruecos abría un espacio -a través de la desactivación de estas funciones arquitectónicas- mediante el cual se conectaban ambos espacios de una manera excepcional no sujeta a las regulaciones vigentes, sino a la contingencia que emana del propio acontecimiento.

Tres son las condiciones espaciales que aparecen en estos acontecimientos de ruptura que abren vías de oportunidad, fisuras dentro de la estabilidad y solidez de la atmósfera construida a través de las cuales es posible operar. La primera, el alto grado de violencia espacial desplegado que afecta tanto a los cuerpos como a las normas que éstos encarnan, donde la materia es susceptible de ser dañada o destruida pero que a la vez permite una serie de maniobras a través de tácticas arquitectónicas menores para operar con el espacio. La segunda es el almacenamiento de información en la propia materia que, a consecuencia del 
grado de violencia espacial incorporan los cuerpos y escenarios involucrados en los acontecimientos, dañados o destruidos debido a la materialización de dicha violencia a la vez que convertidos en testigos materiales capaces de evidenciar lo ocurrido. Y la tercera que es la reconfiguración inmediata de las conexiones entre agentes así como de las funciones que cada uno desempeña dentro de la disposición concreta del ensamblaje, así de una manera inmediata los acontecimientos de ruptura sirven como detonantes capaces de alterar y subvertir la in/significancia en los roles dentro del dispositivo abriendo nuevas vías y posibilidades espaciales de manera inmediata. Tres fisuras producidas en tiempos diferentes, materiales y funcionales, que logran devolver la operatividad a un sistema congelado y rígido, a la vez que visibiliza de manera directa las condiciones espaciales. Tres líneas de fuga a través de las que los cuerpos, deviniendo arquitectos menores, son capaces de operar a través de tácticas con el espacio que los rodea.

Estas condiciones abren la puerta a que, durante estos acontecimientos se visibilicen las situaciones y emane de ellas la posibilidad de una justicia espacial no dependiente de instituciones externas sino de la propia confrontación, diálogo y afectos establecidos entre las partes involucradas -tanto en la espacialidad propia del acontecimiento como en una dimensión mucho más expandida-. Este término, introducido por la geografía radical de la mano de Harvey o Soja, y basándose en la afirmación de Levfebre acerca de la relevancia del espacio como "reto principal de las luchas y acciones que apuntan hacia un objetivo [...] que se ha convertido en algo más que el teatro, escenario indiferente o marco de los actos" ${ }^{20}$. Se apoya esta noción en la condición espacial ontológica del ser, en la producción social del espacio y en la dialéctica socio-espacial para plantear la necesidad de interrogar al espacio entendiendo que "la justicia y la injusticia están embebidas en él, en las geografías multiescalares que habitamos, desde el espacio del cuerpo y la casa, las ciudades, regiones y estados nación hasta la escala global” ${ }^{21}$. El giro espacial desplazó en su momento el foco al propio territorio y lugares donde se desarrollaban las acciones, cuestionando cómo la estructuración del espacio era foco de desajustes respecto a la distribución equitativa de los bienes o la generación de focos de injusticia. Este planteamiento "se aleja de la espacialidad cuando el concepto de justicia espacial se trata, en realidad, no como espacial sino como justicia territorial y distributiva” como afirma Philippopoulos-Mihalopoulos, que coincide además en una de las tesis principales señaladas por Springer acerca de las limitaciones de la geografía radical de corte marxista: las soluciones siempre emanan de instituciones externas -el Estado sin ir más lejos- en vez de emanar de los propios agentes involucrados en su producción ${ }^{22}$. Frente a esta aproximación y, como consecuencia lógica del desarrollo teórico previo, la noción de justicia espacial que plantea Philipoppoulos-Mihalopoulos ayuda a aclarar la relevancia del espacio entendido como una amalgama en transformación constante de cuerpos, afectos y normas, reconociendo la imposibilidad de alcanzar soluciones estables sino como una oportunidad de visibilización de los conflictos internos:

Lo máximo a lo que puede aspirar [la justicia espacial] es a delinear el problema, iniciar una discusión sobre las condiciones, reconocer el hasta ahora invisibilizado factor espacial: en definitiva: reconociendo y trabajando a través de la imposibilidad de una solución, la justicia espacial pone de manifiesto las condiciones de dicha imposibilidad, permitiendo un instante de oportunidad a través del cual discurrir.

\section{Hacia una justicia espacial encarnada}

\#espacio como medio

\#producción social del espacio

\#giro espacial

\#imposibilidad de soluciones definitivas

20 Henry Lefebvre, La producción del espacio (Madrid: Capitán Swing, 2013), 440.

21 Edward D. Soja, "The city and Spatial Justice”, Spatial Fustice vo.I, (2009).

22 Simon Springer, "Why a radical geographer must be anarchist", Dialogues in Human Geography, vol.4 n3 (2014), 249-270. 
\# imposibilidad de la justicia espacial como veredicto

\#justicia como corte

\#reconocimiento del conflicto

\#conflicto como motor de transformación del dispositivo
Intentemos trasladar esta idea de justicia espacial, para detectar cómo a través de los cuerpos, de su confrontación y de la construcción de acontecimientos es posible hacerla emerger. Una justicia que surge de la amalgama de cuerpo, norma y espacio sin depender de instituciones externas que dictaminen donde reside ésta centrándonos exclusivamente en qué efectos y condiciones tiene a nivel espacial. Tomemos como punto de partida dos expresiones coloquiales que nos permitan entender qué justicia puede emanar de estos acontecimientos de ruptura donde los cuerpos, a través de tácticas arquitectónicas menores logran alterar y revertir la disposición del ensamblaje. En la expresión "se ha hecho justicia”, la justicia asume la forma de veredicto: una resolución final que termina con un conflicto existente entre diferentes partes y que requiere la mediación de una autoridad externa -humana o divina-. Si trasladamos esta idea de justicia a las lógicas del dispositivo no resultará difícil encontrar las fallas que presenta. Primero porque dentro del dispositivo resulta difícil establecer dualidades o posiciones claras ya que la multiplicidad de agentes y las interrelaciones tejidas entre estos lo imposibilita. Pero además, su carácter dinámico obliga a asumir que cualquier solución o punto final sólo puede ser entendido de manera temporal, como una reconfiguración del ensamblaje que ha de provocar nuevos conflictos. Y, por último entender la imposibilidad de cualquier figura externa -superiorcapaz de dictar sentencia o establecer justicia entre las partes ya que, pasaría inmediatamente a formar parte del dispositivo situándose al mismo nivel que el resto de agentes. Por ello, bajo esta óptica donde nada escapa al dispositivo, la justicia puede ser promovida o reclamada por cualquier agente que forme parte de él -aunque obviamente existan asimetrías a la hora de reorientar y desplazar las configuraciones del dispositivos para encontrar soluciones favorables a sus deseos-.

La segunda acepción de justicia la encontramos en la frase "reclamar justicia", que podemos asociar al espacio de la corte o el tribunal: la creación de un espacio y un tiempo encapsulados donde las partes exponen públicamente la situación. Esto es que, como precondición se reconoce el conflicto y pruebas, datos y argumentos son presentados por los agentes implicados. Aparentemente esta acepción no sería incongruente respecto a las presuposiciones señaladas dado que no implica ninguna resolución estable, sino una simple exposición pública. Además, abre la posibilidad de que sea el propio sistema -y ningún agente externo- el que, a través de diferentes mecanismos internos, sea capaz de equilibrar las condiciones del dispositivo a través de reconfiguraciones no habituales. Pero, sobre todo, esta acepción nos da la capacidad de entender el conflicto no como un exceso o anomalía que ha de ser solucionada o tapada una explosión de violencia subjetiva ${ }^{23}$ - sino que puede ser entendido como un motor interno de transformación del dispositivo. Es decir, detectar los conflictos existentes, las reorganizaciones violentas de funciones, agentes y conexiones que se producen en los acontecimientos de ruptura no sólo permite transformar el dispositivo sino comprender cómo se puede operar con él, al hacer visible bien en el momento o bien en forma de cicatrices y evidencias materiales- las relaciones existentes dentro de él.

Son los cuerpos que encarnan las leyes los que logran abrir fisuras a través de las cuales retirar su presencia de atmósferas cuidadosamente diseñadas, de espacios ritualizados donde todas las posibilidades espaciales están cristalizadas. Para ello, despliegan un repertorio de tácticas arquitectónicas menores que emanan de la propia relación material fraguada en el espacio y no de abstracciones externas. A través de esta operatividad táctica, en la que exponen los cuerpos propios y ajenos a su destrucción parcial o total -tanto física como de las leyes que estos encarnan- logran anular la ritualización del espacio y, por tanto, este se vuelve

23 Slavoj Zizek, Sobre la violencia: seis reflexiones marginales (Barcelona: Paidós Ibérica, 2009). 
manipulable. Es en ese preciso instante, cuando las arquitectónicas menores han logrado sustraer a los cuerpos de la atmósfera donde aparece una justicia que no pretende emitir veredicto, sino construir un espacio temporal donde las partes evidencien el conflicto, una justicia que sólo emana del espacio porque para ello requiere una serie de operaciones arquitectónicas y territoriales como precondición para que éste se construya. 

6. CONCLUSIONS

THE BORDER AS

A MULTIPLE AND

UNATTAINABLE OBJECT 

We are again at the same crossroads that we were at the beginning of this Ph.D.: located at the intersection between Law, body, and space. A point that has never left the space generated by the Border. We have seen how the Border has been deployed in several scenarios: a body on the top of a fence, the Schengen Agreement, the thirty hours that Star stood up in the minimum thickness of a metallic fence, the flesh ripped by the razor barbed-wire that topped Melilla's fence, the virtual line traced between police agents through Ceuta shoreline, the night gunshots that pointed to the bodies swimming on the water, fourteen dead and twenty-three injured migrants at Tarajal, informal camps in the Moroccan mountains, high-tech video surveillance systems, Frontex, restaurants quickly adapted into architectures to intern hundred of people, police stations' basements, military tents, police violence inside a maximum security prison not even opened, several scratches and scribbles that reveals an affective cartography inside Aluche and Fuerteventura CIEs, riots, fires and escapes, blankets, police operations, urban transformations, the same blanket deployed onto the street, Mame Mbaye's death, burnt trash bins, Manteros' Union, the dead bodies that arrived to Cadiz coast in 1988 that we have to add to more than thirty thousand drowned lives in the Mediterranean sea since then. All these events, situations, and architectures that we have focused on have been placed at this crossroads. And, doing so, we were trying to relate the architectural production of spatiality that requires simultaneously Law, bodies, and space to be formulated. This intersection forces us to a constant displacement to deepen the connections of three apparent independent spheres that shape complex architectural assemblages using the Border as the link and the object of study to deploy these concepts.

Naming the Border as a territorial production apparatus and not only as the result of different architectures linked to it have allowed us to unveil how each variable affects the other ones. And, therefore, map an interdependent architecture between an expanded Law, a not-only-human body, and a space defined by the actions in it. Such identification, the Border Apparatus, isolated events of different nature can be seen as specific dispositions and architectural assemblages trying to provide spatial solutions as quickly and efficiently as possible. In particular, these connections, iterations, and transformations detected during the three last decades in Spanish Border are the ones that allow us to observe a clear evolution of the architectures produced by the Border. Architectures that blur built form to propose active forms that can solve emergencies that the inertia of the architectural industry is not capable of solve.

The liquid, transformable, and even elastic condition of border architectures', that enables to transform the sovereignty extent of a territory arbitrarily, has its origin in the operative turn standardized during the first decade of the 2Ist Century -mainly at a spatial dimension. A border managed through an operative condition that assumes its exceptional character to allow and create spatial practices that would not be permitted in other territories emerges versus a historic Border enounced through written Law. So, the creation and proliferation of exceptional borderspaces have a clear impact both in the forms as in the developed architectural formulas -an evolution that can be observed in the case studies. It is possible to translate the operative border concept - a paradigmatic example of this new territorial understanding- to other architectural assemblages far away from borderline. Exceptionality and emergency are the two main criteria that have allowed to capture and transform wedding restaurants, seafood stores, or maximum-security prisons into migrant detention centers. Moreover, they only needed minimum architectural intervention as tents to generate ephemeral camps. The exception has also allowed turning urban zones in free-fire-zones where the migrant body is the trigger that enables this exceptional atmosphere.
Apparatus

Operative condition of the contemporary border 
The Border apparatus is triggered and configured based on bodies' actions.
This operative turn, where the immediacy of ephemeral assemblies -versus homogenous solutions-, provokes three keypoints detected in the case studies. The first one: bodies' acquired relevance as a trigger of architectural assemblies and highly selective spatialities. The second one, a dynamic turn that gives priority to temporary solutions versus stable architectures. And, last one, the deterritorialization or territorial dispersion that translates border logic to any point of the territory. Spain has constituted an architectural laboratory of new border technologies due to its liminal position in the European context and through the implementation of these logics.

Thus, these spatial practices and architectural structures have a fundamental political component where state and international discourses gain the central role versus design issues. As the first chapter shows, we are in front of a territorial apparatus that is not built either in architectural or governmental offices, but mostly through political statements, negotiations, and conflicts. A political dimension that is not exclusively institutional but that is disputed and transformed through activism, social critique, or even through body confrontation. Although it is an architecture with no acknowledged author or a clear architectural project, we cannot deny architectural discipline's responsibilities - by omission or complicity- in the materialization and legitimation of discourses and buildings linked to the Border. If we acknowledge this architectural agency, we will be able to establish a critical notion about these architectures and also start mapping and developing the needed spatial toolkit to operate inside this complex apparatus. An architectural toolkit politically positioned that not reject conflict but comprehends it as an architectural transformation motor. A multiple conflict between agents of different nature with its own interests - shared or confronted- that transforms continuously Border apparatus needs. And, therefore, the spatial solutions produced by it.

The body has become one of the leading agents in border production. It is the body, in its potential, its actions, or the mere displacement over the territory, the one that triggers the architectural assemblages deployed around it. A body that is necessarily post-human that has to be enounced collectively, and that embodies its political and less-than-human condition, a bare life, that can be managed, hurt, or even damaged. The chapter focused on the fence is the one that more clearly has shown how a body that positions itself in a space where it is not authorized transform that scenario completely. The bodies perched on the top of Ceuta and Melilla's fence rendered the network of apparently non-architectural agents that ensured its unpenetrability.

In the same way, the swimming bodies through Tarajal border point -barely detected by surveillance cameras - deployed an exceptional assemblage that transformed the stable architecture of the fence in a mere background. In this event the choreography of moving human and non-human bodies -police agents, rubber-balls, boats, migrants and so on...- transformed spaces just where they were triggered by them and their displacement. Thus, this movement transformed them in absolute exception spaces; this provoked a clear subversión of the normal functioning of each space and building involved temporarily in this situation. In contrast to a nitid, stable, and topographical boundary drawn by the perimeter national sovereign line -easily recognized by the architecture of the fence- appears an operative border that is only represented by a field of variable intensities. Each body activated an opposite-oriented answer based on its action. They were the bodies, their movement on the water, or reaching the shoreline, the ones that enabled a specific spatial disposition. Moreover, this idea is translatable to the corpus of analyzed architecture, where each action done by the migrant body has a highly specific and almost instantaneous response. As a 
result of the reduced responsivity of stable architecture, the Border apparatus demands new architectural mechanisms: fast architectural assemblages with high adaptation to different contexts.

Architecture as a built fact becomes, due to the acquired relevance of bodies, to a second plane. It is dispossessed of the primary functions that historically have represented, the embodiment of Law in the thickness of its walls, and simultaneously acquires a growing symbolic and representational charge. The theatrical condition of these architectures, the progressive militarization of the architecture of the fence, the deportation centers, or even urban zones shows us the significant efforts to transform it into symbols that should render political agendas. Architecture, dispossessed of a real function, manifests it exclusively through a representative and mainly political function. As the border fence was growing and being more complex, the hot-deportations and an operative concept of the Border were gaining relevance. In the same way, the Spanish government made great mediatic efforts to show architectural improvements in new-built deportation centers while, at the same time, informal camps and unused buildings were barely adapted to temporarily incarcerate migrants proliferated. These architectural skeletons contrast radically with the police operations and spatial deployments defined only by its dynamic condition -with a duration that is limited to what is strictly necessary.

During the research, we have identified the dynamic turn produced in territorial management that consequently affects border architectures. We could confirm it in all the cases where it appeared as innovative mechanisms that emerged of tactical thinking -temporary resolution of highly specific problems-in opposition to architectural inertia based on strategic thinking. This evolution -from built objects to adaptative and temporary solutions- is noticeable in the chapter focused on enclosure architectures. The territorial evolution of the Deportation Centers shows us a shrinking network of formal centers that coexists with a variable group of informal camps and captured architectures that allow to alter and make more effective the deportation apparatus. Although this dynamic condition is not exclusive of this period, we can confirm the acquired weight during the last two decades. This is an architectural approach that has resonance with the managerial turn of the Border: the optimization of economic, material, and human resources to "make it better with less. " This political shift has an evident impact on the architectural decisions taken during the last two decades - both tactic and strategic. Specific interventions have substituted the enormous investments intended to update obsolete architectures. The failure in the lifespan of some Deportation Centers built during 2005 and 2006 unveils the crisis of a model based on the architectural industry's inertia: high economic investment, delays during the building process, and poor adaptability. Therefore, this dynamic turn tries to fix these assumed logics and, to do so, implement and strengthen architectural mechanisms which are adaptable to different kind of situations and that, moreover, their deployment over the territory last the least as possible.

Border apparatus has focused on the development of protocols, tactics, and architectural active forms through that operate through redispositions of agents depending on each demand. Precise instructions, police protocols, and elaborated norms configure a series of short-duration assemblages. As militaries assembled plate steel tubes and clothes to conform new deportation modules in existing CETIs, razor barbed-wire was deployed in Ceuta's beaches to increase border point efficiency -as migrant irregular crossing showed how
The Border Apparatus has suffered a dynamic turn that promotes tactical, temporary and highly specific mechanisms instead of static building or strategical thinking.

Tactic thinking over strategic thinking. Ephemeral, dynamic and instant assemblages. 
The Border apparatus has a high deterritorialization grade. This provokes that is not limited by the scenarios historically linked to it. . inefficient was. Beyond this transformation capacity and temporality, dynamic turn also affects more solid buildings. This normalized-emergency situation has an immediate consequence: the reduction of spatial warranties due to their temporariness. Meanwhile, at an institutional level, efforts are put in to increase architectural comfort; the consolidation of the dynamic turn provokes that these efforts have no validity. The emergency precarizes reduces (or even cancel) regulated standards relying on its exceptional condition that has to be calmed. Tarajal's direct shots onto migrant bodies, infrapenitentiary condition of informal camps, lack of sanitary installations, police operations...all of them are the consequence of how the raising of dynamic over static approaches has been consolidated as a more efficient mechanism. A mechanism that assures the optimal functioning of the Border, prioritizing its functionality over spatial standard and established warranties.

The dynamic turn has unveiled the deterritorialization feature of the analyzed architectural assemblages -a topic that is not exclusive of our temporal framework $^{2}$, but that has suffered deep transformations due to the contemporary territorial management regime. The Border is not limited exclusively to the architecture and Laws embodied by the fence in the same way that the whole apparatus associated with it is reduced to just buildings. Naming the Border as an apparatus, we can render the role of apparently-non-architectural agents and the relevance of territorial disperse architectures. Apparently-non-architectural agents can be defined as agents not included in historical architecture analysis due to their ephemeral, temporary condition, or just to no be relevant enough to define a determined construction. However, it is precisely through these minor agents -human and non-human- how contemporary Border is configured.

Furthermore, on the other side, we have detected how the apparent autonomy of these architectures required the presence and links with other agents to ensure the efficient functioning of each of them. Thus, it is a disperse performance, the one that is defining Border territorial reality. A reality that is full of connections between static and ephemeral elements and can be moved through the territory and has high efficiency in solving any unexpected situation.

The main consequence is that the Border blurs the architectures, landscapes, and territories where it operates to expands its logics far beyond its legally defined boundaries. This expansion has a different scale and impact in each case study - some kilometers in the territorial assemblages of Ceuta and Melilla versus the whole country in the post-metropolis chapter-. However, all of them share the same idea of expanded border logic. Even more, if we intertwine three case studies through apparatus notion, we can establish clear relations about migrants' flow regulation in all Spanish territory. In this reiterative and turbulent flow, we can associate each case study with a precise function in this territorial infrastructure. We have detected three causes linked to this deterritorialization that, without being strictly architectural, they cause deep spatial transformations. The first one, technological advances increasing relevance that enables the remote connection between agents -independently of their contextual and topographical situation. The second one, border management's externalization through suprastatal coordination between different countries and economic investments. And, last one, an externalization that flows between public and private realm - as a result of the apparition of an increasing number of enterprises linked to border management. All this parastatal infrastructure broadens each case extension, stressing it in different dimensions, not only geographical but political, sovereign, and technological.

2 However, it has been a key transformation due to a territorial management model based on contingency. 
As a result of this investigation appears a cartography of a much more diffuse and interlaced apparatus that, a priori, one could associate to the Border. An assemblage that extents and overlay over the whole territory -in which the Border has stopped to be a perimeter enclosure to dilute into the whole territory. This provokes a deterritorialization that is not foreign to the body, but it is the one who triggers this Border with his movement. We have seen how even in the historical center of the main Spanish metropolis mechanisms have been developed to contain, limit, and punish a migrant body that resists being funneled through regular flows of Border Apparatus. This body is expelled from the public sphere through multiple tactics, and when he access it, he exposes itself to the attempts of being neutralized by the Border Apparatus. The example of Manteros, as a body that consciously and collectively Access and reclaim their right to public space, allowed us to analyze how this assemblage is able to capture and transform each space just with the action of a body. The simple variation of a blanket over a sidewalk, a mínimum deployment of sale space, activates a whole set of architectural mechanisms. Moreover, this simple action brings a series of apparatus' alterations that produce an immediate spatiality in each point of territory. This action sums up how contemporary Border is produced, as an assemblage able to affect the whole territory dynamically, that generates instantaneously exceptional spaces that appear and disappear as required. A spatial production where bodies - not just human bodies because they incorporate the political dimension of the Border in their flesh-are the main producers of these spaces and logics. However, we have also found how the same gestures, the conscious transgression of a series of rules, allowed bodies to access a public space that it is politically denied despite their physical position on it. Bodies, through these resistance actions, achieve to reach the public sphere -conscious that they expose their body to architectural violence associated with breaking the Law and also of their infrapolitical or spectral situation. And they also subvert with their actions the balance between forces between the agents assembled in the apparatus. In brief, the migrant body deploying a blanket or setting it into fire inside a cell, or stood up at the top of a fence for more than thirty hours, manages to render what a body can do, but also claim a status that is constantly denied to them. Furthermore, on the other side, we have detected how the apparent autonomy of these architectures required the presence and links with other agents to ensure the efficient functioning of each of them. Thus, it is a disperse performance, the one that is defining Border territorial reality. A reality that is full of connections between static and ephemeral elements and can be moved through the territory and has high efficiency in solving any unexpected situation.

Analyze carefully any aspect of the reality implies, necessarily, leaving out of the focus the rest of them. By shedding light on the architectural production of contemporary Border with the limitations of any doctoral research, it multiplies the shadow áreas. Pointing the out-of-focus areas of the research, waiting to be retaken for further development, also supposes acknowledging the roads not traveled through the research. Realities and scopes that, being present in an implicit way, were not explicitly deployed.

The Border has appeared as a multiple and unattainable object, crossed by multiple meanings and spatial conditions condensed in just one notion. Focusing just in its architectural-normative-repressive dimension through migrant bodies - the ones that are not allowed to enter in the territory that Border encloses- leave out of focus key points to understand its complexity. Keypoints, as the economic dimension, how domestic space or sense of belonging are
The Border as a difuse and intertwinned assemblage.
The Border as an unattainable body. Research limitations. 
built inside Border apparatus would have built new layers of complexity -with a fundamental architectural condition. We have approached how, through different resistance tactics, the migrant body was able to establish a network of material and personal affects to reconnect it with a broader territory inside punitive architectures. However, it is important to remark that this analysis was always conditioned by its location inside each of the cases selected. This situation excluded all the migrant bodies that -without being conditioned by analyzed architectures- produce the same affective networks.

The Border also appears as an always-changing reality -especially in the media sphere. A reality where centers of gravity displace quickly at a geopolitical level but also in the highlighted architectures that gain relevance. And, consequently, the migrant figures associated with them. A quick news analysis will reveal how Mediterranean hotspots were displaced based on political decisions, but also how ships replaced boats and pateras, formal deportation centers were substituted by informal camps, or even how the menace invasion of migrants is now of asylum seekers. This immediacy has forced the research to anchor it in a concrete territorial and temporal frame; this provokes to leave out of our analysis similar architectural operations. With the political conviction that Spain has played a crucial role as an experimental laboratory of border technologies in the last decades -able to achieve maximum levels of spatial violence- we establish the origin of our coordinate in the European Border in Spanish territory. Eventhough displacements to other territories are made to supplement case studies, the logics unveiled in Spanish context are totally extrapolated to other European borderscapes.

We have employed the term migrant body as a homogeneous concept that tries to include a series of conditioners around it -through which we have based our research. It is necessary to clarify that this term is not a generalization but the minimum common denominator between different singularities and stories of life. However, we have to ask ourselves which bodies are excluded from our analysis. Establishing our framework based on certain architectures and scenarios, these are the ones who define the migrant body -as a user. The fence, the deportation architectures and even the post-metropolis -chapter focused on manteros- our migrant body is mediated continuously by them. A body that is mainly a male one, where women's presence is very inferior -although women embody more than a half of global migration. This absence allows us to comprehend the causes of this asymmetry, but also the consequences that are not limited to statistical data but direct spatial implications: it augments the grade of violence -both spatial and normative- exposed by this migrant body.

Methodological limitations. Voiceless bodies.
We have also to point that the tools developed to analyze the Border Apparatus have left behind them some black spots. And it is precisely the analysis of the migrant body where we have found a critical friction point while elaborating on this methodology. Naming the Border as an apparatus, where each of the agents has some agency, and there is no hierarchy between them, the central role of the human body disappears. This methodological consideration establishes a first critical distance respect the migrant body because it equates human and nonhuman agents while analyzing the Border spatial production. However, if at a theoretical level, does not supposes a conflict, it happens due to the high spatial violence that this human body suffers. Moreover, we have established a second critical distance - this time fully conscious and based on political decisionsdeveloping tools that give priority to material traces -actions of bodies on architectures and viceversa...- over other kinds of traces -as testimonies...-. This provokes that the migrant body speaks through their scars or actions, but it does not elaborate its own story. The body speaks but rarely uses words. This 
decision $^{3}$ has tried to enable a careful listening to migrants instead of speak for them or appropriate a scope that does not belong to us. This critical distance has allowed us to produce a scope where they are the main agents but does not pretend to overlap and silence their voices. The Border Apparatus reduces and erases any singularity to convert each migrant in a body without value -a bare life- through spatial violence. Therefore, we also have to position our research in the same scenario. Thus, precisely this shifting, from people to bodies, is the one that justifies the use of the term migrant body.

We are aware that any exhaustion attempt will fail immediately due to the fast transformation of border architectural assemblages in the last decades. This attempt would be overflowed by new spatial productions, spaces, and dispositions. That is the central core of the Apparatus, a territorial production mechanism that possesses a constant ability of capture, innovation, and transformation. Hence, before this foreseeable overflow, we have decided not to base our research on this exhaustion that will lead us to analyze every police deployment or event produced in Spanish territory or travel beyond paradigmatic examples as Gaza or Calais' Jungle. And even doing it, we would be missing scenarios. The aim of the cartography was not tracing with accuracy contemporary border territories but the underlying and veiled logic of it, as guidelines to allow new researches to travel those paths not taken.

We need to keep positioning ourselves in the Border, to be conscious of the spatial violence that it generates and its global scale. This problematic requires not only answers but also to be problematized from different scopes and disciplines - and the frictions and contaminated zones generated between them. To do so, it is necessary to embrace these grey extradisciplinary areas produced by similar political positions that need to be complementary to approach the immensity of an object as unassailable as urgent: contemporary borderscaping. By doing so, we will also be able to stretch and expand our own disciplinary boundaries. So, from this position, we have to assume the architectural implications that surround border production, but also the disciplinary abilities and tools that allow us to comprehend the different problems implicit in it. And, consequently, the development of tools and scopes to shed light, gain agency and infiltrate in the realm produced by the Border. We need an architecture engaged with this political commitment, even though this implies dissolution and hybridization of traditional roles into new contaminated roles. Disciplinary roles able to sense and being affected by the urgency of this territorial struggle; and, from there, develop new architectural repertoires to operate with them.

The scenarios that we have traveled are infinite, their extent expands far beyond the physical established boundaries, and their architecture cannot be understood without the bodies that trigger and build the spaces. With the evidence that these scenarios will constantly be transforming, that new hotspot, new migratory flows will appear and, therefore, new spatial tactics to counteract this forthcoming migrant body, the main result of this thesis does not rely on the concrete analysis but in the shared logics unveiled. Logics and conditions of the Border Apparatus are not exclusive of this field but easily translatable to the whole architectural corpus as spatial tools.

3 This position departs from a political engagement that acknowledges the oppression that migrant and racialized bodies suffer, where discourses pronounced by privileged subjects silence their voice. As a consequence of this position, we have to question the legitimacy of European Academia to produce knowledge through the appropriation of other voices. 
Operate through unveiled architectural logic.

Maneuvering the Apparatus through operative destruction.
So, we have to look at these unveiled logics and learn how to operate with them. Because these are the tools that are defining border construction, therefore, doing so through our political position, gain new agencies that go beyond mere formalization. Border logics abandon traditional design processes and inertias to focus on procedural and changing realities where protocols, active forms, and overlaying laws emerge in front of an inefficient architecture. The abandonment of these processes does not imply the abandonment of architectural language and elements, but a reconfiguration through new variables -an operative reorganization able to compose new analysis and spatial intervention tools. So, it is urgent to incorpore at our critical spatial repertoires the dynamic tactics, ephemeral assemblages, and performative condition that we have found in the Border. Because only through them we will be able to intervene in the spatial conditions produced by the Border.

However, we should not only expand architectural interest field in this dimension, but we have also to interrogate the body that triggers and operates this apparatus despite its apparent insignificance. Let us close this research positioning ourselves again in one of the first locations where we have taken contact with the Border, Benzú crossing paint. Let us remember Star at the top of the fence exposing his flesh and physical integrity; and becoming a minor architect that transforms its architecture finding the cracks and pores on it. It is this minor a precarious dimension, where bodies establish a struggle with surrounding matter, where we will can explore alternative ways to mainstream architectural practice. Because, at the time that this transgression is established, this produces a ruptures of embodied Law in the architectural flesh of the fence to open a new horizon of possibilities that extends far beyond the planned ones. Meanwhile the design is conceived from an ideal reality that during its translation to matter provokes cracks and mistakes, minor architects read this materiality as the first step to alter it. So, only the body that exposes itself to this spatial violence derived from a conscious architectural transgression is able to expand and imagine new spatial configurations. In other words, as someone wrote in one of the walls of Fuerteventura Deportation Center to domesticate an architecture transforming it into an own but shared space: "Who wants the honey has to have the corauge to face the bees" ${ }^{4}$. 


\section{CONCLUSIONES LA FRONTERA COMO OBJETO MÚLTIPLE E INABARCABLE}



Nos encontramos de nuevo en la misma encrucijada en la que nos situamos al inicio de esta tesis doctoral: en la intersección entre norma, cuerpo y espacio. Un cruce que, sin salir del espacio generado por la frontera, hemos visto cómo se ha desplegado en multitud de escenarios: un cuerpo situado en lo alto de la valla de Ceuta, el acervo de Schengen, Star encaramado durante treinta horas al espesor ínfimo de una alambrada, la carne desgarrada por las concertinas que coronan la línea fronteriza, la línea virtual hilvanada entre los agentes de policía a lo largo de una playa en Ceuta, los disparos al agua en la noche y los impactos en cuerpos que nadan, los catorce muertos y veintitrés heridos del Tarajal, los campamentos informales en los montes marroquíes, los sistemas de videovigilancia de alta tecnología, la creación de Frontex, los cocederos de marisco y restaurante transformados en arquitecturas para internar a centenares de personas, los sótanos de comisarías, las tiendas militares, la violencia policial en el interior de una cárcel de máxima seguridad por inaugurar, las infinitas pintadas que revelan una cartografía afectiva en el interior de los CIE, los motines, incendios y fugas, el plan de Seguridad de Lavapiés, los dispositivos policiales, las transformaciones urbanas, una manta extendida sobre el suelo, la muerte de Mame Mbaye, los contenedores incendiados, el sindicato de manteros, los cuerpos inertes que llegaron a la costa gaditana en 1988 y que se suman a los más de treinta mil ahogados en el Mediterráneo desde entonces. Todos estos acontecimientos, situaciones y arquitecturas a través de las que ha transitado la tesis se situaron en esta encrucijada intentando relacionar la construcción arquitectónica de una espacialidad que necesariamente requiere de norma, cuerpo y espacio para ser formulada. Un desplazamiento que no intenta más que profundizar en las conexiones de tres esferas aparentemente independientes pero que dan forma a complejos dispositivos arquitectónicos usando la frontera como el vehículo capaz de desplegar estos conceptos.

Enunciar la frontera como un dispositivo de construcción territorial y no simplemente como la suma de una serie de arquitecturas vinculadas a ella ha permitido desvelar las implicaciones que cada variable ejerce sobre el resto, y así cartografiar una arquitectura interdependiente entre una norma expandida, un cuerpo que ya no es sólo humano y un espacio definido en base a acciones. A través de esta identificación, el dispositivo frontera, lo que podría interpretarse como episodios o acontecimientos aislados de diversa índole, se pueden ver ahora como disposiciones y ensamblajes específicos que intentan proporcionar soluciones espaciales de la manera más eficaz e inmediata posible. Son precisamente estas conexiones, iteraciones y transformaciones detectadas a lo largo de las tres últimas décadas en la frontera española las que permiten observar una evolución de las arquitecturas generadas por este dispositivo que diluyen la forma y el objeto construido para presentar formas activas, capaces de llegar a donde las inercias propias de la industria arquitectónica no se lo permiten.

Esta condición líquida, variable, incluso elástica de la arquitectura de la frontera, que hace posible modificar arbitrariamente la extensión soberana de un territorio, tiene su origen en el giro operativo que se ha ido normalizando desde mediados de la primera década del siglo XXI, fundamentalmente a nivel espacial. Frente a una frontera enunciada desde la norma, la ley escrita, encontramos una frontera gobernada en base a una condición operativa, que asume su carácter excepcional para permitir y elaborar prácticas espaciales que no tendrían cabida dentro de un marco normal. Así, la instauración y creación de espacios y territorios de excepción vinculados a la frontera tiene un impacto directo tanto en las formas como en las fórmulas arquitectónicas desarrolladas, evolución clara que se aprecia en los diferentes casos de estudio analizados. Si el término de "frontera operativa” y las “devoluciones en caliente" tal vez sean un ejemplo paradigmático de esta nueva concepción territorial es posible trasladarla a otros ensamblajes arquitectónicos alejados de la línea fronteriza. La excepcionalidad y carácter de emergencia es lo que ha permitido apropiarse, capturar y transformar

Condición operativa de la frontera contemporánea 
efímeramente restaurantes de bodas, cocederos de mariscos, en prisiones de alta seguridad para internar migrantes, o convertir explanadas y zonas portuarias -únicamente a través del despliegue de tiendas militares- en campamentos improvisados. Y también ha sido capaz de convertir enclaves urbanos en zonas de excepción absoluta de manera muy localizada, siendo el cuerpo migrante aquel que detona esta atmósfera de excepcionalidad.

De esta transformación, donde prima la inmediatez de ensamblajes efímeros muy adaptados ante soluciones homogéneas, se derivan fundamentalmente tres aspectos claves detectados a lo largo de esta investigación. El primero y de mayor calado: la relevancia adquirida por el cuerpo como detonador de ensamblajes arquitectónicos y espacialidades altamente selectivas; el segundo, un giro dinámico que prima soluciones temporales a arquitecturas sólidas; y, por último, la desterritorialización o dispersión territorial que traslada las lógicas de la frontera a cualquier punto del territorio. A través de la implementación de estas nuevas lógicas territoriales y, dada su posición liminar dentro del conjunto europeo, España se ha constituido un laboratorio arquitectónico de vanguardia en cuanto al desarrollo de tecnologías de frontera.

Así pues, estas prácticas espaciales y construcciones arquitectónicas tienen un componente fundamentalmente político, donde los discursos y las lógicas estatales e internacionales cobran un papel protagonista frente a cuestiones de diseño. Tal y como se muestra en el primer capítulo, estamos ante un dispositivo territorial que no es construido en despachos profesionales $u$ oficinas gubernamentales, sino fundamentalmente en base a declaraciones, negociaciones y conflictos políticos. Una política que no es únicamente institucional sino que se cuestiona, rebate y transforma también desde el activismo, la crítica social o la confrontación corporal. Aunque sea una arquitectura donde no hay un único brazo ejecutor, un proyecto arquitectónico en el sentido más clásico del término, no se puede negar la responsabilidad que, por omisión o complicidad activa, la disciplina ha tenido en la materialización, formalización y legitimación de los discursos y edificios vinculados a la frontera. Reconocer este agenciamiento arquitectónico visible permite no sólo establecer una noción crítica sobre las construcciones, sino comenzar a cartografiar y desarrollar las herramientas espaciales necesarias que sean capaces de operar dentro de este complejo dispositivo. Unas herramientas arquitectónicas posicionadas políticamente que no renuncian al conflicto, sino que son capaces de comprenderlo como un motor de transformación arquitectónico: un conflicto múltiple entre agentes de diferente naturaleza con intereses propios, compartidos o enfrentados, que transforma constantemente las necesidades del dispositivo frontera y, por tanto, las soluciones espaciales producidas por este.

El dispositivo frontera es activado y configurado a través de las acciones de los cuerpos.
El cuerpo se ha convertido en uno de los agentes fundamentales en la construcción de la frontera. Es él, en su potencia, sus acciones o su mero desplazamiento por el territorio el que detona las arquitectónicas que se despliegan a su alrededor. Un cuerpo necesariamente post-humano, enunciado en colectivo, que encarna su condición política y menos-que-humana, una nuda vida, que puede ser gestionada, dañada o herida. El capítulo centrado en la valla es el que más claro ha mostrado cómo un cuerpo que se sitúa o accede a un espacio al que no es autorizado políticamente, transforma por completo un escenario. A través de la sucesión de cuerpos encaramados a la valla de Ceuta y Melilla se visibilizaban la red de agentes aparentemente no-arquitectónicos capaces de asegurar su impermeabilidad, del mismo modo que los cuerpos a nado en el paso fronterizo del Tarajal apenas detectados por las cámaras de vigilancia desplegaron un operativo excepcional que convertía a la arquitectura estable de la valla y el paso fronterizo en un telón de fondo. En este acontecimiento, la coreografía de cuerpos en movimiento -agentes de policía, pelotas de goma, 
embarcaciones, migrantes en el agua...- transformaba los espacios en los que se situaba a medida que se iba desplazando por el territorio. Y, este movimiento los convertía en espacios de excepción absoluta, lo que provocaba una subversión clara de las funciones y objetivos de diseño de cada espacio o arquitectura que, de manera temporal, se viese involucrada en este avance a lo largo de la costa. Frente al recinto nítido, sólido y topográfico dibujado por la línea soberana a lo largo de todo el perímetro nacional, reconocible con precisión por la arquitectura de la valla, se presentaba una frontera operativa que sólo puede ser representada como un campo de intensidades variables. Así, cada cuerpo activaba en función de sus acciones una respuesta en sentido contrario. Eran ellos, su movimiento en el agua, o al pisar tierra, los que propiciaban una construcción espacial específica. Esta idea es trasladable al conjunto de arquitecturas analizadas donde cada acción por parte del cuerpo migrante tiene una respuesta espacial altamente específica y de forma prácticamente instantánea. Y, frente a la responsividad reducida de arquitecturas estables, aparecen nuevos mecanismos arquitectónicos de respuesta rápida y alta capacidad de adaptación.

La arquitectura como hecho construido pasa, ante el peso adquirido de los cuerpos, a un segundo plano. Se la desposee de las funciones primarias que históricamente se le habían asociado, la encarnación de la norma en el espesor de sus muros, a la vez que adquiere una carga simbólica y de representación cada vez mayor. La teatralidad de estas arquitecturas, los esfuerzos en convertirlas en símbolos que cristalicen ideas o posiciones políticas, se ha visto en la militarización progresiva de la arquitectura de la valla, pero también en la evolución de los centros de internamiento e incluso en operaciones urbanas. Desposeída de función real se manifiesta únicamente con una función representativa fundamentalmente política. A medida que la valla fronteriza crecía y se complejizaba en Ceuta y Melilla, las devoluciones en caliente y el concepto operativo de frontera iba cobrando mayor relevancia. Del mismo modo, mientras proliferaban los campos informales de internamiento de migrantes o se ocupaban temporalmente edificios en desuso con unas condiciones infrapenitenciarias, el gobierno español ponía todo el foco mediático en anunciar las mejoras espaciales de CIEs de nueva creación. Esqueletos arquitectónicos que contrastan radicalmente con las operaciones y despliegues definidos por una condición dinámica, cuya duración se limita a lo estrictamente necesario.

A lo largo de la investigación hemos identificado el giro dinámico que se ha producido en cuanto a la gestión del territorio y, por tanto, cómo éste afecta a las arquitecturas de la frontera. Su constatación está presente en todos los casos de estudio analizados, donde, frente a las inercias tradicionales de la disciplina basadas en un pensamiento estratégico, aparecen mecanismos innovadores surgidos de un pensamiento táctico: la resolución temporal de problemas altamente específicos. Esta evolución desde una serie de objetos construidos a soluciones transformables y temporales se observa claramente en el capítulo dedicado a las arquitectónicas del internamiento. A través de la evolución del Centro de Internamiento, desde su creación a su configuración territorial actual, se ha identificado cómo una red cada vez más exigua de CIE formales convive y se retroalimenta de un grupo variable de campos informales, arquitecturas ocupadas o transformaciones arquitectónicas puntuales que permiten alterar y hacer más eficaz el dispositivo de internamiento a nivel estatal. A pesar de que esta condición dinámica de la frontera no es exclusivo del período más reciente, sí que podemos concluir el peso que ha adquirido en las últimas dos décadas. Un planteamiento arquitectónico que tiene eco en el llamado giro gerencial de la frontera: la optimización de recursos económicos, materiales y efectivos para lograr "hacerlo mejor con menos" ${ }^{\text {. }}$ Este cambio político tiene un impacto
El dispositivo frontera ha sufrido un giro dinámico que prima mecanismos tácticos, temporales y altamente específicos a mecanismos estratégicos y construcciones estables. 
Pensamiento táctico frente a pensamiento estratégico. Construcciones efímeras, inmediatas y dinámicas. evidente en las actuaciones arquitectónicas tanto estratégicas como tácticas tomadas en las últimas dos décadas. Las grandes inversiones destinadas a la actualización de arquitecturas obsoletas han sido sustituidas por actuaciones mucho más precisas. El fracaso en la vida útil de determinados centros de internamiento creados durante los años 2005 y 2006 pone de manifiesto un modelo en crisis derivado de las inercias propias de la industria arquitectónica: elevado gasto económico, dilatación en los procesos de construcción y escasa adaptabilidad. Así pues, este giro dinámico intenta corregir estas lógicas y para ello genera, implementa y consolida mecanismos arquitectónicos que sean adaptables a diferentes tipos de situaciones y que además su despliegue sobre el territorio dure lo menos posible.

Frente a edificios que perduran en el tiempo, el dispositivo frontera se ha centrado en la construcción de protocolos, tácticas y formas arquitectónicas activas donde operar a través de la redisposición de elementos y agentes en función de cada demanda. Instrucciones precisas, protocolos policiales y normas de actuación configuran una serie de construcciones de duración reducida. Con la misma facilidad que efectivos del ejército ensamblan telas y perfiles de acero para levantar nuevos módulos de internamiento en CIEs y CETIs existentes, las concertinas se despliegan en playas ceutís para aumentar la eficacia de un paso fronterizo obsoleto ante los cruces de migrantes. Más allá de la temporalidad y capacidad de transformación, el giro dinámico también afecta de manera clara a las construcciones más estables. Esta situación de emergencia normalizada tiene una consecuencia inmediata: la reducción de garantías espaciales ligadas a la temporalidad. Mientras que a nivel institucional se aumentan los esfuerzos por garantizar unas mejores condiciones arquitectónicas, la consolidación del giro dinámico hace que éstas no se cumplan. De esta forma, la emergencia precariza y reduce (o anula) los estándares regulados amparándose en la urgencia o excepcionalidad a la que se tiene que hacer frente. Los disparos en el Tarajal directamente contra cuerpos en el agua, las condiciones infrapenitenciarias de los campos improvisados, la falta de instalaciones sanitarias, los despliegues policiales...todos ellos son consecuencia de cómo la normalización de lo dinámico frente a lo estático se ha consolidado como un mecanismo más efectivo para asegurar el funcionamiento óptimo de la frontera, priorizando su funcionalidad por encima de los estándares espaciales y garantías establecidas.

El giro dinámico ha puesto de relevancia una cuestión que tampoco es exclusiva de nuestro marco temporal ${ }^{2}$, al lograr visibilizar la capacidad de desterritorialización de los ensamblajes arquitectónicos analizados. La frontera ya no se limita exclusivamente a la arquitectura que encarna la valla del mismo modo que todo el dispositivo asociada a ella tampoco lo hace al contorno de los edificios y construcciones. Al enunciar la frontera como un dispositivo observamos la importancia de agentes aparentemente no arquitectónicos y la capacidad de acción conjunta de arquitecturas dispersas territorialmente. Los agentes aparentemente no arquitectónicos pueden definirse como agentes no incluidos dentro de los análisis históricos de la arquitectura por su temporalidad, su condición efímera o por no resultar relevantes a la hora de definir una determinada construcción; sin embargo, es precisamente a través de estos elementos menores y periféricos -humanos y no-humanos- como se configura la frontera contemporánea. Y, por otro lado, al analizar estos casos de estudio se ha detectado como la aparente autonomía de uso de las arquitecturas existentes era puesta en cuestión al requerir de otros agentes y conexiones que asegurasen un funcionamiento efectivo de cada una de ellas. Es por ello que un funcionamiento

deportación». InDret. Revista para el Análisis del Derecho, no 4 (2016), 1-25.

2 Sin embargo, sí ha sido una transformación fundamental por el modelo de gestión territorial basado en la operatividad. 
disperso define la realidad territorial de la frontera, plagada de conexiones entre elementos estables y elementos efímeros, móviles, pero con alta capacidad de respuesta y desplazamiento.

La consecuencia primordial es que las arquitecturas, paisajes y territorios donde la frontera opera se difuminan para expandir sus lógicas mucho más allá de sus contornos legalmente definidos. En cada caso de estudio esta expansión tiene una escala y un impacto determinados -apenas unos kilómetros en los ensamblajes de Ceuta y Melilla frente a todo un país en el caso de los manteros-, pero todos ellos comparten esta misma cuestión. Más aún, si enlazamos los tres casos de estudio a través del concepto de dispositivo, podemos establecer relaciones claras de regulación del flujo de migrantes a lo largo de todo el territorio español, donde cada arquitectura o escenario juega una función precisa en esta infraestructura territorial. Se han detectado además tres causas ligadas a esta desterritorialización que, sin ser estrictamente arquitectónicas, causan profundas transformaciones espaciales. La primera, el incremento de capacidad tecnológica que propicia las conexiones remotas entre agentes independientemente del contexto. La segunda, la externalización de la gestión de la frontera a través de la coordinación supraestatal entre diferentes países soberanos y las inyecciones económicas. Y, tercera, una externalización que fluctúa entre el ámbito de lo público y lo privado con la aparición creciente de empresas privadas vinculadas a la gestión del espacio fronterizo y que afecta a todos los casos de estudio. Toda esta infraestructura paraestatal amplia los contornos de los casos, los tensiona en diferentes dimensiones que no son exclusivamente geográfica, sino también políticas, soberanas y tecnológicas.

Como resultado de la investigación se encuentra la cartografía de un ensamblaje mucho más difuso e interconectado de lo que a priori se puede apreciar al aproximarse a la frontera. Un ensamblaje que se extiende y superpone a la totalidad del territorio, donde la frontera ha dejado de ser un contenedor perimetral para imbricarse y diluirse en la totalidad del mismo. Una desterritorialización que no es ajena al cuerpo, sino que es él quien detona esta frontera allá donde vaya. Hemos visto como en el centro de las principales metrópolis españolas se han desarrollado mecanismos para contener, limitar y castigar a este cuerpo migrante que se resiste a ser canalizado a través de los flujos regulares del dispositivo frontera. Este cuerpo es expulsado de la esfera pública a través de múltiples tácticas y cuando accede a ella se expone a que el dispositivo frontera intente neutralizar su entrada y permanencia. El ejemplo de los manteros, como un cuerpo que colectiva y conscientemente accede y reclama su derecho al espacio público de nuestras ciudades, nos permitió analizar hasta qué punto este dispositivo se impregna, captura y transforma cualquier espacio simplemente con la acción de un cuerpo. Simplemente con la variación en la posición de una manta sobre el pavimento de cualquier acera, un despliegue mínimo que genera un espacio de venta, ese cuerpo activa toda una serie de mecanismos arquitectónicos. Y esta sencilla acción trae consigo una serie de alteraciones en el dispositivo que construyen en cualquier punto del territorio una espacialidad inmediata. Esta acción resume cómo se construye la frontera contemporánea, como un dispositivo capaz de afectar a la totalidad del territorio de manera dinámica, generando instantáneamente espacios de excepción que desaparecen y aparecen según sean requeridos y donde el cuerpo -un cuerpo que ya no es sólo humano sino que incorpora la frontera política en sus carnes- es el principal constructor de estos espacios. Pero, también, hemos encontrado cómo ese mismo gesto, la transgresión consciente de una serie de normas le permite acceder a un espacio público que, de otra manera, le es negado por más que se sitúe físicamente en él. A través de estas acciones de resistencia, consciente de que expone su cuerpo a la violencia arquitectónica asociada a quebrantar la ley, logra, aunque sea por unos instantes, alcanzar la esfera pública y subvertir con
El dispositivo frontera posee un alto grado de desterritorialización, no limitándose a los escenarios históricamente asociados a él.

Frontera como ensamblaje difuso e interconectado 
La frontera como cuerpo inabarcable. Limitaciones de la investigación sus acciones el equilibrio de fuerzas entre agentes que componen el dispositivo consciente de su situación infrapolítica o espectral. En definitiva, el cuerpo migrante desplegando una manta, prendiéndole fuego en el interior de una celda, o encaramado a una valla durante más de treinta horas logra visibilizar $l o$ que puede un cuerpo, pero además reclamar un estatus que constantemente le es negado.

Observar con detenimiento cualquier aspecto de la realidad implica, necesariamente, dejar fuera de foco el resto. $\mathrm{Al}$ arrojar luz sobre la construcción arquitectónica de la frontera contemporánea desde las limitaciones propias de cualquier investigación doctoral, estas zonas en penumbra se multiplican.

Señalar estas zonas que ha dejado fuera de foco la investigación, a la espera de un posterior desarrollo, supone reconocer también las tentativas y caminos finalmente no transitados a lo largo de la construcción de la tesis. Realidades y enfoques que, estando tal vez presentes de manera implícita, no se han llegado a desplegar.

La frontera se ha presentado ante nosotros como un objeto múltiple e inabarcable, atravesado por múltiples significados y condiciones espaciales que se concentran en un único término. Centrarse únicamente en su dimensión normativa-represiva-arquitectónica a través de los cuerpos migrantes, no autorizados a entrar o permanecer en el territorio que ésta delimita, deja fuera del análisis aspectos fundamentales para comprender la complejidad del término. Aspectos clave como la dimensión económica o cómo se construye la idea de pertenencia o domesticidad dentro de este dispositivo frontera, habrían aportado, sin salirse de nuestro binomio de análisis, nuevas capas de complejidad a la investigación donde la componente arquitectónica resulta fundamental. A través del análisis de múltiples tácticas de resistencia nos hemos aproximado a cómo, dentro de estas arquitecturas normativas y punitivas, el cuerpo migrante era capaz de, apropiándose de un espacio genérico para transformarlo, establecer una red de afectos personales y materiales a través de la cual reconectarse con un territorio más amplio. Sin embargo, es importante señalar que este este análisis siempre ha estado condicionado por su localización dentro de los casos de estudio, dejando fuera a todos los cuerpos migrantes que, de manera cotidiana, construyen estas mismas redes de afectos.

La frontera aparece también, sobre todo en la esfera mediática, como una realidad cambiante, donde los centros de gravedad se desplazan con gran rapidez tanto a nivel geopolítico como en las arquitecturas que ganan relevancia, y también en los propios cuerpos migrantes. Un análisis rápido de la hemeroteca dejaría ver cómo, en en el transcurso de la investigación, los puntos calientes del Mediterráneo se fueron moviendo en base a decisiones políticas, pero también cómo los barcos de rescate -o militares- sustituyeron las pateras, los centros de internamiento fueron reemplazados por campos, y hasta la "amenaza" del migrante fue sustituida por la del refugiado o solicitante de asilo. Esta inmediatez ha obligado a la investigación a anclarla a un ámbito territorial y temporal concreto, deja fuera operaciones arquitectónicas similares pese a formar parte de procesos de construcción territorial totalmente diferentes. Por la convicción política del papel que ha jugado España como laboratorio de tecnologías de frontera en las últimas décadas, capaz de desplegar un alto grado de violencia espacial -eclipsada en los últimos años por otros muros más mediáticos-, definimos nuestro origen de coordenadas en las fronteras de la Unión Europea presentes 
en España. Las incursiones a otros territorios se hacen de manera puntual para complementar los casos de estudio, aunque las lógicas de análisis y producción territorial son totalmente extrapolables dentro de todo el contexto europeo.

Por último, empleamos cuerpo migrante, como un término homogéneo que pretende aglutinar una serie de condicionantes en torno a él y a través del cual construimos la investigación. Es necesario aclarar que, frente a una generalización, se propone como el mínimo denominador común entre múltiples singularidades e historias de vida. Sin embargo, debemos preguntarnos ¿qué cuerpos estamos excluyendo en nuestro análisis? Al establecer nuestro marco de estudio en base a unas arquitecturas y escenarios concretos, son éstas las que en última instancia definen al cuerpo migrante. La valla, las arquitectónicas del internamiento e incluso la ciudad -al usar en ella los manteros como foco principal del análisis urbano- nuestro cuerpo migrante, por más que pretendamos extrapolarlo a un conjunto más amplio, está mediado por su relación con estas arquitecturas. Pero, además, si nos remitimos a datos estadísticos, es un cuerpo enunciado fundamentalmente en masculino, donde la presencia de la mujer es muy inferior pese a que más de la mitad de la migración mundial sea femenina. Esta ausencia permite comprender las causas de esta asimetría, pero también sus consecuencias, que no se limitan simplemente a un dato estadístico, sino que tiene implicaciones espaciales directas, aumentando en muchos casos el grado de violencia -espacial y normativa- al que se exponen estos cuerpos migrantes.

Respecto a las herramientas empleadas para analizar el dispositivo frontera es importante señalar que estas también han dejado tras de sí puntos ciegos. Y es precisamente en el análisis del cuerpo migrante donde podemos encontrar un punto de fricción crítico a la hora de la elaboración de esta metodología. Al formular la frontera como un dispositivo, donde cada uno de los agentes posee una cierta capacidad de agencia y no existe una jerarquía clara de relaciones, el papel central del cuerpo humano pasa a un segundo lugar. Esto establece una primera distancia crítica respecto al cuerpo migrante, al obligar a equiparar agentes humanos con no-humanos a la hora de analizar la construcción espacial de la frontera. Sin embargo, lo que a nivel teórico no supone mayor conflicto, sí resulta extraño dado el alto grado de violencia espacial a la que este cuerpo es sometido. Por otro lado, se ha establecido una segunda distancia crítica, esta de manera consciente y en base a un posicionamiento político, al emplear unas herramientas de análisis en las que se priorizan las trazas materiales -las acciones de los cuerpos sobre las construcciones arquitectónicas o viceversa, las acciones de los ensamblajes arquitectónicos sobre los cuerpos- sobre trazas de otro tipo -testimoniales, relatos, inmateriales...- el cuerpo migrante habla, en la mayoría de las ocasiones, a través de sus cicatrices o sus acciones, no construye su propio relato. Su cuerpo habla, pero casi nunca emplea la palabra. Esta decisión ${ }^{3}$ ha intentado generar una escucha atenta a los migrantes, en vez de hablar por ellos o apropiarse de un relato que no nos pertenece. Ha sido el establecimiento de esta distancia respecto a ellos la que nos permite construir un relato en el que, si bien ellos son los agentes principales en su desarrollo, no pretende apropiarse de su voz. Si el dispositivo frontera, a través de la violencia espacial que es capaz de desplegar, reduce y elimina toda singularidad, toda historia de vida para convertir a cada migrante en un simple cuerpo desposeído de todo valor debemos situarnos también en ese escenario. Y es precisamente este desplazamiento, de la persona al cuerpo, el que justifica el empleo del término cuerpo migrante.

3 Posición que parte de un compromiso político que reconoce la opresión de los cuerpos migrantes y racializados, que tiende a silenciar su voz frente a discursos -afines o no- pronunciados por sujetos privilegiados. Derivado de este posicionamiento se cuestiona, entre muchas otras cosas, la legitimidad de la Academia europea para construir conocimiento a través de la apropiación del relato de terceros.
Limitaciones metodológicas. Cuerpos sin voz. 
Somos conscientes también de que, dadas las rápidas transformaciones que los ensamblajes arquitectónicos de la frontera han sufrido en las últimas dos décadas, toda tentativa de agotamiento habría fracasado inmediatamente. Esta se vería desbordada por nuevas producciones espaciales, nuevos escenarios y disposiciones. En eso consiste precisamente el dispositivo, un mecanismo de construcción territorial con capacidad constante de captura, innovación y transformación. Por tanto, ante este previsible desborde inmediato, se ha decidido no construir la tesis en base a este agotamiento, que podría llevarnos de Ceuta al muro de Gaza, del CIE de Aluche a la Jungla de Calais o detenernos en analizar con precisión cada despliegue policial contra migrantes producidos en territorio español. Y, aún así, seguirían quedando escenarios por analizar. El objetivo de esta cartografía que hemos construido no ha sido tanto trazar con precisión el territorio de la frontera contemporánea, sino las lógicas que subyacen detrás de ella, como pautas y guías para que estos caminos no seguidos sean investigados en el futuro.

Necesitamos seguir situándonos en la frontera y ser conscientes de la violencia espacial que ésta genera, de la escala global de una problemática que requiere, no sólo respuestas, sino que sea problematizada desde diferentes disciplinas y las contaminaciones que se produzcan entre estas. Para ello, hay que abrazar, y no rehuir, estas zonas de fricción generadas por posiciones políticas que necesitan complementarse para abordar la inmensidad de un objeto tan inabarcable como urgente: la frontera contemporánea. Y, a su vez capaces de estirar los límites propios de cada disciplina. Y, desde esta posición, hemos de asumir las implicaciones arquitectónicas que rodean la construcción de la frontera, pero también las habilidades disciplinares que nos permiten comprender las problemáticas implícitas en ella, construyendo herramientas y enfoques capaces de arrojar luz, tomar agencia e infiltrarse en la realidad que la frontera genera. Necesitamos que la arquitectura asuma este compromiso político, aunque esto obligue a la disolución e hibridación de los roles tradicionales en nuevas figuras contaminadas, capaces de sentir y afectarse por la urgencia de esta realidad territorial, para desde ahí construir nuevos repertorios disciplinares desde los que actuar.

Alto grado de transformación.

Los escenarios que hemos recorrido son infinitos, su extensión se prolonga mucho más allá de los límites físicos establecidos, su arquitectura no puede entenderse sin los cuerpos que la accionan y construyen. Con la evidencia de que cada uno de estos escenarios mutará constantemente, que aparecerán nuevos focos, nuevos flujos migratorios y, por tanto, nuevas tácticas espaciales para contrarrestar e intentar detener a este cuerpo migrante, el aporte más claro de esta tesis no reside tanto en los análisis concreto sino en las lógicas compartidas que emanan del dispositivo frontera, condiciones que no son exclusivas de estas arquitecturas sino que fácilmente podemos extrapolar al conjunto de la disciplina como herramientas de creación y transformación de proyectos arquitectónicos.

Operar a través de las lógicas arquitectónicas desveladas.
Por ello, miremos a las lógicas desveladas y aprendamos a operar con ellas, con las herramientas que realmente están definiendo la construcción de la frontera para, a través de nuestro posicionamiento político, generar nuevas agencias arquitectónicas que vayan más allá de la mera formalización. Las lógicas de la frontera abandonan los procesos tradicionales de diseño e inercias derivadas de la industria de la construcción para desvelar realidades procesuales y cambiantes donde los protocolos, las formas activas y la superposición de normas toman el relevo ante la inoperancia de una arquitectura que, por estática resulta ineficaz. Abandonar estos procesos no implica el abandono del lenguaje y elementos que 
conforman la disciplina, sino una reconfiguración a través de nuevas variables, una reordenación operativa capaz de componer nuevas herramientas de análisis e intervención en el espacio. Así pues, es pertinente que asumamos como propias las tácticas dinámicas, los ensamblajes efímeros y el carácter performativo que hemos encontrado al aproximarnos a la frontera. Pues, solo a través de ellas podremos intervenir en las condiciones espaciales que produce.

Pero, no sólo debemos expandir el campo de interés de lo arquitectónico en esta dimensión, sino que debemos también interrogar al cuerpo que activa, detona y manipula este dispositivo a pesar de su aparente insignificancia. Cerremos esta investigación posicionándonos de nuevo en una de las primeras localizaciones donde establecimos contacto con la realidad de la frontera, en la valla del Benzú, recordemos a Star durante más de treinta horas exponiendo su carne, su integridad física para devenir un arquitecto menor capaz de transformar una arquitectura estable a través de las fisuras detectadas en ella. Es en esta dimensión menor y precaria, donde los cuerpos establecen un conflicto con la realidad material que los rodea, donde podremos explorar también vías alternativas a la práctica arquitectónica tradicional. Pues, en el mismo instante que se establece esa transgresión y se produce una ruptura de las leyes y normas encarnadas en la materia arquitectónica de la valla, se abre un nuevo horizonte de posibilidades que van también mucho más allá de las originalmente diseñadas. Mientras que el diseño se concibe desde una realidad ideal que, en su traslado material genera fisuras, grietas y errores no previstos, lxs arquitectxs menores leen esta materialidad y desde ahí, la alteran y subvierten. Así, solo el cuerpo que se expone a esta violencia espacial fruto de una transgresión arquitectónica consciente, es capaz de ampliar e imaginar nuevas configuraciones espaciales. $\mathrm{O}$, como alguien grabó en uno de los paramentos del Centro de Internamiento de Extranjeros de Fuerteventura para domesticar una arquitectura, transformándola así en un espacio propio pero compartido: "quien quiere la miel debe tener el coraje de enfrentarse a las abejas"4.
Maniobrar el dispositivo a través de destrucciones operativas. 

7. BIBLIOGRAFÍA 



\section{BIBLIOGRAFÍA}

Agamben, Giorgio. ¿Qué es un dispositivo?. Barcelona: Anagrama, 2015

——_. “¿ Qué Es Un Campo?” Nombres: Revista De Filosofía, 2012.

_—_. Profanaciones. Buenos Aires: Adriana Hidalgo Editora, 2005.

- - Homo Sacer: El poder soberano y la nuda vida. Valencia: Pre-Textos 2005.

———. Homo Sacer II: Estado De Excepción. Valencia: Pre-Textos 2004.

———. "No al tatuaje biopolítico". Le Monde, 22 de enero de 2004.

Allen, Stan. «Field Conditions». Architectural Design,1996.

Andersson, Ruben. Illegality, Inc.: Clandestine Migration and the Business of Bordering Europe. Oakland: University of California Press, 2014.

Aureli, Pier Vittorio. The Possibility of an Absolute Architecture. Chicago: MIT press, 2011.

Baldassar, Loretta y Merla, Laura. "Locating Transnational Care Circulation in Migration and Family Studies." Transnational Families, Migration and the Circulation of Care: Understanding Mobility and Absence in Family Life. (2014): 25-58.

Balibar, Étienne. « Topology: Borders as space of transformation», Topology. Conferencia pronunciada en la Tate Modern el 5 de noviembre de 2011.

Banham, Reyner. “The Great Gizmo.” Industrial Design 12, no. 9 (1965).

Barajas, Diego. Dispersion: A Study of a Global Mobility and the Dynamics of a Fictional Urbanism. Rotterdam: Episode publishers, 2003.

Bauman, Zygmunt. Archipiélago De Excepciones. Barcelona: Katz editores, 2008.

Benjamin, Walter. “The Destructive Character.” Revue Française De Psychanalyse 78, no. 4 (2014): 958-959.

——_. “Hacia La Crítica De La Violencia.” Obras, Libro II I, (1921): I83.

Bennett, Jane. Vibrant Matter: A Political Ecology of Things. Duke University Press, 2009.

-——. New materialisms: Ontology, agency, and politics. Duke University Press, 2010.

Bessa, Cristina Fernández. "Movilidad Bajo Sospecha. El Conveniente Vínculo Entre Inmigración y Criminalidad En Las Políticas Migratorias De La Unión Europea." REMHU-Revista Interdisciplinar Da Mobilidade Humana I8, no. 35 (2010): 137-154.

Betsky, Aaron. Queer Space: Architecture and same sex desire. Nueva York: William and Morrow, 1997.

Borges, Jorge Luis. “Del Rigor De La Ciencia.” Arte y Parte no. 4 (1996): 65-65. 
Borrego, Ignacio. «Materia Informada.” Deformación, Conformación y Codificación, Los Tres Procedimientos De Almacenamiento De Información En La Materia». Tesis doctoral. Universidad Politécnica de Madrid, 2012.

Bradbury, Simon. "Learning from Actor-Network Theory". Architecture $\mathcal{G}$ Education Fournal, no II, (2014), 453:470.

Brambilla, Chiara. "Exploring the Critical Potential of the Borderscapes Concept." Geopolitics 20, no. I (2015): 14-34.

Brandariz García, José Ángel y Fernández Bessa, Cristina. "La Construcción De Los Migrantes Como Categoría De Riesgo Para El Sistema Penal Español.” Estudios De Derecho Penaly Criminología, Comares, Granada (2010).

Brown, Wendy. Estados Amurallados, Soberanía En Declive. Barcelona: Herder Editorial, 2015.

Butler, Judith. Cuerpos Que Importan. Barcelona: Paidós, 2002.

Cardona, Steven Navarrete. "Más allá Del Enfoque! Edward Soja y La Geografía Contemporánea." Cuadernos De Geografía 20, no. 2 (2011): 139.

Casas, Maribel, Sebastian Cobarrubias, y John Pickles. "Stretching Borders Beyond Sovereign Territories? Mapping EU and Spain's Border Externalization Policies." Geopolitica (s) 2, no. I (2010): 71-90.

Casas-Cortes, Maribel, Sebastian Cobarrubias, Nicholas De Genova, Glenda Garelli, Giorgio Grappi, Charles Heller, Sabine Hess, Bernd Kasparek, Sandro Mezzadra, y Brett Neilson. "New Keywords: Migration and Borders." Cultural Studies 29, no. I (2015): 55-87.

Chak, Tings. Undocumented: The Architecture of Migrant Detention. Eindhoven: The Architecture Observer, 2014.

Cobarrubias, Sebastian. Mapping Machines: Activist Cartographies of the Border and Labor Lands of Europe. Chapel Hill: The University of North Carolina, 2009.

Cooper, Anthony. "Where are Europe's New Borders? Ontology, Methodology and Framing". Fournal of Contemporary European Studies Volume 23, ํㅡ 4 (2015), 447:458.

Crampton, Jeremy W. and John Krygier. "An Introduction to Critical Cartography." ACME: An International E-Fournal for Critical Geographies 4, no. I (2005): II-33.

Cruz, Teddy. "Radicalizing the Local: 6o Linear Miles of Transborder Conflict." Diacritics 38, no. 4 (2008; 2010): 107-c2.

Cuttitta, Paolo. "Territorial and Non-Territorial: The Mobile Borders of Migration Controls." In Borderities and the Politics of Contemporary Mobile Borders (2015), 241-255:.

Davis, Mike. Control Urbano, La Ecología Del Miedo: Más allá De Blade Runner. Barcelona: Virus, 200I.

- - - "Fortress Los Angeles: The Militarization of Urban Space." Variations on a Theme Park (1992): 154-180. 
De Certeau, Michel. La Invención De Lo Cotidiano: Artes De Hacer. I. Vol. I. Universidad Iberoamericana, 1996.

De Genova, Nicholas. “Spectacles of Migrant 'illegality': The Scene of Exclusion, the Obscene of Inclusion.” Ethnic and Racial Studies 36, no. 7 (2013): I180-I198.

De La Lastra, Pablo Domenech. "Cruzando El Cuerpo. Dispositivos De Frontera y Procesos De Subjetivación.” Daimon Revista Internacional De Filosofia (2016): 667-677.

CAMPAÑA ESTATAL POR EL CIERRE de LOS CIE. “Paremos Los Vuelos.” Las Deportaciones De Inmigrantes y El Boicot a Air Europa. Oviedo: Cambalache, 2014 .

De Landa, Manuel. Assemblage Theory. Edimburgo: Edinburgh University Press, 2016.

De Landa, Manuel, and Jonathan Crary. A thousand years of nonlinear history. Nueva York: Zone Books, 1997.

Deleuze, Gilles. “Cursos Sobre Spinoza: Vincennes, 1978-1981.” Fortaleza: EdUECE , 2009.

———. "Posdata Sobre Las Sociedades De Control.” El Lenguaje Literario (1991): $\mathrm{I}-4$.

———. Foucault. Barcelona: Paidós, 2007.

- ——. "Post-Scriptum Sobre Las Sociedades De Control." Polis.Revista Latinoamericana no. 13 (2006).

——_. "What is a Dispositif." Michel Foucault: Philosopher (1992): 159-168.

Deleuze, Gilles y Guattari, Felix. Mil Mesetas: Capitalismo y Esquizofrenia. Valencia: Pre-textos, 2005.

Delgado, Manuel. El Espacio Público Como Ideología. Madrid: Catarata, 2011.

Dell'Agnese, Elena y Anne-Laure Amilhat Szary. "Borderscapes: From Border Landscapes to Border Aesthetics”. Geopolitics, vol. 20 (2015), 4:13.

Deutsche, Rosalyn. Evictions: Art and Spatial Politics. Cambridge: MIT Press, 1996.

Easterling, Keller. Critical Spatial Practice 4: Subtraction. Berlin: Sternberg Press, 2014 .

- ——. "Disposition." Cognitive Architecture: From Bio-politics to noo-politics (2010): $250-265$.

- - Enduring Innocence: Global Architecture and its Political Masquerades. Cambridge: Mit Press, 2005.

——_. "An Internet of things". E-flux Fournal, 2012, vol. 31, p. I-8.

- - - Extrastatecraft: The Power of Infrastructure Space. Londres: Verso Books, 2014 . 
Evans, Robin. Traducciones. Valencia: Pre-textos, 2006.

Fallan, Kjetil. «Architecture in action: Traveling with actor-network theory in the land of architectural research». Architectural Theory Review, $\mathrm{n}^{\circ}{ }^{\mathrm{O}}{ }_{3}$, (2008) 8096

Fernández Bessa, Cristina. "El Dispositiu De Deportació. Anàlisi Criminològica De La Detenció, Internament i Expulsió d'immigrants En El Context Espanyol." .Tesis doctoral. Universidad Autónoma de Barcelona (2016).

Fernández Bessa, Cristina y José Angel Brandáriz García. “Transformaciones De La Penalidad Migratoria En El Contexto De La Crisis Económica: El Giro Gerencial Del Dispositivo De Deportación.” InDret.Revista Para El Análisis Del Derecho, 2016, Num.4/2016, (2016): 1-25.

Fogué, Uriel. El diálogo del ventrílocuo: bases hermenéuticas para una conversación entre humanos y no humanos. En Planos de (Inter) sección: materiales para un diálogo entre filosofía y arquitectura. (2011): 238-273.

———. «Ecología política y economía de la visibilidad de los dispositivos tecnológicos de escala urbana durante el siglo XX Abriendo la caja negra». Tesis Doctoral. Universidad Politécnica de Madrid, 2015.

Forensic Architecture. Forensis: The Architecture of Public Truth. Londres: Stenberg Press, 2014.

Foucault, Michel. Dits et écrits vol.III. París: Bibliotheque des sciences humaines, 1994.

———. Microfisica Del Poder. Madrid: Ediciones La Piqueta, 1992.

——_. "Of Other Spaces." Diacritics 16, no. I (1986): 22-27.

——. Vigilar y Castigar. México:Siglo XXI, 1984.

García Cortés, José Miguel. Politicas Del Espacio: Arquitectura, Género y Control Social. Barcelona: Actar, 2006.

-——. La Ciudad Cautiva: Orden y Vigilancia En El Espacio Urbano. Madrid: Ediciones AKAL, 2010.

García de Jalón Oyarzun, Lucía. “Insignificance and Minor Architecture.”. Eurau'Io: VENUSTAS, architecture / market /, 2011.

- - - «Excepción y cuerpo rebelde: lo político como generador de una arquitectónica menor». Tesis doctoral. Universidad Politécnica de Madrid, 2017.

Garelli, Glenda, Federica Sossi, and Martina Tazzioli. Spaces in Migration: Postcards of a Revolution. 2013.

Garelli, Glenda and Martina Tazzioli. Challenging the Discipline of Migration: Militant Research in Migration Studies, an Introduction (2013).

- - - "Migration Discipline Hijacked: Distances and Interruptions of a Research Militancy." Postcolonial Studies 16, no. 3 (2013): 299-308.

Gissen, David. “Architecture’s Geographic Turns.” Log no. 12 (2008): 59-67. 
González, Iker Barbero. "El Control Selectivo De Las Fronteras y La Transnacionalización De Sus Resistencias.” Arbor 186, no. 744 (2010): 689-703.

Gonzalo, Ignacio Mendiola. "La Frontera Incorporada: Espacio, Cuerpo y Seguridad.” Revista Mexicana De Análisis Político y Administración Pública 7, no. 2 (2018): 13-32.

Graham, Stephen. Cities Under Siege: The New Military Urbanism. Londres: Verso Books, 2011.

Gutierrez Vazquez,Lucía. "Arquitectónica de la exclusión en espacios fronterizos”, Tesis fin de Grado. Universidad Politécnica de Madrid, 2016.

Hailey, Charlie. Camps: A Guide to 2Ist-Century Space. Cambridge: Mit Press, 2009.

Hardt, Michael; Negri, Antonio. Imperio. Barcelona: Editorial Paidos, 2003.

Harley, John B. "Cartography, Ethics and Social Theory." Cartographica: The International Fournal for Geographic Information and Geovisualization 27, no. 2 (1990): 1-23.

Harvey, David. “Listen, Anarchist!'A Personal Response to Simon Springer's 'Why a Radical Geography must be Anarchist." Dialogues in Human Geography 7 , no. 3 (2017): 233-250.

———. Urbanismo y Desigualdad Social. Siglo XXI Madrid: Siglo XXI, 1977.

Heller, T., Lorenzo Pezzani, and Situ Studio. "Report on the "left-to-Die Boat"." London: Forensic Architecture Project Goldsmiths University of London II, (2012).

Herb, Guntram H., Jouni Häkli, Mark W. Corson, Nicole Mellow, Sebastian Cobarrubias, and Maribel Casas-Cortes. "Intervention: Mapping is Critical!" Political Geography 28, no. 6 (2009): 332-342.

HIRSCH, Nikolaus; MIESSEN, Markus. What Is Critical Spatial Practice?. Berlin: Sternberg Press, 2012.

Holmes, Brian. "Investigaciones Extradisciplinares. Hacia Una Nueva Crítica De Las Instituciones.” Producción Cultural y Prácticas Instituyentes.Líneas De Ruptura En La Crítica Institucional (2008): 203-215.

Invisible, Comité. La Insurrección Que Viene. Melusina, 2009.

Klatt, Martin. The Border Multiple: The Practicing of Borders between Public Policy and Everyday Life in a Re-Scaling Europe. Nueva York: Routledge, 2016.

Koolhaas, Rem; MAU, Bruce. S, M, L, XL. Monacelli Press, 1998.

- - Elements of Architecture. Colonia: Taschen, 2018.

Lambert, Leopold. The Funambulist Pamphlets. Nueva York: Punctum books, 2013.

——_. "5.2 the Law Turned into Walls." Volume no. 38 (2013): 82. 
- - Weaponized Architecture: The Impossibility of Innocence. Barcelona: dpr-barcelona, 2012.

———. Léopold Lambert, «The political», Colon III, 2015.

Lapayese, Concha y Gazapo de Aguilera, Darío. La Construcción Del Paisaje...: Entre La Interioridad y La Exterioridad. DAPP Publicaciones Jurídicas, 2009.

——_. “¿ Desde Dónde... Se Construye El Paisaje?” Revista AUS no. 7 (2010).

Latour, Bruno. Reensamblar lo social. Buenos Aires: Manantial, 2008.

Lefebvre, Henri. La Producción Del Espacio. Madrid: Capitán Swing Libros, 2013.

Lucas, Javier de. "Inmigración, Diversidad Cultural, Reconocimiento Político."

Papers: Revista De Sociología no. 94 (2009): 11-27.

——_. "Inmigrantes: Del Estado De Excepción Al Estado De Derecho." Oñati Socio-Legal Series I, no. 3 (2011).

———. Puertas Que Se Cierran: Europa Como Fortaleza. Icaria Editorial, 1996.

Martínez Escamilla, Margarita, José Miguel Sánchez Tomás, José Luis Segovia Bernabé, José Luis Díez Ripollés, Elisa García España, Enrique Gimbernat Ordeig, and Julio V. González García. “"Expulsiones En Caliente”: Cuando El Estado Actúa Al Margen De La Ley." Madrid: Universidad Complutense (2014).

Martínez, Juan Iglesias. "En La Horma De Otros Zapatos Los Trabajadores Inmigrantes y El Enfoque De La Nueva Precariedad Étnica/'in a Last of Other Shoes' Immigrants Workers and the Approach of the New Ethnic Precariousness." Politica y Sociedad 49, no. I (2012): 47.

Martínez, Tony. CIE: El Guantánamo Español. Barcelona: Universidad Abierta de Cataluña, 2016.

Massey, Doreen. For Space. Londres: Sage Publications, 2005.

———. “Spaces of Politics.” Human Geography Today 279, (1999): 294.

Medina, Paula Abal. "Notas Sobre La Noción De Resistencia En Michel De Certeau.” KAIROS: Revista De Temas Sociales no. 20 (2007): I.

Merla, Laura. "La Circulación De Cuidados En Las Familias transnacionales/The Circulation of Care in Transnational Families." Revista CIDOB d'Afers Internacionals (2014): 85-104.

Mesa del Castillo Clavel, Miguel. «La arquitectura de la ontología orientada a objetos: como poner las prácticas en primer plano». En I International Conference on Architectural Design $\mathcal{B}$ Criticism, Madrid: DPA Prints, 2014.

_- — . «Víctimas De Un Mapa: Arquitectura y Resistencia En El Tiempo De La Cultura Flexible». Tesis Doctoral. Universidad de Alicante, 2012.

Mesquita, André Luiz. «Mapas Dissidentes: Proposições Sobre Um Mundo Em Crise (1960-2010)». Tesis doctoral. Universidad de Sao Paulo, 2013. 
Mezzadra, Sandro. Derecho De Fuga: migraciones, Ciudadanía y Globalización. Madrid: Traficantes de Sueños, 2005.

Mezzadra, Sandr; Neilson, Brett. "Between Inclusion and Exclusion: On the Topology of Global Space and Borders." Theory, Culture $\mathcal{G}$ Society 29, no. 4-5 (2012): 58-75.

- - - Border as Method, Or, the Multiplication of Labor. Durham: Duke University Press, 2013.

Miessen, Markus. Crossbenching: Toward Participation as Critical Spatial Practice. Berlín: Sternberg Press, 2016.

- - - «Crossbenching: Towards a Proactive Mode of Participation as a Critical Spatial Practice». Tesis doctoral. Universidad de Londres, 2017.

Miessen, Markus; Basar, Shumon . Did Someone Say Participate?: An Atlas of Spatial Practice. Cambridge: Mit Press, 2006.

Migreurop. Atlas of Migration in Europe: A Critical geography of migration policies. Londre: New Internationalist Publications STD, 2012.

Mogel, Lize and Alexis Bhagat. An Atlas of Radical Cartography. Journal of Aesthetics \& Protest Press, 2008.

Morán, Adriana Jarrín. "La Construcción De La Persona Inmigrante En El Limbo Jurídico: Ni Expulsables Ni Regularizables En España." Cadernos De Campo 21, no. 2I (2012): 301-318.

Nail, Thomas. The Figure of the Migrant. Stanford: Stanford University Press, 2015 .

———. Theory of the Border. Oxford: Oxford University Press, 2016.

———."What is an Assemblage?" Substance 46, no. I (2017): 21-37.

Naïr, Sami, María Cordón, y Malika Embarek. Y Vendrán...: Las Migraciones En Tiempos Hostiles. Barcelona: Planeta, 2006.

Negri, Antonio. Movimientos En El Imperio: Pasajes y Paisajes. Barcelona: Grupo Planeta (GBS), 2006.

Norris, Clive; Armstrong, Gary. The Maximum Surveillance Society: The Rise of CCTV. Berg Publishers, 1999.

Orgaz Alonso, Christian. «Emergencia e Institucionalización Del Encierro De Extranjeros En España: El Caso De Los Cies». Tesis doctoral. Universidad Autónoma de Madrid, 2018.

Orgaz Alonso, Christian y Cristina Fernández Bessa. "Historias Interrumpidas y Fragmentos De Castigos: El CIE Como Institución Punitiva." Observatori del Sistema Penal i els Drets Humans, OSPDH, 2017.

Palsky, Gilles. “Cartographie Participative, Cartographie Indisciplinée.” L'Information Géographique 77, no. 4 (2013): 10-25. 
Pardo, José Luis. Políticas de la intimidad (ensayo sobre la falta de excepciones). Madrid: Escolar y Mayo, 2012.

Passaro, Andrés Martín. "El Berlín De Koolhaas.” DC PAPERS, Revista De Crítica y Teoría De La Arquitectura no. 2 (1999): 163-174.

Pérez de Lama, José; Toret Medina, Javier. “Devenir Cyborg, Era Postmediática y Máquinas Tecnopolíticas Guattari En La Sociedad Red.” Félix Guattari.Los Ecos Del Pensar.Entre La Filosofía, El Arte y La Clínica, Valencia: Ediciones Letras Salvajes (2012).

- — - "La Avispa y La Orquídea Hacen Mapa En El Seno De Un Rizoma Cartografía y Máquinas, Releyendo a Deleuze y Guattari.” Pro-Posições 20, no. 3 (2009): 12I-I 45 .

Pérez De Lama, José, Pablo de Soto, Régine Debatty, José M. Torres Nadal, y Miguel Mesa del Castillo. "Cartografiando Gaza." Pasajes De Arquitectura y Crítica (2009): 37-39.

Philippopoulos-Mihalopoulos, Andreas. Absent Environments: Theorising Environmental Law and the City. Nueva York: Routledge-Cavendish, 2007.

- — . "Actors Or Spectators? Vulnerability and Critical Environmental Law." Vulnerability and Critical Environmental Law (April 10, 2013).Oñati Socio-Legal Series 3, no. 5 (2013).

- — - "Critical Autopoiesis and the Materiality of Law." International Fournal for the Semiotics of Law-Revue Internationale De Sémiotique Furidique 27, no. 2 (2014): 389-418.

—_- Law and the City. Nueva York: Routledge, 2007.

_- - "Mapping the Lawscape: Spatial Law and the Body." The Arts and the Legal Academy, 133-148: Routledge, 2016.

———. Niklas Luhmann: Law, Fustice, Society. Nueva York: Routledge, 2009.

-—-. Spatial Fustice: Body, Lawscape, Atmosphere. Nueva York: Routledge, 2014.

- - - "Spatial Justice: Law and the Geography of Withdrawal." International Fournal of Law in Context 6, no. 3 (2010): 201-216.

Philippopoulos-Mihalopoulos, Andreas;FitzGerald, Sharron. "From Space Immaterial: The Invisibility of the Lawscape." Griffith Law Review 17, no. 2 (2008): 438-453.

Pickles, John. A History of Spaces: Cartographic Reason, Mapping, and the Geo-Coded World. Psychology Press, 2004.

Piqué i Batalle, David. «El fenómeno okupa / antisistema circunscrito al distrito de Gràcia (Barcelona), como factor de riesgo para la convivencia y potencial foco de percepción de inseguridad. Políticas públicas de seguridad aplicables para evitar que se convierta en un problema de orden público o delincuencial y consecuentemente de solución únicamente policial». Tesina, Universidad de Barcelona, 2009. 
Pisk, Marjeta. The Spatial Turn: Interdisciplinary Perspectives. Ljubljana: Slavisticno Drustvo Slovenije, 2012.

Porretta, Daniele. "Barcelona, $¿$ Ciudad Del Miedo?: Urbanismo" Preventivo" y Control Del Espacio Público." DC PAPERS, Revista De Crítica y Teoría De La Arquitectura no. 19 (2010): 183-192.

Preciado, Beatriz "El Flâneur Perverso, La Lesbiana Topofóbica y La Puta Multicartográfica, o Cómo Hacer Una Cartografía 'zorra'con Annie Sprinkle.” Cartografias Disidentes. Madrid: SEACEX, 2008.

Pullan, Wendy. "Conflict's Tools. Borders, Boundaries and Mobility in Jerusalem's Spatial Structures." Mobilities 8, no. I (2013): 125-147.

- - . "Frontier Urbanism: The Periphery at the Centre of Contested Cities." The Fournal of Architecture 16, no. I (2011): 15-35.

Rael, Ronald. Borderwall as Architecture: A Manifesto for the US-Mexico Boundary. San Francisco: Univ of California Press, 2017.

Ruiz Chasco, Santiago. «Madrid de Norte a Sur: Análisis sociológico de las desigualdades sociales y la inseguridad ciudadana en los barrios de Lavapiés y Salamanca». Tesis doctoral. Universidad Complutense de Madrid, 2017. https:// eprints.ucm.es/49572/r/T40387.pdf

Saddiki, Said. World of Walls. Cambridge: Open Book Publishers, 2017.

Said, Edward W. The Politics of Dispossession: The Struggle for Palestinian Self-Determination, 1969-1994. Vintage, 2012.

Sánchez, Miguel Angel Acosta. "Las Fronteras Terrestres De España En Melilla: Delimitación, Vallas Fronterizas y Tierra De Nadie.” Revista Electrónica De Estudios Internacionales (REEI) no. 28 (2014): 7-34.

Sassen, Saskia. Expulsiones: Brutalidad y Complejidad En La Economía Global. Barcelona: Katz Editores, 2015.

Scott, Felicity D. Outlaw territories: Environments of insecurity/architectures of counterinsurgency. Cambridge: MIT Press, 2016.

Schrijver, Lara. "OMA as Tribute to OMU: Exploring Resonances in the Work of Koolhaas and Ungers." The Fournal of Architecture 13, no. 3 (2008): 235-261.

Shoshan, Malkit; Grootens, Joost. Atlas of the Conflict: Israel-Palestine. Rotterdam: oio Publishers, 2010.

Soja, Edward W. Postmodern Geographies: The Reassertion of Space in Critical Social Theory. Londres:Verso, 1989.

_- - Seeking Spatial Fustice. Minneapolis: University of Minnesota Press, 2010.

- - Thirdspace: Fourneys to Los Angeles and Other Real-and-Imagined Places. Oxford: Blackwell, 1996.

- - Postmetropolis: Critical Studies of Cities and Regions. Oxford: Blackwell Publishers, 2000. 
Soriano, Federico. Ioo Hipermínimos: Escritos de Arquitectura. Zaragoza: Lampreave Ediciones, 2009.

Springer, Simon. "Why a Radical Geography must be Anarchist." Dialogues in Human Geography 4, no. 3 (2014): 249-270.

Stavrides, Stavros. Hacia la ciudad de umbrales. Madrid: Akal, 2016.

Stoner, Jill. Hacia una arquitectura menor. Madrid: Bartlebooth, 2018.

Szary, Anne-Laure Amilhat and Frédéric Giraut. Borderities: The Politics of Contemporary Mobile Borders. Springer, 2015.

Till, Karen E., Juanita Sundberg, Wendy Pullan, Charis Psaltis, Chara Makriyianni, Rana Zincir Celal, Meltem Onurkan Samani, and Lorraine Dowler. "Interventions in the Political Geographies of Walls." Political Geography 33, no. 5 (2013).

Tiqqun, Colectivo. La Hipótesis Cibernética. Madrid: Acuarela, 2013.

Trauttmansdorff, Paul. "The Politics of Digital Borders." Border Politics, 107-126: Springer, 2017.

Tschumi, Bernard. Architecture and Disjunction. Cambridge: MIT press, 1996.

- - - Red is not a color. Architecture concepts. Nueva York: Rizzoli International Publications, INC, 2012.

Valdecantos, Antonio. La excepción permanente: o, La construcción totalitaria del tiempo. Madrid: Díaz \& Pons, 2014.

Varona Martínez, Gema. "Estudio Exploratorio Sobre Los Efectos Del Uso Policial De La Videovigilancia En Lugares Públicos. Propuesta Criminológica De Un Sistema De Indicadores Sobre Su Adecuación y Proporcionalidad En Materia De Seguridad.”. Tesis fin de Máster. Universidad del País Vasco (2013).

VV.AA. Enclaves de riesgo: gobierno neoliberal, desigualdad y control social. Madrid: Traficantes de sueños, 2015 .

Vukov, Tamar; Sheller, Mimi. "Border Work: Surveillant Assemblages, Virtual Fences, and Tactical Counter-Media." Social Semiotics 23, no. 2 (2013): 225-241.

Walters, William. "No Border: Games with (Out) Frontiers." Social Fustice 33, no. I (IO3 (2006): 2I-39.

Wastl-Walter, Doris; Jagetic Andersen, Dorte; Sandberg, Marie, Klatt, Martin. The Border Multiple: The Practicing of Borders between Public Policy and Everyday Life in a Re-Scaling Europe. Ashgate Publishing, Ltd., 2012.

Weheliye, Alexander. Habeas viscus: Racializing assemblages, biopolitics, and black feminist theories of the human. Durham: Duke University Press, 2014.

Weizman, Eyal. Forensic Architecture: Violence at the Threshold of Detectability. Nueva York: Zone Books, 2017.

- - . Hollow Land: Israel's Architecture of Occupation. Londres: Verso, 2012. 
- - - The Least of all Possible Evils: Humanitarian Violence from Arendt to Gaza Londres: Verso, 2011.

_—_. "Political Plastic (Interview)." Collapse: Philosophical Research and Development, VI, 2010.

Wood, Denis Fels, John. The Power of Maps. Guilford: Guilford Press, 1992.

ZEMOS98. Panel De Control. Interruptores Críticos Para Una Sociedad Vigilada. Sevilla: ZEMOS98, 2008.

Zizek, Slavoj. Sobre La Violencia: Seis Reflexiones Marginales. Barcelona: Paidós Ibérica, 2009.

. The Parallax View. Cambridge: MIT Press, 2009. 


\section{NOTICIAS, ARTÍCULOS PERIODÍSTICOS, NORMATIVAS,}

WEB Y OTROS RECURSOS.

Alexandre, Albert. "Barrio Chino: cuando la frontera es un buen negocio". Ctxt. es, 28 de marzo de 2018.

Alsina, Carlos. "Más de uno" [Entrevista con Mariano Rajoy Brey], Onda Cero, 26 de enero de 2017.

Archdaily. «Call for Entries: Building the Border Wall?», Archdaily, 4 de marzo de 2016.

Architecture Lobby. «\#notourwall». Acceso el I2 de mayo de 2019. http://architecture-lobby.org/project/notourwall/

ASDPR. «Statement on Inmigration Enforcement», ASDPR, acceso el 12 de mayo de 2019. https://www.adpsr.org/blog/2018/8/8/statement-on-immigration-enforcement-in-the-united-states?rq=cages

Ayuntamiento de Madrid. «Plan Integral de Mejora de la Seguridad y Convivencia del Barrio de Lavapiés de Madrid». 2012.

Babiker, Sarah. “Cinco reflexiones tras la muerte de Mame Mbaye”. El Salto, I8 de marzo de 2018.

Barbulo, Tomás. "Interior abre en Tenerife un Centro de Internamiento para 250 inmigrantes”. El Pais, 24 de noviembre de 2003.

——_. “El fiasco de 'Guantanamito’”. El País, ro de julio de 2008.

Barroso, Francisco Javier. "Adiós a unas instalaciones que sólo permitían el hacinamiento". El País, 20 de junio de 2005.

- _ - "Un policía dispara dos tiros al aire en el arresto de un 'mantero' en Lavapiés. El País, 28 de mayo de 2012.

Bécares, Roberto. "El gobierno de Melilla asegura que Marruecos paraliza la construcción de la tercera valla". El Mundo, 29 de noviembre de 2005.

Betsky, Aaron. «"Architects may, heaven save their mortal souls, have to work on Trump's wall"», Dezeen, 27 de abril de 2018. Acceso el 15 de mayo de 2019. https://www.dezeen.com/2017/o4/18/opinion-aaron-betsky-ethical-architecture-donald-trump-us-mexico-border-wall/

Building the Border Wall. Versión del sitio web del 15 de marzo de 2016. Acceso el 15 de mayo de 2019. http://web.archive.org/web/20160315183030/http://buildingtheborderwall.com/

Cabero, Ángel. "Así son las heridas que provocan las concertinas en Melilla”. 20 Minutos, 18 de marzo de 2014.

Caminando Fronteras. «Informe de análisis de hechos y recopilación de testimonios de la tragedia que tuvo lugar el 6 de febrero de 2014 en la zona fronteriza de Ceuta», (Informe, Caminando Fronteras, 2014).

Cembrero, Ignacio. "El Ministerio del Interior reintroduce las cuchillas en la verja de Melilla”. El País, 31 de octubre de 2013. 
Cenizo, Néstor. "Encuentran ahorcado en la cárcel-CIE de Archidona a uno de los inmigrantes internos”. Eldiario.es, 29 de diciembre de 2017.

Comisión General de la Seguridad Ciudadana. Circular sobre empleo de material antidisturbios, de 13 de septiembre de 2013, de la Comisión General de la Seguridad Ciudadana (Documento interno, 2013).

Comparecencia del Señor ministro del Interior (Fernández Díaz) en la Comisión de Interior sesión no 25 celebrada el 13 de febrero de 2014 (Diario de Sesiones del Congreso de los Diputados no ${ }^{5}$ Oo, 13 de febrero de 2014), 4 .

Operación Conjunta Mos Maiorum, del ro de julio, Consejo de la Unión Europa (Nota presidencial, I1671/14, ro de julio de 2014).

Cornish, Audie. «Kevin McAleenan Says the Border Patrol Doesn't Make the Laws». New York Times, 7 de agosto de 2018.

De la Cal, Lucas. "Los chicos del bosque que van hacia España”. El Mundo, 27 de noviembre de 2017.

Defensor del Pueblo. "Informe Anual 20ro de Prevención de la Tortura», (Defensor del Pueblo, 2010), 253.

Duva, Jesús. "Mañana se abre en Moratalaz un centro de detención para extranjeros en vías de expulsión”. El País, 4 de noviembre de 1988.

- - - "Interior admite que los policías drogaron a los 103 inmigrantes y abre una investigación”. El País, 20 de julio de 1996.

Efe Noticias. "El informe de Interior sobre las cuchillas de la valla de Melilla no contempla retirarlas". 20 Minutos, 22 de noviembre de 2013.

_——. "Sindicato de manteros: "Al pobre no le permiten ocupar el espacio público"”. Público, 13 de agosto de 2019.

El País. "Belloch anuncia la "impermeabilización" la frontera con Marruecos por Ceuta”. El Pais, 19 de octubre de 1995.

El Patín, «Aprueban la construcción de un skatepark en la Barceloneta». Acceso el I de octubre de 2019, http://elpatin.com/aprueban-la-construccion-de-un-skatepark-en-la-barceloneta/

El Pueblo de Ceuta, "La Guardia Civil propone sustituir las concertinas por planchas metálicas y cilindros rotatorios". El pueblo de Ceuta, 19 de febrero de 2019.

Esparch, Pau. "El top manta entra a les andanes del metro per esquivar la policía”. Diario Ara, 12 de febrero de 2018.

Europapress. "Fernández Díaz: Las cuchillas de la valla causan heridas "superficiales"”. Europapress,25 de noviembre de 2013.

- _ . "Grande-Marlaska dice que se retirarán las concertinas "con carácter inmediato" y apuesta por "medios menos cruentos"”. Europa Press, 26 de julio de 2018. 
- — - "Los guardias civiles presentes en la tragedia de El Tarajal (Ceuta) defienden que el uso de antidisturbios fue "gradual”". Europapress, 7 de diciembre de 2014 .

- — - "Piden el cierre del centro de inmigrantes por una plaga de pulgas y por amenaza de ruina". El Mundo, 3 de febrero de 2010.

- - - Llegan 50 inmigrantes subsaharianos en patera a las Islas Chafarinas. Europapress, 3 de junio de 2019.

Face the Nation. Programa del 23 de agosto de 2015. CBS, 23 de agosto de 2015.

Factbasevideos. "Speech: Donald Trump in Manassas, VA", vídeo de Youtube, I:19:15. Factbasevideos. 2 de diciembre de 2015. https://www.youtube.com/wat$\mathrm{ch}$ ? $\mathrm{v}=\mathrm{sVvUZEcXoUU}$

Federal Business Oportunities. «Design-Build Structure», Federal Business Oportunities, acceso el 12 de mayo de 2019. https://www.fbo.gov/index?s=opportunity\&mode=form\&id=b8erb2a6876519caoaedd748ere49icf\&tab=core

Fig Projects. «\#BoycottArchdaily», Facebook. 14 de marzo de 2016. https://www. facebook.com/figprojects/photos/a.701219669935886/1082652245125958/?-

type $=3$ \& theater

Galup, Laura. "Salas de inadmitidos de Barajas: viajeros retenidos durante días sin sus enseres personales”. Eldiario.es, 9 de mayo de 2015.

García, Ángel. “Tras las mantas”. 5 W, 16 de agosto de 2018.

Guil, Janot. "La nueva Verneda de los inmigrantes". $A B C$, 12 de agosto de 2006.

Gutierrez, Iciar y Gabriela Sánchez. "El Gobierno aprueba la construcción del nuevo CIE de Algeciras ideada en la etapa de Rajoy”. Eldiario.es, I8 de enero de 2019 .

Informe final de la Operación Conjunta Mos Maiorum, del 22 de enero, Consejo de la Unión Europea (Nota de la Delegación Italiana ST 5474 2015, 22 de enero de 2015).

Kopan, Tal. « ICE official stands by comparing detention centers to 'summer camp', won't say if he'd send his kids to one.». CNN, I8 de septiembre de 2018.

Lambert, Léopold. «\# weaponized architecture /// Temple Grandin's humane slaughterhouses and the architectural politics of the lesser evil», The Funambulist.

de Llano, Pablo. "Geometría de una patera”. El País, 8 de mayo de 2011.

Lizarralde, Chema. "Un policía herido de bala y 150 inmigrantes ilegales detenidos en una batalla campal en Ceuta”. El Pais, 12 de octubre de 1995.

Maleno, Helena. "Star, tras 30 horas sobre la valla de Ceuta: "Me devolvieron mientras me arrastraba”. Eldiario.es, 27 de junio de 2016.

Meloni Gonzalez, Carolina. "Los Gillets Noir y el devenir negro del mundo". El Salto, 20 de septiembre de 2019. 
Nadir.org, «Map Mos Maiorum». Acceso el 15 de noviembre de 2017. http://map. nadir.org/

Oms, Javier. “Ofensiva policial para acabar con el 'top manta' en Barcelona”. $E l$ Mundo, 15 de julio de 2016.

Ordiz, Emilio. "Las concertinas, recurso extremo en la frontera de Ceuta y Melilla: qué son, dónde se fabrican y quién las instaló”. 20 Minutos, 14 de junio de 2018.

Ortiz, Alberto. "Cómo son las redadas de inmigrantes desde el comienzo de la operación policial europea”, Eldiario.es, 24 de octubre de 2014.

Periodistadigital. "El inmigrante que permaneció encaramado a una farola cuatro horas tras saltar la valla de Melilla”. Periodistadigital, 29 de marzo de 2014.

Redacción El Salto. "Un vendedor ambulante muere en Lavapiés tras ser perseguido por la Policía”. El Salto, 15 de marzo de 2018.

- — - "El Sindicato de Manteros protesta por la criminalización en una charla de Rita Maestre”. El Salto, 15 de diciembre de 2018.

- - - Una placa para que la muerte de Mame Mbaye no caiga en el olvido. $E l$ Salto, 15 de marzo de 2019.

Sánchez, Juan Luis. "Una persona murió desangrada en 2009 por cortes con el alambre de cuchillas de la valla de Ceuta”. Eldiario.es, 22 de noviembre de 2013.

- - - " Qué pasó con el hombre desplomado en Lavapiés por un porrazo de la Policía”. Eldiario.es, 16 de marzo de 2018.

Sindicato Popular de Vendedores Ambulantes, «Manifiesto por la despenalización del Top Manta». Acceso el I de octubre de 2019. https://manteros.org/comunicados/\#1488655372018-0124eeaI-2boa

Singel, Ryan. Border Patrol Calculus, Wired Magazine. 27 de noviembre de 2016. Acceso el 15 de mayo de 2019. https://www.wired.com/2006/Ir/border-patrol-c/

Territorio Doméstico. «Levántate empleada del hogar». Acceso el 2 de octubre de 2019, https://soundcloud.com/territoriodomestico/5-levantate-empleada-del-hogar

Territorio Doméstico. «Me duele to». Acceso el 2 de octubre de 2019, https:// soundcloud.com/territoriodomestico/8-me-duele-to

Torres, José. "El CIE de Capuchinos: peligro real para policías e internos". La Opinión de Málaga, II de febrero de 2010.

Trump, Donald. SECURE THE BORDER, BUILD A WALL!, 5 de agosto de 2014, 13:34. https://twitter.com/realDonaldTrump/status/496756082489171968

_-——.Americanist: @ofccadjust @AnnCoulter GW Bush was open borders like @JebBush. TERRORISTS CAN COME ACROSS MEXICAN BORDER AT WILL!", I8 de octubre de 2015, 21:59. https://twitter.com/realdonaldtrump/status/655853353793159168 
- - - We, as a country, either have borders or we don't. IF WE DON'T HAVE BORDERS, WE DON'T HAVE A COUNTRY!, 12 de noviembre de 2015, 07:50.

- - - Arizona, together with our Military and Border Patrol, is bracing for a massive surge at a NON-WALLED area. WE WILL NOT LET THEM THROUGH. Big danger. Nancy and Chuck must approve Boarder Security and the Wall!, 6 de diciembre de 2018, 22:15.

Tschumi, Bernard. Advertisements for Architecture, 1976.

Unión Europea. «Agencia Europea de la Guardia de Fronteras y Costas». Acceso el 23 de julio de 2019, https://europa.eu/european-union/about-eu/agencies/

frontex_es

Wall Street Journal, « Transcript of Donald Trump Interview With The Wall Street Journal». The New York Times, 14 de enero de 2018. https://www.wsj. com/articles/transcript-of-donald-trump-interview-with-the-wall-street-journal-1515715481 

